\title{
Silver-Mediated Decarboxylation Reactions: Expanding Reaction Scope through Kinetic Analysis
}

\author{
Robert Anthony Crovak \\ West Virginia University, racrovak@mix.wvu.edu
}

Follow this and additional works at: https://researchrepository.wvu.edu/etd

Part of the Organic Chemistry Commons

\section{Recommended Citation}

Crovak, Robert Anthony, "Silver-Mediated Decarboxylation Reactions: Expanding Reaction Scope through Kinetic Analysis" (2020). Graduate Theses, Dissertations, and Problem Reports. 7932.

https://researchrepository.wvu.edu/etd/7932

This Dissertation is protected by copyright and/or related rights. It has been brought to you by the The Research Repository @ WVU with permission from the rights-holder(s). You are free to use this Dissertation in any way that is permitted by the copyright and related rights legislation that applies to your use. For other uses you must obtain permission from the rights-holder(s) directly, unless additional rights are indicated by a Creative Commons license in the record and/ or on the work itself. This Dissertation has been accepted for inclusion in WVU Graduate Theses, Dissertations, and Problem Reports collection by an authorized administrator of The Research Repository @ WVU.

For more information, please contact researchrepository@mail.wvu.edu. 
Silver-Mediated Decarboxylation Reactions:

Expanding Reaction Scope through Kinetic Analysis

\title{
Robert Crovak
}

Dissertation submitted

to the Eberly College of Arts and Sciences

at West Virginia University

\author{
in partial fulfillment of the requirements for the degree of \\ Doctor of Philosophy in \\ Chemistry
}

\author{
Jessica Hoover, Ph.D., Committee Chairperson \\ Brian Popp, Ph.D. \\ Carsten Milsmann, Ph.D. \\ Björn Söderberg, Ph.D. \\ Lori Hazelhurst, Ph.D.
}

\section{Department of Chemistry}

\author{
Morgantown, West Virginia \\ 2020
}

Keywords: Decarboxylative Cross-Coupling, Silver, Coupling Reactions, Field Effect, Silver benzoate complexes, Silver Heteroaromatic Carboxylate Complexes, Protodecarboxylation

Copyright 2020 Robert Crovak 


\begin{abstract}
Silver-Mediated Decarboxylation Reactions: Expanding Reaction Scope through Kinetic Analysis
\end{abstract}

\title{
Robert Crovak
}

Transition metal-catalyzed decarboxylative coupling reactions have received considerable attention in recent years as a method to obtain biaryl compounds. However, the oxidative version of this reaction class is still in its infancy, limited to specific substitution patterns on the benzoic acids - ortho-substitution - used in these transformations. This thesis describes our attempts to understand the key decarboxylation step of this important class of reactions.

The first chapter of this thesis discusses an introduction into cross-coupling reactions, decarboxylative cross-coupling reactions, and outlines relevant physical organic parameters. The following chapter details the synthesis of a series of (1,10-phenanthroline)silver(benzoate) complexes. This chapter also describes their usage in the development of a model of the decarboxylation of the (phen) $\mathrm{Ag}$ (benzoate) complexes enabling the prediction of new benzoic acids to be used in oxidative decarboxylative coupling reactions. The last chapter discusses our recent progress on the extension of our decarboxylation methodology to silver heteroaromatic acid carboxylates. This final chapter also describes our preliminary attempts to correlate the rates of decarboxylation of $\mathrm{Ag}$ (heteroaromatic carboxylate) complexes with various electronic parameters. 
Dedicated to my parents, Katie and Mark Crovak 


\section{Acknowledgements}

The path to this dissertation has been long and taxing. The completion of this dissertation is largely due to the important people that supported, stuck with me and challenged me along the way. I would like to first thank my advisor, Dr. Jessica Hoover, for her encouragement and guidance throughout my graduate school career. I truly appreciate the amount of support she has given me at the various stages of my $\mathrm{PhD}$ and will continue to reap the rewards of being guided by her. I wish her the best in all her future endeavors.

I would also like to thank my remaining committee members, Carsten Milsmann, Brian Popp, Björn Söderberg and Lori Hazelhurst for their thoughtful feedback and guidance through the years. I thank Dr. Novruz Akhmedov for his comedy and NMR expertise. I also thank the WVU Chemistry staff members Becky, Brenda, Allan, Randy, Sherman, and JR. for their wonderful support, efforts, and help throughout my time in the department.

In addition to my committee, I would like to thank my colleagues from the Hoover research lab (Dr. Aaron Honeycutt, Dr. Oliver Mitevski, Jiaqi Liu, Michael Stanton, Beka Krupa, Sierra Ciccone, Joey Lokant, Mariah Murray, Gage Jackson, Dr. Minhao Li, Dr. Kerry-Ann Green, Dr. Shannen Lorraine, and Prof. Andreas Baur). Without your constant critiques, sarcasm, and comedy, I would not have been able to make it this far. I will never forget the "promising" chemistry jokes or enjoyable times that we spent together. I consider many of you guys as family and wish you all the best of luck in your future careers and hope we will all keep in touch. I would like to specially thank Dr. Aaron Honeycutt and Mike ('\$\$ Mike') Stanton for making working long hours at the fume hood enjoyable and for always being available to bounce ideas against. I will miss working in lab with you guys and listening to the various genres of music, 'Hardcore History,' DOTA podcasts, and/or all the random Joe Rogan interviews. I'd additionally like to thank specially thank Beka Krupa for dealing with my random office pranks and shenanigans.

Lastly, I would like to thank my family for always supporting me through my schooling. I know it was probably a little annoying when I was "speaking a different language" to you guys when you asked about school and had to backtrack and explain things to you "like a child." I would not have been able to do it without you! 


\section{Table of Contents}

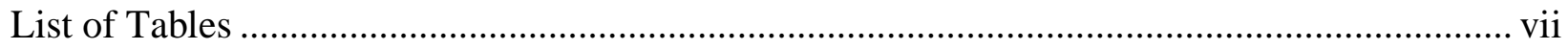

List of Schemes

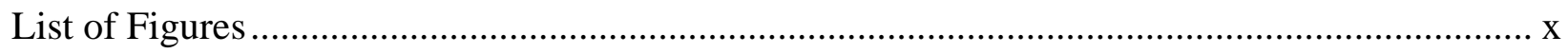

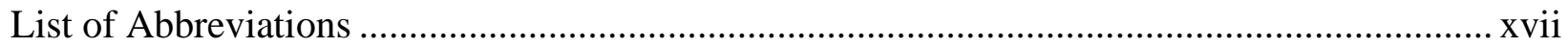

Chapter 1 - Introduction ............................................................................................ 1

1.1 Traditional Cross-Coupling for the Generation of Biaryl Compounds ........................ 1

1.2 Redox-Neutral Decarboxylative Cross-Coupling .................................................. 3

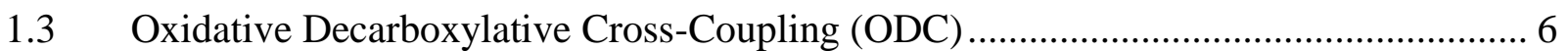

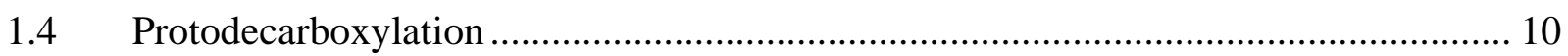

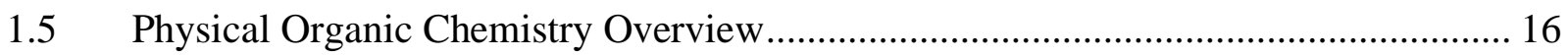

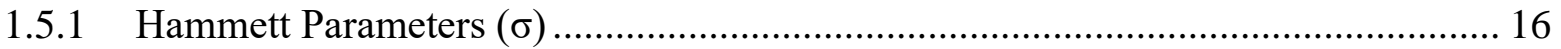

1.5.2 Field/Inductive $(F)$ and Resonance $(R)$ Parameters .......................................... 18

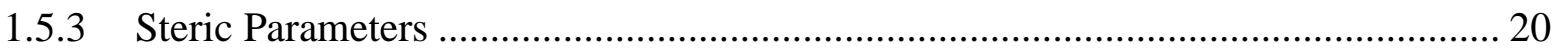

1.5.4 Applications to Organic Reactions ................................................................... 21

Chapter 2 - Development of a Predictive Model for Decarboxylation of Silver Benzoate

Complexes Relevant to Decarboxylative Coupling Reactions ............................................... 23

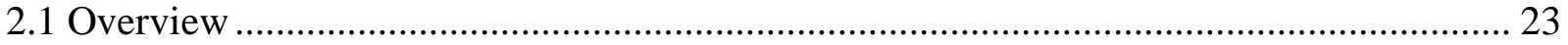

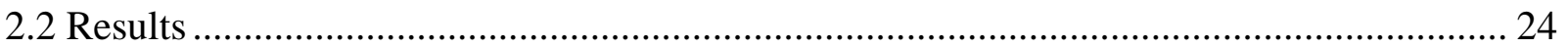

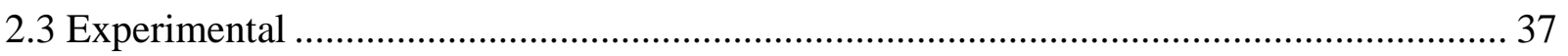

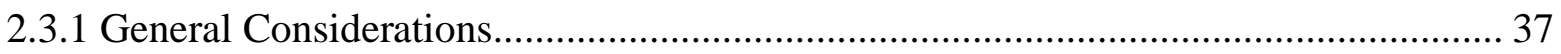

2.3.2 General Method for the Decarboxylation Reactions.............................................. 38

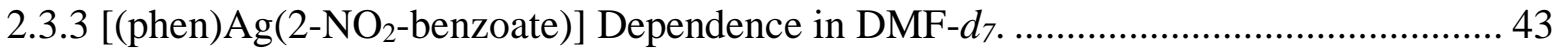

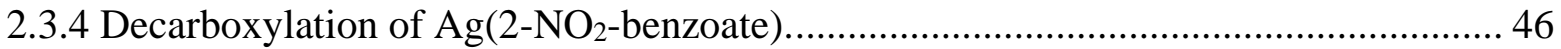

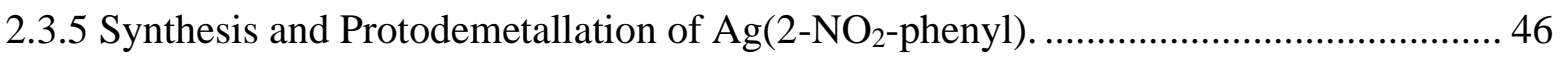

2.3.6 Decarboxylation of (phen) Ag(benzoate) Complexes........................................... 48

2.3.7 Calculation of Fujita-Nishioka Parameters............................................................ 54

2.3.8 General Method for the Catalytic Decarboxylative Arylation Reactions.................... 58 
2.3.9 Synthesis and Characterization of Silver Benzoate Complexes.

Chapter 3 - Progress in the Decarboxylation of $\mathrm{Ag}$ (Heteroaromatic Carboxylate) Complexes 80

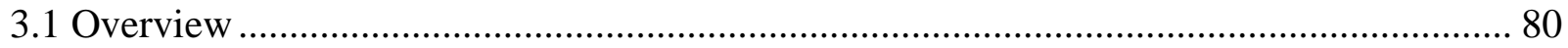

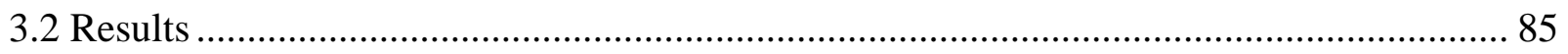

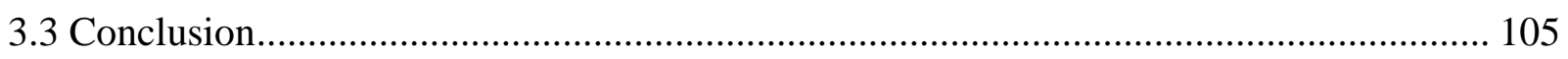

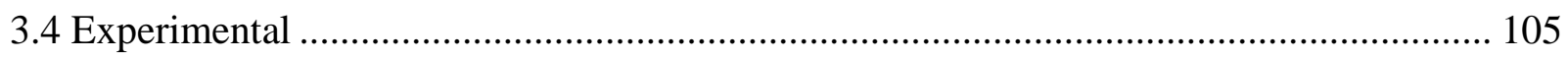

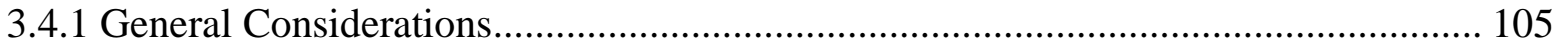

3.4.2 Decarboxylation of Silver Carboxylate Complexes. ................................................... 106

3.4.5 Synthesis and Characterization of Silver Complexes.............................................. 113

3.4.6 Synthesis and Characterization of Silver Heteroaromatic Carboxylates ..................... 121

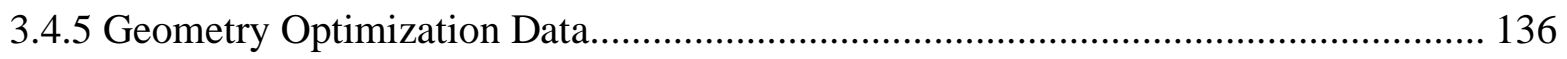

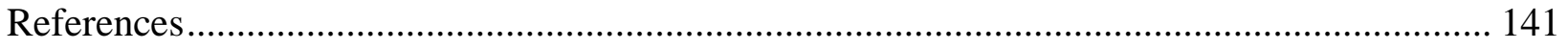

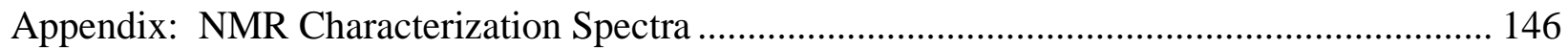

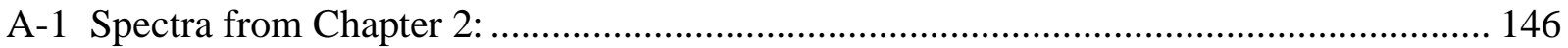

A-1.1 ${ }^{1} \mathrm{H}$ and ${ }^{13} \mathrm{C}$ NMR Spectra of (1,10-Phenanthroline)Silver(Benzoate) Complexes ... 146

AI-1.2 ${ }^{1} \mathrm{H}$ and ${ }^{13} \mathrm{C}$ NMR Spectra of Silver Aryl Complexes ........................................... 200

AI-1.3 ${ }^{1} \mathrm{H}$ and ${ }^{13} \mathrm{C}$ NMR Spectra of 2-(2-benzoxazolyl)-1-(4-methylbenzenesulfonate)-

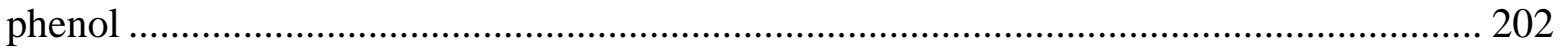

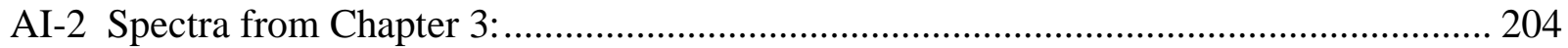

AI-2.1 ${ }^{1} \mathrm{H}$ and ${ }^{13} \mathrm{C}$ NMR Spectra of (1,10-Phenanthroline)Silver(Benzoate) Complexes.. 204

AI-2.2 ${ }^{1} \mathrm{H}$ and ${ }^{13} \mathrm{C}$ NMR Spectra of Silver(Benzoate) Complexes.................................... 211

AI-2.3 ${ }^{1} \mathrm{H}$ and ${ }^{13} \mathrm{C}$ NMR Spectra of Silver(Heteroaromatic Carboxylate) Complexes ...... 235

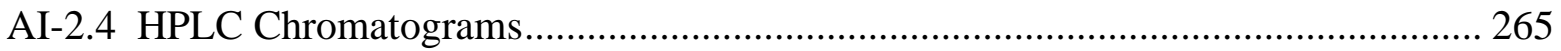




\section{List of Tables}

TABLE 1-1: ACTIVATION BARRIERS CALCULATED FOR THE SILVER CATALYZED PROTODECARBOXYLATION OF ORTHO-SUBSTITUTED BENZOIC ACIDS (SCHEME 1-11). THE VALUES ARE THE SOLVATION-CORRECTED FREE ENERGY BARRIERS.

TABLE 1-2: HAMMETT'S $\Sigma_{P}$ AND $\Sigma_{M}$ CONSTANTS FOR COMMON SUBSTITUENTS. VALUES OF ALL PARAMETERS ARE FROM REFERENCE [62].

TABLE 1-3: $F$ AND $R$ CONSTANTS OF COMMON SUBSTITUENTS. VALUES OF ALL PARAMETERS ARE FROM REFERENCE ${ }^{[62]}$ 20

TABLE 2-4: ${ }^{1}$ H NMR SPECTRA INTEGRATION VALUES AND RESULTING CONCENTRATIONS FOR THE DECARBOXYLATION OF (PHEN)AG(2-NO 2 -BENZOATE) GIVING RISE TO THE REACTION TIME COURSE (FIGURES 2-1B AND 2-2) AND USED TO DETERMINE THE INITIAL RATE OF DECARBOXYLATION FOR (PHEN)AG(2-NO2-BENZOATE). 41

TABle 2-5: The DATA USED TO CALCUlATE THE FuJitA-NishioKA PARAMETERS. ${ }^{A}$. 55

TABLE 2-6: THE DATA USED TO DETERMINE THE PREDICTABILITY OF THE DECARBOXYLATION OF (PHEN)AG(BENZOATE) COMPLEXES. ${ }^{A}$ 55

TABLE 3-7: KINETIC DATA FOR THE DECARBOXYLATION OF AG(BENZOATE) COMPLEXES 90

TABLE 3-8: KinETIC DATA FOR THE DECARBOXYLATION OF (PHEN)AG(BENZOATE COMPLEXES AS A COMPARISON. DATA IS FROM REFERENCE ${ }^{[142]}$ 90

TABLE 9: TABULATED DATA FOR THE DECARBOXYLATION OF AG(HETEROAROMATIC CARBOXYLATE) COMPLEXES BY HPLC. 97

TABLE 3-10: MOLECULAR PROPERTIES OF A SMALL SET OF HETEROAROMATIC CARBOXYLIC ACIDS. 102 


\section{List of Schemes}

SCHEME 1-1: EXAMPLES OF TRADITIONAL CROSS-COUPLING REACTIONS. THE FORMED BOND IS INDICATED IN BOLD

SCHEME 1-2: A) NILSSON'S DECARBOXYLATIVE CROSS-COUPLING OF NITROBENZOIC ACID WITH ARYL IODIDES. B) STEGLICH AND CO-WORKERS' SYNTHESIS OF LAMELLARIN G ( $R=M E)$ AND LAMELLARIN L $\left(\mathrm{R}={ }^{I} \mathrm{PR}\right)$. C) MYERS’ Pd/Ag DECARBOXYLATIVE HECK COUPLING OF CARBOXYLIC ACIDS WITH ALKENE REAGENTS

SCHEME 1-3: GOOßEN AND CO-WORKERS' PD/CU CATALYZED DECARBOXYLATIVE COUPLING OF BENZOIC ACIDS WITH ARYL BROMIDES.

Scheme 1-4: The Oxidative DeCARboxylative Coupling (ODC) ReACTION........................ 7

SCHEME 1-5: OXIDATIVE DECARBOXYLATIVE COUPLING REACTIONS DEVELOPED BY CRABTREE, GLORIUS, LARROSA, AND SU.

SCHEME 1-6: THE COPPER-CATALYZED DECARBOXYLATIVE ARYLATION REPORTED BY HOOVER (TOP) AND MAITI (BOTTOM)

SCHEME 1-7: ZHANG AND LU's (TOP) AND KALYANI's (BOTTOM) Ni/AG SYSTEMS FOR THE OXIDATIVE DECARBOXYLATIVE CROSS-COUPLING C-H ARYLATION OF BENZOXAZOLES. ....... 10

SCHEME 1-8: COPPER-CATALYZED PROTODECARBOXYLATIONS BY THE SHEPARD GROUP (TOP) AND THE GOOßEN GROUP (BOTTOM).

SCHEME 1-9: AG-CATALYZED PROTODECARBOXYLATION BY THE GOOßEN (TOP) AND LARROSA (BOTTOM) GROUPS

SCHEME 1-10: GOOßEN'S CALCULATED PATHWAY FOR DECARBOXYLATION (TOP) AND THE PROPOSED PATHWAY FOR DECARBOXYLATION (BOTTOM).

SCHEME 1-11: SU'S MODEL SYSTEM FOR THE COMPUTATIONAL STUDIES OF THE DECARBOXYLATION OF ORTHO-SUBSTITUTED BENZOIC ACIDS AND THEIR DFT CALCULATED TRANSITION STATES OF THE DECARBOXYLATION OF DIFFERENTLY SUBSTITUTED (DMSO)AG(BENZOATE) COMPLEXES FOR THE DECARBOXYLATION OF THE DMSO LIGATED SILVER $O$-NITROBENZOATE (LEFT), SILVER $M$-NITROBENZOATE (MIDDLE), AND SILVER $P$ NITROBENZOATE (RIGHT) COMPLEXES. VALUES CORRESPOND TO THE SOLVATION-CORRECTED RELATIVE FREE ENERGIES AND ARE GIVEN IN KCAL $\cdot \mathrm{MOL}^{-1}$ 14

SCHEME 1-12: LARROSA AND CO-WORKER'S AG-CATALYZED PROTODECARBOXYLATION OF BENZOIC ACIDS AND THE FUJITA-NISHIOKA RELATIONSHIP. 
SCHEME 1-13: IONIZATION OF BENZOIC ACIDS BY HAMMETT FOR THE DETERMINATION OF $\Sigma$

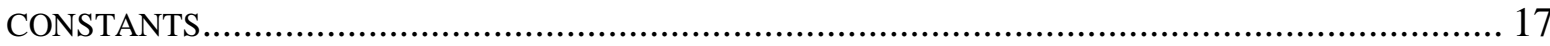

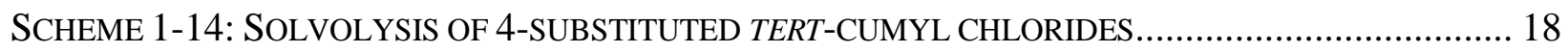

SCHEME 1-15: THE DISSOCIATION OF 4-SUBSTITUTED PHENOLS. .............................................. 18

SCHEME 1-16: THE DISSOCIATION OF 4-SUBSTITUTED BICYCLO[2.2.2]OCTANE-1-CARBOXYLIC ACIDS

SCHEME 1-17: GROB AND SCHLAGETER'S IONIZATION OF QUINUCLIDINES. 19

SCHEME 1-18: ESTER HYDROLYSIS UNDER BASE CATALYZED (TOP) AND ACID CATALYZED

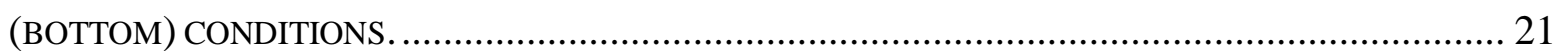

SCHEME 2-1: ProtodeCARboXylation OF (PHEN)Ag BENZOATE COMPLEXES .......................... 24

SCHEME 2-2: A) DECARBOXYLATION OF (PHEN)AG(2-NO $2-B E N Z O A T E) ~ I N ~ D M F-D 7$ AT $110^{\circ} \mathrm{C}$. B) DECARBOXYLATION OF (PHEN)AG(2-NO2-BENZOATE) IN DMF- $D 7$ IN THE PRESENCE OF 0.7

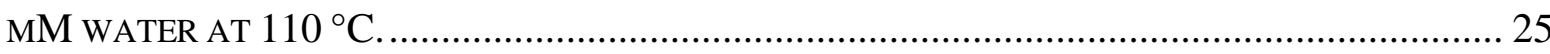

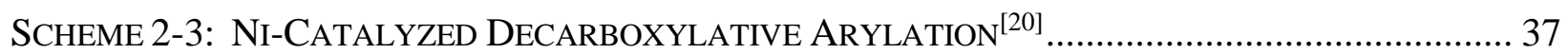

SCHEME 3-1: EXAMPLES OF SILVER-CATALYZED PROTODECARBOXYLATION OF HETEROAROMATIC

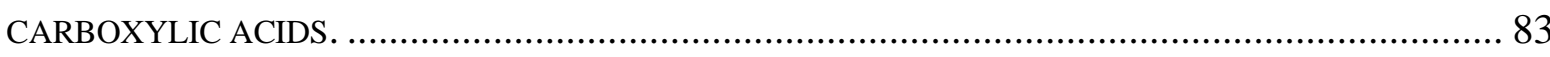

SCHEME 3-2: PRotodeCARboXYLATION OF Ag(HETEROAROMATIC CARBOXYLATE) COMPLEXES. 85

SCHEME 3-3: SYNTHESIS OF A SMALL SERIES OF AG(BENZOATE) COMPLEXES. ........................... 86

SCHEME 3-4: THE PROTODECARBOXYLATION OF SUBSTITUTED AG(BENZOATE) COMPLEXES IN

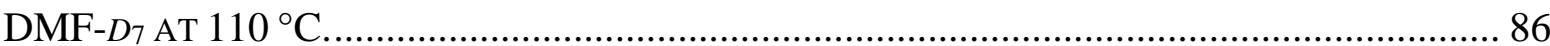

SCHEME 3-5: SYNTHESIS OF THE SERIES OF AG(HETEROAROMATIC CARBOXYLATES) USED IN THIS STUDY. 93 


\section{List of Figures}

FIGURE 1-1: GENERAL REACTION MECHANISM FOR TRADITIONAL PALLADIUM-CATALYZED CROSSCOUPLING IN WHICH A PALLADIUM(0) CATALYST UNDERGOES OXIDATIVE ADDITION (OA),

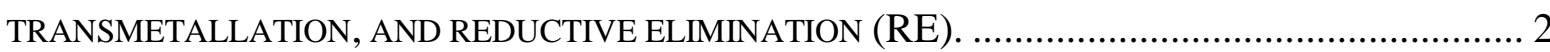

FIGURE 1-2: PROPOSED MECHANISM FOR THE DECARBOXYLATIVE COUPLING OF BENZOIC ACIDS WITH ARYL HALIDES UNDER THE PD/CU SYSTEM.................................................................. 5

FIGURE 1-3: TYPICAL BENZOIC ACID SCOPE THAT UNDERGO EFFICIENT CROSS-COUPLING IN BOTH REDOX-NEUTRAL AND OXIDATIVE DECARBOXYLATIVE CROSS-COUPLING REACTIONS.

FIGURE 1-4: VERLOOP'S STERIMOL PARAMETERIZATION. L = LENGTH, B B $_{1}=$ MINIMUM WIDTH, AND

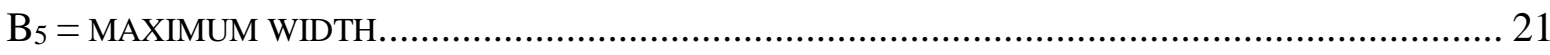

FIGURE 2-1: A) ${ }^{1}$ H NMR TIME COURSE AND B) REACTION PROFILE FOR THE DECARBOXYLATION OF (PHEN)AG(2-NO 2 -BENZOATE) $(3.5 \mathrm{MM}, \boldsymbol{\varpi})$ TO FORM NITROBENZENE $(\bullet)$ IN DMF- $D 7$ WITH 0.7 $\mathrm{MM} \mathrm{H}_{2} \mathrm{O}$ AT $110^{\circ} \mathrm{C}$. THE ASTERISK DENOTES THE RESIDUAL SOLVENT SIGNAL...................... 26

FigURE 2-2: REACTION PROFILE OF THE DECARBOXYLATION OF (PHEN)AG(2-NO 2 -BENZOATE) (3.5 MM) IN DMF- $D 7$ AT $110^{\circ} \mathrm{C}$. A) EARLY REACTION TIMES AND B) THE FULL-TIME COURSE FIT TO AN EXPONENTIAL DECAY MODEL Y $=0.5457+3.2124 \mathrm{E}^{-1.3078 \mathrm{x}}$

FIGURE 2-3: REACTION TIME COURSES FOR THE PROTODEMETALLATION OF A) AG(2-NO 2 -PHENYL) (6.0 MM; INITIAL RATE $\left.=25.5 \mathrm{MM} \mathrm{H}^{-1} ; \mathrm{K}=4.28 \mathrm{H}^{-1}\right)$ AND B) AG(2-NO - -PHENYL) WITH PHEN (5.4 MM; INITIAL RATE $=15.85 \mathrm{MM} \mathrm{H}^{-1} ; \mathrm{K}=2.935 \mathrm{H}^{-1}$ ) IN DMF- $D_{7}$ WITH $0.7 \mathrm{MM}$ OF $\mathrm{H}_{2} \mathrm{O}$ AT $110^{\circ} \mathrm{C}$.

FIGURE 2-4: KINETIC DATA FROM THE DECARBOXYLATION OF [(PHEN)AG(2-NO 2 -BENZOATE)] IN DMF- $D 7$ WITH 0.7 MM H $\mathrm{H}_{2} \mathrm{O}$ AT $110^{\circ} \mathrm{C}$ ASSESSING THE DEPENDENCE ON [(PHEN)AG(2-NO ${ }_{2}-$ BENZOATE)]. INITIAL RATES WERE DETERMINED USING ${ }^{1} \mathrm{H}$ NMR SPECTROSCOPY. 30

FIGURE 2-5: REACTION TIME COURSE FOR THE DECARBOXYLATION OF AG(2-NO2-BENZOATE) (6.6 $\mathrm{MM} ; \mathrm{K}=0.787 \mathrm{H}^{-1}$ ) IN DMF- $D_{7}$ WITH $0.7 \mathrm{MM} \mathrm{H}_{2} \mathrm{O}$ AT $110^{\circ} \mathrm{C}$

FiguRE 2-6: A) PROFILES OF THE KINETIC PLOTS FOR THE DECARBOXYLATION OF VARIOUS (PHEN)AG(2-R-BENZOATE) COMPLEXES WHERE $\mathrm{R}=\mathrm{ME}, \mathrm{CF}_{3}, \mathrm{OME}, \mathrm{CL}, \mathrm{F}$ AND $\mathrm{NO}_{2}$. THE TRACES ARE NOT FITS AND ARE ONLY MEANT AS A VISUAL GUIDE. B) FUITAA-NISHIOKA LINEAR FREE ENERGY CORRELATION FIT TO THE RATES OF DECARBOXYLATION OF (PHEN)AG(2-R- 
BENZOATE) UNDER STANDARD CONDITIONS. CONDITIONS: 8 MM (PHEN)AG(2-R-BENZOATE) IN 0.5 ML DMF- $D 7$ WITH 0.7 MM H $\mathrm{H}_{2} \mathrm{O}$ AT $110^{\circ} \mathrm{C}$.

FIGURE 2-7: REACTION TIME COURSE FOR THE DECARBOXYLATION OF A) (PHEN)AG(3-NO ${ }_{2}-$ BENZOATE) (8.15 MM, K = 8.10 X 10 $\left.0^{-3} \mathrm{H}^{-1}\right)$ AND B) (PHEN)AG(4-CF 3 -BENZOATE) (10.15 MM, K $=1.106 \times 10^{-2}$ ) IN DMF- $D_{7}$ WITH $0.7 \mathrm{MM} \mathrm{H}_{2} \mathrm{O}$ AT $110^{\circ} \mathrm{C}$ 33

FIGURE 2-8: A) FUJITA-NISHIOKA LINEAR FREE ENERGY CORRELATION FIT TO THE RATES OF DECARBOXYLATION OF VARIOUS (PHEN)AG(BENZOATE) COMPLEXES IN 0.5 ML DMF-D7 WITH $0.7 \mathrm{MM} \mathrm{H}_{2} \mathrm{O}$ AT $110^{\circ} \mathrm{C}$. ThE REACTION TIME COURSES ARE SHOWN IN FIGURES 2-7, 2-14, 2 15, AND 2-16. B) SIMPLIFIED CORRELATION OF THE LOG(K) WITH THE FIELD EFFECT PARAMETER (F). THE SHADED AREA INDICATES THE LARGEST EXPERIMENTAL ERROR IN LOG (K) IF APPLIED TO ALL POINTS.

FIGURE 2-9: ${ }^{1}$ H NMR SPECTRA AND INTEGRATION VALUES FOR THE DECARBOXYLATION OF (PHEN)AG(2-NO 2 -BENZOATE) IN DMF-D7 AT $110{ }^{\circ} \mathrm{C}$ AT T $=1,5,10,15,20,30,60$, AND 90 MIN

FIGURE 2-10: ${ }^{1}$ H NMR STACKED PLOT OF THE AG(2-NO 2 -BENZOATE), DECARBOXYLATION OF $($ PHEN)AG(2-NO2-BENZOATE) AT T $=0$ MIN AND T $=60$ MIN, AND 1,10-PHENANTHROLINE IN DMF-D7.

FIGURE 2-11: ${ }^{1} \mathrm{H}$ NMR TIME COURSE FOR THE DECARBOXYLATION OF (PHEN)AG(2-NO2BENZOATE) (5.7 MM, BLUE) TO FORM NITROBENZENE (RED) AND 2,2'-DINITROBIPHENY (YELLOW) IN DRY DMF- $D 7$ AT $110^{\circ} \mathrm{C}$. THE ASTERISK DENOTES THE RESIDUAL SOLVENT SIGNALS

FIGURE 2-12: REACTION PROFILE AND INITIAL RATE FITS FOR THE DECARBOXYLATION OF (PHEN)AG(2-NO ${ }_{2}$-BENZOATE) IN DMF-D 7 WITH $0.7 \mathrm{MM} \mathrm{H}_{2} \mathrm{O}$ AT $110{ }^{\circ} \mathrm{C}$. CONCENTRATIONS AT A) 14.4 MM, B) 12.2 MM, C) 8.5 MM, D) 8.3 MM, E) 5.5 MM AND F) $3.5 \mathrm{MM}$. 45

FiguRE 2-13: KINETIC PROFILES FOR THE DECARBOXYLATION OF (PHEN)AG(2-R-BENZOATE) WHERE $\mathrm{R}=\mathrm{ME}, \mathrm{CF}_{3}, \mathrm{OME}, \mathrm{CL}, \mathrm{F}$, AND NO 2 . A) REACTION PROFILE GIVEN AS \% (PHEN)AG(2R-BENZOATE) OVER TIME. TRACES ARE NOT FITS AND ARE ONLY MEANT TO GUIDE THE EYE. B) REACTION TIME COURSE DATA FIT TO PROVIDE THE INITIAL REACTION RATES. STANDARD CONDITIONS ARE $8 \mathrm{MM}$ (PHEN)AG(2-R-BENZOATE) IN 0.5 ML DMF-D7 WITH 0.7 MM H $\mathrm{M}_{2} \mathrm{O}$ AT $110^{\circ} \mathrm{C}$ 
FIGURE 2-14 REACTION TIME COURSE FOR THE DECARBOXYLATION OF A) (PHEN)AG(2-MEBENZOATE) (8.15 MM; $\left.K=1.57 \times 10^{-2} \mathrm{H}^{-1}\right)$, B) (PHEN)AG(2-OME-BENZOATE) $(7.55 \mathrm{MM} ; K=$ $\left.0.247 \mathrm{H}^{-1}\right)$, C) (PHEN)AG(2-F-BENZOATE) $\left(8.19 \mathrm{MM} ; K=0.377 \mathrm{H}^{-1}\right)$, D) (PHEN)AG(2-CLBENZOATE) (8.42 MM; $\left.K=0.313 \mathrm{H}^{-1}\right)$, E) (PHEN)AG(2-CF - -BENZOATE) $(8.86 \mathrm{MM} ; K=9.71 \mathrm{X}$ $10^{-2} \mathrm{H}^{-1}$ ) IN DMF-D7 WITH $0.7 \mathrm{MM} \mathrm{H} \mathrm{H}_{2} \mathrm{O}$ AT $110{ }^{\circ} \mathrm{C}$. 50

FIGURE 2-15: REACTION TIME COURSE FOR THE DECARBOXYLATION OF A) (PHEN)AG(2,4-DI-NO $2_{2}^{-}$

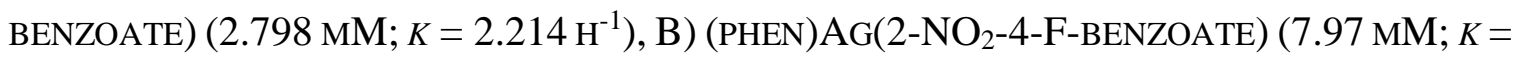
$\left.\left.3.49 \mathrm{H}^{-1}\right), \mathrm{C}\right)(\mathrm{PHEN}) \mathrm{AG}\left(2-\mathrm{NO}_{2}-4-\mathrm{F}-\mathrm{BENZOATE}\right)\left(3.89 \mathrm{MM} ; K=1.17 \mathrm{H}^{-1}\right)$, D) (PHEN)AG $\left(2-\mathrm{NO}_{2}-\right.$ 4-Me-BENZOATE) (6.64 MM; $\left.K=2.49 \mathrm{H}^{-1}\right)$, E) (PHEN)AG(2-NO 2 -4-OME-BENZOATE) (4.56 $\left.\mathrm{MM} ; K=1.46 \mathrm{H}^{-1}\right)$ AND F) (PHEN)AG(2-NO $2-5$-OME-BENZOATE) $\left(7.58 \mathrm{MM} ; K=2.80 \mathrm{H}^{-1}\right) \mathrm{IN}$ DMF- $D_{7}$ WITH $0.7 \mathrm{MM} \mathrm{H}_{2} \mathrm{O}$ AT $110^{\circ} \mathrm{C}$

FIGURE 2-16: REACTION TIME COURSE FOR THE DECARBOXYLATION OF A) (PHEN)AG(2-F-6-NO ${ }_{2}^{-}$ BENZOATE) (8.57 MM; $\left.K=12.15 \mathrm{H}^{-1}\right)$, B) (PHEN)AG(2-F-6-ME-BENZOATE) $(10.40 \mathrm{MM} ; K=$ $\left.\left.0.242 \mathrm{H}^{-1}\right), \mathrm{C}\right)(\mathrm{PHEN}) \mathrm{AG}(2,6-\mathrm{DI}-\mathrm{F}-\mathrm{BENZOATE})\left(8.26 \mathrm{MM} ; K=5.63 \mathrm{H}^{-1}\right)$ IN DMF-D7 WITH 0.7 $\mathrm{MM} \mathrm{H}_{2} \mathrm{O}$ AT $110^{\circ} \mathrm{C}$

FIGURE 2-17: REACTION TIME COURSE FOR THE DECARBOXYLATION OF A) (PHEN)AG(2-CL-6$\mathrm{NO}_{2}$-BENZOATE) (7.79 MM; $K=3.45 \mathrm{H}^{-1}$ ), B) (PHEN)AG(2-ME-6-NO - -BENZOATE) (8.92 MM; $\left.\left.K=0.785 \mathrm{H}^{-1}\right), \mathrm{C}\right)(\mathrm{PHEN}) \mathrm{AG}(2-\mathrm{OAC}-\mathrm{BENZOATE})\left(7.23 \mathrm{MM} ; K=1.57 \mathrm{H}^{-1}\right)$, D) (PHEN)AG(2OTs-BENZOATE) (6.62 MM; $\left.K=0.203 \mathrm{H}^{-1}\right)$, E) (PHEN)AG(2,3,4,5-TETRAFLUOROBENZOATE) $\left(7.12 \mathrm{MM} ; K=1.93 \mathrm{H}^{-1}\right)$ IN DMF- $D_{7}$ WITH $0.7 \mathrm{MM} \mathrm{H}_{2} \mathrm{O}$ AT $110^{\circ} \mathrm{C}$ 53

FIGURE 2-18: CORRELATION OF THE LOG $(K)$ WITH THE FIELD EFFECT PARAMETER $(F)$ SHOWING A) DECARBOXYLATION REACTIONS RUN IN DUPLICATE, TRIPLICATE OR QUINTUPLICATE AND THEIR ASSOCIATED ERRORS (GIVEN AS TWICE THE STANDARD DEVIATION) IN LOG( $K)$. B) A STANDARD ERROR OF 1.1 (THE LARGEST OF THE OBSERVED ERRORS IN FIGURE 2-18A) APPLIED TO ALL DATA POINTS USED TO DETERMINE THE FUJITA-NISHIOKA LINEAR FREE ENERGY RELATIONSHIP COEFFICIENTS. 56

FIGURE 2-19: CORRELATION OF THE LOG $(K)$ WITH A) THE HAMMETT PARAMETER $(\Sigma)$, B) THE STERIC PARAMETER $\left(E_{S}\right)$ AND C) THE FIELD EFFECT PARAMETER $(F)$. THE TRAINING SET IS INDICATED WITH $\bullet, \boldsymbol{\square}, \bullet$ AND $\star$ AND THE VALIDATION SET IS INDICATED WITH $\bullet \ldots \ldots \ldots \ldots . . . . .57$

FIGURE 3-1: HETERO-BIARYL SCAFFOLDS USED IN THE PHARMACEUTICAL INDUSTRY. 81 
FIGURE 3-2: A REPRESENTATIVE SCOPE OF HETEROAROMATIC CARBOXYLIC ACIDS USED IN DECARBOXYLATIVE CROSS-COUPLING REACTIONS. 82

FIGURE 3-3: HETEROAROMATIC CARBOXYLIC ACIDS THAT WERE REPORTED TO BE SUCCESSFUL (TOP) AND UNSUCCESSFUL (BOTTOM) IN THE LARROSA AND JAENICKE REPORTS. 84

FIGURE 3-4: ${ }^{1} \mathrm{H}$ NMR SPECTROSCOPY REACTION TIME COURSES FOR THE DECARBOXYLATION OF A) (PHEN)AG(2,6-DI-OME-BENZOATE) (1) (5.23 MM; $K=0.57 \mathrm{H}^{-1}$ ) B) (PHEN)AG(2-F-6-CF3BENZOATE) (2) (5.90 MM; $\left.K=1.19 \mathrm{H}^{-1}\right)$ AND C) (PHEN)AG(2,4,6-ME-BENZOATE) (3) (5.33 $\left.\mathrm{MM} ; K=0.04 \mathrm{H}^{-1}\right) \mathrm{IN}$ DMF- $D_{7} \mathrm{AT} 110^{\circ} \mathrm{C}$. RED POINTS INDICATE FIT. .87

FIGURE 3-5: ${ }^{1} \mathrm{H}$ NMR SPECTROSCOPY REACTION TIME COURSES FOR THE DECARBOXYLATION OF A) AG(2-NO 2 -BENZOATE) (4) (6.55 MM; $\left.\left.K=0.79 \mathrm{H}^{-1}\right) \mathrm{B}\right) \mathrm{AG}(2,6-\mathrm{F}-\mathrm{BENZOATE})(5)(7.47 \mathrm{MM} ; K=$ $\left.\left.\left.2.71 \mathrm{H}^{-1}\right) \mathrm{C}\right) \mathrm{Ag}(2,6-\mathrm{OME}-\mathrm{BENZOATE})(6)\left(2.96 \mathrm{MM} ; K=0.51 \mathrm{H}^{-1}\right) \mathrm{D}\right) \mathrm{AG}\left(2-\mathrm{CO}_{2} \mathrm{ME}-\right.$ BENZOATE) (7) (7.77 MM; $\left.\left.K=0.11 \mathrm{H}^{-1}\right) \mathrm{E}\right)$ OF AG(2-F-BENZOATE) (8) (8.88 MM; $\left.K=0.09 \mathrm{H}^{-1}\right)$ AND F) AG(2-F-6-NO 2 -BENZOATE) (9) (6.95 MM; $\left.K=8.60 \mathrm{H}^{-1}\right)$ IN DMF- $D_{7}$ AT $110^{\circ} \mathrm{C}$. RED POINTS INDICATE FIT. 88

FIGURE 3-6: ${ }^{1} \mathrm{H}$ NMR SPECTROSCOPY REACTION TIME COURSE FOR THE DECARBOXYLATION OF A) Ag(2-F-6-OME-BEnZOATE) (10) (6.50 MM; $K=0.89$ H$\left.^{-1}\right)$ B) AG(2-PH-BENZOATE) (11) (8.39 $\left.\left.\mathrm{MM} ; K=0.01 \mathrm{H}^{-1}\right) \mathrm{C}\right)$ OF AG(2-CF $-\mathrm{CF}_{3}$ BENZATE) (12) (7.69 MM; $\left.K=0.03 \mathrm{H}^{-1}\right)$ AND D) AG(2-F-6-CF 3 -BENZOATE) (13) $\left(7.28 \mathrm{MM} ; K=0.36 \mathrm{H}^{-1}\right)$ IN DMF-D7 AT $110^{\circ} \mathrm{C}$. RED POINTS INDICATE FIT.

FIGURE 3-7: A COMPARISON OF THE 1,10-PHENANTHROLINE LIGATED SILVER BENZOATE COMPLEXES AND THE UNLIGATED SILVER BENZOATE COMPLEXES. A) THE TRENDS BASED ON THE FULL DATA SET COLLECTED. DATA FOR THE (PHEN)AG(BENZOATE) COMPLEX SERIES IS FROM REFERENCE ${ }^{[142]}$. B) A SUBSET OF THE DATA SET ALLOWING FOR THE DIRECT COMPARISON OF THE RATES OF DECARBOXYLATION BETWEEN (PHEN)AG(BENZOATE) AND AG(BENZOATE) COMPLEXES.

FIGURE 3-8: A) THE REACTION PROFILE OF THE DECARBOXYLATION OF 25 MONITORED BY ${ }^{1}$ H NMR SPECTROSCOPY. B) THE REACTION PROFILES OF THE PRODUCT FORMATION OF THE DECARBOXYLATION OF 25 FROM TWO DIFFERENT TRIALS 
FigURE 3-9: REACTION PROFILE OF THE DECARBOXYLATION OF 14 (1.828 MM) IN DMF-D7 AT 110 ${ }^{\circ} \mathrm{C}$. A) EARLY REACTION TIMES AND B) THE FULL-TIME COURSE. RED POINTS INDICATE FIT OF THE CARBOXYLATE. ORANGE POINTS INDICATE FIT OF THE ARENE. 96

FigURE 3-10: KinETIC PROFILES FOR THE DECARBOXYLATION OF 14, 15, 16 AND 17. A) REACTION PROFILE GIVEN AS \% AG(HETEROAROMATIC CARBOXYLATE) OVER TIME. THE TRACES ARE NOT FITS AND ARE ONLY MEANT TO GUIDE THE EYE. B) REACTION TIME COURSE DATA FIT TO PROVIDE THE INITIAL REACTION RATES. STANDARD CONDITIONS ARE $1.62 \mathrm{MM}$ AG(HETEROAROMATIC CARBOXYLATE) IN 20 ML DMF WITH $1.6 \mathrm{MM} \mathrm{H}_{2} \mathrm{O}$ AT $110^{\circ} \mathrm{C}$.......... 98 FIGURE 3-11: HPLC REACTION TIME COURSE FOR THE DECARBOXYLATION OF 18 (2.251 MM; $K=$ 0.007) IN DMF AT $110^{\circ} \mathrm{C}$. RED POINTS INDICATE FIT OF THE CARBOXYLATE. ORANGE POINTS INDICATE FIT OF THE ARENE. 100

FigURE 3-12: HPLC REACTION TIME COURSE FOR THE DECARBOXYLATION OF 23 (1.659 MM; $K=$ 0.005) IN DMF AT $110^{\circ} \mathrm{C}$. RED POINTS INDICATE FIT OF THE CARBOXYLATE. ORANGE POINTS INDICATE FIT OF THE ARENE. 100

FigURE 3-13: HPLC REACTION TIME COURSE FOR THE DECARBOXYLATION OF 21 (1.633 MM; $K=$ 0.308) IN DMF AT $110^{\circ} \mathrm{C}$. RED POINTS INDICATE FIT OF THE CARBOXYLATE. ORANGE POINTS INDICATE FIT OF THE ARENE. 101

FiguRE 3-14: PRELIMINARY DATA ON THE CORRELATION OF LOG(K) WITH A) C=O STRETCHING FREQUENCIES, B) CARBONYL ${ }^{13}$ C SIGNALS, C) HOMO ENERGIES, D) LUMO ENERGIES AND E) THE MAGNITUDE OF THE DIPOLE MOMENT. 103

FIGURE 3-15: AN EXPANDED AND MORE INCLUSIVE SCOPE OF HETEROAROMATIC CARBOXYLIC ACIDS PROPOSED FOR THE CONTINUATION OF THIS STUDY. $X=\mathrm{S}, \mathrm{O}$, NME 104

FIGURE 3-16: THE HPLC CALIBRATION CURVES FOR BENZOTHIOPHENE-2-CARBOXYLIC ACID (RED) AND BENZOTHIOPHENE (BLACK). SAMPLES WERE RUN ON A 4.6 X 75 MM 3.5MM ZORBAX SBPHENYL COLUMN AT $50{ }^{\circ} \mathrm{C}$ WITH A $1.5 \mathrm{ML} / \mathrm{MIN}$ FLOW RATE UNDER GRADIENT ELUTION OF MEOH:MeCN:0.1\% TFA IN WATER WITH A UV DETECTOR SET TO 254 NM. 107

FIGURE 3-17: THE HPLC CALIBRATION CURVES FOR 3-METHYLBENZOTHIOPHENE-2-CARBOXYLIC ACID (RED) AND 3-METHYLBENZOTHIOPHENE (BLACK). SAMPLES WERE RUN ON A 4.6 X 75 MM 3.5MM ZoRbAX SB-PHENYL COLUMN AT $50{ }^{\circ} \mathrm{C}$ UNDER GRADIENT ELUTION OF MECN:0.1\% TFA IN WATER WITH A UV DETECTOR SET TO 254 NM. 108 
FIGURE 3-18: THE HPLC CALIBRATION CURVES FOR BENZOFURAN-2-CARBOXYLIC ACID (RED) AND BENZOFURAN (BLACK). SAMPLES WERE RUN ON A 4.6 X 75 MM 3.5MM ZORBAX SB-PHENYL COLUMN AT $50{ }^{\circ} \mathrm{C}$ WITH A 1.5 ML/MIN FLOW RATE UNDER GRADIENT ELUTION OF MEOH:MECN:0.1\% TFA IN WATER WITH A UV DETECTOR SET TO 254 NM. 108

FIGURE 3-19: THE HPLC CALIBRATION CURVES FOR 3-METHYLBENZOFURAN-2-CARBOXYLIC ACID (RED) AND 3-METHYLBENZOFURAN (BLACK). SAMPLES WERE RUN ON A 4.6 X 75 MM 3.5MM ZORBAX SB-PHENYL COLUMN AT $50{ }^{\circ} \mathrm{C}$ WITH A $1.5 \mathrm{ML} / \mathrm{MIN}$ FLOW RATE UNDER GRADIENT ELUTION OF MECN:0.1\% TFA IN WATER WITH A UV DETECTOR SET TO 254 NM. 109

FIGURE 3-20: THE HPLC CALIBRATION CURVES FOR PYRIDINE-2-CARBOXYLIC ACID (RED) AND PYRIDINE (BLACK). SAMPLES WERE RUN ON A 4.6 X 250 MM 3.5MM SIELC PRIMESEP 100 COLUMN AT $30{ }^{\circ} \mathrm{C}$ WITH A $1.0 \mathrm{ML} / \mathrm{MIN}$ FLOW RATE UNDER GRADIENT ELUTION OF MECN:0.1\% TFA IN WATER WITH A UV DETECTOR SET TO 254 NM. 109

FIGURE 3-21: THE HPLC CALIBRATION CURVES FOR 2-TRIFLUOROMETHYLPYRIDINE-3CARBOXYLIC ACID (RED) AND 2-TRIFLUOROMETHYLPYRIDINE (BLACK). SAMPLES WERE RUN ON A 4.6 X 250 MM 5MM LICHROSPHER 100 RP-18 ENDCAPPED COLUMN AT $40^{\circ} \mathrm{C}$ WITH A 1.0 ML/MIN FLOW RATE UNDER GRADIENT ELUTION OF MECN:MEOH:0.1\% TFA IN WATER WITH A UV DETECTOR SET TO 254 NM. 110

FIGURE 3-22: THE HPLC CALIBRATION CURVES FOR 4-CHLOROPYRIDINE-2-CARBOXYLIC ACID (RED) AND 4-CHLOROPYRIDINE (BLACK). SAMPLES WERE RUN ON A 4.6 X 250 MM 3.5MM SIELC PRIMESEP 100 COLUMN AT $30{ }^{\circ} \mathrm{C}$ WITH A $1.0 \mathrm{ML} / \mathrm{MIN}$ FLOW RATE UNDER GRADIENT ELUTION OF MECN:0.1\% TFA IN WATER WITH A UV DETECTOR SET TO 254 NM...... 110

FIGURE 3-23: HPLC REACTION TIME COURSE FOR THE DECARBOXYLATION OF 14 (1.828 MM; $K=$ 0.924) IN DMF AT $110^{\circ} \mathrm{C}$. RED POINTS INDICATE FIT OF THE CARBOXYLATE. ORANGE POINTS INDICATE FIT OF THE ARENE. 111

FIGURE 3-24: HPLC REACTION TIME COURSE FOR THE DECARBOXYLATION OF 15 (1.833 MM; $K=$ 0.840) IN DMF AT $110^{\circ} \mathrm{C}$. RED POINTS INDICATE FIT OF THE CARBOXYLATE. ORANGE POINTS INDICATE FIT OF THE ARENE. 111

FIGURE 3-25: HPLC REACTION TIME COURSE FOR THE DECARBOXYLATION OF 16 (2.003 MM; $K=$ 0.402) IN DMF AT $110^{\circ} \mathrm{C}$. RED POINTS INDICATE FIT OF THE CARBOXYLATE. ORANGE POINTS INDICATE FIT OF THE ARENE. 
FigURE 3-26: HPLC REACTION TIME COURSE FOR THE DECARBOXYLATION OF 17 (1.599 MM; $K=$ 0.892) IN DMF AT $110^{\circ} \mathrm{C}$. RED POINTS INDICATE FIT OF THE CARBOXYLATE. ORANGE POINTS

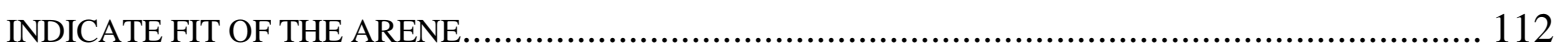




\section{List of Abbreviations}

${ }^{1} \mathrm{H}$ NMR

${ }^{13} \mathrm{C}$ NMR

${ }^{19} \mathrm{~F}$ NMR

$\sigma$

$\AA$

$\mathrm{AcOH}$

ATR

BP

BQ

${ }^{\circ} \mathrm{C}$

Calc'ed

cat.

d

DFT

DMA

DMF

DMSO

Et

equiv.

$E_{s}$

ESI

F

FT-IR

g

h

Het

HOMO

HRMS
Proton Nuclear Magnetic Resonance

Carbon Nuclear Magnetic Resonance

Fluorine Nuclear Magnetic Resonance

Hammett's Substituent Constant Parameter

Ångstrom

Acetic acid

Attenuated Total Reflection

Boiling Point

Benzoquinone

Degrees Celsius

Calculated

Catalytic

Day

Density Functional Theory

$\mathrm{N}, \mathrm{N}$-dimethylacetamide

$N, N$-dimethylformamide

Dimethyl sulfoxide

Ethyl

Equivalent

Steric Substituent Constants

Electrospray Ionization

Swain-Lupton-Hansch Field Effect Parameter

Fourier Transform Infrared Spectroscopy

Gram

Hour

Heteroaromatic

Highest Occupied Molecular Orbital

High-Resolution Mass Spectrometry 


\begin{tabular}{|c|c|}
\hline${ }^{i} \mathrm{Pr}$ & Isopropyl \\
\hline LFER & Linear Free Energy Relationship \\
\hline LUMO & Lowest Unoccupied Molecular Orbital \\
\hline M & Molar \\
\hline $\mathrm{mM}$ & Millimolar \\
\hline $\mathrm{Me}$ & Methyl \\
\hline $\mathrm{MHz}$ & Megahertz \\
\hline Min & Minutes \\
\hline mol & Mole \\
\hline mmol & Millimole \\
\hline $\mathrm{mp}$ & Melting Point \\
\hline $\mathrm{m} / \mathrm{z}$ & Mass to Charge Ratio \\
\hline MS & Molecular Sieves \\
\hline MW & Microwave \\
\hline NMP & $N$-methyl-2-pyrrolidone \\
\hline NMR & Nuclear Magnetic Resonance \\
\hline $\mathrm{OA}$ & Oxidative Addition \\
\hline OAc & Acetate \\
\hline ODC & Oxidative Decarboxylative Coupling \\
\hline OTf & Trifluoromethyl sulfonate \\
\hline $\mathrm{Ph}$ & Phenyl \\
\hline phen & 1,10-Phenanthroline \\
\hline ppm & Parts per Million \\
\hline $\mathrm{RE}$ & Reductive Elimination \\
\hline SET & Single Electron Transfer \\
\hline TFA & Trifluoroacetate \\
\hline$X$ & Halogen atom \\
\hline
\end{tabular}




\section{Chapter 1 - Introduction}

\subsection{Traditional Cross-Coupling for the Generation of Biaryl Compounds}

The biaryl motif has become a ubiquitous structure in a variety of pharmaceutical and industrially relevant compounds. ${ }^{[1,2]}$ This motif can be constructed via a number of well-known reactions, such as the Suzuki-Miyaura, Kumada-Tamao-Corriu, Negishi, Stille and Hiyama coupling reactions (Scheme 1-1). These reactions all utilize a palladium (or nickel) catalyst and undergo similar $\mathrm{Pd}^{0} / \mathrm{Pd}^{\mathrm{II}}$ ( or $\mathrm{Ni}^{0} / \mathrm{Ni}^{\mathrm{II}}$ ) catalytic cycles consisting of three characteristic elementary steps: oxidative addition (OA), transmetallation, and reductive elimination (RE) (Figure 1-1). ${ }^{[3]}$ Overall, these powerful reactions are widely used for their relative ease and functional group tolerances. This has been well demonstrated in 2010 when Pd-catalyzed cross-coupling reactions won the Nobel Prize in Chemistry. ${ }^{[4]}$ While these reactions have received considerable attention, the pharmaceutical industry has begun to move away from their utilization because they all suffer from the use of expensive and/or reactive pre-generated organometallic starting materials and a toxic and difficult to remove palladium catalyst. These challenges with traditional cross-coupling reactions have fueled the rapid development of alternative methods for the construction of the biaryl motif through cross-coupling reactions using base metal catalysts, such as complexes of $\mathrm{Ni}$,

$\mathrm{Co}, \mathrm{Fe}$, or $\mathrm{Cu},{ }^{[5-8]}$ as well as the exploration of less expensive and reactive starting materials, such as carboxylic acids. 


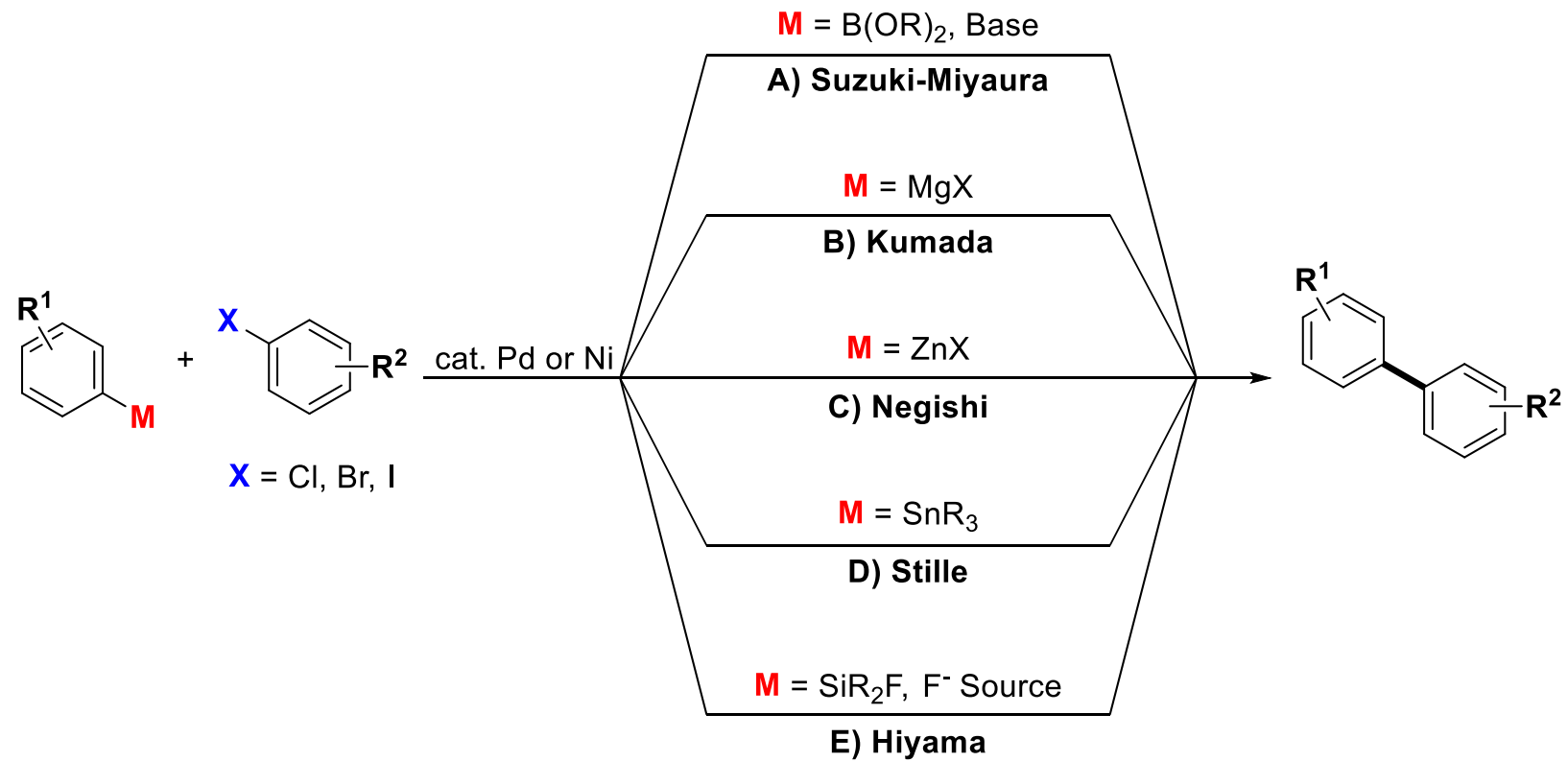

Scheme 1-1: Examples of traditional cross-coupling reactions. The formed bond is indicated in bold.

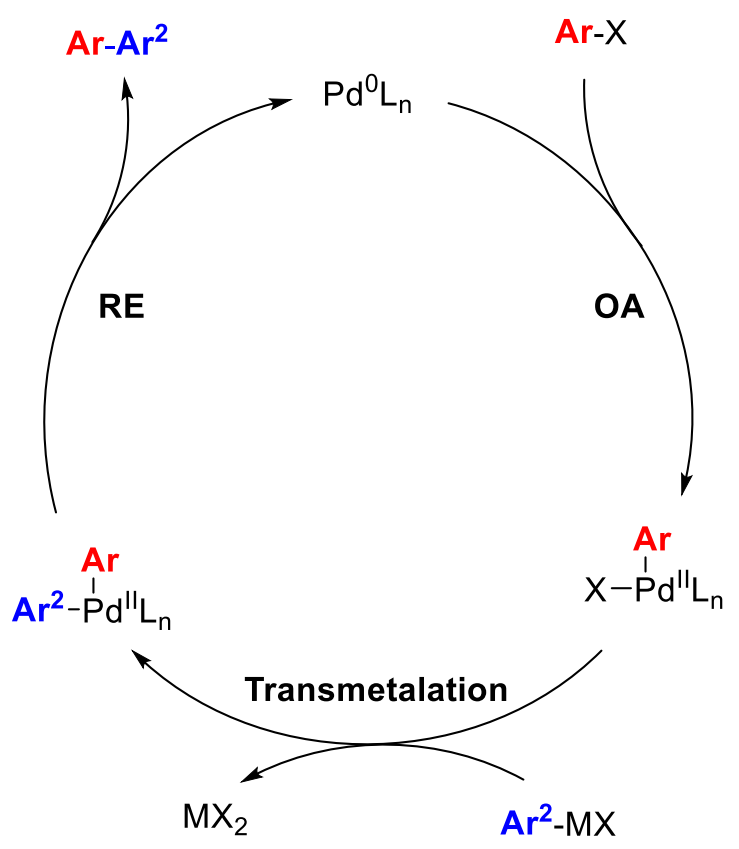

Figure 1-1: General reaction mechanism for traditional palladium-catalyzed cross-coupling in which a palladium $(0)$ catalyst undergoes oxidative addition (OA), transmetallation, and reductive elimination (RE). 


\subsection{Redox-Neutral Decarboxylative Cross-Coupling}

Decarboxylative cross-coupling has become a powerful alternative to the traditional cross-coupling protocols mentioned in the previous section. These systems attempt to solve the need for an expensive organometallic starting material by utilizing cheap and readily available carboxylic acid starting materials. The first decarboxylative synthesis of biaryl compounds was reported in 1966 by Nilsson. ${ }^{[9]}$ In this report, ortho-nitrobenzoic acids were found to undergo decarboxylative coupling with aryl iodides in the presence of stoichiometric copper (Scheme 1-2A). Although this initial reaction utilizes rather harsh conditions $\left(240{ }^{\circ} \mathrm{C}\right)$, it showcased the use of benzoic acids as nucleophilic coupling partners for cross-coupling reactions. This insight did not see further use until 1997 and 2000 when Steglich and co-workers performed the biomimetic total synthesis of Lamellarin G and Lamellarin L (Scheme 1-2B). ${ }^{[10,11]}$ These reports illustrated the first reported Pd catalyzed decarboxylative coupling of two aryl fragments. This reaction quickly sparked further investigation of decarboxylative Heck-type reactions by the Myers group in 2002. In this seminal report, a Pd/Ag system was employed to generate 18 examples of the decarboxylative coupling of both benzoic acids and heteroaromatic acids with alkene reagents in good to excellent yields (Scheme 1-2C). ${ }^{[12]}$ Unfortunately, this report showcases a limited scope of (hetero)aromatic carboxylic acids: 2- $\mathrm{NO}_{2}-\mathrm{C}_{6} \mathrm{H}_{4}, 2-\mathrm{OMe}-\mathrm{C}_{6} \mathrm{H}_{4}$, 2,6- $\mathrm{F}_{2}-\mathrm{C}_{6} \mathrm{H}_{3}, \mathrm{C}_{6} \mathrm{~F}_{5}, 2,4,6-\mathrm{Me}_{3}-\mathrm{C}_{6} \mathrm{H}_{2}$, 5-Ar-2-furan, 2-OMe-3-pyridine, 3-Me-2-benzofuran, and 3-Me-2-thiophene.

In 2006, Gooßen and co-workers reported the first $\mathrm{Pd} / \mathrm{Cu}$ co-catalytic system for the decarboxylative coupling of benzoic acids with aryl halides (Scheme 1-3). ${ }^{[13]}$ Under the catalytic conditions, the decarboxylative coupling was limited to benzoic acids bearing ortho-nitro, ortho-formyl, ortho-acyl, ortho-fluoro, ortho-methoxy, or ortho-sulfonyl groups. Further investigation into this reaction by the Goossen group in 2007 revealed that conditions utilizing a co-catalytic $\mathrm{PdBr}_{2} / \mathrm{CuBr}$ system, allowed for the decarboxylative coupling of a small set of benzoic acids (ortho-nitro, ortho-formyl, ortho-acyl, ortho-fluoro, ortho-methoxy, ortho-cyano, ortho-trifluoromethyl, or ortho-sulfonyl groups) (Scheme 1-3). ${ }^{[14]}$ In a follow-up study, it was suggested that bromide ions compete with the carboxylates for coordination to copper making the anion exchange step of the proposed mechanism (Figure 1-2) difficult. This issue was initially 
solved by utilizing stoichiometric amounts of the copper reagent, but a later report by the same group utilized aryl triflates in an attempt to expand the scope of the catalytic copper reaction. ${ }^{[15]}$ This new approach eliminated the need for the ortho-substituent of the benzoic acids because the triflate anion weakly bonds to copper allowing for the easy displacement by the carboxylate anion regardless of the substitution pattern of the benzoic acid. This protocol showcased a broader scope of ortho-, meta-, and para- substituted benzoic acids.

A) Nilsson (1966):

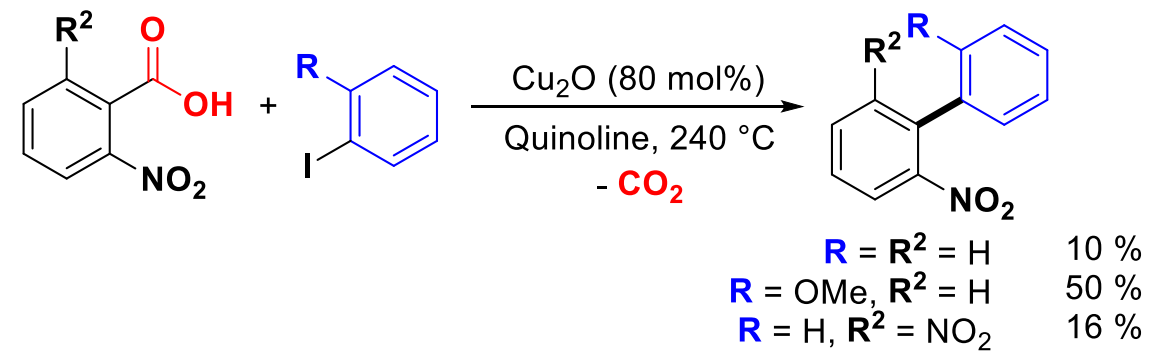

B) Steglich (1997 \& 2000):<smiles>[R]Oc1cc(CCn2c(C(=O)O)c(-c3ccc(OC)c([R6])c3)c3c4cc(OC)c(OC)cc4oc(=O)c32)c(Br)cc1OC</smiles>

$\mathrm{Pd}(\mathrm{OAc})_{2}$ (1 equiv)

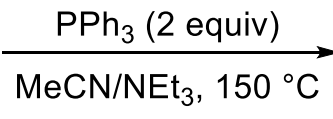
$-\mathrm{CO}_{2}$<smiles>[R]OC1=Cc2oc(=O)c3c4cc(OC)c(OC)cc2c2c(-c5ccc(OC)c(O[R])c5)c=3c4n2CCc2cc(O[R])c(OC)cc21</smiles>

C) Myers (2002):
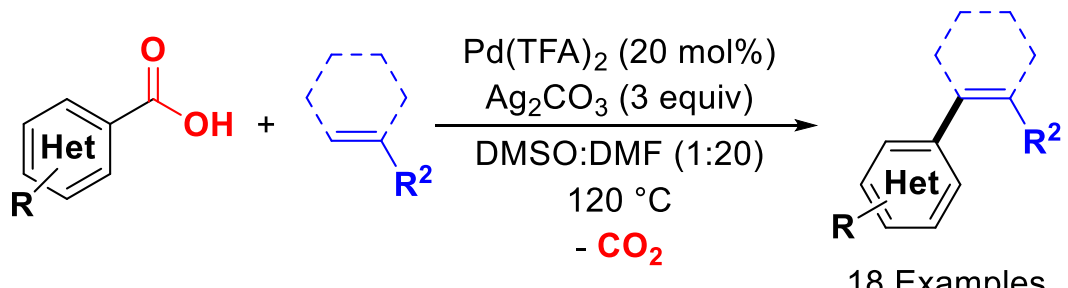

$(42-99 \%)$

Scheme 1-2: A) Nilsson's decarboxylative cross-coupling of nitrobenzoic acid with aryl iodides. B) Steglich and co-workers' synthesis of Lamellarin $\mathrm{G}(\mathrm{R}=\mathrm{Me})$ and Lamellarin $\mathrm{L}\left(\mathrm{R}={ }^{i} \mathrm{Pr}\right)$. C) Myers' $\mathrm{Pd} / \mathrm{Ag}$ decarboxylative Heck coupling of carboxylic acids with alkene reagents. 


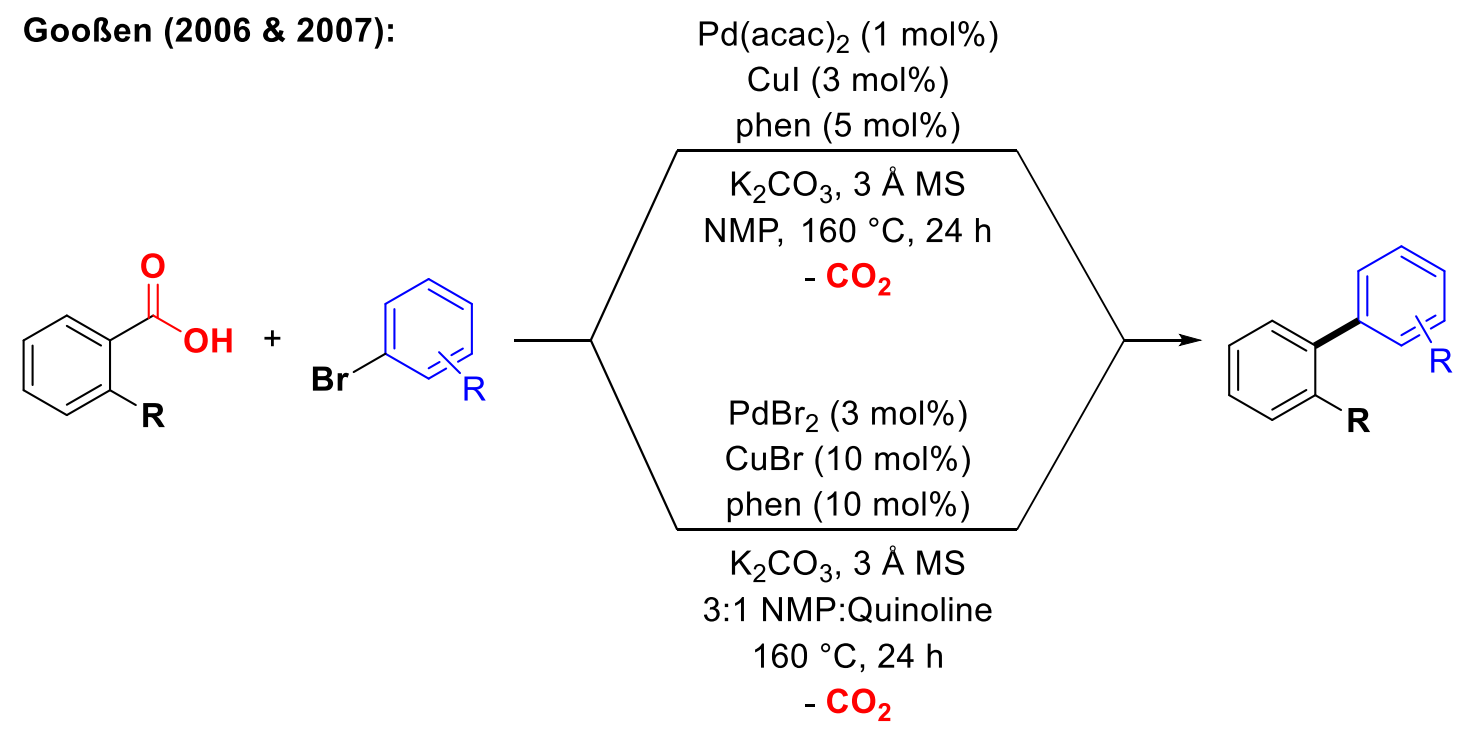

Scheme 1-3: Gooßen and co-workers' Pd/Cu catalyzed decarboxylative coupling of benzoic acids with aryl bromides.

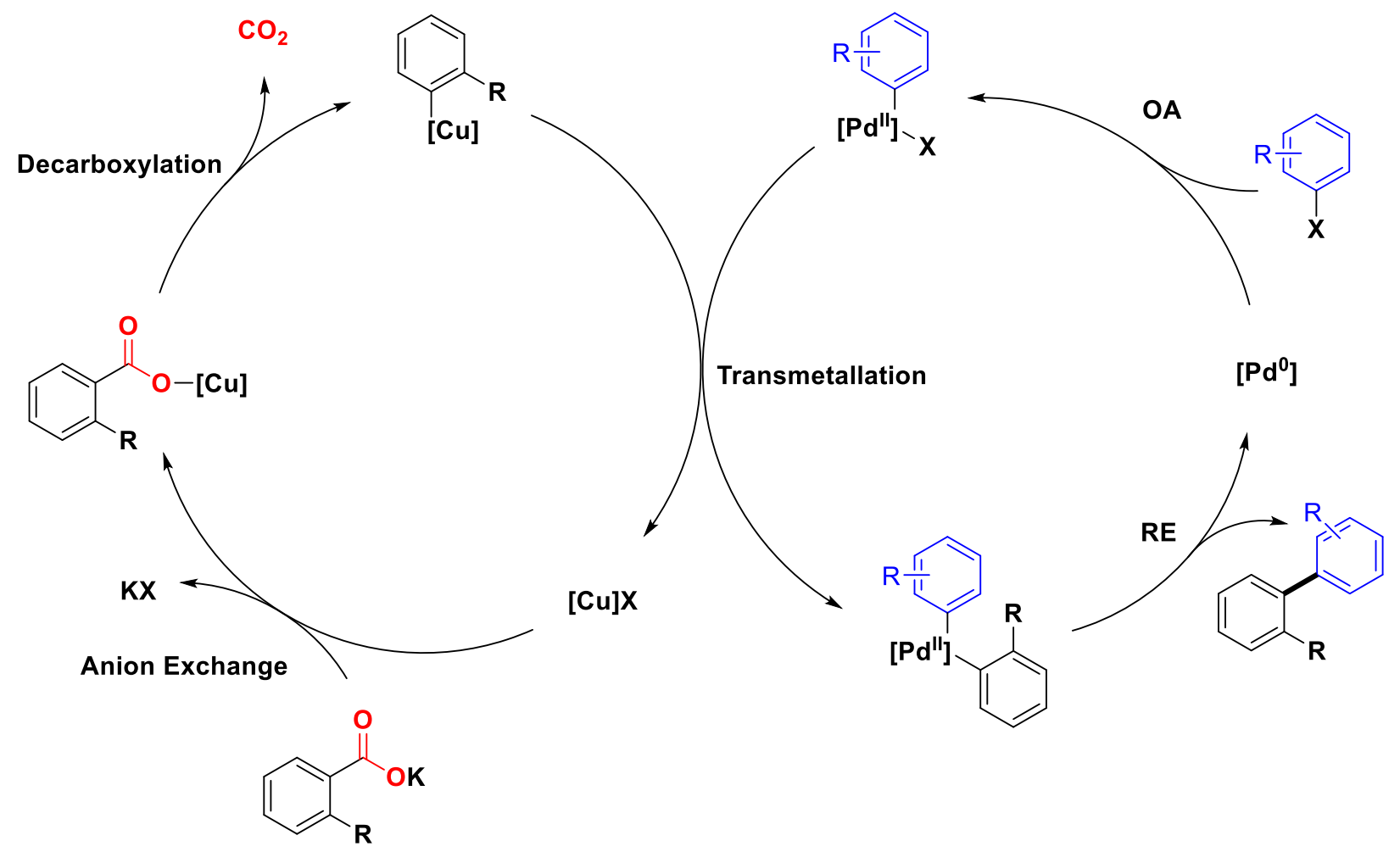

Figure 1-2: Proposed mechanism for the decarboxylative coupling of benzoic acids with aryl halides under the $\mathrm{Pd} / \mathrm{Cu}$ system. 
Based on the realization that copper can effectively decarboxylate a broad scope of benzoic acids, Liu and co-workers developed a $\mathrm{Cu}$ only system for the decarboxylative coupling of fluorinated benzoates with aryl halides. ${ }^{[16]}$ In this study, density-functional theory (DFT) calculations suggest a pathway in which a copper(I) carboxylate extrudes $\mathrm{CO}_{2}$ to form a perfluorophenyl copper(I) species that subsequently reacts with an aryl halide via an OA/RE sequence to yield an unsymmetrical biaryl.

\subsection{Oxidative Decarboxylative Cross-Coupling (ODC)}

The previous section discussed redox neutral decarboxylative cross coupling reactions. While those reactions utilize an aryl halide compound as coupling partner, a potentially more powerful class of decarboxylative cross-coupling reaction also can be seen in literature, known as oxidative decarboxylative cross-coupling. This oxidative variant allows for the utilization of nucleophilic coupling partners rather than halogenated coupling partners. ${ }^{[17]}$ This oxidative variant is powerful because it allows for the direct arylation of $\mathrm{C}-\mathrm{H}$ and $\mathrm{X}-\mathrm{H}$ bonds using (hetero)aromatic carboxylic acids (Scheme 1-4) and display high regioselectivity as well as high atom efficiency. The oxidative decarboxylative cross-coupling reaction class is comprised of many sub-classes depending on the type of coupling partners used in the transformation (C-H, N-H, S-H, P-H, etc.). The $\mathrm{C}-\mathrm{H}$ functionalization strategy for ODC reactions are particularly attractive due to the elimination of the prefunctionalized coupling partners used in traditional and redox-neutral decarboxylative cross-coupling reactions. A variety of different systems $\left(\mathrm{Ni} / \mathrm{Ag},{ }^{[18-20]} \mathrm{Pd} / \mathrm{Ag},{ }^{[21]}\right.$ $\mathrm{Cu} / \mathrm{O}_{2},{ }^{[22-24]} \mathrm{Cu} / \mathrm{Ag},{ }^{[25]}$ and others) have been employed to achieve ODC reactions. The early reports, however, employ peroxide- or persulfate-based oxidants and proceed through a radical or single electron transfer (SET) pathway. ${ }^{[26-34]}$ 
ODC reactions with $\mathrm{X}-\mathrm{H}$ coupling partners:

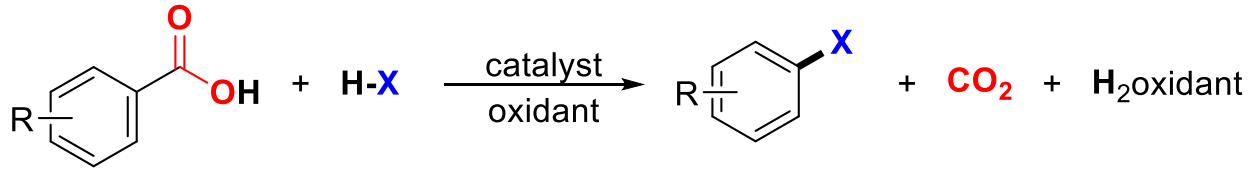

$X=O R, S R, N R_{2}, P(O) R_{2}$, etc

ODC reactions with $\mathrm{C}-\mathrm{H}$ coupling partners:

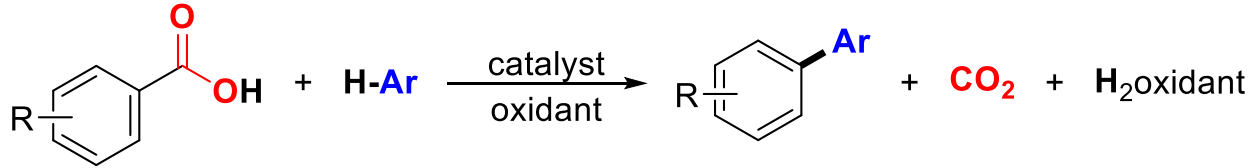

Scheme 1-4: The Oxidative Decarboxylative Coupling (ODC) Reaction

Crabtree, ${ }^{[35]}$ Larrosa, ${ }^{[36]} \operatorname{Tan}^{[37]} \mathrm{Su}^{[38-41]}{ }^{\text {Gooßen }}{ }^{[13,15,42-44]}$ and others ${ }^{[18-20,25,45]}$ have studied ODC reactions and all reports are largely limited to the decarboxylative coupling of a small set of ortho-substituted benzoic acids (Figure 1-3), as well as a small scope of heteroaromatic acids. The early system for ODC developed by Crabtree allowed for both the intramolecular and intermolecular arylation of arenes with electron-rich aromatic carboxylates. ${ }^{[35]}$ Utilizing this methodology, Glorius and co-workers were able to construct a variety of dibenzofurans via the intramolecular arylation of 2-phenoxybenzoic acids. ${ }^{[46]}$ Through the efforts of Larrosa ${ }^{[47]}$ and $\mathrm{Su}^{[38]}$ the benzoic acid scope for the oxidative decarboxylative cross-coupling of $N$-protected indoles was expanded to include both electron-rich and electron-deficient ortho-substituted benzoic acids (Scheme 1-5). Under these conditions, electron-deficient benzoic acids formed the 3-arylindole product while electron-rich benzoic acids formed the 2-arylindole product.<smiles>O=C(O)c1cc[R]#cc1[N+](=O)[O-]</smiles><smiles>O=C(O)c1cc[R]#cc1F</smiles><smiles>O=C(O)c1cc[R]#cc1Cl</smiles><smiles>[R]#CC=C(C(=O)O)C(=O)OC</smiles>

Figure 1-3: Typical benzoic acid scope that undergo efficient cross-coupling in both redox-neutral and oxidative decarboxylative cross-coupling reactions. 


\section{Crabtree (2008):}

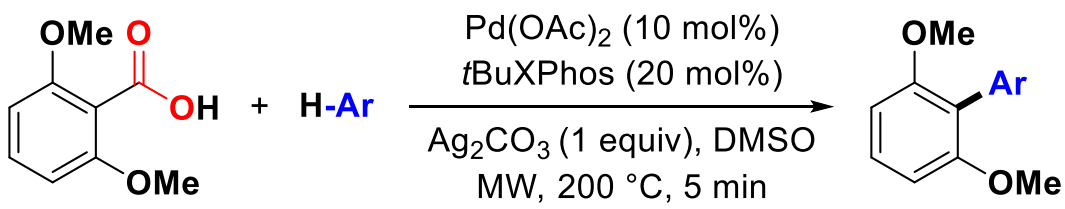

Glorius (2009):

- $\mathrm{CO}_{2}$

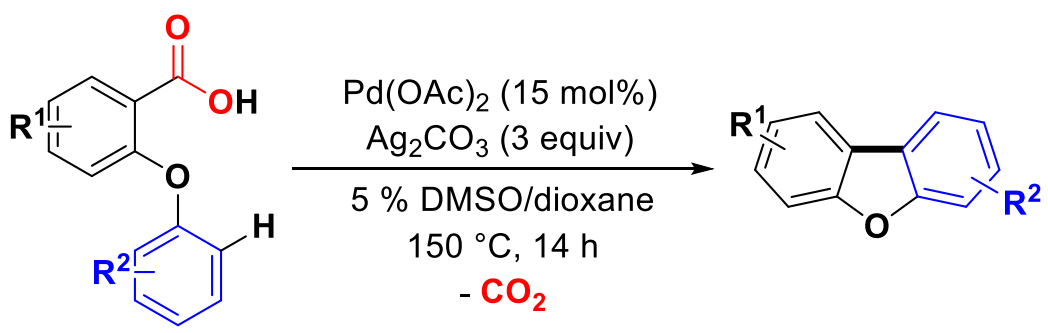

Larrosa (2009):

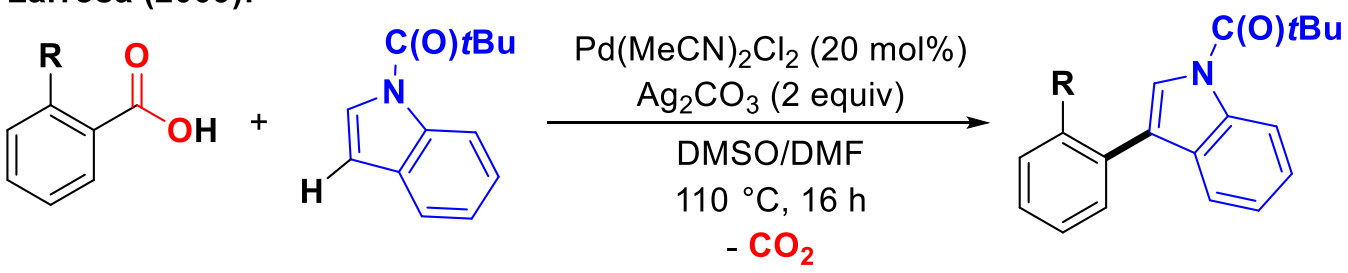

Su (2010):<smiles>[R]c1ccccc1C(=O)O</smiles><smiles>[R]n1ccc2ccccc21</smiles>

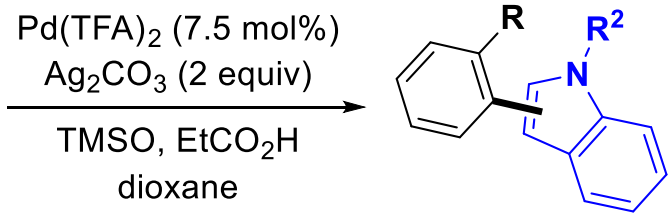

$80^{\circ} \mathrm{C}, 24 \mathrm{~h}$ $-\mathrm{CO}_{2}$

Scheme 1-5: Oxidative decarboxylative coupling reactions developed by Crabtree, Glorius, Larrosa, and Su.

While the palladium-catalyzed oxidative decarboxylative coupling reactions have been well studied, these systems still suffer from the ortho-substituted benzoic acid substrate limitation. Recent work on oxidative decarboxylative cross-coupling reactions has shifted interest to other catalytic systems $\left(\mathrm{Cu} / \mathrm{Ag}, \mathrm{Cu} / \mathrm{O}_{2}, \mathrm{Ni} / \mathrm{Ag}\right)$ attempting to expand this limited scope of benzoic acids while also utilizing more abundant catalysts. The Hoover ${ }^{[25]}$ and Maiti ${ }^{[24]}$ groups have developed protocols for oxidative decarboxylative cross-coupling of benzoic acids with benzoxazoles and benzothiazoles using a copper catalyst paired with either a silver-based oxidant or oxygen (Scheme 1-6). Under Hoover's $\mathrm{Cu} / \mathrm{Ag}$ conditions, the scope of benzoic acids was limited to solely 
derivatives of 2-nitrobenzoic acid. Maiti's $\mathrm{Cu} / \mathrm{O}_{2}$ conditions, however, allowed for a slight improvement in the substrate scope of the benzoic acids to include fluorinated benzoic acids as well as 2-nitrobenzoic acid derivatives. Interestingly, these reactions are limited to these two benzoic acids, while other commonly used benzoic acid derivatives, such as 2-methyoxybenzoic acid, are unreactive under either reaction conditions. The Maiti group proposed a mechanism in which the benzoic acid is decarboxylated by copper to form an arylcopper(I) intermediate which then reacts with benzoxazole and $\mathrm{O}_{2}$ to form the coupled product. In the Hoover group's reaction both copper and silver could be responsible for the decarboxylation step. Various groups have also investigated $\mathrm{Ni} / \mathrm{Ag}$ systems for the oxidative decarboxylative cross-coupling of benzoic acids. ${ }^{[18,45]}$ In 2014, Zhang and Lu and in 2015 the Kalyani group published Ni/Ag systems analogous to the Hoover reaction conditions (Scheme 1-7). ${ }^{[20,45]}$ Unfortunately, both of these reactions were also limited to only ortho-nitro or ortho-fluorobenzoic acids. These results suggest that the benzoic acid scope limitation may be caused by traits inherent to the benzoic acid that cannot be overcome by tuning the catalyst system.

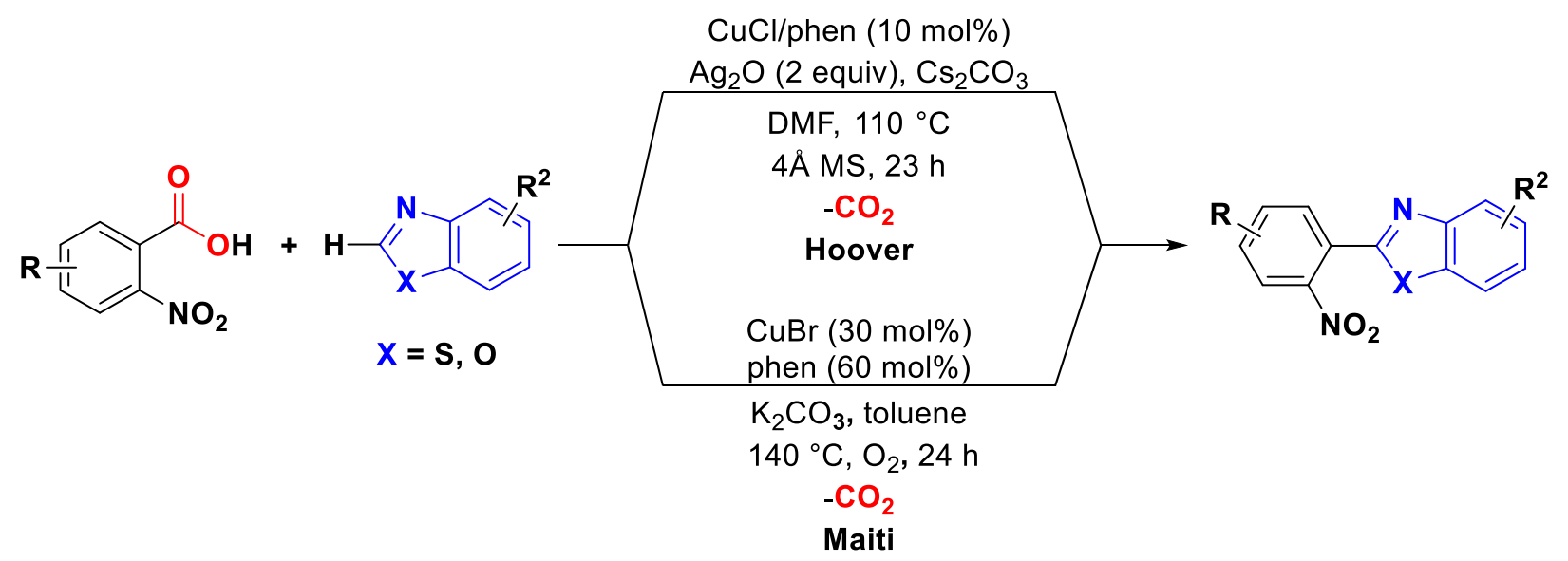

Scheme 1-6: The copper-catalyzed decarboxylative arylation reported by Hoover (top) and Maiti (bottom) 


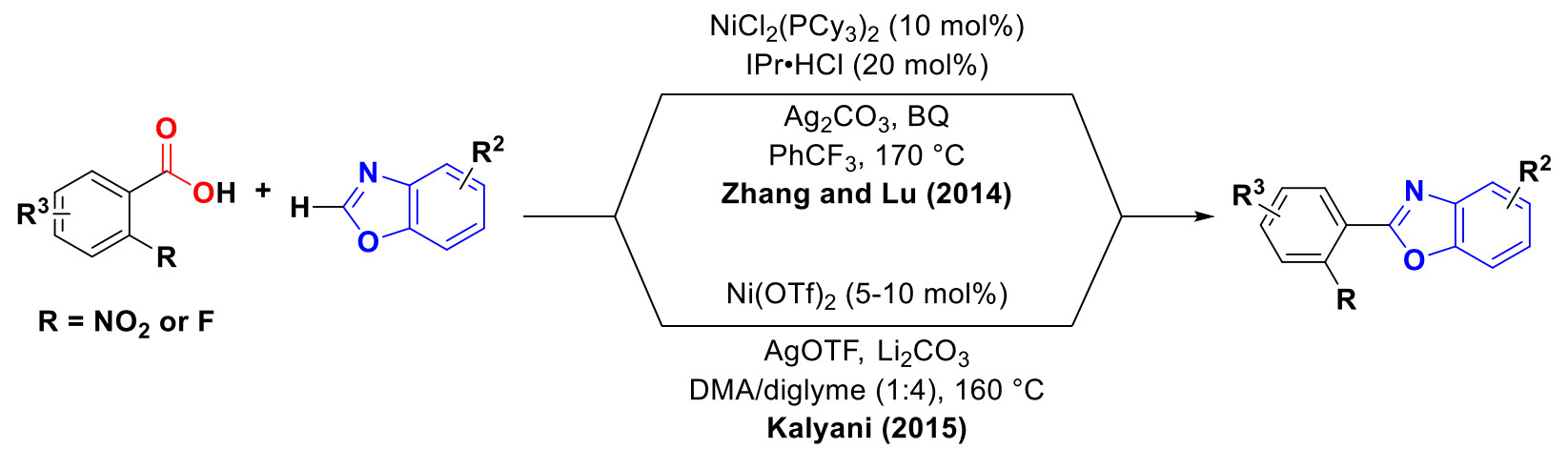

Scheme 1-7: Zhang and Lu's (top) and Kalyani's (bottom) Ni/Ag systems for the oxidative decarboxylative cross-coupling $\mathrm{C}-\mathrm{H}$ arylation of benzoxazoles.

\subsection{Protodecarboxylation}

While redox-neutral and oxidative decarboxylative coupling reactions involve the transition metal-catalyzed/mediated decarboxylation of a carboxylic acid followed by transmetallation to enable cross-coupling, protodecarboxylation involves the transition metalcatalyzed/mediated decarboxylation followed by a protodemetallation. This removal of the carboxylic acid functional group may not immediately seem synthetically useful, as generally chemists aim to add functionality to molecules; however, protodecarboxylation allows for the selective and facile introduction of a hydrogen into an arene system. This technique is also essential for studying the key decarboxylation step independently. In many of the studies mentioned above the protodecarboxylation product is observed as a byproduct, nevertheless, interesting trends can be observed by looking at these reactions. Many of the systems for protodecarboxylation have broader scopes of viable carboxylic acid substrates than those of their redox-neutral and oxidative decarboxylative cross-coupling counterparts. ${ }^{[36,43,48-53]}$ However, the protodecarboxylation of many substrates requires rather harsh temperatures $\left(110-250{ }^{\circ} \mathrm{C}\right)$, such as the first example of a copper-promoted decarboxylation of furanoic acids at $250{ }^{\circ} \mathrm{C}$ by Shepard ${ }^{[54]}$ in 1930 (Scheme 1-8 top). Nilsson, ${ }^{[55]}$ Sheppard ${ }^{[56]}$ and Cohen ${ }^{[57]}$ further developed the scope of this reaction to include benzoic acids with various electron-deficient ortho-substituents, phenylacetic acids, and 2-thienoic acids but still requiring stoichiometric copper loadings in most cases. A few decades later, Gooßen and co-workers were able to greatly enhance Shepard's reaction by utilizing catalytic amounts of copper(I) oxide with phenanthroline or 
bathophenanthroline as a ligand in a mixture of NMP and quinoline (Scheme 1-8 bottom). ${ }^{[48]}$ These new reaction conditions allowed for the decarboxylation of an assortment of benzoic acids bearing ortho-, meta-, and para-substituents such as nitro, methoxy, fluoro, chloro, amines, formyl, cyano, hydroxy, and sulfonyl. A few years later, Gooßen and co-workers developed a new protocol for the Ag-catalyzed protodecarboxylation of benzoic acids (Scheme 1-9) allowing for the decarboxylation of ortho-substituted benzoic acids $\left(\mathrm{R}=2-\mathrm{OMe} ; 2-\mathrm{NO}_{2} ; 2,6-\mathrm{OMe}\right.$; 2-Br; 2,6$\mathrm{Cl} ; 2-\mathrm{SO}_{2} \mathrm{Me} ; 2-\mathrm{CF}_{3} ; 2-\mathrm{C}(\mathrm{O}) \mathrm{O}$ Pr; 2-Ac; and 2-CN) at lower temperatures than their previous $\mathrm{Cu}-$ catalyzed report. ${ }^{[43]}$ Concurrent with Gooßen's report, Larrosa and co-workers revealed a very similar protocol for the Ag-catalyzed protodecarboxylation of benzoic acids, again requiring the presence of an ortho-substituent $\left(\mathrm{R}=2-\mathrm{Cl} ; 2-\mathrm{NO}_{2} ; 2-\mathrm{NO}_{2}-6-\mathrm{Me}\right.$; 2-Br; 2,6-Cl; 2,6-F; 2,6-OMe; 2 $\mathrm{OMe} ; 2,6-\mathrm{OH}$; and 2-F-6- $\left.\mathrm{NH}_{2}\right)\left(\right.$ Scheme 1-9). ${ }^{[51]}$

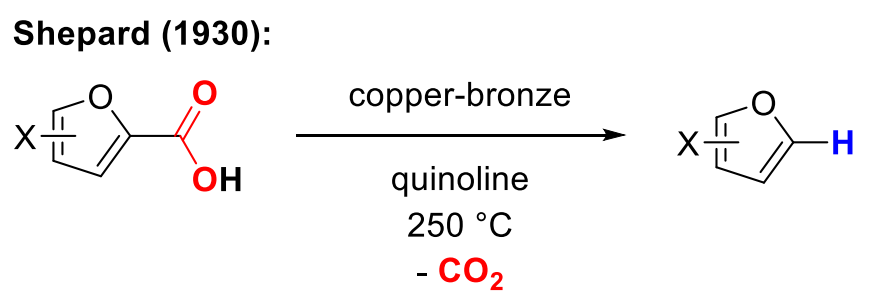

Gooßen (2007):

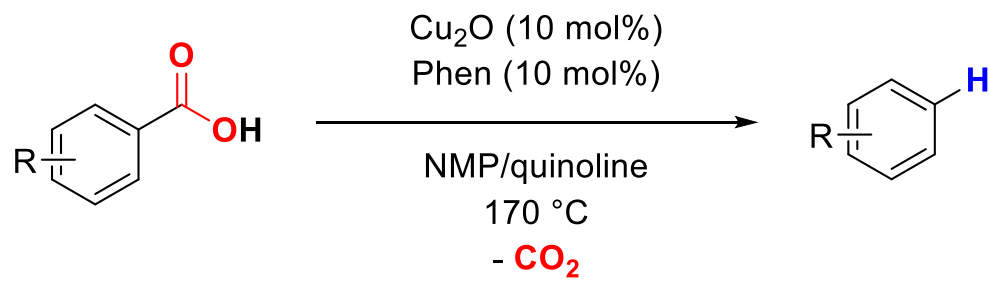

Scheme 1-8: Copper-catalyzed protodecarboxylations by the Shepard group (top) and the Gooßen group (bottom). 


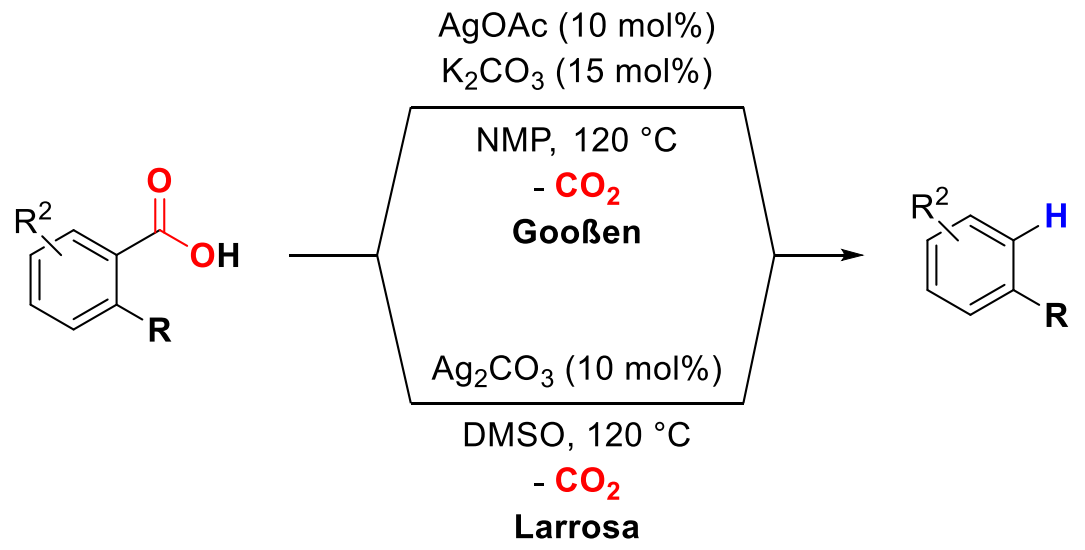

Scheme 1-9: Ag-Catalyzed protodecarboxylation by the Gooßen (top) and Larrosa (bottom) groups.

Attempting to understand the influence of the benzoic acid substituents on the decarboxylation step and substrate limitation in these Ag-catalyzed systems, various groups set out to study these reactions in more detail. In 2010, Gooßen and co-workers utilized both computational and experimental methods to investigate the influence of 1) the metal and 2) substituent position on the benzoic acid during the decarboxylation step (Scheme 1-10). ${ }^{[58]}$ Using both copper and silver catalyst systems, the decarboxylation was calculated to proceed through a transition state in which the aryl fragment binds to both the carbonyl carbon and the metal atom (Scheme 1-10, bottom). Calculating the activation barriers for the decarboxylation step of the reactions at $120{ }^{\circ} \mathrm{C}$ shows a lower activation energy barrier for the silver-mediated protodecarboxylation than for the copper analogue (silver with phen ligand: $\Delta \mathrm{G}_{393}^{\ddagger}=29.5 \mathrm{kcal} \cdot \mathrm{mol}^{-1}$; copper: $\left.\Delta \mathrm{G}_{393}^{\ddagger}=31.3 \mathrm{kcal} \cdot \mathrm{mol}^{-1}\right)$. Changing the substitution from the ortho to the para position increases the activation energy barrier (silver with phen ligand: $\Delta \mathrm{G}_{393}^{\ddagger}=33.2 \mathrm{kcal} \cdot \mathrm{mol}^{-1}$; copper: $\left.\Delta \mathrm{G}_{393}^{\ddagger}=34.2 \mathrm{kcal} \cdot \mathrm{mol}^{-1}\right)$. Su and Lin studied the ortho-substrate limitation in decarboxylation reactions by computational methods (Scheme 1-11). ${ }^{[59]}$ In this study, initial calculations of the protodecarboxylation of silver benzoate complexes show no clear correlation between the activation barriers and the electronic properties (Table 1-1), but definitively show $\mathrm{NO}_{2}, \mathrm{C}(\mathrm{O}) \mathrm{R}\left(\mathrm{R}=\mathrm{H}, \mathrm{Me}, \mathrm{NMe}_{2}\right)$ substituents give low reaction energy barriers while $\mathrm{NH}_{2}$ and $\mathrm{OH}$ substituents give higher barriers. Further calculations showed that ortho-substituents destabilize the starting complex via steric effects while stabilizing the transition 
state through coordination of the substituent to the metal center (Scheme 1-11). These two studies combined show three important aspects for protodecarboxylation reactions 1) silver lowers the activation energy barrier more than copper, 2) ortho-substituents lower the energy barrier more than para-substituents, and 3) coordinating ortho-substituents destabilize the starting complex while stabilizing the transition state during the decarboxylation reaction.

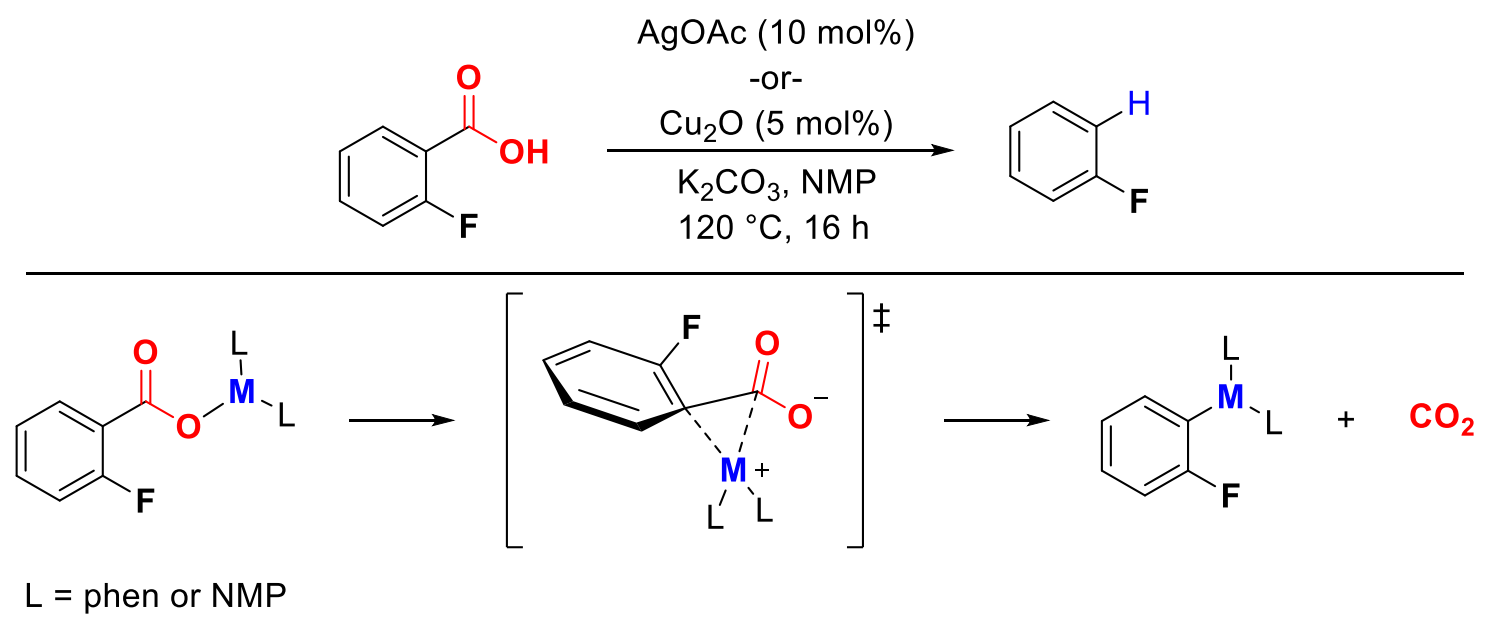

Scheme 1-10: Gooßen's calculated pathway for decarboxylation (top) and the proposed pathway for decarboxylation (bottom). 


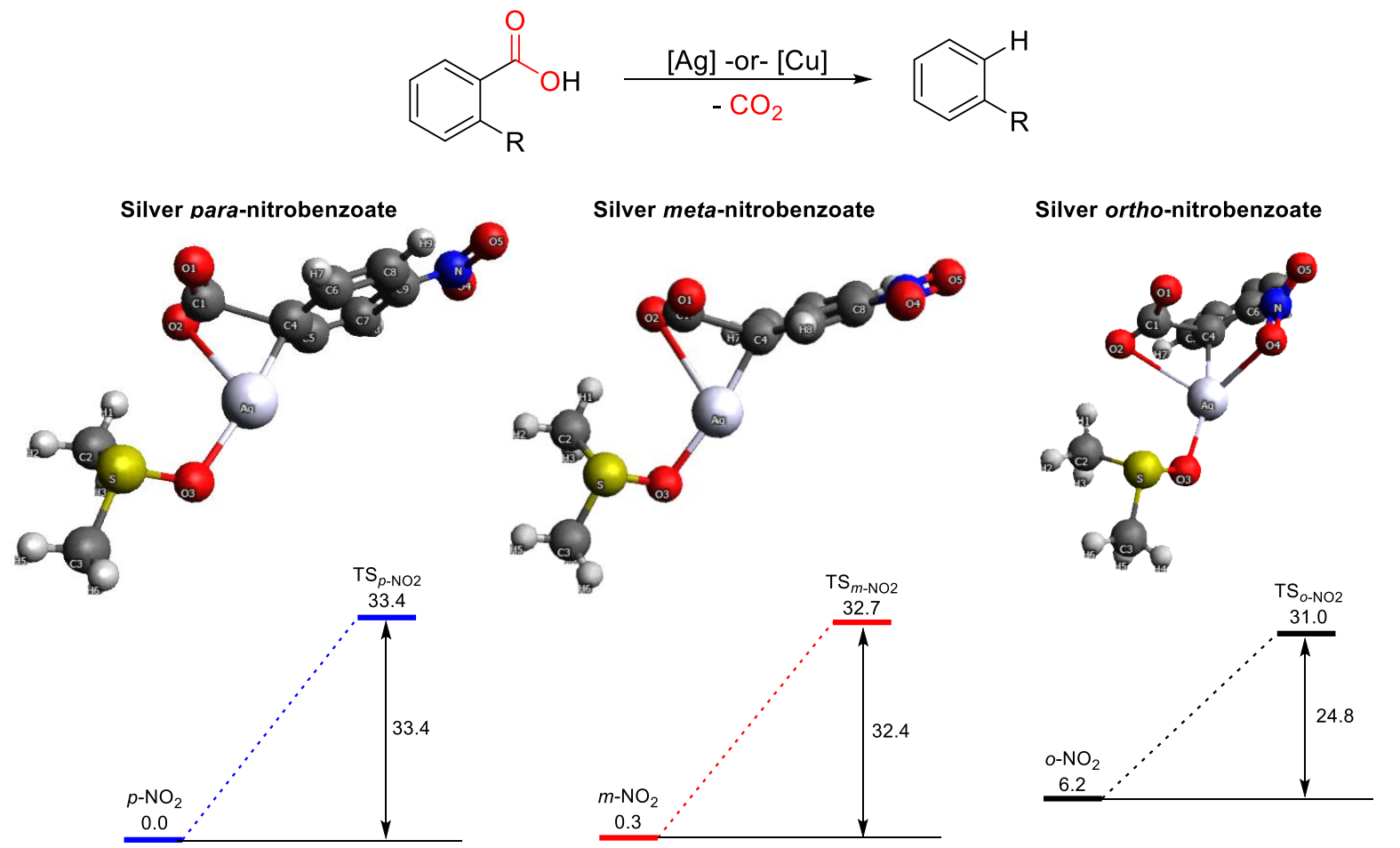

Scheme 1-11: Su's model system for the computational studies of the decarboxylation of ortho-substituted benzoic acids and their DFT calculated transition states of the decarboxylation of differently substituted (DMSO)Ag(benzoate) complexes for the decarboxylation of the DMSO ligated silver $o$-nitrobenzoate (left), silver $m$-nitrobenzoate (middle), and silver $p$-nitrobenzoate (right) complexes. Values correspond to the solvation-corrected relative free energies and are given in $\mathrm{kcal} \cdot \mathrm{mol}^{-1}$. 
Table 1-1: Activation barriers calculated for the silver catalyzed protodecarboxylation of ortho-substituted benzoic acids (Scheme 1-11). The values are the solvation-corrected free energy barriers.

\begin{tabular}{cc}
\hline $\boldsymbol{R}$ & $\boldsymbol{\Delta} \mathbf{G}_{\text {DMSO }}^{\ddagger}\left(\mathbf{k c a l} \cdot \mathbf{m o l}^{-\mathbf{1}}\right)$ \\
\hline $\mathrm{H}$ & 33.2 \\
ortho $-\mathrm{NO}_{2}$ & 24.8 \\
ortho $\mathrm{C}(\mathrm{O}) \mathrm{H}$ & 25.9 \\
ortho $\mathrm{C}(\mathrm{O}) \mathrm{Me}$ & 26.4 \\
ortho $\mathrm{C}(\mathrm{O}) \mathrm{NMe}_{2}$ & 25.5 \\
ortho-OMe & 26.8 \\
ortho- $\mathrm{Cl}$ & 28.1 \\
ortho $-\mathrm{Br}$ & 27.5 \\
ortho $-\mathrm{CN}$ & 30.7 \\
ortho-Me & 31.6 \\
ortho- $\mathrm{NH} \mathrm{N}_{2}$ & 32.0 \\
ortho- $\mathrm{OH}$ & 34.9 \\
\hline
\end{tabular}

In 2014, the Larrosa group reported an elegant computational and experimental mechanistic study in an attempt to further understand the effect of ortho-substituents in silvercatalyzed protodecarboxylation in an attempt to expand the limited scope of viable benzoic acid coupling partners (Scheme 1-12). ${ }^{[52]}$ In this study, Larrosa and co-workers again showed that ortho substituents significantly lower the activation energy barrier for decarboxylation compared to meta or para substituents because of both steric and electronic effects. The Fujita-Nishioka multiparameter linear free-energy relationship (LFER) was invoked as a method to compare ortho, meta, and para substituents as this LFER separates the polar and steric effects into three factors: "ordinary" polar, "proximity" polar, and steric. In this LFER, the "ordinary" and "proximity" polar contributions are represented by the Hammett and Swain-Lupton-Hansch constants, respectively, while the steric contribution is derived from the van der Waals radius of the functional group (more details on parameters used linear free-energy relationships, such as the FujitaNishioka, can be found in Section 1.5). Utilization of the Fujita-Nishioka relationship revealed that proximity polar effects enhance reaction rate, while steric effects diminish reaction rate. 


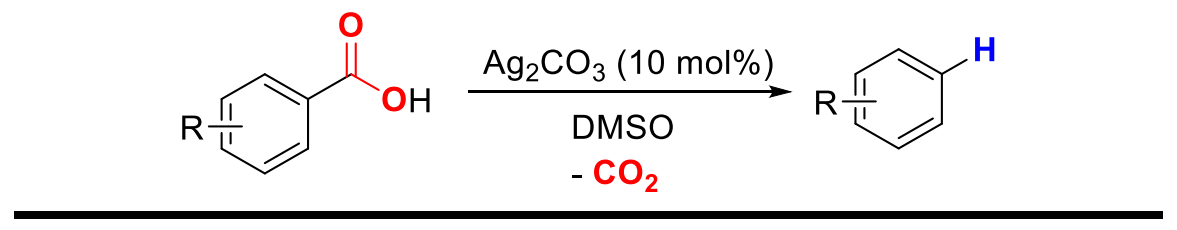

Fujita-Nishioka Equation:

$$
\ln \left(\frac{k_{R}}{k_{M e}}\right)=a \sigma+b E_{s}+c F+d
$$

Scheme 1-12: Larrosa and co-worker's Ag-catalyzed protodecarboxylation of benzoic acids and the Fujita-Nishioka relationship.

\subsection{Physical Organic Chemistry Overview}

This section will give a brief overview of important parameters that will be discussed in later chapters. The birth of the field of physical organic chemistry began in the 20th century with studies by Louis Hammett. This field of chemistry utilizes physical and thermodynamic parameters to explain reactivity patterns in organic reactions. Since the $20^{\text {th }}$ century, Hammett and many others have created many different correlations between kinetic parameters (e.g. rate or rate constant) and a range of physical and/or thermodynamic parameters describing electronic, geometric, or steric properties (eq. $\mathrm{pK}_{\mathrm{a}}$ values, sterimol values, bond lengths, bond dipoles, and electrostatic potentials, just to name a few). ${ }^{[60]}$ Collectively, these correlations are termed Linear Free-Energy Relationships.

\subsubsection{Hammett Parameters ( $\sigma)$}

The Hammett equation (Equation 1-1) is by far the most well-known linear free-energy relationship. This equation was proposed as an empirical method to relate reaction rates or equilibrium constants with the $\mathrm{pK}_{\mathrm{a}}$ values of a substituted benzoic acid. In Hammett's work, substituent constants, $\sigma$, were defined from the logarithm of the ionization constants of substituted benzoic acid and the logarithm of the ionization constant of unsubstituted benzoic acid (Scheme 1-13). ${ }^{[61]}$ These $\sigma$ values are dependent on the position of the substituent on the aryl ring ring $-\sigma_{p}$ and $\sigma_{m}$ for para and meta respectfully (common examples are shown in Table 1-2). This is because 
the $\sigma$ values are combinations of the field/inductive $\left(\sigma_{\mathrm{I}}\right)$ and resonance $\left(\sigma_{\mathrm{R}}\right)$ components, which will be described in further detail in section 1.5.2 (Equation 1-2). ${ }^{[62,63]}$

$$
\begin{aligned}
& \log \left(\frac{k}{k_{0}}\right)=\sigma \rho \\
& \sigma_{p}=\sigma_{I}+\sigma_{R}
\end{aligned}
$$

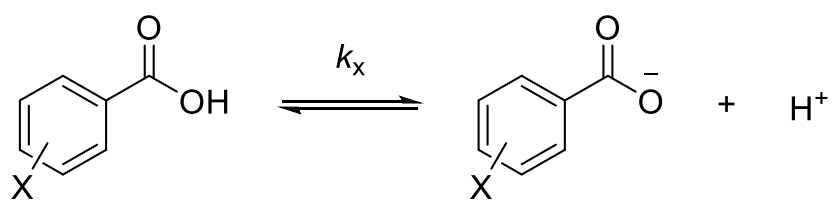

Scheme 1-13: Ionization of benzoic acids by Hammett for the determination of $\sigma$ constants.

Table 1-2: Hammett's $\sigma_{p}$ and $\sigma_{m}$ constants for common substituents. Values of all parameters are from reference [62].

\begin{tabular}{ccc}
\hline Substituent & $\sigma_{\boldsymbol{m}}$ & $\boldsymbol{\sigma}_{\boldsymbol{p}}$ \\
\hline$-\mathrm{NO}_{2}$ & 0.71 & 0.78 \\
$-\mathrm{CO}_{2} \mathrm{CH}_{3}$ & 0.37 & 0.45 \\
$-\mathrm{C}(\mathrm{O}) \mathrm{CH}_{3}$ & 0.38 & 0.50 \\
$-\mathrm{CH}_{3}$ & -0.07 & -0.17 \\
$-\mathrm{NH}_{2}$ & -0.16 & -0.66 \\
$-\mathrm{Br}$ & 0.37 & 0.23 \\
$-\mathrm{Cl}$ & 0.37 & 0.23 \\
$-\mathrm{F}$ & 0.34 & 0.06 \\
$-\mathrm{CN}$ & 0.56 & 0.66 \\
$-\mathrm{N}(\mathrm{CH})_{2}$ & -0.16 & -0.83 \\
$-\mathrm{H}$ & 0.00 & 0.00 \\
$-\mathrm{OH}$ & 0.12 & -0.37 \\
$-\mathrm{OCH}_{3}$ & 0.12 & -0.27 \\
$-\mathrm{Ph}^{-\mathrm{CF}_{3}}$ & 0.06 & 0.01 \\
\end{tabular}

Several refinements to Hammett's parameters have emerged since the original development. The original Hammett parameter values often fail for reactions that involve transition states where a positive or negative charge can be stabilized by delocalization via 
resonance with the substituent. Therefore, two new types of Hammett parameters were produced to account for these types of reactions $\left(\sigma^{-}\right.$and $\left.\sigma^{+}\right)$. While analyzing the rates of solvolysis of tertcumyl chlorides, Brown and co-workers ${ }^{[64-66]}$ realized that the reaction rate did not correlate well with electron donating substituents. In these substitution reactions, substrates bearing electron donating groups can stabilize the cationic transition state formed in the reaction (Scheme 1-14). Due to this effect, Brown was able to describe the $\sigma^{+}$parameter as a method to correlate reaction rate for reactions involving electrophilic transitions states stabilized by resonance.

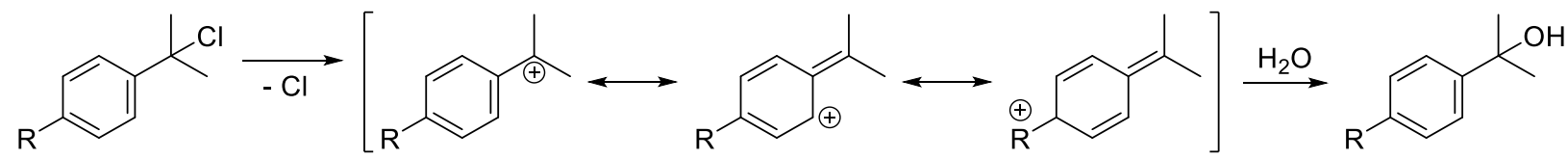

Scheme 1-14: Solvolysis of 4-substituted tert-cumyl chlorides.

Similarly, reactions involving negative charges in the transition states do not correlate well with the original Hammett values. For example, the dissociation of phenols was studied by Cohen and Jones (Scheme 1-15). ${ }^{[67]}$ Due to this, the $\sigma^{-}$parameter series was developed as a method to correlate reaction rates involving resonance in anionic reactions.<smiles>CCC(C)(C)c1cc([N+](=O)[O-])cc(C(C)(C)C)c1O</smiles>

Scheme 1-15: The dissociation of 4-substituted phenols.

\subsubsection{Field/Inductive $(F)$ and Resonance $(R)$ Parameters}

The field/inductive and resonance components of the Hammett parameters have been heavily investigated. To extract the contribution of each of these components, Roberts and Moreland $^{[63]}$ studied the ionization of 4-substituted bicyclo[2.2.2] octane-1-carboxylic acids (Scheme 1-16). These acids were selected to provide an unambiguous system as the rigidity and saturation of the carboxylic acid eliminates the possibility for resonances and polarization, leaving only field and inductive effects to influence the ionization. By isolating the inductive and field 
effects $\left(\sigma_{\mathrm{I}}\right)$ in this manner, Roberts and Moreland were able to define the contribution of these effects on the Hammett parameters. In addition, Grob and Schlageter utilized the ionization of protonated quinuclidines (Scheme 1-17) as an additional method to calculate the inductive and field effects $\left(\sigma_{\mathrm{I}}\right)$. This system was advantageous because the protonated amine is more sensitive to the effects of the substituent. ${ }^{[68]} \quad$ Using Equation 1-2, Taft ${ }^{[69,70]}$ used the contributions of the inductive and field effects to calculate the contribution of the resonance effects $\left(\sigma_{\mathrm{R}}\right)$ on the Hammett parameter.

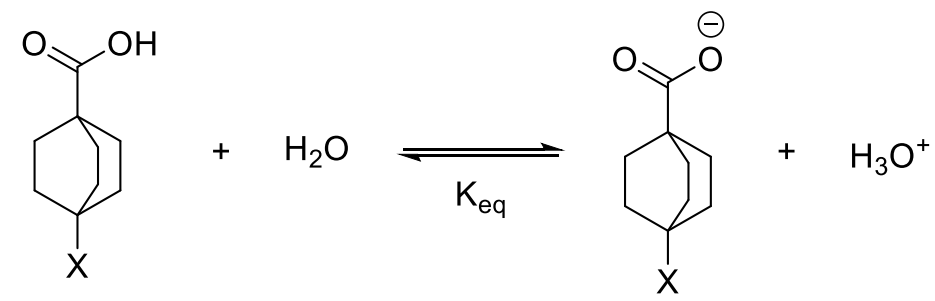

Scheme 1-16: The dissociation of 4-substituted bicyclo[2.2.2] octane-1-carboxylic acids.

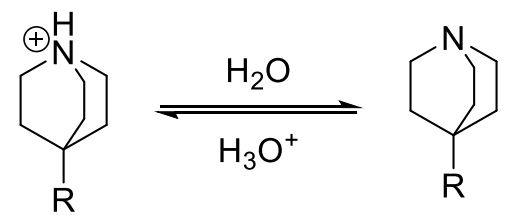

Scheme 1-17: Grob and Schlageter's ionization of quinuclidines.

Swain and Lupton ${ }^{[71]}$ redefined all $\sigma$ parameters as linear combinations of two effects - resonance, $R$, and field, $F$, effects. In this refinement, the field effect parameter $(F)$ defines the through-space electrostatic effect of each substituent. The resonance effects $(R)$ were calculated assuming that $\sigma_{\mathrm{p}}$ is the sum of $F$ and $R$ and $R=0$ for $\mathrm{N}^{+}\left(\mathrm{CH}_{3}\right)_{3}$ (Equation 1-3). Hansch and co-workers later recalculated Swain and Lupton's $F$ values to bring them to the same scale as Hammett's parameters (Table 1-3). ${ }^{[62,72]}$ With the quantification of the field effect and resonance parameters, the development of more sophisticated LFERs was made possible.

$$
\sigma_{p}=\alpha F+R
$$


Table 1-3: $F$ and $R$ constants of common substituents. Values of all parameters are from reference [62].

\begin{tabular}{ccc}
\hline Substituent & $\boldsymbol{F}$ & $\boldsymbol{R}$ \\
\hline$-\mathrm{NO}_{2}$ & 0.65 & 0.13 \\
$-\mathrm{CO}_{2} \mathrm{CH}_{3}$ & 0.34 & 0.11 \\
$-\mathrm{C}(\mathrm{O}) \mathrm{CH}_{3}$ & 0.33 & 0.17 \\
$-\mathrm{OC}(\mathrm{O}) \mathrm{CH}_{3}$ & 0.42 & -0.11 \\
$-\mathrm{CH}_{3}$ & 0.01 & -0.18 \\
$-\mathrm{NH}_{2}$ & 0.08 & -0.74 \\
$-\mathrm{Br}$ & 0.45 & -0.22 \\
$-\mathrm{Cl}$ & 0.42 & -0.19 \\
$-\mathrm{F}$ & 0.45 & -0.39 \\
$-\mathrm{CN}$ & 0.51 & 0.15 \\
$-\mathrm{NHCH}$ & 0.03 & -0.73 \\
$-\mathrm{H}$ & 0.03 & 0.00 \\
$-\mathrm{OH}$ & 0.33 & -0.70 \\
$-\mathrm{OCH}_{3}$ & 0.29 & -0.56 \\
$-\mathrm{Ph}_{-}$ & 0.12 & -0.13 \\
$-\mathrm{CF}_{3}$ & 0.38 & 0.16 \\
\hline
\end{tabular}

\subsubsection{Steric Parameters}

The Hammett LFER mentioned in 1.5.1 was shown to include field, inductive, and resonance effects. This correlation is generally not applicable to ortho-substituted compounds due to steric interactions between the ortho-substituent and the reaction center causing changes to steric, inductive, and resonance effects. ${ }^{[73]}$ Taft realized that the rates of hydrolysis for orthosubstituted benzoate compounds is proportional to the relative size of the ortho-substituent. With this realization, Taft sought to develop a parameter that defines the steric contribution of a substituent via the rate of ester hydrolysis under both acidic and basic conditions (Scheme 1-18). ${ }^{[69,74,75]}$ Taft quickly realized that under basic conditions, the negative charge in the transition state would be influenced by both resonance and inductive effects. To account for only the steric effects, Taft used the rates of acid catalyzed ester hydrolysis to define the total steric contribution of a substituent as $E_{s}$ (Equation 1-4). With this parameter, the steric influence of substituents was finally able to be considered while developing LFERs. 


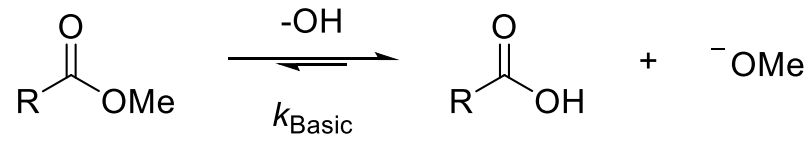

$\mathrm{R}_{\mathrm{OMe}}^{\mathrm{O}} \stackrel{\mathrm{H}^{+}}{\rightleftharpoons} \stackrel{\mathrm{R}}{\mathrm{H}}_{\mathrm{OH}}^{\mathrm{O}}+\mathrm{H}_{2} \mathrm{O}$

Scheme 1-18: Ester hydrolysis under base catalyzed (top) and acid catalyzed (bottom) conditions.

$$
\log \left(\frac{k}{k_{M e}}\right)=\delta E_{S}
$$

However, this derivation of Taft's steric parameter has been debated. While Charton showed that the $E_{\mathrm{s}}$ value correlates well with van der Waals radii ${ }^{[70,76]}$, other types of steric parameters have been discussed in the literature. ${ }^{[77]}$ For example, Verloop developed a method to calculate several dimensional properties for a single substituent based on atomic models. ${ }^{[78]}$ In Verloop's sterimol model, each substituent is divided into two width ( $\mathrm{B}_{1}$ and $\mathrm{B}_{5}$ ) and one length (L) parameters, allowing for a more accurate description of the steric bulk of a substituent (Figure 1-4). A more modern type of steric parameter is buried volume. ${ }^{[79]}$
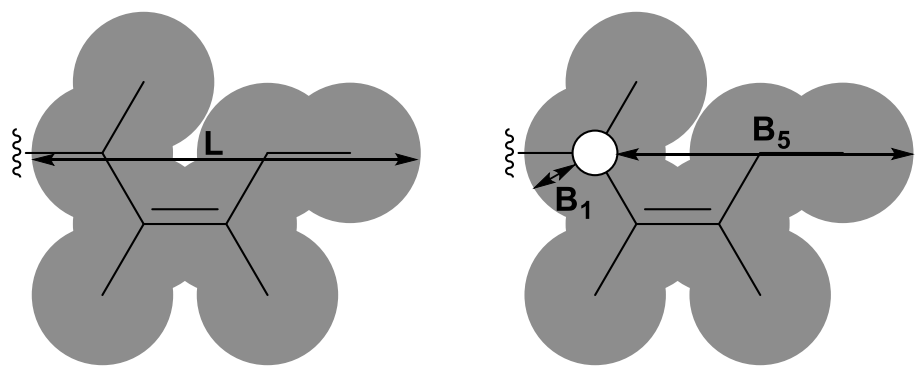

Figure 1-4: Verloop's sterimol parameterization. $\mathrm{L}=$ length, $\mathrm{B}_{1}=$ minimum width, and $\mathrm{B}_{5}=$ maximum width.

\subsubsection{Applications to Organic Reactions}

The parameters discussed in the previous sections have been applied to a wide variety of organic transformations to understand the reaction mechanism. The Hammett equation for instance is effective at distinguishing charge buildup in the transition states. The use of multiple of these parameters is also seen in literature. Multivarient LFERs such as the Fujita-Nishioka 
equation have been used for a number of different transformations, including ester hydrolysis, ${ }^{[81,82]}$ formanilide hydrolysis, ${ }^{[83]}$ benzamide hydrolysis, ${ }^{[84]}$ and Ag-catalyzed decarboxylation of benzoic acids. ${ }^{[52]}$

As mentioned in section 1.4, the Fujita-Nishioka equation is a LFER allowing for the analysis of differently substituted benzoates (ortho-, meta-, para-, and multi-substituted) as a single data set. ${ }^{[85]}$ This LFER utilizes Hammett's ordinary polar $(\sigma)$, Swain and Lupton's proximity polar $(F)$, and Taft's steric effects $\left(E_{s}\right)$ (Equation 1-5). In this equation, the Hammett parameter $(\sigma)$, is assumed to be equal for both ortho- and para-substitution $\left(\sigma_{\text {ortho }}=\sigma_{\text {para }}\right)$. This assumption however may over- or under-estimate the inductive effects in the ortho-position. The coefficients, $a, b$, and $c$, of this LFER correspond to the sensitivities of the respective parameters, $\sigma, E_{s}$, and $F$. In chapter 2, we will see the application of the Fujita-Nishioka equation to correlate the rates of decarboxylation of a series of (phen) $\mathrm{Ag}$ (benzoate) complexes.

$$
\ln \left(\frac{k_{R}}{k_{M e}}\right)=a \sigma+b E_{s}+c F+d
$$




\section{Chapter 2 - Development of a Predictive Model for Decarboxylation of Silver Benzoate}

Complexes Relevant to Decarboxylative Coupling Reactions

\subsection{Overview}

Despite recent progress, decarboxylative coupling reactions are typically limited to only ortho-nitro or ortho-fluorobenzoic acids that have the ability to undergo efficient decarboxylative coupling. ${ }^{[18-20,25,42,45,86-91]}$ Mechanistically, this limitation could arise from the decarboxylation step and/or the coupling step(s) of the catalytic cycle. Many oxidative decarboxylative cross-coupling (ODC) reactions employ $\mathrm{Pd},{ }^{[37-40,46,92-95]} \mathrm{Cu},{ }^{[25,42,87]}$ or $\mathrm{Ni}^{[18-20,45]}$ catalysts paired with Ag-based stoichiometric oxidants. Silver salts are well-known to promote decarboxylation reactions $^{[36,41,43,51,58,59,96,97]}$ and are likely responsible for the crucial decarboxylation step in reactions that employ them. While limited studies investigating decarboxylation from a silver carboxylate exist in the literature, ${ }^{[36,43,58,59,98]}$ the influence of benzoate substitution on the decarboxylation of silver carboxylate species has been studied computationally ${ }^{[59]}$ and silver-catalyzed protodecarboxylation has been studied experimentally. ${ }^{[52,85]}$ However, trends in catalytic protodecarboxylation reactions are not necessarily the same as those observed for the decarboxylation step when measured from well-defined carboxylate complexes. This is because the rates of complex formation and protodemetallation may also contribute to the overall catalytic rate. ${ }^{[99-101]}$ Due to this insight, the decarboxylation step is important for understanding catalytic ODC reactions, yet, to our knowledge, no studies probe this step directly.

Initially, we set out to understand the decarboxylation step of catalytic ODC reactions by investigating the decarboxylation of (1,10-phenanthroline)silver benzoate complexes due to the large literature precedence and support for silver-based decarboxylation. ${ }^{[43,52,85]}$ We hypothesized that protodecarboxylation of this class of benzoate complexes could be achieved in the presence of a high boiling point solvent, water, and heat (Scheme 2-1) and would provide significant mechanistic information on the decarboxylation step of the reaction. 


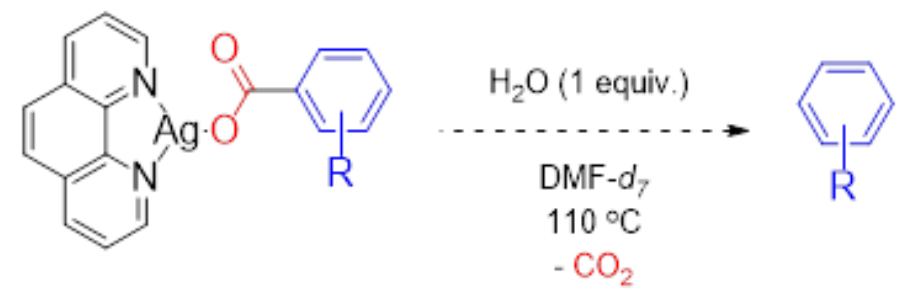

Scheme 2-1: Protodecarboxylation of (phen)Ag benzoate complexes

\subsection{Results}

With the goal of studying the decarboxylation of a series of (phen) $\mathrm{Ag}$ (benzoate) complexes in mind, we initially synthesized (phen) $\mathrm{Ag}\left(2-\mathrm{NO}_{2}\right.$-benzoate). This complex can be successfully synthesized according to a modified literature procedure ${ }^{[102]}$ through the addition of the substituted benzoic acid to a slurry of silver(I) oxide in acetonitrile. Upon filtration, a solution of 1,10phenanthroline can be added to precipitate the desired complex from solution in $80 \%$ yield. This complex was characterized by ${ }^{1} \mathrm{H}$ and ${ }^{13} \mathrm{C}$ NMR spectroscopy, IR spectroscopy, and elemental analysis (see experimental). With this complex in hand, we set out to probe the decarboxylation. The (phen) $\mathrm{Ag}\left(2-\mathrm{NO}_{2}\right.$-benzoate) complex readily undergoes decarboxylation at $110^{\circ} \mathrm{C}$ in DMF- $d_{7}$ to yield nitrobenzene and 2,2'-dinitrobiphenyl (Scheme 2-2A) when monitored by ${ }^{1} \mathrm{H}$ NMR spectroscopy with 1,3,5-trimethoxybenzene as an internal standard. To achieve reproducible rates and product distribution, $0.7 \mathrm{mM}$ of water was added, this minor change resulted in the protodecarboxylated arene as the sole product (Scheme 2-2B, Figure 2-1A). Following these conditions, decarboxylation of a sample of $3.5 \mathrm{mM}$ (phen) $\mathrm{Ag}\left(2-\mathrm{NO}_{2}\right.$-benzoate) at $110{ }^{\circ} \mathrm{C}$ follows an exponential decay, taking $3 \mathrm{~h}$ to reach $83 \%$ completion (Figure 2-1B). The initial rate of decarboxylation $\left(3.6 \mathrm{mM} \mathrm{h}^{-1}\right)$ was determined with a linear fit to the early reaction times (Figure 2-2). 
a)<smiles>O=C(O[14c]1cc2ccc3cccn1c32)c1ccccc1[N+](=O)[O-]</smiles>

b)<smiles>O=C(O[Al]1c2ccc3ccc4cccn1c4c23)c1ccccc1[N+](=O)[O-]</smiles>
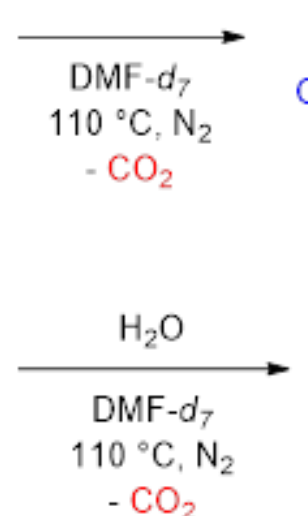<smiles>O=[N+]([O-])c1ccccc1</smiles><smiles>O=[N+]([O-])c1ccccc1-c1ccccc1[N+](=O)[O-]</smiles>

Scheme 2-2: a) Decarboxylation of (phen) $\mathrm{Ag}\left(2-\mathrm{NO}_{2}\right.$-benzoate) in DMF- $d_{7}$ at $110{ }^{\circ} \mathrm{C}$. b) Decarboxylation of (phen) $\mathrm{Ag}\left(2-\mathrm{NO}_{2}\right.$-benzoate) in $\mathrm{DMF}-d_{7}$ in the presence of $0.7 \mathrm{mM}$ water at 110 ${ }^{\circ} \mathrm{C}$. 
A)

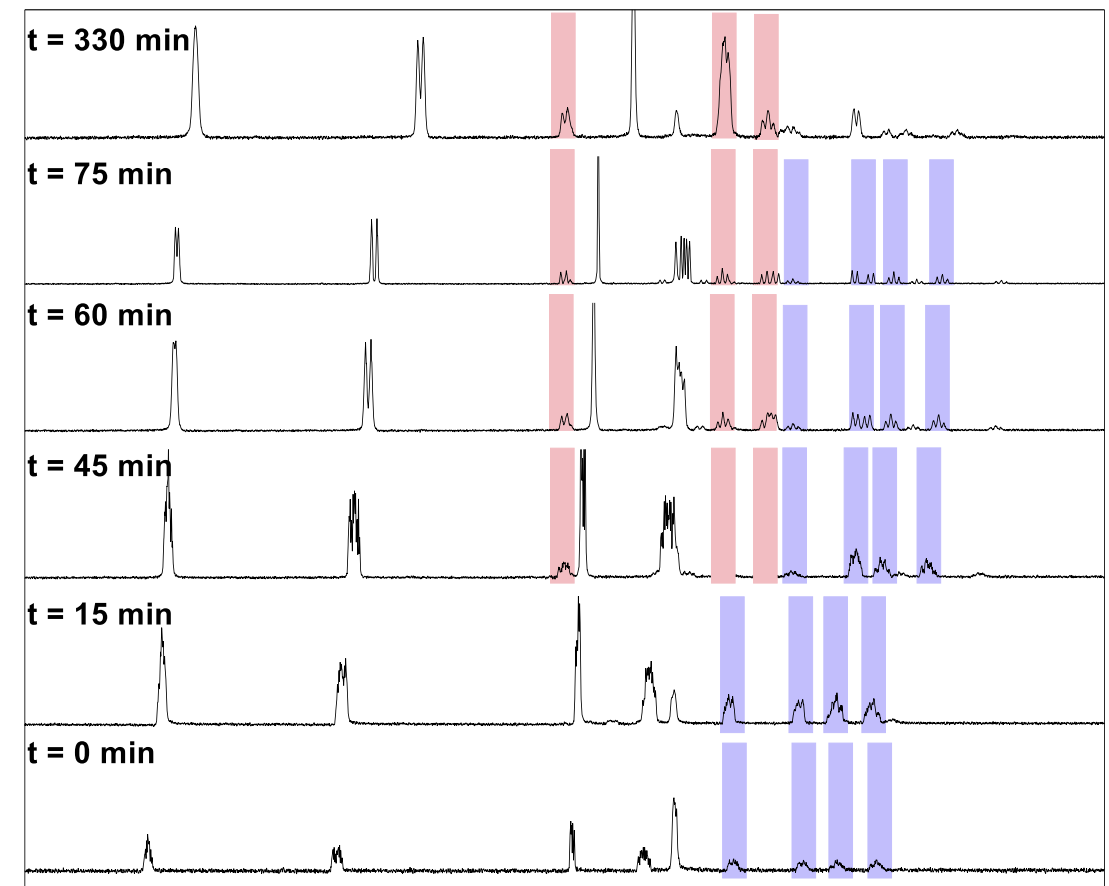

$\begin{array}{llllllllllllllllllllllllllll}9.5 & 9.4 & 9.3 & 9.2 & 9.1 & 9.0 & 8.9 & 8.8 & 8.7 & 8.6 & 8.5 & 8.4 & \begin{array}{c}8.3 \\ \mathrm{ppm}\end{array} & 8.2 & 8.1 & 8.0 & 7.9 & 7.8 & 7.7 & 7.6 & 7.5 & 7.4 & 7.3 & 7.2 & 7.1 & 7.0\end{array}$

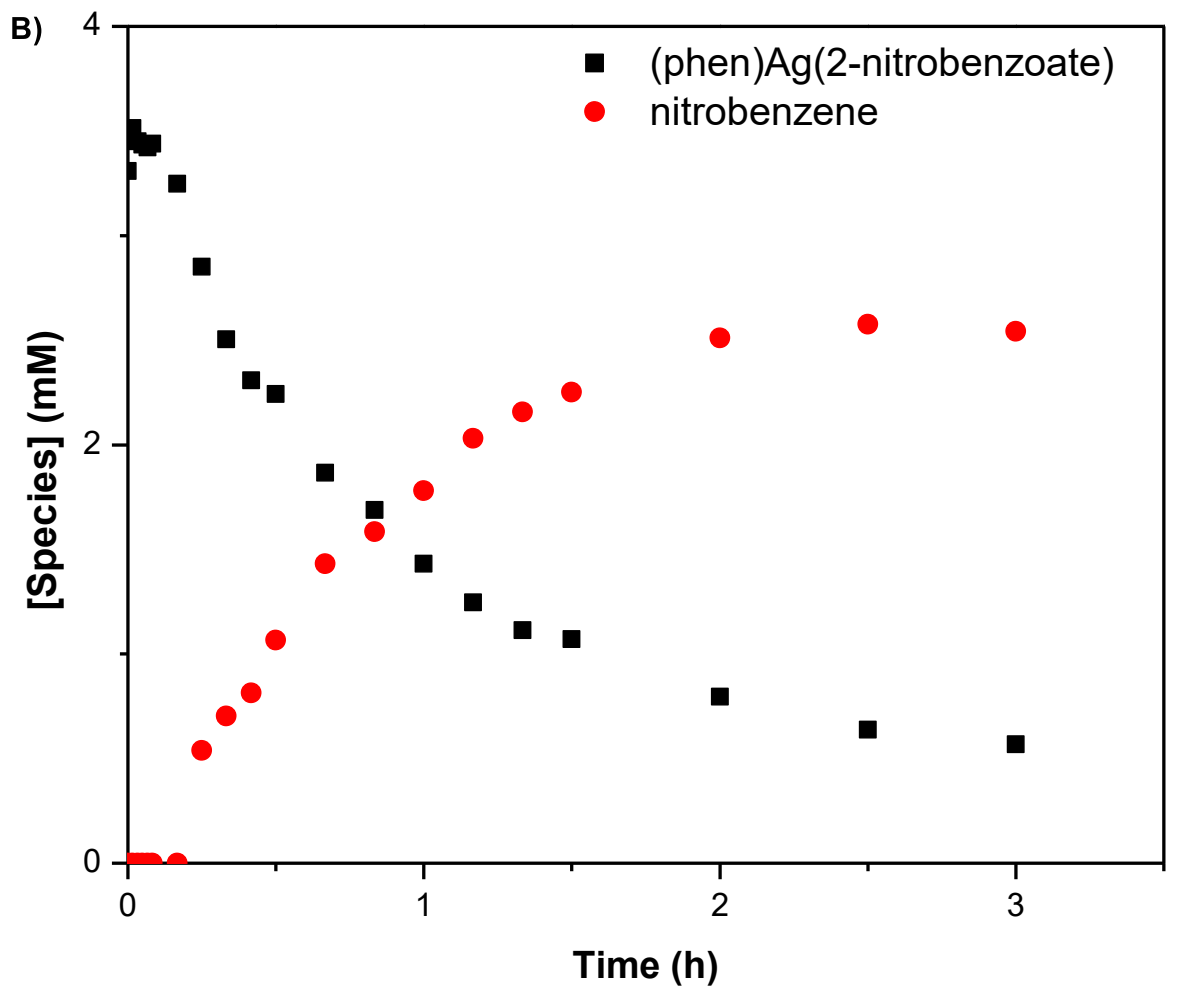

Figure 2-1: A) ${ }^{1} \mathrm{H}$ NMR time course and B) reaction profile for the decarboxylation of (phen) $\mathrm{Ag}\left(2-\mathrm{NO}_{2}\right.$-benzoate) $(3.5 \mathrm{mM}, \boldsymbol{\square})$ to form nitrobenzene $(\bullet)$ in DMF- $d_{7}$ with $0.7 \mathrm{mM} \mathrm{H} \mathrm{H}_{2} \mathrm{O}$ at $110{ }^{\circ} \mathrm{C}$. The asterisk denotes the residual solvent signal. 

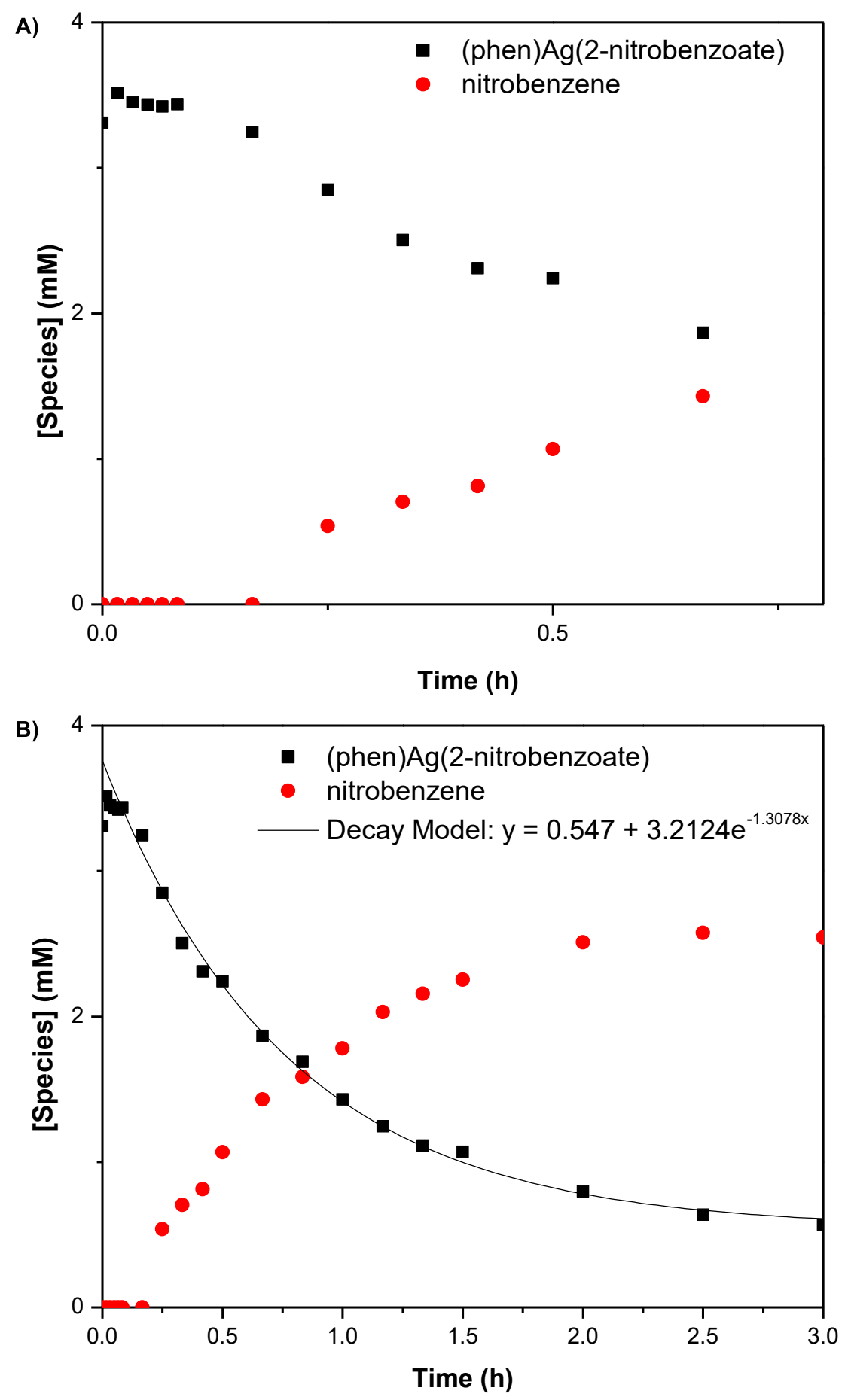

Figure 2-2: Reaction profile of the decarboxylation of (phen) $\mathrm{Ag}\left(2-\mathrm{NO}_{2}\right.$-benzoate) $(3.5 \mathrm{mM})$ in $\mathrm{DMF}-d_{7}$ at $110^{\circ} \mathrm{C}$. A) Early reaction times and B) the full-time course fit to an exponential decay model $\mathrm{y}=0.5457+3.2124 \mathrm{e}^{-1.3078 \mathrm{x}}$. 
Decarboxylative coupling reactions of benzoic acids are suggested to proceed through an initial decarboxylation to form an organometallic reagent in situ. ${ }^{[103]}$ In silver-mediated/catalyzed decarboxylation reactions, a silver aryl intermediate is suspected to be formed. The presence of this expected silver aryl intermediate could not be detected during the study, suggesting that protodemetallation is significantly more rapid than decarboxylation in these systems. The $\operatorname{Ag}(2-$ $\mathrm{NO}_{2}$-phenyl ${ }^{[102]}$ complex was synthesized independently to confirm this conclusion. The rate of protodemetallation was measured in the presence and absence of the phenanthroline ligand (Figure 2-3A and B). In the presence of 1 equivalent of 1,10-phenanthroline in DMF- $d_{7}$ at $110{ }^{\circ} \mathrm{C}$, a 5.4 $\mathrm{mM}$ sample of the $\mathrm{Ag}\left(2-\mathrm{NO}_{2}\right.$-phenyl) complex undergoes protodemetallation at a rate of 15.85 $\mathrm{mM} \mathrm{h}^{-1}$ while in the absence of phenanthroline, a $6.0 \mathrm{mM}$ sample of the $\operatorname{Ag}\left(2-\mathrm{NO}_{2}\right.$-phenyl) complex undergoes protodemetallation at a rate of $25.5 \mathrm{mM} \mathrm{h}^{-1}$. The lack of an observable silver aryl intermediate during the decarboxylation reactions is consistent with this rapid rate of protodemetallation as well as the calculated energy barriers previously reported for related catalytic reactions. ${ }^{[58,59]}$ 
A)

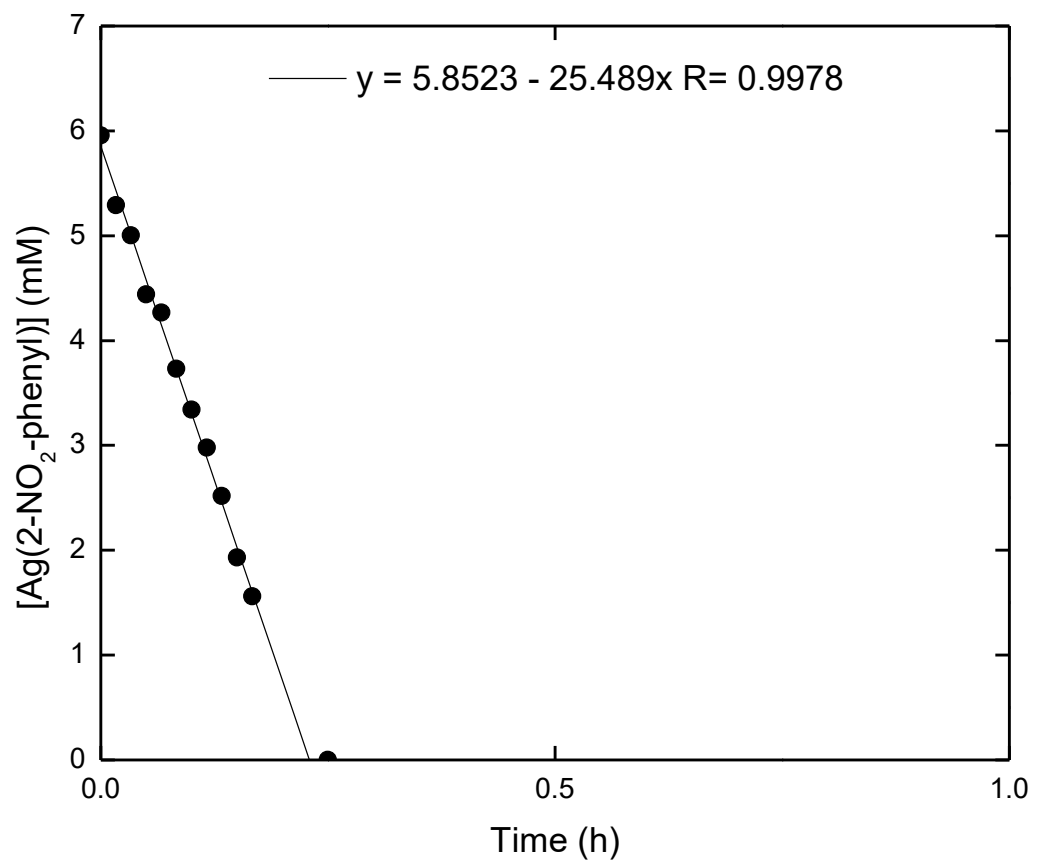

B)

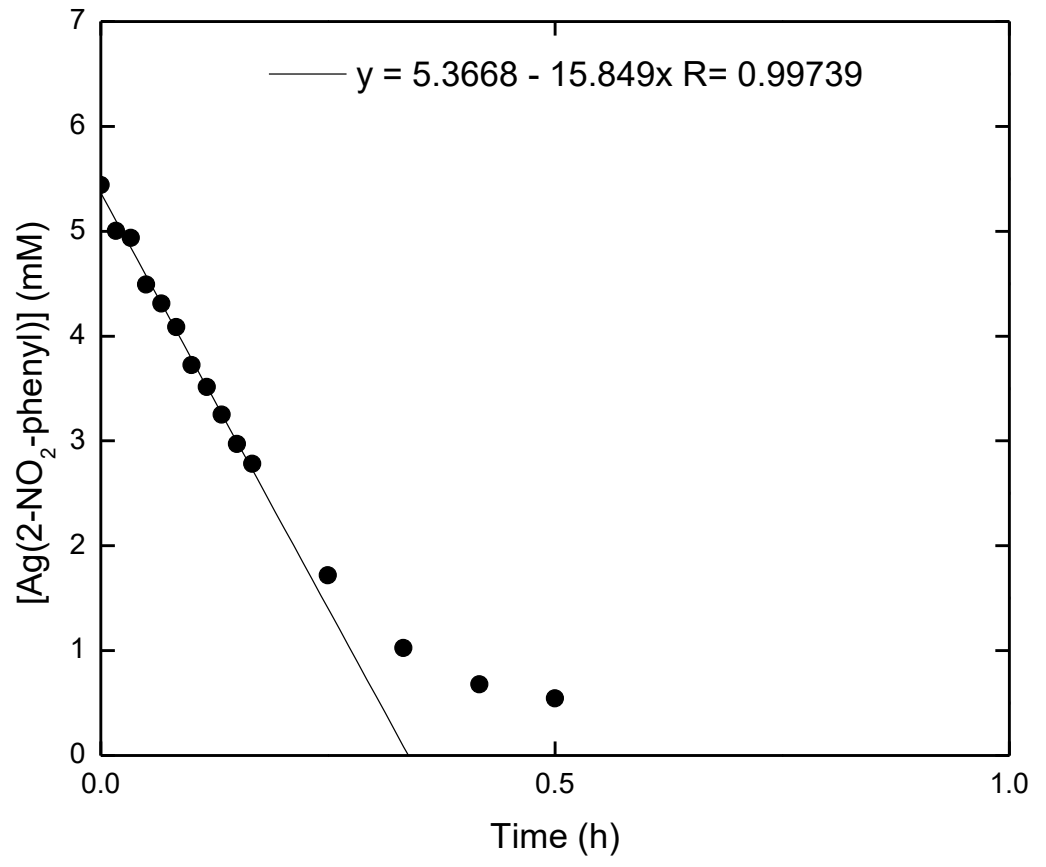

Figure 2-3: Reaction time courses for the protodemetallation of A) $\mathrm{Ag}\left(2-\mathrm{NO}_{2}\right.$-phenyl) $(6.0 \mathrm{mM}$; initial rate $\left.=25.5 \mathrm{mM} \mathrm{h}^{-1} ; \mathrm{k}=4.28 \mathrm{~h}^{-1}\right)$ and $\left.\mathrm{B}\right) \mathrm{Ag}\left(2-\mathrm{NO}_{2}\right.$-phenyl $)$ with phen $(5.4 \mathrm{mM}$; initial rate $=15.85 \mathrm{mM} \mathrm{h}^{-1} ; \mathrm{k}=2.935 \mathrm{~h}^{-1}$ ) in DMF- $d_{7}$ with $0.7 \mathrm{mM}$ of $\mathrm{H}_{2} \mathrm{O}$ at $110^{\circ} \mathrm{C}$. 
Next, the concentration of (phen) $\mathrm{Ag}\left(2-\mathrm{NO}_{2}\right.$-benzoate) was varied to determine the dependence of the reaction on the concentration of the complex. A series of runs reveal a firstorder dependence on (phen) $\mathrm{Ag}\left(2-\mathrm{NO}_{2}\right.$-benzoate) (Figure 2-4). To compare the influence of the phenanthroline ligand on the decarboxylation, the unligated $\operatorname{Ag}\left(2-\mathrm{NO}_{2}\right.$-benzoate $)$ complex was prepared by the addition of 2-nitrobenzoic acid to a slurry of $\mathrm{Ag}_{2} \mathrm{O}$ in $\mathrm{MeCN}$. After removing undissolved $\mathrm{Ag}_{2} \mathrm{O}$ by filtering through celite, the desired complex was precipitated with hexane as a tan solid in $40 \%$ yield (see experimental for characterization details). The unligated $\mathrm{Ag}\left(2-\mathrm{NO}_{2}-\right.$ benzoate) complex undergoes decarboxylation with a similar reaction profile and rate to the (phen) $\mathrm{Ag}\left(2-\mathrm{NO}_{2}\right.$-benzoate) complex when heated to $110^{\circ} \mathrm{C}$ in DMF- $d_{7}$ with $0.7 \mathrm{mM} \mathrm{H}_{2} \mathrm{O}$ (Figure 2-5). From this observation, it appears that the phenanthroline ligand provides a minor accelerating effect on decarboxylation of this type of silver complex. ${ }^{[58]}$ Because of the stark difference in isolability between the ligated and unligated complexes, the more isolable complexes bearing the phenanthroline ligand were used to continue the study and a series of complexes bearing different substitution on the benzoate were synthesized (for further details, see section $2.3)$.

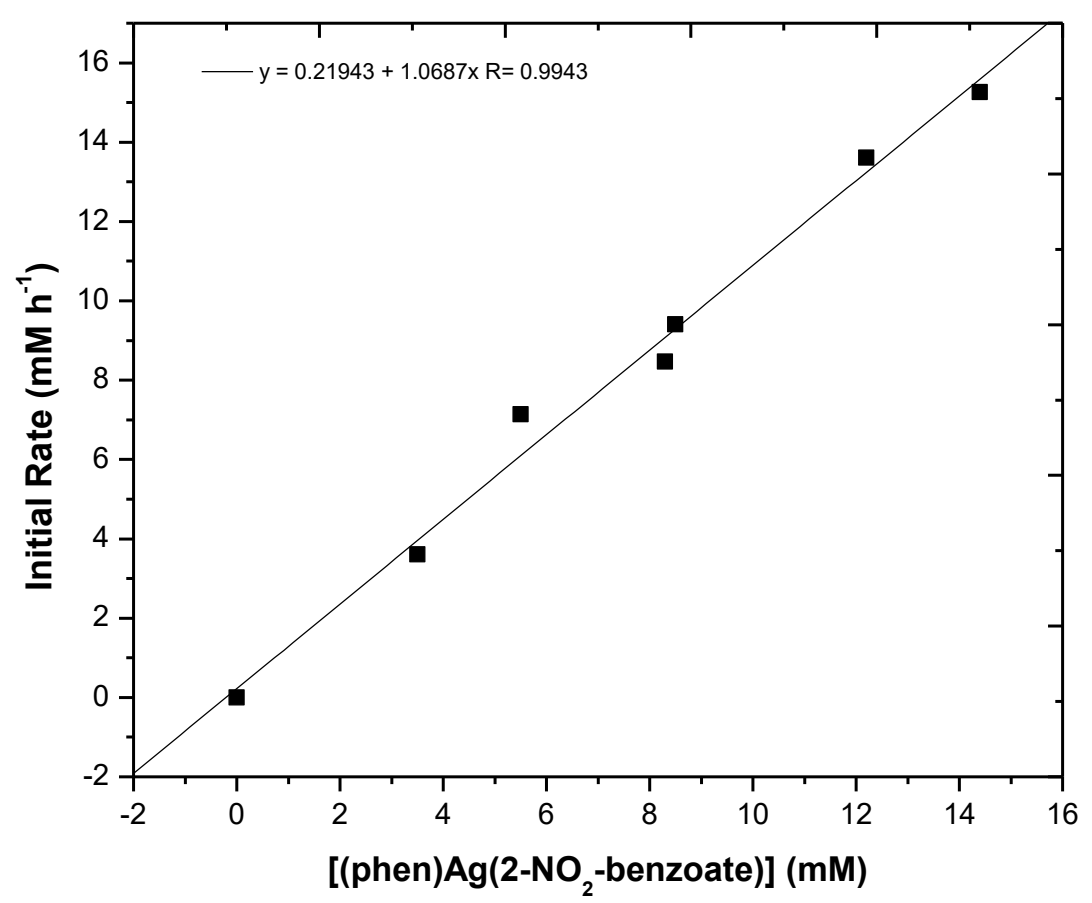

Figure 2-4: Kinetic data from the decarboxylation of [(phen) $\mathrm{Ag}\left(2-\mathrm{NO}_{2}\right.$-benzoate $\left.)\right]$ in DMF- $d_{7}$ with $0.7 \mathrm{mM} \mathrm{H} \mathrm{O}_{2}$ at $110{ }^{\circ} \mathrm{C}$ assessing the dependence on [(phen) $\mathrm{Ag}\left(2-\mathrm{NO}_{2}\right.$-benzoate $\left.)\right]$. Initial rates were determined using ${ }^{1} \mathrm{H}$ NMR spectroscopy. 


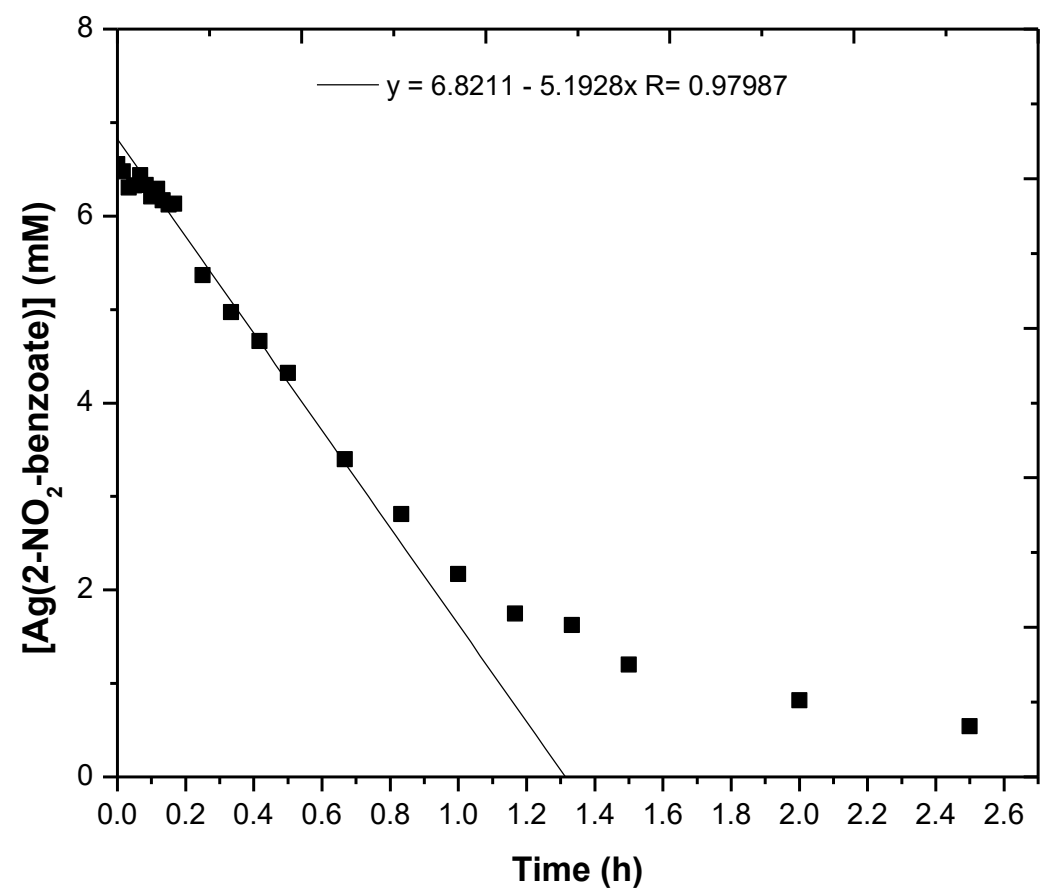

Figure 2-5: Reaction time course for the decarboxylation of $\mathrm{Ag}\left(2-\mathrm{NO}_{2}\right.$-benzoate $)(6.6 \mathrm{mM} ; \mathrm{k}=$ $0.787 \mathrm{~h}^{-1}$ ) in DMF- $d_{7}$ with $0.7 \mathrm{mM} \mathrm{H}_{2} \mathrm{O}$ at $110{ }^{\circ} \mathrm{C}$.

Since decarboxylative coupling reactions are largely limited to ortho-substituted carboxylates, a series of silver benzoate complexes bearing various ortho-substituents, (phen) $\operatorname{Ag}(2-\mathrm{R}$-benzoate), were synthesized in order to probe the dependence of decarboxylation rate on the substitution of the benzoate. When these complexes were heated in DMF- $d_{7}$ at $110{ }^{\circ} \mathrm{C}$ in the presence of $0.7 \mathrm{mM} \mathrm{H}_{2} \mathrm{O}$, we observed faster rates of decarboxylation for benzoates bearing resonance and inductively electron-withdrawing substituents than electron-donating ones (Figure 2-6A). The data are well fitted with the Fujita-Nishioka linear energy correlation (equation 2-1, Figure 2-6B, Figure 2-13), ${ }^{[85]}$ similar to other protodecarboxylation studies. ${ }^{[52]}$ This linear free energy relationship allows for the analysis of differently substituted benzoates (ortho-, meta-, para-, and multiply-substituted) as a single data set. This correlation is comprised of three parameters: an ordinary polar effect $(\sigma)$, a proximity polar effect (the Swain-Lupton Hansch field effect, $F$ ) and a steric effect $\left(E_{s}\right)$. Our system, however, shows a strong dependence on the SwainLupton-Hansch field effect parameter $(8.428 \mathrm{~F})$, while the contributions from the Hammett parameter $(-1.392 \sigma)$ and steric contribution $\left(0.204 \mathrm{E}_{\mathrm{s}}\right)$ are quite small.

$\ln \left(\frac{k_{R}}{k_{M e}}\right)=a \sigma+b E_{S}+c F+d$ 


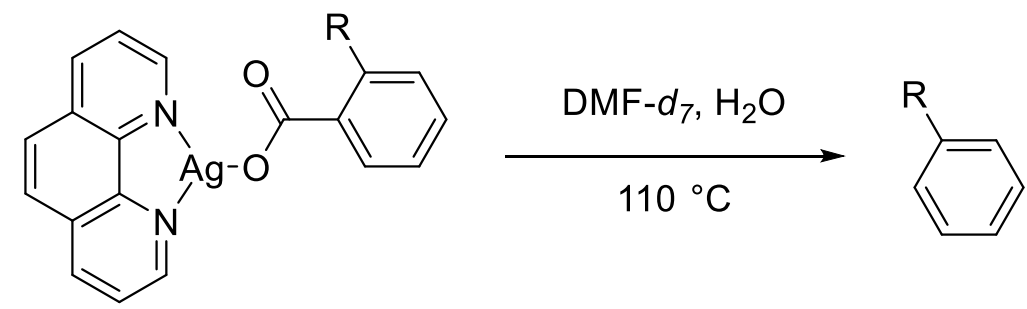

A)

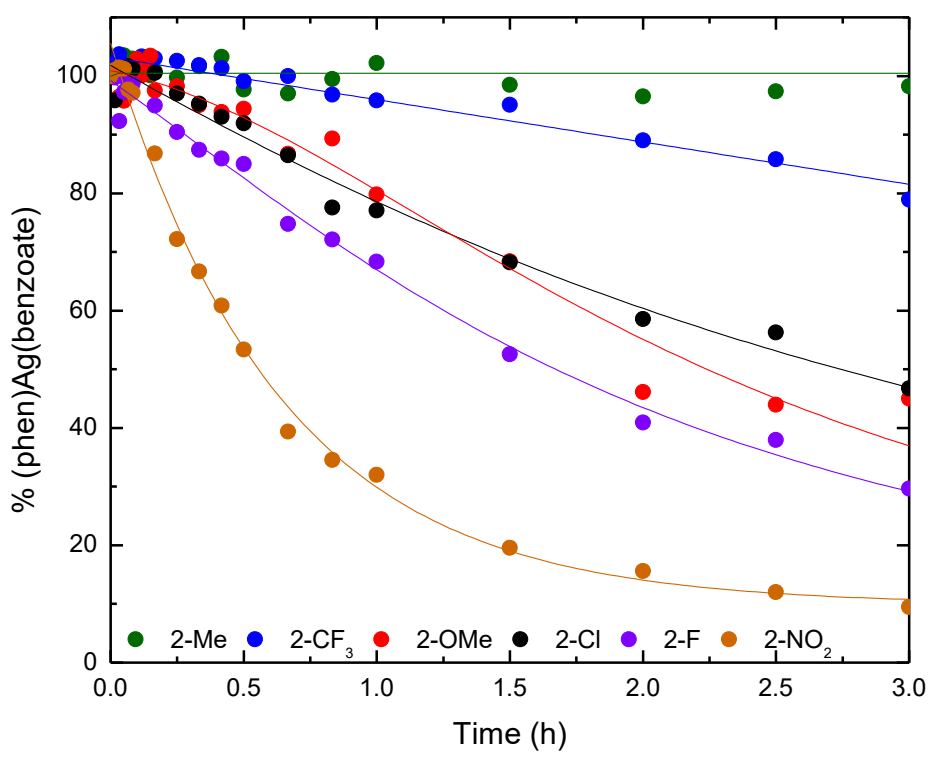

B)

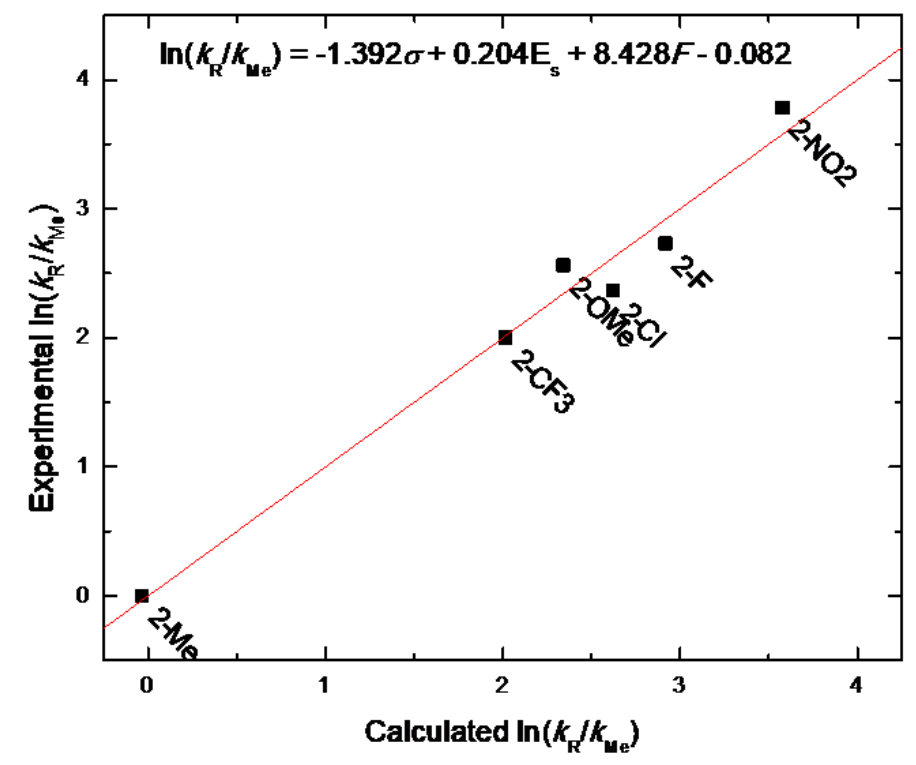

Figure 2-6: A) Profiles of the kinetic plots for the decarboxylation of various (phen) $\mathrm{Ag}\left(2-\mathrm{R}\right.$-benzoate) complexes where $\mathrm{R}=\mathrm{Me}, \mathrm{CF}_{3}, \mathrm{OMe}, \mathrm{Cl}, \mathrm{F}$ and $\mathrm{NO}_{2}$. The traces are not fits and are only meant as a visual guide. B) Fujita-Nishioka linear free energy correlation fit to the rates of decarboxylation of (phen) $\mathrm{Ag}(2-\mathrm{R}$-benzoate) under standard conditions. Conditions: 8 $\mathrm{mM}$ (phen) $\mathrm{Ag}\left(2-\mathrm{R}\right.$-benzoate) in $0.5 \mathrm{~mL} \mathrm{DMF-} d_{7}$ with $0.7 \mathrm{mM} \mathrm{H}_{2} \mathrm{O}$ at $110^{\circ} \mathrm{C}$. 
A)

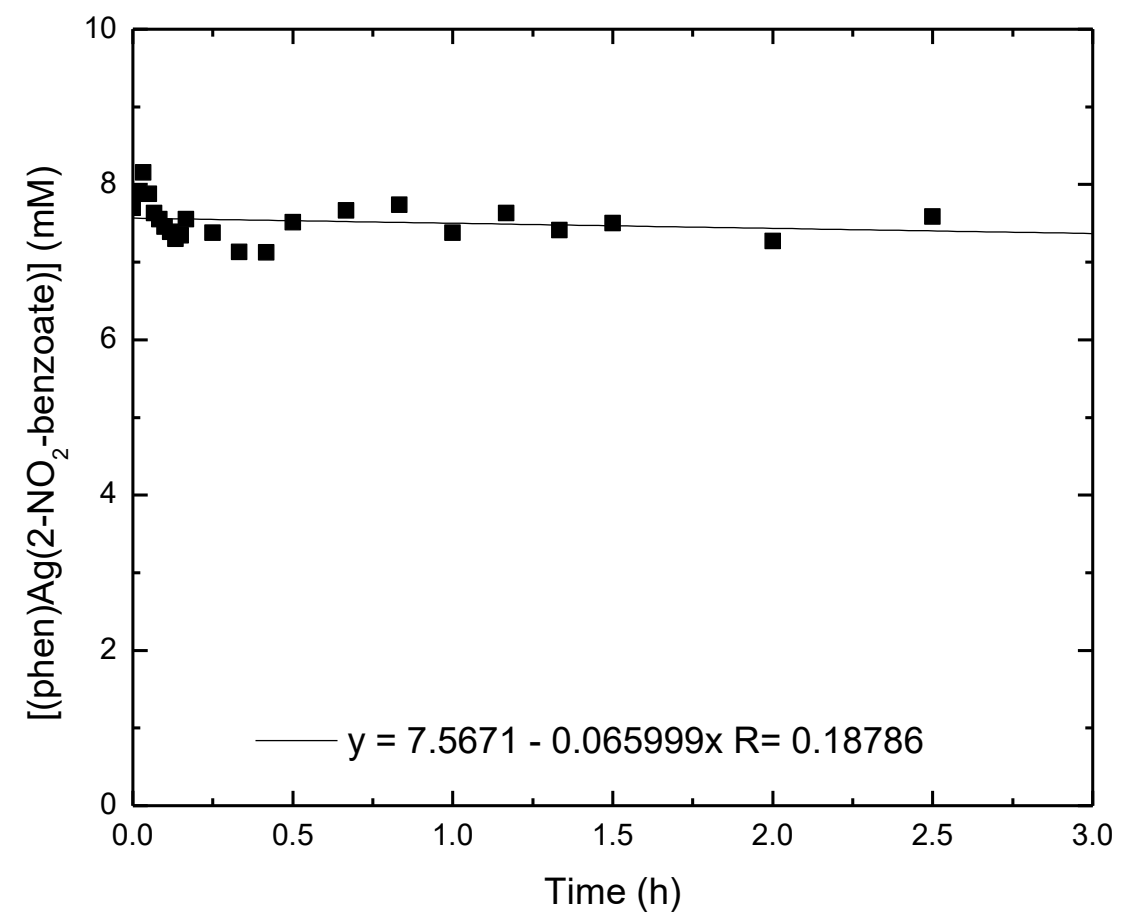

B)

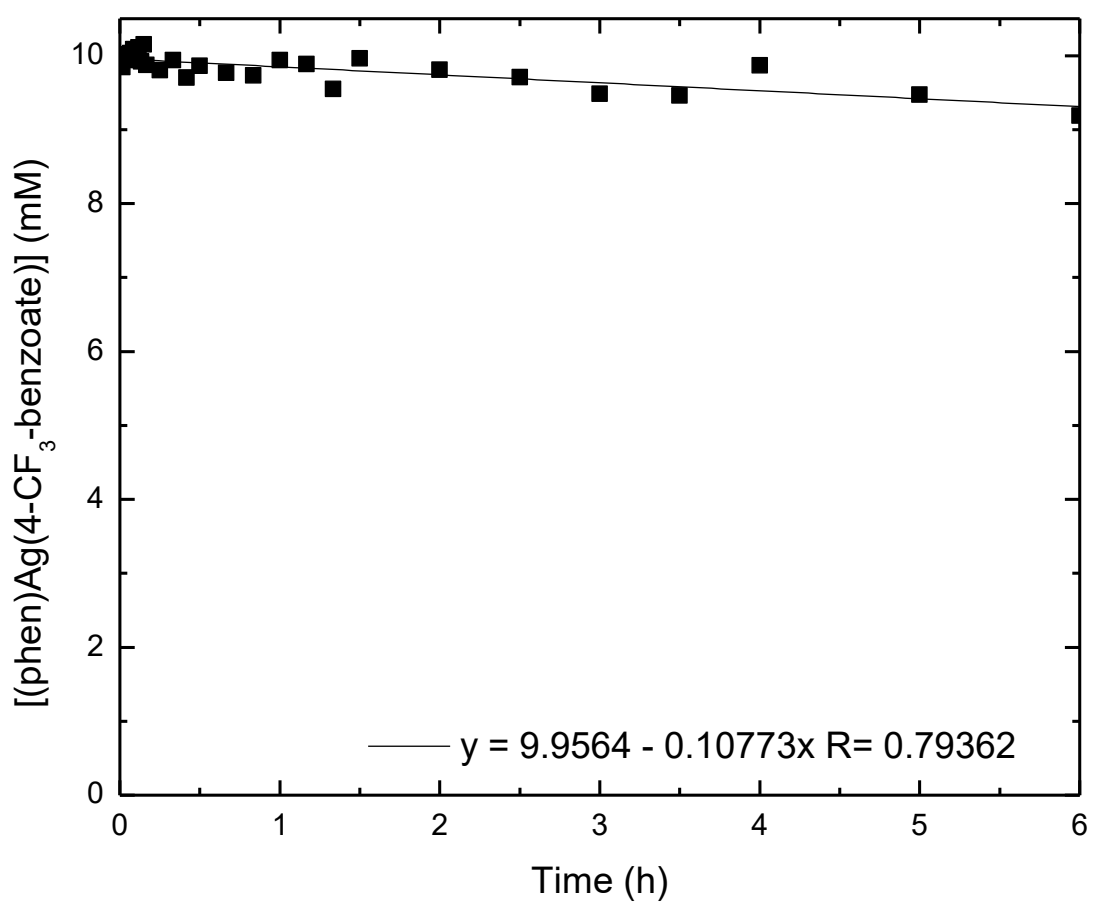

Figure 2-7: Reaction time course for the decarboxylation of A) (phen) $\mathrm{Ag}\left(3-\mathrm{NO}_{2}\right.$-benzoate) $\left(8.15 \mathrm{mM}, \mathrm{k}=8.10 \times 10^{-3} \mathrm{~h}^{-1}\right)$ and $\left.\mathrm{B}\right)($ phen $) \mathrm{Ag}\left(4-\mathrm{CF}_{3}\right.$-benzoate $)\left(10.15 \mathrm{mM}, \mathrm{k}=1.106 \times 10^{-2}\right)$ in DMF- $d 7$ with $0.7 \mathrm{mM} \mathrm{H}_{2} \mathrm{O}$ at $110{ }^{\circ} \mathrm{C}$. 
Because the influence of the field effect parameter $(F)$ decreases with distance from the site where the reaction occurs, the field effect of meta- and para-substituted benzoates is negligible. ${ }^{[62,85]}$ In an effort to probe the importance of the field effect, the (phen) $\mathrm{Ag}\left(3-\mathrm{NO}_{2}\right.$-benzoate) and (phen) $\mathrm{Ag}\left(4-\mathrm{CF}_{3}\right.$-benzoate) complexes were synthesized and heated under our standard conditions of DMF- $d_{7}$ with $0.7 \mathrm{mM} \mathrm{H}_{2} \mathrm{O}$ at $110{ }^{\circ} \mathrm{C}$. In both cases, the rate of decarboxylation is slow ( 0.066 and $0.108 \mathrm{mM} \mathrm{h}^{-1}$, respectively) reaching $<10 \%$ conversion after $2 \mathrm{~h}$ of heating (Figure 2-7A and B). This data shows the field effect of the ortho-substituent to be the major influence on the rate of decarboxylation. A large selection of mono- and disubstituted benzoates was studied to explore the generality of this trend. The inclusion of these silver benzoates refines the correlation showing small changes in both $\sigma$ and $E_{s}$, while the field effect parameter remains the major contributor $\left(-0.22 \sigma, 0.271 E_{s}, 7.210 \mathrm{~F}\right.$, Figure 2-8A). This data confirms the influence of the field effect for the enhancement of the rate of decarboxylation. The Fujita-Nishioka correlation has been applied to a number of organic transformations, ${ }^{[52,104-107]}$ however, we are unaware of any examples in which the field effect coefficient is orders of magnitude larger than the steric or Hammett coefficients. The significant dependence on the field effect parameter suggests that decarboxylation of these complexes proceeds by way of a polar transition state stabilized by the electrostatic effects of the nearby ortho-substituent. 

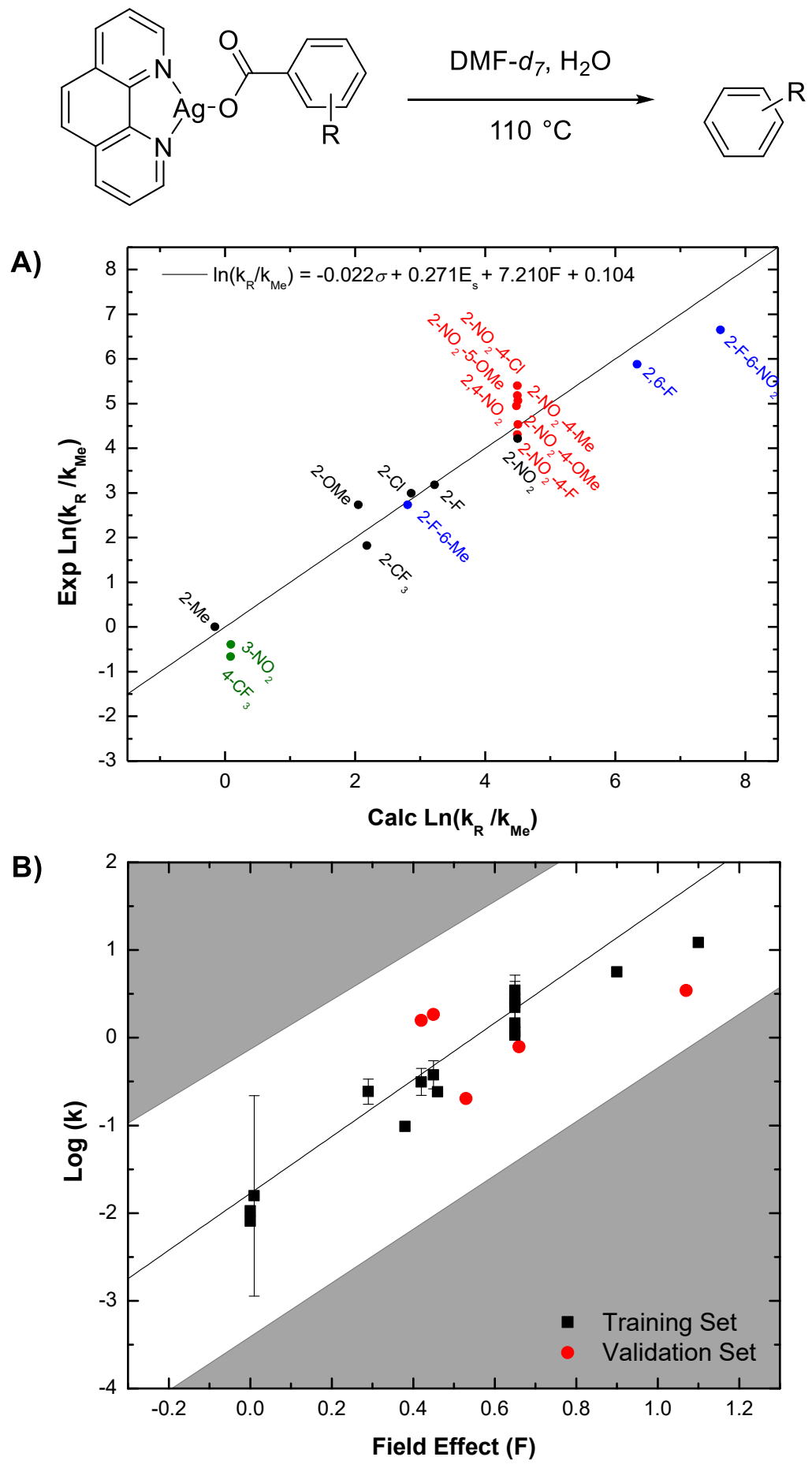

Figure 2-8: A) Fujita-Nishioka linear free energy correlation fit to the rates of decarboxylation of various (phen) $\mathrm{Ag}$ (benzoate) complexes in $0.5 \mathrm{~mL} \mathrm{DMF}-d_{7}$ with $0.7 \mathrm{mM} \mathrm{H}_{2} \mathrm{O}$ at $110{ }^{\circ} \mathrm{C}$. The reaction time courses are shown in Figures 2-7, 2-14, 2-15, and 2-16. B) Simplified correlation of the $\log (\mathrm{k})$ with the field effect parameter $(\mathrm{F})$. The shaded area indicates the largest experimental error in $\log (\mathrm{k})$ if applied to all points. 
Considering the significant dependence on the field effect parameter in this system, the possibility of correlating the rates directly with $\mathrm{F}$ was explored. Plotting $\log (k)$ vs $\mathrm{F}$ shows good correlation and enables the easy prediction of carboxylates that undergo decarboxylation (Figure 2-8B). To probe the predictive power of these findings, a few additional silver benzoate complexes were synthesized, and rates measured (see Figure 2-17 in section 2.3: experimental). As an example, the rates of decarboxylation of these additional complexes were well-predicted by the field effect parameter (Figure 2-8B, red data series). The rates of decarboxylation of the 2,3,4,5-tetrafluorobenzoate $\left(k=1.93 \mathrm{~h}^{-1}, F=0.45\right)$ and the 2-Cl-6-NO -benzoate $\left(k=3.45 \mathrm{~h}^{-1}\right.$, $F=1.07)$ complexes show reasonable fits to the correlation. Notably, the 2-tosylbenzoate complex $(F=0.53)$ also undergoes facile decarboxylation $\left(k=0.203 \mathrm{~h}^{-1}\right)$. This benzoate is synthetically attractive because of its ability to be further functionalized or deprotected and because it is easily accessible from salicylic acid. ${ }^{[108]}$

Literature reports demonstrate that the ortho-nitro- $(F=0.65)$ and pentafluoro-substituted $(F=0.90)$ benzoates are efficient coupling partners in ODC reactions ${ }^{[20,25,36,37,39,40,42,45,46,86-95]}$ which is consistent with the rapid decarboxylation featured by benzoates bearing substituents with large field effect parameters. Intrigued with this connection, we wondered if a high field effect value may facilitate decarboxylative coupling in addition to decarboxylation. Kalyani and co-workers ${ }^{[20]}$ nickel-catalyzed decarboxylative arylation utilizing bench-stable reagents and silver triflate as an oxidant is an attractive test reaction because only ortho-nitro and fluorobenzoates were reported for this transformation (Scheme 2-3). Applying our findings to this reaction with the intention to expand the scope of decarboxylative coupling reactions, we attempted to utilize the ortho-tosylate- $(\mathrm{F}=0.53)$ and ortho-acetyl- $(\mathrm{F}=0.33)$ substituted benzoates under the reported conditions. Gratifyingly, the corresponding products were formed in $53 \%$ and $72 \%$ yield respectively, similar to the yield obtained with the ortho-nitrobenzoic acid (54\%). These results highlight the ability to utilize synthetically attractive benzoates in previously limited ODC reactions. 


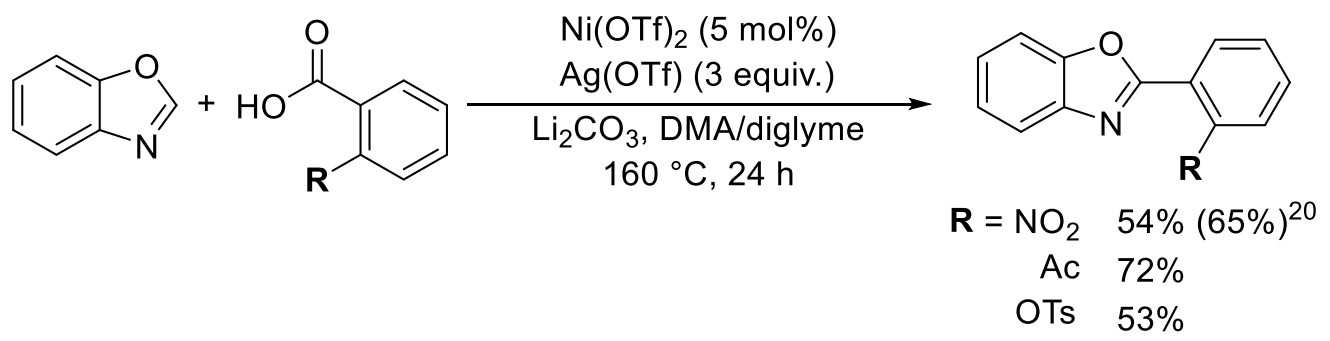

Scheme 2-3: Ni-Catalyzed Decarboxylative Arylation ${ }^{[20]}$

In conclusion, the role of benzoate substitution on the rate of decarboxylation of well-defined silver benzoate complexes was evaluated. The rate of decarboxylation is predominantly influenced by the field effect parameter, enabling easy prediction of benzoates that undergo facile decarboxylation. Utilizing the rates of decarboxylation of several new benzoates (ortho-tosyl-, tetrafluoro- and 2-Cl-6- $\mathrm{NO}_{2}$-substituted benzoates), the predictive power of this finding was demonstrated. Additionally, the synthetic power of this finding was highlighted by the efficient catalytic decarboxylative coupling of the ortho-tosyl- and ortho-acetyl-substituted benzoates.

\subsection{Experimental}

\subsubsection{General Considerations.}

All decarboxylation reactions were performed under $\mathrm{N}_{2}$ and the reaction mixtures were prepared using an inert-atmosphere glovebox. DMF- $d_{7}$ (Cambridge Isotopes) was stored over $4 \AA$ molecular sieves in a $\mathrm{N}_{2}$ filled glovebox. All proteo solvents were taken from a Glass Contours solvent system, in which the solvent is passed through a column of activated alumina with a pressure of Argon. All other commercial reagents and NMR solvents were used without further purification unless otherwise stated. ${ }^{1} \mathrm{H}$ and ${ }^{13} \mathrm{C}\left\{{ }^{1} \mathrm{H}\right\}$ NMR spectra were recorded on an Agilent $400 \mathrm{MHz}$ spectrometer, Joel $400 \mathrm{MHz}$ spectrometer, or a Varian INOVA $600 \mathrm{MHz}$ spectrometer at room temperature, unless otherwise noted. Chemical shifts $(\delta)$ are given in parts per million and referenced to the residual solvent signal ${ }^{[109]}$ (DMSO- $d_{6}$ is referenced to the solvent peaks at 2.50 ppm and $39.52 \mathrm{ppm}$ for ${ }^{1} \mathrm{H}$ and ${ }^{13} \mathrm{C}$ NMR spectra respectively, and DMF- $d_{7}$ is referenced to 8.02 ppm for all kinetic experiments); and all coupling constants $(J)$ are reported in Hz. IR spectra were recorded on a Perkin Elmer (Spectrum 100) FT-IR spectrometer. High resolution mass spectra 
were obtained on a Thermofisher Scientific Q Exactive Mass Spectrometer. Elemental analyses were performed by Atlantic Microlab, Inc., Norcross, GA.

\subsubsection{General Method for the Decarboxylation Reactions.}

\section{Reaction Setup.}

(1,10-phenanthroline) $\mathrm{Ag}\left(2-\mathrm{NO}_{2}\right.$-benzoate) $(1.6 \mathrm{mg}, 3.5 \mu \mathrm{mol})$ was added to a J. Young NMR tube wrapped in aluminum foil. In a nitrogen-filled glovebox, $0.5 \mathrm{~mL}$ of a $24 \mathrm{mM}$ solution of 1,3,5-trimethoxybenzene and $0.7 \mathrm{mM}$ water in DMF- $d_{7}$ was added and the J. Young NMR tube was sealed and brought out of the glovebox and shaken for 5 minutes. (For the low concentration reactions, $1.0 \mathrm{~mL}$ of the DMF- $d_{7}$ solution was used.) $\mathrm{A}{ }^{1} \mathrm{H}$ NMR spectrum of the solution was obtained to verify the initial concentration of the complex. The J. Young NMR tube was then heated at $40{ }^{\circ} \mathrm{C}$ for 15 minutes with agitation and a ${ }^{1} \mathrm{H}$ NMR spectrum was once again obtained to verify that all of the complex was dissolved. The NMR tube was then heated at $110{ }^{\circ} \mathrm{C}$ for 1 minute and a ${ }^{1} \mathrm{H}$ NMR spectrum was taken. To collect a spectrum, the tubes were removed from the oil bath and the samples were walked to the spectrometer where the aluminum foil covering was removed and the NMR tube was cleaned with hexanes prior to placing it into the spectrometer and acquiring a spectrum. The aluminum foil covering was then replaced and the tube was then returned to the $110{ }^{\circ} \mathrm{C}$ oil bath. This process was repeated for 10 data points after which, the reaction mixture was heated and spectra collected at 15, 20, 25, 30, 40, 50, 60, 70, 80, 90, 120, 150, 180 minute, and 23 hour time points. The time the sample spent in the oil bath corresponds to the time points used for all kinetic measurements.

\section{Data Collection.}

${ }^{1} \mathrm{H}$ NMR spectra were collected at $25^{\circ} \mathrm{C}$ on an Agilent $400 \mathrm{MHz}$ NMR spectrometer with VNMRJ 4.2 Revision A software using a gradient shimming protocol and a standard ${ }^{1} \mathrm{H}$ NMR pulse sequence with a one-second relaxation delay, no dummy scans, and five acquisition scans.

\section{Data Analysis.}

After Fourier transform of the FID, an auto-phasing protocol was applied, and the spectra were manually phased and manually integrated with no further baseline correction. The integration values of the aromatic peak of the 1,3,5-trimethoxybenzene internal standard (6.3 ppm) and the 
benzoate resonances of (phen) $\mathrm{Ag}\left(2-\mathrm{NO}_{2}\right.$-benzoate) $(7.7 \mathrm{ppm}$ at $1 \mathrm{~min})$ were used to calculate the concentration of the (phen) $\mathrm{Ag}\left(2-\mathrm{NO}_{2}\right.$-benzoate) in the sample (Figure 2-1 A and Table 1). These concentration values provided the kinetic time course data shown in Figures 2-4, 2-5, 2-7, 2-12, $2-14,2-15,2-16$, and 2-17. The initial rates were determined from a linear fit of the early reaction times of the time course plots immediately following the induction period. The early reaction times, typically corresponding to the first 15 minutes of product formation, however, because the duration of the linear region of the early reaction times vary for the differently substituted carboxylates, the early reaction times were determined as the reaction time before the product formation begins to slow. 


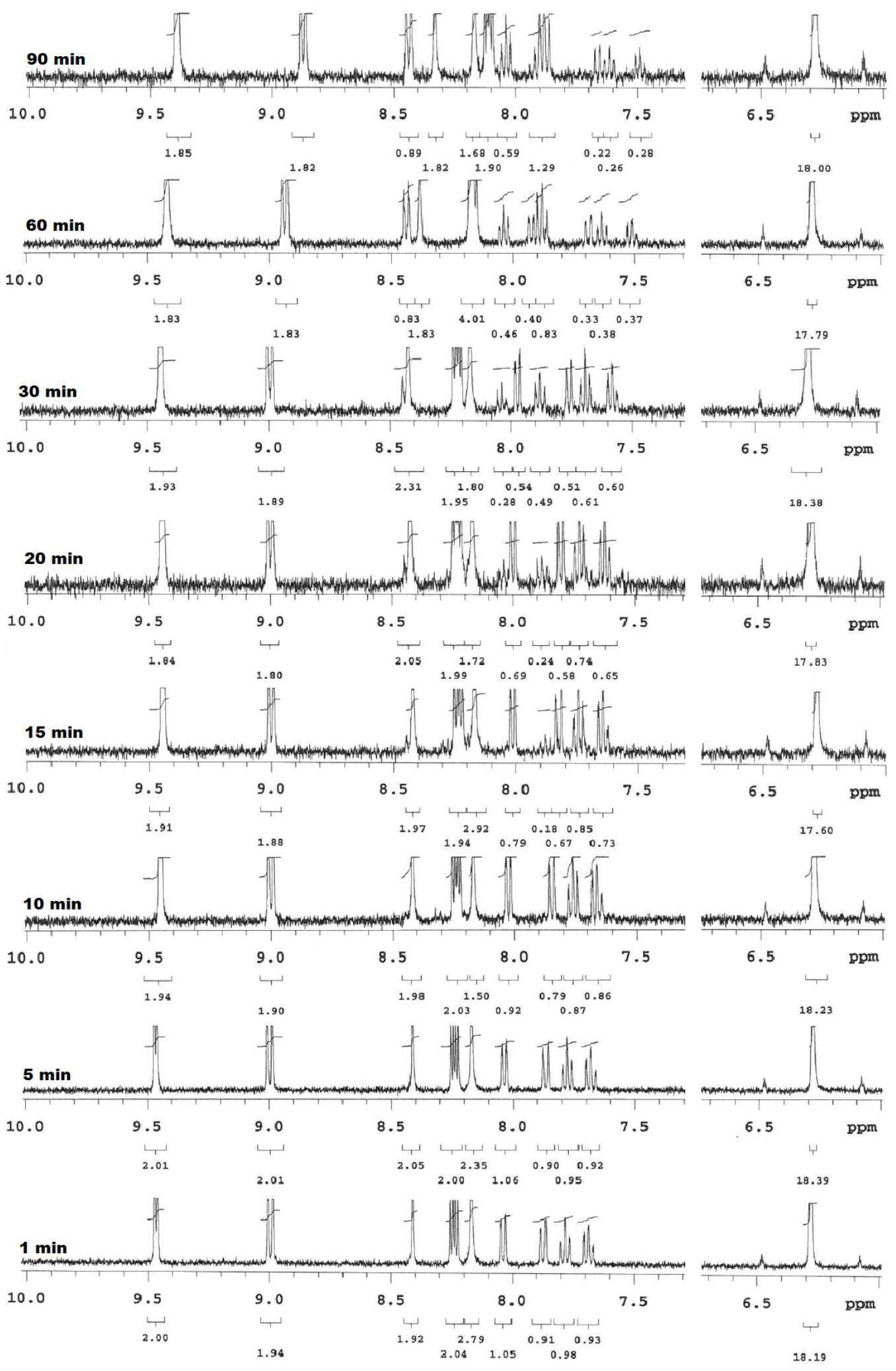

Figure 2-9: ${ }^{1} \mathrm{H}$ NMR spectra and integration values for the decarboxylation of (phen) $\mathrm{Ag}\left(2-\mathrm{NO}_{2}\right.$-benzoate) in DMF- $d_{7}$ at $110{ }^{\circ} \mathrm{C}$ at $\mathrm{t}=1,5,10,15,20,30,60$, and 90 min. 
Table 2-4: ${ }^{1} \mathrm{H}$ NMR spectra integration values and resulting concentrations for the decarboxylation of (phen) $\mathrm{Ag}\left(2-\mathrm{NO}_{2}\right.$-benzoate) giving rise to the reaction time course (Figures 2-1B and 2-2) and used to determine the initial rate of decarboxylation for (phen) $\mathrm{Ag}\left(2-\mathrm{NO}_{2}\right.$-benzoate).

\begin{tabular}{|c|c|c|c|c|}
\hline Time (h) & $\begin{array}{c}\text { Ag benzoate } \\
\text { integration }\end{array}$ & $\begin{array}{c}\text { Internal standard } \\
\text { integration }\end{array}$ & $\begin{array}{c}\text { Ag benzoate } \\
\text { (mmol) }\end{array}$ & $\begin{array}{c}\text { [Ag benzoate] } \\
\text { (mM) }\end{array}$ \\
\hline $0.017^{a}$ & 0.93 & 18.19 & 0.00351 & 3.51 \\
\hline 0.033 & 0.91 & 18.11 & 0.00345 & 3.45 \\
\hline 0.050 & 0.89 & 17.80 & 0.00343 & 3.43 \\
\hline 0.067 & 0.93 & 18.68 & 0.00342 & 3.42 \\
\hline $0.083^{a}$ & 0.92 & 18.39 & 0.00344 & 3.44 \\
\hline $0.167^{a}$ & 0.86 & 18.23 & 0.00325 & 3.25 \\
\hline $0.250^{a}$ & 0.73 & 17.60 & 0.00285 & 2.85 \\
\hline $0.333^{a}$ & 0.65 & 17.83 & 0.00250 & 2.50 \\
\hline 0.417 & 0.61 & 18.15 & 0.00231 & 2.31 \\
\hline $0.500^{a}$ & 0.60 & 18.38 & 0.00224 & 2.24 \\
\hline 0.667 & 0.52 & 19.15 & 0.00187 & 1.87 \\
\hline 0.833 & 0.49 & 19.95 & 0.00169 & 1.69 \\
\hline $1.03^{a}$ & 0.37 & 17.79 & 0.00143 & 1.43 \\
\hline 1.167 & 0.35 & 19.30 & 0.00125 & 1.25 \\
\hline 1.333 & 0.30 & 18.54 & 0.00111 & 1.11 \\
\hline 1.500 & 0.28 & 18.00 & 0.00107 & 1.07 \\
\hline 2.000 & 0.22 & 19.03 & 0.00080 & 0.80 \\
\hline 2.500 & 0.17 & 18.32 & 0.00064 & 0.64 \\
\hline 3.000 & 0.15 & 18.15 & 0.00057 & 0.57 \\
\hline
\end{tabular}

${ }^{a}$ Data corresponding to the ${ }^{1} \mathrm{H}$ NMR spectra included in Figure 2-1A. 


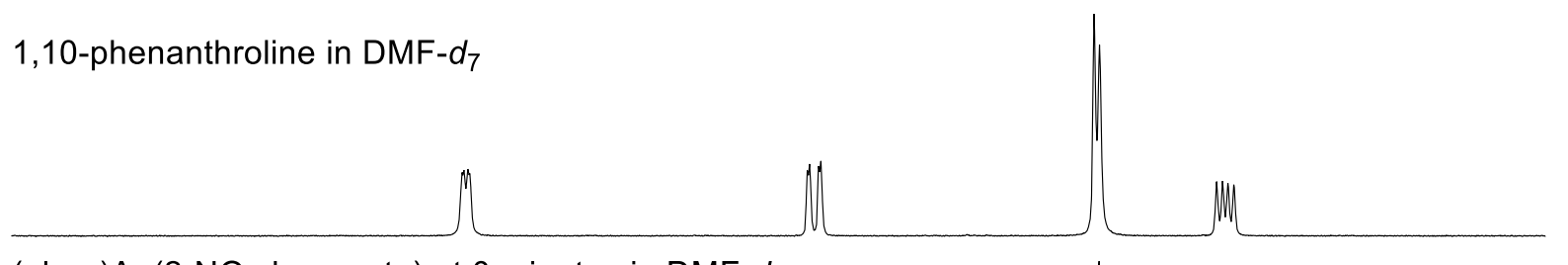

(phen)Ag(2- $\mathrm{NO}_{2}$-benzoate) at 0 minutes in DMF- $d_{7}$

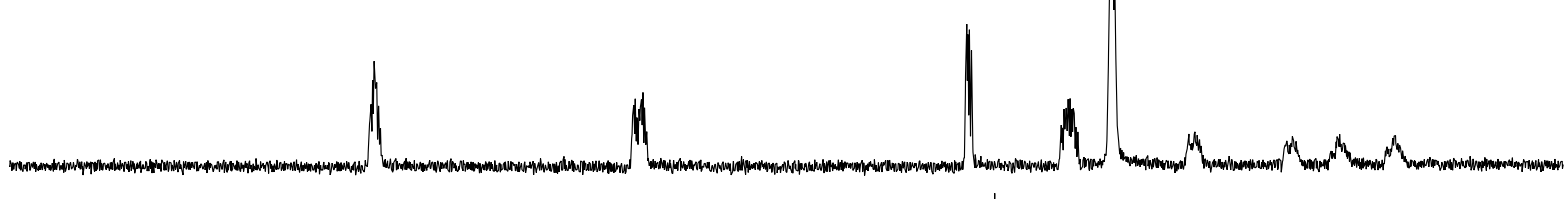
(phen)Ag(2- $\mathrm{NO}_{2}$-benzoate) at 60 minutes in DMF- $d_{7}$

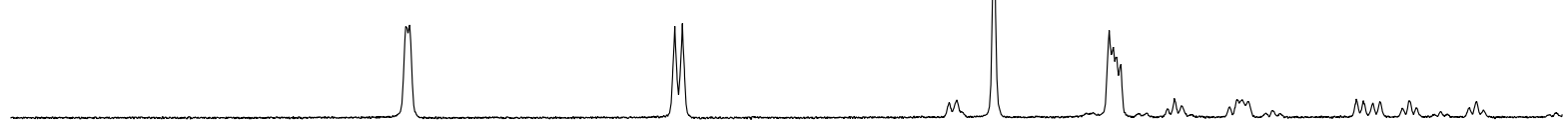

$\mathrm{Ag}\left(2-\mathrm{NO}_{2}\right.$-benzoate $)$ in DMF- $d_{7}$

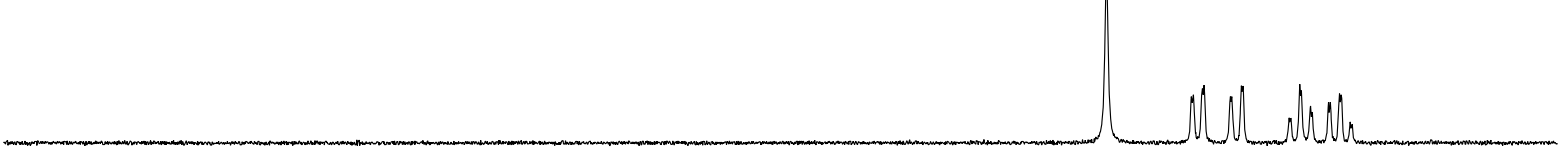

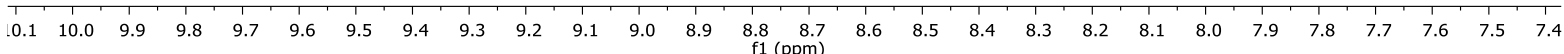

Figure 2-10: ${ }^{1} \mathrm{H}$ NMR stacked plot of the $\mathrm{Ag}\left(2-\mathrm{NO}_{2}\right.$-benzoate), decarboxylation of (phen) $\mathrm{Ag}\left(2-\mathrm{NO}_{2}\right.$-benzoate) at $\mathrm{t}=0 \mathrm{~min}$ and $\mathrm{t}=60 \mathrm{~min}$, and 1,10-phenanthroline in DMF- $d_{7}$.

\section{On the Inclusion of Water.}

When water is excluded from the reaction mixtures and DMF- $d_{7}$ dried over $4 \AA$ molecular sieves is used, both nitrobenzene and 2,2' -dinitrobiphenyl are formed. In the reaction time course (Figure 2-11 below), the biphenyl peaks (indicated in yellow) overlap with the (phen) Ag(2-NO2-benzoate) complex (blue) and the nitrobenzene (red). To ensure the generation of clean ${ }^{1} \mathrm{H}$ NMR spectra with reproducible and reliable integrations, we included water in the reaction mixture to form nitrobenzene as the sole reaction product. 

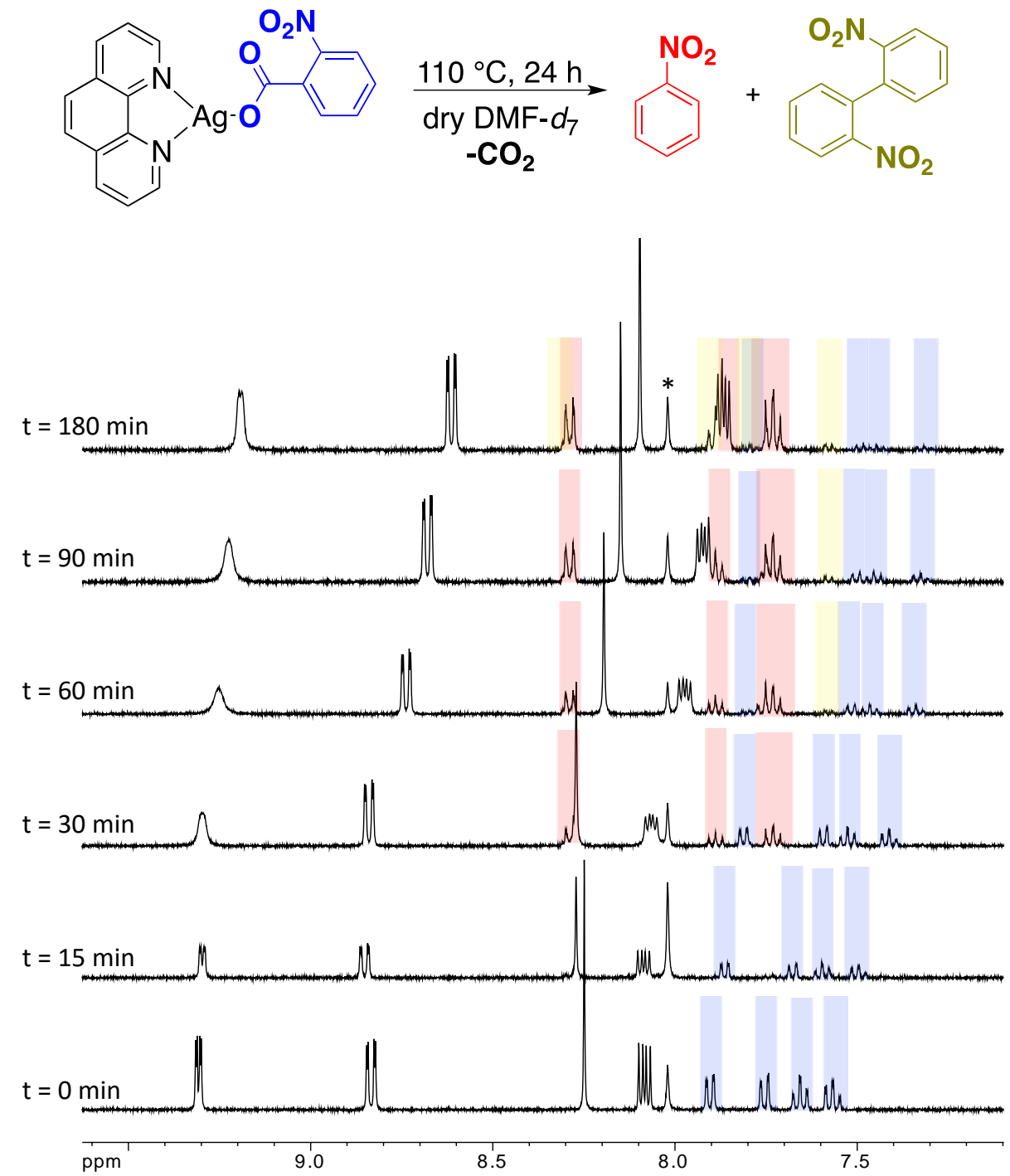

Figure 2-11: ${ }^{1} \mathrm{H}$ NMR time course for the decarboxylation of (phen) $\mathrm{Ag}\left(2-\mathrm{NO}_{2}\right.$-benzoate) (5.7 $\mathrm{mM}$, blue) to form nitrobenzene (red) and 2,2'-dinitrobipheny (yellow) in dry DMF- $d_{7}$ at $110{ }^{\circ} \mathrm{C}$. The asterisk denotes the residual solvent signals.

\section{2,2'-dinitrobiphenyl.}

${ }^{1} \mathrm{H}$ NMR (400 MHz, DMF- $\left.d_{7}\right): \delta=8.30(\mathrm{dd}, J=8.2,1.2 \mathrm{~Hz}, 2 \mathrm{H}), 7.90(\mathrm{td}, J=8.8,1.3 \mathrm{~Hz}, 2 \mathrm{H})$, $7.79(\mathrm{td}, J=8.24,1.48 \mathrm{~Hz}, 2 \mathrm{H}), 7.58(\mathrm{dd}, J=7.6,1.3 \mathrm{~Hz}, 2 \mathrm{H})$.

\subsection{3 [(phen)Ag(2-NO2-benzoate)] Dependence in DMF- $d 7$.}

To five separate J. Young NMR tubes wrapped in aluminum foil, $7.27 \mu \mathrm{mol}(3.3 \mathrm{mg}), 5.50 \mu \mathrm{mol}$ (2.5 mg), $4.18 \mu \mathrm{mol}(1.9 \mathrm{mg}), 3.52 \mu \mathrm{mol}$ (1.6 mg), $2.42 \mu \mathrm{mol}$ (1.1 mg), respectively, of 
(phenanthroline) $\mathrm{Ag}$ (2-nitrobenzoate) was added. In a nitrogen filled glovebox, $0.5 \mathrm{~mL}$ of a $24.0 \mathrm{mM}$ solution of 1,3,5-trimethoxybenzene in DMF- $d_{7}$ containing $0.7 \mathrm{mM}$ water was added to each J. Young NMR tube and the tube was then sealed and brought out of the glovebox and shaken for 5 minutes. In a sixth J. Young NMR tube, $3.30 \mu$ mol $(1.5 \mathrm{mg})$ of (phenanthroline) $\operatorname{Ag}(2$-nitrobenzoate) was added. In the nitrogen filled glovebox, $1 \mathrm{~mL}$ of a $24.0 \mathrm{mM}$ solution of 1,3,5-trimethoxybenzene in DMF- $d 7$ with $0.7 \mathrm{mM}$ water was added, the NMR tube was sealed and brought out of the glovebox. This tube was shaken for 5 minutes as well. A ${ }^{1} \mathrm{H}$ NMR spectrum was obtained to verify the amount of the complex dissolved into solution. The J. Young NMR tube was then heated at $40{ }^{\circ} \mathrm{C}$ for 15 minutes with agitation and a ${ }^{1} \mathrm{H}$ NMR spectrum was once again obtained to verify that all of the complex was dissolved. The NMR tube was then heated at $110{ }^{\circ} \mathrm{C}$ for 1 minute and a ${ }^{1} \mathrm{H}$ NMR spectrum was taken. This process was repeated for 10 data points after which, the reaction mixture was heated and spectra collected at $15,20,25,30,40,50,60,90,120,150$, and 180 minute time points. Please refer to Figure 2-2 for the plot of the dependence study. 
A)

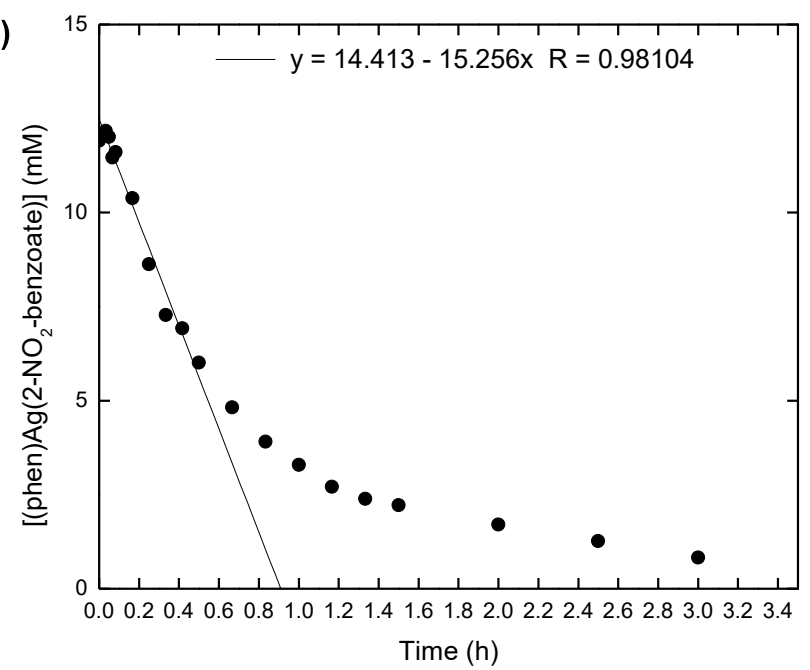

C)

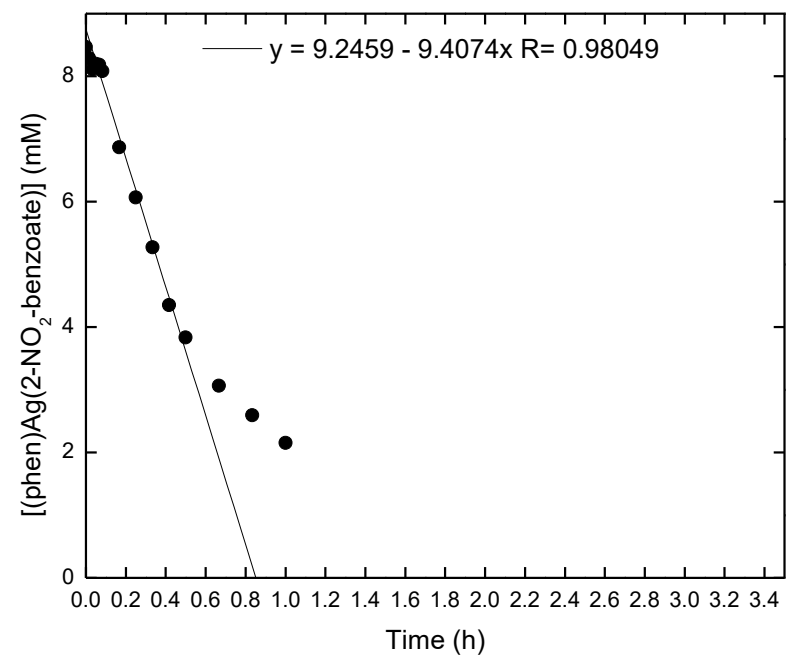

E)

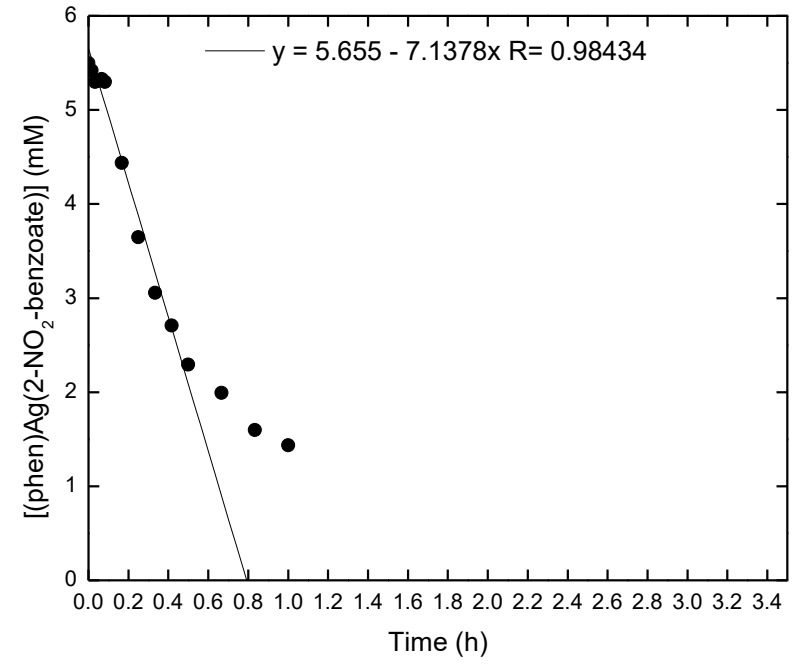

B)

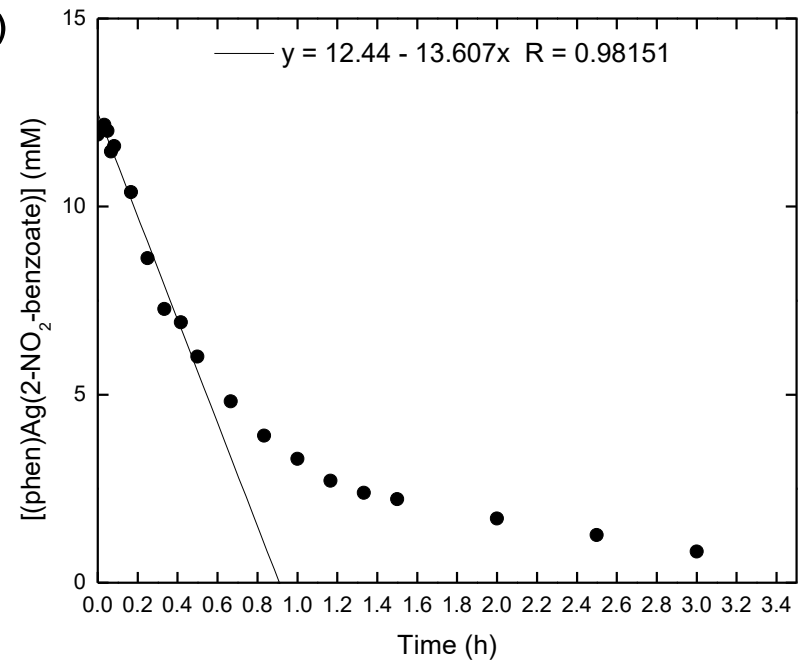

D)

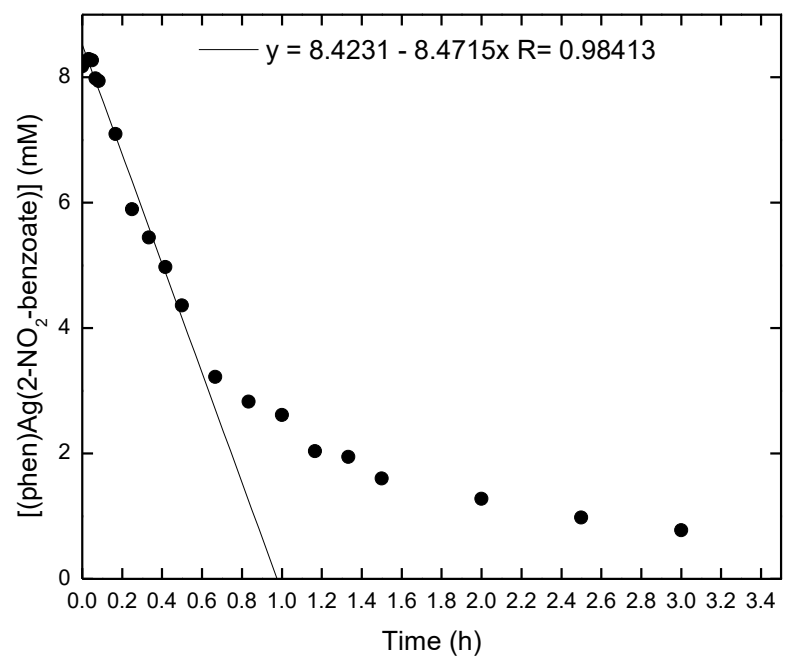

F)

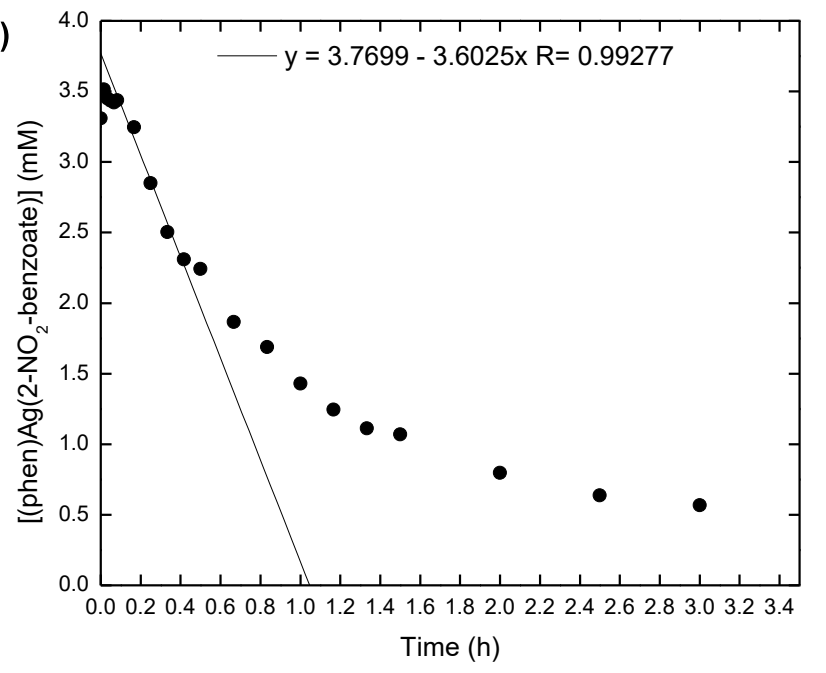

Figure 2-12: Reaction profile and initial rate fits for the decarboxylation of (phen) $\mathrm{Ag}\left(2-\mathrm{NO}_{2}\right.$-benzoate) in DMF-d 7 with $0.7 \mathrm{mM} \mathrm{H}_{2} \mathrm{O}$ at $110{ }^{\circ} \mathrm{C}$. Concentrations at A) 14.4 $\mathrm{mM}$, B) $12.2 \mathrm{mM}$, C) $8.5 \mathrm{mM}$, D) $8.3 \mathrm{mM}$, E) $5.5 \mathrm{mM}$ and F) $3.5 \mathrm{mM}$. 


\subsubsection{Decarboxylation of $\mathrm{Ag}\left(2-\mathrm{NO}_{2}\right.$-benzoate).}

$\mathrm{Ag}\left(2-\mathrm{NO}_{2}\right.$-benzoate $)(1.9 \mathrm{mg}, 6.9 \mu \mathrm{mol})$ was added to a $20 \mathrm{~mL}$ vial. In a nitrogen-filled glovebox, $1.0 \mathrm{~mL}$ of a $24.0 \mathrm{mM}$ solution of 1,3,5-trimethoxybenzene and $0.7 \mathrm{mM}$ water in DMF- $d_{7}$ was added. The solution was mixed until fully dissolved, after which, $0.5 \mathrm{~mL}$ of the solution was added to a J. Young NMR tube, which was then sealed and brought out of the glovebox and shaken for 5 minutes. A ${ }^{1} \mathrm{H}$ NMR spectrum of the solution was obtained to verify the initial concentration of the complex. The J. Young NMR tube was then heated at $40{ }^{\circ} \mathrm{C}$ for 15 minutes with agitation and a ${ }^{1} \mathrm{H}$ NMR spectrum was once again obtained to verify that all of the complex was dissolved. The NMR tube was then heated at $110^{\circ} \mathrm{C}$ for 1 minute and a ${ }^{1} \mathrm{H}$ NMR spectrum was taken. This process was repeated for 10 data points after which, the reaction mixture was heated and spectra collected at $15,20,25,30,40,50,60,70,80,90,120$, and $150 \mathrm{~min}$, and $23 \mathrm{~h}$ time points. Please refer to Figure 2-3 for the reaction time course plot.

\subsubsection{Synthesis and Protodemetallation of $\mathrm{Ag}\left(2-\mathrm{NO}_{2}-\right.$ phenyl).}<smiles>CC1(C)COB(c2ccccc2[N+](=O)[O-])OC1</smiles>

2-nitrophenylboronic acid neopentylglycol ester. This compound was synthesized by modification of a literature procedure. ${ }^{[110]}$ In a mortar and pestle, 2-nitrophenylboronic acid (1.00 g, $6.0 \mathrm{mmol}$ ) was combined with 2,2-dimethyl-1,3-propanediol (620. mg, $5.95 \mathrm{mmol})$ until a dark brown oil was formed. This oil was then mixed with silica gel to produce a tan free-flowing powder. The resulting powder was then added to a fritted filter and eluted through a pad of silica gel with a $20 \%$ solution of ethyl acetate in hexane to produce a yellow solution. The solvent was then removed to yield $1.31 \mathrm{~g}(5.56 \mathrm{mmol}, 94 \%)$ of the title compound as a red-brown oil. ${ }^{1} \mathrm{H}$ NMR (400 MHz, Chloroform- $d$ ): $\delta=8.10(\mathrm{dd}, J=8.2,1.1 \mathrm{~Hz}, 1 \mathrm{H}), 7.63(\mathrm{td}, J=7.3,1.1 \mathrm{~Hz}, 1 \mathrm{H}), 7.56$ $(\mathrm{dd}, J=7.4,1.6 \mathrm{~Hz}, 1 \mathrm{H}), 7.49(\mathrm{ddd}, J=8.1,7.2,1.6 \mathrm{~Hz}, 1 \mathrm{H}), 3.81(\mathrm{~s}, 4 \mathrm{H}), 1.12(\mathrm{~s}, 6 \mathrm{H})$. Spectroscopic characterization is consistent with literature values. ${ }^{[110]}$ 
<smiles>O=[N+]([O-])c1ccccc1[As]</smiles>

$\operatorname{Ag}\left(\mathbf{2}-\mathrm{NO}_{2}\right.$-phenyl). This compound was prepared according to the literature procedure. ${ }^{[102]}$ In a light protected $100 \mathrm{~mL}$ round bottom flask inside of a $\mathrm{N}_{2}$ filled glovebox, $\mathrm{AgF}$ (267 mg, $2.12 \mathrm{mmol}$ ) was suspended in $20 \mathrm{~mL}$ of $\mathrm{MeCN}$ with rapid stirring. In a separate vial, 2-nitrophenylboronic acid neopentylglycol ester (498 mg, $2.12 \mathrm{mmol}$ ) was dissolved in $20 \mathrm{~mL}$ $\mathrm{MeCN}$. This solution was added to the suspension of $\mathrm{AgF}$ and the resulting mixture was allowed to stir for 90 minutes. The reaction was then filtered and rinsed with $50 \mathrm{~mL}$ of ether and dried under vacuum to yield $324 \mathrm{mg}(1.41 \mathrm{mmol}, 66 \%)$ of a yellow powder. ${ }^{1} \mathrm{H}$ NMR (400 MHz, DMSO- $\left.d_{6}\right): \delta=8.01(\mathrm{dd}, J=8.1,1.1 \mathrm{~Hz}, 1 \mathrm{H}), 7.94(\mathrm{dd}, J=6.9,1.5 \mathrm{~Hz}, 1 \mathrm{H}), 7.53(\mathrm{td}, J=7.1,1.2$ $\mathrm{Hz}, 1 \mathrm{H}), 7.40$ (ddd, $J=8.1,7.2,1.6 \mathrm{~Hz}, 1 \mathrm{H}$ ). Spectroscopic characterization is consistent with literature values. ${ }^{[102]}$

\section{Protodemetallation of $\mathrm{Ag}\left(2-\mathrm{NO}_{2}\right.$-phenyl).}<smiles>O=C(C=Cc1ccccc1[N+](=O)[O-])OCCOc1ccccc1[N+](=O)[O-]</smiles>

In a light protected vial inside of a $\mathrm{N}_{2}$ filled glovebox, a stock solution of $\mathrm{Ag}\left(2-\mathrm{NO}_{2}\right.$-phenyl) was prepared by dissolving $\mathrm{Ag}\left(2-\mathrm{NO}_{2}\right.$-phenyl $)(2.6 \mathrm{mg}, 11.0 \mu \mathrm{mol})$ into a stock solution of DMF- $d_{7}$ and water $(1.5 \mathrm{~mL}, 0.7 \mathrm{mM}$ water). Of this solution, $0.5 \mathrm{~mL}$ was placed into a J. Young NMR tube wrapped in aluminum foil and sealed. The J. Young NMR tube was then taken out of the glovebox and heated to $110{ }^{\circ} \mathrm{C}$ and monitored by ${ }^{1} \mathrm{H}$ NMR spectroscopy at $0,1,2,3,4,5,6,7,8$, $9,10,15,20,25$, and 30 minutes. Please refer to Figure 2-4A for the reaction time course plot.

\section{Protodemetallation of $\mathrm{Ag}\left(2-\mathrm{NO}_{2}\right.$-phenyl) with phen.}

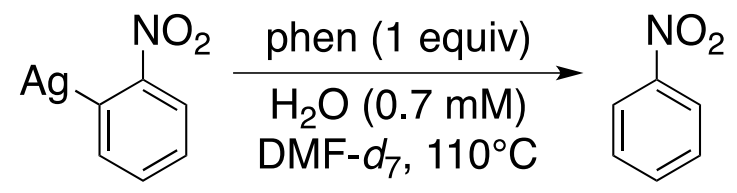


Inside of a $\mathrm{N}_{2}$ filled glovebox, 1,10-phenanthroline $(0.7 \mathrm{mg}, 3.9 \mu \mathrm{mol})$ was placed into an aluminum foil wrapped J. Young NMR tube. A stock solution of $\operatorname{Ag}\left(2-\mathrm{NO}_{2}\right.$-phenyl) was prepared in a light protected vial by dissolving $\mathrm{Ag}\left(2-\mathrm{NO}_{2}\right.$-phenyl $)(2.6 \mathrm{mg}, 11.0 \mu \mathrm{mol})$ into a stock solution of DMF- $d_{7}$ and water $(1.5 \mathrm{~mL}, 0.7 \mathrm{mM}$ water). Of this solution, $0.5 \mathrm{~mL}$ was placed into the $\mathrm{J}$. Young NMR tube wrapped in aluminum foil and sealed. The J. Young NMR tube was then taken

out of the glovebox and heated to $110{ }^{\circ} \mathrm{C}$ and monitored by ${ }^{1} \mathrm{H}$ NMR spectroscopy at $0,1,2,3,4$, $5,6,7,8,9,10,15,20,25$, and 30 minutes. Please refer to Figure 2-4B for the reaction time course plot.

\subsubsection{Decarboxylation of (phen)Ag(benzoate) Complexes.}

A foil-wrapped J. Young NMR tube was charged with the (phen)Ag(benzoate) complex (3.5 $\mu$ mol unless otherwise noted below). This was then taken into a $\mathrm{N}_{2}$ filled glovebox, where $0.5 \mathrm{~mL}$ of a DMF- $d_{7}$ and water $(0.7 \mathrm{mM})$ solution (unless otherwise noted below) was added and the NMR tube was sealed. The J. Young NMR tube was then taken out of the glovebox and heated to $110{ }^{\circ} \mathrm{C}$ and monitored by ${ }^{1} \mathrm{H}$ NMR spectroscopy at $0,1,2,3,4,5,6,7,8,9,10,15,20,25,30,40,50,60$, $70,80,90,120,150,180,210,240,270$, and 300 minutes of heating.

For the (phen) $\mathrm{Ag}\left(2-\mathrm{NO}_{2}-4-\mathrm{R}\right.$-benzoate) complexes $1.0 \mathrm{~mL}$ of the DMF- $d_{7}$ and water $(0.7 \mathrm{mM})$ stock solution was used: (phen) $\mathrm{Ag}\left(2-\mathrm{NO}_{2}-4-\mathrm{F}-\right.$ benzoate), (phen) $\mathrm{Ag}\left(2-\mathrm{NO}_{2}-4-\mathrm{OMe}-\right.$ benzoate), and (phen) $\mathrm{Ag}\left(2-\mathrm{NO}_{2}-4-\mathrm{NO}_{2}\right.$-benzoate). 


\subsubsection{Ortho-Substituted Benzoate Complexes in Figure 2-8A}

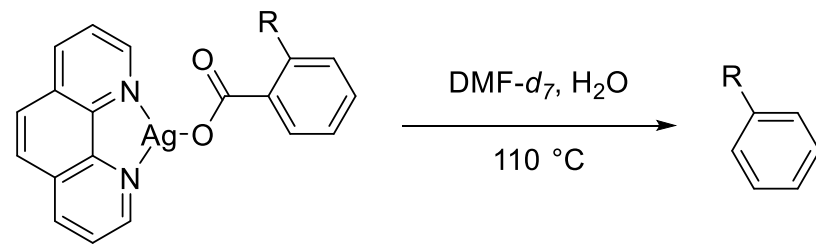

A)

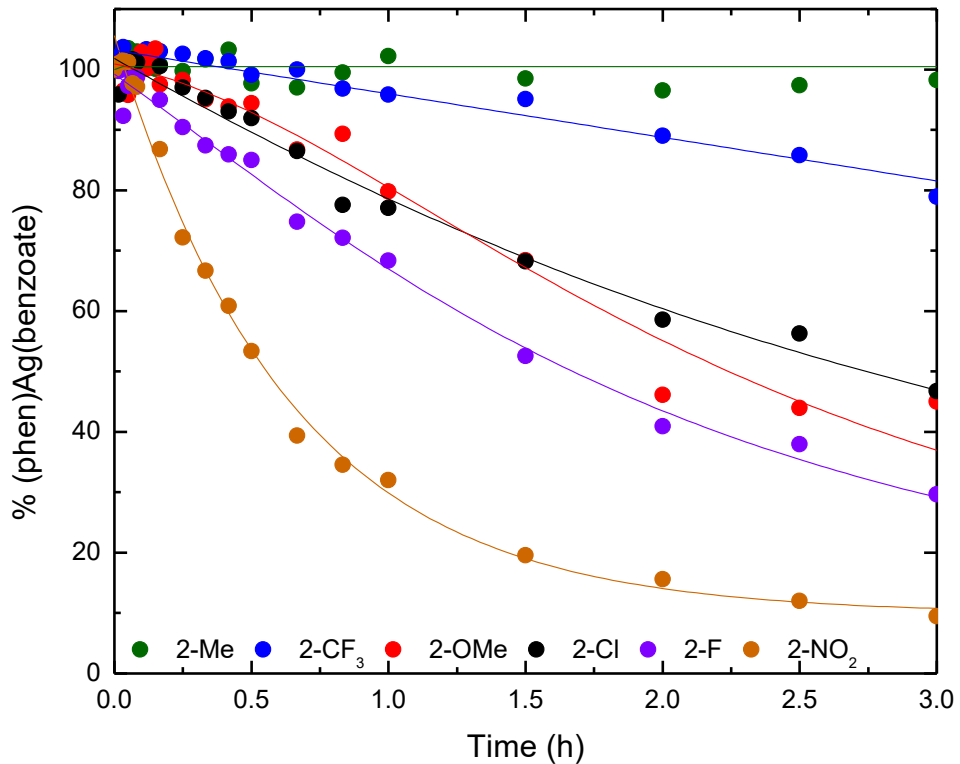

B)

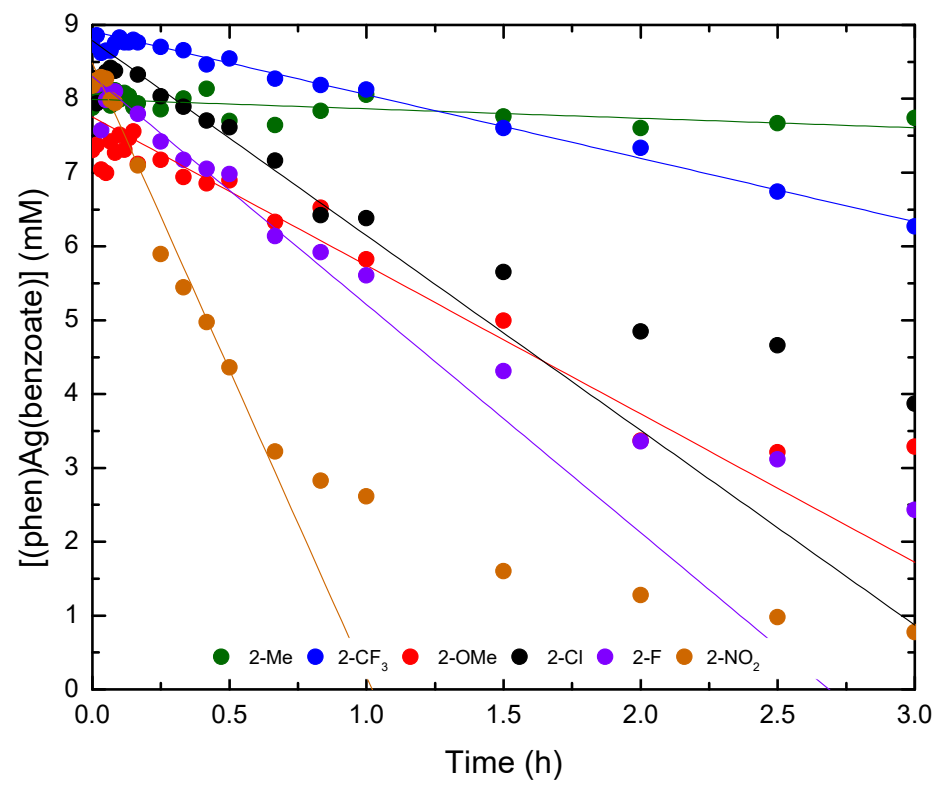

Figure 2-13: Kinetic profiles for the decarboxylation of (phen) $\mathrm{Ag}(2-\mathrm{R}$-benzoate) where $\mathrm{R}=\mathrm{Me}$, $\mathrm{CF}_{3}$, OMe, $\mathrm{Cl}, \mathrm{F}$, and $\mathrm{NO}_{2}$. A) Reaction profile given as \% (phen)Ag(2-R-benzoate) over time. Traces are not fits and are only meant to guide the eye. B) Reaction time course data fit to provide the initial reaction rates. Standard conditions are $8 \mathrm{mM}$ (phen) $\mathrm{Ag}(2$-R-benzoate) in $0.5 \mathrm{~mL}$ DMF- $\mathrm{d}_{7}$ with $0.7 \mathrm{mM} \mathrm{H}_{2} \mathrm{O}$ at $110{ }^{\circ} \mathrm{C}$. 
A)

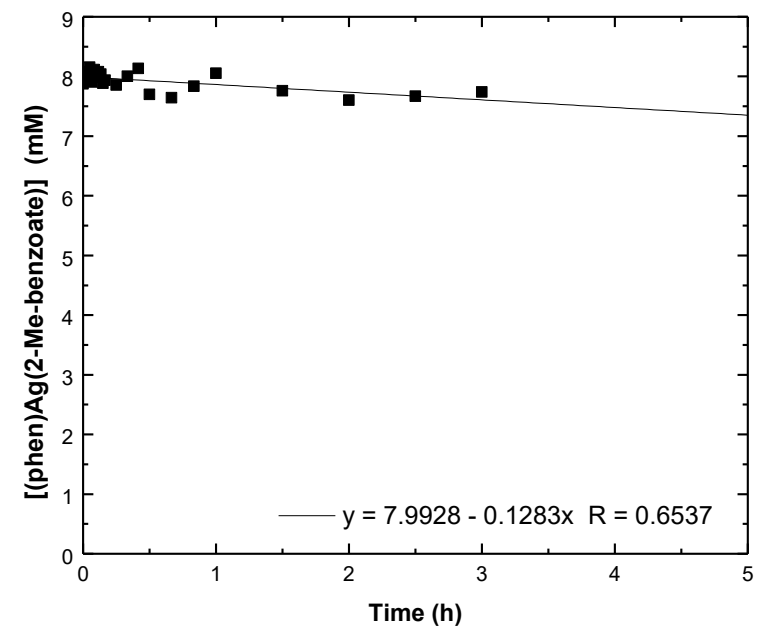

C)

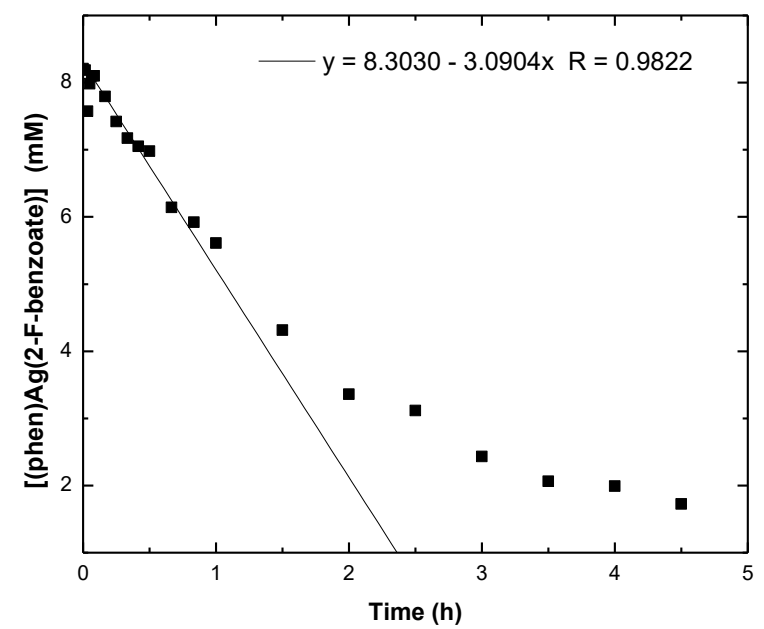

B)

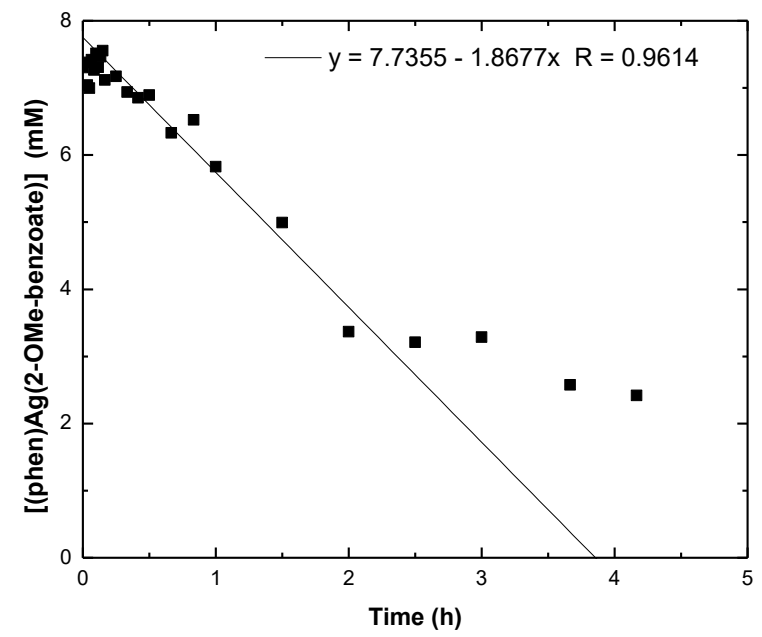

D)

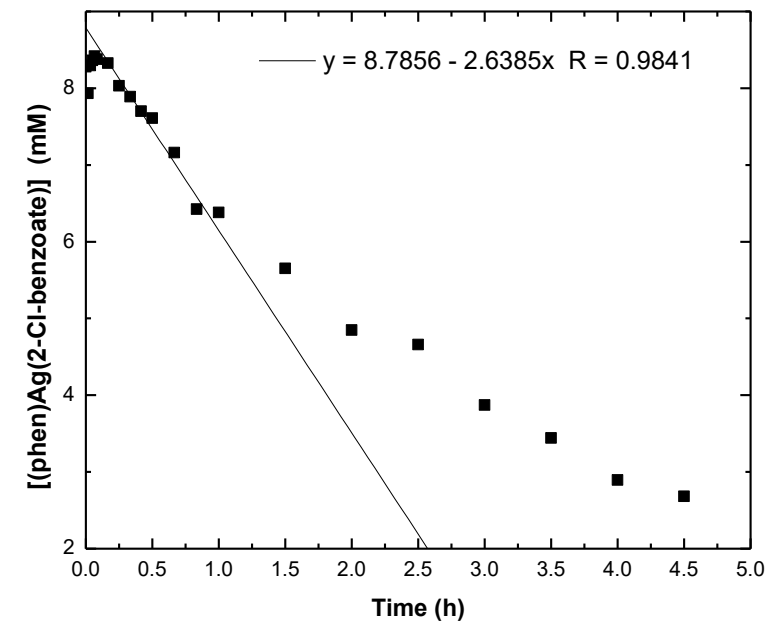

E)

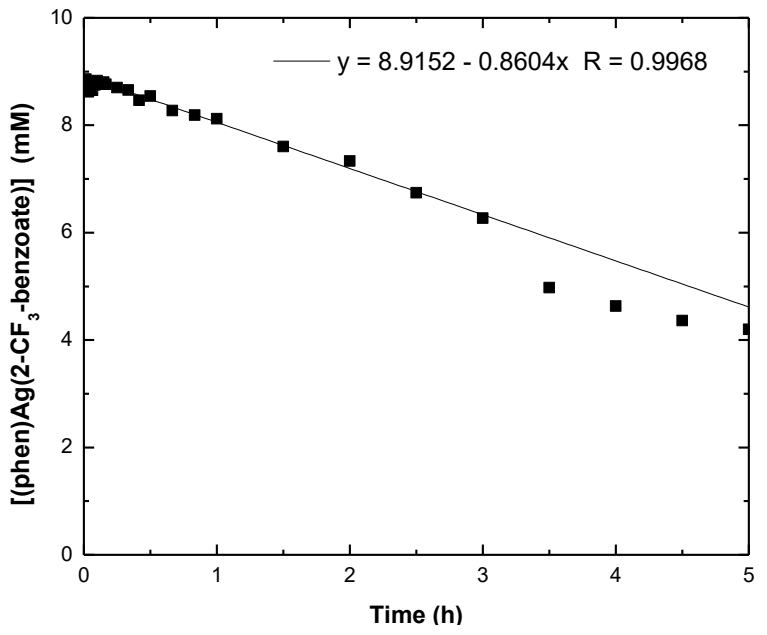

Figure 2-14 Reaction time course for the decarboxylation of A) (phen) $\mathrm{Ag}$ (2-Me-benzoate) (8.15 $\left.\left.\mathrm{mM} ; k=1.57 \times 10^{-2} \mathrm{~h}^{-1}\right), \mathrm{B}\right)$ (phen)Ag(2-OMe-benzoate) (7.55 mM; $\left.\left.k=0.247 \mathrm{~h}^{-1}\right), \mathrm{C}\right)$ (phen)Ag(2-F-benzoate) (8.19 mM; $\left.\left.k=0.377 \mathrm{~h}^{-1}\right), \mathrm{D}\right)$ (phen)Ag(2-Cl-benzoate) (8.42 mM; $\left.k=0.313 \mathrm{~h}^{-1}\right)$, E) (phen) $\mathrm{Ag}\left(2-\mathrm{CF}_{3}\right.$-benzoate) $\left(8.86 \mathrm{mM} ; k=9.71 \times 10^{-2} \mathrm{~h}^{-1}\right)$ in DMF- $d_{7}$ with 0.7 $\mathrm{mM} \mathrm{H} \mathrm{H}_{2} \mathrm{O}$ at $110^{\circ} \mathrm{C}$. 


\subsubsection{Di-Substituted Benzoate Complexes in Figure 2-8A}

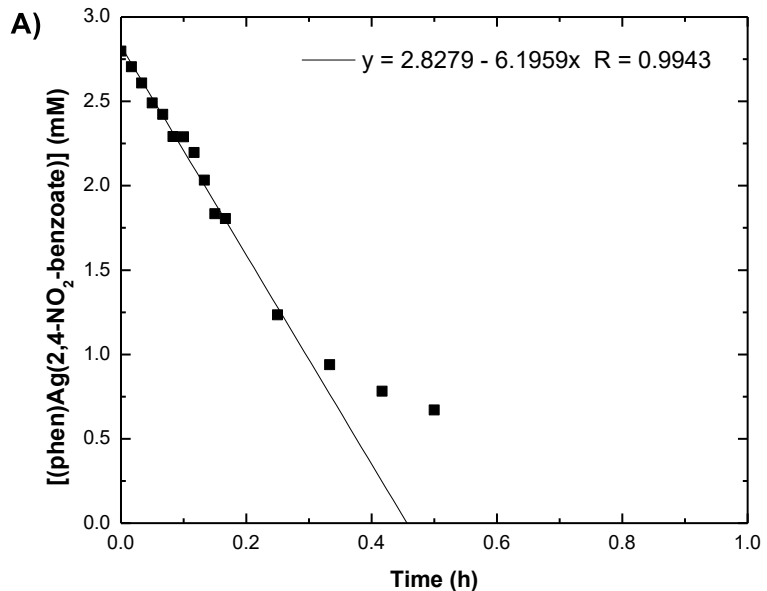

B)
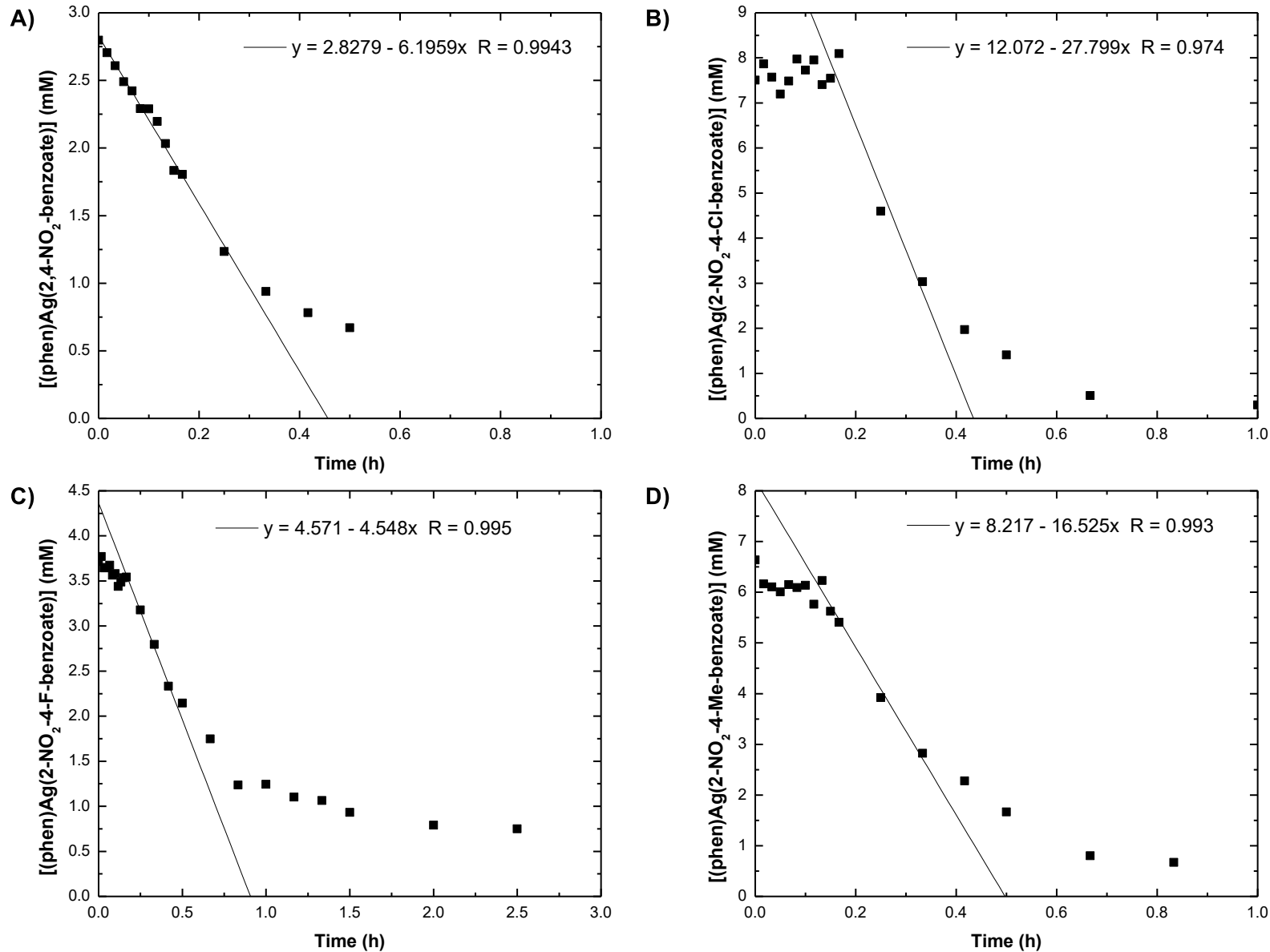

D)

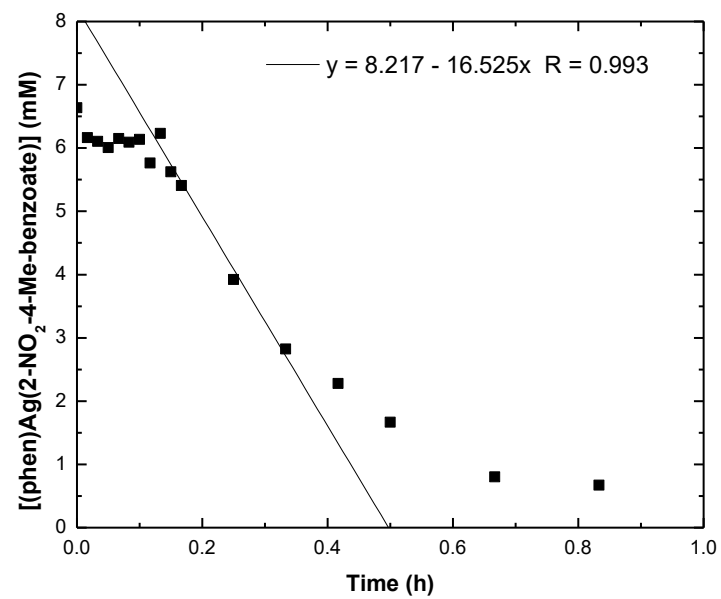

E)

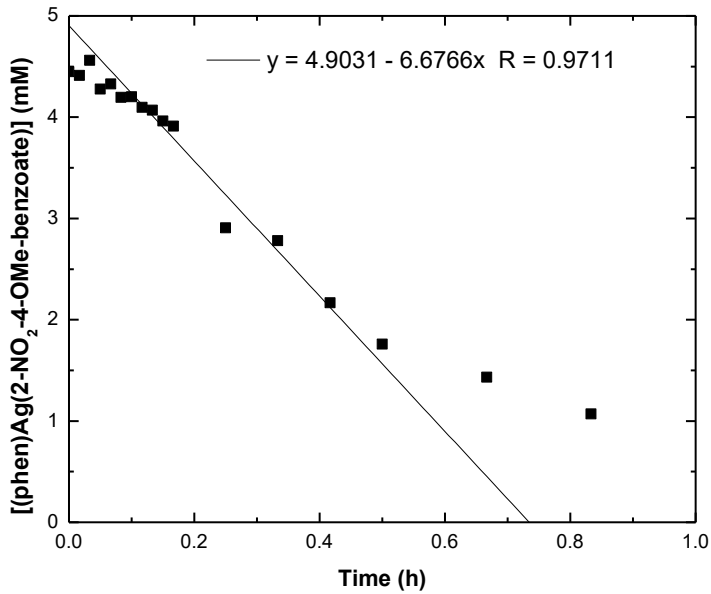

F)

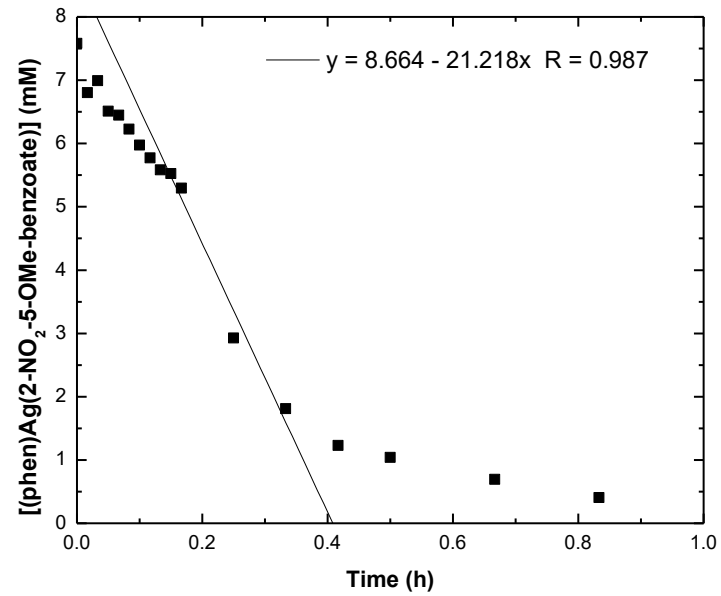

Figure 2-15: Reaction time course for the decarboxylation of A) (phen) $\mathrm{Ag}\left(2,4-\right.$ di- $\mathrm{NO}_{2}$-benzoate) (2.798 mM; $\left.\left.k=2.214 \mathrm{~h}^{-1}\right), \mathrm{B}\right)$ (phen)Ag(2-NO2-4-F-benzoate) (7.97 mM; $\left.k=3.49 \mathrm{~h}^{-1}\right), \mathrm{C}$ ) (phen)Ag(2-NO $\left.\left.{ }_{2}-4-F-b e n z o a t e\right)\left(3.89 \mathrm{mM} ; k=1.17 \mathrm{~h}^{-1}\right), \mathrm{D}\right)$ (phen) $\mathrm{Ag}\left(2-\mathrm{NO}_{2}-4-\mathrm{Me}\right.$-benzoate) (6.64 mM; $\left.\left.k=2.49 \mathrm{~h}^{-1}\right), \mathrm{E}\right)$ (phen) $\mathrm{Ag}\left(2-\mathrm{NO}_{2}-4-O M e-b e n z o a t e\right)\left(4.56 \mathrm{mM} ; k=1.46 \mathrm{~h}^{-1}\right)$ and $\left.\mathrm{F}\right)$ (phen) $\mathrm{Ag}\left(2-\mathrm{NO}_{2}-5-\mathrm{OMe}-\right.$ benzoate $)\left(7.58 \mathrm{mM} ; k=2.80 \mathrm{~h}^{-1}\right)$ in DMF- $d_{7}$ with $0.7 \mathrm{mM} \mathrm{H}_{2} \mathrm{O}$ at 110 ${ }^{\circ} \mathrm{C}$. 
A)

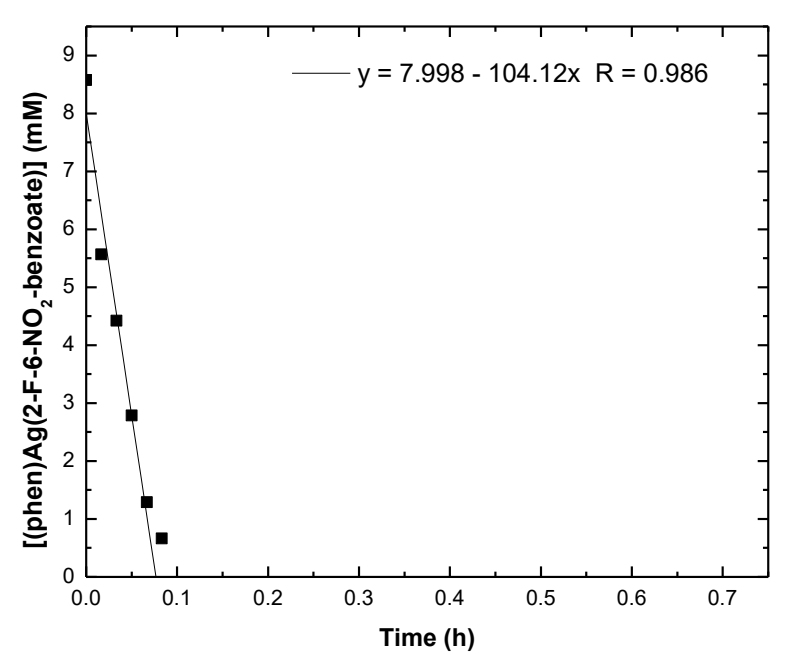

B)

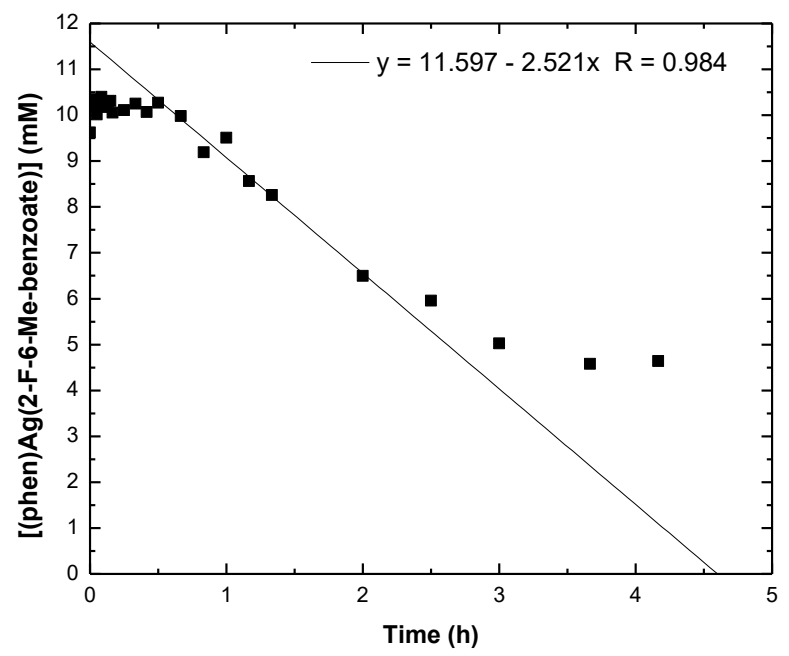

C)

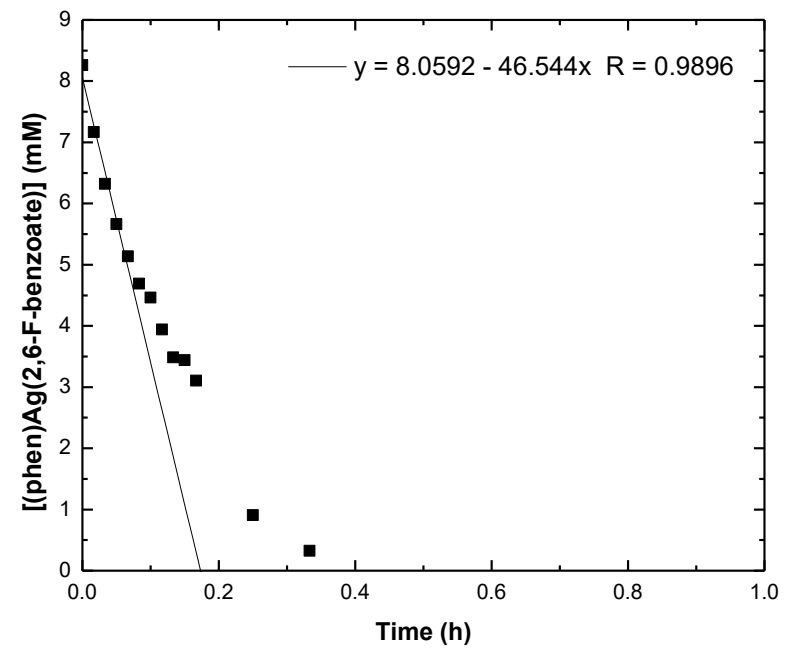

Figure 2-16: Reaction time course for the decarboxylation of A) (phen) $\mathrm{Ag}\left(2-\mathrm{F}-6-\mathrm{NO}_{2}\right.$-benzoate) (8.57 mM; $\left.\left.k=12.15 \mathrm{~h}^{-1}\right), \mathrm{B}\right)$ (phen)Ag(2-F-6-Me-benzoate) $\left.\left(10.40 \mathrm{mM} ; k=0.242 \mathrm{~h}^{-1}\right), \mathrm{C}\right)$ (phen) $\mathrm{Ag}\left(2,6\right.$-di-F-benzoate) $\left(8.26 \mathrm{mM} ; k=5.63 \mathrm{~h}^{-1}\right)$ in DMF- $d 7$ with $0.7 \mathrm{mM} \mathrm{H}_{2} \mathrm{O}$ at $110{ }^{\circ} \mathrm{C}$. 


\subsubsection{Substituted Benzoate Complexes of Silver used in the Validation Set (Figure 2-8B,}

red points [not included in the fit])

A)

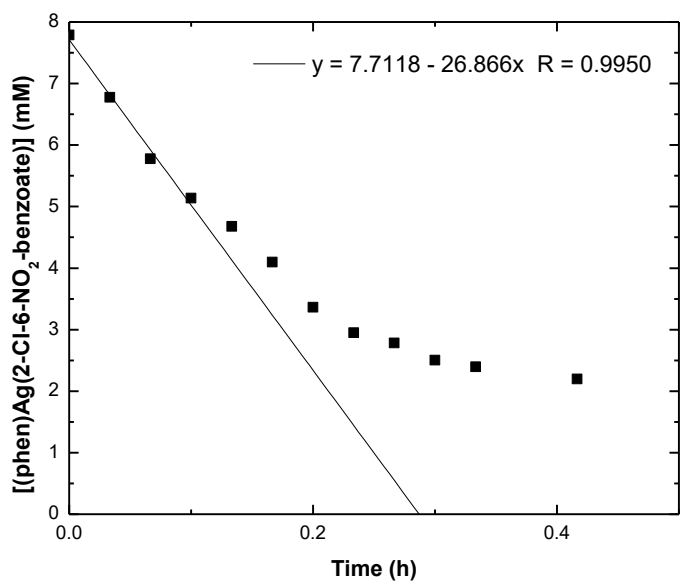

c)

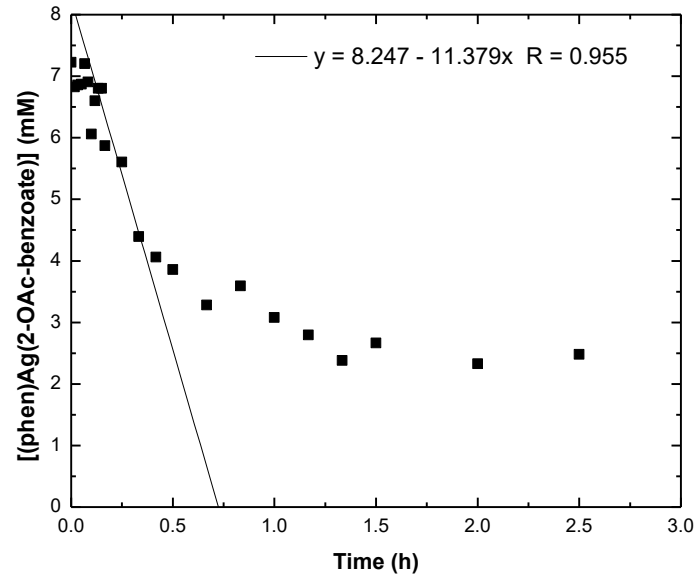

B)

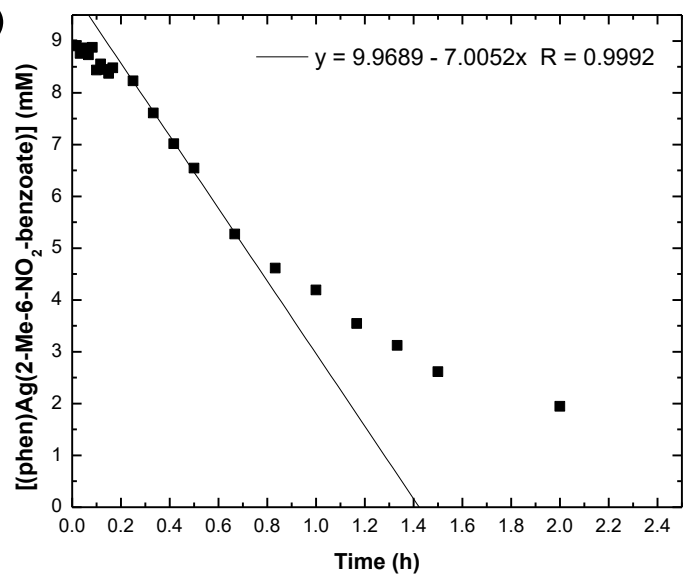

D)

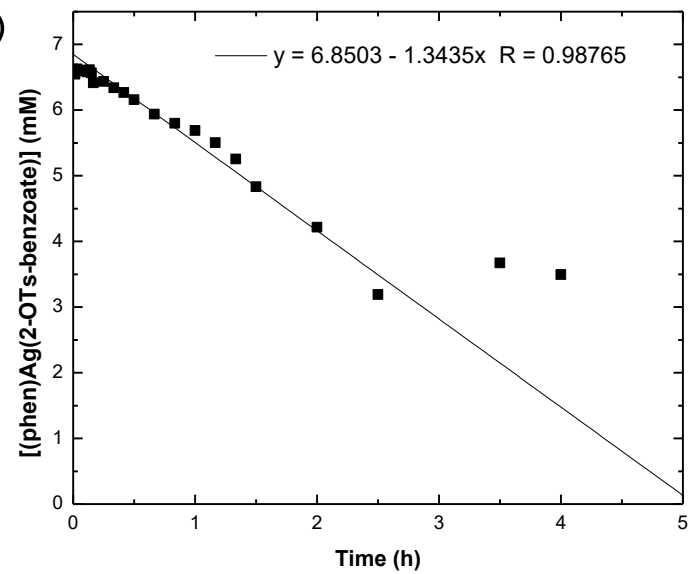

E)

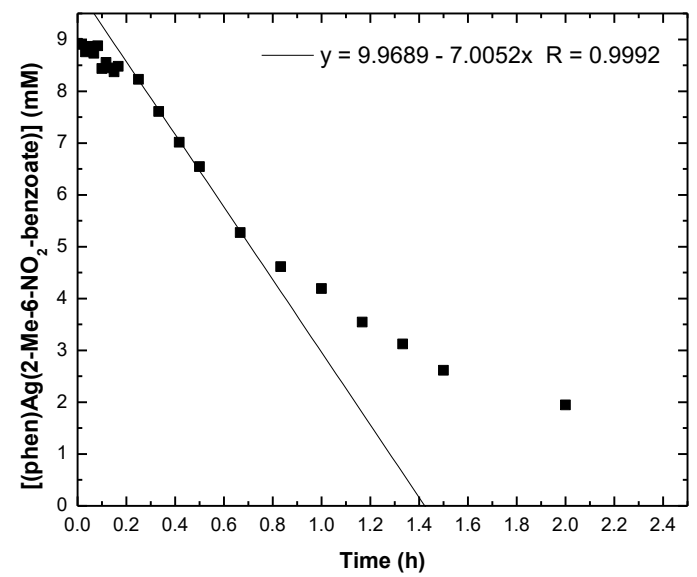

Figure 2-17: Reaction time course for the decarboxylation of A) (phen) $\mathrm{Ag}\left(2-\mathrm{Cl}-6-\mathrm{NO}_{2}-\right.$ benzoate $^{-}$ (7.79 mM; $\left.\left.k=3.45 \mathrm{~h}^{-1}\right), \mathrm{B}\right)$ (phen)Ag(2-Me-6-NO2-benzoate) $\left.\left(8.92 \mathrm{mM} ; k=0.785 \mathrm{~h}^{-1}\right), \mathrm{C}\right)$ (phen)Ag(2-OAc-benzoate) (7.23 mM; $\left.\left.k=1.57 \mathrm{~h}^{-1}\right), \mathrm{D}\right)$ (phen)Ag(2-OTs-benzoate) (6.62 mM; $\left.k=0.203 \mathrm{~h}^{-1}\right)$, E) (phen) $\operatorname{Ag}\left(2,3,4,5\right.$-tetrafluorobenzoate) $\left(7.12 \mathrm{mM} ; k=1.93 \mathrm{~h}^{-1}\right)$ in DMF- $d_{7}$ with $0.7 \mathrm{mM} \mathrm{H}_{2} \mathrm{O}$ at $110{ }^{\circ} \mathrm{C}$. 


\subsubsection{Calculation of Fujita-Nishioka Parameters.}

The Fujita-Nishioka correlation ${ }^{[85]}$ is a linear free energy relationship that allows the analysis of differently substituted benzoates (ortho-, meta-, para-, and multiply-substituted) as a single data set equation 2-2. In this correlation, the 'ortho-effect' is defined as a combination of three parameters: an ordinary polar effect $(\sigma)$, a proximity polar effect $(F)$, and a steric effect $\left(E_{\mathrm{s}}\right)$.

$$
\ln \left(\frac{k_{R}}{k_{M e}}\right)=a \sigma+b E_{s}+c F+d
$$

The ordinary polar effect $(\sigma)$ includes both resonance and inductive polar effects, which are assumed to be equal for ortho- and para-substitution $\left(\sigma_{\text {ortho }}=\sigma_{\text {para }}\right)$, while the proximity polar effect, also known as the Swain-Lupton-Hansch field effect $(F)$ accounts for differences in the inductive effects of ortho- and para-substituents in addition to including a through-space electrostatic effect. ${ }^{[71,72,111,112]}$ Finally, the Taft-Kutter-Hansch steric parameter $\left(E_{\mathrm{s}}\right)$ approximates the steric influence of the substituent using its van der Waals radius. ${ }^{[13,114]}$

The Swain-Lupton-Hansch field effect constants $(F)$ were originally determined from the $\mathrm{p} K_{\mathrm{a}}$ values of 4-substituted bicylco[2.2.2]octane-1-carboxylic acids. ${ }^{[63,115-117]}$ These substrates are sterically constrained placing the substituent and the reaction site in spacial proximity leading to through-space electrostatic influences of the substituent on the acidity of the carboxylic acid.

The parameters of the Fujita-Nishioka equation were calculated using a linear regression calculated by R computation software version 3.4.2 and the data shown in Table 2-2. 
Table 2-5: The data used to calculate the Fujita-Nishioka Parameters. ${ }^{a}$

\begin{tabular}{|c|c|c|c|c|}
\hline $\mathrm{R}$ & $\ln \left(\mathrm{k}_{\mathrm{R}} / \mathrm{k}_{\mathrm{Me}}\right)$ & $\sigma_{\text {calced }^{b}}$ & Es $_{\text {ortho }}{ }^{2}$ & $\mathrm{~F}_{\text {ortho }}{ }^{\mathrm{C}}$ \\
\hline $2-\mathrm{NO}_{2}-4-\mathrm{Cl}$ & 5.400932 & 1.01 & -1.01 & 0.65 \\
\hline $2-\mathrm{NO}_{2}-4-\mathrm{F}$ & 4.308121 & 0.84 & -1.01 & 0.65 \\
\hline 2-NO $2-4-\mathrm{OMe}$ & 4.532912 & 0.51 & -1.01 & 0.65 \\
\hline 2-NO $2-4-\mathrm{Me}$ & 5.879953 & 0.61 & -1.01 & 0.65 \\
\hline $2,4-\mathrm{NO}_{2}$ & 4.946557 & 1.56 & -1.01 & 0.65 \\
\hline $2-\mathrm{NO}_{2}$ & 4.213103 & 0.78 & -1.01 & 0.65 \\
\hline 2-NO2-5-OMe & 5.180519 & 0.9 & -1.01 & 0.65 \\
\hline $3-\mathrm{NO}_{2}$ & -0.664700 & 0.71 & 0 & 0 \\
\hline 2-Me & 0 & -0.17 & -1.24 & 0.01 \\
\hline $2-\mathrm{CF}_{3}$ & 1.823343 & 0.54 & -2.40 & 0.38 \\
\hline 2-Cl & 2.991789 & 0.23 & -0.97 & 0.42 \\
\hline 2-F & 3.177498 & 0.06 & -0.46 & 0.45 \\
\hline $2,6-F$ & 5.880533 & 0.12 & -0.92 & 0.9 \\
\hline 2-F-6-NO2 & 6.648202 & 0.84 & -1.47 & 1.1 \\
\hline 2-F-6-Me & 2.734424 & -0.11 & -1.70 & 0.46 \\
\hline 2-OMe & 2.735786 & -0.27 & -0.55 & 0.29 \\
\hline $4-\mathrm{CF}_{3}$ & -0.309030 & 0.54 & 0 & 0 \\
\hline
\end{tabular}

${ }^{a} \sigma_{\text {calced, }} E_{s}$ and $F$ values for di-ortho-substituted complexes were calculated additively. ${ }^{[104,105]}$ ${ }^{b}$ Values for $\sigma$ are from reference [62]. ${ }^{c}$ Values for Es ortho $_{\text {are from reference [70] and assume }}$ $\sigma_{o}=\sigma_{p}$. The $E_{\mathrm{s}}$ value for the nitro group is for the minimum perpendicular dimension. ${ }^{d}$ Values for $\mathrm{F}_{\text {ortho }}$ are from reference [62].

Table 2-6: The data used to determine the predictability of the decarboxylation of (phen) $\operatorname{Ag}\left(\right.$ benzoate) complexes. ${ }^{a}$

\begin{tabular}{ccrrr}
\hline $\mathrm{R}$ & $\ln \left(\mathrm{k}_{\mathrm{R}} / \mathrm{k}_{\mathrm{Me}}\right)$ & $\sigma_{\text {calced }^{b}}$ & Es $_{\text {ortho }}{ }^{c}$ & $\mathrm{~F}_{\text {ortho }^{d}}$ \\
\hline $\mathbf{2 - O T s}^{e}$ & 2.555630 & 0.29 & -0.55 & 0.54 \\
$\mathbf{2 , 3 , 4 , 5 - F 5}$ & 4.764267 & 0.46 & -0.46 & 0.45 \\
$\mathbf{2 - O A c}$ & 4.605707 & 0.31 & -0.55 & 0.42 \\
$\mathbf{2 - M e - 6 - N O} \mathbf{N}_{2}$ & 3.909481 & 0.66 & -2.25 & 0.66 \\
2-Cl-6-NO $_{2}$ & 5.390122 & 1.01 & -1.98 & 1.07 \\
\hline
\end{tabular}

${ }^{a} \sigma_{\text {calced, }} E_{s}$ and $F$ values for di-ortho-substituted complexes were calculated additively. ${ }^{[104,105]}$ ${ }^{b}$ Values for $\sigma$ are from reference [62]. ${ }^{c}$ Values for Es ${ }_{\text {ortho }}$ are from references [70] and assume $\sigma_{o}=\sigma_{p}$. The $E_{\mathrm{s}}$ value for the nitro group is for the minimum perpendicular dimension. ${ }^{d}$ Values for $\mathrm{F}_{\text {ortho }}$ are from reference [62]. ${ }^{e}$ Values for the 2-OTs come from the following references: Es $\mathrm{s}_{\text {ortho }}$ was approximated as -OR according to reference [62] and $\sigma_{\text {calced }}$ and $F_{\text {ortho }}$ are from reference ${ }^{[18]}$. 
The approximated error in $\log (k)$ show in Figure 2-8B was determined from multiple decarboxylation reactions.

A)

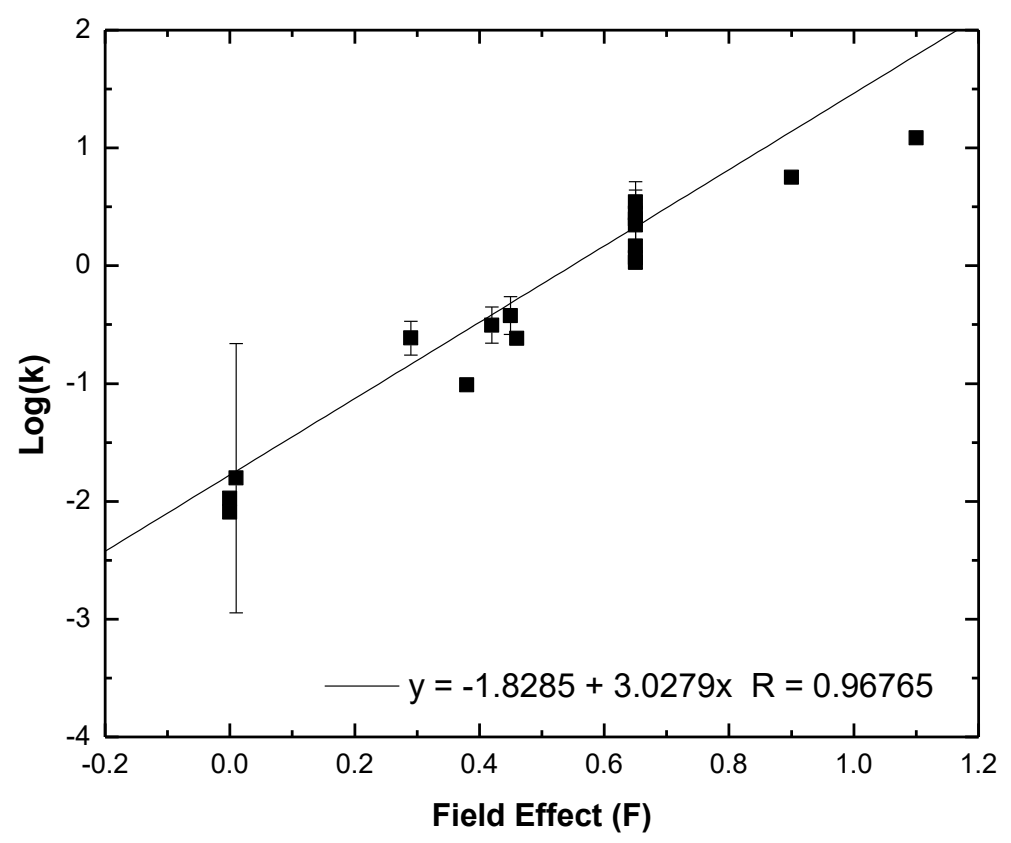

B)

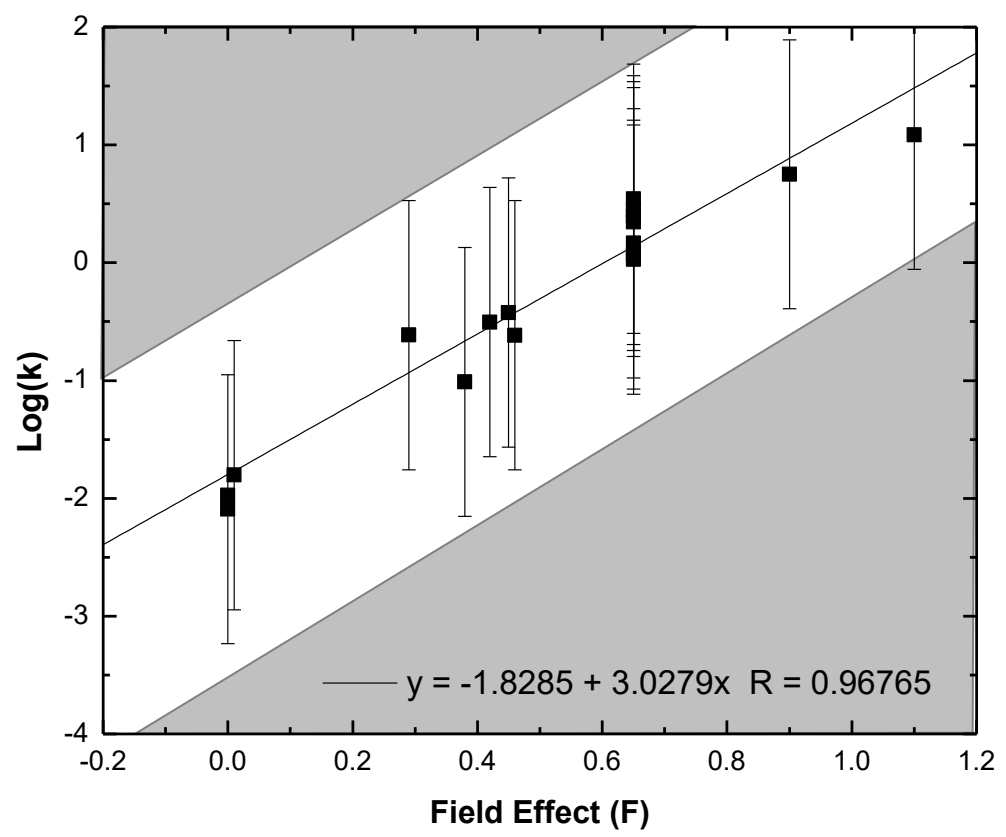

Figure 2-18: Correlation of the $\log (k)$ with the Field Effect parameter $(F)$ showing A) Decarboxylation reactions run in duplicate, triplicate or quintuplicate and their associated errors (given as twice the standard deviation) in $\log (k)$. B) A standard error of 1.1 (the largest of the observed errors in Figure 2-18A) applied to all data points used to determine the Fujita-Nishioka linear free energy relationship coefficients. 
The $\log (k)$ value for each reaction was also compared with the Hammett and steric parameters as shown below:
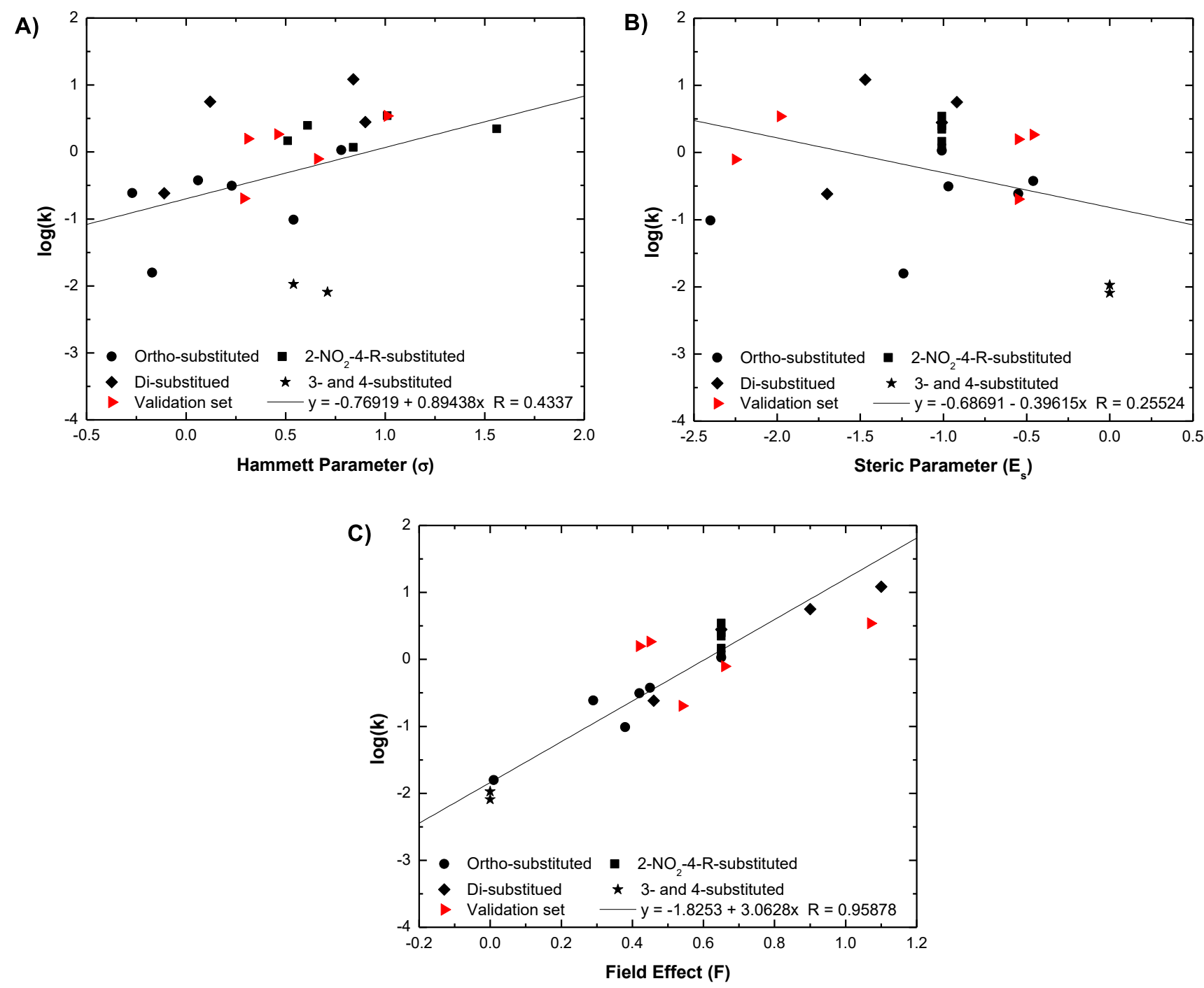

Figure 2-19: Correlation of the $\log (k)$ with $\mathrm{A})$ the Hammett parameter $(\sigma), \mathrm{B})$ the steric parameter $\left(E_{s}\right)$ and $\mathrm{C}$ ) the Field Effect parameter $(F)$. The training set is indicated with $\bullet, \mathbf{\square}, \downarrow$ and $\star$ and the validation set is indicated with $\boldsymbol{}\rangle$. 


\subsubsection{General Method for the Catalytic Decarboxylative Arylation Reactions.}

The catalytic decarboxylative arylation reactions were conducted according to the literature protocol $^{[20]}$ and are described below.

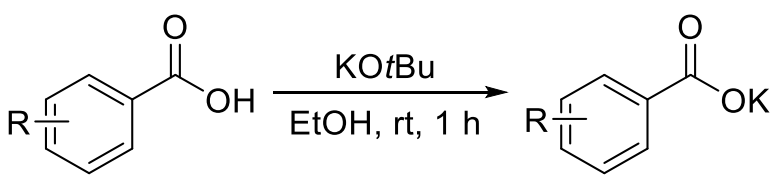

On the benchtop, a dry $100 \mathrm{~mL}$ round bottom flask containing a magnetic stir bar was charged with the substituted benzoic acid $(10 \mathrm{mmol})$. The flask was sealed with a rubber septum and the benzoic acid was dissolved with $20 \mathrm{~mL}$ of ethanol. To this flask, a solution of potassium tert-butoxide $(10 \mathrm{mmol})$ dissolved in ethanol $(20 \mathrm{~mL})$ was added slowly by pipet over 2 hours. The mixture was allowed to stir for 1 hour at room temperature, after which a precipitate formed. The resulting precipitate was then filtered and washed twice with ethanol $(10 \mathrm{~mL})$ and cold $\left(0{ }^{\circ} \mathrm{C}\right)$ ether $(10 \mathrm{~mL})$, dried under vacuum and the solid was then used without further purification.

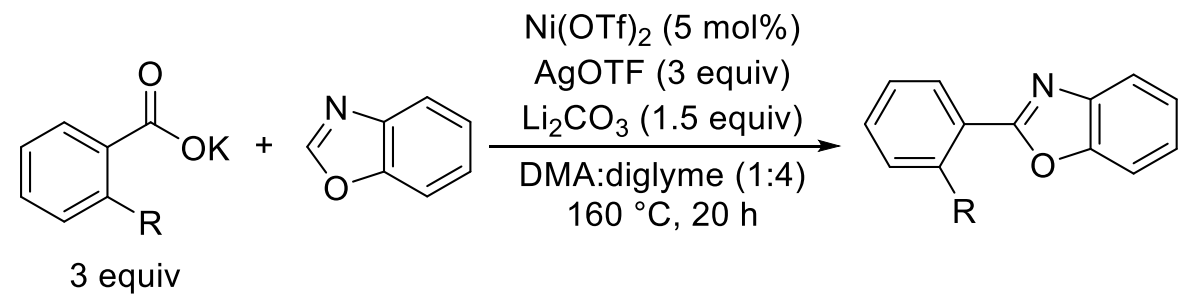

An oven dried 50-mL Schlenk tube was charged with lithium carbonate ( $55 \mathrm{mg}, 0.75 \mathrm{mmol}$ ), silver triflate $(390 \mathrm{mg}, 1.5 \mathrm{mmol})$, and the potassium benzoate $(1.5 \mathrm{mmol})$. The Schlenk tube was taken into a $\mathrm{N}_{2}$ filled glovebox, and nickel triflate $(8.9 \mathrm{mg}, 0.025 \mathrm{mmol})$ was added. The reaction vessel was sealed and removed from the glovebox. A $10 \mathrm{~mL}$ round bottom flask was then charged with benzoxazole (60 mg, $0.5 \mathrm{mmol}$ ), quickly sealed with a septum and purged with nitrogen gas for 5 minutes. To this flask, a mixture of 1:4 dry DMA:diglyme was added and the benzoxazole was dissolved. The mixture was added to the sealed Schlenk tube by syringe. The reaction mixture was then allowed to stir at $160{ }^{\circ} \mathrm{C}$ for 20 hours and then allowed to cool to room temperature. The reaction mixture was then filtered through a fritted filter containing $4 \mathrm{~cm}$ of Celite (bottom layer) and $4 \mathrm{~cm}$ of silica gel (top layer) and eluted with ethyl acetate $(150 \mathrm{~mL})$ and concentrated. ${ }^{1}{ }^{1} \mathrm{H}$ 
NMR was then taken with 1,3,5-trimethoxybenzene as an internal standard to obtain ${ }^{1} \mathrm{H}$ NMR yield unless otherwise noted below.

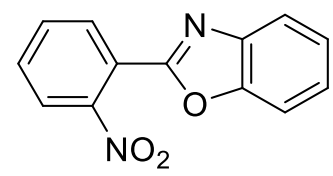

2-(2-nitrophenyl)-benzoxazole. The title compound was formed in $54 \%$ yield $(0.27 \mathrm{mmol})$ as determined by ${ }^{1} \mathrm{H}$ NMR spectroscopy ${ }^{[20]}$ using 1,3,5-trimethoxybenzene as an internal standard from the reaction of $60 \mathrm{mg}(0.5 \mathrm{mmol})$ of benzoxazole and $308 \mathrm{mg}(1.50 \mathrm{mmol})$ of the potassium 2-nitrobenzoate.

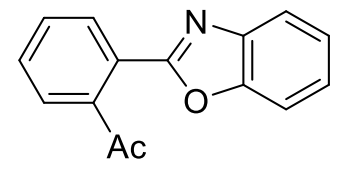

2-(2-acetylphenyl)-benzoxazole. The title compound was formed in $72 \%$ yield $(0.36 \mathrm{mmol})$ as determined by ${ }^{1} \mathrm{H}$ NMR spectroscopy ${ }^{[119]}$ using 1,3,5-trimethoxybenzene as an internal standard from the reaction of $60 \mathrm{mg}(0.5 \mathrm{mmol})$ of benzoxazole and $327 \mathrm{mg}(1.50 \mathrm{mmol})$ of the potassium $o$-acetylbenzoate.

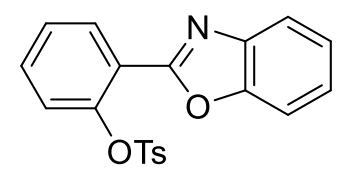

2-(2-benzoxazolyl)-1-(4-methylbenzenesulfonate)-phenol. The title compound was formed in $53 \%$ yield ( $0.27 \mathrm{mmol})$ as determined by ${ }^{1} \mathrm{H}$ NMR spectroscopy using 1,3,5-trimethoxybenzene as an internal standard from the reaction of $60 \mathrm{mg}(0.5 \mathrm{mmol})$ of benzoxazole and $496 \mathrm{mg}(1.50$ mmol) of the potassium 2-[[(4-methylphenyl)-sulfonyl]-oxy]-benzoate. Isolation of the product using silica column chromatography (hexanes : DCM : methanol 1:1:0 to 0:19:1 v/v) resulted in a $46 \%$ yield $(86.9 \mathrm{mg}, 0.23 \mathrm{mmol}) .{ }^{1} \mathrm{H}$ NMR (400 MHz, acetone- $\left.d_{6}\right): \delta=8.05(\mathrm{dd}, J=7.8,1.8 \mathrm{~Hz}$, 1H), $7.75-7.68(\mathrm{~m}, 2 \mathrm{H}), 7.63(\mathrm{td}, J=7.9,1.9 \mathrm{~Hz}, 1 \mathrm{H}), 7.52(\mathrm{td}, J=7.6,1.2 \mathrm{~Hz}, 1 \mathrm{H}), 7.48-7.40$ (m, 4H), $7.29(\mathrm{dd}, J=8.1,6.6 \mathrm{~Hz}, 1 \mathrm{H}), 7.26-7.20(\mathrm{~m}, 2 \mathrm{H}), 7.07(\mathrm{dd}, J=8.2,1.1 \mathrm{~Hz}, 1 \mathrm{H}), 2.43$ $(\mathrm{s}, 3 \mathrm{H}) .{ }^{13} \mathrm{C}$ NMR $\left(100 \mathrm{MHz}\right.$, acetone- $\left.d_{6}\right): \delta=162.74,150.96,147.86,146.00,133.97,132.38$, 
$132.09,129.99,129.32,128.46,127.44,125.87,125.54,123.88,121.73,78.30,78.08,77.86$, 20.69. IR (ATR, $\left.\mathrm{cm}^{-1}\right): 2925.47$ (w), 1747.10 (m), 1596.96 (w), $1485.72(\mathrm{w}), 1449.58(\mathrm{w})$, $1376.64(\mathrm{~m}), 1289.75(\mathrm{~m}), 1246.59$ (m), 1193.88 (s), 1173.10 (s), 1112.02 (w), $1093.80(\mathrm{~m})$, 1073.38 (w), 1052.30 (m), 874.20 (m), 845.99 (w), $812.71(\mathrm{w}), 776.35$ (m), 749.05 (w), 727.82 (m), 690.51 (w), 669.89 (w). Melting point: $145{ }^{\circ} \mathrm{C}$. HRMS (ESI-MS) m/z: [M+H] ${ }^{+}$Calc'ed for $\left[\mathrm{C}_{20} \mathrm{H}_{16} \mathrm{NO}_{4} \mathrm{~S}\right]^{+}$366.0800; Found 366.0800.

\subsubsection{Synthesis and Characterization of Silver Benzoate Complexes.}

\subsubsection{1. ortho-Nitrobenzoate Complexes of Silver.}

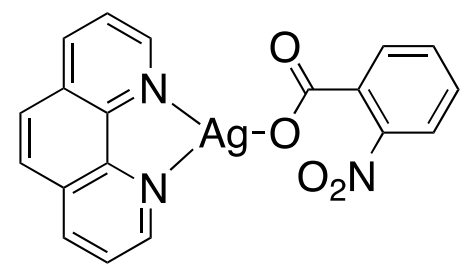

(phenanthroline)Ag(2-NO2-benzoate). The title compound was synthesized according to our previously reported procedure. ${ }^{[102]}$ To a mixture of $\mathrm{Ag}_{2} \mathrm{O}(194 \mathrm{mg}, 1.67 \mathrm{mmol} \mathrm{Ag})$ in $\mathrm{MeCN}$ (20 $\mathrm{mL}$ ) on the benchtop protected from light was added a solution of 2-nitrobenzoic acid ( $279 \mathrm{mg}$, $1.67 \mathrm{mmol})$ in $\mathrm{MeCN}(20 \mathrm{~mL})$. The mixture was allowed to stir at room temperature. After $2 \mathrm{~h}$, the silver oxide had dissolved to leave a colorless solution, which was then filtered through a pad of Celite to remove residual undissolved $\mathrm{Ag}_{2} \mathrm{O}$. A solution of 1,10-phenanthroline (300 mg, 1.67 $\mathrm{mmol})$ in $\mathrm{MeCN}(20 \mathrm{~mL})$ was added slowly to the filtrate with rapid stirring. Upon addition, the title compound precipitated from solution as a white solid. The product was collected, washed with $\operatorname{MeCN}(5 \mathrm{~mL})$ and then ether $(100 \mathrm{~mL})$, and dried to yield $603 \mathrm{mg}(1.33 \mathrm{mmol}, 80 \%$ yield $)$ of the title compound. ${ }^{1} \mathrm{H}$ NMR (400 MHz, DMSO- $\left.d_{6}\right): \delta=9.13(\mathrm{dd}, J=4.5,1.7 \mathrm{~Hz}, 2 \mathrm{H}), 8.71$ (dd, $J=8.2,1.7 \mathrm{~Hz}, 2 \mathrm{H}), 8.14(\mathrm{~s}, 2 \mathrm{H}), 7.97(\mathrm{dd}, J=8.2,4.5 \mathrm{~Hz}, 2 \mathrm{H}), 7.67(\mathrm{dd}, J=7.6,1.5 \mathrm{~Hz}, 1 \mathrm{H})$, $7.62(\mathrm{dd}, J=7.9,1.3 \mathrm{~Hz}, 1 \mathrm{H}), 7.53(\mathrm{td}, J=7.5,1.3 \mathrm{~Hz}, 1 \mathrm{H}), 7.42(\mathrm{td}, J=7.6,1.5 \mathrm{~Hz}, 1 \mathrm{H}) .{ }^{1} \mathrm{H}$ NMR (600 MHz, DMF- $\left.d_{7}\right): \delta 9.30(\mathrm{dd}, J=4.5,1.6 \mathrm{~Hz}, 2 \mathrm{H}), 8.83(\mathrm{dd}, J=8.2,1.7 \mathrm{~Hz}, 2 \mathrm{H}), 8.24$ (s, 2H), $8.07(\mathrm{dd}, J=8.2,4.5 \mathrm{~Hz}, 2 \mathrm{H}), 7.87(\mathrm{~d}, J=7.4 \mathrm{~Hz}, 1 \mathrm{H}), 7.70(\mathrm{~d}, J=7.8 \mathrm{~Hz}, 1 \mathrm{H}), 7.61(\mathrm{t}$, $J=7.3 \mathrm{~Hz}, 1 \mathrm{H}), 7.53(\mathrm{t}, J=7.3 \mathrm{~Hz}, 1 \mathrm{H}) .{ }^{13} \mathrm{C}$ NMR $\left(100 \mathrm{MHz}, \mathrm{DMSO}-d_{6}\right): \delta=167.63,151.70$, 149.47, 142.20, 138.77, 136.07, 132.00, 130.12, 129.27, 129.03, 127.53, 125.32, 122.76. IR (ATR, 
$\mathrm{cm}^{-1}$ ): 3063 (w), 1619 (s), 1605 (s), 1567 (m), 1529 (s), 1509 (m), 1418 (m), 1365 (s), 1303 (w), 1263 (w), 1219 (w), 1140 (w), 1099 (w), 1078 (w), 966 (w), 896 (w), 861 (m), 839 (s), 782 (m), 766 (m), 743 (m), 725 (s), 694 (s). Elemental Analysis: calculated $\mathrm{C}_{19} \mathrm{H}_{12} \mathrm{AgN}_{3} \mathrm{O}_{4} \mathrm{C}$ 50.25; H 2.66; N 9.25; measured C 50.47, H 2.64, N 9.37. The spectroscopic data are consistent with the reported values. $^{[4]}$

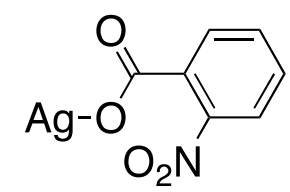

$\operatorname{Ag}$ (2-NO2-benzoate). To a mixture of $\mathrm{Ag}_{2} \mathrm{O}$ (194 mg, $1.67 \mathrm{mmol} \mathrm{Ag}$ ) in $\mathrm{MeCN}(20 \mathrm{~mL})$ on the benchtop protected from light was added a solution of 2-nitrobenzoic acid (280 $\mathrm{mg}, 1.67 \mathrm{mmol}$ ) in $\mathrm{MeCN}(20 \mathrm{~mL})$. The mixture was allowed to stir at room temperature. After $2 \mathrm{~h}$, silver oxide had dissolved to leave a colorless solution, which was then filtered through a pad of Celite to remove residual undissolved $\mathrm{Ag}_{2} \mathrm{O}$. Hexanes $(100 \mathrm{~mL})$ was then added and the title compound precipitated from solution as a white solid. The product was collected, washed with MeCN (5 mL) and hexanes $(100 \mathrm{~mL})$, and dried to yield $183 \mathrm{mg}(0.680 \mathrm{mmol}, 40 \%$ yield $)$ of the title compound as a tan solid. ${ }^{1} \mathrm{H}$ NMR (400 MHz, DMSO- $\left.d_{6}\right): \delta=7.66(\mathrm{td}, J=7.7,1.4 \mathrm{~Hz}, 2 \mathrm{H}), 7.55(\mathrm{td}, J=7.5$, $1.3 \mathrm{~Hz}, 1 \mathrm{H}), 7.46(\mathrm{td}, J=7.7,1.5 \mathrm{~Hz}, 1 \mathrm{H}) .{ }^{1} \mathrm{H}$ NMR (400 MHz, DMF- $\left.d_{7}\right): \delta 7.87(\mathrm{dd}, J=7.6,1.4$ $\mathrm{Hz}, 1 \mathrm{H}), 7.83-7.77(\mathrm{~m}, 1 \mathrm{H}), 7.72-7.66(\mathrm{~m}, 1 \mathrm{H}), 7.66-7.58(\mathrm{~m}, 1 \mathrm{H}) .{ }^{13} \mathrm{C} \mathrm{NMR}(100 \mathrm{MHz}$, DMSO-d $\left.d_{6}\right): \delta=168.01,149.47,134.89,132.15,130.15,129.51,122.90$. IR (ATR, $\left.\mathrm{cm}^{-1}\right): 3113$ (w), 1560 (m), 1519 (s), 1481 (m), 1438 (w), 1391 (s), 1339 (s), 1306 (m), 1262 (m), 1143 (m), 1076 (m), 1038 (w), 992 (w), 962 (w), 888 (w), 862 (m), 833 (m), 792 (m), 784 (m), 758 (m), 735 (m), 699 (s). Elemental Analysis: calculated $\mathrm{C}_{7} \mathrm{H}_{4} \mathrm{AgNO}_{4} \mathrm{C} 30.69 ; \mathrm{H} \mathrm{1.47;} \mathrm{N} \mathrm{5.11;} \mathrm{measured}$ C30.71, H 1.65, N 5.07. 


\subsubsection{2 ortho-Substituted Benzoate Complexes of Silver (Figure 2-5B)}

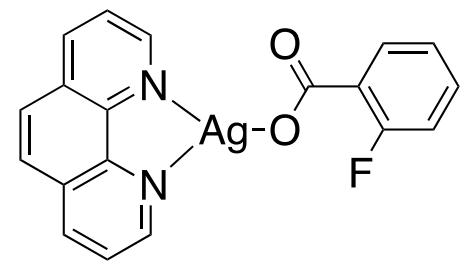

(phenanthroline)Ag(2-F-benzoate). This synthesis was performed on the benchtop protected from light. To a mixture of $\mathrm{Ag}_{2} \mathrm{O}$ (195 mg, $1.7 \mathrm{mmol} \mathrm{Ag}$ ) in $\mathrm{MeCN}$ (20 mL) was added a solution of 2-fluorobenzoic acid (238 mg, $1.70 \mathrm{mmol})$ in $\mathrm{MeCN}(20 \mathrm{~mL})$. The mixture was allowed to stir at room temperature. After $2 \mathrm{~h}$, the silver oxide had dissolved to leave a colorless solution, which was then filtered through a pad of Celite to remove residual undissolved $\mathrm{Ag}_{2} \mathrm{O}$. A solution of 1,10phenanthroline (309 mg, $1.71 \mathrm{mmol}$ ) in $\mathrm{MeCN}$ (20 mL) was added slowly to the filtrate with rapid stirring. Upon addition, the title compound precipitated from solution as a white solid. The product was collected, washed with $\mathrm{MeCN}(5 \mathrm{~mL})$ and then ether $(100 \mathrm{~mL})$, and dried to yield $461 \mathrm{mg}$ (1.08 mmol, $64 \%$ yield) of the title compound. ${ }^{1} \mathrm{H}$ NMR (400 MHz, DMSO- $\left.d_{6}\right): \delta=9.15$ (dd, $J=4.5,1.7 \mathrm{~Hz}, 2 \mathrm{H}), 8.70(\mathrm{dd}, J=8.1,1.7 \mathrm{~Hz}, 2 \mathrm{H}), 8.13(\mathrm{~s}, 2 \mathrm{H}), 7.97(\mathrm{dd}, J=8.1,4.5 \mathrm{~Hz}, 2 \mathrm{H})$, $7.66(\mathrm{td}, J=7.6,2.0 \mathrm{~Hz}, 1 \mathrm{H}), 7.34-7.24(\mathrm{~m}, 1 \mathrm{H}), 7.12-7.00(\mathrm{~m}, 2 \mathrm{H}) .{ }^{13} \mathrm{C} \mathrm{NMR}(100 \mathrm{MHz}$, DMSO- $\left.d_{6}\right): \delta=168.39(\mathrm{~d}, \mathrm{~J}=2.1 \mathrm{~Hz}), 161.66,159.18,151.73,142.17,138.78,131.57(\mathrm{~d}, \mathrm{~J}=3.5$ Hz), 130.49 (d, J = 8.3 Hz), 129.25, 128.62 (d, J = 14.2 Hz), 127.53, 125.36, 123.86 (d, J = 3.5 $\mathrm{Hz}), 116.23(\mathrm{~d}, \mathrm{~J}=23.2 \mathrm{~Hz}) .{ }^{19} \mathrm{~F}$ NMR $\left(376 \mathrm{MHz}, \mathrm{DMSO}-d_{6}\right) \delta=-113.02--113.08(\mathrm{~m})$. IR (ATR, $\mathrm{cm}^{-1}$ ): $3067.55(\mathrm{w}), 1964.95(\mathrm{w}), 1897.16(\mathrm{w}), 1621.32(\mathrm{w}), 1606.76(\mathrm{w}), 1584.78(\mathrm{~s}), 1556.7(\mathrm{~s})$, 1509.2 (m), 1497.1 (m), 1481.35 (m), 1446.11 (m), 1423.29 (m), 1372.5 (s), 1343.07 (m), 1264.24 (w), 1214.25 (m), $1139.96(\mathrm{~m}), 1091.93$ (m), 1042.92 (w), $982.85(\mathrm{w}), 960.08(\mathrm{w}), 880.89(\mathrm{w})$, $853.65(\mathrm{~m}), 841.91(\mathrm{~m}), 793.34(\mathrm{~m}), 779.12(\mathrm{~s}), 765.23(\mathrm{~m}), 726.74(\mathrm{~s}), 714.84(\mathrm{~m}), 652.4(\mathrm{~m})$. Elemental Analysis: calculated $\mathrm{C}_{19} \mathrm{H}_{12} \mathrm{AgN}_{2} \mathrm{O}_{2} \mathrm{~F}$ C 53.42; H 2.83; N 6.56; measured C 53.44, H 2.86, N 6.62. 


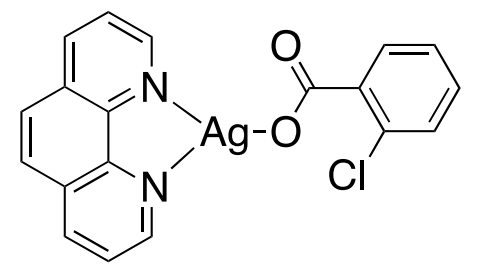

(phenanthroline)Ag(2-Cl-benzoate). This synthesis was performed on the benchtop protected from light. To a mixture of $\mathrm{Ag}_{2} \mathrm{O}$ (193 mg, $1.67 \mathrm{mmol} \mathrm{Ag}$ ) in THF (50 mL) was added a solution of 2-chlorobenzoic acid (261 mg, $1.67 \mathrm{mmol})$ in THF (50 mL). The mixture was allowed to stir at room temperature. After $2 \mathrm{~h}$, the silver oxide had dissolved to leave a colorless solution, which was then filtered through a pad of Celite to remove residual undissolved $\mathrm{Ag}_{2} \mathrm{O}$. A solution of 1,10-phenanthroline (300 mg, $1.66 \mathrm{mmol})$ in THF (20 mL) was added slowly to the filtrate with rapid stirring. Upon addition, the title compound precipitated from solution as a tan solid. The product was collected, washed with THF $(5 \mathrm{~mL})$ and then ether $(100 \mathrm{~mL})$, and dried to yield 651 $\mathrm{mg}$ (1.47 mmol, 89\% yield) of the title compound. ${ }^{1} \mathrm{H}$ NMR (400 MHz, DMSO- $\left.d_{6}\right): \delta=9.16$ (dd, $J=4.6,1.5 \mathrm{~Hz}, 2 \mathrm{H}), 8.73(\mathrm{dd}, J=8.1,1.5 \mathrm{~Hz}, 2 \mathrm{H}), 8.16(\mathrm{~s}, 2 \mathrm{H}), 7.99(\mathrm{dd}, J=8.1,4.5 \mathrm{~Hz}, 2 \mathrm{H})$, $7.47-7.39(\mathrm{~m}, 1 \mathrm{H}), 7.28(\mathrm{dd}, J=6.8,2.4 \mathrm{~Hz}, 1 \mathrm{H}), 7.24-7.13(\mathrm{~m}, 2 \mathrm{H}) .{ }^{13} \mathrm{C} \mathrm{NMR}(100 \mathrm{MHz}$, DMSO-d $\left.d_{6}\right): \delta=170.47,151.69,142.24,141.72$, 138.74, 129.99, 129.62, 129.35, 129.26, 128.68, 127.52, 126.78, 125.31. IR (ATR, $\left.\mathrm{cm}^{-1}\right): 3055.54(\mathrm{w}), 1596.83$ (s), 1583.01 (s), 1557.61 (m), $1509.27(\mathrm{~m}), 1495.8(\mathrm{w}), 1470.55(\mathrm{w}), 1421.49$ (m), 1374.69 (s), $1261.74(\mathrm{w}), 1219.81(\mathrm{w})$, 1140.55 (w), 1123.89 (w), 1098.44 (w), 1047.99 (m), 1029.86 (m), $982.7(\mathrm{w}), 948.7(\mathrm{w}), 896.14$ (w), 860.56 (w), 839.48 (s), 759.86 (s), 724.7 (s), 717.66 (s). Elemental Analysis: calculated $\mathrm{C}_{19} \mathrm{H}_{12} \mathrm{AgN}_{2} \mathrm{O}_{2} \mathrm{Cl}$ C 51.44; H 2.73; N 6.31; measured C 51.62, H 2.59, N 6.34.

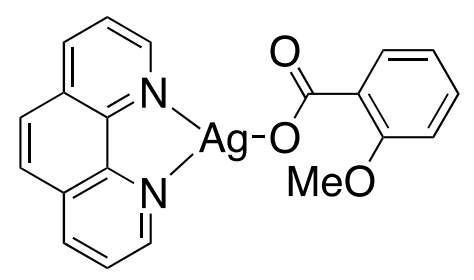

(phenanthroline)Ag(2-OMe-benzoate). This synthesis was performed on the benchtop protected from light. To a mixture of $\mathrm{Ag}_{2} \mathrm{O}$ (194 mg, $1.67 \mathrm{mmol} \mathrm{Ag}$ ) in $\mathrm{MeCN}$ (200 mL) was added a solution of 2-methoxybenzoic acid (304 mg, $2.00 \mathrm{mmol}$ ) in $\mathrm{MeCN}$ (20 mL). The mixture was allowed to stir at room temperature overnight. The silver oxide had dissolved to leave a light brown 
solution, which was then filtered through a pad of Celite to remove residual undissolved $\operatorname{Ag}_{2} \mathrm{O}$. A solution of 1,10-phenanthroline $(270 \mathrm{mg}, 1.50 \mathrm{mmol})$ in $\mathrm{MeCN}(20 \mathrm{~mL})$ was added slowly with rapid stirring. The solution was allowed to stir for 2 hours, after which, $150 \mathrm{~mL}$ of ether was added and the mixture was stirred for an additional hour. The solvent was then removed and the light brown solid was washed with $\mathrm{MeCN}(5 \mathrm{~mL})$ and then ether $(100 \mathrm{~mL})$, and dried to yield $373 \mathrm{mg}$ (0.85 mmol, $57 \%$ yield) of the title compound as a tan solid. ${ }^{1} \mathrm{H}$ NMR (400 MHz, DMSO- $\left.d_{6}\right)$ : $\delta=9.16(\mathrm{dd}, J=4.6,1.5 \mathrm{~Hz}, 2 \mathrm{H}), 8.71(\mathrm{dd}, J=8.1,1.5 \mathrm{~Hz}, 2 \mathrm{H}), 8.15(\mathrm{~s}, 2 \mathrm{H}), 7.98(\mathrm{dd}, J=8.0$, $4.7 \mathrm{~Hz}, 2 \mathrm{H}), 7.31$ (dd, $J=7.4,1.7 \mathrm{~Hz}, 1 \mathrm{H}), 7.18$ (td, $J=7.9,1.7 \mathrm{~Hz}, 1 \mathrm{H}), 6.90$ (d, $J=8.3 \mathrm{~Hz}, 1 \mathrm{H})$, $6.82(\mathrm{t}, J=7.2 \mathrm{~Hz}, 1 \mathrm{H}), 3.70(\mathrm{~s}, 3 \mathrm{H}) .{ }^{13} \mathrm{C} \mathrm{NMR}\left(100 \mathrm{MHz}, \mathrm{DMSO}-d_{6}\right): \delta=171.84,156.32,151.66$, 142.23 , 138.69, 131.63, 129.21, 128.74, 127.48, 125.27, 120.10, 112.05, 55.69, 40.59, 40.38, 40.17, 39.96, 39.75, 39.55, 39.34. IR (ATR, $\mathrm{cm}^{-1}$ ): 3063.95 (w), $2945.52(\mathrm{w}), 2831.25$ (w), $1673.02(\mathrm{w}), 1619.77$ (w), 1582.97 (m), 1550.48 (s), 1509.40 (m), 1485.85 (m), 1462.95 (m), $1422.26(\mathrm{~m}), 1364.05$ (s), 1296.22 (m), 1268.05 (m), 1237.42 (s), 1165.37 (m), 1140.46 (m), 1097.42 (m), 1047.42 (w), 1020.96 (m), 953.83 (m), 857.17 (m), 839.85 (s), 767.96 (s), 727.15 (s), 718.09 (s), 657.38 (m). Elemental Analysis: calculated $\mathrm{C}_{20} \mathrm{H}_{15} \mathrm{AgN}_{2} \mathrm{O}_{3} \mathrm{C}$ 54.69; H 3.44; $\mathrm{N}$ 6.38; measured C 54.94, H 3.52, N 6.40.

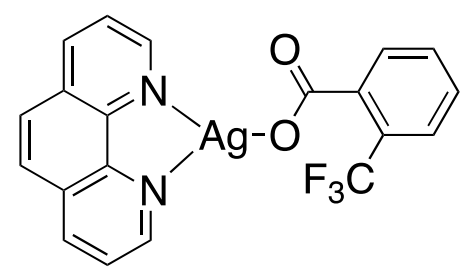

(phenanthroline)Ag(2-CF3-benzoate). This synthesis was performed on the benchtop protected from light. To a mixture of $\mathrm{Ag}_{2} \mathrm{O}$ (194 mg, $1.67 \mathrm{mmol} \mathrm{Ag}$ ) in $\mathrm{MeCN}$ (20 mL) was added a solution of 2-trifluoromethylbenzoic acid (316 mg, $1.66 \mathrm{mmol}$ ) in $\mathrm{MeCN}$ (20 mL). The mixture was allowed to stir at room temperature. After $2 \mathrm{~h}$, the silver oxide had dissolved to leave a colorless solution, which was then filtered through a pad of Celite to remove residual undissolved $\operatorname{Ag}_{2} \mathrm{O}$. A solution of 1,10-phenanthroline (299 mg, $1.66 \mathrm{mmol})$ in MeCN (20 mL) was added slowly to the filtrate with rapid stirring. Upon addition, the title compound precipitated from solution as a tan solid. The product was collected, washed with $\mathrm{MeCN}(5 \mathrm{~mL})$ and then ether $(100 \mathrm{~mL})$, and dried to yield $502 \mathrm{mg}$ (1.05 mmol, $64 \%$ yield) of the title compound. ${ }^{1} \mathrm{H}$ NMR (400 MHz, DMSO- $d_{6}$ ): 
$\delta=9.15(\mathrm{dd}, J=4.5,1.7 \mathrm{~Hz}, 2 \mathrm{H}), 8.73(\mathrm{dd}, J=8.2,1.7 \mathrm{~Hz}, 2 \mathrm{H}), 8.16(\mathrm{~s}, 2 \mathrm{H}), 7.99$ (dd, $J=8.1$, $4.5 \mathrm{~Hz}, 2 \mathrm{H}), 7.55(\mathrm{~d}, J=7.8 \mathrm{~Hz}, 1 \mathrm{H}), 7.53-7.43(\mathrm{~m}, 2 \mathrm{H}), 7.35(\mathrm{t}, J=7.5 \mathrm{~Hz}, 1 \mathrm{H}) .{ }^{13} \mathrm{C}$ NMR $(100$ MHz, DMSO- $\left.d_{6}\right): \delta=171.24,151.82,142.40,138.90,132.20,129.41,128.77,127.67,127.37$, $125.82(\mathrm{~d}, \mathrm{~J}=5.1 \mathrm{~Hz}), 125.46,125.13(\mathrm{~d}, \mathrm{~J}=30.8 \mathrm{~Hz}) .{ }^{19} \mathrm{~F}$ NMR $\left(376 \mathrm{MHz}\right.$, DMSO- $\left.d_{6}\right)$ : $\delta=-58.07$. IR (ATR, $\left.\mathrm{cm}^{-1}\right): 1615.64(\mathrm{~s}), 1600.04(\mathrm{~s}), 1577.71(\mathrm{~m}), 1509.81(\mathrm{~m}), 1421.72(\mathrm{~m})$, 1375.34 (s), 1312.97 (s), 1268.12 (w), 1174.46 (m), 116.45(m), 1128.53 (s), 1107.94 (m), 1053.83 (m), 1033.01 (m), 860.8 (w), 843.55 (s), 804.29 (w), 779.97 (m), 726.75 (s), 684.47 (m). Elemental Analysis: calculated $\mathrm{C}_{20} \mathrm{H}_{12} \mathrm{AgN}_{2} \mathrm{O}_{2} \mathrm{~F}_{3} \mathrm{C}$ 50.34; H 2.53; N 5.87; measured C 50.35, H 2.49, N 6.04.

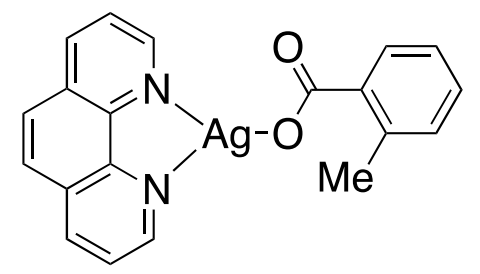

(phenanthroline)Ag(2-Me-benzoate). This synthesis was performed on the benchtop protected from light. To a mixture of $\mathrm{Ag}_{2} \mathrm{O}(194 \mathrm{mg}, 1.67 \mathrm{mmol} \mathrm{Ag})$ in $\mathrm{THF}(20 \mathrm{~mL})$ was added a solution of 2-methylbenzoic acid (227 mg, $1.67 \mathrm{mmol})$ in THF (20 mL). The mixture was allowed to stir at room temperature. After $2 \mathrm{~h}$, the silver oxide had dissolved to leave a colorless solution, which was then filtered through a pad of Celite to remove residual undissolved $\operatorname{Ag}_{2} \mathrm{O}$. A solution of 1,10-phenanthroline (301 $\mathrm{mg}, 1.67 \mathrm{mmol}$ ) in THF (20 mL) was added slowly to the filtrate with rapid stirring. Upon addition, the title compound precipitated from solution as a white solid. The product was collected, washed with THF $(5 \mathrm{~mL})$ and then ether $(100 \mathrm{~mL})$, and dried to yield 453 $\mathrm{mg}\left(1.07 \mathrm{mmol}, 64 \%\right.$ yield) of the title compound. ${ }^{1} \mathrm{H}$ NMR $\left(400 \mathrm{MHz}\right.$, methanol- $\left.d_{4}\right)$ : $\delta=8.97-8.90(\mathrm{~m}, 2 \mathrm{H}), 8.46(\mathrm{ddd}, J=8.1,1.7,0.7 \mathrm{~Hz}, 2 \mathrm{H}), 7.90(\mathrm{~d}, J=0.8 \mathrm{~Hz}, 2 \mathrm{H}), 7.77(\mathrm{dd}$, $J=8.1,4.6 \mathrm{~Hz}, 2 \mathrm{H}), 7.56(\mathrm{dd}, J=7.4,1.4 \mathrm{~Hz}, 1 \mathrm{H}), 7.23-7.06(\mathrm{~m}, 3 \mathrm{H}), 2.49(\mathrm{~s}, 3 \mathrm{H}) .{ }^{13} \mathrm{C} \mathrm{NMR}$ (100 MHz, methanol- $\left.d_{4}\right): \delta=178.19,152.35,143.14,140.16,139.48,136.95,131.47,130.46$, 129.75, 129.10, 128.21, 126.28, 125.81, 21.09. IR (ATR, $\left.\mathrm{cm}^{-1}\right): 3055.27$ (w), $2962.1(\mathrm{w}), 2923.07$ (w), $1620.32(\mathrm{w}), 1602.57(\mathrm{~m}), 1584.75(\mathrm{~s}), 1555.22(\mathrm{~s}), 1509.1(\mathrm{~m}), 1496.04(\mathrm{~m}), 1421.88(\mathrm{~s})$, 1352.95 (s), 1220.54 (w), 1150.09 (m), 1098.93 (m), 1046.93 (w), 986.89 (w), 951.79 (w), 895.24 (w), 860.13 (m), 844.67 (s), 818.65 (m), 784.17 (m), 747.04 (s), 726.43 (s), 662.79 (s). Elemental Analysis: calculated $\mathrm{C}_{20} \mathrm{H}_{15} \mathrm{AgN}_{2} \mathrm{O}_{2}$ C 56.76; H 3.57; N 6.62; measured C 56.77, H 3.46, N 6.67. 


\subsubsection{Mono-Substituted Benzoate Complexes of Silver (Figure 2.7A)}<smiles>O=C(O[Te][Te]1N2C=CC=c3ccc4c(c32)N1C=CC=4)c1cccc([N+](=O)[O-])c1</smiles>

(phenanthroline)Ag(3-NO2-benzoate). This synthesis was performed on the benchtop protected from light. To a mixture of $\mathrm{Ag}_{2} \mathrm{O}$ (194 mg, $1.67 \mathrm{mmol} \mathrm{Ag}$ ) in $\mathrm{MeCN}$ (20 mL) was added a solution of 3-nitrobenzoic acid $(278 \mathrm{mg}, 1.66 \mathrm{mmol})$ in $\mathrm{MeCN}(20 \mathrm{~mL})$. The mixture was allowed to stir at room temperature. After $2 \mathrm{~h}$, the silver oxide had dissolved to leave a brown solution, which was then filtered through a pad of Celite to remove residual undissolved $\mathrm{Ag}_{2} \mathrm{O}$. A solution of 1,10-phenanthroline (306.4 mg, $1.68 \mathrm{mmol})$ in $\mathrm{MeCN}(20 \mathrm{~mL})$ was added slowly to the filtrate with rapid stirring. Upon addition, the title compound precipitated from solution as a tan solid. The product was collected, washed with $\mathrm{MeCN}(5 \mathrm{~mL})$ and then ether $(100 \mathrm{~mL})$, and dried to yield $571.8 \mathrm{mg}$ (1.26 mmol, $76 \%$ yield) of the title compound. ${ }^{1} \mathrm{H}$ NMR (400 MHz, DMSO- $\left.d_{6}\right): \delta=9.17$ $(\mathrm{dd}, J=4.5,1.7 \mathrm{~Hz}, 2 \mathrm{H}), 8.73(\mathrm{dd}, J=8.1,1.7 \mathrm{~Hz}, 2 \mathrm{H}), 8.63(\mathrm{dd}, J=2.5,1.5 \mathrm{~Hz}, 1 \mathrm{H}), 8.29(\mathrm{dt}$, $J=7.6,1.3 \mathrm{~Hz}, 1 \mathrm{H}), 8.19(\mathrm{ddd}, J=8.1,2.5,1.1 \mathrm{~Hz}, 1 \mathrm{H}), 8.17(\mathrm{~s}, 2 \mathrm{H}), 7.99$ (dd, $J=8.1,4.5 \mathrm{~Hz}$, $2 \mathrm{H}), 7.60(\mathrm{t}, J=7.8 \mathrm{~Hz}, 1 \mathrm{H}) .{ }^{13} \mathrm{C} \mathrm{NMR}\left(100 \mathrm{MHz}, \mathrm{DMSO}-d_{6}\right): \delta=189.85,151.75,147.89,142.33$, 138.82, 135.87, 129.64, 129.34, 127.58, 125.37, 124.60, 123.93, 115.27. IR (ATR, cm $\left.{ }^{-1}\right): 1625.9$ (m), $1574.53(\mathrm{w}), 1523.52(\mathrm{~m}), 1510.75(\mathrm{~m}), 1473.14(\mathrm{w}), 1423.08(\mathrm{~m}), 1362.14(\mathrm{w}), 1341.76(\mathrm{~m})$, $1263.48(\mathrm{w}), 1150.74(\mathrm{w}), 1066.43(\mathrm{w}), 902.61(\mathrm{w}), 843.95(\mathrm{~m}), 826.79(\mathrm{w}), 817.31(\mathrm{w}), 781.88$ (w), 770.31 (w), 719.85 (s). Elemental Analysis: calculated $\mathrm{C}_{19} \mathrm{H}_{12} \mathrm{AgN}_{3} \mathrm{O}_{4} \mathrm{C}$ 50.25; H 2.66; N 9.25; measured C 50.36, H 2.61, N 9.27.<smiles></smiles>

(phenanthroline)Ag(4-CF 3-benzoate). This synthesis was performed on the benchtop protected from light. To a mixture of $\mathrm{Ag}_{2} \mathrm{O}$ (194 mg, $1.67 \mathrm{mmol} \mathrm{Ag}$ ) in THF (20 mL) was added a solution 
of 4-trifluoromethylbenzoic acid $(318 \mathrm{mg}, 1.67 \mathrm{mmol})$ in THF $(20 \mathrm{~mL})$. The mixture was allowed to stir at room temperature. After $2 \mathrm{~h}$, the silver oxide had dissolved to leave a colorless solution, which was then filtered through a pad of Celite to remove residual undissolved $\operatorname{Ag}_{2} \mathrm{O}$. A solution of 1,10-phenanthroline (301 mg, $1.67 \mathrm{mmol})$ in THF $(20 \mathrm{~mL})$ was added slowly to the filtrate with rapid stirring. Upon addition, the title compound precipitated from solution as a light-yellow solid. The product was collected, washed with THF $(5 \mathrm{~mL})$ and then ether $(100 \mathrm{~mL})$, and dried to yield $610 \mathrm{mg}$ (1.28 mmol, $77 \%$ yield) of the title compound. ${ }^{1} \mathrm{H}$ NMR (400 MHz, DMSO- $\left.d_{6}\right): \delta=9.12$ $(\mathrm{dd}, \mathrm{J}=4.4,1.6 \mathrm{~Hz}, 2 \mathrm{H}), 8.68(\mathrm{dd}, \mathrm{J}=8.1,1.7 \mathrm{~Hz}, 2 \mathrm{H}), 8.14(\mathrm{~s}, 2 \mathrm{H}), 8.04(\mathrm{~d}, \mathrm{~J}=8.0 \mathrm{~Hz}, 2 \mathrm{H}), 7.93$ $(\mathrm{dd}, \mathrm{J}=8.1,4.5 \mathrm{~Hz}, 2 \mathrm{H}), 7.72(\mathrm{~d}, \mathrm{~J}=8.0 \mathrm{~Hz}, 2 \mathrm{H}) .{ }^{13} \mathrm{C}$ NMR (100 MHz, DMSO-d $): \delta=169.06$, 151.86, 142.89, 142.32, 138.89, 130.43, 130.15, 129.84, 129.37, 127.64, 126.33, 125.46, 125.08, 125.04, 125.00, 124.96, 123.62. ${ }^{19} \mathrm{~F}$ NMR (376 MHz, DMSO- $\left.d_{6}\right) \delta=-61.58$. IR $\left(\mathrm{ATR}, \mathrm{cm}^{-1}\right)$ : 3046.27 (w), 1596.02 (m), 1552.82 (s), 1508.74 (m), 1425.67 (m), 1380.93 (m), $1346.84(\mathrm{w})$, 1319.55 (s), 1259.57 (s), 1259.57 (w), 1221.57 (w), 1162.55 (s), 1132.25 (m), 1097.25 (s), 1057.78 (s), $1018.95(\mathrm{~m}), 982.48(\mathrm{~m}), 970.79(\mathrm{w}), 884.52(\mathrm{~m}), 860.40(\mathrm{~m}), 843.69$ (s), 786.34 (s), 766.13 (s), 728.46 (s), 717.53 (m), 708.45 (s). Elemental Analysis: calculated $\mathrm{C}_{20} \mathrm{H}_{12} \mathrm{AgN}_{2} \mathrm{O}_{2} \mathrm{~F}_{3} \mathrm{C}$ 50.34; H 2.53; N 5.87; measured C 50.06, H 2.68, N 5.79.

\subsubsection{Di-Substituted Benzoate Complexes of Silver (Figure 2.7A)}

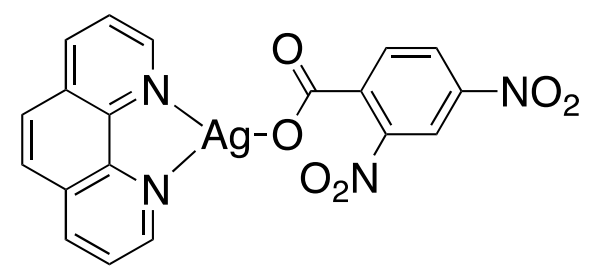

(phenanthroline)Ag(4-NO2-2-NO2-benzoate). This synthesis was performed on the benchtop protected from light. To a mixture of $\mathrm{Ag}_{2} \mathrm{O}$ (193 mg, $\left.1.67 \mathrm{mmol} \mathrm{Ag}\right)$ in $\mathrm{MeCN}$ (20 mL) was added a solution of 2,4-dinitrobenzoic acid $(352 \mathrm{mg}, 1.66 \mathrm{mmol}$ ) in $\mathrm{MeCN}$ (20 mL). The mixture was allowed to stir at room temperature. After $2 \mathrm{~h}$, the silver oxide had dissolved to leave a light-yellow solution, which was then filtered through a pad of Celite to remove residual undissolved $\operatorname{Ag}_{2} \mathrm{O}$. A solution of 1,10-phenanthroline (270 mg, $1.50 \mathrm{mmol})$ in $\mathrm{MeCN}$ (20 mL) was added slowly to the filtrate with rapid stirring. Upon addition, the title compound precipitated from solution as a yellow 
solid. The product was collected, washed with $\mathrm{MeCN}(5 \mathrm{~mL})$ and then ether $(100 \mathrm{~mL})$, and dried to yield $633 \mathrm{mg}$ (1.27 mmol, $85 \%$ yield) of the title compound. ${ }^{1} \mathrm{H}$ NMR (400 MHz, DMSO- $\left.d_{6}\right)$ : $\delta=9.13(\mathrm{dd}, J=4.5,1.7 \mathrm{~Hz}, 2 \mathrm{H}), 8.75(\mathrm{dd}, J=8.1,1.7 \mathrm{~Hz}, 2 \mathrm{H}), 8.54(\mathrm{~d}, J=2.2 \mathrm{~Hz}, 1 \mathrm{H}), 8.39$ $(\mathrm{dd}, J=8.4,2.3 \mathrm{~Hz}, 1 \mathrm{H}), 8.19(\mathrm{~s}, 2 \mathrm{H}), 7.99(\mathrm{dd}, J=8.1,4.5 \mathrm{~Hz}, 2 \mathrm{H}), 7.86(\mathrm{~d}, J=8.4 \mathrm{~Hz}, 1 \mathrm{H})$. ${ }^{13} \mathrm{C}$ NMR (150 MHz, DMSO- $\left.d_{6}\right): \delta=164.92,151.66,148.36,146.35,143.90,142.55,138.76$, 131.15, 129.40, 127.57, 126.77, 125.27, 118.54. IR (ATR, $\mathrm{cm}^{-1}$ ): 3117.58 (w), 3060.05 (w), 1613.03 (s), 1599.87 (s), 1536.43 (s), 1518.5 (s), 1508.89 (s), 1475.83 (w), 1425.68 (m), 1399.24 (w), $1375.86(\mathrm{~m}), 1344.81(\mathrm{~s}), 1243.57(\mathrm{w}), 1222.42(\mathrm{w}), 1148.16(\mathrm{~m}), 1118.74(\mathrm{w}), 1099.96(\mathrm{w})$, $1084(w), 1061.08(w), 986.93(w), 963.27(w), 922.58(w), 887.59(\mathrm{~m}), 856.19(w), 841.63(\mathrm{~s})$, 824.94 (s), 789.56 (m), 769.9 (m), 763.12 (m), 741.58 (m), 724.96 (s), 695.27 (m), 663.18 (m). Elemental Analysis: calculated $\mathrm{C}_{19} \mathrm{H}_{11} \mathrm{AgN}_{4} \mathrm{O}_{6} \mathrm{C}$ 45.72; $\mathrm{H}$ 2.22; N 11.22; measured C 45.88, H 2.17, N 11.22.

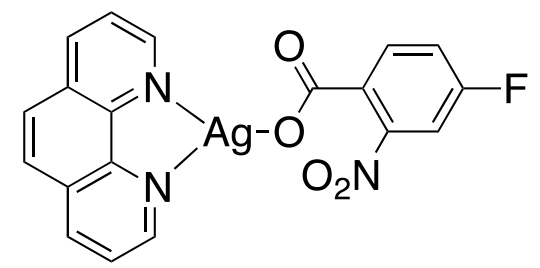

(phenanthroline)Ag(4-F-2-NO2-benzoate). This synthesis was performed on the benchtop protected from light. To a mixture of $\mathrm{Ag}_{2} \mathrm{O}(193 \mathrm{mg}, 1.66 \mathrm{mmol} \mathrm{Ag})$ in THF (20 mL) was added a solution of 2-nitro-4-fluorobenzoic acid (307 mg, $1.66 \mathrm{mmol})$ in THF (20 mL). The mixture was allowed to stir at room temperature. After $2 \mathrm{~h}$, the silver oxide had dissolved to leave a yellow solution, which was then filtered through a pad of Celite to remove residual undissolved $\operatorname{Ag}_{2} \mathrm{O}$. A solution of 1,10-phenanthroline $(301 \mathrm{mg}, 1.67 \mathrm{mmol})$ in THF $(20 \mathrm{~mL})$ was added slowly to the filtrate with rapid stirring. Upon addition, the title compound precipitated from solution as a white solid. The product was collected, washed with THF $(5 \mathrm{~mL})$ and then ether $(100 \mathrm{~mL})$, and dried to yield $693 \mathrm{mg}$ (1.47 mmol, $88 \%$ yield) of the title compound. ${ }^{1} \mathrm{H}$ NMR (400 MHz, DMSO-d6): $\delta=9.13(\mathrm{dd}, \mathrm{J}=4.5,1.7 \mathrm{~Hz}, 2 \mathrm{H}), 8.70(\mathrm{dd}, \mathrm{J}=8.1,1.7 \mathrm{~Hz}, 2 \mathrm{H}), 8.13(\mathrm{~s}, 2 \mathrm{H}), 7.97(\mathrm{dd}, \mathrm{J}=8.1$, $4.5 \mathrm{~Hz}, 2 \mathrm{H}), 7.79$ (dd, J = 8.6, 6.0 Hz, 1H), 7.63 (dd, J = 8.6, 2.6 Hz, 1H), 7.40 (td, J = 8.5, 2.6 Hz, 1H). ${ }^{13} \mathrm{C}$ NMR (100 MHz, DMSO-d $): \delta=166.42,161.43(\mathrm{~d}, \mathrm{~J}=248.2 \mathrm{~Hz}), 151.80,150.63(\mathrm{~d}, \mathrm{~J}$ = 9.1 Hz), 142.26, 138.88, 132.84 (d, J = 8.5 Hz), 131.55 (d, J = 3.6 Hz), 129.37, 127.64, 125.44, 
$118.66(\mathrm{~d}, \mathrm{~J}=20.8 \mathrm{~Hz}), 110.45(\mathrm{~d}, \mathrm{~J}=26.9 \mathrm{~Hz}) .{ }^{19} \mathrm{~F}$ NMR $\left(376 \mathrm{MHz}, \mathrm{DMSO}-d_{6}\right): \delta=-111.27$ (td, J = 8.6, 6.0 Hz). IR (ATR, $\mathrm{cm}^{-1}$ ): $2970.92(\mathrm{w}), 1738.31$ (m), 1625.18 (m), 1604.11 (m), 1580.98 (m), 1532.10 (m), 1486.73 (w), 1423.36 (m), 1377.33 (s), 1357.25 (s), 1296.70 (w), $1255.74(\mathrm{~m}), 1219.32(\mathrm{~s}), 1137.31(\mathrm{w}), 1122.15(\mathrm{w}), 1099.05(\mathrm{w}), 1061.70(\mathrm{w}), 937.63(\mathrm{w}), 860.91$ (s), 852.60 (s), 828.83 (s), 802.46 (m), 790.86 (m), 780.80 (m), 729.84 (s), 716.43 (m), 693.77 (m), 671.61 (w). Elemental Analysis: calculated $\mathrm{C}_{19} \mathrm{H}_{11} \mathrm{AgFN}_{3} \mathrm{O}_{4} \mathrm{C}$ 48.33; H 2.35; N 8.90; measured C 48.34, H 2.22, N 8.86.

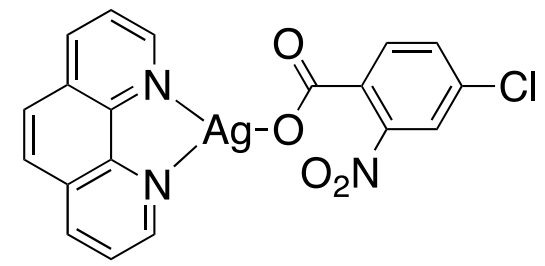

(phenanthroline)Ag(4-Cl-2-NO2- benzoate). This synthesis was performed on the benchtop protected from light. To a mixture of $\mathrm{Ag}_{2} \mathrm{O}(192 \mathrm{mg}, 1.66 \mathrm{mmol} \mathrm{Ag})$ in $\mathrm{MeCN}(20 \mathrm{~mL})$ was added a solution of 2-nitro-4-chlorobenzoic acid (337 mg, $1.67 \mathrm{mmol}$ ) in $\mathrm{MeCN}$ (20 mL). The mixture was allowed to stir at room temperature. After $2 \mathrm{~h}$, the silver oxide had dissolved to leave a lightyellow solution, which was then filtered through a pad of Celite to remove residual undissolved $\mathrm{Ag}_{2} \mathrm{O}$. A solution of 1,10-phenanthroline (180 mg, $1.0 \mathrm{mmol}$ ) in $\mathrm{MeCN}$ (20 mL) was added slowly to the filtrate with rapid stirring. Upon addition, the title compound precipitated from solution as a white solid. The product was collected, washed with $\mathrm{MeCN}(5 \mathrm{~mL})$ and then ether $(100 \mathrm{~mL})$, and dried to yield $338 \mathrm{mg}$ (0.69 mmol, $69 \%$ yield) of the title compound. ${ }^{1} \mathrm{H} \mathrm{NMR}(400 \mathrm{MHz}$, DMSO- $\left.d_{6}\right): \delta=9.14(\mathrm{dd}, J=4.4,1.7 \mathrm{~Hz}, 2 \mathrm{H}), 8.73(\mathrm{dd}, J=8.2,1.7 \mathrm{~Hz}, 2 \mathrm{H}), 8.16(\mathrm{~d}, J=1.1 \mathrm{~Hz}$, 2H), $8.03-7.95(\mathrm{~m}, 2 \mathrm{H}), 7.78(\mathrm{t}, J=1.4 \mathrm{~Hz}, 1 \mathrm{H}), 7.70(\mathrm{dd}, J=8.2,1.2 \mathrm{~Hz}, 1 \mathrm{H}), 7.58(\mathrm{dt}, J=8.3$, $1.6 \mathrm{~Hz}, 1 \mathrm{H}) .{ }^{13} \mathrm{C}$ NMR $\left(100 \mathrm{MHz}, \mathrm{DMSO}-d_{6}\right): \delta=166.15,151.71,150.24,142.22,138.81,134.40$, 132.99, 132.09, 131.66, 129.31, 127.56, 125.34, 122.55. IR (ATR, $\left.\mathrm{cm}^{-1}\right): 3049.52(\mathrm{w}), 3026.44$ (w), 1607.68 (m), 1563.7 (m), 1537.52 (s), $1508.75(\mathrm{~m}), 1445.43$ (w), 1426.43 (m), $1413.06(\mathrm{w})$, 1374.87 (m), 1358.79 (s), 1339.61 (s), 1279.95 (m), 1260.89 (m), 1219.89 (m), 1187.68 (w), $1148.51(\mathrm{~m}), 1104.28$ (m), 987.13 (w), 963.07 (w), 911.3 (w), 889.06 (m), 861.29 (w), 841.45 (s), 832.36 (s), 786.88 (m), 761.83 (m), 726.97 (s), 719.97 (s), 695.11 (m), 663.17 (m). Elemental Analysis: calculated $\mathrm{C}_{19} \mathrm{H}_{11} \mathrm{AgClN}_{3} \mathrm{O}_{4} \mathrm{C}$ 46.70; H 2.27; N 8.60; measured C 46.45, H 2.17, N 8.49. 


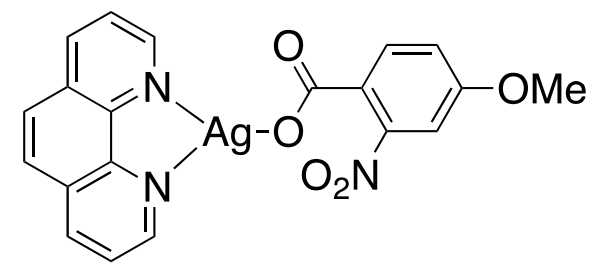

(phenanthroline)Ag(4-OMe-2-NO2-benzoate). This synthesis was performed on the benchtop protected from light. To a mixture of $\mathrm{Ag}_{2} \mathrm{O}$ (194 mg, $1.67 \mathrm{mmol} \mathrm{Ag}$ ) in $\mathrm{MeCN}$ (20 mL) was added a solution of 2-nitro-4-methoxybenzoic acid (330 mg, $1.67 \mathrm{mmol})$ in $\mathrm{MeCN}(20 \mathrm{~mL})$. The mixture was allowed to stir at room temperature. After $2 \mathrm{~h}$, the silver oxide had dissolved to leave a colorless solution, which was then filtered through a pad of Celite to remove residual undissolved $\mathrm{Ag}_{2} \mathrm{O}$. A solution of 1,10-phenanthroline (271 mg, $\left.1.50 \mathrm{mmol}\right)$ in $\mathrm{MeCN}(20 \mathrm{~mL})$ was added slowly to the filtrate with rapid stirring. Upon addition, the title compound precipitated from solution as a tan solid. The product was collected, washed with MeCN (5 mL) and then ether (100 $\mathrm{mL}$ ), and dried to yield $588 \mathrm{mg}\left(1.22 \mathrm{mmol}, 81 \%\right.$ yield) of the title compound. ${ }^{1} \mathrm{H}$ NMR (400 MHz, DMSO- $\left.d_{6}\right): \delta=9.14(\mathrm{dd}, J=4.5,1.6 \mathrm{~Hz}, 2 \mathrm{H}), 8.72(\mathrm{dd}, J=8.1,1.7 \mathrm{~Hz}, 2 \mathrm{H}), 8.15(\mathrm{~s}, 2 \mathrm{H})$, $7.98(\mathrm{dd}, J=8.1,4.5 \mathrm{~Hz}, 2 \mathrm{H}), 7.72(\mathrm{~d}, J=8.5 \mathrm{~Hz}, 1 \mathrm{H}), 7.14$ (d, $J=2.5 \mathrm{~Hz}, 1 \mathrm{H}), 7.07$ (dd, $J=8.6$, $2.6 \mathrm{~Hz}, 1 \mathrm{H}), 3.79$ (s, 3H). ${ }^{13} \mathrm{C}$ NMR (100 MHz, DMSO-d $): \delta=167.30,160.04,151.76,151.60$, 142.22 , 138.81, 132.44, 129.31, 127.58, 126.08, 125.37, 117.03, 107.89, 56.48, 40.70, 40.49, 40.28, 40.07, 39.86, 39.65, 39.44. IR (ATR, $\mathrm{cm}^{-1}$ ): 3056.94 (w), 2989.35 (w), 1605.89 (s), 1585.85 (m), $1564.64(\mathrm{~m}), 1523.27$ (s), $1509.31(\mathrm{~m}), 1495.63(\mathrm{~m}), 1439.07(\mathrm{w}), 1423.07$ (m), $1406.7(\mathrm{w})$, 1357.85 (s), 1344.25 (s), 1308.12 (s), 1274.31 (s), 1232.8 (s), 1192.32 (w), 1151.62 (m), 1135.52 (m), 1101.25 (w), 1059.18 (w), 1047.83 (w), 1019.75 (s), 926.04 (w), 858.73 (m), 842.8 (s), 800.3 (m), $779.95(\mathrm{~m}), 758.56(\mathrm{~m}), 728.89$ (s), $719.34(\mathrm{~m}), 704.56(\mathrm{w}), 672.56(\mathrm{w})$. Elemental Analysis: calculated $\mathrm{C}_{20} \mathrm{H}_{14} \mathrm{AgN}_{3} \mathrm{O}_{5} \mathrm{C} 49.61 ; \mathrm{H} 2.91 ; \mathrm{N} 8.68$; measured C 49.71, H 2.94, N 8.68.<smiles>Cc1ccc(C(=O)O[Ga]2c3c4ccc(cccn32)n4O)c([N+](=O)[O-])c1</smiles>

(phenanthroline)Ag(4-Me-2-NO2-benzoate). This synthesis was performed on the benchtop protected from light. To a mixture of $\mathrm{Ag}_{2} \mathrm{O}(194 \mathrm{mg}, 1.67 \mathrm{mmol} \mathrm{Ag})$ in THF (50 mL) was added 
a solution of 2-nitro-4-methylbenzoic acid (303 mg, $1.67 \mathrm{mmol})$ in THF (50 mL). The mixture was allowed to stir at room temperature. After $2 \mathrm{~h}$, the silver oxide had dissolved to leave a colorless solution, which was then filtered through a pad of Celite to remove residual undissolved $\mathrm{Ag}_{2} \mathrm{O}$. A solution of 1,10-phenanthroline $(301 \mathrm{mg}, 1.67 \mathrm{mmol})$ in THF (20 mL) was added slowly to the filtrate with rapid stirring. Upon addition, the title compound precipitated from solution as a yellow-brown solid. The product was collected, washed with THF $(5 \mathrm{~mL})$ and then ether $(100 \mathrm{~mL})$, and dried to yield $701 \mathrm{mg}(1.50 \mathrm{mmol}, 90 \%$ yield $)$ of the title compound ${ }^{1} \mathrm{H} \mathrm{NMR}$ (400 MHz, DMSO- $\left.d_{6}\right): \delta=9.13(\mathrm{dd}, J=4.5,1.7 \mathrm{~Hz}, 2 \mathrm{H}), 8.70(\mathrm{dd}, J=8.2,1.7 \mathrm{~Hz}, 2 \mathrm{H}), 8.13(\mathrm{~s}$, 2H), $7.97(\mathrm{dd}, J=8.1,4.5 \mathrm{~Hz}, 2 \mathrm{H}), 7.60$ (d, $J=7.8 \mathrm{~Hz}, 1 \mathrm{H}), 7.42$ (dd, $J=1.7,0.8 \mathrm{~Hz}, 1 \mathrm{H}), 7.33$ $(\mathrm{ddd}, J=7.8,1.7,0.9 \mathrm{~Hz}, 1 \mathrm{H}), 2.32(\mathrm{~s}, 3 \mathrm{H}) .{ }^{13} \mathrm{C} \mathrm{NMR}\left(100 \mathrm{MHz}, \mathrm{DMSO}-d_{6}\right): \delta=167.67,151.82$, 150.00, 142.35, 139.47, 138.88, 132.77, 132.33, 130.44, 129.39, 127.65, 125.43, 122.88, 20.84. IR (ATR, cm ${ }^{-1}$ ): $2923.72(\mathrm{w}), 1619.65$ (m), 1607.35 (s), 1561.43 (m), 1523.35 (s), 1424.29 (m), $1380.58(\mathrm{~m}), 1359.01$ (s), $1342.53(\mathrm{~m}), 1219.6(\mathrm{w}), 1138.74(\mathrm{w}), 1098.9(\mathrm{w}), 1080.23(\mathrm{w}), 1042.23$ (w), $956.95(w), 921.88(w), 879.21(w), 850.04(\mathrm{~s}), 828.67(\mathrm{~s}), 793.37(\mathrm{~s}), 779.89(\mathrm{~m}), 730.02(\mathrm{~s})$, 716.29 (m), 697.3 (m), 675.3 (w). Elemental Analysis: calculated $\mathrm{C}_{20} \mathrm{H}_{14} \mathrm{AgN}_{3} \mathrm{O}_{4} \mathrm{C}$ 51.31; $\mathrm{H} 3.01$; N 8.97; measured C 51.34, H 2.94, N 8.79.

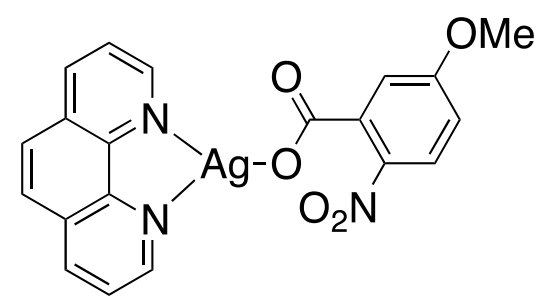

(phenanthroline)Ag(4-OMe-2-NO2-benzoate). This synthesis was performed on the benchtop protected from light. To a mixture of $\mathrm{Ag}_{2} \mathrm{O}(192 \mathrm{mg}, 1.66 \mathrm{mmol} \mathrm{Ag})$ in $\mathrm{MeCN}$ (20 mL) was added a solution of benzoic acid (330 mg, $1.67 \mathrm{mmol})$ in MeCN $(20 \mathrm{~mL})$. The mixture was allowed to stir at room temperature. After $2 \mathrm{~h}$, the silver oxide had dissolved to leave a slightly yellow solution, which was then filtered through a pad of Celite to remove residual undissolved $\operatorname{Ag}_{2} \mathrm{O}$. A solution of 1,10-phenanthroline (267 mg, $1.47 \mathrm{mmol})$ in MeCN (20 mL) was added slowly to the filtrate with rapid stirring. Upon addition, the title compound precipitated from solution as a yellow-tan solid. The product was collected, washed with MeCN (5 mL) and then ether (100 mL), and dried to yield $581 \mathrm{mg}(1.20 \mathrm{mmol}, 82 \%$ yield $)$ of the title compound. ${ }^{1} \mathrm{H} \mathrm{NMR}(400 \mathrm{MHz}$, 
DMSO- $\left.d_{6}\right): \delta=9.13(\mathrm{dd}, J=4.6,1.7 \mathrm{~Hz}, 2 \mathrm{H}), 8.70(\mathrm{dd}, J=8.1,1.7 \mathrm{~Hz}, 2 \mathrm{H}), 8.13(\mathrm{~s}, 2 \mathrm{H}), 7.97$ (dd, $J=8.1,4.5 \mathrm{~Hz}, 2 \mathrm{H}), 7.72(\mathrm{~d}, J=8.9 \mathrm{~Hz}, 1 \mathrm{H}), 6.97(\mathrm{~d}, J=2.9 \mathrm{~Hz}, 1 \mathrm{H}), 6.88(\mathrm{dd}, J=8.9,2.9$ $\mathrm{Hz}, 1 \mathrm{H}), 3.80$ (s, 3H). ${ }^{13} \mathrm{C}$ NMR (100 MHz, DMSO- $\left.d_{6}\right): \delta=168.55,162.60,151.80,142.26$, 141.10, 140.89, 138.87, 129.36, 127.63, 125.78, 125.43, 113.56, 113.51, 56.40, 40.65, 40.44, 40.23, 40.02, 39.81, 39.60, 39.39. IR (ATR, $\left.\mathrm{cm}^{-1}\right): 3054.91$ (w), 2972.94 (w), 1594.82 (m), 1571.05 (s), 1510.79 (s), 1479.67 (m), 1452.56 (w), 1422.9 (m), 1350.71 (s), 1324.18 (m), 1273.59 (m), $1234.46(\mathrm{~m}), 1206.84(\mathrm{~m}), 1152.77(\mathrm{w}), 1141.45(\mathrm{w}), 1103.64(\mathrm{w}), 1072.54(\mathrm{~m}), 1023.79(\mathrm{~m})$, 948.1 (w), 910.37 (w), 892.21 (w), 877.15 (w), 860.25 (w), 844.39 (s), 824.04 (s), 794.95 (m), 755.58 (m), 728.85 (s), 716.79 (m), 697.21 (w), 671.07 (w). Elemental Analysis: calculated: $\mathrm{C}_{20} \mathrm{H}_{14} \mathrm{AgN}_{3} \mathrm{O}_{5} \mathrm{C} 49.61 ; \mathrm{H} 2.91 ; \mathrm{N} 8.68$; measured C 49.38, H 2.92, N 8.69.

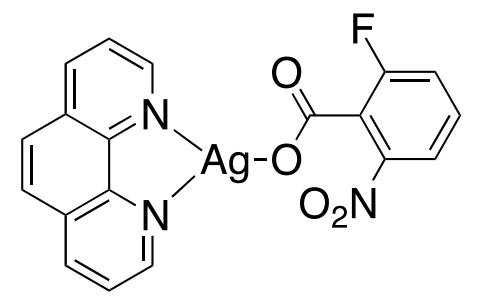

(phenanthroline)Ag(2-F-6-NO2-benzoate). This synthesis was performed on the benchtop protected from light. To a mixture of $\mathrm{Ag}_{2} \mathrm{O}$ (194 mg, $1.67 \mathrm{mmol} \mathrm{Ag}$ ) in $\mathrm{MeCN}$ (20 mL) was added a solution of 2-fluoro-6-nitrobenzoic acid (309 mg, $1.66 \mathrm{mmol})$ in $\mathrm{MeCN}(20 \mathrm{~mL})$. The mixture was allowed to stir at room temperature. After $2 \mathrm{~h}$, the silver oxide had dissolved to leave a light $\tan$ solution, which was then filtered through a pad of Celite to remove residual undissolved $\mathrm{Ag}_{2} \mathrm{O}$. A solution of 1,10-phenanthroline (270 $\mathrm{mg}, 1.50 \mathrm{mmol})$ in $\mathrm{MeCN}(20 \mathrm{~mL})$ was added slowly to the filtrate with rapid stirring. Upon addition, the title compound precipitated from solution as a yellow-brown solid. The product was collected, washed with $\mathrm{MeCN}(5 \mathrm{~mL})$ and then ether $(100 \mathrm{~mL})$, and dried to yield $432 \mathrm{mg}(0.92 \mathrm{mmol}, 62 \%$ yield $)$ of the title compound. ${ }^{1} \mathrm{H}$ NMR (400 MHz, DMSO- $\left.d_{6}\right): \delta=9.15(\mathrm{dd}, \mathrm{J}=4.6,1.7 \mathrm{~Hz}, 2 \mathrm{H}), 8.74(\mathrm{dd}, \mathrm{J}=8.1,1.7 \mathrm{~Hz}, 2 \mathrm{H}), 8.17(\mathrm{~s}$, 2H), $7.99(\mathrm{dd}, \mathrm{J}=8.1,4.5 \mathrm{~Hz}, 2 \mathrm{H}), 7.68(\mathrm{dt}, \mathrm{J}=8.1,0.9 \mathrm{~Hz}, 1 \mathrm{H}), 7.46(\mathrm{td}, \mathrm{J}=8.5,1.1 \mathrm{~Hz}, 1 \mathrm{H})$, $7.36(\mathrm{td}, \mathrm{J}=8.2,5.6 \mathrm{~Hz}, 1 \mathrm{H}) .{ }^{13} \mathrm{C}$ NMR $\left(100 \mathrm{MHz}, \mathrm{DMSO}-d_{6}\right) \delta=163.94,158.44(\mathrm{~d}, \mathrm{~J}=245.4$ $\mathrm{Hz}), 151.72,146.70$ (d, J = 7.7 Hz), 142.11, 138.84, 129.29, 128.63 - 127.95 (m), 125.37, 121.52 $(\mathrm{d}, \mathrm{J}=23.3 \mathrm{~Hz}), 119.90(\mathrm{~d}, \mathrm{~J}=3.1 \mathrm{~Hz}) .{ }^{19} \mathrm{~F}$ NMR $\left(376 \mathrm{MHz}, \mathrm{DMSO}-d_{6}\right) \delta=-113.92$. IR (ATR, $\left.\mathrm{cm}^{-1}\right)$ : $3063.80(\mathrm{w}), 1588.76(\mathrm{~s}), 1510.03(\mathrm{~m}), 1461.67(\mathrm{~m}), 1422.50(\mathrm{~m}), 1352.17(\mathrm{~s}), 1254.23(\mathrm{~m})$, 
$1236.66(\mathrm{~m}), 1163.06(\mathrm{w}), 1139.23(\mathrm{~m}), 1098.16(\mathrm{w}), 1075.11(\mathrm{w}), 1021.64(\mathrm{w}), 948.12(\mathrm{~m})$, 860.35 (w), 839.26 (s), 780.36 (m), 765.30 (m), 740.15 (m), 725.17 (s), 695.23 (m). Elemental Analysis: calculated $\mathrm{C}_{19} \mathrm{H}_{11} \mathrm{AgFN}_{2} \mathrm{O}_{4} \mathrm{C} 48.33$; H 2.35; N 8.90; measured C 48.26, H2.50, N 8.93.<smiles></smiles>

(phenanthroline) $\mathbf{A g}$ (2,6-di-F-benzoate). This synthesis was performed on the benchtop protected from light. To a mixture of $\mathrm{Ag}_{2} \mathrm{O}$ (194 mg, $1.67 \mathrm{mmol} \mathrm{Ag}$ ) in THF (20 mL) was added a solution of 2,6-difluorobenzoic acid $(260 \mathrm{mg}, 1.65 \mathrm{mmol})$ in THF $(20 \mathrm{~mL})$. The mixture was allowed to stir at room temperature. After $2 \mathrm{~h}$, the silver oxide had dissolved to leave a yellow solution, which was then filtered through a pad of Celite to remove residual undissolved $\operatorname{Ag}_{2} \mathrm{O}$. A solution of 1,10-phenanthroline (299 mg, $1.66 \mathrm{mmol})$ in THF $(20 \mathrm{~mL})$ was added slowly to the filtrate with rapid stirring. Upon addition, the title compound precipitated from solution as a white solid. The product was collected, washed with THF $(5 \mathrm{~mL})$ and then ether $(100 \mathrm{~mL})$, and dried to yield $610 \mathrm{mg}$ ( $1.37 \mathrm{mmol}, 83 \%$ yield) of the title compound. ${ }^{1} \mathrm{H}$ NMR (400 MHz, DMSO- $\left.d_{6}\right)$ : $\delta=9.15(\mathrm{~d}, J=5.3 \mathrm{~Hz}, 2 \mathrm{H}), 8.72(\mathrm{t}, J=5.2 \mathrm{~Hz}, 2 \mathrm{H}), 8.15(\mathrm{t}, J=3.8 \mathrm{~Hz}, 2 \mathrm{H}), 7.98(\mathrm{p}, J=3.7 \mathrm{~Hz}$, $2 \mathrm{H}), 7.23-7.13(\mathrm{~m}, 1 \mathrm{H}), 6.92(\mathrm{~d}, J=7.2 \mathrm{~Hz}, 2 \mathrm{H}) .{ }^{13} \mathrm{C}$ NMR $\left(100 \mathrm{MHz}\right.$, DMSO- $\left.d_{6}\right): \delta=164.16$, $160.08,159.97,157.65,157.55,151.80,142.31,138.91$, 129.40, 128.10, 128.01, 127.66, 125.46, 121.56, 111.86, 111.80, 111.67, 111.61. ${ }^{19} \mathrm{~F}$ NMR $\left(376 \mathrm{MHz}\right.$, DMSO- $\left.d_{6}\right) \delta=-114.47$. IR (ATR, $\mathrm{cm}^{-1}$ ): 1601.07 (m), $1509.64(\mathrm{w}), 1462.67(\mathrm{~m}), 1424.9(\mathrm{~m}), 1367.8(\mathrm{~m}), 1237.72(\mathrm{w}), 997.46(\mathrm{~m})$, 843 (s), 801.24 (m), 764.33 (w), 726.04 (s). Elemental Analysis: calculated $\mathrm{C}_{19} \mathrm{H}_{12} \mathrm{AgN}_{2} \mathrm{O}_{2} \mathrm{~F}_{2}$ C 51.26; H 2.49; N 6.29; measured C 51.44, H 2.52, N 6.53.<smiles>COC(=O)c1c(F)cccc1F</smiles> 
(phenanthroline)Ag(2-F-6-Me-benzoate). This synthesis was performed on the benchtop protected from light. To a mixture of $\mathrm{Ag}_{2} \mathrm{O}(194 \mathrm{mg}, 1.67 \mathrm{mmol} \mathrm{Ag}$ ) in $\mathrm{MeCN}(20 \mathrm{~mL})$ was added a solution of benzoic acid $(257 \mathrm{mg}, 1.67 \mathrm{mmol})$ in $\mathrm{MeCN}(20 \mathrm{~mL})$. The mixture was allowed to stir at room temperature. After $2 \mathrm{~h}$, the silver oxide had dissolved to leave a faintly brown solution, which was then filtered through a pad of Celite to remove residual undissolved $\operatorname{Ag}_{2} \mathrm{O}$. A solution of 1,10-phenanthroline (270 mg, $1.50 \mathrm{mmol})$ in $\mathrm{MeCN}(20 \mathrm{~mL})$ was added slowly to the filtrate with rapid stirring. Upon addition, the title compound precipitated from solution as a white solid. The product was collected, washed with $\mathrm{MeCN}(5 \mathrm{~mL})$ and then ether $(100 \mathrm{~mL})$, and dried to yield $410 \mathrm{mg}$ (0.93 mmol, $61 \%$ yield) of the title compound. ${ }^{1} \mathrm{H}$ NMR (400 MHz, DMSO- $\left.d_{6}\right): \delta=9.15$ $(\mathrm{dd}, \mathrm{J}=4.3,1.7 \mathrm{~Hz}, 2 \mathrm{H}), 8.72(\mathrm{dd}, \mathrm{J}=8.2,1.7 \mathrm{~Hz}, 2 \mathrm{H}), 8.15(\mathrm{~s}, 2 \mathrm{H}), 7.98(\mathrm{dd}, \mathrm{J}=8.2,4.6 \mathrm{~Hz}$, $2 \mathrm{H}), 7.02(\mathrm{q}, \mathrm{J}=7.4 \mathrm{~Hz}, 1 \mathrm{H}), 6.92-6.76(\mathrm{~m}, 2 \mathrm{H}), 2.23$ (s, 3H). ${ }^{13} \mathrm{C}$ NMR (100 MHz, DMSO- $\left.d_{6}\right)$ : $\delta=169.23,159.45,157.06,151.81,142.35,138.89,135.83,129.39,127.66,127.17,125.56$, 125.45, 112.54, 19.91. ${ }^{19} \mathrm{~F}$ NMR (376 MHz, DMSO-d $)$ : $\delta=-117.83--117.87$ (m). IR (ATR, $\mathrm{cm}^{-1}$ ): $3063.26(\mathrm{w}), 1606.94$ (s), 1572.35 (s), 1510.44 (s), 1497.02 (m), 1461.78 (s), 1422.66 (s), 1351.22 (s), 1254.85 (m), 1236.98 (s), 1163.52 (w), 1139.17 (m), 1098.01 (w), 1075.35 (w), 1022.27 (m), 947.73 (m), 860.78 (m), 840.14 (s), 791.13 (s), 781.12 (s), 765.67 (s), 740.04 (s), 724.86 (s). Elemental Analysis: calculated $\mathrm{C}_{19} \mathrm{H}_{14} \mathrm{AgFN}_{2} \mathrm{O}_{2} \mathrm{C}$ 54.45; H 3.20; N 6.35; measured C 54.65, H 3.39, N 6.44.

\subsubsection{Silver Benzoate Complexes Used in Validation Set (Figure 2-7B, red points)}

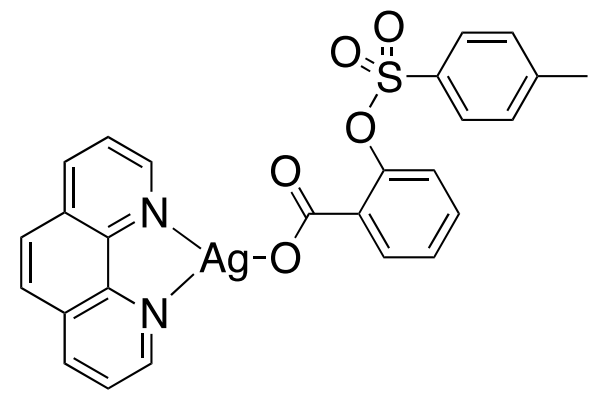

(phenanthroline)Ag(2-OTs-benzoate). This synthesis was performed on the benchtop protected from light. To a solution of $\mathrm{NaOH}(66.8 \mathrm{mg}, 1.67 \mathrm{mmol})$ and water $(20 \mathrm{~mL})$, 2-(((4-methylphenyl)sulfonyl)oxy)benzoic acid (488 mg, $1.67 \mathrm{mmol})$ was added with stirring until 
completely dissolved. To the mixture, $\operatorname{Ag}(\mathrm{OTf})(429 \mathrm{mg}, 1.67 \mathrm{mmol})$ was then added and allowed to stir for 1 hour. The precipitate was then removed by filtration and dried under vacuum. The dried $\mathrm{Ag}$ (2-OTs-benzoate) was then dissolved in $\mathrm{MeCN}(20 \mathrm{~mL})$ and a solution of 1,10-phenanthroline ( $270 \mathrm{mg}, 1.50 \mathrm{mmol}$ ) in $20 \mathrm{~mL}$ of $\mathrm{MeCN}$ was added slowly over the course of 20 minutes with rapid stirring. Upon this addition, the title compound precipitated from solution as a grey solid. The product was collected, washed with $\mathrm{MeCN}(5 \mathrm{~mL})$ and then ether $(100 \mathrm{~mL})$, and dried to provide $555 \mathrm{mg}\left(0.960 \mathrm{mmol}, 64 \%\right.$ yield) of the title compound. ${ }^{1} \mathrm{H}$ NMR ( $400 \mathrm{MHz}$, DMSO- $\left.d_{6}\right): \delta=9.16(\mathrm{dd}, \mathrm{J}=4.5,1.6 \mathrm{~Hz}, 2 \mathrm{H}), 8.72(\mathrm{dd}, \mathrm{J}=8.2,1.7 \mathrm{~Hz}, 2 \mathrm{H}), 8.15(\mathrm{~s}, 2 \mathrm{H}), 7.99$ $(\mathrm{dd}, \mathrm{J}=8.1,4.5 \mathrm{~Hz}, 2 \mathrm{H}), 7.82-7.75(\mathrm{~m}, 2 \mathrm{H}), 7.62(\mathrm{dd}, \mathrm{J}=7.5,2.0 \mathrm{~Hz}, 1 \mathrm{H}), 7.28(\mathrm{td}, \mathrm{J}=7.7,1.6$ $\mathrm{Hz}, 3 \mathrm{H}), 7.22(\mathrm{td}, \mathrm{J}=7.4,1.3 \mathrm{~Hz}, 1 \mathrm{H}), 7.02(\mathrm{dd}, \mathrm{J}=8.0,1.3 \mathrm{~Hz}, 1 \mathrm{H}), 2.23(\mathrm{~s}, 3 \mathrm{H}) .{ }^{13} \mathrm{C}$ NMR $(100$ MHz, DMSO- $\left.d_{6}\right): \delta=168.69,151.84,146.68,145.44,142.29,138.88,134.79,133.13,131.40$, 130.24, 129.83, 129.35, 128.94, 127.64, 127.05, 125.44, 122.62, 21.59. IR (ATR, $\left.\mathrm{cm}^{-1}\right): 3067.47$ (w), 1589.35 (s), $1557.64(\mathrm{~m}), 1511.95$ (m), 1493.57 (w), 1478.18 (w), 1444.27 (w), 1425.37 (m), 1368.39 (s), 1295.29 (w), 1194.27 (m), 1180.51 (m), 1166.85 (s), 1139.90 (m), $1120.56(\mathrm{w})$, 1096.40 (m), 1082.17 (s), 1036.98 (w), 1019.39 (w), 959.67 (w), 879.86 (s), 862.41 (w), 840.15 (s), 827.73 (s), 786.83 (s), 770.10 (m), 741.96 (s), 727.27 (s), 708.37 (m), 661.51 (s). Elemental Analysis: calculated $\mathrm{C}_{26} \mathrm{H}_{19} \mathrm{AgN}_{2} \mathrm{O}_{5} \mathrm{~S}$ C 53.90; H 3.31; N 4.84; measured C 53.01, H 3.37, N 4.68. This data is consistent with a trace water impurity.<smiles>COc1ccccc1C(=O)O</smiles>

2-[[(4-methylphenyl)-sulfonyl]-oxy]-benzoic acid. This synthesis was performed on the benchtop. Salicylic acid (20.0 g, $0.145 \mathrm{~mol})$ was added to a solution of $\mathrm{NaOH}(11.6 \mathrm{mg}, 0.290$ $\mathrm{mol})$ in water $(100 \mathrm{~mL})$. $p$-toluenesulfonyl chloride $(27.6 \mathrm{~g}, 0.145 \mathrm{~mol})$ was then added to the solution in aliquots over the course of 20 minutes. The solution was allowed to stir overnight at room temperature and then acidified with $10 \% \mathrm{HCl}$ to a $\mathrm{pH}$ of 6 . The resulting white precipitate was collected by filtration and dissolved in a $2 \mathrm{~N}$ solution of $\mathrm{NaOH}$. The resulting solution was again re-acidified with $10 \% \mathrm{HCl}$ and the precipitate collected and washed with boiling water. The 
white powder $(22.5 \mathrm{~g}, 0.077 \mathrm{~mol}, 52 \%)$ was then dried under vacuum. ${ }^{1} \mathrm{H}$ NMR (400 MHz, Methanol- $\left.d_{4}\right) \delta=7.81(\mathrm{ddt}, J=7.8,4.1,2.9 \mathrm{~Hz}, 1 \mathrm{H}), 7.70-7.60(\mathrm{~m}, 2 \mathrm{H}), 7.54-7.46(\mathrm{~m}, 1 \mathrm{H})$, 7.36 (dddd, $J=11.7,7.6,6.1,2.6 \mathrm{~Hz}, 3 \mathrm{H}), 7.14-7.04(\mathrm{~m}, 1 \mathrm{H}), 2.42(\mathrm{~d}, J=3.9 \mathrm{~Hz}, 3 \mathrm{H})$. Spectroscopic data is consistent with literature values. ${ }^{[120]}$

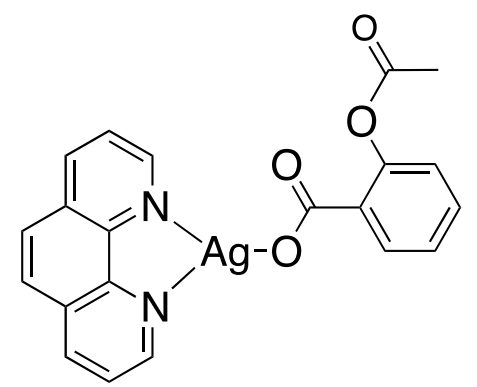

(phenanthroline)Ag(2-OAc-benzoate). This synthesis was performed on the benchtop protected from light. To a mixture of $\mathrm{Ag}_{2} \mathrm{O}$ (194 mg, $1.67 \mathrm{mmol} \mathrm{Ag}$ ) in $\mathrm{MeCN}$ (20 mL) was added a solution of 2-acetoxybenzoic acid (301 mg, $1.67 \mathrm{mmol})$ in $\mathrm{MeCN}(20 \mathrm{~mL})$. The mixture was allowed to stir at room temperature. After $2 \mathrm{~h}$, the silver oxide had dissolved to leave a colorless solution, which was then filtered through a pad of Celite to remove residual undissolved $\operatorname{Ag}_{2} \mathrm{O}$. A solution of 1,10-phenanthroline (301 mg, $1.67 \mathrm{mmol})$ in $\mathrm{MeCN}(20 \mathrm{~mL})$ was added slowly to the filtrate with rapid stirring. Upon addition, the title compound precipitated from solution as a white solid. The product was collected, washed with $\mathrm{MeCN}(5 \mathrm{~mL})$ and then ether $(100 \mathrm{~mL})$, and dried to yield $499 \mathrm{mg}$ (1.07 mmol, $64 \%$ yield) of the title compound. ${ }^{1} \mathrm{H}$ NMR (400 MHz, DMSO- $\left.d_{6}\right): \delta=9.17$ $(\mathrm{d}, \mathrm{J}=4.5 \mathrm{~Hz}, 2 \mathrm{H}), 8.73(\mathrm{~d}, \mathrm{~J}=7.7 \mathrm{~Hz}, 2 \mathrm{H}), 8.17(\mathrm{~d}, \mathrm{~J}=1.9 \mathrm{~Hz}, 2 \mathrm{H}), 8.00(\mathrm{~d}, \mathrm{~J}=7.5 \mathrm{~Hz}, 2 \mathrm{H})$, $7.84(\mathrm{~d}, \mathrm{~J}=7.7 \mathrm{~Hz}, 1 \mathrm{H}), 7.31(\mathrm{~d}, \mathrm{~J}=8.1 \mathrm{~Hz}, 1 \mathrm{H}), 7.18(\mathrm{~d}, \mathrm{~J}=8.3 \mathrm{~Hz}, 1 \mathrm{H}), 6.96(\mathrm{~d}, \mathrm{~J}=7.9 \mathrm{~Hz}$, $1 \mathrm{H}), 2.22-2.13(\mathrm{~m}, 3 \mathrm{H}) .{ }^{13} \mathrm{C}$ NMR (100 MHz, DMSO- $\left.d_{6}\right): \delta=169.86,168.57,151.83,150.25$, 142.48, 138.89, 132.00, 130.64, 129.42, 127.68, 125.62, 125.46, 123.34, 21.90. IR (ATR, cm $\left.{ }^{-1}\right)$ : $3070.81(\mathrm{w}), 1773.72$ (m), $1753.76(\mathrm{~m}), 1607.17$ (m), 1566.85 (m), 1510.62 (m), $1494.74(\mathrm{w})$, 1477.73 (w), 1422.99 (m), 1348.03 (s), 1218.68 (s), 1189.65 (s), 1140.10 (w), 1089.75 (m), 1039.85 (w), 1009.44 (w), 955.06 (w), 919.49 (m), 884.82 (w), 855.90 (m), 844.25 (s), 814.41 (m), $782.92(\mathrm{w}), 772.79(\mathrm{w}), 756.84$ (s), 728.59 (s), 718.58 (s), 708.43 (s), 677.05 (m). Elemental Analysis: calculated $\mathrm{C}_{21} \mathrm{H}_{15} \mathrm{AgN}_{2} \mathrm{O}_{4}$ C 53.98; H 3.24; N 6.00; measured C 54.09, H 3.38, N 6.09. 


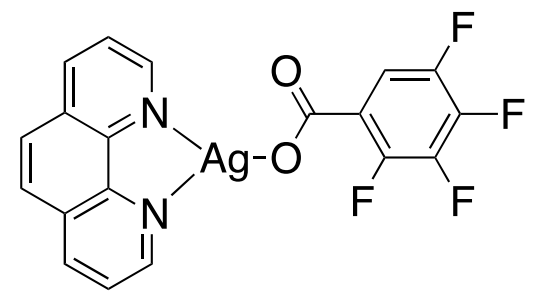

(phenanthroline)Ag(2,3,4,5-tetra-F-benzoate). This synthesis was performed on the benchtop protected from light. To a mixture of $\mathrm{Ag}_{2} \mathrm{O}$ (194 mg, $1.67 \mathrm{mmol} \mathrm{Ag}$ ) in $\mathrm{MeCN}$ (20 mL) was added a solution of 2,3,4,5-tetrafluorobenzoic acid (324.1 mg, $1.67 \mathrm{mmol})$ in $\mathrm{MeCN}(20 \mathrm{~mL})$. The mixture was allowed to stir at room temperature. After $2 \mathrm{~h}$, the silver oxide had dissolved to leave a yellow solution, which was then filtered through a pad of Celite to remove residual undissolved $\mathrm{Ag}_{2} \mathrm{O}$. A solution of 1,10-phenanthroline $(270 \mathrm{mg}, 1.50 \mathrm{mmol})$ in $\mathrm{MeCN}(20 \mathrm{~mL})$ was added slowly to the filtrate with rapid stirring. Upon addition, the title compound precipitated from solution as a light-yellow solid. The product was collected, washed with MeCN (5 mL) and then ether (100 mL), and dried to yield $628 \mathrm{mg}\left(1.30 \mathrm{mmol}, 87 \%\right.$ yield) of the title compound. ${ }^{1} \mathrm{H}$ NMR $\left(400 \mathrm{MHz}, \mathrm{DMSO}-d_{6}\right): \delta=9.15(\mathrm{~d}, \mathrm{~J}=4.5 \mathrm{~Hz}, 2 \mathrm{H}), 8.74(\mathrm{dd}, \mathrm{J}=8.1,1.6 \mathrm{~Hz}, 2 \mathrm{H}), 8.17(\mathrm{~s}, 2 \mathrm{H})$, 7.99 (dd, J = 8.2, $4.5 \mathrm{~Hz}, 2 \mathrm{H}), 7.45-7.35$ (m, 1H). ${ }^{19} \mathrm{~F}$ NMR (376 MHz, DMSO-d $)^{\text {) }} \delta=-140.61$, $-141.46(\mathrm{dt}, J=23.9,12.5 \mathrm{~Hz}),-157.30(\mathrm{t}, J=22.1 \mathrm{~Hz}),-158.11$. IR (ATR, $\left.\mathrm{cm}^{-1}\right): 3091.30(\mathrm{w})$, 1610.58 (s), $1585.88(\mathrm{~m}), 1512.79$ (m), $1471.03(\mathrm{~m}), 1422.33$ (m), 1369.60 (s), 1340.55 (m), 1327.40 (w), 1257.93 (w), 1183.23 (w), 1094.84 (m), 1022.66 (m), 905.44 (w), 843.28 (s), 791.12 (w), 761.71 (s), 724.96 (s), 718.95 (s), 708.92 (m), 692.17 (w). Elemental Analysis: calculated $\mathrm{C}_{19} \mathrm{H}_{9} \mathrm{AgF}_{4} \mathrm{~N}_{2} \mathrm{O}_{2} \mathrm{C}$ 47.43; H 1.89; N 5.82; measured C 47.72, H 1.75, N 5.83.<smiles></smiles>

(phenanthroline)Ag(2-Cl-6-NO2-benzoate). This synthesis was performed on the benchtop protected from light. To a mixture of $\mathrm{Ag}_{2} \mathrm{O}(174 \mathrm{mg}, 1.50 \mathrm{mmol} \mathrm{Ag})$ in $\mathrm{MeCN}(20 \mathrm{~mL})$ was added a solution of 2-chloro-6-nitrobenzoic acid $(302 \mathrm{mg}, 1.50 \mathrm{mmol})$ in $\mathrm{MeCN}(20 \mathrm{~mL})$. The mixture 
was allowed to stir at room temperature. After $2 \mathrm{~h}$, the silver oxide had dissolved to leave a yellow solution. A solution of 1,10-phenanthroline (180 mg, $1.00 \mathrm{mmol})$ in MeCN (20 mL) was added slowly with rapid stirring. Upon addition, the title compound precipitated from solution as a tan solid. The product was collected, washed with $\mathrm{MeCN}(5 \mathrm{~mL})$ and then ether $(100 \mathrm{~mL})$, and dried to yield $364 \mathrm{mg}\left(0.74 \mathrm{mmol}, 74 \%\right.$ yield) of the title compound. ${ }^{1} \mathrm{H}$ NMR (400 MHz, DMSO- $\left.d_{6}\right)$ : $\delta=9.14(\mathrm{dd}, \mathrm{J}=4.6,1.6 \mathrm{~Hz}, 2 \mathrm{H}), 8.73(\mathrm{dt}, \mathrm{J}=8.0,1.5 \mathrm{~Hz}, 2 \mathrm{H}), 8.16(\mathrm{~d}, \mathrm{~J}=1.3 \mathrm{~Hz}, 2 \mathrm{H}), 7.98$ $(\mathrm{ddd}, \mathrm{J}=8.0,4.6,1.3 \mathrm{~Hz}, 2 \mathrm{H}), 7.80(\mathrm{dd}, \mathrm{J}=8.2,1.1 \mathrm{~Hz}, 1 \mathrm{H}), 7.65(\mathrm{dd}, \mathrm{J}=8.0,1.2 \mathrm{~Hz}, 1 \mathrm{H}), 7.31$ $(\mathrm{td}, \mathrm{J}=8.1,1.3 \mathrm{~Hz}, 1 \mathrm{H}) .{ }^{13} \mathrm{C}$ NMR (100 MHz, DMSO- $\left.d_{6}\right): \delta=165.06,151.72,146.66,142.27$, 139.04, 138.81, 134.77, 130.79, 129.33, 127.57, 127.51, 125.34, 122.60, 40.39, 40.25, 40.11, 39.98, 39.84, 39.70, 39.56. IR (ATR, $\mathrm{cm}^{-1}$ ): $3049.06(\mathrm{w}), 1607.32$ (s), $1567.91(\mathrm{~m}), 1523.75$ (s), $1509.29(\mathrm{~s}), 1449.76(\mathrm{~m}), 1423.72$ (m), 1357.81 (s), 1288.33 (m), 1227.24 (m), 1157.71 (m), $1104.19(\mathrm{~m}), 1062.18$ (w), 1001.00 (w), 973.77 (w), 956.69 (w), 888.03 (w), 847.24 (s), 835.98 (s), $805.26(\mathrm{~m}), 779.92(\mathrm{~m}), 753.18$ (s), 725.93 (s), 692.06 (s). Elemental Analysis: calculated $\mathrm{C}_{19} \mathrm{H}_{11} \mathrm{AgClN}_{3} \mathrm{O}_{4} \mathrm{C} 46.70 ; \mathrm{H} 2.27$; N 8.60; measured C 46.90, H 2.12, N 8.69.

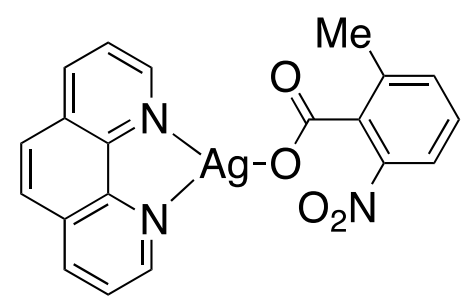

(phenanthroline)Ag(2-Me-6-NO2-benzoate). This synthesis was performed on the benchtop protected from light. To a mixture of 2-methyl-6-nitrobenzoic acid (5.00 mmol, $910 \mathrm{mg}$ ) in THF $(5 \mathrm{~mL})$ was added a solution of $\mathrm{NaOH}(5.00 \mathrm{mmol}, 200 \mathrm{mg})$ in water $(5 \mathrm{~mL})$. This mixture was allowed to stir for 10 minutes and resulted in a yellow solution. To this solution, an additional 5.0 $\mathrm{mL}$ of THF was then added followed by a solution of $\mathrm{AgNO}_{3}(3.00 \mathrm{mmol}, 480 \mathrm{mg}$ ) in water (5 $\mathrm{mL})$. The mixture was allowed to stir for 5 minutes. The silver benzoate was filtered and dried under vacuum resulting in a yellow solid (570 mg, $1.0 \mathrm{mmol}, 66 \%$ yield). Immediately, MeCN (20 $\mathrm{mL}$ ) was then added to the dried silver benzoate. To the resulting slurry, a solution of 1,10-phenanthroline (1.60 mmol, $288 \mathrm{mg})$ in MeCN (20 mL) was added slowly over the course of 5 minutes with rapid stirring. A pale-yellow precipitant formed which was then collected, washed 
with $\mathrm{MeCN}(5 \mathrm{~mL})$ and then ether $(100 \mathrm{~mL})$, and dried under vacuum to yield $472.1 \mathrm{mg}(1.0 \mathrm{mmol}$, $63 \%$ yield) of the title compound. ${ }^{1} \mathrm{H}$ NMR (400 MHz, DMSO- $\left.d_{6}\right): \delta=9.14(\mathrm{~d}, \mathrm{~J}=4.6 \mathrm{~Hz}, 2 \mathrm{H})$, $8.72(\mathrm{~d}, \mathrm{~J}=8.2 \mathrm{~Hz}, 2 \mathrm{H}), 8.14(\mathrm{~s}, 2 \mathrm{H}), 8.04-7.85(\mathrm{~m}, 2 \mathrm{H}), 7.62(\mathrm{~d}, \mathrm{~J}=8.2 \mathrm{~Hz}, 1 \mathrm{H}), 7.42$ (d, J = 7.6 $\mathrm{Hz}, 1 \mathrm{H}), 7.22$ (t, J = $7.9 \mathrm{~Hz}, 1 \mathrm{H}), 2.31(\mathrm{~s}, 3 \mathrm{H}) .{ }^{13} \mathrm{C}$ NMR (100 MHz, DMSO-d $): \delta=168.93$, 151.81, 146.51, 142.33, 139.04, 138.87, 136.06, 135.28, 129.38, 127.64, 126.67, 125.41, 121.05, 20.11. IR (ATR, $\mathrm{cm}^{-1}$ ): 3061.74 (w), 1617.79 (m), 1601.62 (m), 1520.80 (s), 1509.41 (s), 1457.96 (w), $1422.03(\mathrm{~m}), 1338.58(\mathrm{~s}), 1293.82(\mathrm{~m}), 1220.45(\mathrm{w}), 1182.11(\mathrm{w}), 1165.05(\mathrm{w}), 1137.51(\mathrm{~m})$, 1097.30 (w), 1079.90 (w), 1038.13 (w), 922.09 (w), 860.46 (w), 839.80 (s), 803.78 (m), 777.76 (m), 763.60 (m), 744.18 (m), 725.00 (s), 699.57 (m). Elemental Analysis: calculated $\mathrm{C}_{20} \mathrm{H}_{14} \mathrm{AgN}_{3} \mathrm{O}_{4} \mathrm{C}$ 51.31; H 3.01; N 8.97; measured C 51.59, H 2.99, N 9.06. 


\section{Chapter 3- Progress in the Decarboxylation of Ag(Heteroaromatic Carboxylate)}

\section{Complexes}

\subsection{Overview}

As previously shown in Chapter 2, a predictive model was developed for the decarboxylation of silver benzoate complexes relevant to decarboxylative cross-coupling reactions. While this study has expanded the understanding of the decarboxylation of benzoic acids, a parallel to other classes of carboxylic acids used in decarboxylative coupling reactions, such as heteroaromatic acids, cannot be easily drawn. Knowing that our previous system allows for the simple and direct study of the decarboxylation of carboxylic acids by monitoring the decarboxylation of the preformed silver carboxylates, we should be able to extend this system to a series of silver heteroaromatic carboxylate complexes.

The hetero-biaryl scaffold is a ubiquitous structure in biologically active molecules, ${ }^{[121,122]}$ such as kinase inhibitors, ${ }^{[123]}$ antibiotics, ${ }^{[124]}$ anticancer therapeutics, ${ }^{[125]}$ and anti-HIV drugs, ${ }^{[126]}$ due to the fact that these scaffolds are considered privileged structures (Figure 3-1). These scaffolds are usually constructed through a Pd-catalyzed cross-coupling reaction (Suzuki-Miyaura, Heck, Negishi, Stille, Buchwald-Hartwig, etc.) that requires the use of prefunctionalized starting materials. ${ }^{[127,128]}$ Often, these prefunctionalized starting materials are not commercially available or are expensive. Given this, alternative pathways to construct the hetero-biaryl scaffold, such as decarboxylative coupling reactions, could provide a powerful alternative to replace these expensive materials. To this end, an increased interest in readily available heteroaromatic carboxylic acids for use in these decarboxylative cross-coupling reactions has been seen as an alternative to the expensive prefunctionalized heteroaromatic reagents. 
<smiles>Cc1c(-c2ccc(-c3ccccc3F)cc2)nc2ccc(F)cc2c1C(=O)O</smiles>

Brequinar Immunosuppressant<smiles>c1ccc2[nH]c(-c3cscn3)nc2c1</smiles>

Thiabendazole Antihelmintic<smiles>COc1ccc(-c2sc3cc(O)ccc3c2Oc2ccc(OCCN3CCCCC3)cc2)cc1</smiles>

Arzoxifene Antineoplastic<smiles>Cc1ccc(-c2ncc(Cl)cc2-c2ccc(S(C)(=O)=O)cc2)cn1</smiles>

Etoricoxib Pain/Inflammation<smiles>Cc1ccc(NC(=O)c2ccc(N3CCN(C)CC3)cc2)cc1Nc1nccc(-c2cccnc2)n1</smiles>

Imatinib

Myelogenous Leukemia

Figure 3-1: Hetero-biaryl scaffolds used in the pharmaceutical industry.

The construction of the hetero-biaryl motif by decarboxylative coupling reactions have been sparsely reported by a number of groups. ${ }^{[13,18,19,87,93,129-138]}$ While many of these reports showcase a wide scope of ortho-functionalized benzoic acids, the reported heteroaromatic carboxylic acid scope is largely limited to a small selection, typically with the heteroatom in the position alpha to the carboxylic acid functionality (Figure 3-2). Intriguingly, a similar scope can be seen for protodecarboxylation reactions of heteroaromatic carboxylic acids. ${ }^{[36,43,50,53,139-141]}$ Of these reported decarboxylation reactions that utilize heteroaromatic carboxylic acids, the use of Ag-based oxidants is a common factor for many of them. 
<smiles>O=C(O)c1ccccn1</smiles><smiles>O=C(O)c1cccnc1</smiles><smiles>O=C(O)c1ccncc1</smiles><smiles></smiles><smiles>O=C(O)c1ccc2ccccc2n1</smiles><smiles>O=C(O)c1nccc2ccccc12</smiles><smiles>[R]n1c(C(=O)O)cc2ccccc21</smiles><smiles>O=C(O)c1cc2ccccc2o1</smiles><smiles>O=C(O)c1cc2ccccc2s1</smiles><smiles>O=C(O)c1csc2ccccc12</smiles><smiles>[R]n1nccc1C(=O)O</smiles><smiles>O=C(O)c1cnco1</smiles><smiles>O=C(O)c1cncs1</smiles><smiles>[R]n1ncc(C(=O)O)n1</smiles>

Figure 3-2: A representative scope of heteroaromatic carboxylic acids used in decarboxylative cross-coupling reactions.

In 2009, Gooßen and co-workers reported the silver-catalyzed protodecarboxylation of carboxylic acids (Scheme 3-1A). ${ }^{[4]}$ Within this report, both thiophene-2-carboxylic acid and thiophene-3-carboxylic acid were shown to undergo protodecarboxylation at $120{ }^{\circ} \mathrm{C}$ in the presence of catalytic silver acetate $(\mathrm{AgOAc})$. Concurrently, Larrosa and co-workers reported the successful protodecarboxylation of ten different classes of heteroaromatic acids (Scheme 3-1B). ${ }^{\text {[36] }}$ In Larrosa's report, a heteroatom or electron deficient substituent alpha to the carboxylic acid functional group was required for the protodecarboxylation to proceed. For example, attempting to use benzofuran-3-carboxylic acid under their conditions resulted in no protodecarboxylation product. Interestingly, the decarboxylation of benzofuran-2,3-dicarboxylic acid resulted in the mono-protodecarboxylated product benzofuran-3-carboxylic acid. 
A) Gooßen (2009):

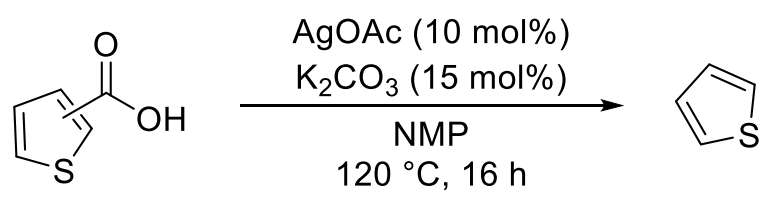

B) Larrosa (2009):

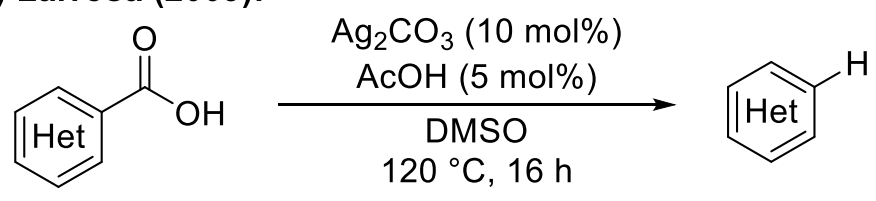

C) Larrosa (2012):

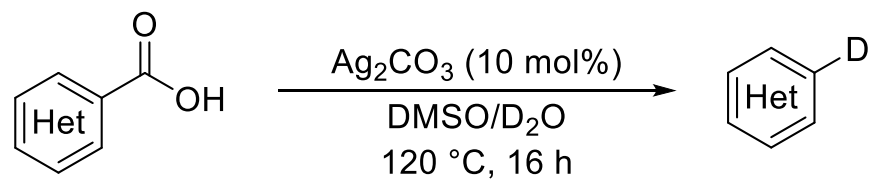

D) Jaenicke (2014):

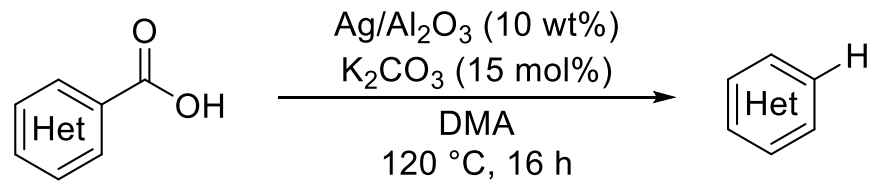

Scheme 3-1: Examples of silver-catalyzed protodecarboxylation of heteroaromatic carboxylic acids.

Unfortunately, recent examples of the protodecarboxylation of heteroaromatic carboxylates have had little success in further expanding the reaction scope. For example, in 2012, Larrosa and co-workers published a minor modification to their previous report of heteroaromatic carboxylic acid protodecarboxylation allowing for the deuterodecarboxylation of seven classes of heteroaromatic carboxylates (Scheme 3-1C). ${ }^{[53]}$ However, the acid scope of this reaction was still limited to heteroaromatic carboxylic acids with heteroatoms or electron deficient substituents in the alpha position (Figure 3-3). Additionally, in 2014 the Jaenicke group published a heterogenous protocol allowing for the protodecarboxylation of 5 classes of heteroaromatic carboxylic acids (Scheme 3-1D, Figure 3-3). ${ }^{[141]}$ 


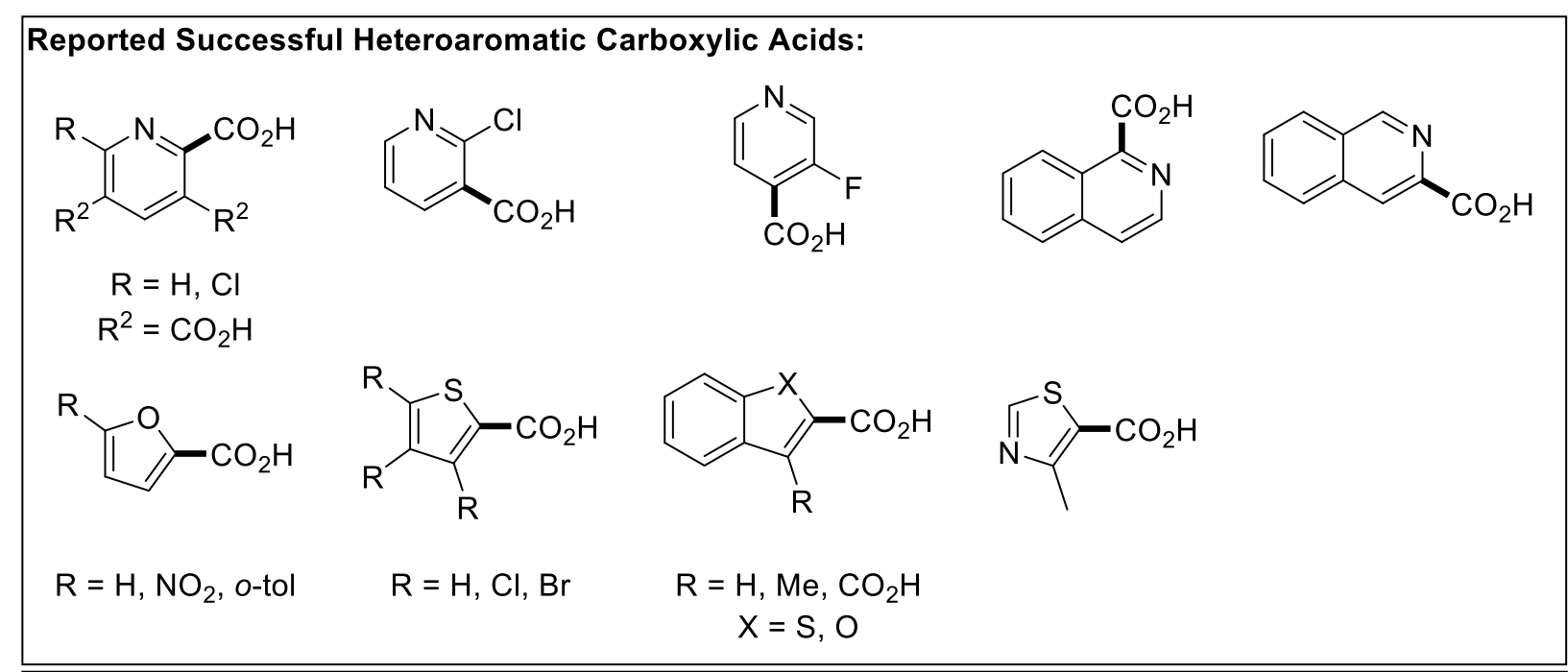

Reported Unsuccessful Heteroaromatic Carboxylic Acids:<smiles>O=C(O)c1coc2ccccc12</smiles>

Figure 3-3: Heteroaromatic carboxylic acids that were reported to be successful (top) and unsuccessful (bottom) in the Larrosa and Jaenicke reports.

Despite the recent progress with decarboxylative cross-coupling reactions, a detailed understanding of the decarboxylation of heteroaromatic carboxylic acids remains elusive. Given the progress on developing a method to predict the protodecarboxylation rates of benzoic acids through the study of (phen) $\mathrm{Ag}$ (benzoate) complexes, ${ }^{[142]}$ we turned our attention to the study of heteroaromatic carboxylic acids. Understanding the protodecarboxylation of heteroaromatic substrates could enable an expansion to the scope of heteroaromatic carboxylic acids known to undergo decarboxylative cross-coupling reactions and potentially allowing for the prediction of the reactivity over a large range of heterocycle classes. Since many of the oxidative decarboxylative cross-coupling and protodecarboxylation reactions of heteroaromatic carboxylic acids employ Ag-based oxidants and/or catalysts, we reasoned that our strategy for monitoring protodecarboxylation from Chapter 2 could be expanded to the protodecarboxylation of a series of $\mathrm{Ag}$ (heteroaromatic carboxylate) complexes (Scheme 3-2). 


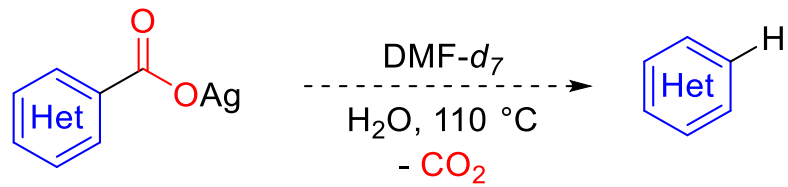

Scheme 3-2: Protodecarboxylation of Ag(heteroaromatic carboxylate) complexes.

\subsection{Results}

Due to the drastically different solubilities of heteroaromatic carboxylic acids, we hypothesized that unligated $\mathrm{Ag}$ (heteroaromatic carboxylate) complexes would allow for the broadest scope of silver carboxylates for our study. We first sought to evaluate the rates of protodecarboxylation of (phen) $\mathrm{Ag}$ (benzoate) complexes with unligated $\mathrm{Ag}$ (benzoate) complexes to enable a direct comparison to the rate of decarboxylation of unligated $\mathrm{Ag}$ (heteroaromatic carboxylate) complexes. Initially, a small subset of the benzoic acids employed in our previous studies were used to synthesize a series of unligated $\operatorname{Ag}$ (benzoate) complexes. These $\mathrm{Ag}$ (benzoate) complexes were selected to cover a wide range of decarboxylation rates based on our previous studies. These complexes were synthesized by the slow addition of an aqueous solution of silver nitrate to a solution of the substituted benzoic acid and sodium hydroxide in water. The desired $\mathrm{Ag}$ (benzoate) complexes were isolated via filtration and dried in vacuo (Scheme 3-3). The Ag(benzoate) complexes readily undergo decarboxylation at $110{ }^{\circ} \mathrm{C}$ in DMF$d_{7}$ with $0.7 \mathrm{mM} \mathrm{H}_{2} \mathrm{O}$ to yield the substituted arenes when monitored by ${ }^{1} \mathrm{H}$ NMR spectroscopy with 1,3,5-trimethoxybenzene as an internal standard (Scheme 3-4, Table 3-7, Figure 3-4, 3-5, and 3-6). 


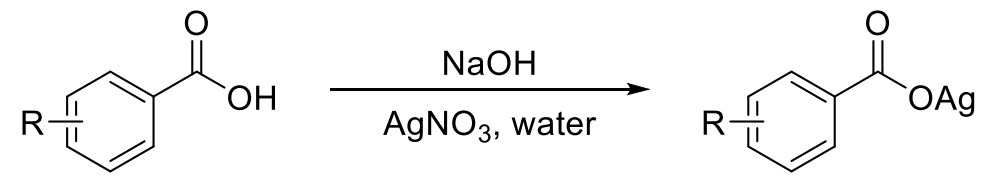<smiles>O=C(O[Na])c1ccccc1[N+](=O)[O-]</smiles>

4<smiles>O=C(O[Na])c1c(F)cccc1[N+](=O)[O-]</smiles>

9<smiles>O=C(O[Na])c1c(F)cccc1F</smiles>

5<smiles>COc1cccc(F)c1C(=O)OCc1ccccc1</smiles>

10<smiles>COC(=O)c1c(OC)cccc1OC</smiles>

6<smiles>CC(C)(C)OC(=O)c1ccccc1-c1ccccc1</smiles>

11<smiles>COC(=O)c1ccccc1C(=O)OC</smiles>

7<smiles>CC(F)(F)O[Ga]OC(=O)c1ccccc1C(F)(F)F</smiles>

12<smiles>O=C(O[Na])c1ccccc1F</smiles>

8<smiles>O=C(O[Na])c1c(F)cccc1C(F)(F)F</smiles>

13

Scheme 3-3: Synthesis of a small series of $\mathrm{Ag}($ benzoate) complexes.

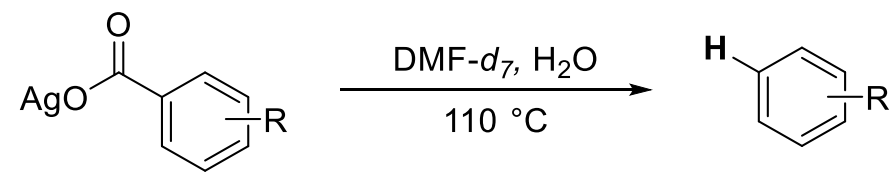

Scheme 3-4: The protodecarboxylation of substituted Ag(benzoate) complexes in DMF- $d_{7}$ at 110 ${ }^{\circ} \mathrm{C}$. 

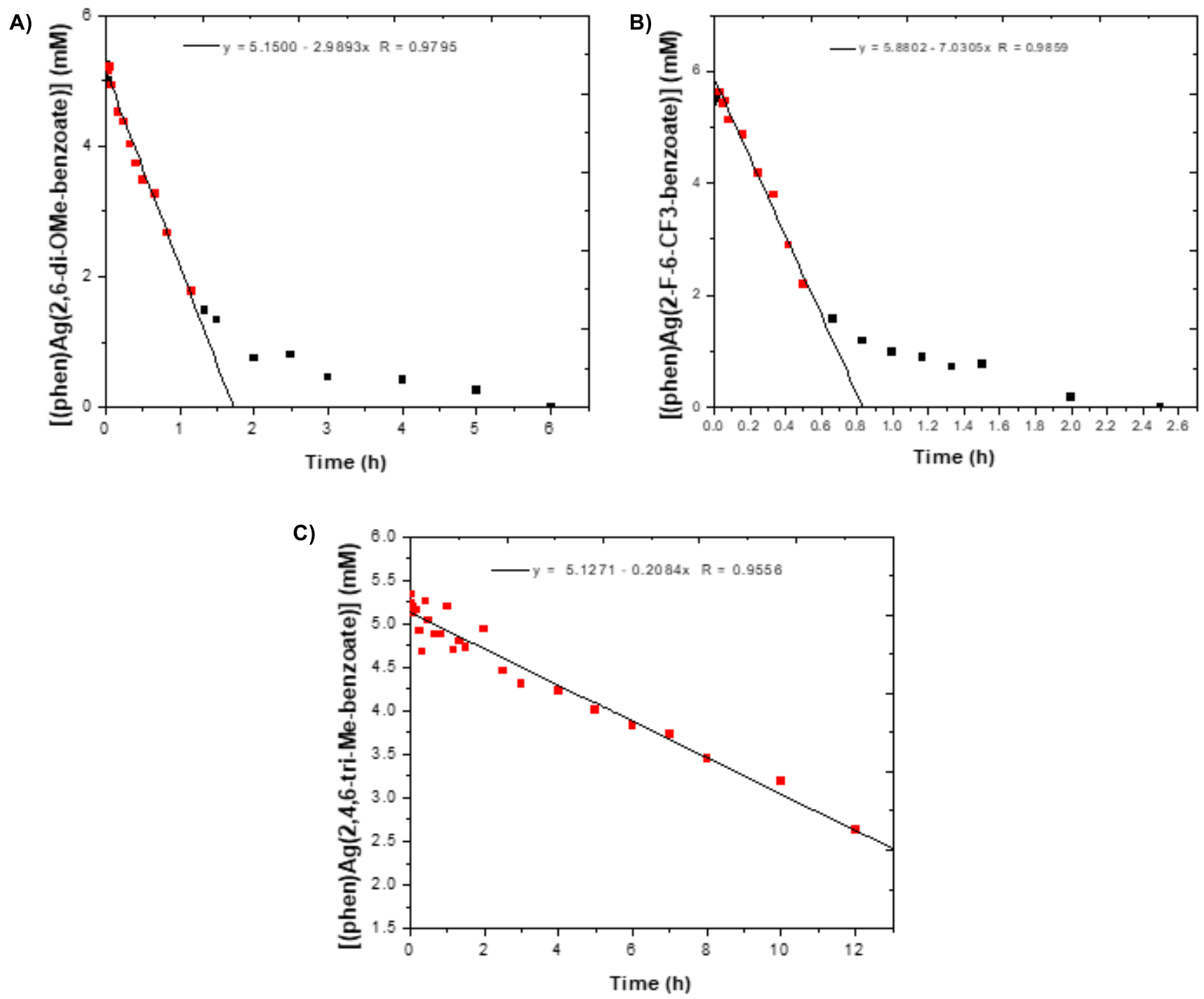

Figure 3-4: ${ }^{1} \mathrm{H}$ NMR spectroscopy reaction time courses for the decarboxylation of $\mathrm{A}$ ) (phen) $\mathrm{Ag}\left(2,6\right.$-di-OMe-benzoate) (1) $\left.\left(5.23 \mathrm{mM} ; k=0.57 \mathrm{~h}^{-1}\right) \mathrm{B}\right)$ (phen) $\mathrm{Ag}\left(2-\mathrm{F}-6-\mathrm{CF}_{3}\right.$-benzoate) (2) $\left(5.90 \mathrm{mM} ; k=1.19 \mathrm{~h}^{-1}\right)$ and C) (phen) $\mathrm{Ag}\left(2,4,6\right.$-Me-benzoate) (3) $\left(5.33 \mathrm{mM} ; k=0.04 \mathrm{~h}^{-1}\right)$ in DMF- $d_{7}$ at $110^{\circ} \mathrm{C}$. Red points indicate fit. 

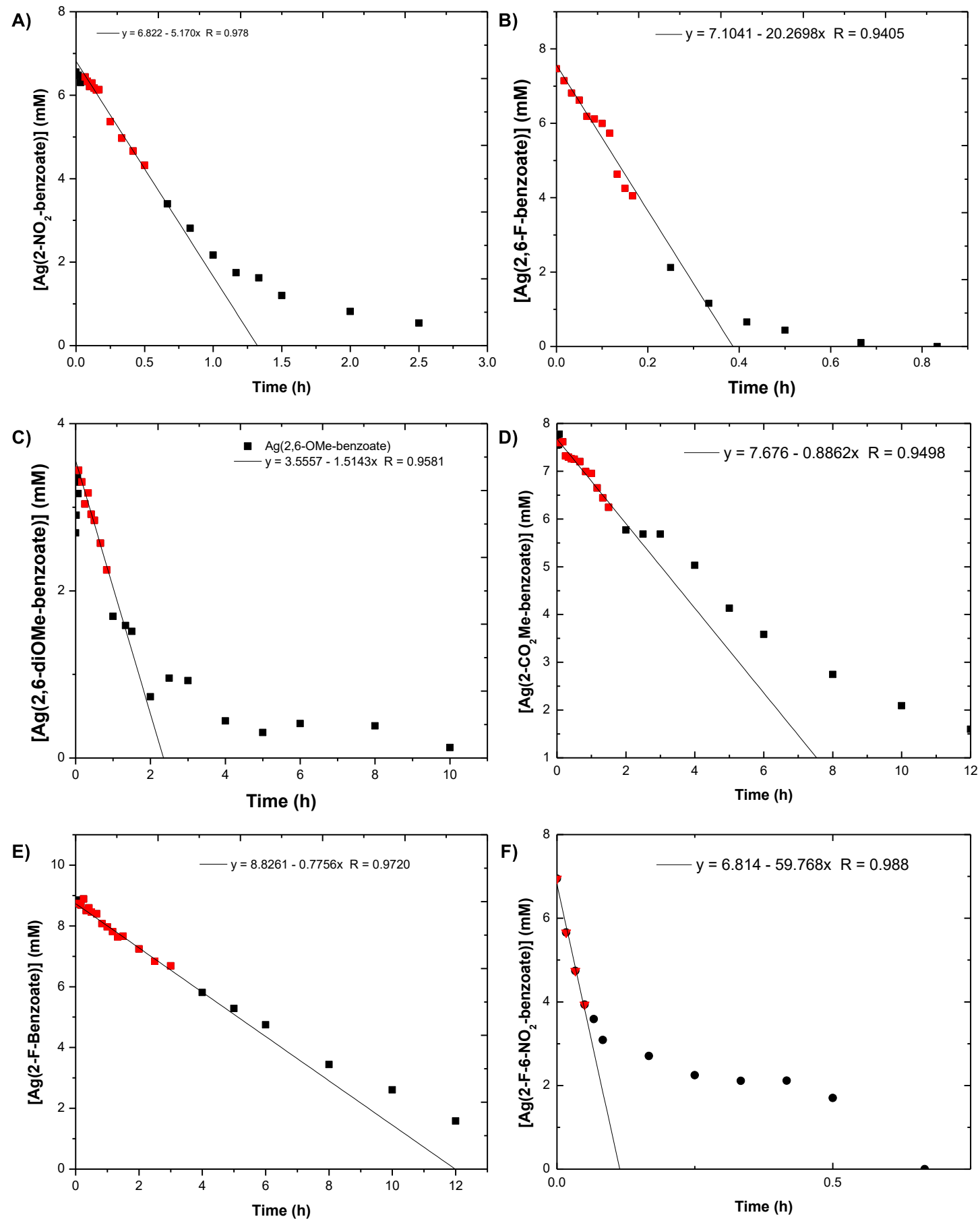

Figure 3-5: ${ }^{1} \mathrm{H}$ NMR spectroscopy reaction time courses for the decarboxylation of $\mathrm{A}$ ) $\mathrm{Ag}\left(2-\mathrm{NO}_{2}\right.$-benzoate) (4) $\left.\left(6.55 \mathrm{mM} ; k=0.79 \mathrm{~h}^{-1}\right) \mathrm{B}\right) \mathrm{Ag}(2,6-\mathrm{F}$-benzoate) (5) (7.47 mM; $k=2.71$ $\left.\left.\mathrm{h}^{-1}\right) \mathrm{C}\right) \mathrm{Ag}\left(2,6-\mathrm{OMe}\right.$-benzoate) (6) $\left.\left(2.96 \mathrm{mM} ; k=0.51 \mathrm{~h}^{-1}\right) \mathrm{D}\right) \mathrm{Ag}\left(2-\mathrm{CO}_{2} \mathrm{Me}\right.$-benzoate) (7) (7.77 $\left.\mathrm{mM} ; \quad k=0.11 \mathrm{~h}^{-1}\right)$ E) of $\mathrm{Ag}(2$-F-benzoate $)(8)\left(8.88 \mathrm{mM} ; k=0.09 \mathrm{~h}^{-1}\right)$ and $\left.\mathrm{F}\right)$ $\mathrm{Ag}\left(2-\mathrm{F}-6-\mathrm{NO}_{2}\right.$-benzoate) (9) $\left(6.95 \mathrm{mM} ; k=8.60 \mathrm{~h}^{-1}\right)$ in $\mathrm{DMF}-d_{7}$ at $110{ }^{\circ} \mathrm{C}$. Red points indicate fit. 

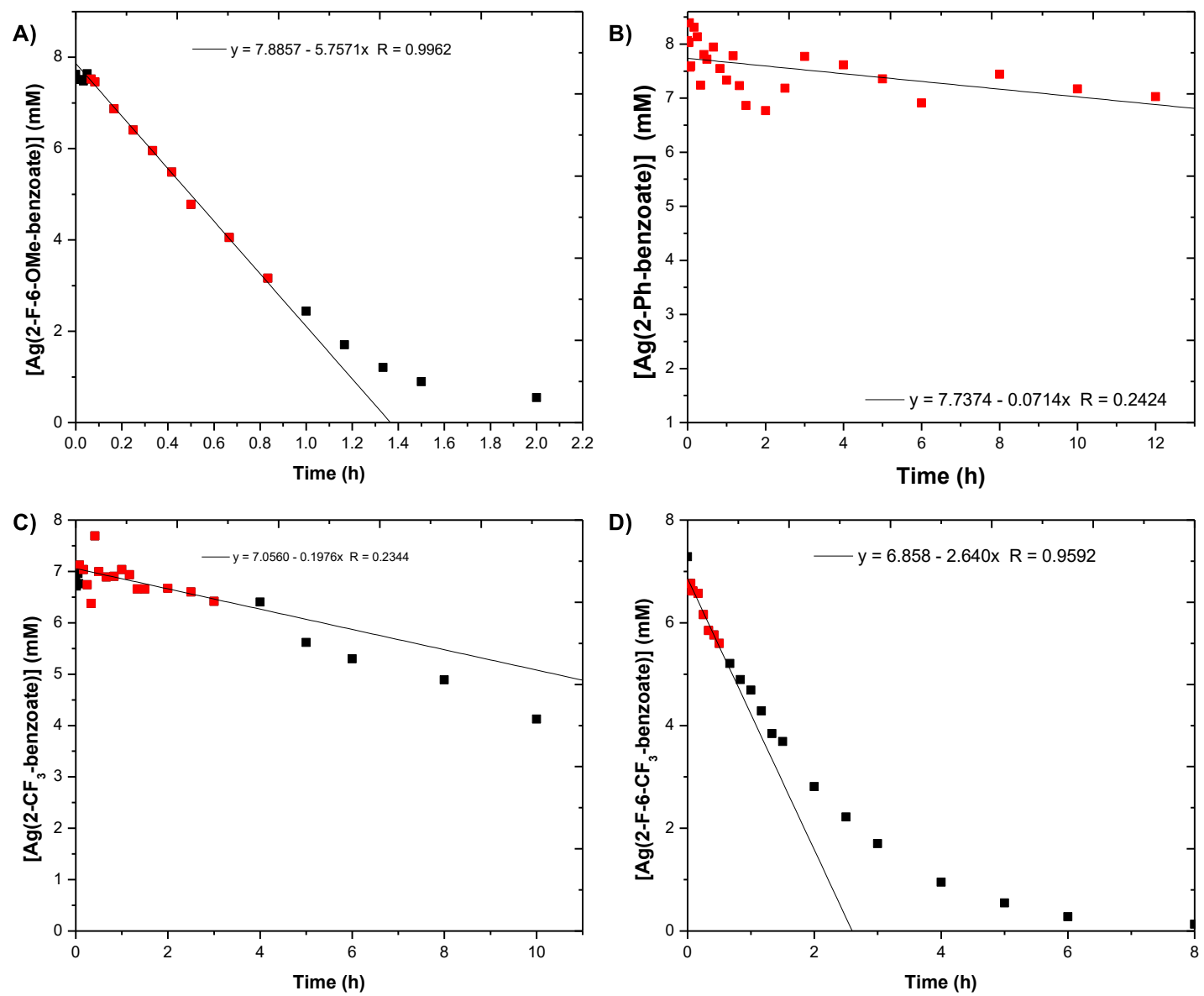

Figure 3-6: ${ }^{1} \mathrm{H}$ NMR spectroscopy reaction time course for the decarboxylation of $\mathrm{A}$ ) $\mathrm{Ag}(2-\mathrm{F}-6-\mathrm{OMe}-$ benzoate $\left.)(\mathbf{1 0})\left(6.50 \mathrm{mM} ; k=0.89 \mathrm{~h}^{-1}\right) \mathrm{B}\right) \mathrm{Ag}(2-\mathrm{Ph}$-benzoate $)(\mathbf{1 1})(8.39 \mathrm{mM}$; $\left.\left.k=0.01 \mathrm{~h}^{-1}\right) \quad \mathrm{C}\right) \quad$ of $\mathrm{Ag}\left(2-\mathrm{CF}_{3}\right.$-benzoate $) \quad(\mathbf{1 2}) \quad\left(7.69 \mathrm{mM} ; \quad k=0.03 \mathrm{~h}^{-1}\right)$ and $\left.\mathrm{D}\right)$ $\mathrm{Ag}\left(2-\mathrm{F}-6-\mathrm{CF}_{3}\right.$-benzoate $)(\mathbf{1 3})\left(7.28 \mathrm{mM} ; k=0.36 \mathrm{~h}^{-1}\right)$ in $\mathrm{DMF}-d_{7}$ at $110^{\circ} \mathrm{C}$. Red points indicate fit. 
Table 3-7: Kinetic data for the decarboxylation of $\mathrm{Ag}($ benzoate) complexes.

\begin{tabular}{|c|c|c|c|c|c|}
\hline $\begin{array}{l}\text { Complex } \\
\text { Number }\end{array}$ & Complex & Rate $\left(\mathbf{m M} \cdot \mathbf{h}^{-1}\right)$ & $\begin{array}{c}\text { Concentration } \\
(\mathrm{mM})\end{array}$ & $\begin{array}{c}\text { Rate Constant } \\
\left(h^{-1}\right)\end{array}$ & Fortho \\
\hline 4 & $\overline{\mathrm{Ag}}\left(2-\mathrm{NO}_{2}\right.$-benzoate $)$ & $5.17 \pm 0.08$ & 6.55 & 0.79 & 0.65 \\
\hline 5 & $\operatorname{Ag}(2,6-F-b e n z o a t e)$ & $20.27 \pm 0.90$ & 7.47 & 2.71 & 0.90 \\
\hline 6 & $\mathrm{Ag}(2,6-\mathrm{OMe}$-benzoate $)$ & $1.51 \pm 0.08$ & 2.96 & 0.51 & 0.58 \\
\hline 7 & $\mathrm{Ag}$ (2-COOMe-benzoate) & $0.89 \pm 0.09$ & 7.77 & 0.11 & 0.34 \\
\hline 8 & Ag(2-F-benzoate) & $0.78 \pm .01$ & 8.88 & 0.09 & 0.45 \\
\hline 9 & $\mathrm{Ag}\left(2-\mathrm{F}-6-\mathrm{NO}_{2}\right.$-benzoate $)$ & $59.77 \pm 5.90$ & 6.95 & 8.60 & 1.10 \\
\hline 10 & $\mathrm{Ag}(2-\mathrm{F}-6-\mathrm{OMe}$-benzoate $)$ & $5.76 \pm 0.80$ & 6.50 & 0.89 & 0.74 \\
\hline 11 & $\operatorname{Ag}(2-\mathrm{Ph}$-benzoate $)$ & $0.07 \pm 0.002$ & 8.39 & 0.01 & 0.12 \\
\hline 12 & $\mathrm{Ag}\left(2-\mathrm{CF}_{3}\right.$-benzoate $)$ & $0.20 \pm 0.09$ & 7.69 & 0.03 & 0.38 \\
\hline 13 & $\mathrm{Ag}\left(2-\mathrm{F}-6-\mathrm{CF}_{3}\right.$-benzoate $)$ & $2.60 \pm 0.3$ & 7.28 & 0.36 & 0.83 \\
\hline
\end{tabular}

Table 3-8: Kinetic data for the decarboxylation of (phen) $\mathrm{Ag}$ (benzoate complexes as a comparison. Data is from reference ${ }^{[142]}$.

\begin{tabular}{ccccc}
\hline Complex & Rate $\left(\mathbf{m M}^{-\mathbf{1}}\right)$ & $\begin{array}{c}\text { Concentration } \\
(\mathbf{m M})\end{array}$ & $\begin{array}{c}\text { Rate Constant } \\
\left(\mathbf{h}^{\mathbf{1}}\right)\end{array}$ & Fortho \\
\hline (phen) $\mathrm{Ag}\left(2-\mathrm{NO}_{2}\right.$-benzoate) & $7.13 \pm 0.05$ & 5.50 & 1.30 & 0.65 \\
(phen) $\mathrm{Ag}(2,6-\mathrm{di}-\mathrm{OMe}$-benzoate) & $2.99 \pm 0.16$ & 5.23 & 0.57 & 0.58 \\
(phen) $\mathrm{Ag}\left(2-\mathrm{F}-6-\mathrm{CF}_{3}\right.$-benzoate) & $7.03 \pm 0.25$ & 5.90 & 1.19 & 0.83 \\
(phen) $\mathrm{Ag}(2,4,6-\mathrm{Me}-$ benzoate) & $0.21 \pm 0.07$ & 5.33 & 0.04 & 0.02 \\
(phen) $\mathrm{Ag}(2,6-\mathrm{F}$-benzoate) & $46.54 \pm 2.61$ & 8.26 & 5.63 & 0.90 \\
(phen) $\mathrm{Ag}(2-\mathrm{F}-$ benzoate) & $3.09 \pm 0.06$ & 8.19 & 0.38 & 0.45 \\
(phen) $\mathrm{Ag}\left(2-\mathrm{F}-6-\mathrm{NO}_{2}\right.$-benzoate) & $104.12 \pm 1.88$ & 8.57 & 12.12 & 1.10 \\
(phen) $\mathrm{Ag}\left(2-\mathrm{CF}_{3}\right.$-benzoate) & $0.86 \pm 0.03$ & 8.86 & $9.71 \times 10^{-2}$ & 0.38 \\
\hline
\end{tabular}

Plotting $\log (k)$ vs $\mathrm{F}$ of the $\operatorname{Ag}($ benzoate) complexes shows good correlation with our previous data; ${ }^{[142]}$ however, the unligated complexes appear to decarboxylate at slightly lower rates 
(Figure 3-7A). This observation is consistent with the results previously reported by the Hoover group. ${ }^{[58]}$ However, a statistical analysis of a set of (phen) $\mathrm{Ag}$ (benzoate) complexes with their unligated counterparts, shows that the rates of decarboxylation are not statistically different. This suggests that the phenanthroline ligand has no effect on the rate of decarboxylation (Figure 3-7B). The unligated $\mathrm{Ag}$ (benzoate) complexes decarboxylate with similar rates and reaction profiles to their corresponding (phen) $\operatorname{Ag}$ (benzoate) complexes. With this realization, we hypothesized that the unligated $\mathrm{Ag}$ (heteroaromatic carboxylate) complexes would undergo decarboxylation in the absence of the phenanthroline ligand. In addition, we hypothesized that the unligated $\mathrm{Ag}$ (heteroaromatic carboxylates) would be more soluble than their phenanthroline ligated counterparts. Due to this hypothesis, we elected to use unligated $\mathrm{Ag}$ (carboxylate) complexes to continue the study. 

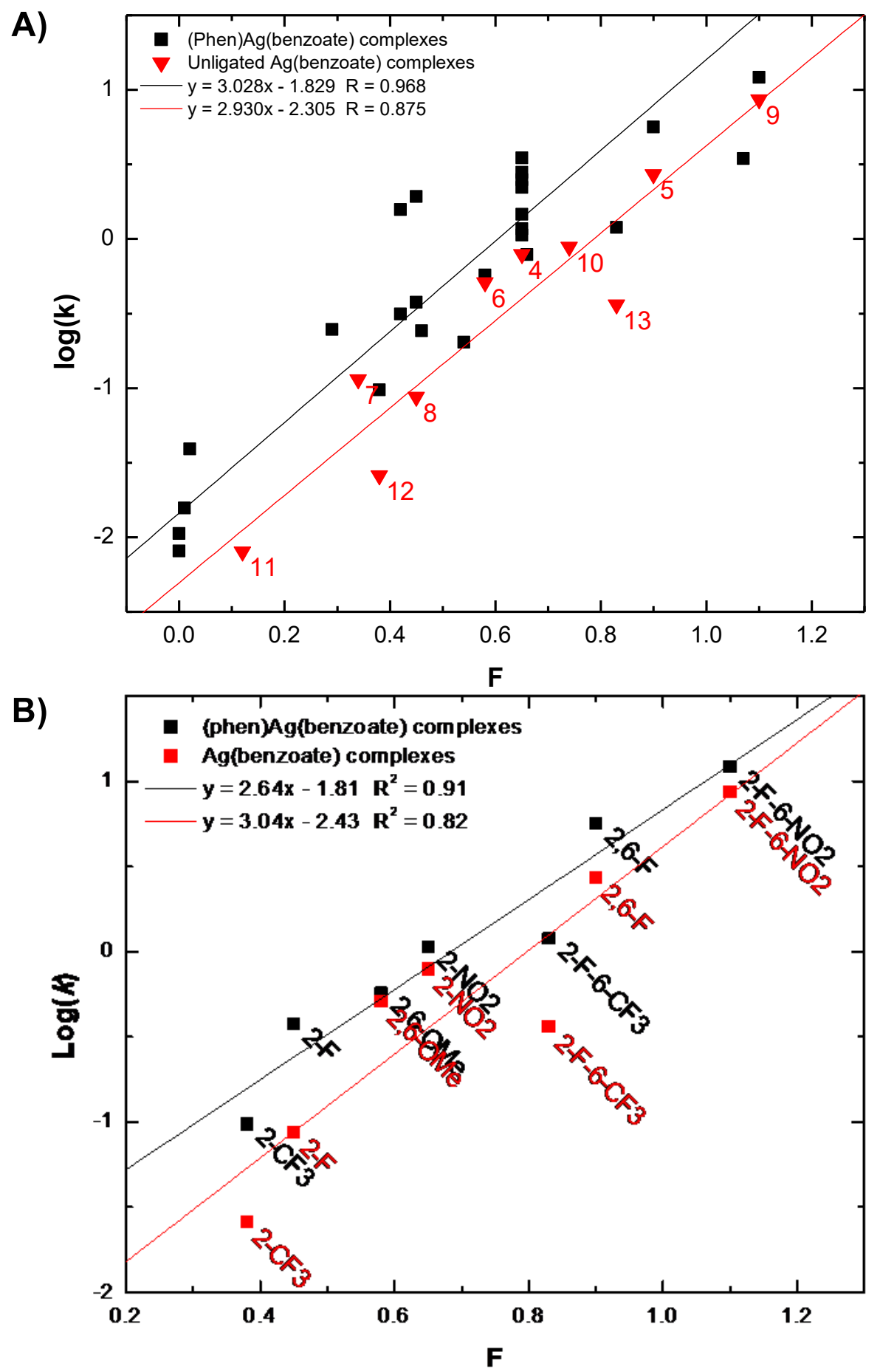

Figure 3-7: A comparison of the 1,10-phenanthroline ligated silver benzoate complexes and the unligated silver benzoate complexes. A) The trends based on the full data set collected. Data for the (phen) $\mathrm{Ag}$ (benzoate) complex series is from reference ${ }^{[142]}$. B) A subset of the data set allowing for the direct comparison of the rates of decarboxylation between (phen)Ag(benzoate) and $\mathrm{Ag}($ benzoate $)$ complexes. 
A small subset of heteroaromatic systems were selected based off the literature precedent for their use in decarboxylation reactions (pyridine, benzofuran, benzothiophene, oxazole, thiazole, pyrazole, and triazole). Heteroaromatic carboxylic acids were then selected to probe the electronic and steric influence in each system. Based on this scope of carboxylic acids, a series of $\operatorname{Ag}$ (heteroaromatic carboxylate) complexes were synthesized to be used as a testing set. These complexes were synthesized by the slow addition of an aqueous solution of silver nitrate to a solution of the heteroaromatic carboxylic acid and triethyl amine (or sodium hydroxide) in 1,10dioxane. The desired $\operatorname{Ag}($ heteroaromatic carboxylate) complexes were isolated via filtration and dried under vacuum (Scheme 3-5, for further details, see the experimental section 3-4).

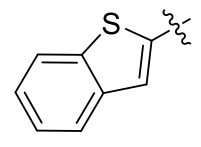

$14,92 \%$<smiles>[Z10]c1cccnc1C(F)(F)F</smiles>

$21,18 \%$<smiles>Cc1nc(-c2ccccc2)sc1C</smiles>

27, $97 \%$

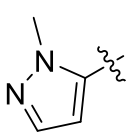

$32,84 \%$

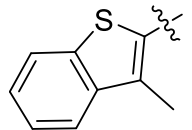

$15,77 \%$<smiles>FC(F)(F)c1ccnc([Tl])c1</smiles>

22, $81 \%$<smiles>[Y]c1sc(C)nc1C</smiles>

28, $60 \%$

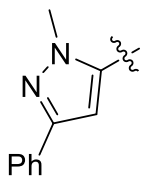

$33,58 \%$

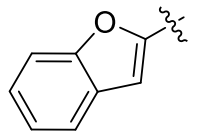

16, $50 \%$<smiles>[Y]c1cc(Cl)ccn1</smiles>

23, $90 \%$<smiles>COc1ccc(-c2nc(C)c(C)s2)cc1</smiles>

29, $69 \%$

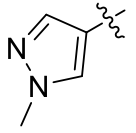

$34,71 \%$

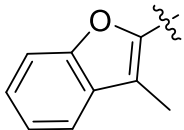

$17,74 \%$<smiles>FC(F)(F)c1ccncc1I</smiles>

$24,73 \%$<smiles>[Y]c1ccccn1</smiles>

$18,74 \%$

19, $74 \%$<smiles>[Y]c1oc(-c2ccccc2)nc1C</smiles>

25, $33 \%$<smiles>Cc1nc(-c2ccc(Cl)cc2)sc1C</smiles>

$30,59 \%$<smiles>[Y]c1ccncc1</smiles>

$20,66 \%$<smiles>[Y]c1oc(C)nc1C</smiles>

26, $87 \%$

31, $76 \%$

Scheme 3-5: Synthesis of the series of $\mathrm{Ag}$ (heteroaromatic carboxylates) used in this study. 
Initial attempts to monitor the decarboxylation by NMR spectroscopy shows incomplete dissolution of some of the $\mathrm{Ag}$ (heteroaromatic carboxylates) on the NMR scale. As an example, monitoring the decarboxylation of a $2.2 \mathrm{mg}$ sample of the silver(oxazole-5-carboxylate) 25 in DMF- $d_{7}(1 \mathrm{~mL} ; 7.10 \mathrm{mM} \mathrm{25})$ with $0.7 \mathrm{mM} \mathrm{H}_{2} \mathrm{O}$ at $110^{\circ} \mathrm{C}$ shows the incomplete dissolution of 25 with concurrent decarboxylation (Figure 3-7A). Upon attempting to lower the concentration by a factor of two $\left(1.1 \mathrm{mg} 25 \mathrm{in} \mathrm{DMF-} d_{7}(1 \mathrm{~mL} ; 3.55 \mathrm{mM} 25)\right.$ ), the rate of product formation did not change (Figure 3-7B). Since incomplete dissolution was observed on the NMR scale, we hypothesized that collecting reaction aliquots from a bulk reaction would allow for further dilution to achieve complete dissolution of the $\mathrm{Ag}$ (heteroaromatic carboxylate). Due to this, high-performance liquid chromatography (HPLC) was chosen for the analysis of the reaction aliquots. In addition to allowing for complete dissolution of the $\mathrm{Ag}$ (heteroaromatic carboxylate), we hypothesized that utilizing HPLC as an analytical technique would offer better reproducibility as the reactions are scaled up allowing for larger amounts of the complex to be used and thus reducing the error associated with measuring such small quantities.

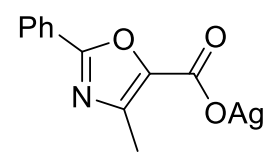

A)

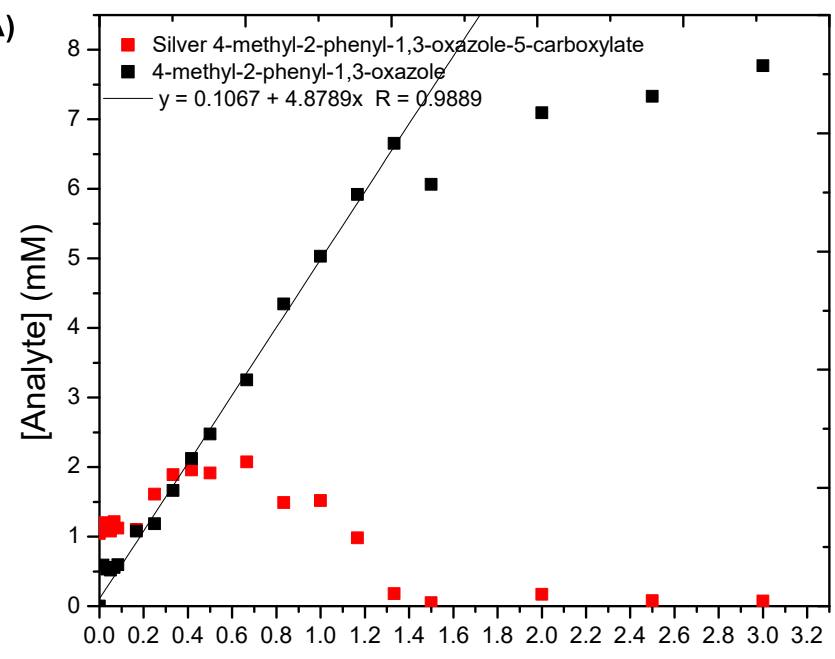

Time (h)

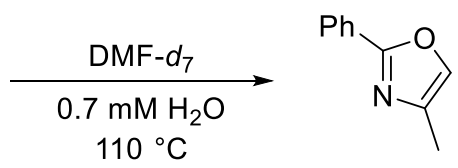

B)

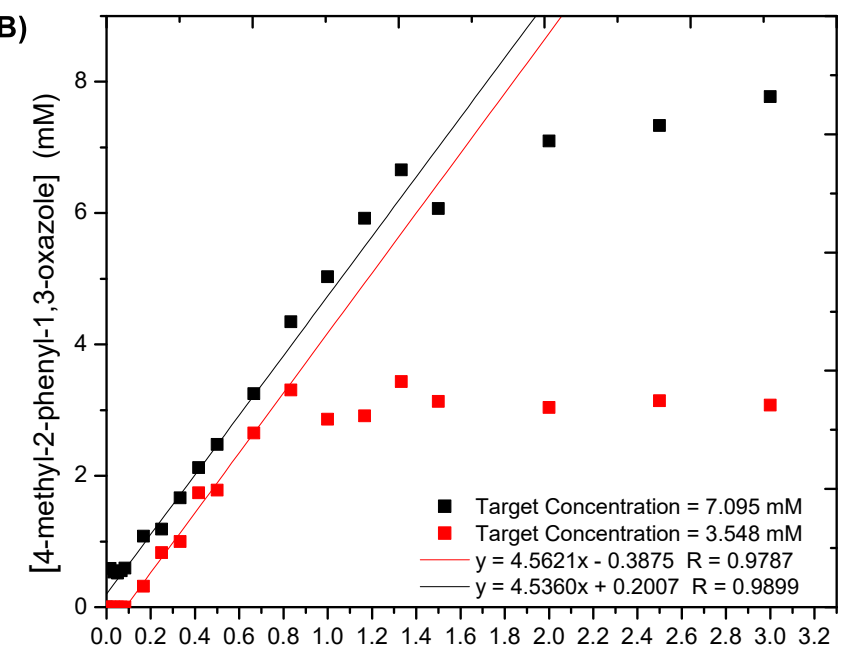

Time (h)

Figure 3-8: A) The reaction profile of the decarboxylation of 25 monitored by ${ }^{1} \mathrm{H}$ NMR spectroscopy. B) The reaction profiles of the product formation of the decarboxylation of $\mathbf{2 5}$ from two different trials. 
Before measuring reaction kinetics, an HPLC method first had to be developed and calibrated (See experimental section for additional details, Section 3-4). After developing analytical methods, kinetics were run by dissolving $32.0 \mu \mathrm{mol}$ of the $\mathrm{Ag}$ (heteroaromatic carboxylate) and 1,3,5-trimethoxybenzene (10.1 mg, $54.2 \mu \mathrm{mol})$ in $20 \mathrm{~mL}$ DMF under $\mathrm{N}_{2}$ and spiked with $0.6 \mu \mathrm{L}$ water $\left(1.62 \mathrm{mM} \mathrm{Ag}\right.$ (heteroaromatic carboxylate; $\left.1.5 \mathrm{mM} \mathrm{H}_{2} \mathrm{O}\right)$. The mixture was stirred at room temperature for 15 minutes to ensure complete dissolution of all solids. An initial aliquot was collected via syringe $(500 \mu \mathrm{L})$ and filtered through a $0.2 \mu \mathrm{m}$ PTFE syringe filter into $200 \mu \mathrm{L}$ vial insert within a chromatography vial. The reaction flask was then dipped into a $110{ }^{\circ} \mathrm{C}$ oil bath and allowed to stir. Additional aliquots were taken at 1, 2, 3, 4, 5, 10, 15, 20, 25, $30,40,50,60,70,80,90,120,150,180,240$, and 300 minutes and filtered through $0.2 \mu \mathrm{m}$ PTFE syringe filters into a $200 \mu \mathrm{L}$ vial inserts within a chromatography vials. The aliquot samples were then run using the respective HPLC method for the given complex. The initial rates were determined from a linear fit of the early reaction times of the time course plots, immediately after the induction period (a representative plot of the reaction profile is shown in Figure 3-9). 

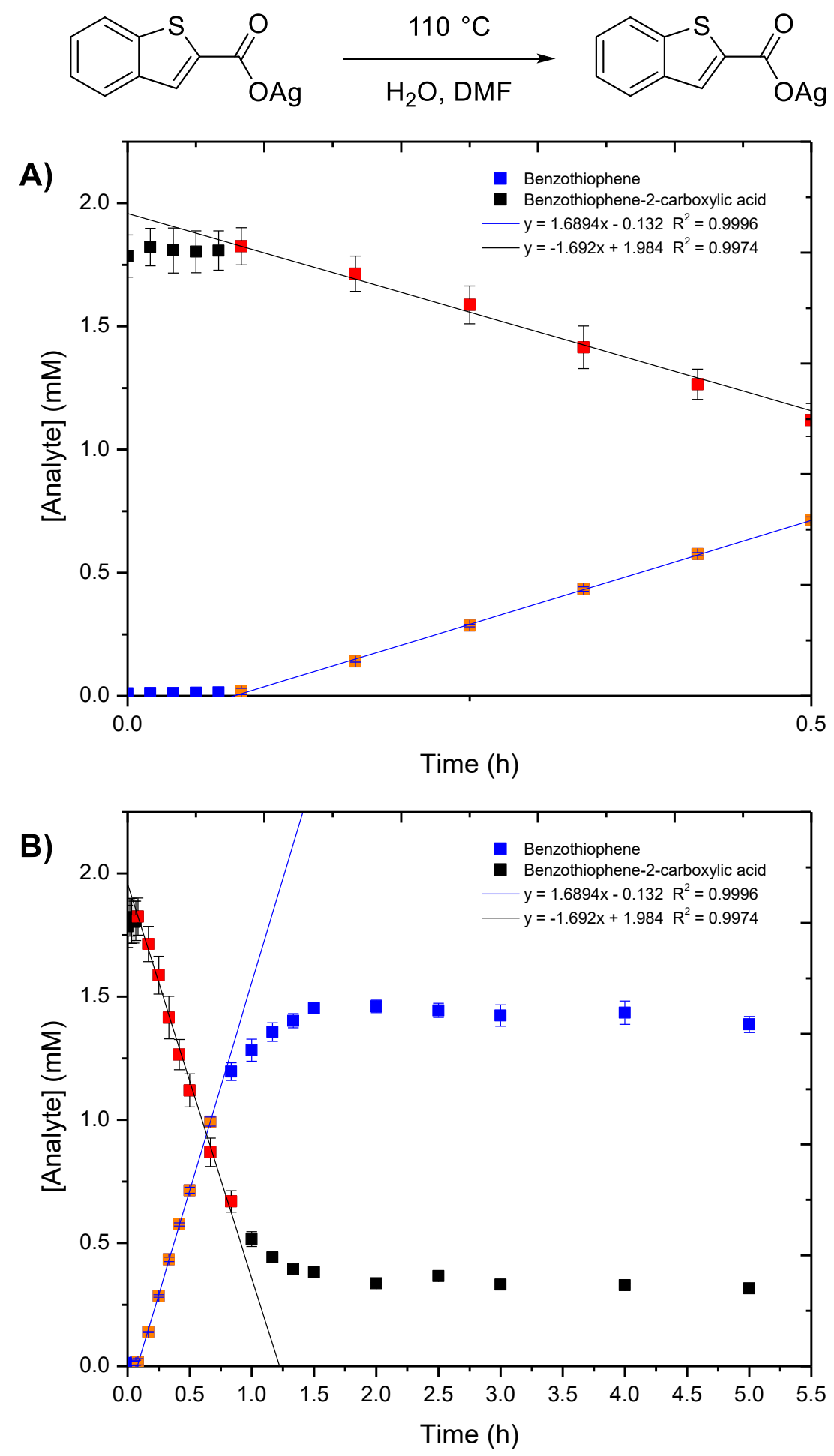

Figure 3-9: Reaction profile of the decarboxylation of $\mathbf{1 4}(1.828 \mathrm{mM})$ in DMF- $d_{7}$ at $110{ }^{\circ} \mathrm{C}$. A) Early reaction times and B) the full-time course. Red points indicate fit of the carboxylate. Orange points indicate fit of the arene. 
Table 9: Tabulated data for the decarboxylation of $\mathrm{Ag}$ (heteroaromatic carboxylate) complexes by HPLC.

\begin{tabular}{cccc}
\hline Complex & Rate $\left(\mathbf{m M} \cdot \mathbf{h}^{\mathbf{- 1}}\right)$ & Concentration $(\mathbf{m M})$ & Rate Constant $\left(\mathbf{h}^{\mathbf{- 1}}\right)$ \\
\hline $\mathbf{1 4}$ & 1.689 & 1.828 & 0.924 \\
$\mathbf{1 5}$ & 1.540 & 1.833 & 0.840 \\
$\mathbf{1 6}$ & 0.805 & 2.003 & 0.402 \\
$\mathbf{1 7}$ & 1.427 & 1.599 & 0.892 \\
$\mathbf{1 8}$ & 0.016 & 2.251 & 0.007 \\
$\mathbf{2 1}$ & 0.503 & 1.633 & 0.308 \\
$\mathbf{2 3}$ & 0.008 & 1.659 & 0.005 \\
\hline
\end{tabular}

$\dagger$ Due to the limited solubility of the silver carboxylate complex in DMF, the mixture of the silver complex, water, DMF, and 1,3,5-trimethoxybenzene was first stirred for 15 minutes at room temperature and then at $50{ }^{\circ} \mathrm{C}$ for 20 minutes prior to the initial time point.

Comparing the rate constants for the decarboxylation of silver carboxylates $\mathbf{1 4}, \mathbf{1 5}, \mathbf{1 6}$, and 17 suggests that the 3-methyl substituent may not a have significant influence on the rate of decarboxylation. This suggests that steric factors may not influence the rate of decarboxylation of heteroaromatic carboxylic acids, similar to our previous findings with (phen) $\mathrm{Ag}($ benzoate) complexes (Figure 3-10). Given that the field effect, a through-space electronic effect, is the predominate factor that determines the rate of decarboxylation of the (phen)Ag(benzoate) complexes with minimal steric influences, we hypothesized that a similar electronic effect could be controlling the decarboxylation of the $\mathrm{Ag}$ (heteroaromatic carboxylates). 

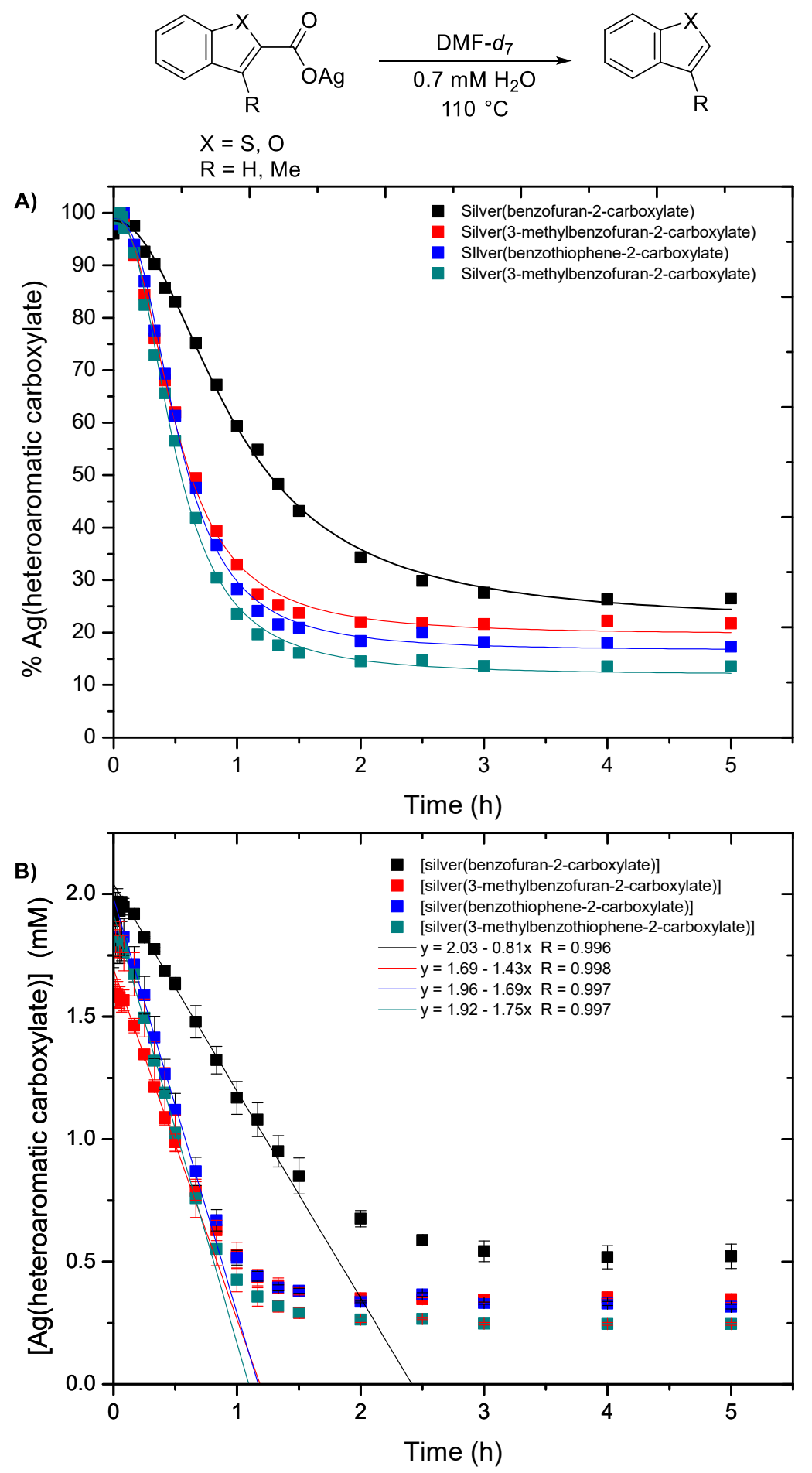

Figure 3-10: Kinetic profiles for the decarboxylation of 14, 15, 16 and 17. A) Reaction profile given as \% $\mathrm{Ag}$ (heteroaromatic carboxylate) over time. The traces are not fits and are only meant to guide the eye. B) Reaction time course data fit to provide the initial reaction rates. Standard conditions are $1.62 \mathrm{mM} \mathrm{Ag(heteroaromatic} \mathrm{carboxylate)} \mathrm{in} 20 \mathrm{~mL}$ DMF with $1.6 \mathrm{mM} \mathrm{H}_{2} \mathrm{O}$ at 110 ${ }^{\circ} \mathrm{C}$. 
Substituent effects, such as the field effect parameter, commonly allow for the convenient correlation of steric and/or electronic properties with reaction rates. Unfortunately, due to the variety of ring sizes, heteroatom configurations, and electronic of heteroarenes, widely used substituent parameters - such as the Hammett parameter or field effect parameter - cannot be correlated with the rate of decarboxylation of $\mathrm{Ag}$ (heteroaromatic carboxylate) complexes. However, electronic effects can also be described by several parameters such as the highest occupied molecular orbital (HOMO) and lowest unoccupied molecular orbital (LUMO) energies, dipole moments, and electrostatic potentials. To develop a linear free energy relationship to explain the trend observed in the rates of decarboxylation of $\mathrm{Ag}$ (heteroaromatic carboxylate) complexes could be a powerful addition to the overall understanding of the reactivity of heteroaromatic compounds. Since the rate of decarboxylation of $14,15,16$, and 17 suggest that the steric influences are minimal in these classes of heteroaromatic carboxylates. The rates of decarboxylation could be correlated with a survey of electronic parameters, including HOMO and LUMO energies, dipole moments, etc.

Next, attention was turned to $\mathrm{Ag}$ (heteroaromatic carboxylate) complexes featuring pyridine. The limited solubility of $\mathrm{Ag}$ (pyridine-2-carboxylate) (18) in DMF and the slow decarboxylation could account for the failure of this substrate to participate in other silver-mediated decarboxylative reactions (Figure 3-11). ${ }^{[18]}$ As shown previously in Figures 3-2 and 3-3, reports of both protodecarboxylation and decarboxylative coupling featuring pyridine carboxylic acids with electron withdrawing substituents or extended aromatic systems have been seen in the literature under similar reaction conditions. ${ }^{[18,19,36,49]}$ Intriguingly however, the $\mathrm{Ag}$ (4-chloropyridine-2-carboxylate) complex 23 (Figure 3-12) decarboxylates with a negligible rate. This result again suggests the importance of electronic effects in these reactions. Future experiments for these substrates will extend the number of aliquots to better represent the reaction profile. The addition of a trifluoromethyl group ortho- to the carboxylate in the pyridine system allows for the decarboxylation of $\mathrm{Ag}$ (2-trifluoromethylpyridine-3-carboxylate) complex $\mathbf{2 1}$ (Figure 3-12). 


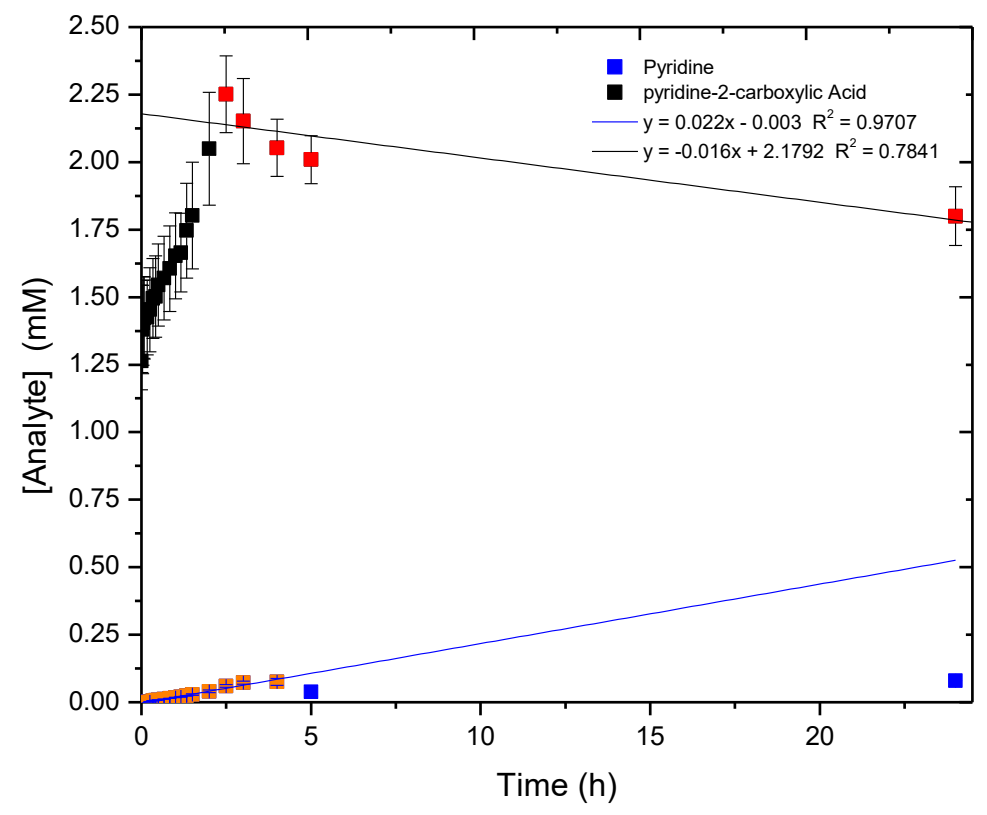

Figure 3-11: HPLC reaction time course for the decarboxylation of $18(2.251 \mathrm{mM} ; k=0.007)$ in $\mathrm{DMF}$ at $110^{\circ} \mathrm{C}$. Red points indicate fit of the carboxylate. Orange points indicate fit of the arene.

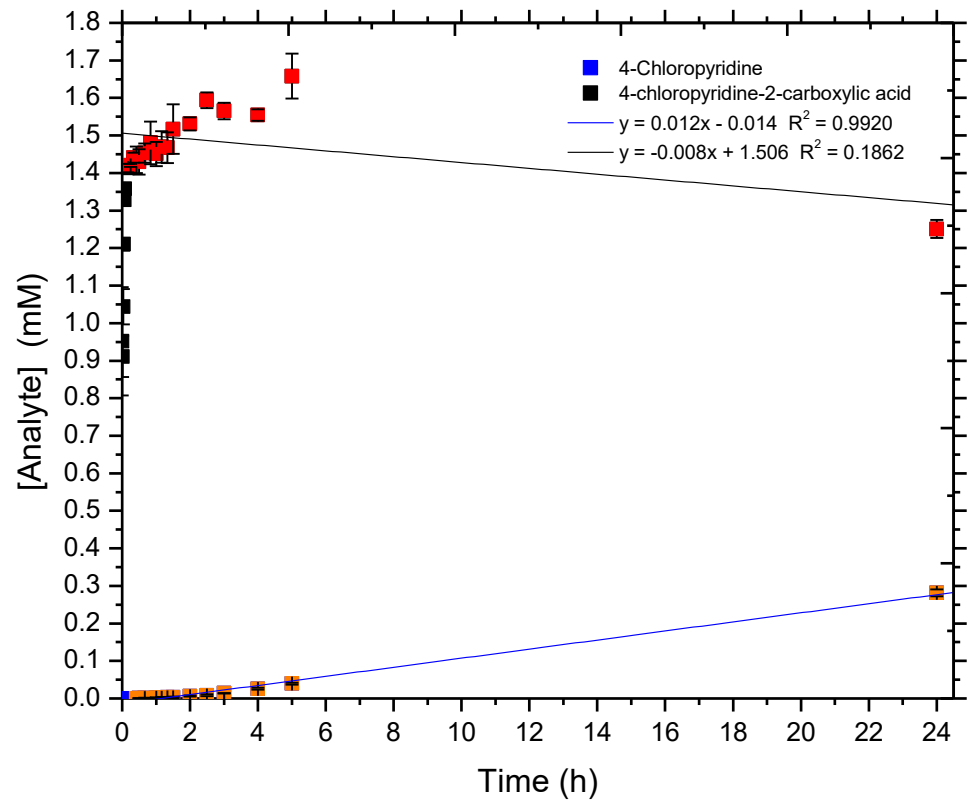

Figure 3-12: HPLC reaction time course for the decarboxylation of $23(1.659 \mathrm{mM} ; k=0.005)$ in $\mathrm{DMF}$ at $110^{\circ} \mathrm{C}$. Red points indicate fit of the carboxylate. Orange points indicate fit of the arene. 


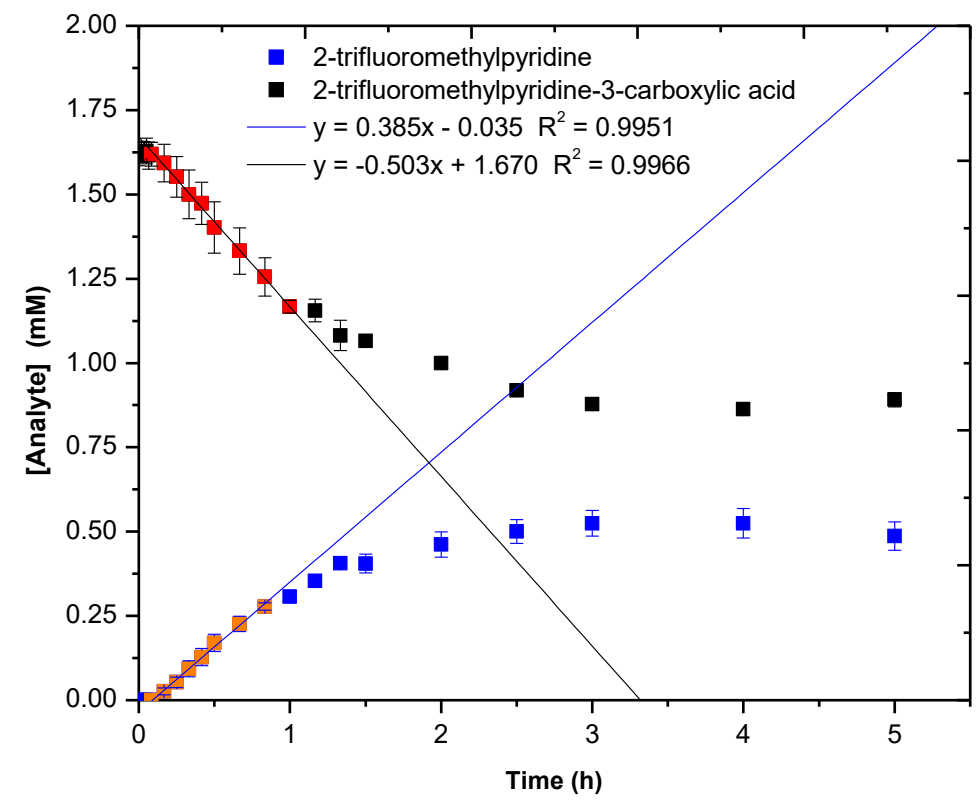

Figure 3-13: HPLC reaction time course for the decarboxylation of $21(1.633 \mathrm{mM} ;=0.308)$ in $\mathrm{DMF}$ at $110^{\circ} \mathrm{C}$. Red points indicate fit of the carboxylate. Orange points indicate fit of the arene.

As seen from the rates of decarboxylation of 14, 15, 16, 17, 18, 21, and 23, the steric influence on the decarboxylation of $\mathrm{Ag}$ (heteroaromatic carboxylate) complexes is minimal. As with the previously studied (phen)Ag(benzoate) complexes, it is hypothesized that electronic influences must be the dominating factor. From this, molecular electronic properties may adequately describe the reactivity seen for the $\mathrm{Ag}$ (heteroaromatic carboxylate) complexes. Initially, the $\mathrm{C}=\mathrm{O}$ stretching frequency obtained from IR spectroscopy, ${ }^{[143,144]}$ the carbonyl signal from ${ }^{13} \mathrm{C}$ NMR spectroscopy, the DFT calculated highest occupied molecular orbital $\left(\right.$ HOMO) ${ }^{[145,146]}$ lowest unoccupied molecular orbital (LUMO) ${ }^{[146]}$ energies, and the dipole magnitude ${ }^{[145-148]}$ of the heteroaromatic carboxylic acids were considered as parameters that could be used to correlate electronics with the rate of decarboxylation in a univariant method (Table 310). Attempting to correlate these parameters with our small preliminary data set shows no univariate correlation with $\mathrm{C}=\mathrm{O}$ stretching frequency, carbonyl signal from ${ }^{13} \mathrm{C} N M R$ Spectroscopy, or the calculated LUMO energy (Figure 3-14A, B, D). Intriguingly, even with this small data set, the HOMO energy and magnitude of the dipole moment show a moderate positive correlation (Figure 3-14C and E). Additionally the polarizability and electrostatic 
potentials ${ }^{[147,148]}$ could also be important parameters for correlation of the rates of decarboxylation to investigate in the future.

Table 3-10: Molecular properties of a small set of heteroaromatic carboxylic acids.

\begin{tabular}{|c|c|c|c|c|c|}
\hline $\begin{array}{l}\text { Carboxylic } \\
\text { Acid }\end{array}$ & $\begin{array}{l}\mathrm{C}=\mathrm{O} \text { Stretching } \\
\text { Frequency }\left(\mathrm{cm}^{-1}\right)\end{array}$ & $\begin{array}{c}{ }^{13} \mathrm{C} \text { NMR } \\
\text { Carbonyl } \\
\text { Signal (ppm) }\end{array}$ & $\begin{array}{c}\text { HOMO } \\
\begin{array}{c}\text { Energy } \\
\left(\mathrm{kcal}^{\mathrm{k}} \mathrm{mol}^{-1}\right)^{\dagger}\end{array}\end{array}$ & $\begin{array}{c}\text { LUMO } \\
\text { Energy } \\
\left({\left.\text { kcal } \cdot \mathbf{m o l}^{-1}\right)^{\dagger}}^{\dagger}\right.\end{array}$ & $\begin{array}{c}\text { Dipole } \\
\text { Magnitude } \\
\text { (Debye) }^{\dagger}\end{array}$ \\
\hline 14 & 1659.73 & 164.45 & -149.5107 & -45.6114 & 5.14806 \\
\hline 15 & 1640.15 & 166.40 & -145.5005 & -42.4706 & 5.37588 \\
\hline 16 & 1675.50 & 161.00 & -154.9899 & -42.9272 & 5.16944 \\
\hline 17 & 1672.61 & 165.07 & -151.3717 & -39.6365 & 5.45294 \\
\hline 18 & 1711.93 & 166.25 & -165.6831 & -39.2629 & 3.72126 \\
\hline 21 & 1721.98 & 166.60 & -177.6769 & -46.7207 & 6.32568 \\
\hline 23 & 1693.98 & 162.70 & -169.0407 & -44.7790 & 1.4835 \\
\hline
\end{tabular}

${ }^{\dagger}$ Calculated with Orca 4.0.1.2 at B3LYP level of theory. ${ }^{[149,150]}$ 

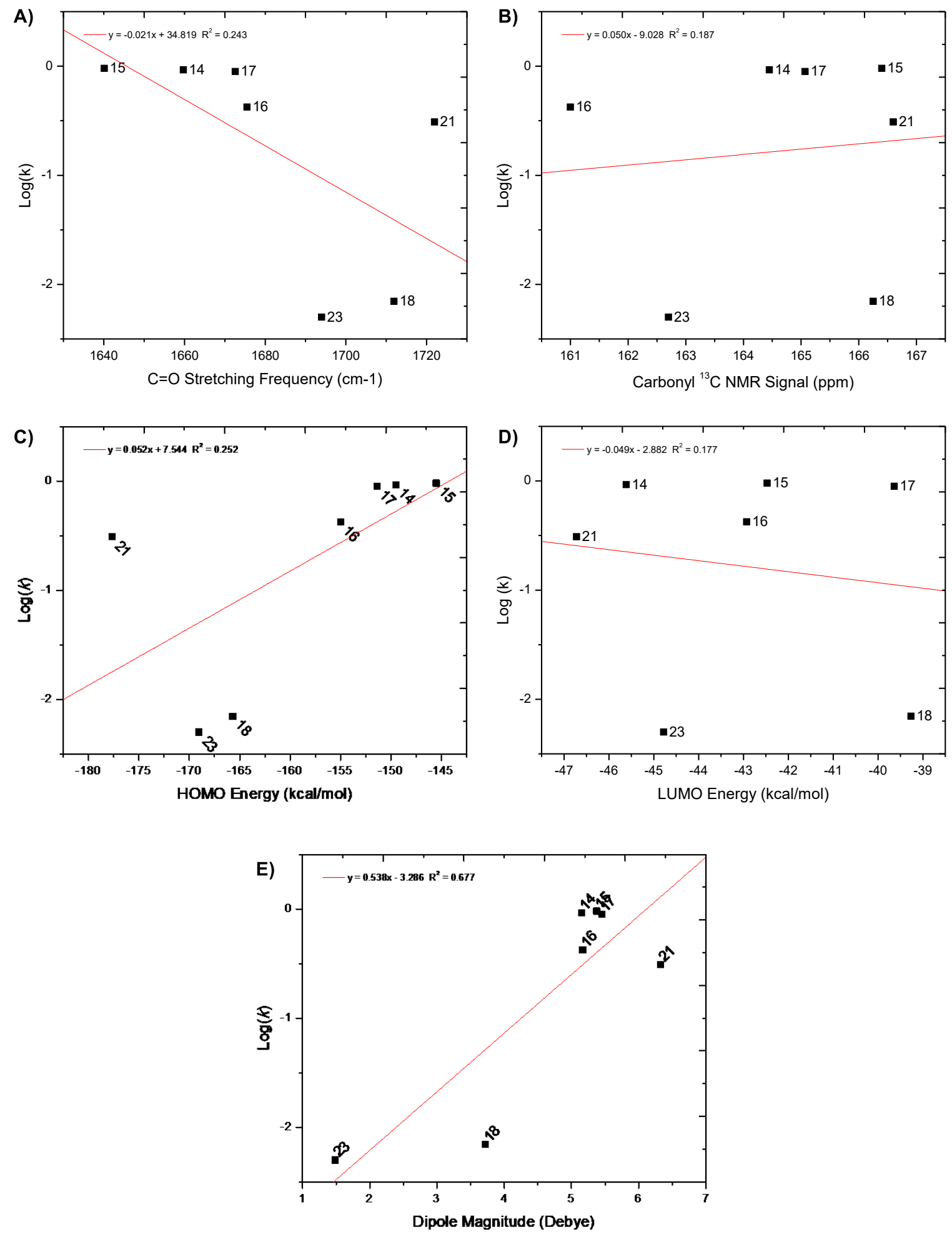

Figure 3-14: Preliminary data on the correlation of $\log (k)$ with $\mathrm{A}) \mathrm{C}=\mathrm{O}$ stretching frequencies, B) carbonyl ${ }^{13} \mathrm{C}$ signals, C) HOMO energies, D) LUMO energies and E) the magnitude of the dipole moment. 
Initially, a small set of 22 heteroaromatic carboxylic acids was used to study this transformation. These substrates largely represent the heteroaromatic carboxylic acids known to undergo decarboxylation reactions, ${ }^{[13,18,19,36,43,50,53,87,93,129-141]}$ however, this scope of carboxylic acids is incomplete given the desire to develop a model to predict the decarboxylation of a larger scope of heteroaromatic carboxylic acids. Given this, a more exhaustive scope of heteroaromatic acids based on commonly used pharmaceutically relevant cores ${ }^{[151]}$ is proposed in Figure 3-15. Within each of these heteroaromatic carboxylic acid systems, a range of electron-rich and electronpoor substituents will also be studied. This new extended scope will allow for modulation of electronic (and steric) properties allowing for further refinement of our model. By studying a broad scope of heteroaromatic carboxylic acid classes, it is hypothesized that a linear free energy relationship that can be used to predict the reactivity of heteroaromatic compounds over a large range of heterocycle classes, much like that of the Hammett equation for benzene based compounds, could be defined.
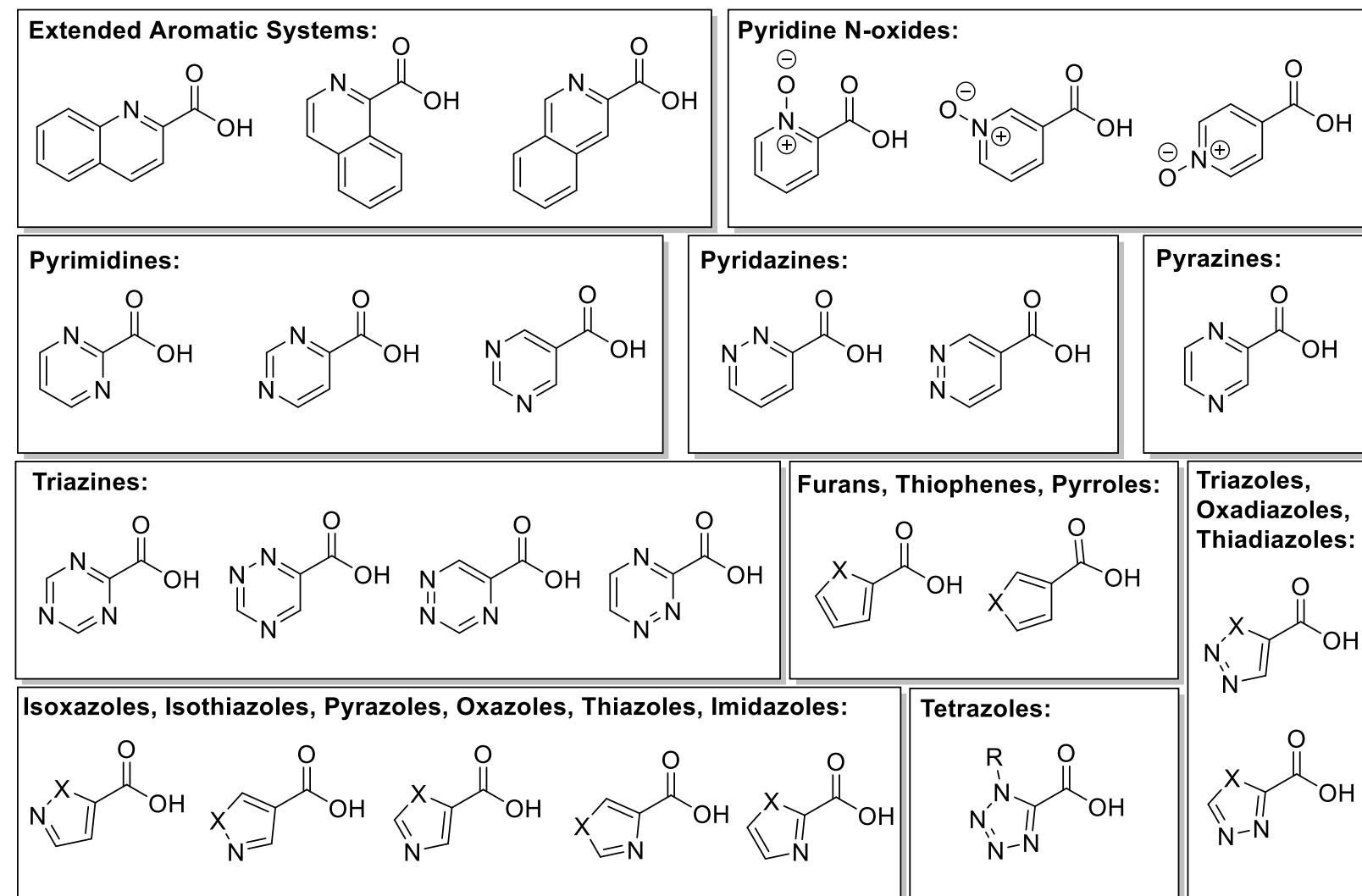

Pyrazines:

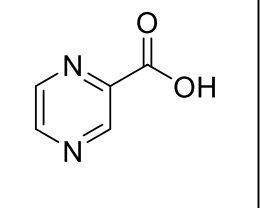

,
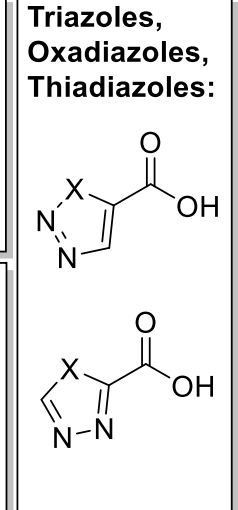

Figure 3-15: An expanded and more inclusive scope of heteroaromatic carboxylic acids proposed for the continuation of this study. $X=S, O, N M e$. 


\subsection{Conclusion}

In this chapter, a protocol to study the decarboxylation rates of various classes of $\mathrm{Ag}$ (heteroaromatic carboxylate) complexes was outlined and demonstrated. While this work is far from complete, the ability to use this methodology to monitor the protodecarboxylation of several complexes was established. This chapter shows promising progress toward our goal of understanding the key factors that influence the decarboxylation of heteroaromatic acids. More work is still underway to monitor a larger scope of $\mathrm{Ag}$ (heteroaromatic carboxylate) complexes as well as to identify electronic parameters that correlate with the reaction rates.

\subsection{Experimental}

\subsubsection{General Considerations.}

All decarboxylation reactions were performed under $\mathrm{N}_{2}$ and the reaction mixtures were either prepared in an inert-atmosphere glovebox or on the benchtop and placed under $\mathrm{N}_{2}$ through a series of 3 evacuations and backfilling with $\mathrm{N}_{2}$ on a Schlenk line. All synthetic reactions were performed on the benchtop. Reactions involving silver were protected from light by wrapping all glassware in aluminum foil. DMF- $d_{7}$ (Cambridge Isotopes) was stored over $4 \AA$ molecular sieves in a $\mathrm{N}_{2}$ filled glovebox. All proteo solvents were taken from a Glass Contours solvent system, in which the solvent is passed through a column of activated alumina with a pressure of Argon. All other commercial reagents and NMR solvents were used without further purification unless otherwise stated.

${ }^{1} \mathrm{H},{ }^{19} \mathrm{~F}$ and ${ }^{13} \mathrm{C}\left\{{ }^{1} \mathrm{H}\right\}$ NMR spectra were recorded on an Agilent $400 \mathrm{MHz}$ spectrometer, Joel $400 \mathrm{MHz}$ spectrometer, or a Varian INOVA $600 \mathrm{MHz}$ spectrometer at room temperature, unless otherwise noted. Chemical shifts $(\delta)$ are given in parts per million and referenced to the residual solvent signal ${ }^{[109]}$ (DMSO- $d_{6}$ is referenced to the residual solvent peaks at $2.50 \mathrm{ppm}$ and $39.52 \mathrm{ppm}$ for ${ }^{1} \mathrm{H}$ and ${ }^{13} \mathrm{C}$ NMR spectra respectively, and DMF- $d_{7}$ is referenced to the residual solvent peak at $8.02 \mathrm{ppm}$ for all kinetic experiments); and all coupling constants $(J)$ are reported in Hz. IR spectra were recorded on a Perkin Elmer (Spectrum 100) FT-IR spectrometer. High resolution mass spectra were obtained on a Thermofisher Scientific Q Exactive Mass 
Spectrometer. Elemental analyses were performed by Atlantic Microlab, Inc., Norcross, GA. HPLC chromatographs were collected on a Shimadzu LC-10vp HPLC system.

\subsubsection{Decarboxylation of Silver Carboxylate Complexes.}

\section{By NMR:}

A foil wrapped J. Young NMR tube was charged with the silver carboxylate complex of interest (7.0 $\mu \mathrm{mol}$ unless otherwise noted below). This was then taken into a $\mathrm{N}_{2}$ filled glovebox, where 1 $\mathrm{mL}$ of a DMF- $d_{7}$ and water $(0.7 \mathrm{mM})$ solution (unless otherwise noted below) was added and the NMR tube was sealed. The J. Young NMR tube was then taken out of the glovebox and heated to $110{ }^{\circ} \mathrm{C}$ and monitored by ${ }^{1} \mathrm{H}$ NMR spectroscopy at $0,1,2,3,4,5,10,15,20,25,30,40,50,60$, $70,80,90,120,150,180,210,240,270$, and 300 minutes of heating.

\section{By HPLC:}

An aluminum foil wrapped $100 \mathrm{~mL}$ round bottomed flask was charged with the silver carboxylate complex of interest (32.0 $\mu \mathrm{mol}$ unless otherwise noted below) and 1,3,5-trimethoxybenzene (10.1 $\mathrm{mg}, 54.2 \mu \mathrm{mol})$. The flask was purged and backfilled with $\mathrm{N}_{2}$ three times; after which, dry DMF ( $20 \mathrm{~mL}$ ) followed by water $(0.6 \mu \mathrm{L}, 33.3 \mu \mathrm{mol})$ was added. The mixture was stirred at room temperature for 15 minutes to ensure dissolution of all solids (unless otherwise noted). A $500 \mu \mathrm{L}$ aliquot was withdrawn, filtered through a $0.2 \mu \mathrm{m}$ PTFE syringe filter into a chromatography vial equipped with a $200 \mu \mathrm{L}$ vial insert and the vial was then sealed. The reaction flask was then dipped into a $110^{\circ} \mathrm{C}$ oil bath and allowed to stir. Additional aliquots $(500 \mu \mathrm{L})$ were taken at 1, 2, 3, 4, 5, $10,15,20,25,30,40,50,60,70,80,90,120,150,180,240$, and 300 minutes. These aliquots were filtered through a $0.2 \mu \mathrm{m}$ PTFE syringe filter into chromatography vials equipped with a 200 $\mu \mathrm{L}$ vial insert and the vial was then sealed. The samples were then run on an HPLC to determine concentrations (method parameters noted below for each compound.) 


\subsubsection{HPLC Calibrations and Kinetic Reaction Profiles of $\mathrm{Ag}$ (heteroaromatic carboxylate) complexes}

\section{HPLC Calibrations}

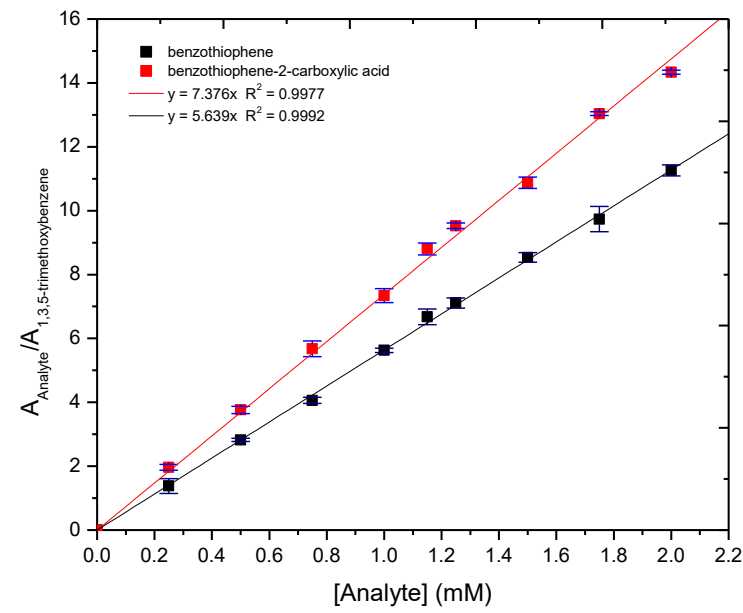

Time Mobile Phase

0 - 4 min $25: 5: 70 \mathrm{MeOH}: \mathrm{MeCN}: 0.1 \%$ TFA in water

$5-9$ min $\mathrm{MeCN}$ to $15 \%$

$4-10 \mathrm{~min} \mathrm{MeOH}$ to $75 \%$

$10-17 \min$ 75:15:10 MeOH:MeCN:0.1\% TFA in water

Figure 3-16: The HPLC calibration curves for benzothiophene-2-carboxylic acid (red) and benzothiophene (black). Samples were run on a $4.6 \times 75 \mathrm{~mm} 3.5 \mu \mathrm{m}$ Zorbax SB-Phenyl column at $50{ }^{\circ} \mathrm{C}$ with a $1.5 \mathrm{~mL} / \mathrm{min}$ flow rate under gradient elution of $\mathrm{MeOH}: \mathrm{MeCN}: 0.1 \%$ TFA in water with a UV detector set to $254 \mathrm{~nm}$. 


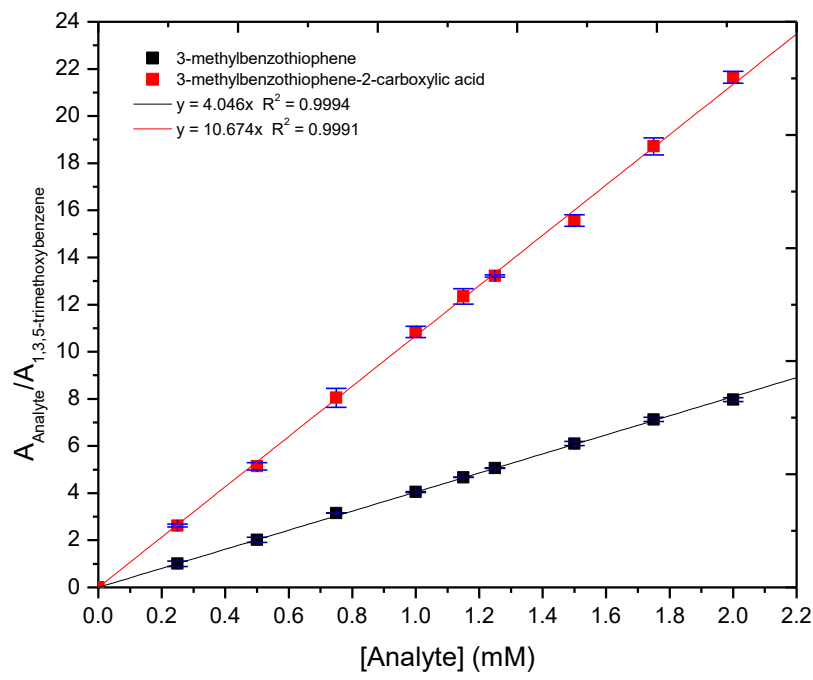
Time Mobile Phase
$0-5 \mathrm{~min} \quad 5: 95 \mathrm{MeCN}: 0.1 \%$ TFA in water
$5-7 \mathrm{~min} \quad \mathrm{MeCN}$ to $25 \%$
$8-10 \mathrm{~min}$ Flow rate $=1.75 \mathrm{~mL} / \mathrm{min}$
$12-17 \mathrm{~min}$ MeCN to $40 \%$

Figure 3-17: The HPLC calibration curves for 3-methylbenzothiophene-2-carboxylic acid (red) and 3-methylbenzothiophene (black). Samples were run on a 4.6 × $75 \mathrm{~mm} 3.5 \mu \mathrm{m}$ Zorbax SB-Phenyl column at $50{ }^{\circ} \mathrm{C}$ under gradient elution of MeCN:0.1\% TFA in water with a UV detector set to $254 \mathrm{~nm}$.
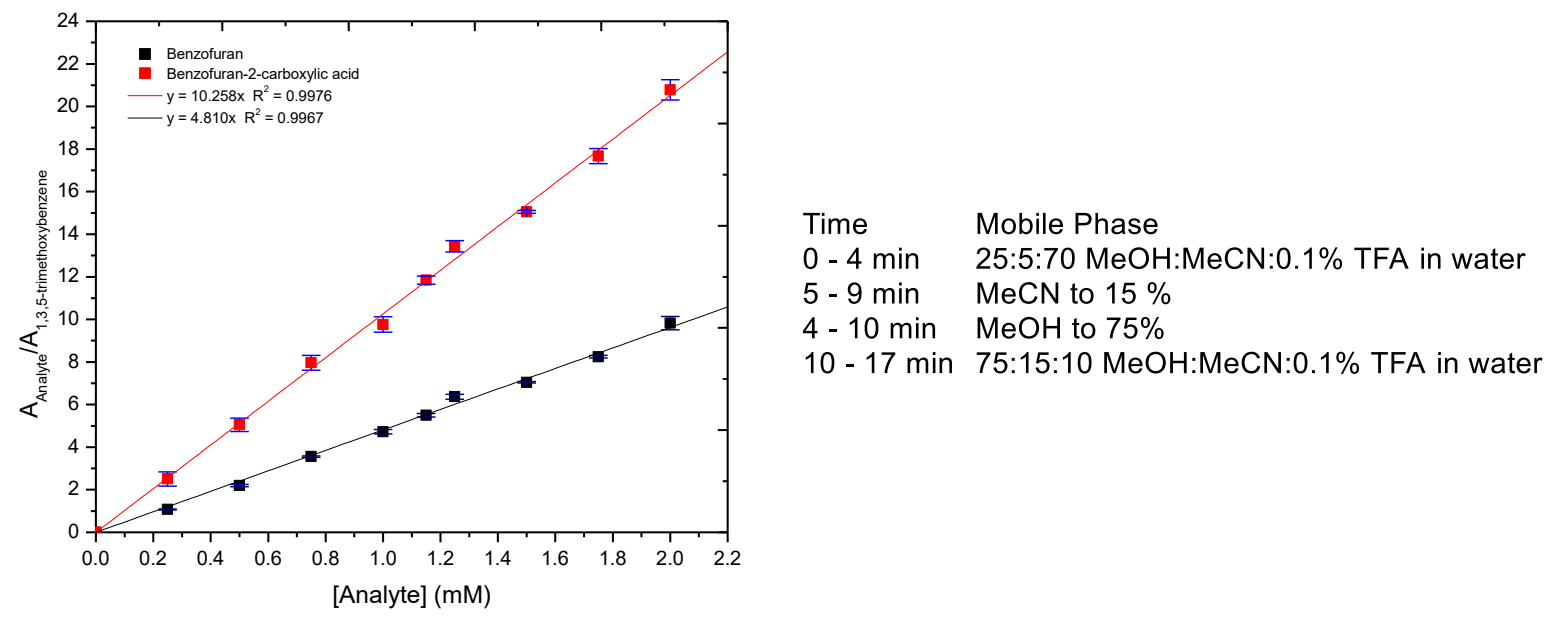

Figure 3-18: The HPLC calibration curves for benzofuran-2-carboxylic acid (red) and benzofuran (black). Samples were run on a $4.6 \times 75 \mathrm{~mm} 3.5 \mu \mathrm{m}$ Zorbax SB-Phenyl column at $50{ }^{\circ} \mathrm{C}$ with a $1.5 \mathrm{~mL} / \mathrm{min}$ flow rate under gradient elution of $\mathrm{MeOH}: \mathrm{MeCN}: 0.1 \%$ TFA in water with a UV detector set to $254 \mathrm{~nm}$. 


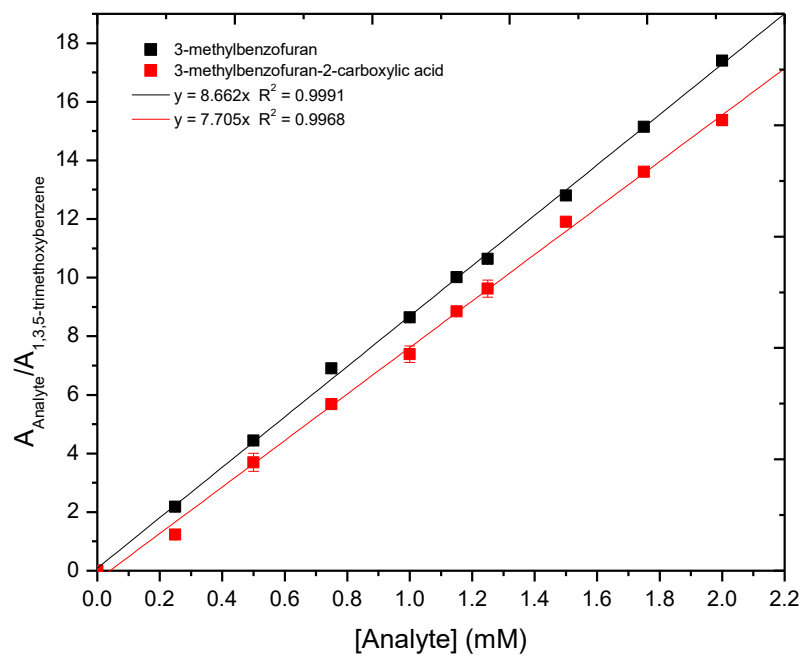

Time Mobile Phase

$0-5 \min \quad 5: 95 \mathrm{MeCN}: 0.1 \%$ TFA in water

$5-7 \mathrm{~min} \quad \mathrm{MeCN}$ to $25 \%$

$8-10 \mathrm{~min}$ Flow rate $=1.75 \mathrm{~mL} / \mathrm{min}$

$12-17 \mathrm{~min} \mathrm{MeCN}$ to $40 \%$

Figure 3-19: The HPLC calibration curves for 3-methylbenzofuran-2-carboxylic acid (red) and 3-methylbenzofuran (black). Samples were run on a 4.6 x $75 \mathrm{~mm} 3.5 \mu \mathrm{m}$ Zorbax SB-Phenyl column at $50{ }^{\circ} \mathrm{C}$ with a $1.5 \mathrm{~mL} / \mathrm{min}$ flow rate under gradient elution of MeCN:0.1\% TFA in water with a UV detector set to $254 \mathrm{~nm}$.

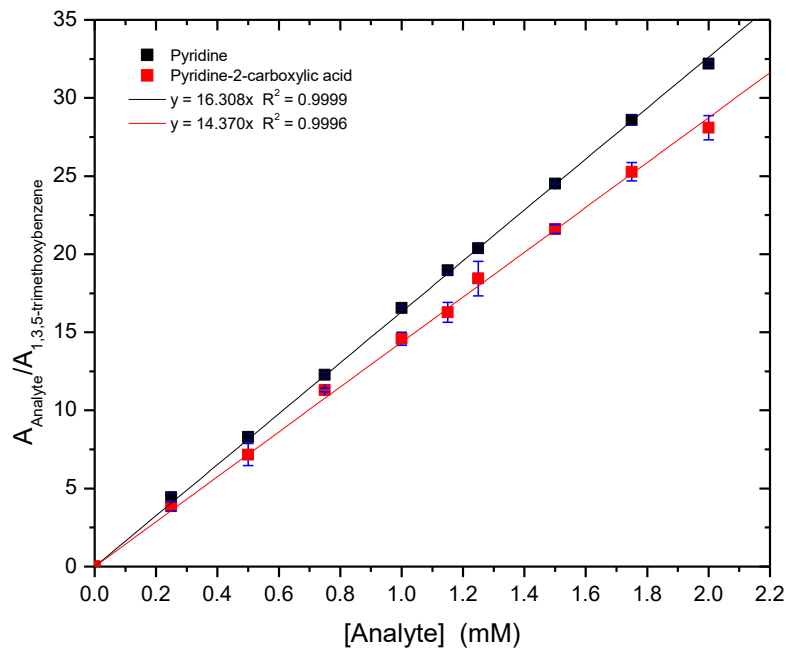

$\begin{array}{ll}\text { Time } & \text { Mobile Phase } \\ 0-10 \min & 5: 95 \mathrm{MeCN}: 0.1 \% \text { TFA in water } \\ \text { 10-17 } \min & \text { MeCN to } 30 \% \\ 23-26 \min & \text { MeCN to } 45 \% \\ 26-35 \text { min } & 45: 55 \mathrm{MeCN}: 0.1 \% \text { TFA in water }\end{array}$

Figure 3-20: The HPLC calibration curves for pyridine-2-carboxylic acid (red) and pyridine (black). Samples were run on a 4.6 x $250 \mathrm{~mm} 3.5 \mu \mathrm{m}$ SIELC Primesep 100 column at $30{ }^{\circ} \mathrm{C}$ with a $1.0 \mathrm{~mL} / \mathrm{min}$ flow rate under gradient elution of MeCN:0.1\% TFA in water with a UV detector set to $254 \mathrm{~nm}$. 


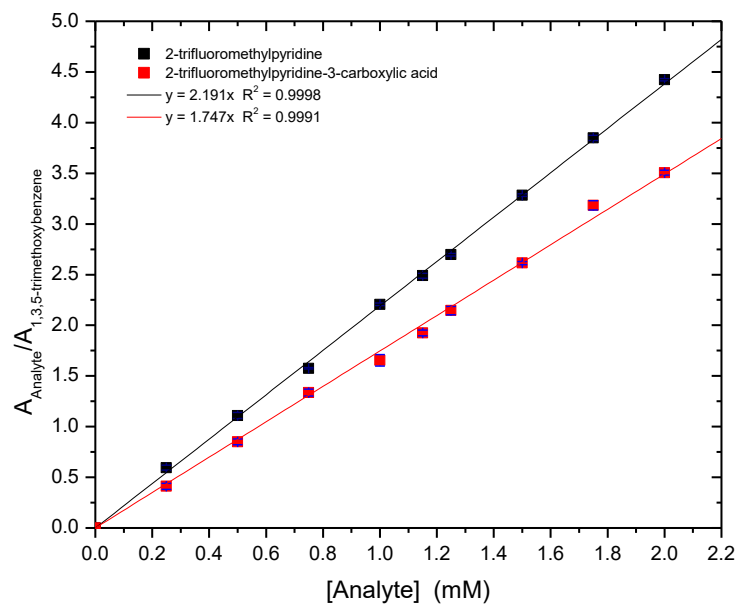

Time Mobile Phase

0-3 min $\quad 2: 20: 78 \mathrm{MeCN}: \mathrm{MeOH}: 0.1 \%$ TFA in water

3-8 $\min \quad \mathrm{MeCN}$ to $100 \%$

4-8 $\min \quad \mathrm{MeOH}$ to $0 \%$

8-16 min 100:0:0 MeCN:MeOH:0.1\% TFA in water

16-17.5 $\mathrm{min} \mathrm{MeCN}$ to $2 \%$ and $\mathrm{MeOH}$ to $20 \%$

Figure 3-21: The HPLC calibration curves for 2-trifluoromethylpyridine-3-carboxylic acid (red) and 2-trifluoromethylpyridine (black). Samples were run on a 4.6 x $250 \mathrm{~mm} 5 \mu \mathrm{m}$ LiChrospher $100 \mathrm{RP}-18$ endcapped column at $40{ }^{\circ} \mathrm{C}$ with a $1.0 \mathrm{~mL} / \mathrm{min}$ flow rate under gradient elution of MeCN:MeOH:0.1\% TFA in water with a UV detector set to $254 \mathrm{~nm}$.

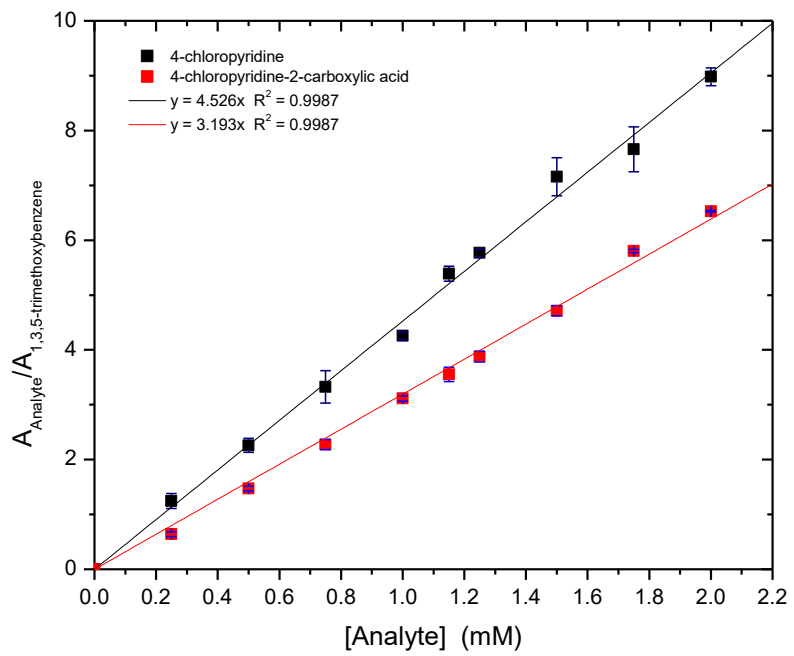

Time Mobile Phase

0-6 min $\quad 10: 90 \mathrm{MeCN}: 0.1 \%$ TFA in water

$6-16$ min $\quad \mathrm{MeCN}$ to $50 \%$

16-23 $\min 50: 50 \mathrm{MeCN}: 0.1 \%$ TFA in water

23-25 $\min \quad \mathrm{MeCN}$ to $75 \%$

26-27 min $75: 25 \mathrm{MeCN}: 0.1 \%$ TFA in water

$29-29 \min \quad \mathrm{MeCN}$ to $10 \%$

Figure 3-22: The HPLC calibration curves for 4-chloropyridine-2-carboxylic acid (red) and 4-chloropyridine (black). Samples were run on a 4.6 x $250 \mathrm{~mm} 3.5 \mu \mathrm{m}$ SIELC Primesep 100 column at $30{ }^{\circ} \mathrm{C}$ with a $1.0 \mathrm{~mL} / \mathrm{min}$ flow rate under gradient elution of MeCN:0.1\% TFA in water with a UV detector set to $254 \mathrm{~nm}$. 


\section{HPLC Reaction Time Courses}

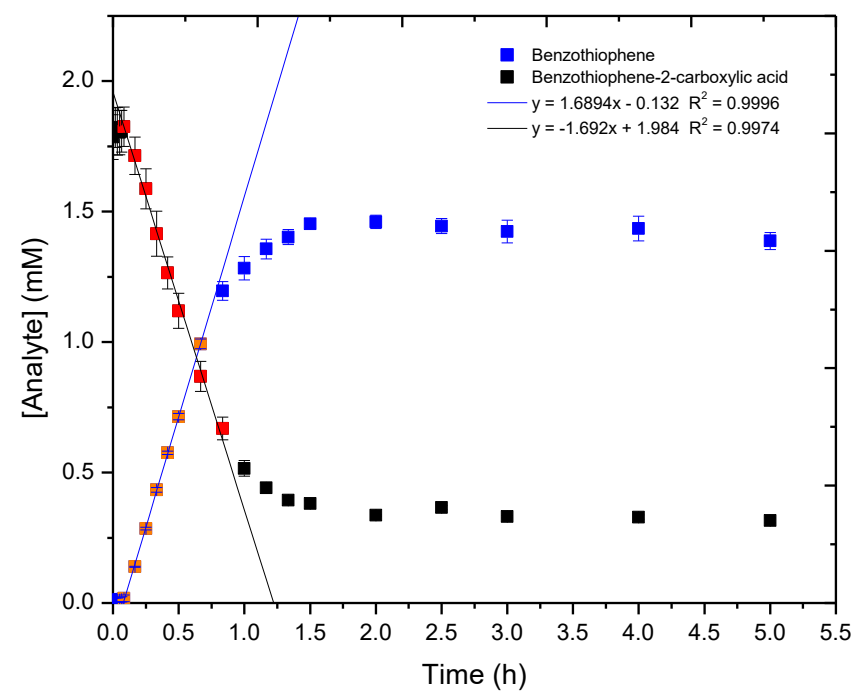

Figure 3-23: HPLC reaction time course for the decarboxylation of $14(1.828 \mathrm{mM} ; k=0.924)$ in $\mathrm{DMF}$ at $110^{\circ} \mathrm{C}$. Red points indicate fit of the carboxylate. Orange points indicate fit of the arene.

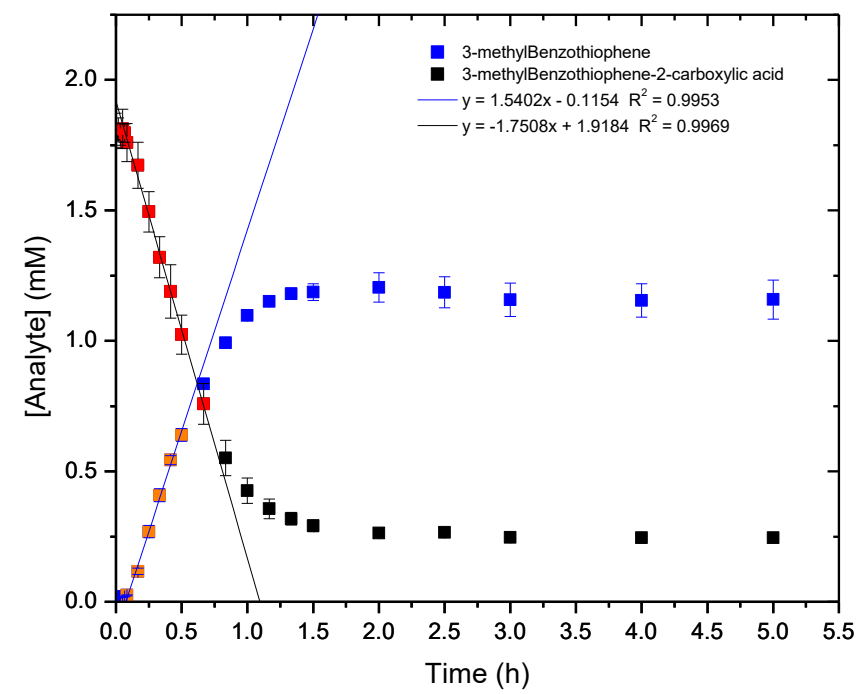

Figure 3-24: HPLC reaction time course for the decarboxylation of $15(1.833 \mathrm{mM} ; k=0.840)$ in DMF at $110{ }^{\circ} \mathrm{C}$. Red points indicate fit of the carboxylate. Orange points indicate fit of the arene. 


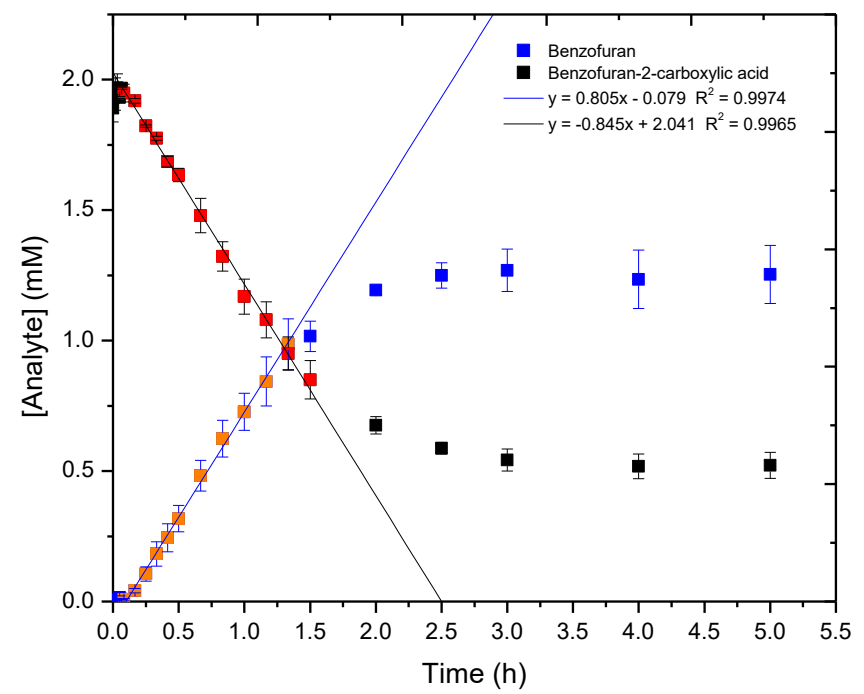

Figure 3-25: HPLC reaction time course for the decarboxylation of $16(2.003 \mathrm{mM} ; k=0.402)$ in $\mathrm{DMF}$ at $110^{\circ} \mathrm{C}$. Red points indicate fit of the carboxylate. Orange points indicate fit of the arene.

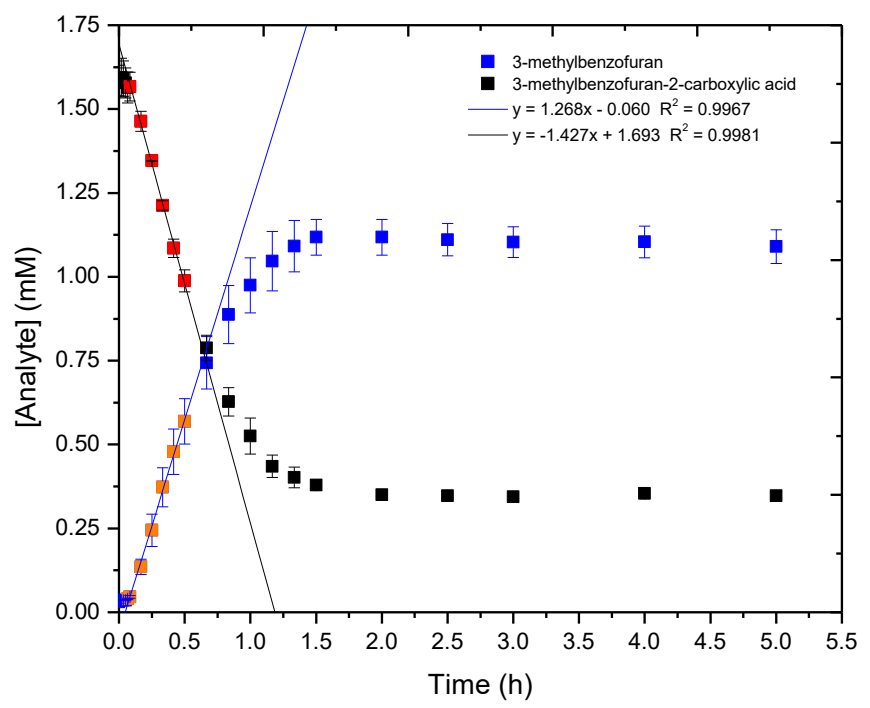

Figure 3-26: HPLC reaction time course for the decarboxylation of $17(1.599 \mathrm{mM} ; k=0.892)$ in $\mathrm{DMF}$ at $110^{\circ} \mathrm{C}$. Red points indicate fit of the carboxylate. Orange points indicate fit of the arene. 


\subsubsection{Synthesis and Characterization of Silver Complexes.}

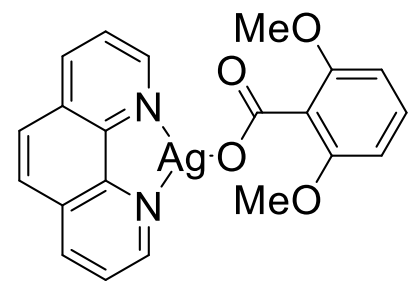

(phenanthroline)silver(2,6-dimethoxybenzoate) (1). The title compound was synthesized according to a modified version of our previously reported procedure. ${ }^{[142]}$ To a mixture of sodium hydroxide (195 mg, $4.89 \mathrm{mmol})$ in water (50 mL) was added 2,6-dimethoxybenzoic acid (916 mg, $5.03 \mathrm{mmol}$ ). The mixture was allowed to stir at room temperature until the benzoic acid was completely dissolved. Then a solution of silver triflate $(1283 \mathrm{mg}, 4.99 \mathrm{mmol})$ dissolved in water $(3 \mathrm{~mL})$ was added dropwise with rapid stirring. The mixture was left to stir overnight, and the white precipitate was collected via vacuum filtration and dried under reduced pressure to yield 807 mg (2.79 mmol, $56 \%$ yield) of silver 2,6-dimethyoxybenzoate (6). ${ }^{1} \mathrm{H} \mathrm{NMR} \mathrm{(400} \mathrm{MHz,}$ DMSO-d $\left.d_{6}\right): \delta=7.07(\mathrm{t}, J=8.3 \mathrm{~Hz}, 1 \mathrm{H}), 6.54(\mathrm{~d}, J=8.3 \mathrm{~Hz}, 2 \mathrm{H}), 3.65(\mathrm{~s}, 6 \mathrm{H})$. IR $\left(\mathrm{ATR}, \mathrm{cm}^{-1}\right)$ : 3002.80 (w), 2955.63 (w), $2924.87(w), 2832.26$ (w), 1591.83 (m), $1531.54(\mathrm{~s}), 1470.29$ (s), 1449.74 (m), 1430.41 (m), 1393.25 (s), 1320.39 (m), 1284.12 (m), 1247.22 (s), 1183.11 (w), $1168.08(\mathrm{~m}), 1139.76(\mathrm{~m}), 1108.86(\mathrm{~s}), 1069.91(\mathrm{~m}), 1032.97(\mathrm{~m}), 902.92(\mathrm{w}), 851.38(\mathrm{w}), 836.89$ (m), 770.68 (m), 730.98 (s), 633.09 (s), 610.95 (m). Elemental Analysis: calculated $\mathrm{C}_{9} \mathrm{H}_{9} \mathrm{AgO}_{4} \mathrm{C}$ 37.40; H 3.14; measured C 37.46; H 3.13.

Silver 2,6-dimethoxybenzoate (6) $(289 \mathrm{mg}, 1.00 \mathrm{mmol}$ ) was then dissolved in MeCN (40 mL). This solution was then rapidly stirred, and a solution of 1,10-phenanthroline (160 mg, $0.89 \mathrm{mmol})$ in $\mathrm{MeCN}(20 \mathrm{~mL})$ was added dropwise. The resulting mixture was then allowed to stir for $\sim 10$ minutes. The product was collected by vacuum filtration, washed with MeCN $(5 \mathrm{~mL})$ and then ether $(100 \mathrm{~mL})$, and dried under reduced pressure to yield $214 \mathrm{mg}(0.51 \mathrm{mmol}, 51 \%$ yield $)$ of the title compound as a white solid. ${ }^{1} \mathrm{H}$ NMR (400 MHz, DMSO- $\left.d_{6}\right): \delta=9.13(\mathrm{dt}, J=3.4,1.6 \mathrm{~Hz}$, 2H), $8.69(\mathrm{dt}, J=8.2,1.7 \mathrm{~Hz}, 2 \mathrm{H}), 8.12(\mathrm{~d}, J=1.7 \mathrm{~Hz}, 2 \mathrm{H}), 7.97(\mathrm{ddd}, J=8.1,4.5,1.7 \mathrm{~Hz}, 2 \mathrm{H})$, $7.04(\mathrm{~d}, J=1.6 \mathrm{~Hz}, 1 \mathrm{H}), 6.52(\mathrm{dd}, J=8.4,1.6 \mathrm{~Hz}, 2 \mathrm{H}), 3.65(\mathrm{~d}, J=1.6 \mathrm{~Hz}, 6 \mathrm{H}) .{ }^{13} \mathrm{C} \mathrm{NMR}(100$ MHz, DMSO- $\left.d_{6}\right): \delta=169.87,155.73,151.73,142.35,138.77,129.30,127.59,127.18,125.37$, 122.53, 104.52, 55.77. IR (ATR, $\mathrm{cm}^{-1}$ ): 2969.01 (w), 2836.6 (w), 1581.99 (s), 1509.46 (w), 
$1467.96(\mathrm{~m}), 1422.96(\mathrm{~m}), 1371.24(\mathrm{~s}), 1311.47$ (w), 1275.55 (w), 1249.90 (s), $1220.89(\mathrm{w})$, 1172.74 (w), 1139.54 (w), 1099.28 (s), 1029.09 (w), 860.40 (w), 844.19 (s), 792.44 (m), 768.17 (m), $742.20(\mathrm{~m}), 727.04(\mathrm{~s}), 633.63(\mathrm{~m})$. Elemental Analysis: calculated $\mathrm{C}_{21} \mathrm{H}_{17} \mathrm{AgN}_{2} \mathrm{O}_{4} \mathrm{C} 53.75$; H 3.65; N 5.97; measured C 54.02; H 3.60; N 6.09.

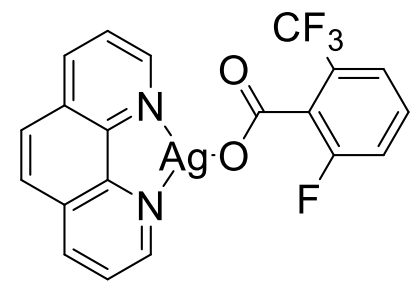

(phenanthroline)silver(2-fluoro-6-(trifluoromethyl)benzoate) (2). The title compound was synthesized according to a modified version of our previously reported procedure. ${ }^{[142]}$ To a mixture of sodium hydroxide $(185 \mathrm{mg}, 4.83 \mathrm{mmol})$ in water $(48 \mathrm{~mL})$ was added 2-fluoro-6trifluoromethylbenzoic acid $(1041 \mathrm{mg}, 5.00 \mathrm{mmol})$. The mixture was allowed to stir at room temperature until the benzoic acid was completely dissolved. Then a sample of silver nitrate (850 $\mathrm{mg}, 5.00 \mathrm{mmol})$ dissolved in water $(5 \mathrm{~mL})$ was added dropwise with rapid stirring. The mixture was left to stir overnight, and the white precipitate was collected via vacuum filtration and dried under reduced pressure to yield $733 \mathrm{mg}(2.33 \mathrm{mmol}, 47 \%$ yield $)$ of silver 2-fluoro-6-trifluoromethylbenzoate (13). ${ }^{1} \mathrm{H}$ NMR (400 MHz, DMSO- $\left.d_{6}\right): \delta=7.47-7.32$ (m, $3 \mathrm{H}) .{ }^{19} \mathrm{~F} \mathrm{NMR}\left(375 \mathrm{MHz}, \mathrm{DMSO}-d_{6}\right) \delta=-58.58(\mathrm{~s}, 3 \mathrm{~F}),-115.43(\mathrm{t}, J=7.0 \mathrm{~Hz}, 1 \mathrm{~F})$. IR (ATR, $\mathrm{cm}^{-}$ $\left.{ }^{1}\right): 1620.98(\mathrm{w}), 1586.23(\mathrm{w}), 1549.22(\mathrm{~m}), 1530.68(\mathrm{~s}), 1482.58(\mathrm{~m}), 1462.00(\mathrm{~m}), 1384.50(\mathrm{~m})$, 1319.07 (s), 1247.39 (m), 1193.09 (m), 1171.80 (m), 1132.89 (s), 1108.53 (m), 1066.70 (m), $974.04(\mathrm{w}), 912.40(\mathrm{~s}), 845.60(\mathrm{~m}), 802.68(\mathrm{~m}), 772.51(\mathrm{~m}), 745.25(\mathrm{~s}), 681.56(\mathrm{~m}), 638.58(\mathrm{w})$. Elemental Analysis: calculated $\mathrm{C}_{8} \mathrm{H}_{3} \mathrm{AgF}_{3} \mathrm{O}_{2} \mathrm{C} 30.51$; $\mathrm{H} 0.96$; measured C 30.31; $\mathrm{H} 0.83$.

Silver 2-fluoro-6-trifluoromethylbenzoate (13) (317 mg, $1.01 \mathrm{mmol}$ ) was then dissolved in MeCN $(40 \mathrm{~mL})$. This solution was then rapidly stirred, and a solution of 1,10-phenanthroline (163 mg, $0.91 \mathrm{mmol})$ in $\mathrm{MeCN}(20 \mathrm{~mL})$ was added dropwise. The mixture was stirred for 5 minutes. The product was collected by vacuum filtration, washed with $\mathrm{MeCN}(5 \mathrm{~mL})$ and then ether $(100 \mathrm{~mL})$, and dried under reduced pressure to yield $195 \mathrm{mg}(0.44 \mathrm{mmol}, 44 \%$ yield $)$ of the colorless crystalline title compound. ${ }^{1} \mathrm{H}$ NMR (400 MHz, DMSO- $\left.d_{6}\right): \delta=9.14(\mathrm{dt}, J=3.9,1.8 \mathrm{~Hz}, 2 \mathrm{H}$ ), 
$8.74(\mathrm{dt}, J=8.2,1.8 \mathrm{~Hz}, 2 \mathrm{H}), 8.17(\mathrm{~d}, J=1.8 \mathrm{~Hz}, 2 \mathrm{H}), 7.99(\mathrm{ddd}, J=8.0,4.6,1.8 \mathrm{~Hz}, 2 \mathrm{H}), 7.34$ $(\mathrm{dt}, J=10.5,7.0 \mathrm{~Hz}, 3 \mathrm{H}) .{ }^{19} \mathrm{~F}$ NMR $\left(375 \mathrm{MHz}, \mathrm{DMSO}-d_{6}\right) \delta=-58.53,-115.59(\mathrm{t}, J=7.0 \mathrm{~Hz})$. ${ }^{13} \mathrm{C}$ NMR $\left(100 \mathrm{MHz}\right.$, DMSO- $\left.d_{6}\right): \delta=165.63,158.43(\mathrm{~d}, \mathrm{~J}=241.8 \mathrm{~Hz}), 151.81,142.35,138.92$, $131.87(\mathrm{~d}, \mathrm{~J}=27.3 \mathrm{~Hz}), 129.42,127.93(\mathrm{~d}, \mathrm{~J}=8.3 \mathrm{~Hz}), 127.68,126.14(\mathrm{dd}, \mathrm{J}=30.9,7.2 \mathrm{~Hz})$, 125.46, $122.83(\mathrm{~d}, \mathrm{~J}=2.7 \mathrm{~Hz}), 121.84(\mathrm{t}, \mathrm{J}=4.0 \mathrm{~Hz}), 119.73(\mathrm{~d}, \mathrm{~J}=23.3 \mathrm{~Hz})$. IR (ATR, $\left.\mathrm{cm}^{-1}\right)$ : $3054.31(\mathrm{w}), 2833.95(\mathrm{w}), 1600.48(\mathrm{~s}), 1587.52(\mathrm{~s}), 1509.81(\mathrm{~m}), 1457.28(\mathrm{~m}), 1425.90(\mathrm{~m})$, $1367.87(\mathrm{~s}), 1316.68(\mathrm{~s}), 1244.74(\mathrm{~s}), 1163.21(\mathrm{~m}), 1127.80(\mathrm{~m}), 1106.91(\mathrm{~s}), 1065.51(\mathrm{~m}), 1030.81$ (m), 991.24 (w), 908.99 (m), 860.81 (w), 839.60 (s), 813.05 (m), 765.77 (w), 749.17 (m), 726.18 (s), $681.96(\mathrm{~m}), 632.07(\mathrm{~m}), 612.54(\mathrm{w})$. Elemental Analysis: calculated $\mathrm{C}_{20} \mathrm{H}_{11} \mathrm{AgF}_{4} \mathrm{~N}_{2} \mathrm{O}_{2} \mathrm{C}$ 48.51; H 2.24; N 5.66; measured C 48.27; H 2.05; N 5.71.

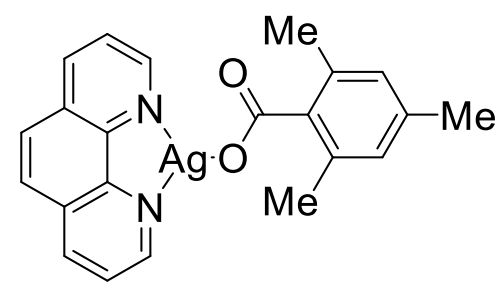

(phenanthroline)silver(2,4,6-trimethylbenzoate) (3). The title compound was synthesized according to a modified version of our previously reported procedure. ${ }^{[142]}$ To a mixture of sodium hydroxide $(63.0 \mathrm{mg}, 1.58 \mathrm{mmol})$ in water $(48 \mathrm{~mL})$ and $\mathrm{MeCN}(10 \mathrm{~mL})$ was added 2,4,6-trimethylbenzoic acid $(280 \mathrm{mg}, 1.71 \mathrm{mmol})$. The mixture was allowed to stir at room temperature until the benzoic acid was completely dissolved. Then a sample of silver nitrate (291 $\mathrm{mg}, 1.71 \mathrm{mmol})$ dissolved in water $(5 \mathrm{~mL})$ was added dropwise with rapid stirring. The mixture was left to stir for 1 hour, and the white precipitate was collected via vacuum filtration and dried under reduced pressure to yield $334 \mathrm{mg}$ ( $1.23 \mathrm{mmol}, 72 \%$ yield) of silver 2,4,6-trimethylbenzoate. ${ }^{1} \mathrm{H}$ NMR (400 MHz, DMSO- $\left.d_{6}\right): \delta=6.70$ (s, 2H), 2.17-2.13(m, 9H). IR (ATR, $\mathrm{cm}^{-1}$ ): $2916.90(\mathrm{w})$, $1679.84(\mathrm{w}), 1611.98$ (w), 1574.55 (m), 1532.95 (s), 1429.73 (m), 1350.36 (s), 1179.83 (m), 1108.13 (m), 1034.96 (m), 884.89 (w), 848.20 (m), 820.01 (m), 786.37 (m), 736.44 (m), 659.04 (w), 606.96 (m). Elemental Analysis: calculated $\mathrm{C}_{10} \mathrm{H}_{11} \mathrm{AgO}_{2} \mathrm{C}$ 44.31; $\mathrm{H} 4.09$; measured $\mathrm{C} 44.03$; H 3.90 . 
Silver 2,4,6-trimethylbenzoate ( $273 \mathrm{mg}, 1.01 \mathrm{mmol}$ ) was then dissolved in MeCN (40 mL). This solution was then rapidly stirred, and a solution of 1,10-phenanthroline (162 mg, $0.90 \mathrm{mmol})$ in $\mathrm{MeCN}(20 \mathrm{~mL})$ was added dropwise. The mixture was stirred for 5 minutes. The product was collected by vacuum filtration, washed with $\mathrm{MeCN}(5 \mathrm{~mL})$ and then ether $(100 \mathrm{~mL})$, and dried under reduced pressure to yield $245 \mathrm{mg}(0.60 \mathrm{mmol}, 60 \%$ yield $)$ of the pale-yellow title compound. ${ }^{1} \mathrm{H}$ NMR (400 MHz, DMSO- $\left.d_{6}\right): \delta=9.15(\mathrm{dt}, J=3.9,1.8 \mathrm{~Hz}, 2 \mathrm{H}), 8.72(\mathrm{dt}, J=8.2,1.8 \mathrm{~Hz}, 2 \mathrm{H})$, $8.15(\mathrm{~d}, J=1.7 \mathrm{~Hz}, 2 \mathrm{H}), 7.98(\mathrm{ddd}, J=8.3,4.5,1.7 \mathrm{~Hz}, 2 \mathrm{H}), 6.65$ (s, 2H), $2.16(\mathrm{~d}, J=1.7 \mathrm{~Hz}$, $6 \mathrm{H}), 2.13(\mathrm{~s}, 3 \mathrm{H}) .{ }^{13} \mathrm{C}$ NMR (100 MHz, DMSO- $\left.d_{6}\right): \delta=174.57,151.78,142.36,141.03,138.84$, 134.49, 132.28, 129.35, 127.64, 127.62, 125.41, 21.14, 20.36. IR (ATR, $\left.\mathrm{cm}^{-1}\right): 2915.85(\mathrm{w})$, 1559.03 (s), 1510.00 (m), $1423.20(\mathrm{~s}), 1359.64$ (s), 1249.88 (w), $1220.80(\mathrm{w}), 1180.68(\mathrm{w})$, $1139.81(\mathrm{w}), 1106.51(\mathrm{w}), 1033.62(\mathrm{w}), 859.45(\mathrm{~m}), 842.26(\mathrm{~s}), 822.46(\mathrm{~m}), 769.06(\mathrm{w}), 726.85$ (s), 633.21 (w), 607.94 (m). Elemental Analysis: calculated $\mathrm{C}_{22} \mathrm{H}_{19} \mathrm{AgN}_{2} \mathrm{O}_{2} \mathrm{C} 58.55 ; \mathrm{H} 4.24 ; \mathrm{N}$ 6.21 ; measured C $57.66 ; \mathrm{H} 4.20 ; \mathrm{N} 6.21$. This data is consistent with a trace water impurity.<smiles>O=C(O[Na])c1c(F)cccc1F</smiles>

Silver 2,6-difluorobenzoate (5). This synthesis was performed on the benchtop protected from light. To a mixture of sodium hydroxide $(198 \mathrm{mg}, 4.95 \mathrm{mmol})$ in water $(15 \mathrm{~mL})$ was added 2,6-difluorobenzoic acid $(790 \mathrm{mg}, 5.00 \mathrm{mmol})$. The mixture was allowed to stir at room temperature until the benzoic acid was completely dissolved. Then a sample of silver nitrate (852 $\mathrm{mg}, 5.01 \mathrm{mmol})$ dissolved in water $(5 \mathrm{~mL})$ was added dropwise with rapid stirring. The mixture was left to stir for an hour, and the white precipitate was collected via vacuum filtration and dried under reduced pressure to yield $351 \mathrm{mg}$ ( $1.32 \mathrm{mmol}, 27 \%$ yield $)$ of the title compound. ${ }^{1} \mathrm{H}$ NMR $\left(400 \mathrm{MHz}\right.$, DMSO- $\left.d_{6}\right): \delta=7.22(\mathrm{tt}, J=8.3,6.6 \mathrm{~Hz}, 1 \mathrm{H}), 6.99-6.87(\mathrm{~m}, 2 \mathrm{H}) .{ }^{13} \mathrm{C}$ NMR $(100$ MHz, DMSO- $\left.d_{6}\right) \delta=163.94,159.56,159.45,157.13,157.02,128.10,128.00,127.91,120.63$, 120.37, 120.11, 111.45, 111.39, 111.26, 111.20. ${ }^{19} \mathrm{~F}$ NMR (375 MHz, DMSO- $\left.d_{6}\right):-114.43$ (t, $J=6.6 \mathrm{~Hz}, 2 \mathrm{~F})$. IR (ATR, $\left.\mathrm{cm}^{-1}\right): 1623.38(\mathrm{~m}), 1589.01(\mathrm{~m}), 1554.73(\mathrm{~m}), 1529.44(\mathrm{~s}), 1460.24(\mathrm{~s})$, 1394.26 (s), 1263.97 (m), 1230.61 (m), 1162.18 (w), 1140.94 (w), $1057.19(\mathrm{w}), 996.84(\mathrm{~s}), 964.20$ 
(m), $881.74(\mathrm{w}), 846.66(\mathrm{~m}), 793.18(\mathrm{~m}), 783.15(\mathrm{~m}), 766.42(\mathrm{~m}), 723.36(\mathrm{~m}), 621.43(\mathrm{w})$.

Elemental Analysis: calculated $\mathrm{C}_{7} \mathrm{H}_{3} \mathrm{AgF}_{2} \mathrm{O}_{2} \mathrm{C} 31.73 ; \mathrm{H} 1.14$; measured C 31.68; $\mathrm{H} 1.09$.<smiles>COC(=O)c1ccccc1C(=O)O</smiles>

2-(methoxycarbonyl)benzoic acid. The title compound was prepared according to a literature procedure. ${ }^{[152]}$ Phthalic anhydride $(2982 \mathrm{mg}, 20.1 \mathrm{mmol})$ was dissolved in acetone $(20 \mathrm{~mL})$ and ethanol $(1.3 \mathrm{~mL})$. A solution of potassium hydroxide $(1120 \mathrm{mg}, 20.0 \mathrm{mmol})$ in methanol (202 $\mathrm{mL}$ ) was then added slowly with rapid stirring. The mixture was stirred for $3 \mathrm{~h}$; after which, the mixture was concentrated to $\sim 25 \mathrm{~mL}$ under reduced pressure. This was then acidified with dilute $\mathrm{HCl}$ to $\mathrm{pH}=2$ and extracted with ethyl acetate $(3 \times 20 \mathrm{~mL})$, washed with brine $(20 \mathrm{~mL})$, and dried over $\mathrm{Na} 2 \mathrm{SO} 4$. Upon removal of solvent under reduced pressure, the title compound was isolated as a colorless oil (3629 mg, $93 \%$ yield). 1H NMR characterization data is consistent with reported literature. $^{[153]}$ 1H NMR (400 MHz, CDCl3) $\delta=7.92(\mathrm{dd}, \mathrm{J}=7.4,1.5 \mathrm{~Hz}, 1 \mathrm{H}), 7.68(\mathrm{dd}, \mathrm{J}=7.1$, $1.9 \mathrm{~Hz}, 1 \mathrm{H}), 7.58$ (pd, J = 7.4, $1.5 \mathrm{~Hz}, 2 \mathrm{H}), 3.91$ (s, 2H). 13C NMR (100 MHz, CDCl3) $\delta=171.85$, $168.60,133.18,132.22,130.88,129.95,129.88,128.73,52.84$.<smiles>COC(=O)c1ccccc1C(=O)OC</smiles>

Silver 2-(methoxycarbonyl)benzoate (7). This synthesis was performed on the benchtop protected from light. To a mixture of sodium hydroxide $(185 \mathrm{mg}, 4.63 \mathrm{mmol})$ in water $(48 \mathrm{~mL})$ was added 2-(methoxycarbonyl)benzoic acid $(901 \mathrm{mg}, 5.00 \mathrm{mmol})$. The mixture was allowed to stir at room temperature until the benzoic acid was completely dissolved. Then a sample of silver nitrate $(850 \mathrm{mg}, 5.00 \mathrm{mmol})$ dissolved in water $(5 \mathrm{~mL})$ was added dropwise with rapid stirring. 
The mixture was left to stir for an hour, and the white precipitate was collected via vacuum filtration and dried under reduced pressure to yield $987 \mathrm{mg}$ ( $3.44 \mathrm{mmol}, 69 \%$ yield) of the title compound. ${ }^{1} \mathrm{H}$ NMR (400 MHz, DMSO- $\left.d_{6}\right): \delta=7.71(\mathrm{~d}, J=7.3 \mathrm{~Hz}, 1 \mathrm{H}), 7.45-7.32(\mathrm{~m}, 3 \mathrm{H})$, 3.69(s, 3H). IR (ATR, $\left.\mathrm{cm}^{-1}\right)$ : $2950.30(\mathrm{w}), 1706.37$ (s), 1597.47 (w), 1537.29 (s), 1490.38 (m), $1435.91(\mathrm{~m}), 1391.75(\mathrm{~s}), 1268.26$ (s), $1193.85(\mathrm{~m}), 1165.38(\mathrm{~m}), 1151.45(\mathrm{~m}), 1135.65(\mathrm{~m})$, 1132.86 (m), 1077.92 (s), 1043.75 (m), 957.89 (m), 898.71 (m), 848.26 (m), 824.56 (m), 805.26 (m), $770.49(\mathrm{~m}), 710.72(\mathrm{~s}), 692.50(\mathrm{~m}), 651.83(\mathrm{~m}), 612.85(\mathrm{~m})$. Elemental Analysis: calculated $\mathrm{C}_{9} \mathrm{H}_{7} \mathrm{AgO}_{4} \mathrm{C}$ 37.66; $\mathrm{H}$ 2.46; measured C 37.69; $\mathrm{H} 2.34$.<smiles>O=C(O[Na])c1ccccc1F</smiles>

Silver 2-fluorobenzoate (8). This synthesis was performed on the benchtop protected from light. To a mixture of sodium hydroxide $(198 \mathrm{mg}, 4.95 \mathrm{mmol})$ in water $(15 \mathrm{~mL})$ was added 2-fluorobenzoic acid $(701 \mathrm{mg}, 5.00 \mathrm{mmol})$. The mixture was allowed to stir at room temperature until the benzoic acid was completely dissolved. Then a sample of silver nitrate $(850 \mathrm{mg}, 5.00$ $\mathrm{mmol})$ dissolved in water $(5 \mathrm{~mL})$ was added dropwise with rapid stirring. The mixture was left to stir for an hour, and the white precipitate was collected via vacuum filtration and dried under reduced pressure to yield $709 \mathrm{mg}$ ( $2.87 \mathrm{mmol}, 57 \%$ yield) of the title compound. ${ }^{1} \mathrm{H}$ NMR (400 MHz, DMSO- $\left.d_{6}\right): \delta=7.65(\operatorname{td}, J=7.7,1.9 \mathrm{~Hz}, 1 \mathrm{H}), 7.33(\mathrm{tdd}, J=7.6,5.0,1.9 \mathrm{~Hz}, 1 \mathrm{H}), 7.14-7.03$ $(\mathrm{m}, 2 \mathrm{H}) .{ }^{13} \mathrm{C}$ NMR $\left(100 \mathrm{MHz}, \mathrm{DMSO}-d_{6}\right) \delta=168.59,161.88,159.39,131.84,131.81,131.26$, 131.18, 127.64, 127.51, 124.13, 124.09, 116.63, 116.40. ${ }^{19} \mathrm{~F}$ NMR (375 MHz, DMSO-d $\left.d_{6}\right):-112.57$ (ddd, $J=10.7,7.5,5.0 \mathrm{~Hz}, 1 \mathrm{~F})$. IR (ATR, $\left.\mathrm{cm}^{-1}\right): 1611.37$ (m), $1586.64(\mathrm{~m}), 1553.07$ (m), 1524.48 (s), $1482.46(\mathrm{~m}), 1448.07$ (m), 1377.61 (s), 1300.90 (m), 1270.34 (m), $1260.16(\mathrm{~m}), 1224.61(\mathrm{~m})$, $1156.15(\mathrm{~m}), 1139.77$ (m), $1092.05(\mathrm{~m}), 1030.09(\mathrm{w}), 950.35$ (w), $874.26(\mathrm{w}), 858.08(\mathrm{~m}), 808.00$ (w), $789.41(w), 747.63(\mathrm{~s}), 710.72(\mathrm{w}), 697.88(\mathrm{~m}), 658.38(\mathrm{~m})$. Elemental Analysis: calculated $\mathrm{C}_{7} \mathrm{H}_{4} \mathrm{AgFO}_{2} \mathrm{C} 34.04 ; \mathrm{H} 1.63$; measured C 34.13; H 1.58. 
<smiles>O=C(O[Na])c1c(F)cccc1[N+](=O)[O-]</smiles>

Silver 2-fluoro-6-nitrobenzoate (9). This synthesis was performed on the benchtop protected from light. To a mixture of sodium hydroxide $(198 \mathrm{mg}, 4.95 \mathrm{mmol})$ in water $(15 \mathrm{~mL})$ was added 2-fluoro-6-nitrobenzoic acid $(926 \mathrm{mg}, 5.00 \mathrm{mmol})$. The mixture was allowed to stir at room temperature until the benzoic acid was completely dissolved. Then a sample of silver nitrate (850 $\mathrm{mg}, 5.00 \mathrm{mmol})$ dissolved in water $(5 \mathrm{~mL})$ was added dropwise with rapid stirring. The mixture was left to stir for an hour, and the yellow precipitate was collected via vacuum filtration and dried under reduced pressure to yield $617 \mathrm{mg}(2.11 \mathrm{mmol}, 42 \%$ yield $)$ of the title compound. ${ }^{1} \mathrm{H}$ NMR $\left(400 \mathrm{MHz}, \mathrm{DMSO}-d_{6}\right): \delta=7.75(\mathrm{~d}, J=8.1 \mathrm{~Hz}, 1 \mathrm{H}), 7.56-7.50(\mathrm{~m}, 1 \mathrm{H}), 7.44(\mathrm{td}, J=8.2,5.7 \mathrm{~Hz}$, $1 \mathrm{H}) .{ }^{13} \mathrm{C}$ NMR $\left(150 \mathrm{MHz}, \mathrm{DMSO}-d_{6}\right) \delta=164.03,159.14,157.51,146.73,128.56,121.55,121.40$, 119.89. ${ }^{19}$ F NMR (375 MHz, DMSO- $\left.d_{6}\right): \delta=-113.86(\mathrm{dd}, J=8.7,5.7 \mathrm{~Hz}, 1 \mathrm{~F})$. IR $\left(\mathrm{ATR}, \mathrm{cm}^{-1}\right)$ : 1519.79 (s), 1461.68 (m), 1451.61 (m), 1382.20 (m), 1351.97 (s), 1306.11 (m), 1249.70 (s), 1187.53 (m), 1156.24 (m), 1065.73 (m), 956.17 (m), 905.20 (w), 840.35 (m), 807.47 (s), 763.50 (m), 736.70 (s), 696.85 (m). Elemental Analysis: calculated $\mathrm{C}_{7} \mathrm{H}_{3} \mathrm{AgFNO}_{4} \mathrm{C} 22.80 ; \mathrm{H} 1.04 ; \mathrm{N}$ 4.80; measured C 28.85; H 0.95; N 4.71.<smiles>COC(=O)c1c(F)cccc1OC(C)(C)C</smiles>

Silver 2-fluoro-6-methoxybenzoate (10). This synthesis was performed on the benchtop protected from light. To a mixture of sodium hydroxide (187 mg, $4.68 \mathrm{mmol})$ in water $(50 \mathrm{~mL})$ was added 2-fluoro-6-methoxybenzoic acid $(851 \mathrm{mg}, 5.00 \mathrm{mmol})$. The mixture was allowed to stir at room temperature until the benzoic acid was completely dissolved. Then a sample of silver nitrate $(854 \mathrm{mg}, 5.02 \mathrm{mmol})$ dissolved in water $(3 \mathrm{~mL})$ was added dropwise with rapid stirring. The mixture was left to stir for an hour, and the white precipitate was collected via vacuum filtration and dried under reduced pressure to yield $824 \mathrm{mg}(2.99 \mathrm{mmol}, 59 \%$ yield $)$ of the title compound. ${ }^{1} \mathrm{H}$ NMR (400 MHz, DMSO-d $): \delta=7.14(\mathrm{td}, J=8.3,6.9 \mathrm{~Hz}, 1 \mathrm{H}), 6.74(\mathrm{~d}, J=8.3$ 
$\mathrm{Hz}, 1 \mathrm{H}), 6.67(\mathrm{td}, 8.5,0.8 \mathrm{~Hz}, 1 \mathrm{H}), 3.69(\mathrm{~s}, 3 \mathrm{H}) .{ }^{13} \mathrm{C}$ NMR $\left(150 \mathrm{MHz}, \mathrm{DMSO}-d_{6}\right) \delta=167.25$, 159.24, 157.64, 156.61, 156.55, 128.43, 128.36, 120.21, 120.05, 107.97, 107.82, 107.57, 107.56, 56.11, 56.09. ${ }^{19} \mathrm{~F}$ NMR (375 MHz, DMSO-d $)$ : -117.22 (dd, $\left.J=8.4,7.2 \mathrm{~Hz}, 1 \mathrm{~F}\right)$. IR (ATR, $\mathrm{cm}^{-1}$ ): $2948.01(\mathrm{w}), 2838.83$ (w), 1709.78 (w), 1612.41 (m), 1581.15 (m), 1538.15 (s), 1465.76 (s), 1430.16 (w), 1389.74 (s), 1299.19 (w), 1272.36 (m), 1237.68 (s), 1170.97 (w), 1140.55 (w), 1124.08 (w), 1076.28 (s), 1065.38 (s), 937.88 (w), 845.57 (m), 793.72 (m), 765.33 (m), 723.26 (m), 629.78 (m). Elemental Analysis: calculated $\mathrm{C}_{8} \mathrm{H}_{6} \mathrm{AgFO}_{3} \mathrm{C} 34.69$; H 2.18; measured C 34.91; H 2.19.<smiles>CC(C)(C)OC(=O)c1ccccc1-c1ccccc1</smiles>

Silver 2-phenylbenzoate (11). This synthesis was performed on the benchtop protected from light. To a mixture of sodium hydroxide $(198 \mathrm{mg}, 4.95 \mathrm{mmol})$ in water $(15 \mathrm{~mL})$ was added 2-phenylbenzoic acid. The mixture was stirred at room temperature until the benzoic acid was completely dissolved. Then a sample of silver nitrate $(855 \mathrm{mg}, 5.03 \mathrm{mmol})$ dissolved in water (5 $\mathrm{mL}$ ) was added dropwise with rapid stirring. The mixture was left to stir for 2 hours, and the white precipitate was collected via vacuum filtration and dried under reduced pressure to yield $1294 \mathrm{mg}$ (4.24 mmol, $85 \%$ yield) of the title compound. ${ }^{1} \mathrm{H}$ NMR (400 MHz, DMSO- $\left.d_{6}\right): 7.44-7.36$ (m, $3 \mathrm{H}), 7.33-7.26(\mathrm{~m}, 3 \mathrm{H}), 7.26-7.20(\mathrm{~m}, 3 \mathrm{H}) .{ }^{13} \mathrm{C}$ NMR $\left(150 \mathrm{MHz}, \mathrm{DMSO}-d_{6}\right) \delta=173.42,142.01$, 138.28, 129.43, 128.25, 127.84, 127.63, 127.39, 126.57, 126.42, 109.95. IR (ATR, $\left.\mathrm{cm}^{-1}\right): 3452.63$ (w), $3055.36(\mathrm{w}), 1596.85(\mathrm{w}), 1556.73(\mathrm{~m}), 1540.35$ (m), $1496.79(\mathrm{~s}), 1449.70(\mathrm{~m}), 1435.29(\mathrm{~m})$, 1383.77 (s), 1151.55 (w), 1102.23 (w), 1076.27 (w), 1050.59 (w), 1007.08 (w), 955.51 (w), 922.14 (w), $846.06(\mathrm{~m}), 807.40(\mathrm{w}), 797.49(\mathrm{w}), 782.90(\mathrm{~m}), 757.46(\mathrm{~s}), 744.38(\mathrm{~s}), 734.72(\mathrm{~s}), 703.05(\mathrm{~s})$, 666.46 (s). Elemental Analysis: calculated $\mathrm{C}_{13} \mathrm{H}_{9} \mathrm{AgO}_{2} \mathrm{C}, 51.18 ; \mathrm{H}, 2.97$; measured C 51.45; H 2.90 
<smiles>COC(=O)c1ccccc1C(F)(F)F</smiles>

Silver 2-(trifluoromethyl)benzoate (12). This synthesis was performed on the benchtop protected from light. To a mixture of sodium hydroxide (198 mg, $4.95 \mathrm{mmol})$ in water $(15 \mathrm{~mL})$ was added 2-trifluoromethylbenzoic acid $(952 \mathrm{mg}, 5.01 \mathrm{mmol})$. The mixture was allowed to stir at room temperature until the benzoic acid was completely dissolved. Then a sample of silver nitrate $(851 \mathrm{mg}, 5.00 \mathrm{mmol})$ dissolved in water $(5 \mathrm{~mL})$ was added dropwise with rapid stirring. The mixture was left to stir for an hour, and the white precipitate was collected via vacuum filtration and dried under reduced pressure to yield $1111 \mathrm{mg}(3.74 \mathrm{mmol}, 75 \%$ yield $)$ of the title compound. ${ }^{1} \mathrm{H}$ NMR (400 MHz, DMSO- $\left.d_{6}\right): \delta=7.58(\mathrm{~d}, J=7.9 \mathrm{~Hz}, 1 \mathrm{H}), 7.53(\mathrm{t}, J=7.4 \mathrm{~Hz}, 1 \mathrm{H})$, $7.47(\mathrm{~d}, J=7.3 \mathrm{~Hz}, 1 \mathrm{H}), 7.40(\mathrm{t}, J=7.6 \mathrm{~Hz}, 1 \mathrm{H}) .{ }^{13} \mathrm{C}$ NMR $\left(150 \mathrm{MHz}, \mathrm{DMSO}-d_{6}\right) \delta=171.41$, $141.40,132.24,128.81,127.84,125.85,125.59,125.40,125.19,124.99,123.78$. ${ }^{19} \mathrm{~F}$ NMR $(375$ MHz, DMSO- $\left.d_{6}\right): \delta=-57.96(\mathrm{~s}, 3 \mathrm{~F})$. IR $\left(\mathrm{ATR}, \mathrm{cm}^{-1}\right): 1604.94(\mathrm{w}), 1550.96(\mathrm{~m}), 1496.87(\mathrm{w})$, 1448.54 (w), 1364.91 (s), 1315.71 (s), 1271.59 (m), 1168.64 (m), 1126.99 (s), 1110.64 (s), 1054.84 (m), 1034.55 (s), 961.55 (w), 887.09 (w), 847.25 (m), 797.83 (w), 772.88 (m), 766.37 (s), 737.17 (m), $686.04(\mathrm{~m}), 645.88(\mathrm{~m}), 601.83(\mathrm{~m})$. Elemental Analysis: calculated $\mathrm{C}_{8} \mathrm{H}_{4} \mathrm{AgF}_{3} \mathrm{O}_{2} \mathrm{C}_{32.35}$; H 1.36; measured C 32.38; H 1.27.

\subsubsection{Synthesis and Characterization of Silver Heteroaromatic Carboxylates}<smiles>COC(=O)c1cc2ccccc2s1</smiles>

Silver 1-benzothiophen-2-carboxylate (14). This synthesis was performed on the benchtop protected from light. To a mixture of sodium hydroxide (198 mg, $4.95 \mathrm{mmol})$ in water $(15 \mathrm{~mL})$ was added 1-benzothiophene-2-carboxylic acid (892 mg, $5.00 \mathrm{mmol})$. The mixture was allowed to stir at room temperature for two hours. Then a sample of silver nitrate (856 mg, $5.04 \mathrm{mmol})$ dissolved in water $(5 \mathrm{~mL})$ was added dropwise with rapid stirring. The mixture was left to stir overnight, and the white precipitate was collected via vacuum filtration and dried under reduced 
pressure to yield $1313 \mathrm{mg}$ ( $4.60 \mathrm{mmol}, 92 \%$ yield) of the title compound. ${ }^{1} \mathrm{H}$ NMR $(600 \mathrm{MHz}$, DMSO- $\left.d_{6}\right): \delta=7.88(\mathrm{dd}, J=3.45,1.2 \mathrm{~Hz}, 2 \mathrm{H}), 7.77(\mathrm{~s}, 1 \mathrm{H}), 7.36(\mathrm{p}, J=1.2 \mathrm{~Hz}, 2 \mathrm{H}) .{ }^{13} \mathrm{C}$ NMR $\left(150 \mathrm{MHz}, \mathrm{DMSO}-d_{6}\right) \delta=165.83,142.77,141.39,139.90,127.03,125.95,125.28,124.79$, 123.09. IR (ATR, $\left.\mathrm{cm}^{-1}\right)$ : $3054.16(\mathrm{w}), 2569.23(\mathrm{w}), 1657.79(\mathrm{w}), 1580.22(\mathrm{w}), 1557.90(\mathrm{~m})$, 1505.14 (s), 1458.38 (w), 1428.80 (w), 1373.27 (s), 1321.21 (m), 1256.37 (w), 1178.25 (m), 1154.47 (m), 1127.97 (w), $1079.94(\mathrm{~m}), 1052.93$ (w), 1011.55 (w), 939.89 (w), 885.97 (w), 874.95 (w), $866.54(\mathrm{w}), 839.95(\mathrm{w}), 784.60(\mathrm{~m}), 764.29(\mathrm{~s}), 742.92(\mathrm{~m}), 723.48(\mathrm{~s}), 717.02(\mathrm{~s})$. Elemental Analysis: Calculated $\mathrm{C}_{9} \mathrm{H}_{5} \mathrm{AgO}_{2} \mathrm{~S} \mathrm{C}, 37.92 ; \mathrm{H}, 1.77$; measured C 37.86; $\mathrm{H} 1.59$.

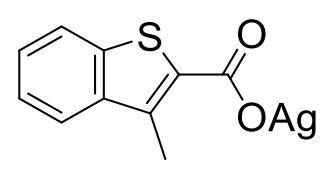

Silver 3-methyl-1-benzothiophen-2-carboxylate (15). This synthesis was performed on the benchtop protected from light. To a mixture of sodium hydroxide (38 $\mathrm{mg}, 0.95 \mathrm{mmol}$ ) in water $(10 \mathrm{~mL})$ was added 3-methyl-1-benzothiophen-2-carboxylic acid (193 mg, $1.00 \mathrm{mmol})$. The mixture was allowed to stir at room temperature for three hours. Then a sample of silver nitrate $(171 \mathrm{mg}, 1.00 \mathrm{mmol})$ dissolved in water $(5 \mathrm{~mL})$ was added dropwise with rapid stirring. The mixture was left to stir overnight, and the white precipitate was collected via vacuum filtration and dried under reduced pressure to yield $230 \mathrm{mg}(0.77 \mathrm{mmol}, 77 \%$ yield $)$ of the title compound. ${ }^{1} \mathrm{H}$ NMR (600 MHz, DMSO- $\left.d_{6}\right): \delta=7.83(\mathrm{dt}, J=6.5,2.7 \mathrm{~Hz}, 1 \mathrm{H}), 7.78-7.72(\mathrm{~m}, 1 \mathrm{H}), 7.39-7.32$ (m, 2H), 2.66 (s, 3H). ${ }^{13} \mathrm{C}$ NMR $\left(150 \mathrm{MHz}\right.$, DMSO- $\left.d_{6}\right) \delta=167.36,141.47,139.22,133.70,125.83$, 124.23, 123.35. 122.75, 110.00, 12.79. IR (ATR, $\left.\mathrm{cm}^{-1}\right): 3058.39$ (w), 2920.60 (w), $1543.46(\mathrm{~s})$, $1459.25(\mathrm{w}), 1432.56(\mathrm{~m}), 1383.29(\mathrm{~s}), 1370.00(\mathrm{~s}), 1328.05(\mathrm{~m}), 1316.03(\mathrm{~m}), 1258.27(\mathrm{~m})$, $1143.36(\mathrm{~m}), 1122.01(\mathrm{~m}), 1060.92(\mathrm{w}), 1003.26(\mathrm{~m}), 932.33(\mathrm{w}), 839.60(\mathrm{~m}), 780.78(\mathrm{~m}), 756.21$ (s), 725.36 (s). Elemental Analysis: calculated $\mathrm{C}_{10} \mathrm{H}_{7} \mathrm{AgO}_{2} \mathrm{~S} \mathrm{C} 40.16$; H 2.36; measured C 40.35; H 2.44 . 


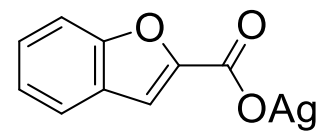

Silver 1-benzofuran-2-carboxylate (16). This synthesis was performed on the benchtop protected from light. To a mixture of triethyl amine ( $280 \mu \mathrm{L} \mathrm{mg}, 2.02 \mathrm{mmol})$ in 1,4-dioxane (10 $\mathrm{mL}$ ) was added 1-benzofuran-2-carboxylic acid (328 mg, $2.02 \mathrm{mmol})$. The mixture was allowed to stir at room temperature for overnight. Then a sample of silver nitrate $(344 \mathrm{mg}, 2.02 \mathrm{mmol})$ dissolved in water $(10 \mathrm{~mL})$ was added dropwise with rapid stirring. The mixture was left to stir for 10 minutes, and the off-white precipitate was collected via vacuum filtration and dried under reduced pressure to yield $270 \mathrm{mg}$ ( $1.00 \mathrm{mmol}, 50 \%$ yield) of the title compound. 1H NMR (400 MHz, DMSO- d6): $\delta=7.62(\mathrm{~d}, \mathrm{~J}=7.8 \mathrm{~Hz}, 1 \mathrm{H}), 7.54(\mathrm{~d}, \mathrm{~J}=8.3 \mathrm{~Hz}, 1 \mathrm{H}), 7.30$ (ddd, J = 8.3, 7.2, $1.4 \mathrm{~Hz}, 1 \mathrm{H}), 7.20$ (t, J = 7.6 Hz, 1H), 7.13 (s, 1H). 13C NMR (150 MHz, DMSO-d6) $\delta=163.32$, 154.69, 153.67, 128.32, 125.83, 123.28, 122.44, 112.04, 109.17. IR (ATR, cm-1): 3124.46 (w), 3061.93 (w), 1693.19 (w), 1615.92 (w), 1575.03 (s), 1512.77 (s), 1475.20 (m), 1449.60 (m), 1394.57 (s), 1338.89 (s), 1316.59 (m), 1264.18 (w), 1242.18 (m), 1187.89 (s), 1143.82 (w), 1119.05 (w), 1103.00 (w), 1005.41 (w), 945.12 (s), 926.02 (w), 891.25 (m), 856.86 (w), 830.71 (m), $773.88(\mathrm{~m}), 766.30(\mathrm{~m}), 758.68(\mathrm{~m}), 742.03$ (s), 727.70 (s). Elemental Analysis: Calculated C9H5AgO3 C, 40.18; H, 1.87; measured C 40.29; H 1.76.

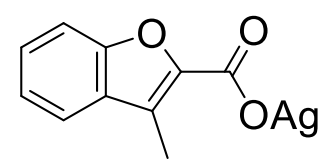

Silver 3-methyl-1-benzofuran-2-carboxylate (17). This synthesis was performed on the benchtop protected from light. To a mixture of sodium hydroxide (38 $\mathrm{mg}, 0.95 \mathrm{mmol}$ ) in water $(10 \mathrm{~mL})$ was added 3-methyl-1-benzofuran-2-carboxylic acid $(177 \mathrm{mg}, 1.00 \mathrm{mmol})$. The mixture was allowed to stir at room temperature for three hours. Then a sample of silver nitrate $(170 \mathrm{mg}$, $1.00 \mathrm{mmol})$ dissolved in water $(5 \mathrm{~mL})$ was added dropwise with rapid stirring. The mixture was left to stir overnight, and the white precipitate was collected via vacuum filtration and dried under reduced pressure to yield $205 \mathrm{mg}$ ( $0.72 \mathrm{mmol}, 74 \%$ yield) of the title compound. 1H NMR (600 MHz, DMSO- d6): $\delta=7.60$ (dt, J = 7.8, $0.9 \mathrm{~Hz}, 1 \mathrm{H}$ ), 7.49 (d, J = 8.2 Hz, 1H), 7.33 (ddd, J = 8.3, 
7.1, $1.3 \mathrm{~Hz}, 1 \mathrm{H}), 7.25$ - $7.19(\mathrm{~m}, 1 \mathrm{H}), 2.48$ (s, 3H). 13C NMR (150 MHz, DMSO-d6) $\delta=164.50$, 153.12, 148.16, 130.26, 125.93, 122.68, 120.86, 118.21, 111.73, 9.75. IR (ATR, cm-1): 3068.93 (w), 1601.95 (m), 1556.62 (s), 1539.06 (m), 1446.07 (w), 1412.90 (s), 1397.14 (m), 1374.45 (m), 1327.48 (s), 1271.56 (m), 1241.41 (w), 1165.70 (m), 1146.68 (w), 1117.80 (w), 1097.11 (w), $1060.01(w), 1002.12(w), 966.36(w), 920.25(w), 882.66(w), 852.96(m), 788.90(w), 767.09$ (m), 760.58 (m), 748.87 (s), 739.74 (s), 722.38 (m). Elemental Analysis: calculated C10H7AgO3 C 42.44; H 2.49; measured C 42.64; H 2.55.

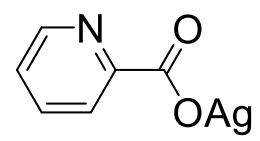

Silver pyridine-2-carboxylate (18). This synthesis was performed on the benchtop protected from light. To a mixture of triethyl amine $(280 \mu \mathrm{L} \mathrm{mg}, 2.02 \mathrm{mmol})$ in 1,4-dioxane $(20 \mathrm{~mL})$ was added pyridine-2-carboxylic acid (246 mg, $2.00 \mathrm{mmol})$. The mixture was allowed to stir at room temperature until the carboxylic acid was completely dissolved. Then a sample of silver nitrate (340 mg, $2.00 \mathrm{mmol}$ ) dissolved in MeCN (2 mL) was added dropwise with rapid stirring. The mixture was left to stir overnight, and the white precipitate was collected via vacuum filtration and washed with 1,4-dioxane $(5 \mathrm{~mL})$ and water $(100 \mathrm{~mL})$. The solid was dried under vacuum to yield $340 \mathrm{mg}$ (1.48 mmol, $74 \%$ yield) of the title compound. 1H NMR (400 MHz, DMSO-d6): $\delta=8.52$ $(\mathrm{d}, \mathrm{J}=5.0 \mathrm{~Hz}, 1 \mathrm{H}), 8.18(\mathrm{~d}, \mathrm{~J}=7.9 \mathrm{~Hz}, 1 \mathrm{H}), 7.94(\mathrm{t}, \mathrm{J}=7.7 \mathrm{~Hz}, 1 \mathrm{H}), 7.52$ (t, J = $6.4 \mathrm{~Hz}, 1 \mathrm{H})$. IR (ATR, cm-1): 3059.16 (w), 1634.63 (m), 1603.32 (m), 1592.28 (m), 1576.33 (m), 1557.82 (s), 1470.84 (w), 1434.90 (w), 1407.44 (m), 1388.00 (s), 1353.67 (s), 1299.06 (m), 1288.88 (m), 1254.85 (m), 1227.00 (m), 1163.97 (w), 1152.03 (m), 1087.34 (m), 1048.30 (m), 1011.12 (m), 961.77 (w), 836.07 (m), 760.21 (m), 740.93 (s), 699.15 (s), 691.08 (s). Elemental Analysis: Calculated C6H4AgO2N C, 31.34; H, 1.75; N 6.09; measured C 31.57; H 1.63; N 5.91. 


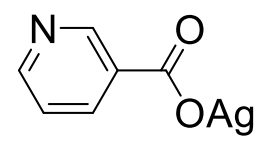

Silver pyridine-3-carboxylate (19). This synthesis was performed on the benchtop protected from light. To a mixture of triethyl amine $(280 \mu \mathrm{L} \mathrm{mg}, 2.02 \mathrm{mmol})$ in 1,4-dioxane $(20 \mathrm{~mL})$ was added pyridine-3-carboxylic acid $(247 \mathrm{mg}, 2.00 \mathrm{mmol})$. The mixture was allowed to stir at room temperature until the carboxylic acid was completely dissolved. Then a sample of silver nitrate (341 mg, $2.00 \mathrm{mmol}$ ) dissolved in $\mathrm{MeCN}(2 \mathrm{~mL})$ was added dropwise with rapid stirring. The mixture was left to stir overnight, and the white precipitate was collected via vacuum filtration and washed with 1,4-dioxane $(5 \mathrm{~mL})$ and water $(100 \mathrm{~mL})$. The solid was dried under vacuum to yield $340 \mathrm{mg}(1.48 \mathrm{mmol}, 74 \%$ yield $)$ of the title compound. ${ }^{1} \mathrm{H}$ NMR $\left(400 \mathrm{MHz}, \mathrm{DMSO}-d_{6}\right): \delta=8.96$ (s, $1 \mathrm{H}), 8.48(\mathrm{~d}, \mathrm{~J}=4.1 \mathrm{~Hz}, 1 \mathrm{H}), 8.11(\mathrm{~d}, \mathrm{~J}=8.4 \mathrm{~Hz}, 1 \mathrm{H}), 7.34-7.27(\mathrm{~m}, 1 \mathrm{H})$. IR (ATR, $\left.\mathrm{cm}^{-1}\right)$ : 3096.74 (w), 1599.68 (s), 1587.89 (m), 1545.23 (s), 1515.26 (w), 1422.73 (w), 1381.69 (s), 1317.82 (w), 1193.75 (m), 1159.01 (w), 1092.00 (m), 1042.94 (m), 1031.59 (m), 997.53 (w), 838.14 (m), 745.64 (s), 693.72 (s). Elemental Analysis: Calculated $\mathrm{C}_{6} \mathrm{H}_{4} \mathrm{AgO}_{2} \mathrm{NC}, 31.34 ; \mathrm{H}, 1.75$; N 6.09; measured C 31.52; H 1.63; N 5.91.

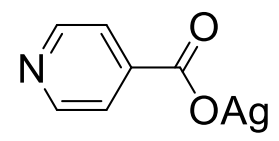

Silver pyridine-4-carboxylate (20). This synthesis was performed on the benchtop protected from light. To a mixture of triethyl amine $(280 \mu \mathrm{L} \mathrm{mg}, 2.02 \mathrm{mmol})$ in 1,4-dioxane $(20 \mathrm{~mL})$ and $\mathrm{MeCN}$ $(1 \mathrm{~mL})$ was added pyridine-4-carboxylic acid $(247 \mathrm{mg}, 2.00 \mathrm{mmol})$. The mixture was allowed to stir at room temperature for a few hours. Then a sample of silver nitrate $(342 \mathrm{mg}, 2.01 \mathrm{mmol})$ dissolved in $\mathrm{MeCN}$ ( $2 \mathrm{~mL}$ ) was added dropwise with rapid stirring. The mixture was left to stir overnight, and the white precipitate was collected via vacuum filtration and washed with 1,4-dioxane $(5 \mathrm{~mL})$ and water $(100 \mathrm{~mL})$. The solid was dried under vacuum to yield $305 \mathrm{mg}$ (1.33 mmol, $66 \%$ yield) of the title compound. ${ }^{1} \mathrm{H}$ NMR (400 MHz, DMSO- $\left.d_{6}\right): \delta=8.52$ (d, J $=4.4$ $\mathrm{Hz}, 2 \mathrm{H}), 7.68$ (d, J = 4.9 Hz, 2H). IR (ATR, $\mathrm{cm}^{-1}$ ): 3114.91 (w), 3042.92 (w), 2454.12 (w), 1951.36 (w), 1624.49 (s), 1607.49 (s), 1550.85 (m), 1492.74 (w), 1413.14 (m), 1382.67 (w), 1329.18 (s), 
$1314.30(\mathrm{~s}), 1226.72(\mathrm{~m}), 1214.72(\mathrm{~m}), 1143.36$ (m), $1086.53(\mathrm{w}), 1053.32$ (m), $1017.15(\mathrm{~m})$, $977.22(\mathrm{w}), 875.17(\mathrm{w}), 859.31(\mathrm{~m}), 841.02$ (m), 762.51 (s), 704.75 (s), 689.48 (s), 660.46 (m). Elemental Analysis: Calculated $\mathrm{C}_{6} \mathrm{H}_{4} \mathrm{AgO}_{2} \mathrm{NC}, 31.34 ; \mathrm{H}, 1.75 ; \mathrm{N}$ 6.09; measured C 31.34; H 1.65; N 5.90 .<smiles>O=C(O[Na])c1cccnc1C(F)(F)F</smiles>

Silver 2-(trifluoromethyl)pyridine-3-carboxylate (21). This synthesis was performed on the benchtop protected from light. To a mixture of sodium hydroxide $(78 \mathrm{mg}, 1.95 \mathrm{mmol})$ in acetonitrile $(15 \mathrm{~mL})$ and water $(1 \mathrm{~mL})$ was added 2-(trifluoromethyl)pyridine-3-carboxylic acid (383 mg, $2.00 \mathrm{mmol}$ ). The mixture was allowed to stir at room temperature until the solids dissolved. Then a sample of silver nitrate $(341 \mathrm{mg}, 2.00 \mathrm{mmol})$ dissolved in acetonitrile $(5 \mathrm{~mL})$ was added dropwise with rapid stirring. The mixture was left to stir overnight. Methyl tert-butyl ether $(60 \mathrm{~mL})$ and diethyl ether $(100 \mathrm{~mL})$ were added to crash the product from solution resulting in a cloudy mixture. The mixture was condensed to $\sim 10 \mathrm{~mL}$ and an additional $20 \mathrm{~mL}$ diethyl ether were added. The off-white precipitate was collected via vacuum filtration and dried under reduced pressure to yield $109 \mathrm{mg}(0.37 \mathrm{mmol}, 18 \%$ yield $)$ of the title compound. ${ }^{1} \mathrm{H} \mathrm{NMR}(400 \mathrm{MHz}$, DMSO-d $\left.d_{6}\right): \delta=8.58-8.52(\mathrm{~m}, 1 \mathrm{H}), 7.85(\mathrm{dd}, \mathrm{J}=7.9,1.6 \mathrm{~Hz}, 1 \mathrm{H}), 7.57(\mathrm{dd}, \mathrm{J}=7.8,4.6 \mathrm{~Hz}, 1 \mathrm{H})$. ${ }^{19} \mathrm{~F}$ NMR (375 MHz, DMSO-d6): $\delta=-63.06$ (s, 3F). IR (ATR, $\mathrm{cm}^{-1}$ ): 1582.29 (s), 1383.43 (s), 1324.87 (s), 1192.57 (s), 1124.01 (s), 1071.46 (s), 1054.91 (m), 852.92 (m), 825.03 (w), 787.77 (m), $702.41(\mathrm{~m}), 653.97(\mathrm{~m})$. Elemental Analysis: Calculated $\mathrm{C}_{7} \mathrm{H}_{3} \mathrm{AgF}_{3} \mathrm{NO}_{2} \mathrm{C}, 28.22 ; \mathrm{H}, 1.01 ; \mathrm{N}$, 4.70; measured C 27.92; H 0.89; N, 4.46. 
<smiles>COC(=O)c1cc(C(F)(F)F)ccn1</smiles>

Silver 4-trifluoromethylpyridine-2-carboxylate (22). This synthesis was performed on the benchtop protected from light. To a mixture of triethyl amine $(280 \mu \mathrm{L} \mathrm{mg}, 2.02 \mathrm{mmol})$ in 1,4-dioxane (10 mL) was added 4-chloro pyridine-2-carboxylic acid (317.1 mg, $2.01 \mathrm{mmol})$. The mixture was allowed to stir at room temperature for $\sim 2$ hours where $3 \mathrm{~mL} \mathrm{H}_{2} \mathrm{O}$ was added and stirred for an additional 10 minutes to fully dissolve the carboxylic acid. Then a sample of silver nitrate $(340 \mathrm{mg}, 2.00 \mathrm{mmol})$ dissolved in $\mathrm{H}_{2} \mathrm{O}(10 \mathrm{~mL})$ was added dropwise with rapid stirring. The mixture was left to stir for $20 \mathrm{~min}$, and the white precipitate was collected via vacuum filtration and washed with 1,4-dioxane $(15 \mathrm{~mL})$, water $(150 \mathrm{~mL})$, and diethyl ether $(15 \mathrm{~mL})$. The solid was dried under vacuum to yield $485 \mathrm{mg}$ (1.63 mmol, $81 \%$ yield) of the title compound. ${ }^{1} \mathrm{H}$ NMR $\left(600 \mathrm{MHz}, \mathrm{DMSO}-d_{6}\right): \delta=8.82(\mathrm{~d}, \mathrm{~J}=5.1 \mathrm{~Hz}, 1 \mathrm{H}), 8.39(\mathrm{~s}, 1 \mathrm{H}), 7.93(\mathrm{~d}, \mathrm{~J}=5.2 \mathrm{~Hz}, 1 \mathrm{H}) .{ }^{19} \mathrm{~F}$ NMR (375 MHz, DMSO-d $\left.)_{6}\right): \delta=-63.58$ (s, 3F). IR (ATR, $\mathrm{cm}^{-1}$ ): $3050.50(\mathrm{w}), 1622.58(\mathrm{~m})$, 1596.58 (s), 1562.99 (m), 1477.22 (w), 1425.38 (w), 1368.74 (m), 1319.00 (s), 1277.52 (m), 1175.60 (m), 1161.81 (s), 1130.26 (s), 1100.60 (m), 1081.39 (m), $1009.84(w), 919.66(w), 877.38$ (w), $858.21(\mathrm{~m}), 769.04(\mathrm{~m}), 786.07$ (m), 708.99 (s), 671.56 (s). Elemental Analysis: Calculated $\mathrm{C}_{7} \mathrm{H}_{3} \mathrm{AgF}_{3} \mathrm{NO}_{2} \mathrm{C}, 28.22 ; \mathrm{H}, 1.01 ; \mathrm{N}, 4.70 ;$ measured C 28.15; H 0.90; N 4.56.<smiles>COC(=O)c1cc(Cl)ccn1</smiles>

Silver 4-chloro-pyridine-2-carboxylate (23). This synthesis was performed on the benchtop protected from light. To a mixture of triethyl amine $(280 \mu \mathrm{L} \mathrm{mg}, 2.02 \mathrm{mmol})$ in 1,4-dioxane (10 $\mathrm{mL}$ ) was added 4-chloro pyridine-2-carboxylic acid (317.1 $\mathrm{mg}, 2.01 \mathrm{mmol}$ ). The mixture was allowed to stir at room temperature for $\sim 2$ hours where $2 \mathrm{~mL} \mathrm{H}_{2} \mathrm{O}$ was added and stirred for an additional 10 minutes to fully dissolve the carboxylic acid. Then a sample of silver nitrate (340 
$\mathrm{mg}, 2.00 \mathrm{mmol})$ dissolved in $\mathrm{H}_{2} \mathrm{O}(8 \mathrm{~mL})$ was added dropwise with rapid stirring. The mixture was left to stir for 4 hours, and the white precipitate was collected via vacuum filtration and washed with 1,4-dioxane $(20 \mathrm{~mL})$, water $(100 \mathrm{~mL})$, and diethyl ether $(20 \mathrm{~mL})$. The solid was dried under vacuum to yield $476 \mathrm{mg}(1.80 \mathrm{mmol}, 90 \%$ yield $)$ of the title compound. ${ }^{1} \mathrm{H} \mathrm{NMR}(600 \mathrm{MHz}$, DMSO-d $\left.d_{6}\right): \delta=8.51(\mathrm{~d}, \mathrm{~J}=5.5 \mathrm{~Hz}, 1 \mathrm{H}), 8.16(\mathrm{~d}, \mathrm{~J}=2.3 \mathrm{~Hz}, 1 \mathrm{H}), 7.68(\mathrm{dd}, \mathrm{J}=5.5,2.2 \mathrm{~Hz}, 1 \mathrm{H})$. IR (ATR, $\mathrm{cm}^{-1}$ ): $3479.96(\mathrm{w}), 3058.03$ (w), 1633.35 (m), 1595.01 (m), 1569.86 (s), 1556.28 (s), 1404.92 (m), 1373.00 (m), 1351.22 (s), 1281.78 (m), 1241.55 (m), 1180.74 (m), 1104.71 (w), 1008.48 (m), $911.16(w), 892.51(w), 871.15(\mathrm{~m}), 850.38(\mathrm{~m}), 793.54(\mathrm{~m}), 755.92(\mathrm{~s}), 703.25(\mathrm{~m})$, 689.77 (m). Elemental Analysis: Calculated $\mathrm{C}_{6} \mathrm{H}_{3} \mathrm{AgClNO}_{2} \mathrm{C}, 27.16 ; \mathrm{H}, 1.14 ; \mathrm{N}, 5.30$; measured C 27.20; H 1.24; N 5.17.<smiles>COCCOCCOC(=O)c1cnccc1C(F)(F)F</smiles>

Silver 4-(trifluoromethyl)pyridine-3-carboxylate (24). This synthesis was performed on the benchtop protected from light. To a mixture of triethyl amine $(140 \mu \mathrm{L} \mathrm{mg}, 1.01 \mathrm{mmol})$ in 1,4-dioxane (10 mL) was added 4-(trifluoromethyl)pyridine-3-carboxylic acid (191 mg, 1.00 mmol). The mixture was allowed to stir at room temperature until the carboxylic acid was completely dissolved. Then a sample of silver nitrate (170 mg, $1.00 \mathrm{mmol})$ dissolved in MeCN (1 $\mathrm{mL}$ ) was added dropwise with rapid stirring. The mixture was left to stir overnight, and the light tan precipitate was collected via vacuum filtration and washed with 1,4-dioxane $(5 \mathrm{~mL})$ and water $(100 \mathrm{~mL})$. The solid was dried under vacuum to yield $217 \mathrm{mg}(0.73 \mathrm{mmol}, 73 \%$ yield $)$ of the title compound. ${ }^{1} \mathrm{H}$ NMR (400 MHz, DMSO- $\left.d_{6}\right): \delta=8.71(\mathrm{~s}, 1 \mathrm{H}), 8.63(\mathrm{~d}, \mathrm{~J}=5.2 \mathrm{~Hz}, 1 \mathrm{H}), 7.57$ (d, J $=5.2 \mathrm{~Hz}, 1 \mathrm{H}) .{ }^{19} \mathrm{~F}$ NMR $\left(375 \mathrm{MHz}, \mathrm{DMSO}-d_{6}\right): \delta=-60.64(\mathrm{~s}, 3 \mathrm{~F}) . \quad \mathrm{IR}\left(\mathrm{ATR}, \mathrm{cm}^{-1}\right): 3123.67(\mathrm{w})$, 1603.25 (m), 1571.65 (s), 1490.71 (w), 1380.31 (s), 1307.45 (s), 1276.91 (s), 1242.64 (m), 1188.89 (m), 1139.31 (s), 1070.06 (m), 1058.61 (s), $949.98(\mathrm{w}), 851.65$ (s), 800.36 (m), 779.37 (m), 731.91 (w), 706.20 (m), 665.80 (s). Elemental Analysis: Calculated $\mathrm{C}_{7} \mathrm{H}_{3} \mathrm{AgF}_{3} \mathrm{O}_{2} \mathrm{~N} \mathrm{C}, 28.22 ; \mathrm{H}, 1.01 ; \mathrm{N}$ 4.70; measured C 28.34; H 0.93; N 4.70. 


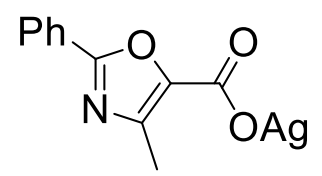

Silver 4-methyl-2-phenyl-1,3-oxazole-5-carboxylate (25). This synthesis was performed on the benchtop protected from light. To a mixture of sodium hydroxide $(18 \mathrm{mg}, 0.45 \mathrm{mmol})$ in water $(10 \mathrm{~mL})$ and ethanol $(15 \mathrm{~mL})$ was added 4-methyl-2-phenyl-1,3-oxazole-5-carboxylic acid (107 $\mathrm{mg}, 0.52 \mathrm{mmol}$ ). The mixture was allowed to stir at room temperature until the carboxylic acid was completely dissolved. Then a sample of silver triflate $(130 \mathrm{mg}, 0.50 \mathrm{mmol})$ dissolved in water $(3 \mathrm{~mL})$ was added dropwise with rapid stirring. The mixture was left to stir for an hour, and the white precipitate was collected via vacuum filtration and dried under reduced pressure to yield 51 mg (0.17 mmol, $33 \%$ yield) of the title compound. ${ }^{1} \mathrm{H}$ NMR (400 MHz, DMSO- $\left.d_{6}\right)$ : $\delta=7.98-7.90(\mathrm{~m}, 2 \mathrm{H}), 7.50(\mathrm{p}, J=3.4 \mathrm{~Hz}, 3 \mathrm{H}), 2.39(\mathrm{~s}, 3 \mathrm{H}) .{ }^{13} \mathrm{C}$ NMR $\left(150 \mathrm{MHz}\right.$, DMSO- $\left.d_{6}\right)$ $\delta=162.46,159.00,143.42,140.96,131.13,129.56,127.36,126.49,13.66$. IR (ATR, $\left.\mathrm{cm}^{-1}\right)$ : 3205.14 (w), 1624.02 (m), 1574.28 (m), 1538.46 (m), 1479.87 (m), 1447.49 (m), 1429.12 (w), 1397.70 (m), 1374.51 (s), 1282.10 (m), 1170.60 (m), 1125.19 (m), 1111.02 (w), 1074.07 (w), 1025.54 (w), 1000.37 (w), 964.97 (w), 922.67 (w), 830.16 (m), 769.63 (m), 786.61 (m), 710.54 (s), 684.99 (s). Elemental Analysis: calculated $\mathrm{C}_{11} \mathrm{H}_{8} \mathrm{AgNO}_{3} \mathrm{C} 42.61 ; \mathrm{H} 2.60 ; \mathrm{N}$ 4.52; measured C 42.48; H 2.79; N 4.58 .

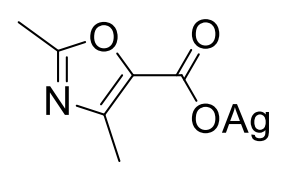

Silver 2,4-dimethyl-1,3-oxazole-5-carboxylate (26). This synthesis was performed on the benchtop protected from light. To a mixture of sodium hydroxide (196 mg, $4.90 \mathrm{mmol}$ ) in water (15 mL) was added 2,4-dimethyl-1,3-oxazole-5-carboxylic acid (713 mg, $5.05 \mathrm{mmol})$. The mixture was allowed to stir at room temperature for two hours. Then a sample of silver nitrate $(852 \mathrm{mg}$, $5.01 \mathrm{mmol})$ dissolved in water $(5 \mathrm{~mL})$ was added dropwise with rapid stirring. The mixture was left to stir overnight, and the off-white precipitate was collected via vacuum filtration and dried under reduced pressure to yield $1077 \mathrm{mg}$ ( $4.34 \mathrm{mmol}, 87 \%$ yield) of the title compound. ${ }^{1} \mathrm{H}$ NMR (400 MHz, DMSO- $\left.d_{6}\right): \delta=2.29$ (s, 3H), 2.23 (s, 3H). IR (ATR, $\left.\mathrm{cm}^{-1}\right): 2925.68(\mathrm{w}), 1624.53(\mathrm{~m})$, 
1589.32 (s), $1559.96(\mathrm{~m}), 1424.13(\mathrm{~m}), 1404.30(\mathrm{~s}), 1385.07(\mathrm{~m}), 1325.71(\mathrm{w}), 1272.74(\mathrm{~m})$, 1168.15 (s), 1108.64 (m), 1041.68 (w), 1001.23 (w), 974.85 (w), 827.70 (s), 785.33 (m), 750.28 (m), 680.09 (w). Elemental Analysis: Calculated $\mathrm{C}_{6} \mathrm{H}_{6} \mathrm{AgNO}_{3} \mathrm{C}, 29.06$; H, 2.44; N 5.65 measured C 28.99; H 2.35; N 5.67.<smiles>Cc1nc(-c2ccccc2)sc1C(=O)O</smiles>

4-methyl-2-phenyl-1,3-thiazole-5-carboxylic acid. This synthesis was prepared following a literature procedure. ${ }^{[18]}$ A mixture of thiobenzamide $(1.89 \mathrm{~g}, 14.0 \mathrm{mmol})$ and ethyl 2-chloroacetoacetate $(1.75 \mathrm{~mL}, 12.5 \mathrm{mmol})$ in methanol $(20 \mathrm{~mL})$ was refluxed for $6 \mathrm{~h}$ in a $100 \mathrm{~mL}$ round bottom flask equipped with a stir bar. The solvent was removed under reduced pressure to yield the crude ethyl carboxylate. To the crude ethyl carboxylate, $24 \mathrm{~mL}$ of a mixture of $(1: 1: 1)$ $\mathrm{THF} / \mathrm{EtOH} / \mathrm{H}_{2} \mathrm{O}$ and $\mathrm{KOH}$ (4 equiv.) were added and the mixture was allowed to stir at room temperature overnight. The reaction was quenched with $2 \mathrm{~N} \mathrm{HCl}$ to $\mathrm{pH}=2$ and the solid was filtered and dried under vacuum to yield $2.15 \mathrm{~g}(9.82 \mathrm{mmol}, 79 \%$ yield $)$ of the title compound. ${ }^{1} \mathrm{H}$ NMR spectral data is consistent with literature. ${ }^{[18]}{ }^{1} \mathrm{H}$ NMR $\left(400 \mathrm{MHz}, \mathrm{CDCl}_{3}\right) \delta=7.97$ (dd, $J=7.6,2.0 \mathrm{~Hz}, 2 \mathrm{H}), 7.52-7.39(\mathrm{~m}, 3 \mathrm{H}), 2.80(\mathrm{~s}, 3 \mathrm{H})$.<smiles>COC(=O)c1sc(-c2ccccc2)nc1C</smiles>

Silver 4-methyl-2-phenyl-1,3-thiazole-5-carboxylate (27). This synthesis was performed on the benchtop protected from light. To a mixture of sodium hydroxide $(36 \mathrm{mg}, 0.90 \mathrm{mmol})$ in water $(10 \mathrm{~mL})$ and ethanol $(5 \mathrm{~mL})$ was added 4-methyl-2-phenyl-1,3-thiazole-5-carboxylic acid (221 $\mathrm{mg}, 1.01 \mathrm{mmol})$. The mixture was allowed to stir at room temperature for three hours. Then a sample of silver nitrate $(171 \mathrm{mg}, 1.00 \mathrm{mmol})$ dissolved in water $(5 \mathrm{~mL})$ was added dropwise with rapid stirring. The mixture was left to stir overnight, and the white precipitate was collected via vacuum filtration and dried under reduced pressure to yield $316 \mathrm{mg}(0.97 \mathrm{mmol}, 97 \%$ yield $)$ of 
the title compound. ${ }^{1} \mathrm{H}$ NMR (600 MHz, DMSO- $\left.d_{6}\right): \delta=7.89(\mathrm{dd}, J=6.6,3.0 \mathrm{~Hz}, 2 \mathrm{H}), 7.45(\mathrm{~m}$, 3H), $2.62(\mathrm{~s}, 3 \mathrm{H})$. IR (ATR, $\left.\mathrm{cm}^{-1}\right): 1573.89(\mathrm{~m}), 1424.60(\mathrm{~m}), 1384.51(\mathrm{~s}), 815.71(\mathrm{~s}), 781.96(\mathrm{~s})$, 756.05 (m), 689.95 (s). Elemental Analysis: calculated $\mathrm{C}_{11} \mathrm{H}_{8} \mathrm{AgNO}_{2} \mathrm{~S} \mathrm{C} 40.51 ; \mathrm{H} 2.47 ; \mathrm{N} 4.30$; measured C 40.25; H 2.47; N 4.11.

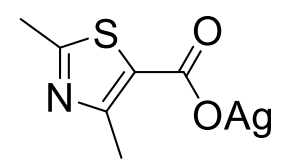

Silver 2,4-dimethyl-1,3-thiazole-5-carboxylate (28). This synthesis was performed on the benchtop protected from light. To a mixture of triethyl amine $(140 \mu \mathrm{L}, 1.01 \mathrm{mmol})$ in 1,4-dioxane (10 mL) was added 2,4-dimethyl-1,3-thiazole-5-carboxylic acid (156 mg, $0.99 \mathrm{mmol})$. The mixture was allowed to stir at room temperature until the carboxylic acid was dissolved. Then a sample of silver nitrate $(170 \mathrm{mg}, 1.00 \mathrm{mmol})$ dissolved in MeCN (1 mL) was added dropwise with rapid stirring. The mixture was left to stir overnight, and the off-white precipitate was collected via vacuum filtration and dried under reduced pressure to yield $158 \mathrm{mg}(0.60 \mathrm{mmol}, 60 \%$ yield $)$ of the title compound. ${ }^{1} \mathrm{H}$ NMR (400 MHz, DMSO- $\left.d_{6}\right): \delta=2.54(\mathrm{~s}, 3 \mathrm{H}), 2.51$ (s, 3H). IR (ATR, $\mathrm{cm}^{-1}$ ): $2924.90(\mathrm{w}), 1558.75$ (s), 1421.38 (m), 1377.30 (s), 1369.43 (s), 1305.12 (m), 1294.49 (m), $1210.60(\mathrm{~m}), 1123.01(\mathrm{~m}), 1040.74(\mathrm{~m}), 962.42$ (w), 806.46 (s), $774.71(\mathrm{~s}), 715.52(\mathrm{w})$. Elemental Analysis: Calculated $\mathrm{C}_{6} \mathrm{H}_{6} \mathrm{AgNO}_{2} \mathrm{~S} \mathrm{C}, 27.29 ; \mathrm{H}, 2.29 ; \mathrm{N} 5.30$ measured C 27.50; H 2.39; N 5.42.<smiles>COc1ccc(-c2nc(C)c(C(=O)O)s2)cc1</smiles>

4-methyl-2-(4-methoxyphenyl)-1,3-thiazole-5-carboxylic acid. This synthesis was prepared following a literature procedure. ${ }^{[18]}$ A mixture of 4-methoxythiobenzamide (194 mg, $\left.1.16 \mathrm{mmol}\right)$ and ethyl 2-chloroacetoacetate $(150 \mu \mathrm{L}, 1.04 \mathrm{mmol})$ in methanol $(20 \mathrm{~mL})$ was refluxed for $6 \mathrm{~h}$ in a $100 \mathrm{~mL}$ round bottom flask equipped with a stir bar. The solvent was removed under reduced pressure to yield the crude ethyl carboxylate. To the crude ethyl carboxylate, $24 \mathrm{~mL}$ of a mixture 
of (1:1:1) THF/EtOH/ $\mathrm{H}_{2} \mathrm{O}$ and $\mathrm{KOH}$ (4 equiv.) were added and the mixture was allowed to stir at room temperature overnight. The reaction was quenched with $2 \mathrm{~N} \mathrm{HCl}$ to $\mathrm{pH}=2$ and the solid was filtered and dried under vacuum to yield $110 \mathrm{mg}(0.44 \mathrm{mmol}, 42 \%$ yield $)$ of the title compound. ${ }^{1} \mathrm{H}$ NMR spectral data is consistent with literature. ${ }^{[18]}{ }^{1} \mathrm{H}$ NMR $\left(400 \mathrm{MHz}, \mathrm{CDCl}_{3}\right) \delta=7.91$ (d, $J=8.7 \mathrm{~Hz}, 2 \mathrm{H}), 6.95(\mathrm{~d}, J=8.8 \mathrm{~Hz}, 2 \mathrm{H}), 3.86(\mathrm{~s}, 3 \mathrm{H}), 2.77(\mathrm{~s}, 3 \mathrm{H})$.

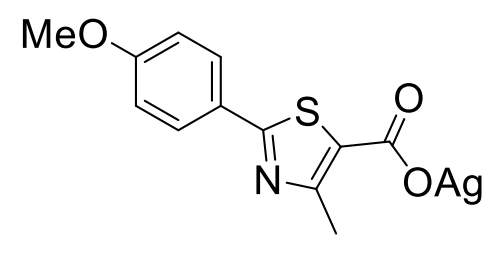

Silver 4-methyl-2-(4-methoxyphenyl)-1,3-thiazole-5-carboxylate (29). This synthesis was performed on the benchtop protected from light. To a mixture of sodium hydroxide (16 mg, 0.40 $\mathrm{mmol})$ in water $(5 \mathrm{~mL})$ and ethanol $(5 \quad \mathrm{~mL})$ was added 4-methyl-2-(4-methoxyphenyl)-1,3-thiazole-5-carboxylic acid (100 mg, $0.40 \mathrm{mmol}$ ). The mixture was allowed to stir at room temperature for three hours. Then a sample of silver nitrate (70 $\mathrm{mg}$, $0.41 \mathrm{mmol})$ dissolved in water $(5 \mathrm{~mL})$ was added dropwise with rapid stirring. The mixture was left to stir overnight, and the white precipitate was collected via vacuum filtration and dried under reduced pressure to yield $98 \mathrm{mg}(0.28 \mathrm{mmol}, 69 \%$ yield $)$ of the title compound. ${ }^{1} \mathrm{H}$ NMR (600 MHz, DMSO-d $)): \delta=7.80(\mathrm{~d}, J=8.7 \mathrm{~Hz}, 2 \mathrm{H}), 6.99(\mathrm{~d}, J=8.8 \mathrm{~Hz}, 2 \mathrm{H}), 3.78(\mathrm{~s}, 3 \mathrm{H}), 2.58(\mathrm{~s}, 3 \mathrm{H})$. IR (ATR, $\mathrm{cm}^{-1}$ ): $3015.03(\mathrm{w}), 2949.70(\mathrm{w}), 2847.58(\mathrm{w}), 2051.72(\mathrm{w}), 1599.04$ (s), 1574.41 (m), 1557.68 (w), 1519.47 (m), 1474.67 (w), 1463.16 (w), 1431.08 (m), 1421.18 (m), 1365.96 (s), 1353.96 (s), 1308.61 (s), 1267.31 (s), 1176.36 (s), 1146.20 (w), 1125.96 (m), 1037.75 (m), 1020.58 (m), 957.98 (w), 832.63 (s), 809.62 (s), 777.07 (m), 757.10 (s), 654.50 (m). Elemental Analysis: calculated $\mathrm{C}_{12} \mathrm{H}_{10} \mathrm{AgNO}_{3} \mathrm{~S} \mathrm{C} 40.47 ; \mathrm{H}$ 2.83; N 4.30; measured C 40.74; H 2.70; N 3.80. 
<smiles>Cc1nc(-c2ccc(Cl)cc2)sc1C(=O)O[Ge]</smiles>

Silver 4-methyl-2-(4-chlorophenyl)-1,3-thiazole-5-carboxylate (30). This synthesis was performed on the benchtop protected from light. To a mixture of triethylamine $(250 \mu \mathrm{L}, 1.79$ $\mathrm{mmol})$ in acetonitrile $(10 \mathrm{~mL})$ was added 4-methyl-2-(4-chlorophenyl)-1,3-thiazole-5-carboxylic acid (382 mg, $1.50 \mathrm{mmol}$ ). The mixture was allowed to stir at room temperature until the acid was fully dissolved. Then a sample of silver nitrate $(258 \mathrm{mg}, 1.52 \mathrm{mmol})$ dissolved in water $(10 \mathrm{~mL})$ was added dropwise with rapid stirring. The mixture was left to stir overnight, and the light tan precipitate was collected via vacuum filtration and washed with water $(100 \mathrm{~mL})$ and acetonitrile $(20 \mathrm{~mL})$ and dried under reduced pressure to yield $431 \mathrm{mg}(0.88 \mathrm{mmol}, 59 \%$ yield $)$ of the title compound. ${ }^{1} \mathrm{H}$ NMR (400 MHz, DMSO- $\left.d_{6}\right): \delta=7.91(\mathrm{~d}, \mathrm{~J}=8.1 \mathrm{~Hz}, 2 \mathrm{H}), 7.53(\mathrm{~d}, \mathrm{~J}=8.2 \mathrm{~Hz}$, 2H), 2.64 (s, 3H). IR (ATR, $\left.\mathrm{cm}^{-1}\right): 3083.69$ (w), 1589.00 (s), 1557.83(w), 1542.08 (w), 1499.72 (w), 1430.74 (m), 1402.99 (m), 1373.79 (s), 1355.24 (s), 1290.77 (w), 1275.96 (w), 1248.53 (w), 1188.22 (w), 1123.00 (m), 1096.68 (s), 1031.86 (w), 1011.58 (m), 966.18 (w), 832.78 (s), 813.95 (s), $777.28(\mathrm{~m}), 768.99(\mathrm{w}), 722.67$ (m), 651.90 (w). Elemental Analysis: Calculated $\mathrm{C}_{11} \mathrm{H}_{7} \mathrm{AgClNO}_{2} \mathrm{~S} \mathrm{C}$, 36.64; H, 1.96; N, 3.88; measured C 36.37; H 1.94; N 3.95.<smiles>CC(=N)C(=N)C(=O)O[Ga]</smiles>

Silver 4-methyl-2-phenyltriazole-5-carboxylate (31). This synthesis was performed on the benchtop protected from light. To a mixture of triethyl amine (140 mg, $1.00 \mathrm{mmol})$ in 1,4-dioxane $(5 \mathrm{~mL})$ and water $(1 \mathrm{~mL})$ was added 4-methyl-2-phenyltriazole-5-carboxylic acid (203 mg, 1.00 $\mathrm{mmol})$. The mixture was allowed to stir at room temperature for two hours. Then a sample of silver nitrate $(172 \mathrm{mg}, 1.01 \mathrm{mmol})$ dissolved in water $(5 \mathrm{~mL})$ was added dropwise with rapid stirring. The mixture was left to stir for 4 hours, and the tan precipitate was collected via vacuum filtration and washed with water $(100 \mathrm{~mL}), 1,4$-dioxane $(20 \mathrm{~mL})$, and diethyl ether $(20 \mathrm{~mL})$. The solids were dried under reduced pressure to yield $235 \mathrm{mg}(0.76 \mathrm{mmol}, 76 \%$ yield $)$ of the title compound. 
${ }^{1} \mathrm{H}$ NMR $\left(600 \mathrm{MHz}, \mathrm{DMSO}-d_{6}\right): \delta=7.95(\mathrm{~d}, \mathrm{~J}=8.3 \mathrm{~Hz}, 2 \mathrm{H}), 7.54-7.48(\mathrm{~m}, 2 \mathrm{H}), 7.35(\mathrm{t}, \mathrm{J}=7.4$ Hz, 1H), 2.48 (s, 3H). IR (ATR, cm $\left.{ }^{-1}\right): 3061.46$ (w), 2931.48 (w), 1594.90 (m), 1555.17 (s), 1517.42 (m), 1488.99 (m), 1462.74 (m), 1440.26 (m), 1378.47 (m), 1351.82 (s), 1325.52 (m), 1310.43 (m), 1230.70 (w), 1169.20 (s), 1095.36 (w), 1073.97 (w), 1014.35 (w), 974.04 (m), 05.82 (w), 828.78 (s), 800.64 (m), 748.22 (s), 684.24 (m), 653.09 (s). Elemental Analysis: Calculated $\mathrm{C}_{10} \mathrm{H}_{8} \mathrm{AgN}_{3} \mathrm{O}_{2} \mathrm{C}, 38.74 ; \mathrm{H}, 2.60 ; \mathrm{N}, 13.55 ;$ measured C 38.73; H 2.62; N 13.46.<smiles>Cn1nccc1C(=O)O[Ge]</smiles>

Silver 1-methylpyrazole-5-carboxylate (32). This synthesis was performed on the benchtop protected from light. To a mixture of sodium hydroxide (196 mg, $4.90 \mathrm{mmol})$ in water $(15 \mathrm{~mL})$ was added 1-methylpyrazole-5-carboxylic acid $(631 \mathrm{mg}, 5.00 \mathrm{mmol})$. The mixture was allowed to stir at room temperature until the carboxylic acid was dissolved. Then a sample of silver nitrate $(851 \mathrm{mg}, 5.00 \mathrm{mmol})$ dissolved in water $(5 \mathrm{~mL})$ was added dropwise with rapid stirring. The mixture was left to stir overnight, and the off-white precipitate was collected via vacuum filtration and dried under reduced pressure to yield $982 \mathrm{mg}$ (4.21 mmol, $84 \%$ yield) of the title compound. ${ }^{1} \mathrm{H}$ NMR (400 MHz, DMSO- $\left.d_{6}\right): \delta=7.22(\mathrm{~s}, 1 \mathrm{H}), 6.39(\mathrm{~s}, 1 \mathrm{H}), 4.03(\mathrm{~s}, 3 \mathrm{H}) . \quad$ IR $\left(\mathrm{ATR}, \mathrm{cm}^{-1}\right)$ : 2949.11 (w), 1579.53 (s), 1513.21 (m), 1472.36 (m), 1438.15 (w), 1371.01 (s), 1308.63 (w), $1289.69(\mathrm{w}), 1272.53(\mathrm{~m}), 1189.85(\mathrm{w}), 1149.32(\mathrm{w}), 1045.21(\mathrm{w}), 1014.78(\mathrm{~m}), 934.95(\mathrm{~m})$, 869.90 (w), 817.77 (m), 760.37 (s), 709.58 (m). Elemental Analysis: Calculated $\mathrm{C}_{5} \mathrm{H}_{5} \mathrm{AgN}_{2} \mathrm{O}_{2} \mathrm{C}$, 25.78; H, 2.16; N 12.02; measured C 25.81; H 1.97; N 11.87.<smiles>Cn1nc(-c2ccccc2)cc1C(=O)O[Ge]</smiles>

Silver 1-methyl-3-phenylpyrazole-5-carboxylate (33). This synthesis was performed on the benchtop protected from light. To a mixture of triethyl amine $(140 \mu \mathrm{L} \mathrm{mg}, 1.01 \mathrm{mmol})$ in 
1,4-dioxane $(10 \mathrm{~mL})$ was added 1-methyl-3-phenylpyrazole-5-carboxylic acid (205 mg, 1.01 mmol). The mixture was allowed to stir at room temperature for a few hours. Then a sample of silver nitrate $(172 \mathrm{mg}, 1.01 \mathrm{mmol})$ dissolved in $\mathrm{MeCN}(1 \mathrm{~mL})$ was added dropwise with rapid stirring. The mixture was left to stir overnight, and then the tan precipitate was collected via vacuum filtration and washed with 1,4-dioxane $(5 \mathrm{~mL})$ and water $(100 \mathrm{~mL})$. The solid was dried under vacuum to yield $180 \mathrm{mg}\left(0.58 \mathrm{mmol}, 58 \%\right.$ yield) of the title compound. ${ }^{1} \mathrm{H}$ NMR (400 MHz, DMSO- $\left.d_{6}\right): \delta=7.74(\mathrm{~d}, \mathrm{~J}=7.2 \mathrm{~Hz}, 2 \mathrm{H}), 7.34(\mathrm{t}, \mathrm{J}=7.7 \mathrm{~Hz}, 2 \mathrm{H}), 7.23(\mathrm{dd}, \mathrm{J}=8.2,6.5 \mathrm{~Hz}$, $1 \mathrm{H}), 6.88(\mathrm{~s}, 1 \mathrm{H}), 4.10(\mathrm{~s}, 3 \mathrm{H})$. IR (ATR, $\left.\mathrm{cm}^{-1}\right): 1591.28(\mathrm{~s}), 1536.15(\mathrm{w}), 1437.00$ (s), 1342.81 (s), $1279.61(\mathrm{~m}), 965.30(\mathrm{w}), 822.32$ (s), $784.24(\mathrm{~m}), 758.12(\mathrm{~s}), 734.21(\mathrm{~m}), 690.21(\mathrm{~s}), 669.33$ (m). Elemental Analysis: Calculated $\mathrm{C}_{11} \mathrm{H}_{9} \mathrm{AgO}_{2} \mathrm{~N}_{2} \mathrm{C}, 42.75 ; \mathrm{H}, 2.94 ; \mathrm{N}$ 9.06; measured C 42.48; H 2.87 ; N 9.14.

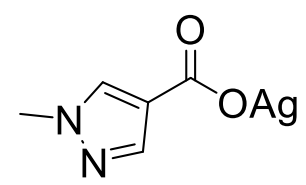

Silver 1-methylpyrazole-4-carboxylate (34). This synthesis was performed on the benchtop protected from light. To a mixture of triethylamine $(280 \mu \mathrm{L}, 2.02 \mathrm{mmol})$ in 1,4-dioxane $(10 \mathrm{~mL})$ was added 1-methylpyrazole-4-carboxylic acid (252 $\mathrm{mg}, 2.00 \mathrm{mmol})$. The mixture was allowed to stir at room temperature for a few hours. Then a sample of silver nitrate $(341 \mathrm{mg}, 2.01 \mathrm{mmol})$ dissolved in water $(10 \mathrm{~mL})$ was added dropwise with rapid stirring. The mixture was left to stir for 20 minutes, and the off-white precipitate was collected via vacuum filtration, washed with water $(150 \mathrm{~mL}), 1,4$-dioxane $(15 \mathrm{~mL})$, and diethyl ether $(20 \mathrm{~mL})$, and dried under reduced pressure to yield $333 \mathrm{mg}$ (1.43 mmol, $71 \%$ yield) of the title compound. IR (ATR, $\left.\mathrm{cm}^{-1}\right)$ : 3111.57 (w), 2938.08 (w), 1543.64 (s), 1520.41 (s), 1447.99 (m), 1427.63 (m), 1409.15 (s), 1395.61 (m), 1313.99 (s), 1287.88 (s), 1187.00 (w), 1131.90 (w), 1064.08 (w), 1006.34 (m), 996.31 (m), 894.16 (m), 841.11 (w), 803.40 (s), 789.11 (w), 775.93 (s), 704.95 (w). Elemental Analysis: Calculated $\mathrm{C}_{5} \mathrm{H}_{5} \mathrm{AgN}_{2} \mathrm{O}_{2}$ C, 25.78; H, 2.16; N, 12.02; measured C 25.89; H 2.14; N 11.88. 
<smiles>Cc1[nH]cnc1C(=O)OC(=O)O</smiles>

Silver 5-methylpyrazole-4-carboxylate (35). This synthesis was performed on the benchtop protected from light. To a mixture of sodium hydroxide $(78 \mathrm{mg}, 1.98 \mathrm{mmol})$ in water $(15 \mathrm{~mL})$ was added 5-methylpyrazole-4-carboxylic acid (255 mg, $2.03 \mathrm{mmol})$. The mixture was allowed to stir at room temperature until the carboxylic acid is completely dissolved. Then a sample of silver nitrate $(343 \mathrm{mg}, 2.02 \mathrm{mmol})$ dissolved in water $(5 \mathrm{~mL})$ was added dropwise with rapid stirring. The mixture was left to stir overnight, and the white precipitate was collected via vacuum filtration and dried under reduced pressure to yield $367 \mathrm{mg}$ (1.57 mmol, $79 \%$ yield $)$ of the title compound. IR (ATR, $\mathrm{cm}^{-1}$ ): $2842.64(\mathrm{w}), 2765.51(\mathrm{w}), 2680.03$ (w), 2606.47 (w), 2546.26 (w), 1660.75 (s), 1523.88 (s), 1494.83 (m), 1426.06 (m), 1372.84 (m), 1353.93 (m), 1278.89 (s), 1265.34 (s), $1188.78(\mathrm{~m}), 1142.15(\mathrm{~m}), 1126.43$ (s), 1063.95 (w), 1031.87 (w), $965.71(\mathrm{~m}), 926.16(\mathrm{~m}), 873.24$ (m), 775.12 (s), 698.00 (m), 666.05 (w). Elemental Analysis: Calculated $\mathrm{C}_{5} \mathrm{H}_{5} \mathrm{AgN}_{2} \mathrm{O}_{2} \mathrm{C}, 25.78$; H, 2.16; N 12.02 measured C 26.01; H 2.10; N 12.09.

\subsubsection{Geometry Optimization Data.}

\subsubsection{Example Input File.}

\#Geometry Opt for benzothiophene-2-carboxylic acid. \#Initial XYZ coordinates were generated in Avogadro.

\section{! B3LYP DEF2-SVP DEF2/J OPT RIJCOSX}

$\begin{array}{lrrr}* \text { XYZ 0 1 } & & \\ \text { C } & -0.0674000000 & 3.2490000000 & -0.3013000000 \\ \text { O } & 0.8317000000 & 3.9180000000 & 0.4684000000 \\ \text { O } & -0.8139000000 & 3.8613000000 & -1.0306000000 \\ \text { C } & -0.1279000000 & 1.7826000000 & -0.2485000000 \\ \text { S } & -1.4426000000 & 0.9118000000 & 0.0544000000 \\ \text { C } & 0.9439000000 & 0.9263000000 & -0.4523000000 \\ \text { C } & -0.7781000000 & -0.5409000000 & -0.0467000000 \\ \text { C } & 0.5619000000 & -0.4037000000 & -0.3332000000 \\ \text { C } & -1.3668000000 & -1.7804000000 & 0.1116000000 \\ \text { C } & -0.5625000000 & -2.9060000000 & -0.0249000000 \\ \text { C } & 1.3684000000 & -1.5175000000 & -0.4699000000\end{array}$




$\begin{array}{lrrr}\mathrm{C} & 0.7958000000 & -2.7753000000 & -0.3124000000 \\ \mathrm{H} & 1.4355000000 & 3.4286000000 & 1.0306000000 \\ \mathrm{H} & 1.9782000000 & 1.2615000000 & -0.6815000000 \\ \mathrm{H} & -2.4502000000 & -1.8755000000 & 0.3404000000 \\ \mathrm{H} & -1.0050000000 & -3.9180000000 & 0.0961000000 \\ \mathrm{H} & 2.4502000000 & -1.4101000000 & -0.6983000000 \\ \mathrm{H} & 1.4270000000 & -3.6841000000 & -0.4162000000 \\ * & & & \end{array}$

\subsubsection{DFT Calculated Coordinates.}

All coordinates are cartesian coordinates in Angstroms and all energy values are in hartree.

\section{Benzothiophene-2-carboxylic acid}

$$
\begin{aligned}
& \text { SCF Energy: -894.41088384 hartree } \\
& \begin{array}{llll}
\text { C } & -0.154597 & 3.318814 & -0.162996
\end{array} \\
& \begin{array}{llll}
\text { O } & 1.025544 & 3.971735 & -0.080647
\end{array} \\
& \begin{array}{lllll}
\text { O } & -1.189666 & 3.926083 & -0.251142
\end{array} \\
& \begin{array}{llll}
\mathrm{C} & -0.093401 & 1.833247 & -0.139388
\end{array} \\
& \begin{array}{llll}
\mathrm{S} & -1.622789 & 0.988153 & -0.019601
\end{array} \\
& \begin{array}{llll}
\text { C } & 0.978225 & 0.981188 & -0.237902
\end{array} \\
& \begin{array}{llll}
\text { C } & -0.807867 & -0.555588 & -0.084878
\end{array} \\
& \begin{array}{llll}
\text { C } & 0.601474 & -0.403981 & -0.212509
\end{array} \\
& \begin{array}{llll}
\text { C } & -1.400597 & -1.827117 & -0.033772
\end{array} \\
& \begin{array}{llll}
\text { C } & -0.579437 & -2.946096 & -0.120029
\end{array} \\
& \begin{array}{llll}
\text { C } & 1.410858 & -1.558359 & -0.300644
\end{array} \\
& \begin{array}{llll}
\text { C } & 0.819534 & -2.813316 & -0.256322
\end{array} \\
& \begin{array}{llll}
\mathrm{H} & 1.750532 & 3.354306 & 0.091049
\end{array} \\
& \begin{array}{llll}
\mathrm{H} & 2.016128 & 1.303853 & -0.353968
\end{array} \\
& \begin{array}{llll}
\mathrm{H} & -2.482476 & -1.936217 & 0.074569
\end{array}
\end{aligned}
$$

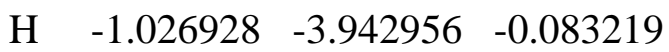

$$
\begin{aligned}
& \mathrm{H} \quad 2.494212 \quad-1.456220 \quad-0.411258
\end{aligned}
$$

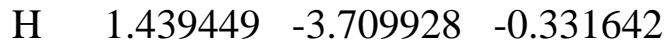

\section{3-Methylbenzothiophene-2-carboxylic acid}

SCF Energy: -933.67009045 hatree
C $\quad-0.456056 \quad 3.303422$
0.151139
$\begin{array}{llll}\mathrm{O} & 0.675832 & 3.977648 & 0.466733\end{array}$
$\begin{array}{llll}\mathrm{O} & -1.485348 & 3.897632 & -0.039352\end{array}$
$\begin{array}{llll}\text { C } & -0.364256 & 1.817913 & 0.086757\end{array}$
S $\quad-1.913947 \quad 0.996786 \quad 0.185251$
$\begin{array}{lrrr}\text { C } & 0.706961 & 0.958025 & -0.057277\end{array}$
$\begin{array}{llll}\text { C } & -1.128374 & -0.555620 & 0.093987\end{array}$ 


$\begin{array}{rrrr}\mathrm{C} & 0.279783 & -0.424977 & -0.040767 \\ \mathrm{C} & -1.745070 & -1.815771 & 0.140391 \\ \mathrm{C} & -0.946420 & -2.951073 & 0.054510 \\ \mathrm{C} & 1.065278 & -1.595693 & -0.130392 \\ \mathrm{C} & 0.453596 & -2.841775 & -0.080717 \\ \mathrm{C} & 2.153588 & 1.335873 & -0.251244 \\ \mathrm{H} & 1.372916 & 3.363971 & 0.735248 \\ \mathrm{H} & -2.829005 & -1.902644 & 0.249469 \\ \mathrm{H} & -1.411879 & -3.939595 & 0.093869 \\ \mathrm{H} & 2.150644 & -1.521558 & -0.238103 \\ \mathrm{H} & 1.060601 & -3.747841 & -0.148570 \\ \mathrm{H} & 2.619359 & 0.685434 & -1.008187 \\ \mathrm{H} & 2.278685 & 2.367404 & -0.611097 \\ \mathrm{H} & 2.743013 & 1.208939 & 0.674451\end{array}$

\section{Benzofuran-2-carboxylic acid}

SCF Energy: -571.51229559 hatree
C $\quad-0.257758 \quad 3.125541 \quad-0.175739$
$\begin{array}{llll}\mathrm{O} & 0.838617 & 3.908246 & -0.050924\end{array}$
$\begin{array}{llll}\text { O } & -1.351756 & 3.596890 & -0.315662\end{array}$
C $\quad 0.012399 \quad 1.664289-0.148969$
$\begin{array}{llll}\text { O } & -1.082257 & 0.859450 & -0.032145\end{array}$
$\begin{array}{llll}\text { C } & 1.161650 & 0.930345 & -0.296884\end{array}$
$\begin{array}{llll}\text { C } & -0.640767 & -0.421028 & -0.104341\end{array}$
$\begin{array}{llll}\text { C } & 0.761634 & -0.450914 & -0.273495\end{array}$
$\begin{array}{llll}\text { C } & -1.429842 & -1.568284 & -0.035287\end{array}$
$\begin{array}{llll}\text { C } & -0.763420 & -2.787490 & -0.146124\end{array}$
C $\quad 1.411510 \quad-1.695463 \quad-0.383627$
$\begin{array}{llll}\text { C } & 0.637923 & -2.849954 & -0.319441\end{array}$
$\begin{array}{llll}\mathrm{H} & 1.615280 & 3.381289 & 0.184720\end{array}$
H $\quad 2.170748 \quad 1.312044 \quad-0.446045$
$\mathrm{H} \quad-2.510618 \quad-1.498617 \quad 0.101154$
$\mathrm{H} \quad-1.337908-3.715716 \quad-0.099300$
$\mathrm{H} \quad 2.493552 \quad-1.752816 \quad-0.526463$
H $\quad 1.120612 \quad-3.826210-0.409626$

\section{3-Methylbenzofuran-2-carboxylic acid}

SCF Energy: -610.77364828 hatree
$\begin{array}{llll}\text { C } & -0.675954 & 3.113306 & 0.109261\end{array}$
$\begin{array}{llll}\mathrm{O} & 0.362513 & 3.925228 & 0.429386\end{array}$
$\begin{array}{llll}\mathrm{O} & -1.762233 & 3.562295 & -0.130435\end{array}$
$\begin{array}{llll}\text { C } & -0.366347 & 1.658268 & 0.086479\end{array}$
$\begin{array}{llll}\text { O } & -1.471429 & 0.854740 & 0.182599\end{array}$
C $\quad 0.791363 \quad 0.923716 \quad-0.060243$ 


$\begin{array}{lrrr}\mathrm{C} & -1.036251 & -0.424286 & 0.122325 \\ \mathrm{C} & 0.365181 & -0.458213 & -0.025678 \\ \mathrm{C} & -1.828864 & -1.569389 & 0.193712 \\ \mathrm{C} & -1.162653 & -2.791812 & 0.120029 \\ \mathrm{C} & 1.016117 & -1.704353 & -0.098327 \\ \mathrm{C} & 0.241577 & -2.858791 & -0.021566 \\ \mathrm{C} & 2.207881 & 1.379886 & -0.260647 \\ \mathrm{H} & 1.113690 & 3.406654 & 0.749750 \\ \mathrm{H} & -2.912338 & -1.496207 & 0.306330 \\ \mathrm{H} & -1.739538 & -3.718218 & 0.175599 \\ \mathrm{H} & 2.101565 & -1.767422 & -0.211959 \\ \mathrm{H} & 0.726352 & -3.836958 & -0.071972 \\ \mathrm{H} & 2.690220 & 0.783734 & -1.051988 \\ \mathrm{H} & 2.277387 & 2.433251 & -0.572177 \\ \mathrm{H} & 2.815361 & 1.240973 & 0.651022\end{array}$

\section{Pyridine-2-carboxylic acid}

SCF Energy: -436.30045897 hatree

$\begin{array}{lrrc}\mathrm{C} & 1.571086 & -1.191497 & -1.077190 \\ \mathrm{C} & 0.177178 & -1.341939 & -1.110998 \\ \mathrm{~N} & -0.662387 & -0.510354 & -0.499515 \\ \mathrm{C} & -0.149199 & 0.518635 & 0.184694 \\ \mathrm{C} & 1.230516 & 0.759061 & 0.284679 \\ \mathrm{C} & 2.104053 & -0.115279 & -0.365701 \\ \mathrm{C} & -1.152871 & 1.426571 & 0.850478 \\ \mathrm{O} & -0.551651 & 2.389973 & 1.588817 \\ \mathrm{O} & -2.348214 & 1.334898 & 0.757534 \\ \mathrm{H} & 2.215464 & -1.904206 & -1.597780 \\ \mathrm{H} & -0.275015 & -2.177617 & -1.659419 \\ \mathrm{H} & 1.598754 & 1.611233 & 0.856369 \\ \mathrm{H} & 3.184914 & 0.045208 & -0.314938 \\ \mathrm{H} & -1.267528 & 2.930712 & 1.962869\end{array}$

\section{4-Chloropyridine-2-carboxylic acid}

SCF Energy: -895.70568550 hatree
$\begin{array}{llll}\text { C } & -1.340738 & -0.687459 & -0.098409\end{array}$
$\begin{array}{llll}\text { C } & -0.670769 & 0.531939 & 0.001931\end{array}$
$\begin{array}{llll}\text { C } & -0.602909 & -1.867645 & -0.215720\end{array}$
$\begin{array}{llll}\text { C } & 0.792923 & -1.765514 & -0.231714\end{array}$
$\begin{array}{llll}\mathrm{N} & 1.451560 & -0.611884 & -0.132925\end{array}$
C $\quad 0.731304 \quad 0.507263 \quad-0.014559$
$\begin{array}{llll}\text { C } & 1.451781 & 1.824832 & 0.122228\end{array}$
$\begin{array}{llll}\text { O } & 2.783925 & 1.711309 & 0.081963\end{array}$ 

$\begin{array}{llll}\text { O } & 0.880636 & 2.882454 & 0.260145\end{array}$
Cl $\quad-3.079035 \quad-0.740516 \quad-0.075122$
$\mathrm{H} \quad-1.199741 \quad 1.480237 \quad 0.098547$
H $\quad-1.102124 \quad-2.834759-0.296092$
H $\quad 1.399922 \quad-2.672701 \quad-0.330902$
$\begin{array}{llll}\mathrm{H} & 3.133365 & 2.614744 & 0.170928\end{array}$

\section{2-Trifluoromethylpyridine-3-carboxylic acid}

SCF Energy: -772.94697894 hatree

$\begin{array}{rrrr}\text { C } & 0.589851 & 2.425227 & -0.327555 \\ \text { O } & 1.530487 & 3.021870 & 0.442180 \\ \text { O } & -0.121613 & 3.063366 & -1.048188 \\ \text { C } & 0.591164 & 0.914808 & -0.261844 \\ \text { C } & 1.811306 & 0.240385 & -0.427937 \\ \text { C } & -0.568406 & 0.121196 & -0.128458 \\ \text { C } & 1.831416 & -1.151323 & -0.492150 \\ \text { N } & -0.546446 & -1.206413 & -0.193196 \\ \text { C } & 0.615481 & -1.831062 & -0.383708 \\ \text { C } & -1.957219 & 0.724518 & 0.103745 \\ \text { F } & -2.745463 & -0.124169 & 0.766629 \\ \text { F } & -1.878324 & 1.852987 & 0.832516 \\ \text { F } & -2.554081 & 1.015963 & -1.058208 \\ \text { H } & 1.912274 & 2.387818 & 1.066316 \\ \text { H } & 2.736559 & 0.812526 & -0.540582 \\ \text { H } & 2.766227 & -1.696519 & -0.639554 \\ \text { H } & 0.576488 & -2.924377 & -0.453604\end{array}$




\section{$\underline{\text { References }}$}

[1] G. Bringmann, R. Walter, R. Weirich, Angew. Chem. Int. Ed. Engl. 1990, 29, 977-991.

[2] C. Liu, C.-L. Ji, Z.-X. Qin, X. Hong, M. Szostak, iScience 2019, 19, 749-759.

[3] C. C. C. Johansson Seechurn, M. O. Kitching, T. J. Colacot, V. Snieckus, Angew. Chem. Int. Ed. 2012, 51, 5062-5085.

[4] "The Nobel Prize in Chemistry 2010," can be found under https://www.nobelprize.org/prizes/chemistry/2010/press-release/, 2010.

[5] I. P. Beletskaya, A. V. Cheprakov, Organometallics 2012, 31, 7753-7808.

[6] D. Friedman, T. Masciangioli, S. Olson, The Role of the Chemical Sciences in Finding Alternatives to Critical Resources, The National Academies Press, Washington, DC, 2012.

[7] J. D. Sears, P. G. N. Neate, M. L. Neidig, J. Am. Chem. Soc. 2018, 140, 11872-11883.

[8] Y. Li, Y. Luo, L. Peng, Y. Li, B. Zhao, W. Wang, H. Pang, Y. Deng, R. Bai, Y. Lan, G. Yin, Nat Commun 2020, 11, 1-13.

[9] M. Nilsson, Acta Chem. Scand. 1966, 20, 423-466.

[10] C. Peschko, C. Winklhofer, W. Steglich, Chem. Eur. J. 2000, 6, 1147-1152.

[11] A. Heim, A. Terpin, W. Steglich, Angew. Chem. Int. Ed. 1997, 36, 155-156.

[12] A. G. Myers, D. Tanaka, M. R. Mannion, J. Am. Chem. Soc. 2002, 124, 11250-11251.

[13] L. J. Goossen, Science 2006, 313, 662-664.

[14] L. J. Goossen, N. Rodriguez, B. Melzer, C. Linder, G. Deng, L. M. Levy, J. Am. Chem. Soc. 2007, 129, 4824-4833.

[15] L. J. Goossen, N. Rodríguez, C. Linder, J. Am. Chem. Soc. 2008, 130, 15248-15249.

[16] R. Shang, Y. Fu, Y. Wang, Q. Xu, H.-Z. Yu, L. Liu, Angew. Chem. Int. Ed. 2009, 48, 9350-9354.

[17] In Oxidative Cross-Coupling Reactions, Wiley-VCH Verlag GmbH \& Co. KGaA, Weinheim, Germany, 2016, pp. 1-5.

[18] A. P. Honeycutt, J. M. Hoover, ACS Catal. 2017, 7, 4597-4601.

[19] A. P. Honeycutt, J. M. Hoover, Org. Lett. 2018, 20, 7216-7219.

[20] J. M. Crawford, K. E. Shelton, E. K. Reeves, B. K. Sadarananda, D. Kalyani, Org. Chem. Front. 2015, 2, 726-729.

[21] D. M. Wiemers, D. J. Burton, J. Am. Chem. Soc. 1986, 108, 832-834.

[22] M. Li, J. M. Hoover, Chem. Commun. 2016, 52, 8733-8736.

[23] K.-A. Green, J. M. Hoover, ACS Catal. 2020, 10, 1769-1782.

[24] T. Patra, S. Nandi, S. K. Sahoo, D. Maiti, Chem. Commun. 2016, 52, 1432-1435.

[25] L. Chen, L. Ju, K. A. Bustin, J. M. Hoover, Chem. Commun. 2015, 51, 15059-15062.

[26] F. Minisci, E. Vismara, U. Romano, Tetrahedron Letters 1985, 26, 4803-4806.

[27] X. Xie, Y. Zhang, J. Hao, W. Wan, Org. Biomol. Chem. 2020, 18, 400-404.

[28] T. Huang, Y. Yu, H. Wang, Y. Lin, Y. Ma, H. Wang, C.-H. Ding, J. Xiao, B. Xu, Synthesis 2020, 52, 239-245.

[29] J. Morley. Anderson, J. K. Kochi, J. Am. Chem. Soc. 1970, 92, 1651-1659.

[30] N. Zhang, D. Yang, W. Wei, L. Yuan, F. Nie, L. Tian, H. Wang, J. Org. Chem. 2015, 80, 3258-3263.

[31] M. Li, J. L. Petersen, J. M. Hoover, Org. Lett. 2017, 19, 638-641.

[32] Z. Cui, X. Shang, X.-F. Shao, Z.-Q. Liu, Chem. Sci. 2012, 3, 2853.

[33] H.-P. Bi, L. Zhao, Y.-M. Liang, C.-J. Li, Angew. Chem. Int. Ed. 2009, 4. 
[34] P. Zhang, L. Zhang, Y. Gao, J. Xu, H. Fang, G. Tang, Y. Zhao, Chem. Commun. 2015, $51,7839-7942$.

[35] A. Voutchkova, A. Coplin, N. E. Leadbeater, R. H. Crabtree, Chem. Commun. 2008, 6312 .

[36] P. Lu, C. Sanchez, J. Cornella, I. Larrosa, Org. Lett. 2009, 11, 5710-5713.

[37] K. Xie, Z. Yang, X. Zhou, X. Li, S. Wang, Z. Tan, X. An, C.-C. Guo, Org. Lett. 2010, 12, $1564-1567$.

[38] J. Zhou, P. Hu, M. Zhang, S. Huang, M. Wang, W. Su, Chemistry - A European Journal 2010, 16, 5876-5881.

[39] K. Pei, X. Jie, H. Zhao, W. Su, Eur. J. Org. Chem. 2014, 2014, 4230-4233.

[40] P. Hu, M. Zhang, X. Jie, W. Su, Angew. Chem. Int. Ed. 2012, 51, 227-231.

[41] J. Kan, S. Huang, J. Lin, M. Zhang, W. Su, Angew. Chem. Int. Ed. 2015, 54, 2199-2203.

[42] S. Bhadra, W. I. Dzik, L. J. Goossen, J. Am. Chem. Soc. 2012, 134, 9938-9941.

[43] L. J. Gooßen, C. Linder, N. Rodríguez, P. P. Lange, A. Fromm, Chem. Commun. 2009, 7173.

[44] L. J. Gooßen, N. Rodríguez, K. Gooßen, Angew. Chem. Int. Ed. 2008, 47, 3100-3120.

[45] K. Yang, P. Wang, C. Zhang, A. A. Kadi, H.-K. Fun, Y. Zhang, H. Lu, Eur. J. Org.

Chem. 2014, 2014, 7586-7589.

[46] C. Wang, I. Piel, F. Glorius, J. Am. Chem. Soc. 2009, 131, 4194-4195.

[47] J. Cornella, P. Lu, I. Larrosa, Org. Lett. 2009, 11, 5506-5509.

[48] L. J. Gooßen, W. R. Thiel, N. Rodríguez, C. Linder, B. Melzer, Adv. Synth. Catal. 2007, 349, 2241-2246.

[49] K. Zhan, Y. Li, Catalysts 2017, 7, 314.

[50] Z. Li, Z. Fu, H. Zhang, J. Long, Y. Song, H. Cai, New J. Chem. 2016, 40, 3014-3018.

[51] J. Cornella, C. Sanchez, D. Banawa, I. Larrosa, Chem. Commun. 2009, 7176.

[52] R. Grainger, J. Cornella, D. C. Blakemore, I. Larrosa, J. M. Campanera, Chem. Eur. J. 2014, 20, 16680-16687.

[53] R. Grainger, A. Nikmal, J. Cornella, I. Larrosa, Org. Biomol. Chem. 2012, 10, 3172.

[54] A. F. Shepard, N. R. Winslow, J. R. Johnson, J. Am. Chem. Soc. 1930, 52, $2083-2090$.

[55] J. Chodowska-Palicka, M. Nilsson, Acta Chem. Scand. 1970, 24, 3353-3361.

[56] Allan. Cairncross, J. R. Roland, R. M. Henderson, W. A. Sheppard, J. Am. Chem. Soc. 1970, $92,3187-3189$.

[57] Theodore. Cohen, R. A. Schambach, J. Am. Chem. Soc. 1970, 92, 3189-3190.

[58] L. J. Gooßen, N. Rodríguez, C. Linder, P. P. Lange, A. Fromm, ChemCatChem 2010, 2, $430-442$.

[59] L. Xue, W. Su, Z. Lin, Dalton Trans. 2011, 40, 11926.

[60] E. V. Anslyn, D. A. Dougherty, Modern Physical Organic Chemistry, University Science, Sausalito, CA, 2006.

[61] L. P. Hammett, J. Am. Chem. Soc. 1937, 59, 96-103.

[62] Corwin. Hansch, A. Leo, R. W. Taft, Chem. Rev. 1991, 91, 165-195.

[63] J. D. Roberts, W. T. Moreland, J. Am. Chem. Soc. 1953, 75, 2167-2173.

[64] Y. Okamoto, H. C. Brown, J. Org. Chem. 1957, 22, 485-494.

[65] H. C. Brown, Y. Okamoto, J. Am. Chem. Soc. 1957, 79, 1913.

[66] H. C. Brown, Y. Okamoto, J. Am. Chem. Soc. 1958, 80, 4979.

[67] C. W. Jones, J. Am. Chem. Soc. 1963, 85, 3397-3402. 
[68] C. A. Grob, M. G. Schlageter, Helv. Chim. Acta 1976, 59, 264-276.

[69] R. W. Taft, J. Am. Chem. Soc. 1952, 74, 2729-2732.

[70] R. W. Taft, in Steric Effects in Organic Chemistry (Ed.: M.S. Newman), Wiley, New York, NY, 1956, pp. 556-675.

[71] C. Gardner. Swain, E. C. Lupton, J. Am. Chem. Soc. 1968, 90, 4328-4337.

[72] C. Hansch, A. Leo, S. H. Unger, K. H. Kim, D. Nikaitani, E. J. Lien, J. Med. Chem. 1973, 16, 1207-1216.

[73] C. Hansch, A. Leo, D. H. Hoekman, Exploring QSAR, American Chemical Society, Washington, DC, 1995.

[74] K. L. E. Kaiser, QSAR in Environmental Toxicology - II, Springer Netherlands, Dordrecht, Holland, 1987.

[75] R. W. Taft, J. Am. Chem. Soc. 1952, 74, 3120-3128.

[76] M. Charton, J. Am. Chem. Soc. 1969, 91, 615-618.

[77] R. Gallo, in Progress in Physical Organic Chemistry (Ed.: R.W. Taft), John Wiley \& Sons, Inc., Hoboken, NJ, USA, 2007, pp. 115-163.

[78] K. C. Harper, E. N. Bess, M. S. Sigman, Nature Chem 2012, 4, 366-374.

[79] H. Clavier, S. P. Nolan, Chem. Commun. 2010, 46, 841.

[80] A. J. Canty, A. Ariafard, G. Koten, Chem. Eur. J. 2020, chem.202003023.

[81] V. Nummert, M. Piirsalu, J. Chem. Soc., Perkin Trans. 2000, 2, 583.

[82] T. Nishioka, T. Fujita, K. Kitamura, M. Nakajima, J. Org. Chem. 1975, 40, 2520-2525.

[83] S. D. Desai, L. E. Kirsch, Int. J. Chem. Kinet. 2015, 47, 471.

[84] T. Sotomatsu, T. Fujita, J. Org. Chem. 1989, 54, 4443-4448.

[85] T. Fujita, T. Nishioka, Prog. Phys. Org. Chem. 1976, 12, 49-89.

[86] Y. Zhang, S. Patel, N. Mainolfi, Chem. Sci. 2012, 3, 3196.

[87] S. Zhao, Y.-J. Liu, S.-Y. Yan, F.-J. Chen, Z.-Z. Zhang, B.-F. Shi, Org. Lett. 2015, 17, 3338-3341.

[88] T. Patra, S. Nandi, S. K. Sahoo, D. Maiti, Chem. Commun. 2016, 52, 1432-1435.

[89] Z. Fu, Z. Li, Y. Song, R. Yang, Y. Liu, H. Cai, The Journal of Organic Chemistry 2016, 81, 2794-2803.

[90] J. M. Hoover, Comments on Inorganic Chemistry 2017, 37, 169-200.

[91] K. Takamatsu, K. Hirano, M. Miura, Angew. Chem. Int. Ed. 2017, 56, 5353-5357.

[92] H. Zhao, Y. Wei, J. Xu, J. Kan, W. Su, M. Hong, J. Org. Chem. 2011, 76, 882-893.

[93] J. Cornella, H. Lahlali, I. Larrosa, Chem. Commun. 2010, 46, 8276.

[94] K. Xie, S. Wang, Z. Yang, J. Liu, A. Wang, X. Li, Z. Tan, C.-C. Guo, W. Deng, Eur. J. Org. Chem. 2011, 2011, 5787-5790.

[95] P. Hu, Y. Shang, W. Su, Angew. Chem. Int. Ed. 2012, 51, 5945-5949.

[96] S. Seo, M. Slater, M. F. Greaney, Org. Lett. 2012, 14, 2650-2653.

[97] S. Seo, J. B. Taylor, M. F. Greaney, Chem. Commun. 2012, 48, 8270.

[98] M. Rudzki, A. Alcalde-Aragonés, W. Dzik, N. Rodríguez, L. Gooßen, Synthesis 2012, 2012, 184-193.

[99] J. S. Dickstein, J. M. Curto, O. Gutierrez, C. A. Mulrooney, M. C. Kozlowski, J. Org. Chem. 2013, 78, 4744-4761.

[100] S. Dupuy, F. Lazreg, A. M. Z. Slawin, C. S. J. Cazin, S. P. Nolan, Chem. Commun. 2011, 47, 5455.

[101] S. Dupuy, L. Crawford, M. Bühl, S. P. Nolan, Chem. Eur. J. 2015, 21, 3399-3408. 
[102] A. Baur, K. A. Bustin, E. Aguilera, J. L. Petersen, J. M. Hoover, Org. Chem. Front. 2017, 4, 519-524.

[103] N. Rodríguez, L. J. Goossen, Chem. Soc. Rev. 2011, 40, 5030.

[104] F. D’Anna, F. Ferroni, V. Frenna, S. Guernelli, C. Z. Lanza, G. Macaluso, V. Pace, G.

Petrillo, D. Spinelli, R. Spisani, Tetrahedron 2005, 61, 167-178.

[105] F. D’Anna, V. Frenna, C. Z. Lanza, G. Macaluso, S. Marullo, D. Spinelli, R. Spisani, G. Petrillo, Tetrahedron 2010, 66, 5442-5450.

[106] V. Frenna, G. Maealuso, G. Consiglio, B. Cosimelli, D. Spinelli, Tetrahedron 1999, 55 , 12885-129896.

[107] S. G. Stratton, G. H. Taumoefolau, G. E. Purnell, M. Rasooly, W. L. Czaplyski, E. J. Harbron, Chem. Eur. J. 2017, 23, 14064-14072.

[108] D. V. Vidhani, M. E. Krafft, J. Phys. Chem. A 2015, 119, 3141-3146.

[109] H. E. Gottlieb, V. Kotlyar, A. Nudelman, J. Org. Chem. 1997, 62, 7512-7515.

[110] M. Schnürch, M. Holzweber, M. D. Mihovilovic, P. Stanetty, Green Chem. 2007, 9, 139145.

[111] M. Charton, Top. Curr. Chem. 1983, 114, 57-91.

[112] M. Charton, in Progress in Physical Organic Chemistry (Ed.: R.W. Taft), John Wiley \&

Sons, Inc., Hoboken, NJ, USA, 1981, pp. 119-251.

[113] E. Kutter, C. Hansch, J. Med. Chem. 1969, 12, 647-652.

[114] T. Fujita, C. Takayama, M. Nakajima, J. Org. Chem. 1973, 38, 1623-1630.

[115] H. D. Holtz, L. M. Stock, J. Am. Chem. Soc. 1964, 86, 5188-5194.

[116] C. F. Wilcox, J. S. McIntyre, J. Org. Chem. 1965, 30, 777-780.

[117] F. W. Baker, R. C. Parish, L. M. Stock, J. Am. Chem. Soc. 1967, 89, 5677-5685.

[118] P. J. Stang, A. G. Anderson, J. Org. Chem. 1976, 41, 781-785.

[119] K. Seth, M. Nautiyal, P. Purohit, N. Parikh, A. K. Chakraborti, Chem. Commun. 2015, 51, 191-194.

[120] S. Luis, P. Ferrer, M. I. Burguete, J. Org. Chem. 1990, 55, 3808-3812.

[121] C. Lamberth, J. Dinges, in Bioactive Heterocyclic Compound Classes (Eds.: J. Dinges, C.

Lamberth), Wiley-VCH Verlag GmbH \& Co. KGaA, Weinheim, Germany, 2013, pp. 1-20.

[122] M. C. Hilton, X. Zhang, B. T. Boyle, J. V. Alegre-Requena, R. S. Paton, A. McNally, Science 2018, 362, 799-804.

[123] R. Mah, in Bioactive Heterocyclic Compound Classes (Eds.: J. Dinges, C. Lamberth),

Wiley-VCH Verlag GmbH \& Co. KGaA, Weinheim, Germany, 2013, pp. 255-273.

[124] K. Shimanaka, Y. Takahashi, H. Iinuma, H. Naganawa, T. Takeuchi, J. Antibiot. 1994, 47, 1145-1152.

[125] V. Abbot, P. Sharma, S. Dhiman, M. N. Noolvi, H. M. Patel, V. Bhardwaj, RSC Adv. 2017, 7, 28313-28349.

[126] M. Seto, K. Aikawa, N. Miyamoto, Y. Aramaki, N. Kanzaki, K. Takashima, Y. Kuze, Y.

Iizawa, M. Baba, M. Shiraishi, J. Med. Chem. 2006, 49, 2037-2048.

[127] C. Torborg, M. Beller, Adv. Synth. Catal. 2009, 351, 3027-3043.

[128] M. J. Buskes, M.-J. Blanco, Molecules 2020, 25, 3493.

[129] D. Nandi, Y.-M. Jhou, J.-Y. Lee, B.-C. Kuo, C.-Y. Liu, P.-W. Huang, H. M. Lee, J. Org. Chem. 2012, 77, 9384-9390.

[130] J. M. Quibell, G. Duan, G. J. P. Perry, I. Larrosa, Chem. Commun. 2019, 55, 6445-6448. 
[131] P. Forgione, M.-C. Brochu, M. St-Onge, K. H. Thesen, M. D. Bailey, F. Bilodeau, J. Am. Chem. Soc. 2006, 128, 11350-11351.

[132] F. Bilodeau, M.-C. Brochu, N. Guimond, K. H. Thesen, P. Forgione, J. Org. Chem. 2010, $75,1550-1560$.

[133] R. A. Daley, A. S. Morrenzin, S. R. Neufeldt, J. J. Topczewski, J. Am. Chem. Soc. 2020, $142,13210-13218$.

[134] D. Hackenberger, P. Weber, D. C. Blakemore, L. J. Goossen, J. Org. Chem. 2017, 82, 3917-3925.

[135] L. R. Chennamaneni, A. D. William, C. W. Johannes, Tetrahedron Letters 2015, 56, 1293-1296.

[136] L. Goossen, C. Linder, N. RodrÃ-guez, P. Lange, Chem. Eur. J. 2009, 15, 9336-9349.

[137] L. J. Gooßen, N. Rodríguez, P. P. Lange, C. Linder, Angew. Chem. Int. Ed. 2010, 49, 1111-1114.

[138] P. Hu, M. Zhang, X. Jie, W. Su, Angew. Chem. Int. Ed. 2012, 51, 227-231.

[139] U. Tilstam, Org. Process Res. Dev. 2012, 16, 1449-1454.

[140] S. Dupuy, S. P. Nolan, Chem. Eur. J. 2013, 19, 14034-14038.

[141] X. Y. Toy, I. I. B. Roslan, G. K. Chuah, S. Jaenicke, Catal. Sci. Technol. 2014, 4, 516523.

[142] R. A. Crovak, J. M. Hoover, J. Am. Chem. Soc. 2018, 140, 2434-2437.

[143] V. Nummert, O. Travnikova, S. Vahur, I. Leito, M. Piirsalu, V. Mäemets, I. Koppel, I. A. Koppel, J. Phys. Org. Chem. 2006, 19, 654-663.

[144] J. Coates, in Encyclopedia of Analytical Chemistry (Ed.: R.A. Meyers), John Wiley \& Sons, Ltd, Chichester, UK, 2006, p. a5606.

[145] P. Ertl, S. Jelfs, J. Muhlbacher, A. Schuffenhauer, P. Selzer, J. Med. Chem. 2006, 49, 4568-4573.

[146] J. De Jesus Silva, M. A. B. Ferreira, A. Fedorov, M. S. Sigman, C. Copéret, Chem. Sci. 2020, 11, 6717-6723.

[147] S. Gibson, R. McGuire, D. C. Rees, J. Med. Chem. 1996, 39, 7056-7072.

[148] X. Q. Lewell, A. C. Jones, C. L. Bruce, G. Harper, M. M. Jones, I. M. Mclay, J.

Bradshaw, J. Med. Chem. 2003, 46, 3257-3274.

[149] F. Neese, WIREs Comput Mol Sci 2012, 2, 73-78.

[150] A. K. Dutta, F. Neese, R. Izsák, The Journal of Chemical Physics 2016, 144, 034102.

[151] E. Vitaku, D. T. Smith, J. T. Njardarson, J. Med. Chem. 2014, 57, 10257-10274.

[152] I. G. Anderson, J. Kenyon, J. Am. Chem. Soc. 1948, 70, 3952-3953.

[153] D. Jiang, Y. Y. Wang, Y. N. Xu, L. Y. Dai, Journal of Chemical Research; London 2009, 2009, 167. 


\section{Appendix: NMR Characterization Spectra}

\section{A-1 Spectra from Chapter 2:}

\section{A-1.1 ${ }^{1} \mathrm{H}$ and ${ }^{13} \mathrm{C}$ NMR Spectra of (1,10-Phenanthroline)Silver(Benzoate) Complexes}

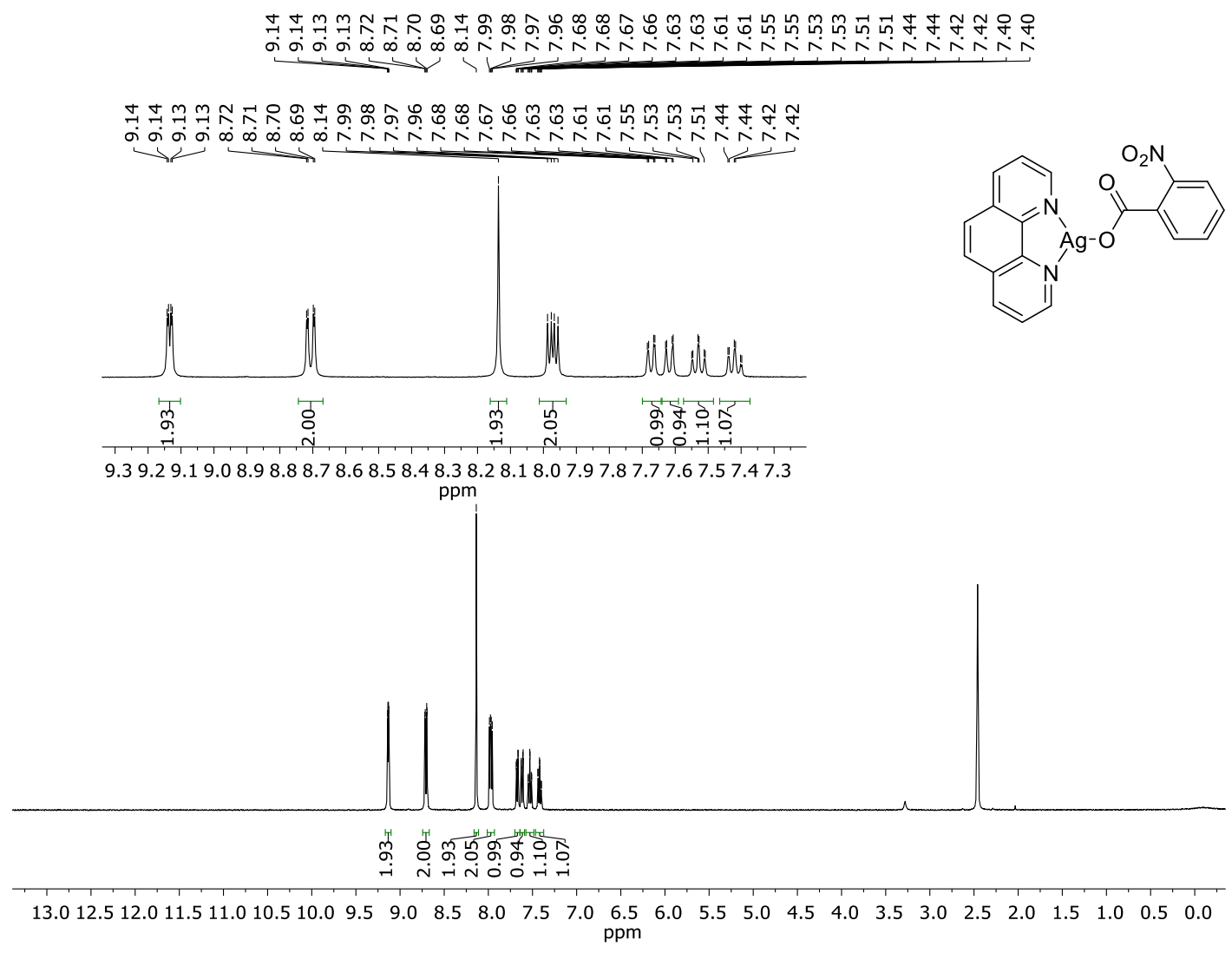

Figure A-1: ${ }^{1} \mathrm{H}$ NMR spectrum of (phen)Ag(2-NO2-benzoate) in DMSO- $d_{6}$ at $400 \mathrm{MHz}$. 


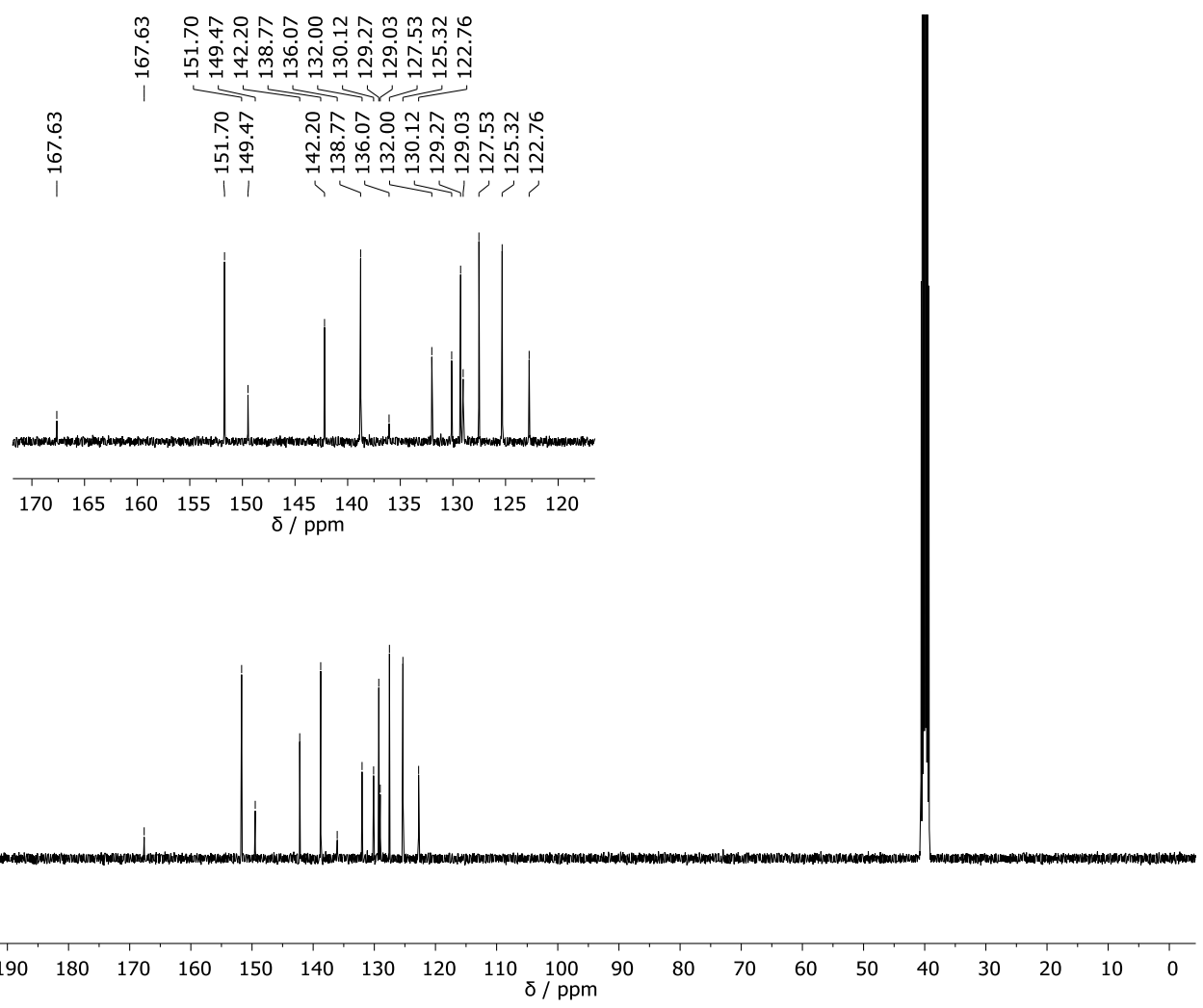

Figure A-2: ${ }^{13} \mathrm{C}$ NMR spectrum of (phen)Ag(2-NO2-benzoate) in DMSO- $d_{6}$ at $100 \mathrm{MHz}$. 


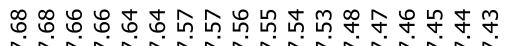

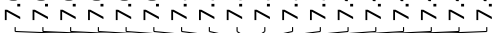

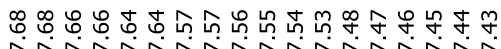

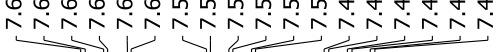
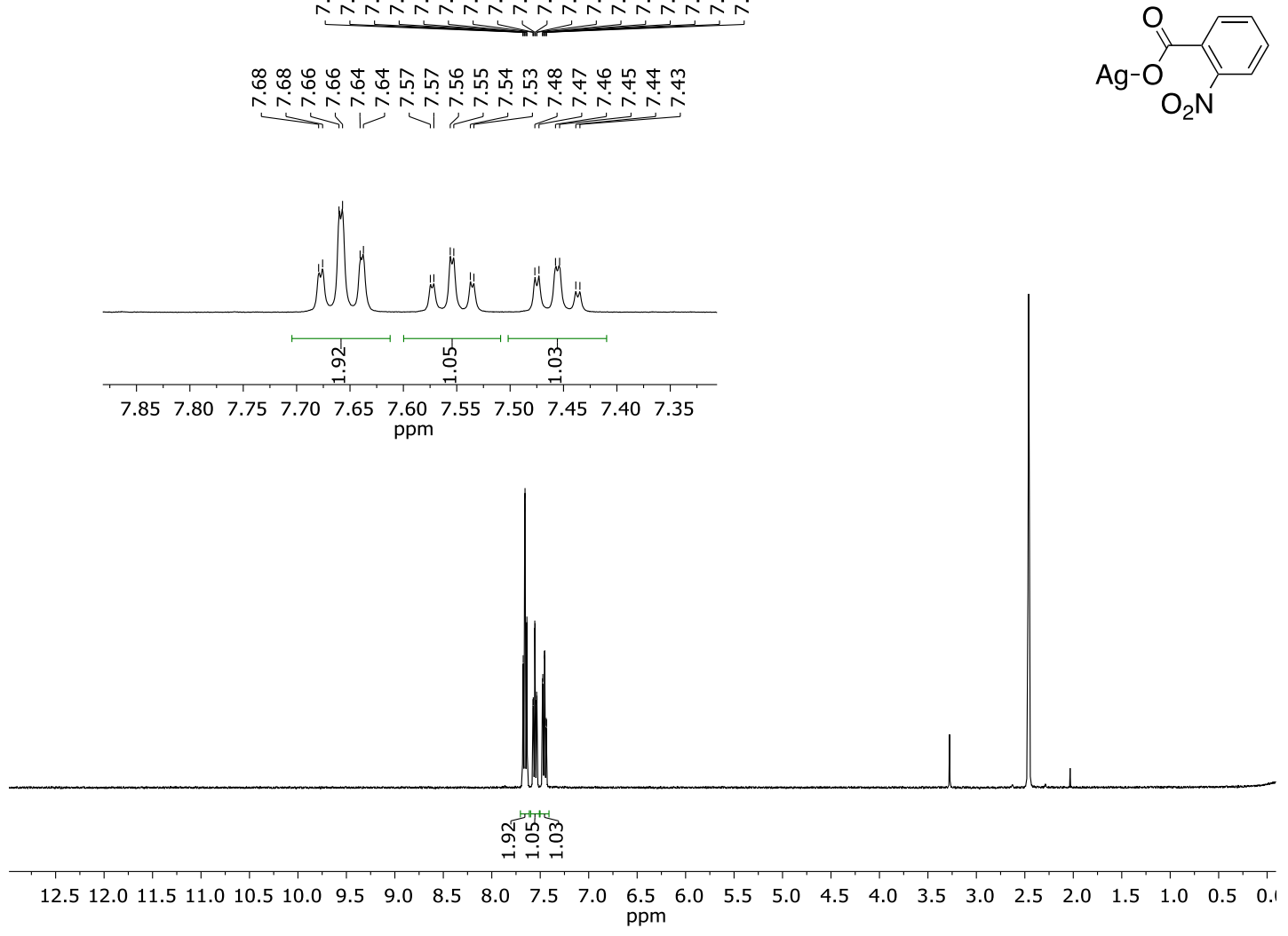

Figure A-3: ${ }^{1} \mathrm{H}$ NMR spectrum of Ag(2-NO2-benzoate) in DMSO-d $d_{6}$ at $400 \mathrm{MHz}$. 

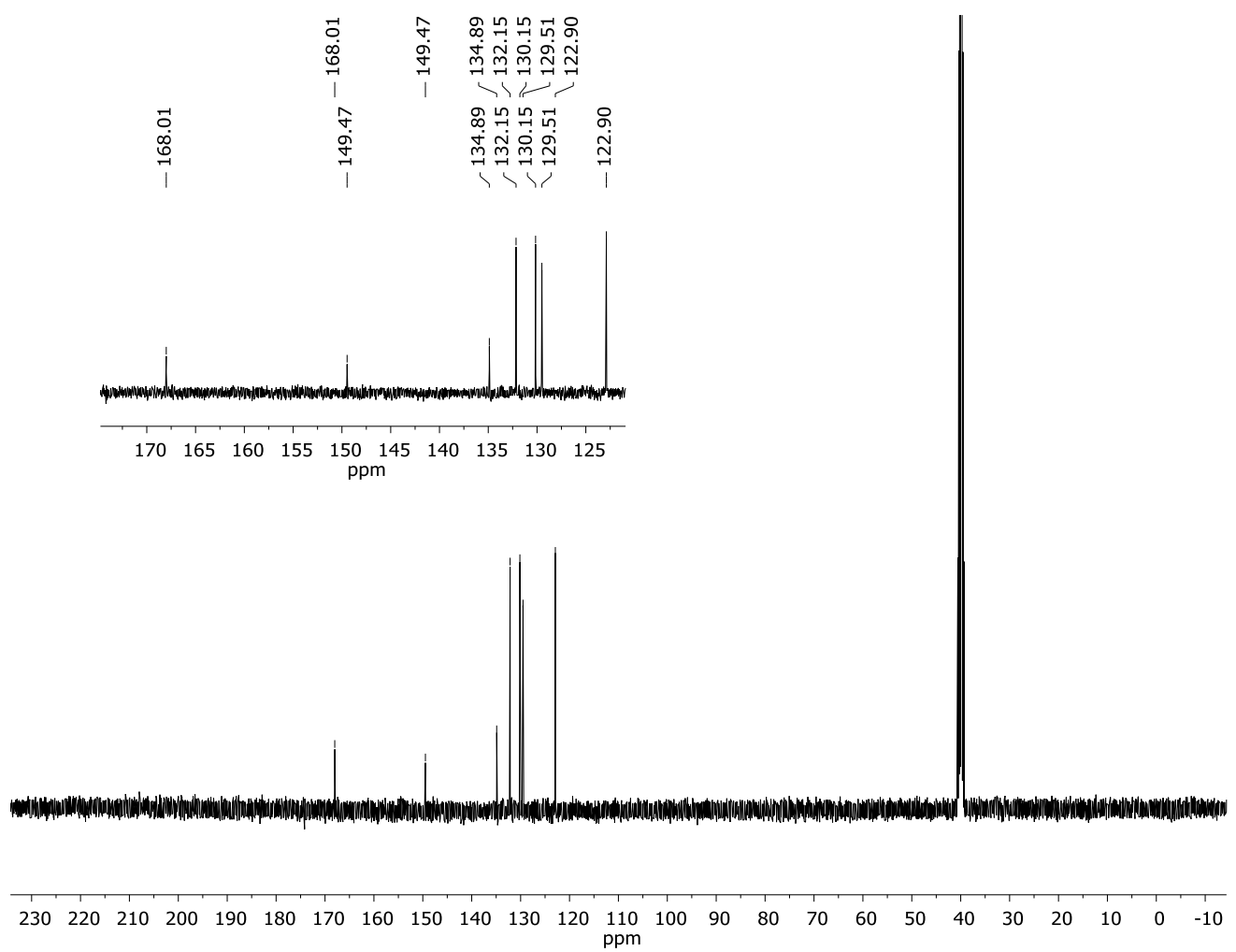

Figure A-4: ${ }^{13} \mathrm{C}$ NMR spectrum of $\mathbf{A g}\left(2-N_{2}\right.$-benzoate) in DMSO- $d_{6}$ at $100 \mathrm{MHz}$. 


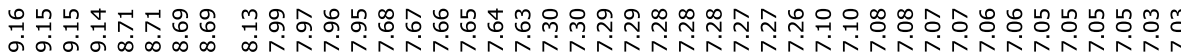
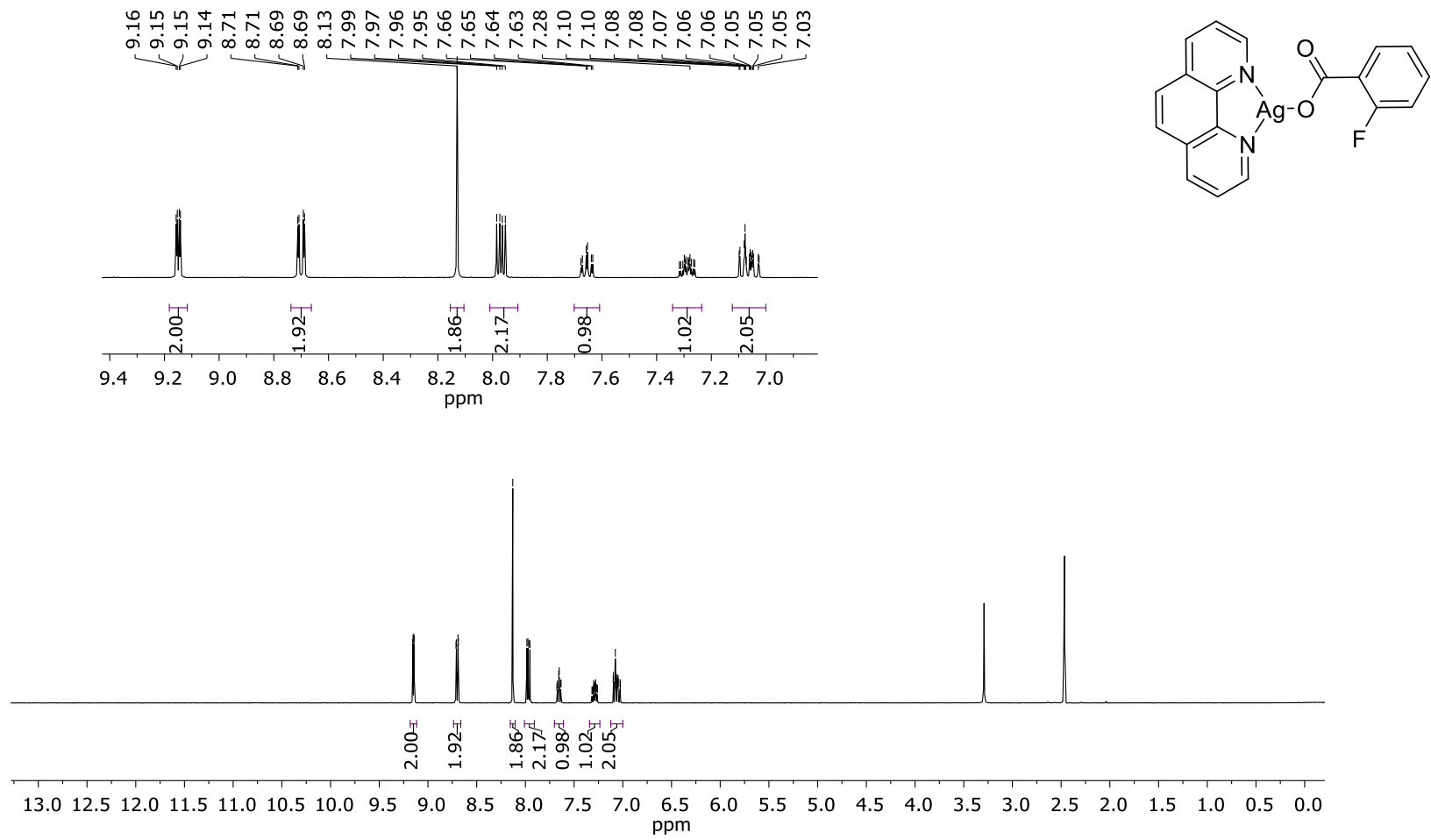

Figure A-5: ${ }^{1} \mathrm{H}$ NMR spectrum of (phen)Ag(2-F-benzoate) in DMSO- $d_{6}$ at $400 \mathrm{MHz}$. 
ㅇํำ

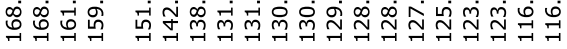
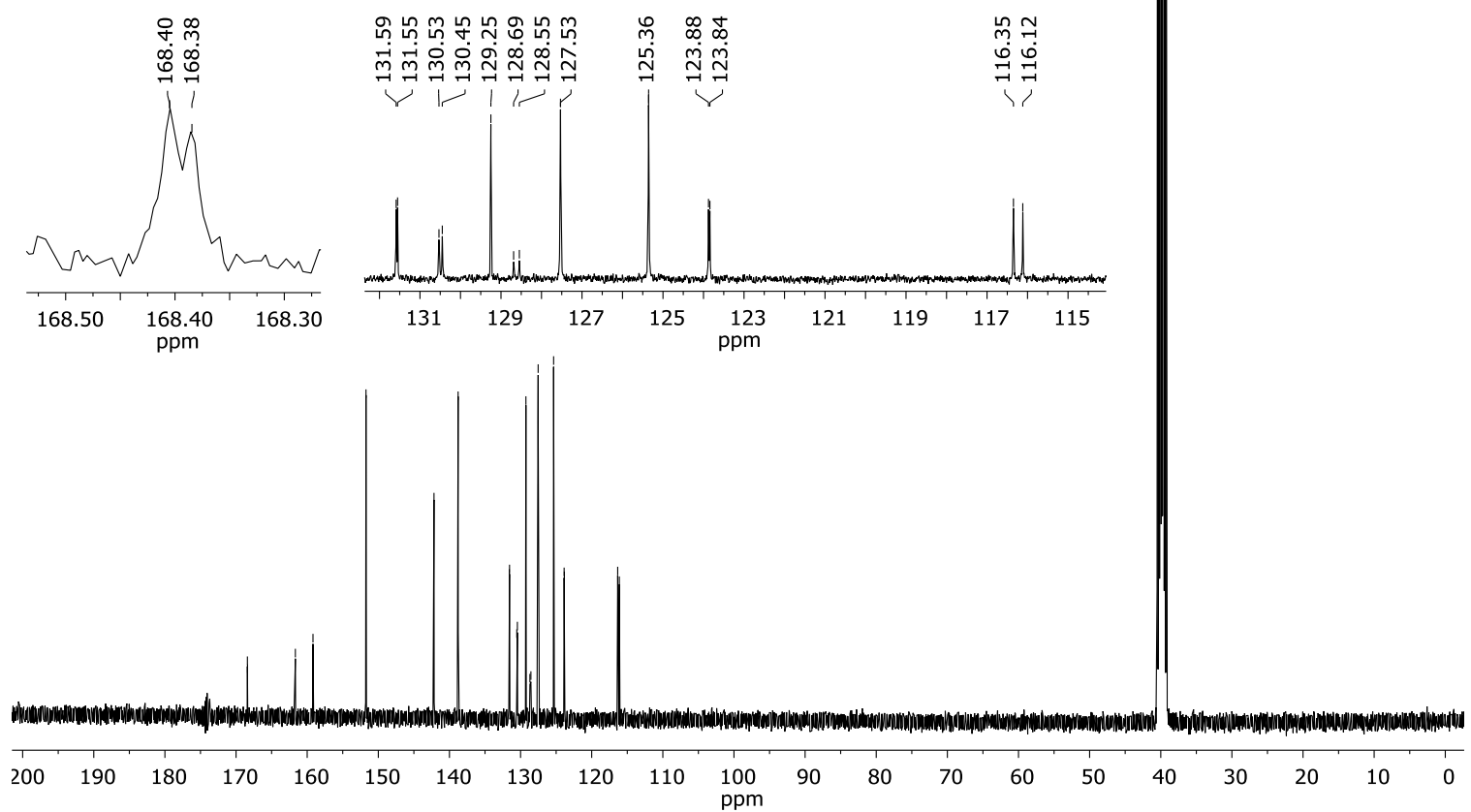

Figure A-6: ${ }^{13} \mathrm{C}$ NMR spectrum of (phen)Ag(2-F-benzoate) in DMSO-d 6 at $100 \mathrm{MHz}$. 


\section{ำ 용}

$\dot{m} \ddot{m} \dot{m} \dot{m} \dot{m}$

ํํㅇํㅇㅇํㅇํำ

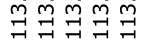

isis

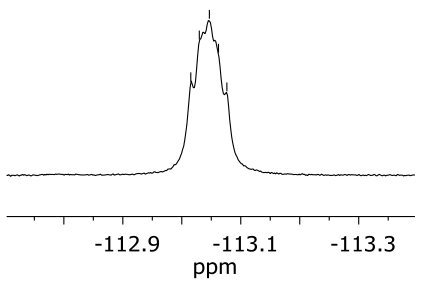

Figure A-7: ${ }^{19} \mathrm{~F}$ NMR spectrum of (phen)Ag(2-F-benzoate) in DMSO- $d_{6}$ at $376 \mathrm{MHz}$. 


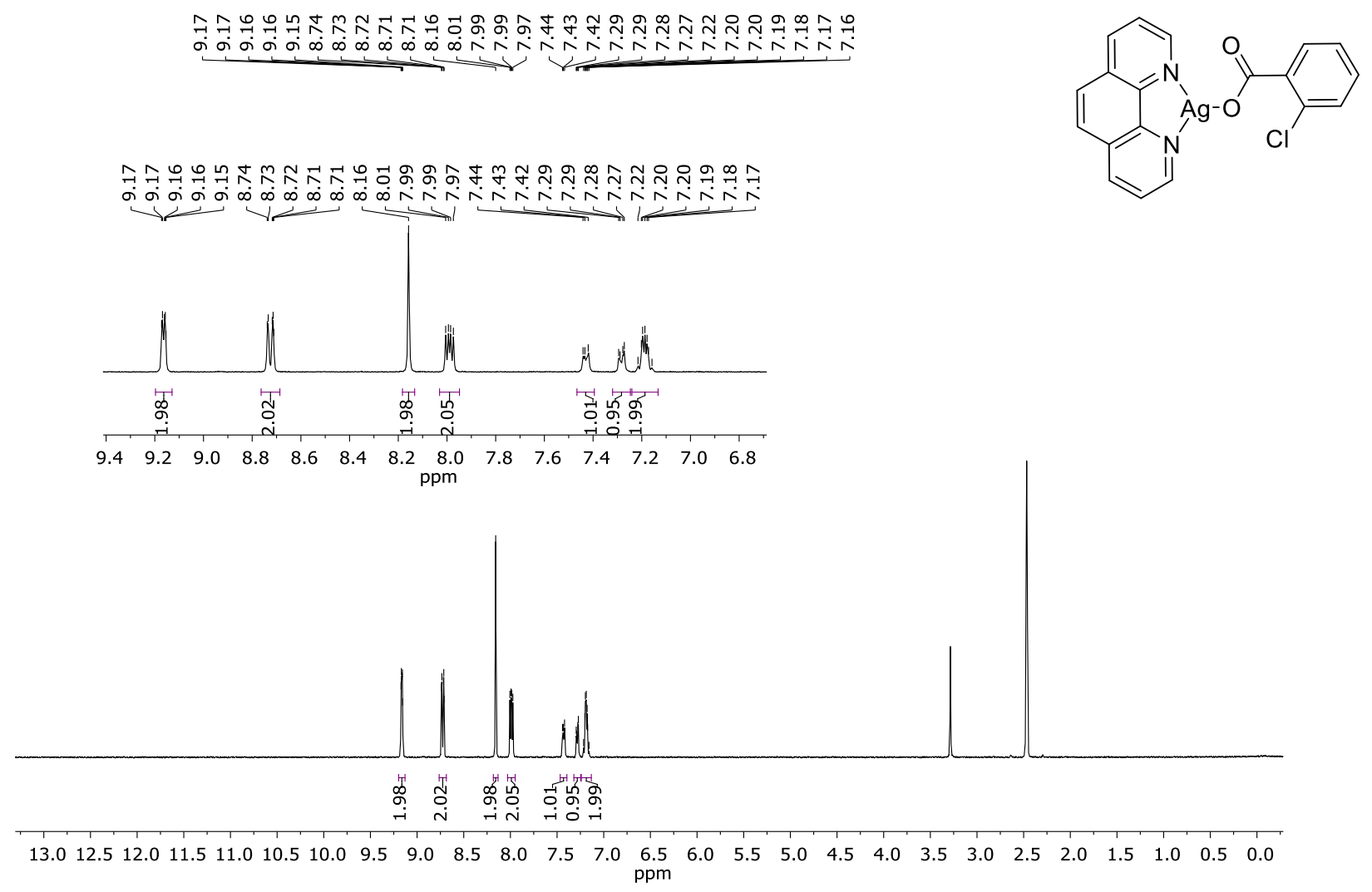

Figure A-8: ${ }^{1} \mathrm{H}$ NMR spectrum of (phen)Ag(2-Cl-benzoate) in DMSO-d 6 at $400 \mathrm{MHz}$. 


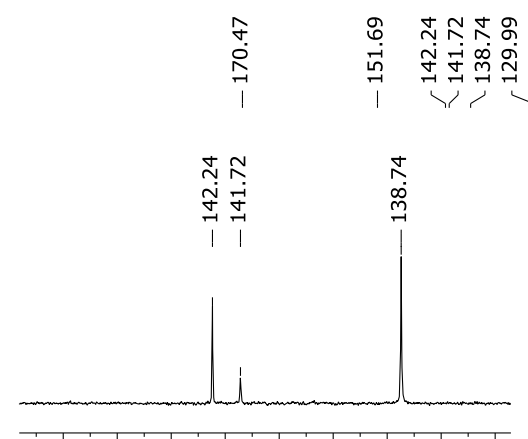

$\begin{array}{lllllllll}145 & 144 & 143 & 142 & 141 & 140 & 139 & 138 & 137\end{array}$
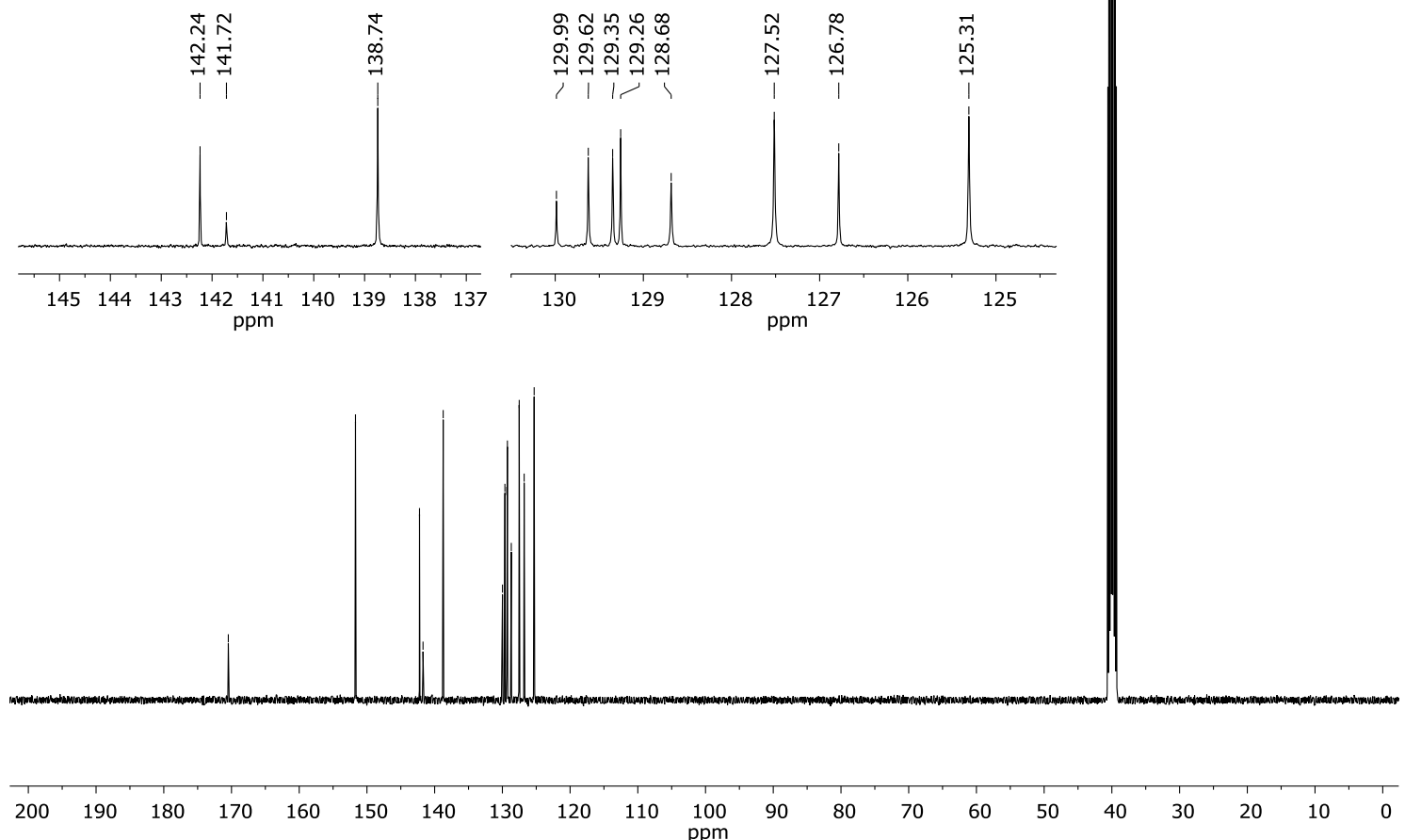

Figure A-9: ${ }^{13} \mathrm{C}$ NMR spectrum of (phen)Ag(2-Cl-benzoate) in DMSO- $d_{6}$ at $100 \mathrm{MHz}$. 


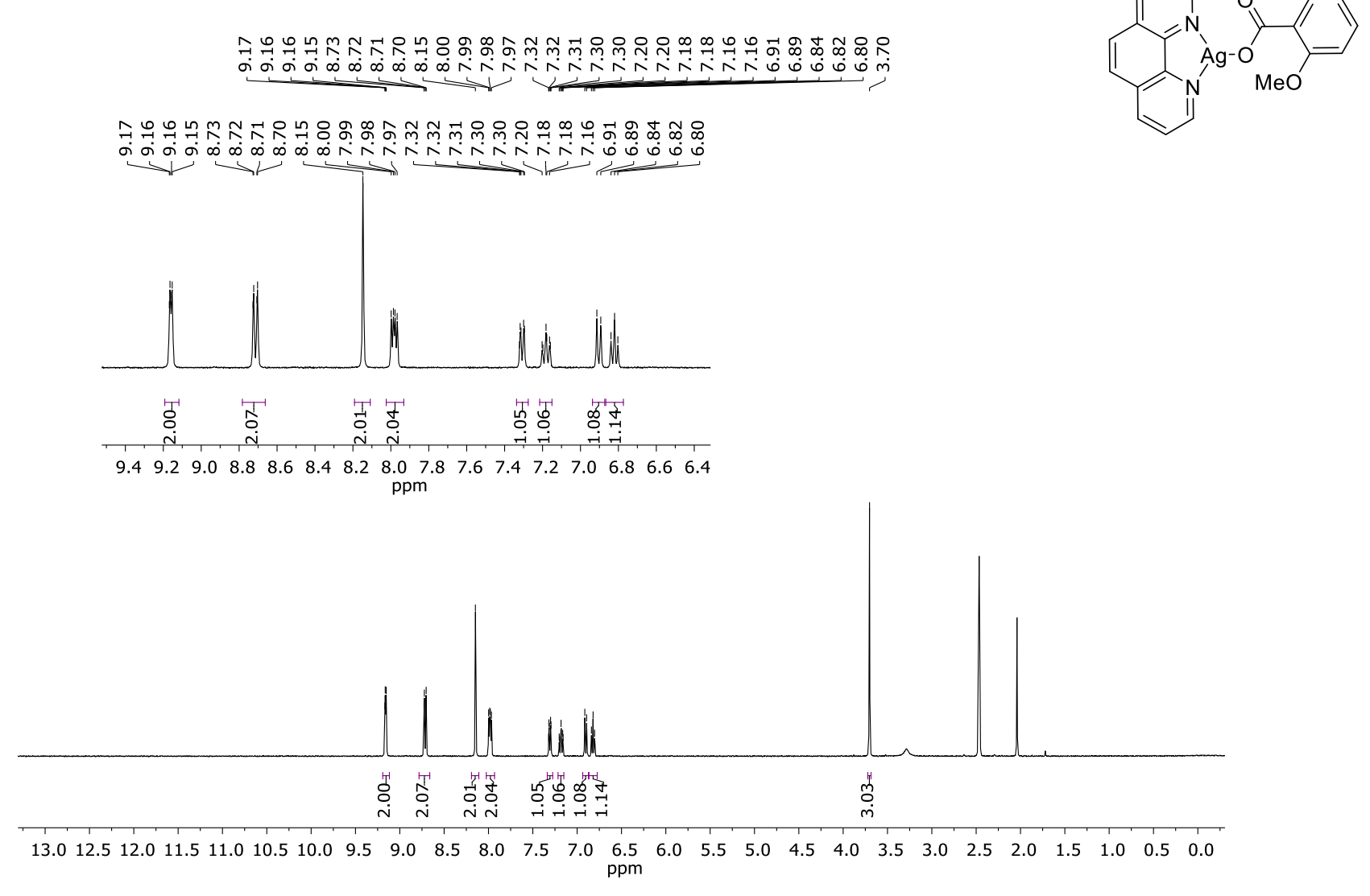

Figure A-10: ${ }^{1} \mathrm{H}$ NMR spectrum of (phen)Ag(2-OMe-benzoate) in DMSO- $d_{6}$ at $400 \mathrm{MHz}$. 


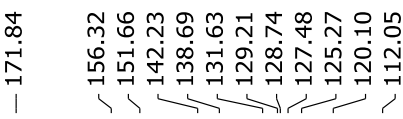

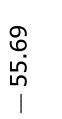

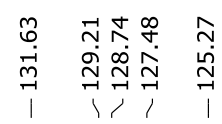

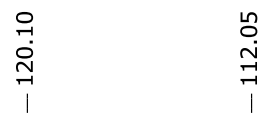
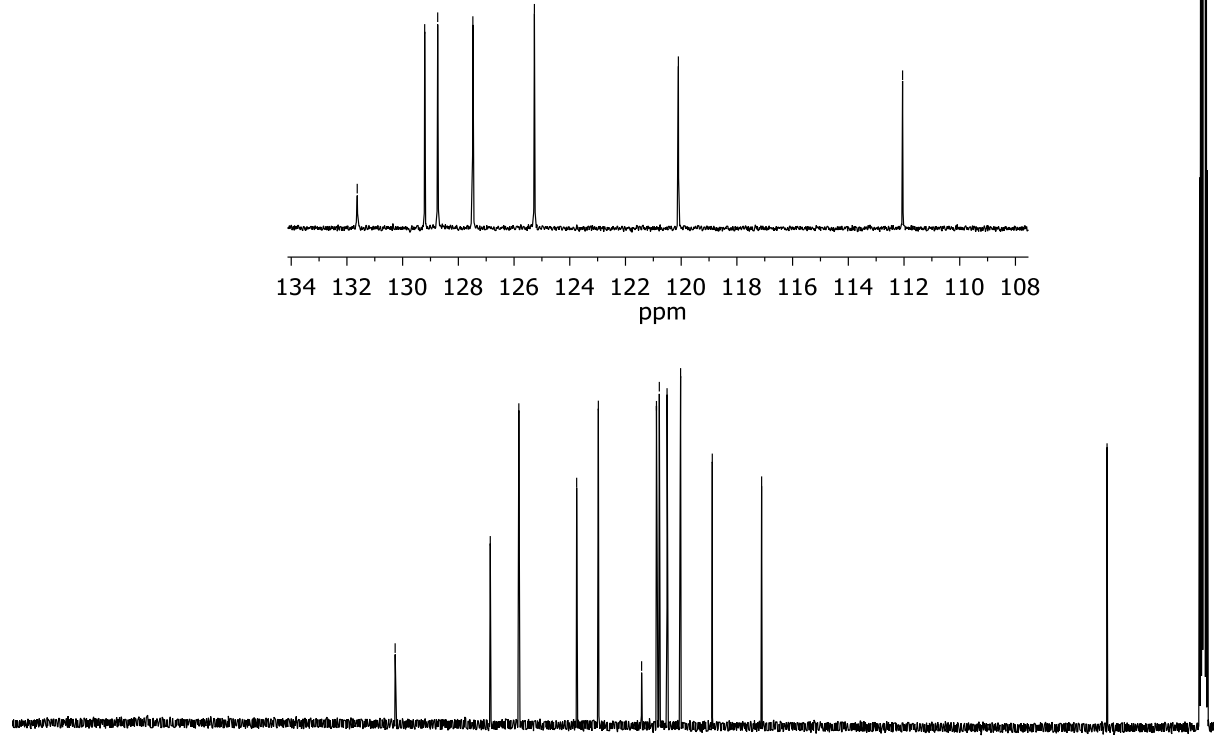

$\begin{array}{lllllllllllllllllllllllll}230 & 220 & 210 & 200 & 190 & 180 & 170 & 160 & 150 & 140 & 130 & 120 & \begin{array}{l}110 \\ \mathrm{ppm}\end{array} & 100 & 90 & 80 & 70 & 60 & 50 & 40 & 30 & 20 & 10 & 0 & -10\end{array}$

Figure A-11: ${ }^{13} \mathrm{C}$ NMR spectrum of (phen)Ag(2-OMe-benzoate) in DMSO- $d_{6}$ at $100 \mathrm{MHz}$. 


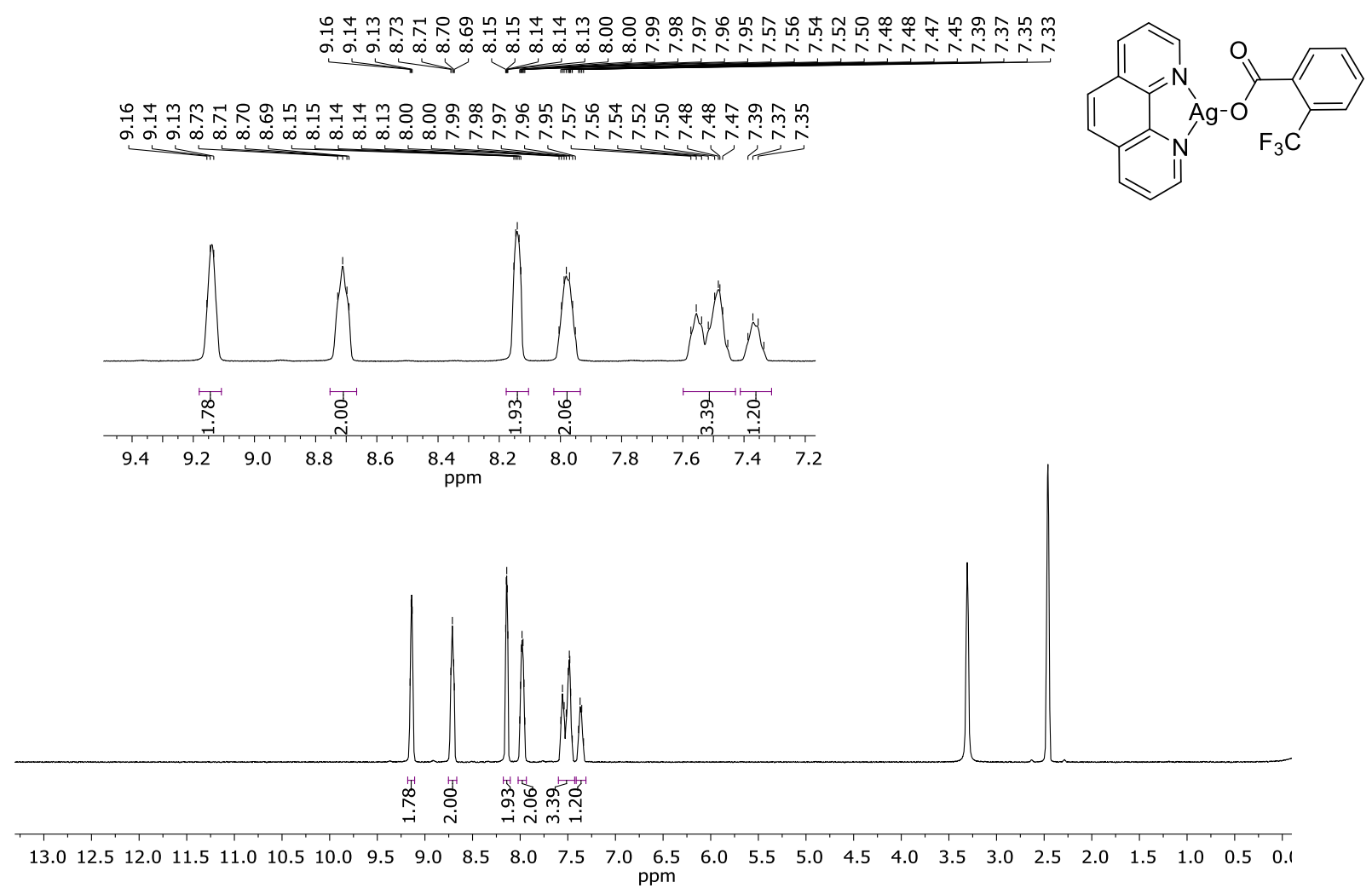

Figure A-12: ${ }^{1} \mathrm{H}$ NMR spectrum of (phen)Ag(2-CF3-benzoate) in DMSO- $d_{6}$ at $400 \mathrm{MHz}$. 


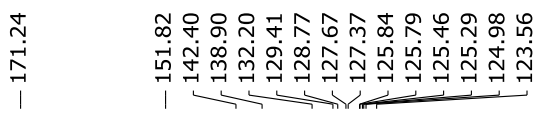

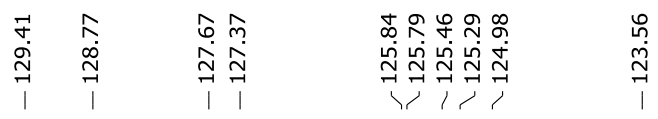
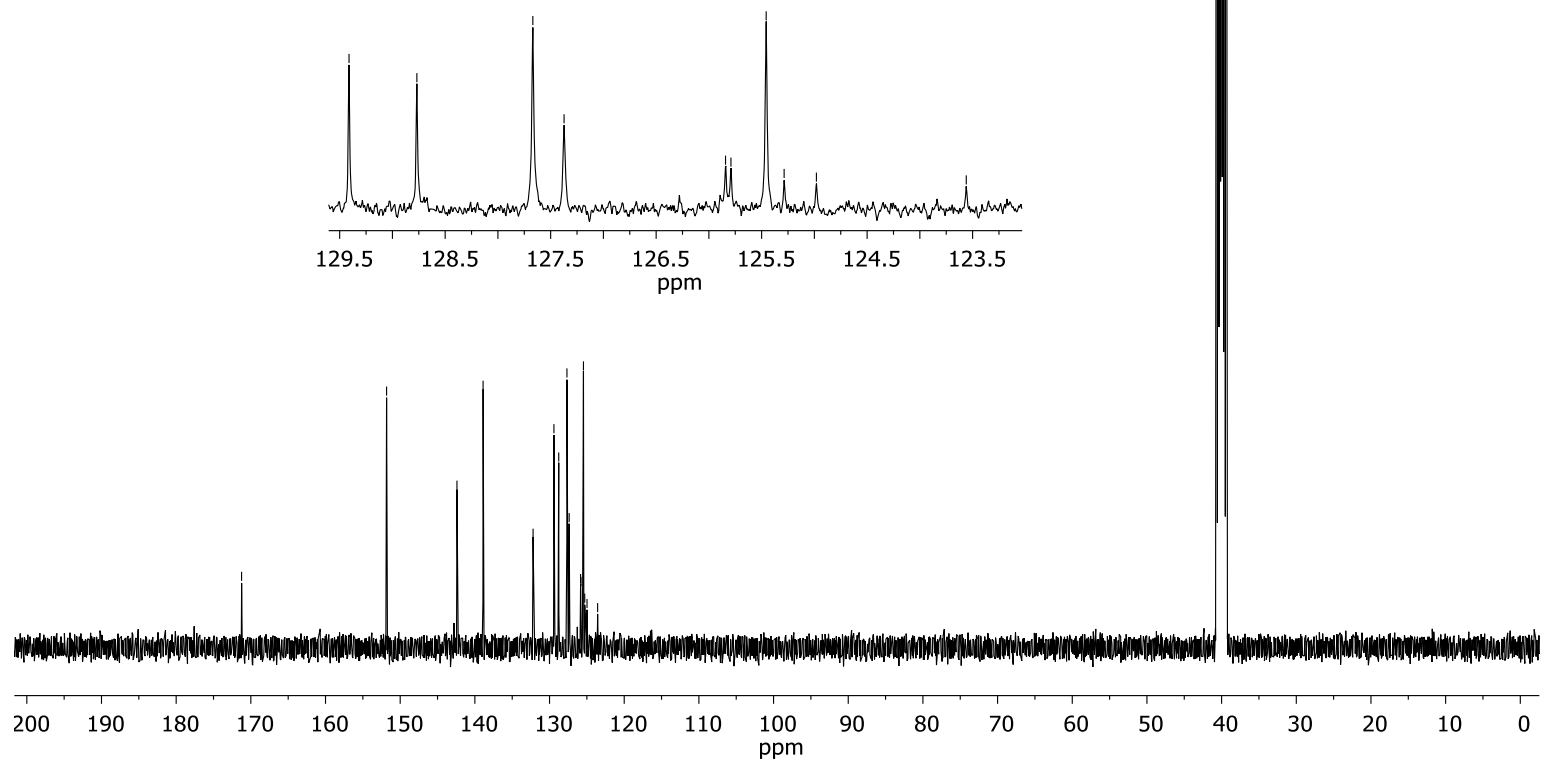

Figure A-13: ${ }^{13} \mathrm{C}$ NMR spectrum of (phen)Ag(2-CF 3 -benzoate) in DMSO- $d_{6}$ at $100 \mathrm{MHz}$. 


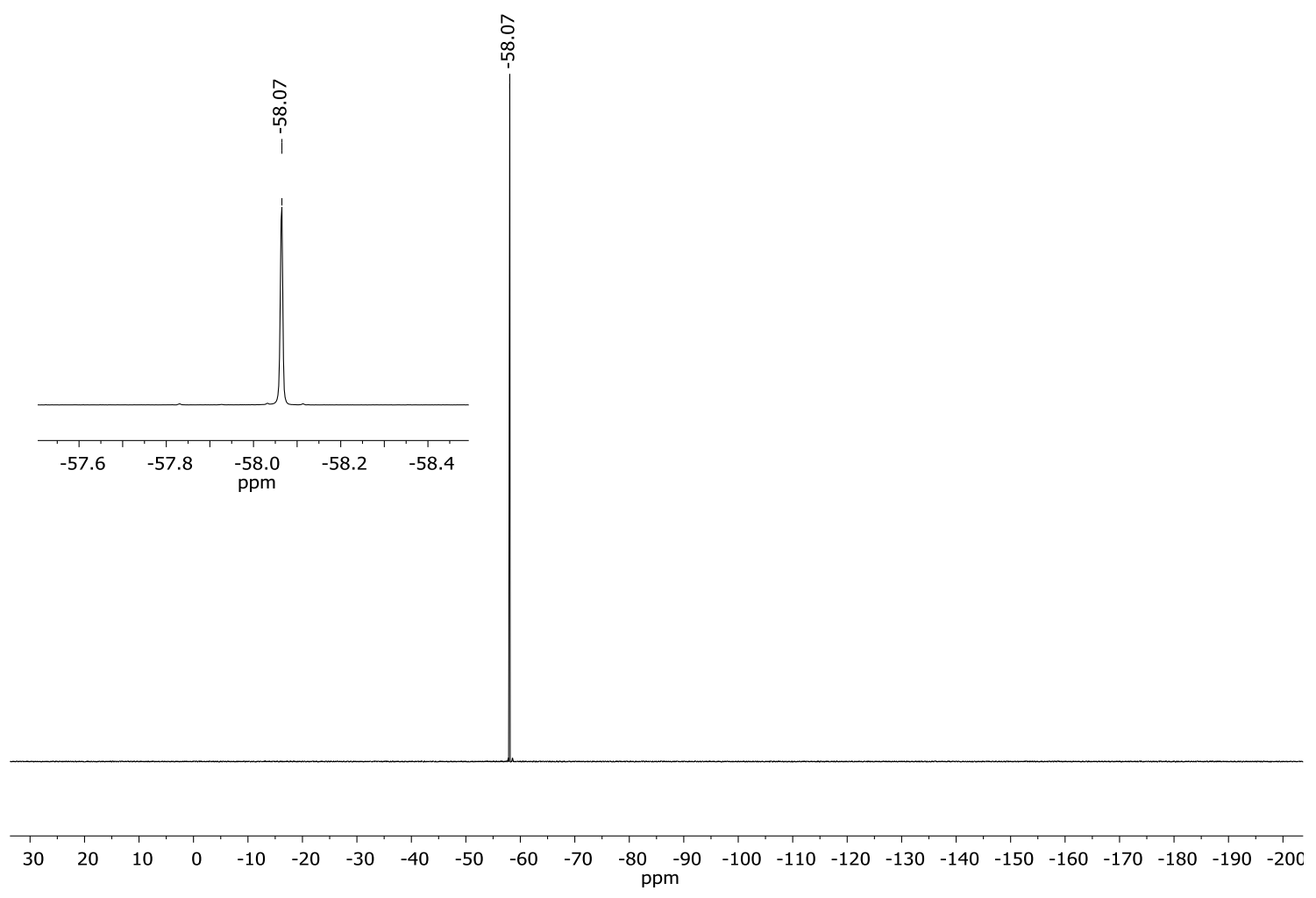

Figure A-14: ${ }^{19}$ F-NMR spectrum of (phen)Ag(2-CF $3-$ benzoate) in DMSO- $d_{6}$ at $376 \mathrm{MHz}$. 


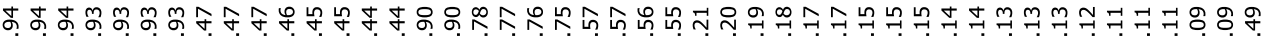

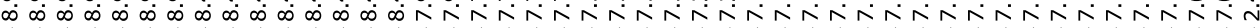

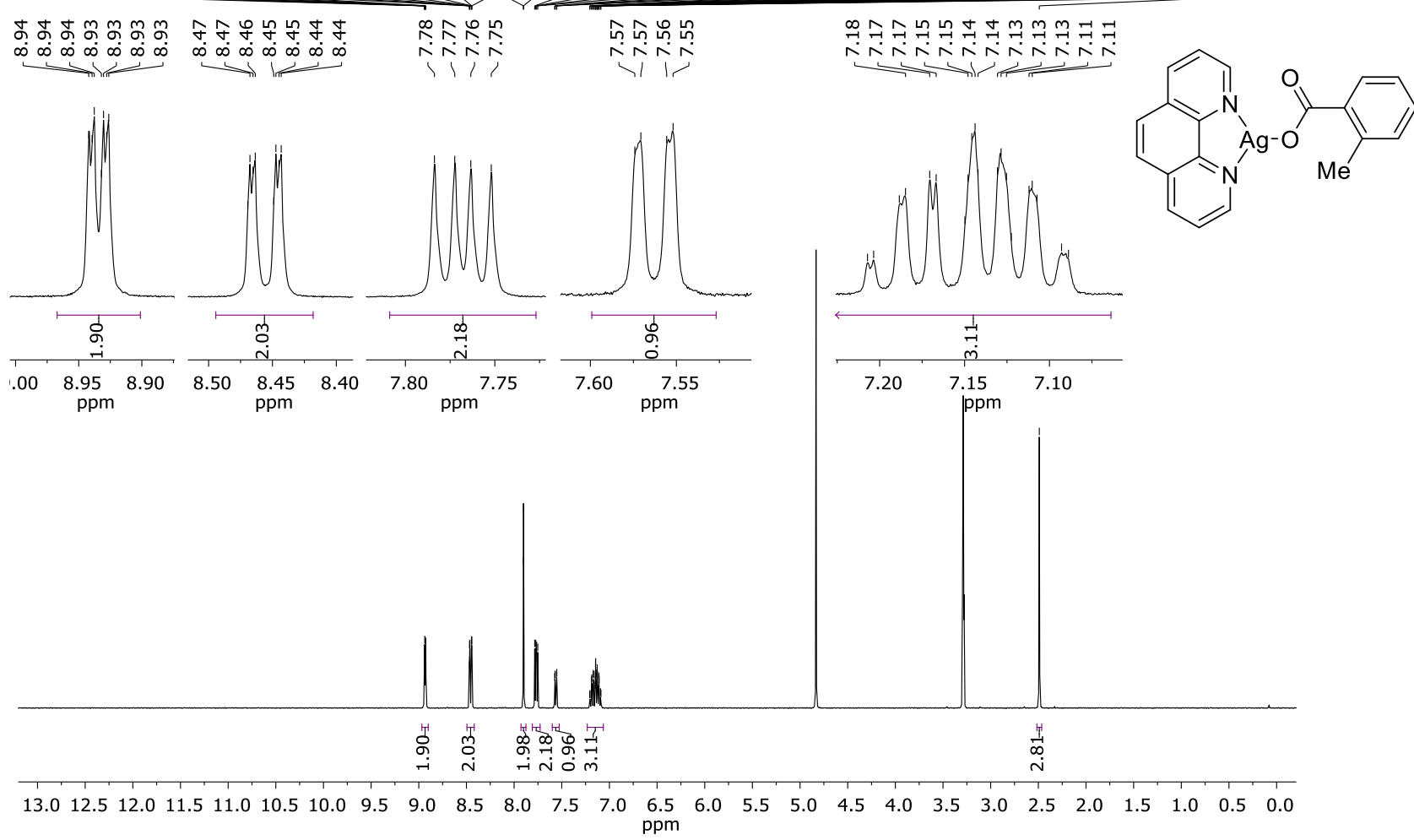

Figure A-15: ${ }^{1} \mathrm{H}$ NMR spectrum of (phen)Ag(2-Me-benzoate) in methanol- $d_{4}$ at $400 \mathrm{MHz}$. 

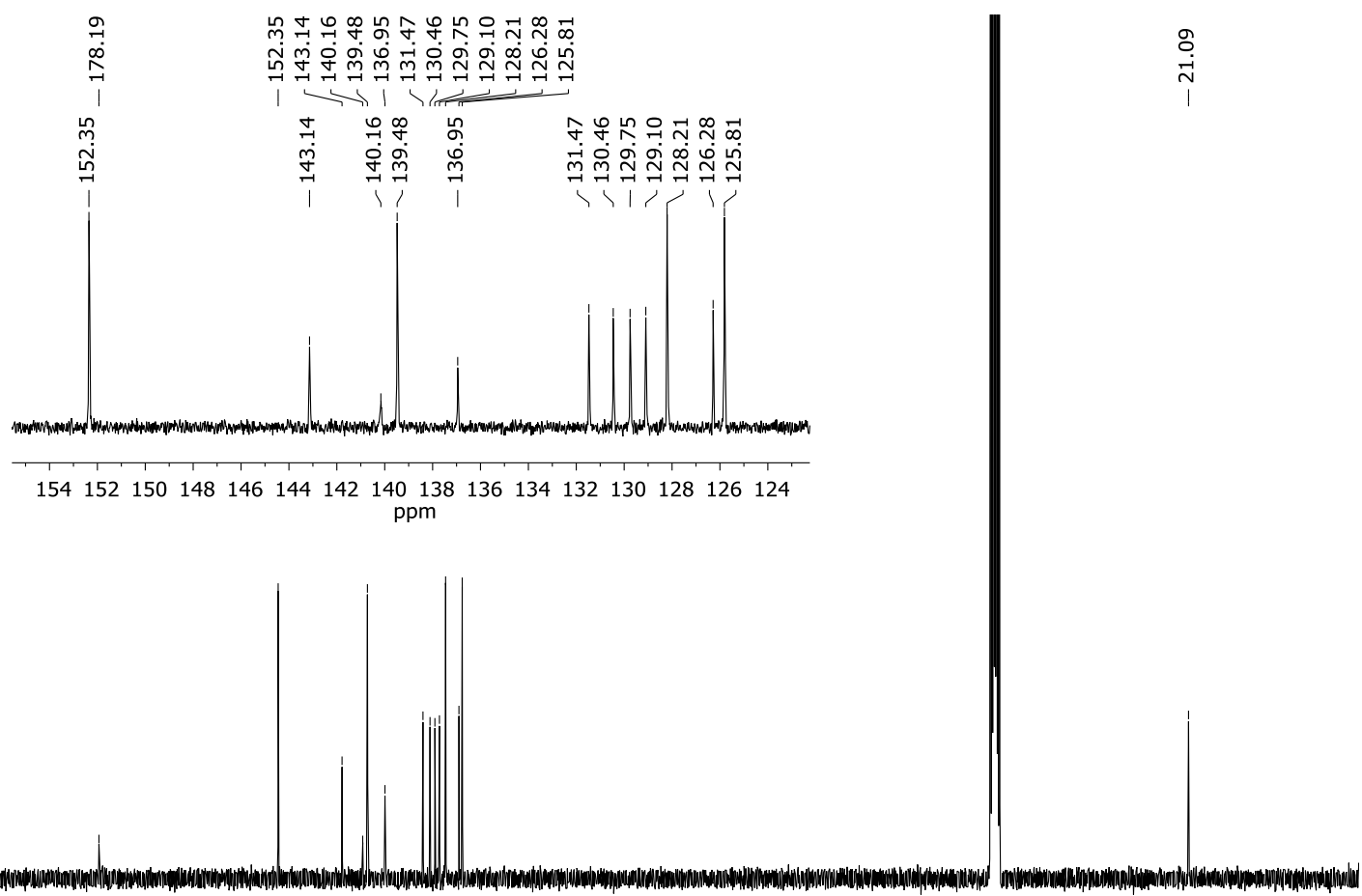

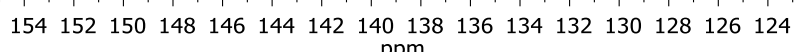

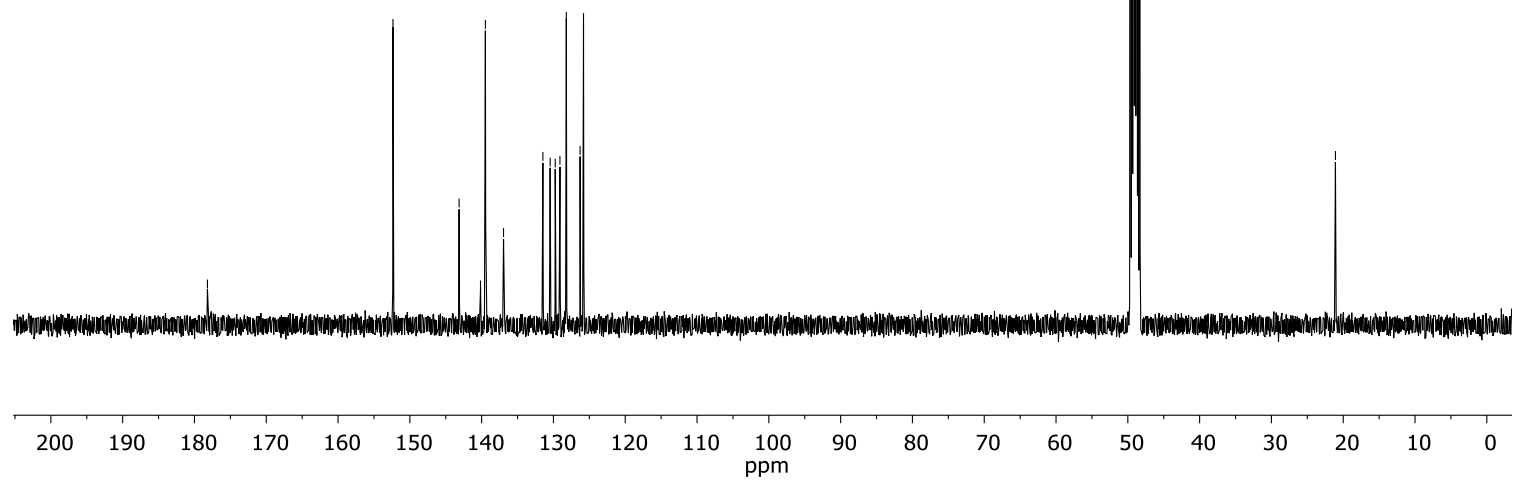

Figure A-16: ${ }^{13} \mathrm{C}$ NMR spectrum of (phen)Ag(2-Me-benzoate) in methanol- $d 4$ at $100 \mathrm{MHz}$. 


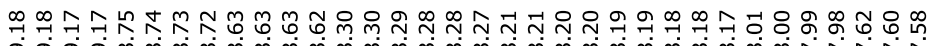

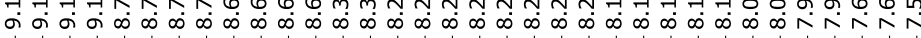

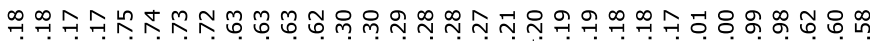

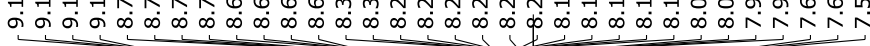
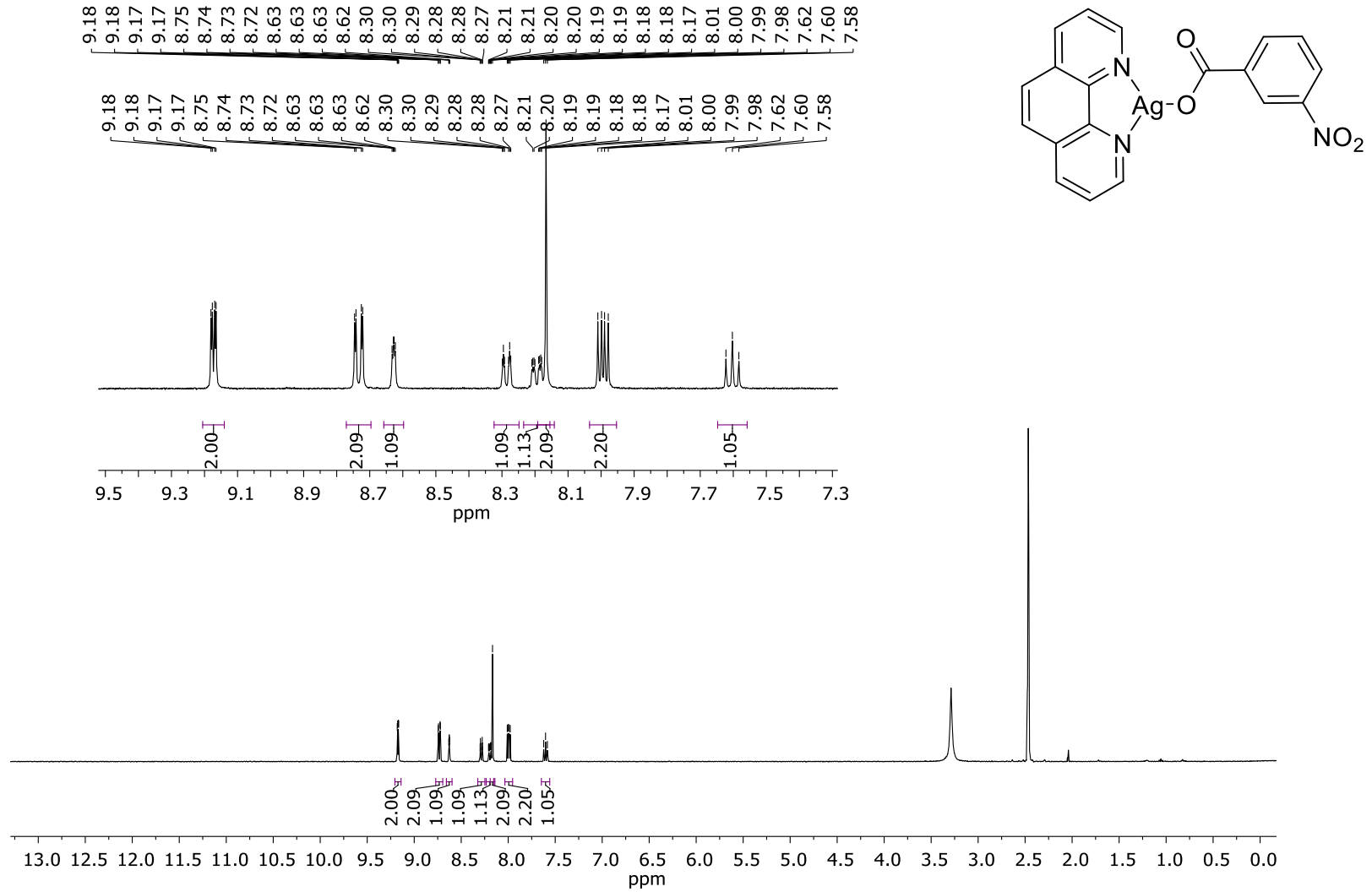

Figure A-17: ${ }^{1} \mathrm{H}$ NMR spectrum of (phen)Ag(3-NO2-benzoate) in DMSO- $d_{6}$ at $400 \mathrm{MHz}$. 

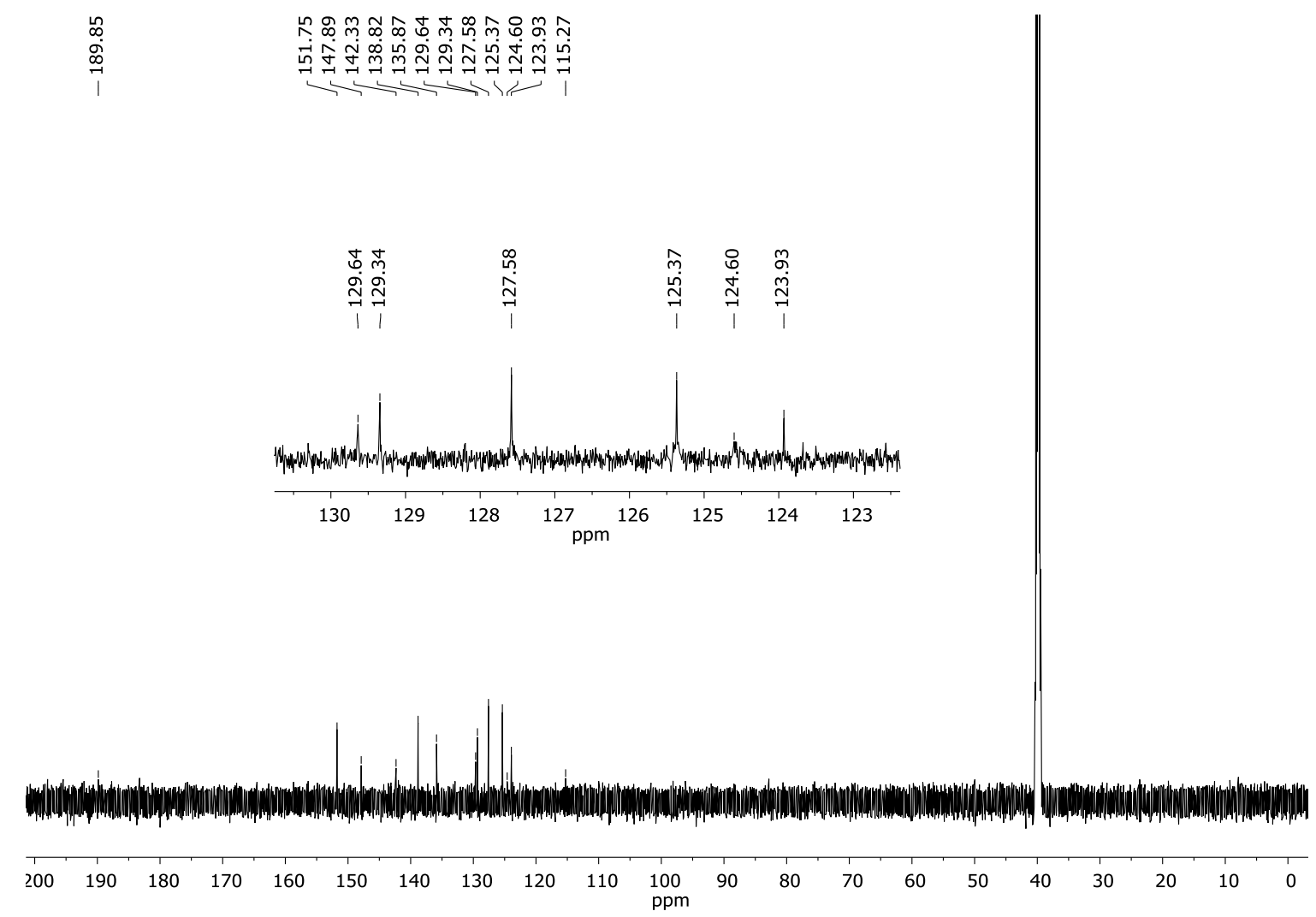

Figure A-18: ${ }^{13} \mathrm{C}$ NMR spectrum of (phen)Ag(3-NO2-benzoate) in DMSO- $d_{6}$ at $150 \mathrm{MHz}$. 


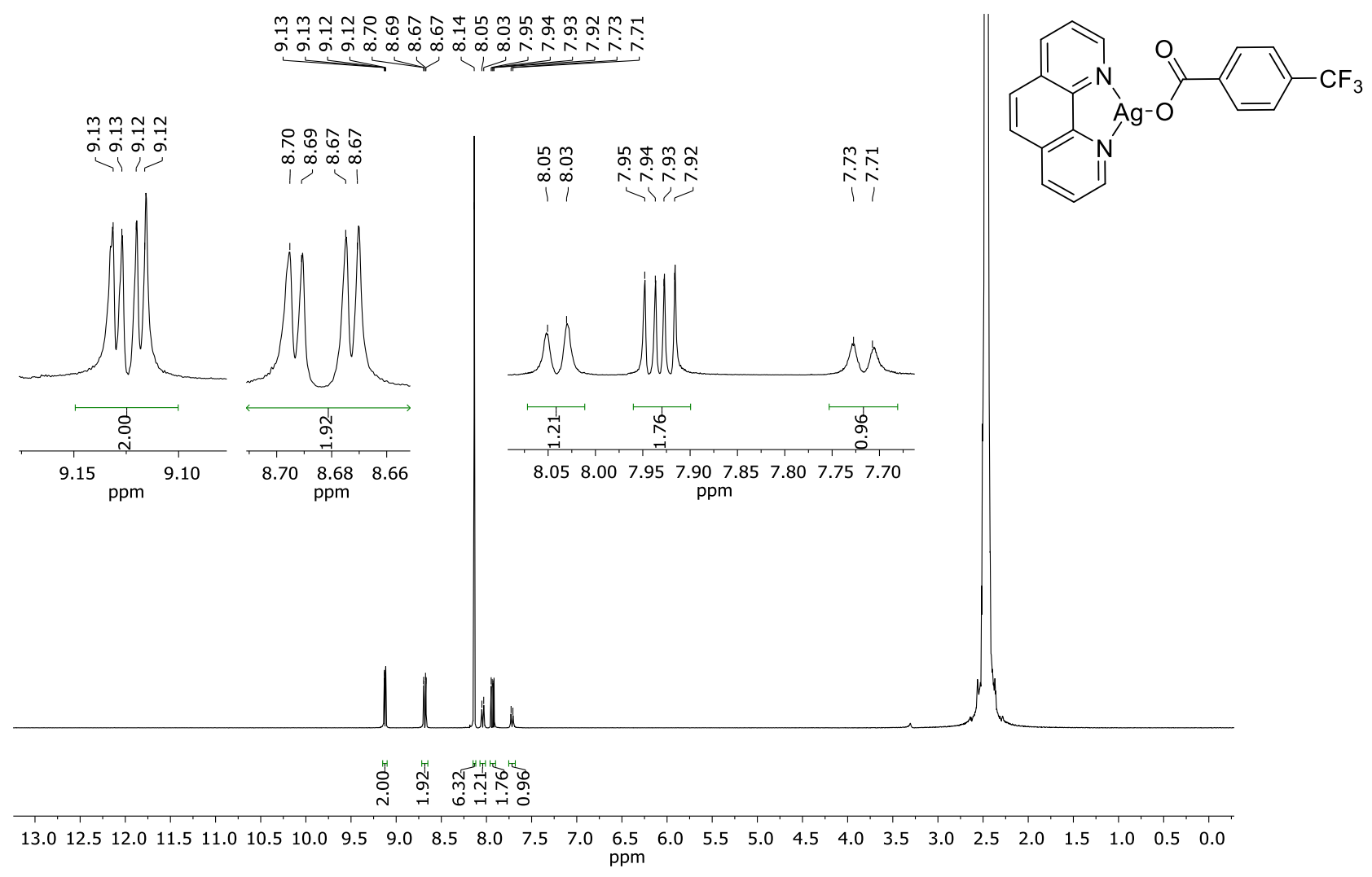

Figure A-19: ${ }^{1} \mathrm{H}$ NMR spectrum of (phen)Ag(4-CF 3 -benzoate) in DMSO- $d_{6}$ at $400 \mathrm{MHz}$. 

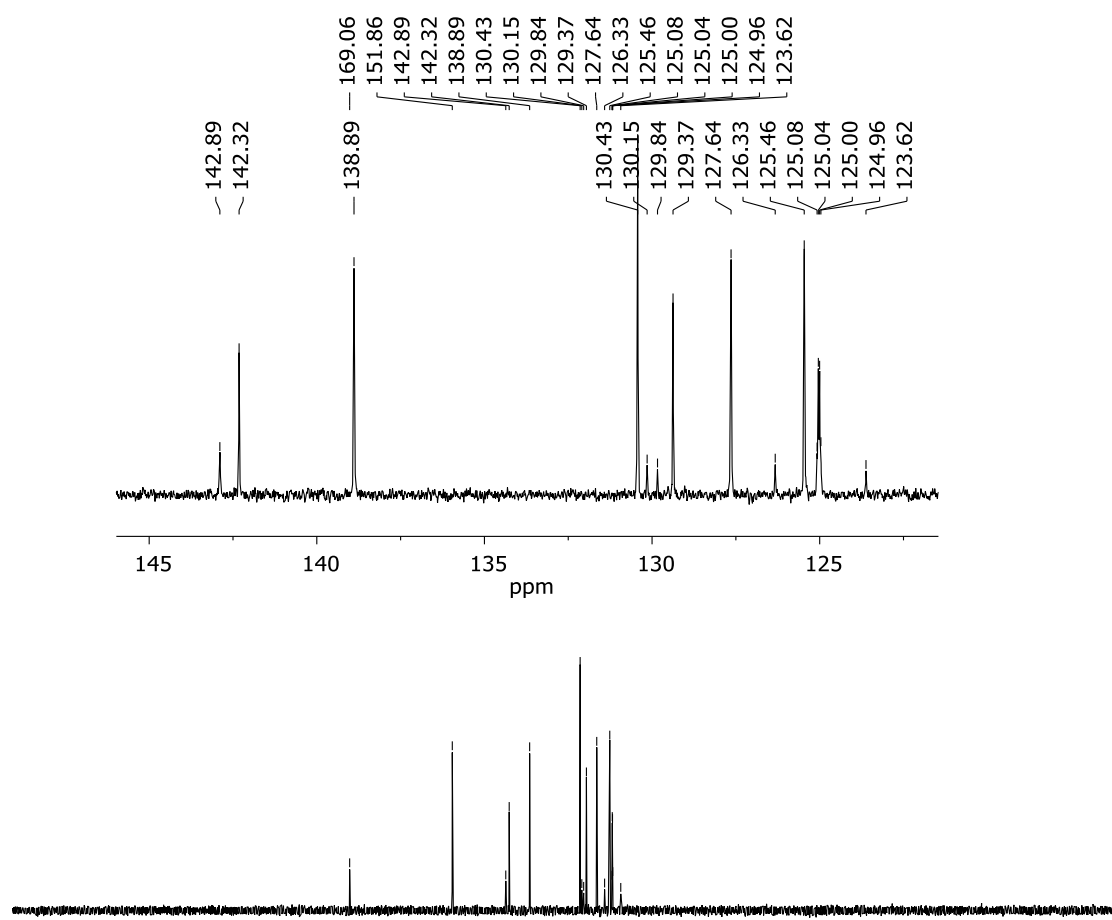

$\begin{array}{lllllllllllllllllllllllllllllll}220 & 210 & 200 & 190 & 180 & 170 & 160 & 150 & 140 & 130 & 120 & 110 & 100 & 90 & 80 & 70 & 60 & 50 & 40 & 30 & 20 & 10 & 0 & -10 & -20\end{array}$

Figure A-20: ${ }^{13} \mathrm{C}$ NMR spectrum of (phen)Ag(4-CF 3 -benzoate) in DMSO- $d_{6}$ at $100 \mathrm{MHz}$. 


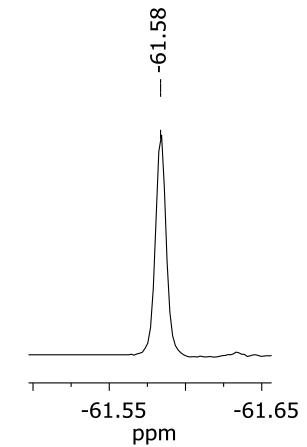

30

$20 \quad 10$

$\begin{array}{lll}0 & -10-\end{array}$

$\begin{array}{lll}-20 & -30 & -40\end{array}$

$\begin{array}{lll}-40 & -50 & -60\end{array}$

$-80-90$

Figure A-21: ${ }^{19}$ F NMR spectrum of (phen)Ag(4-CF3-benzoate) in DMSO- $d_{6}$ at $375 \mathrm{MHz}$. 


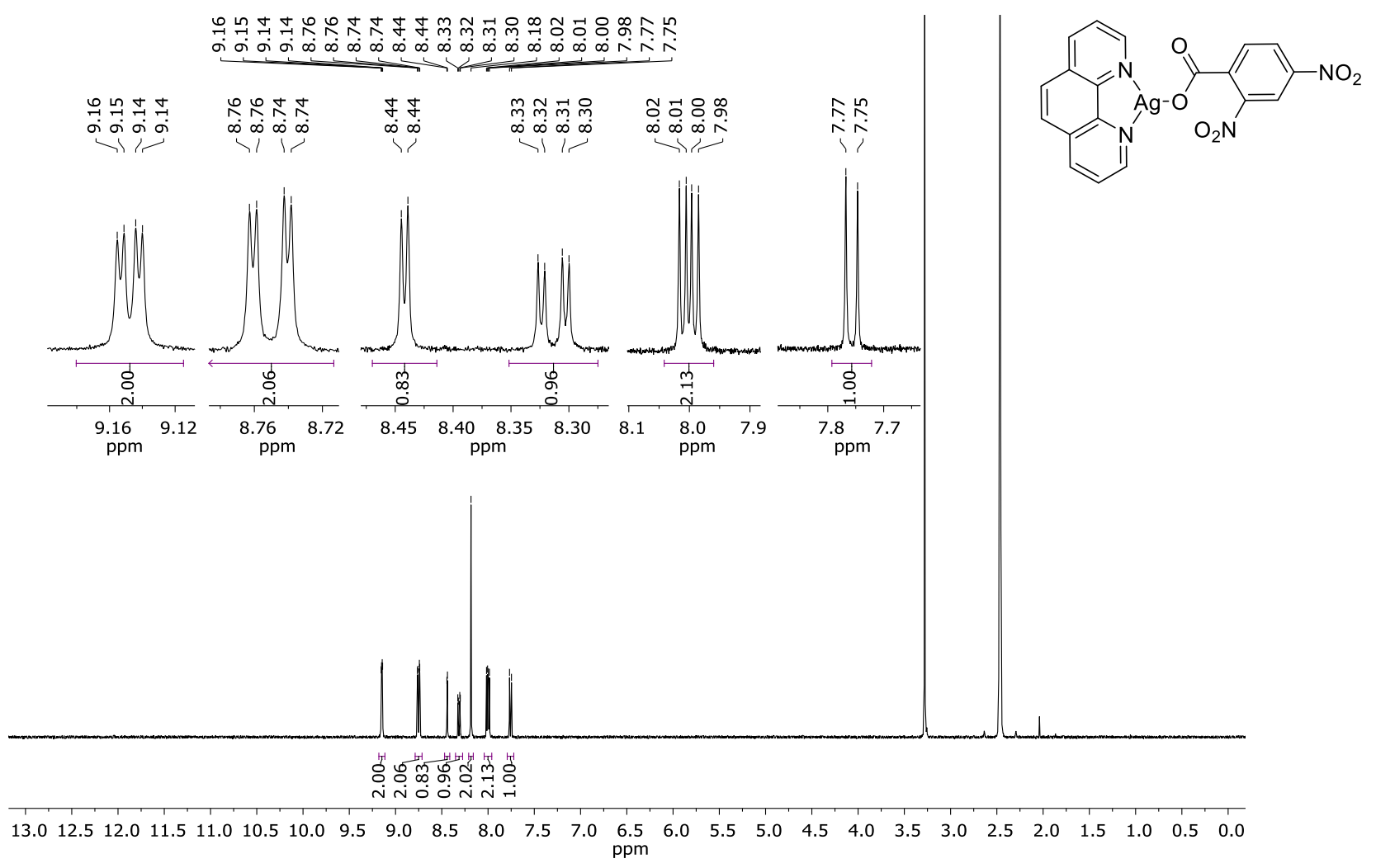

Figure A-22: ${ }^{1} \mathrm{H}$ NMR spectrum of (phen)Ag(2,4-di-NO2-benzoate) in DMSO- $d_{6}$ at $400 \mathrm{MHz}$. 

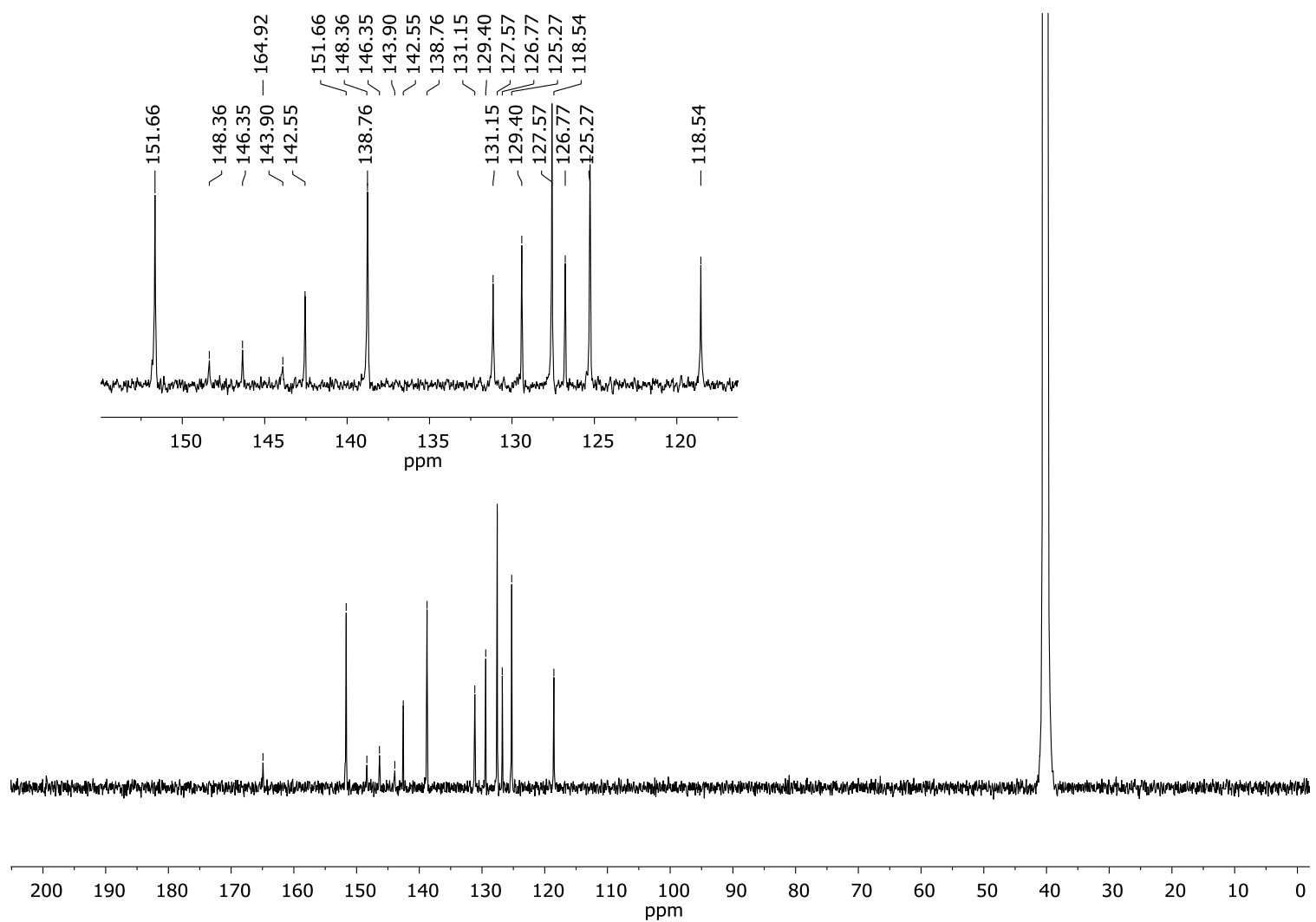

Figure A-23: ${ }^{13} \mathrm{C}$ NMR spectrum of (phen)Ag(2,4-di-NO2-benzoate) in DMSO- $d_{6}$ at $150 \mathrm{MHz}$. 


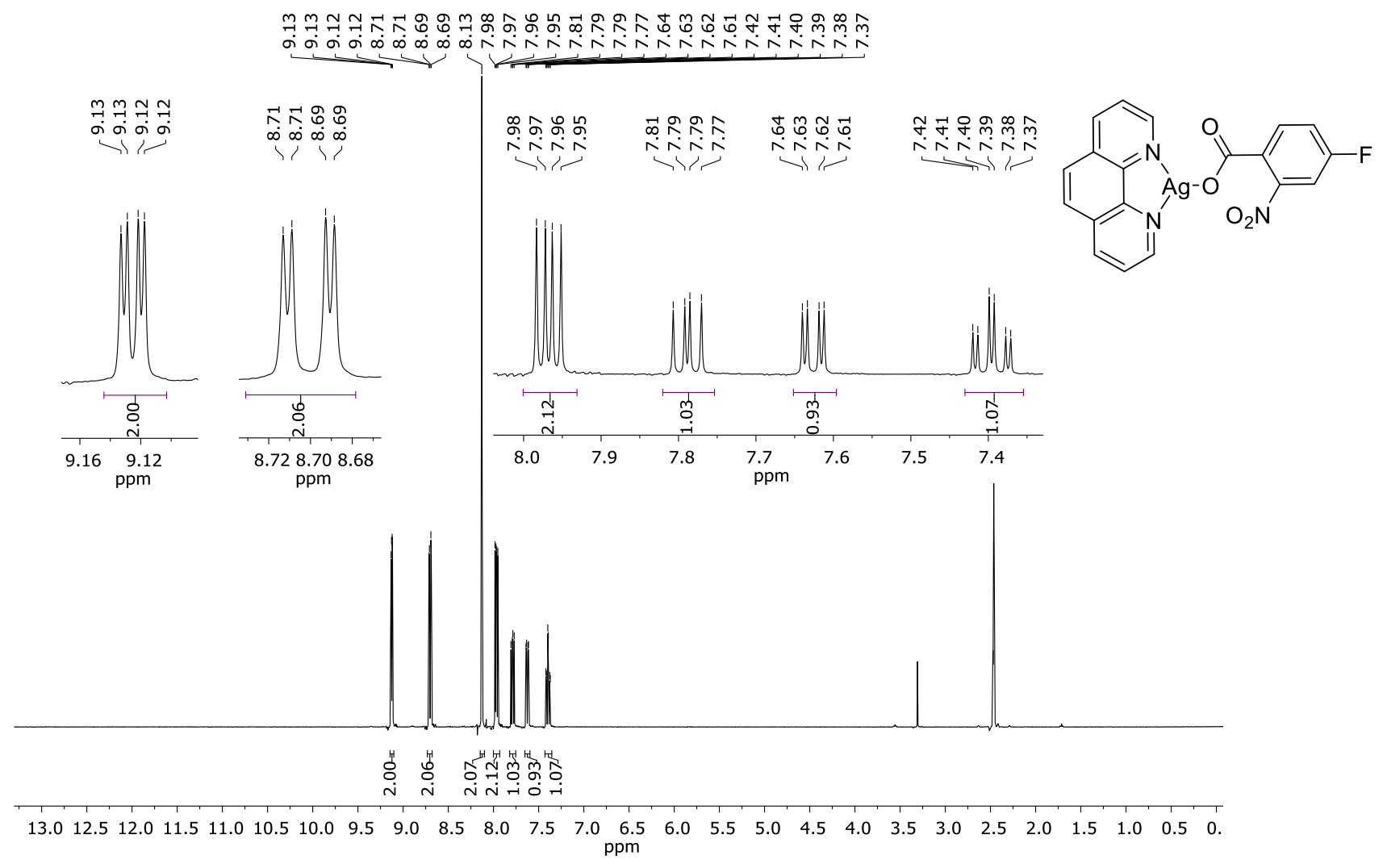

Figure A-24: ${ }^{1} \mathrm{H}$ NMR spectrum of (phen)Ag(4-F-2-NO2-benzoate) in DMSO- $d_{6}$ at $400 \mathrm{MHz}$. 


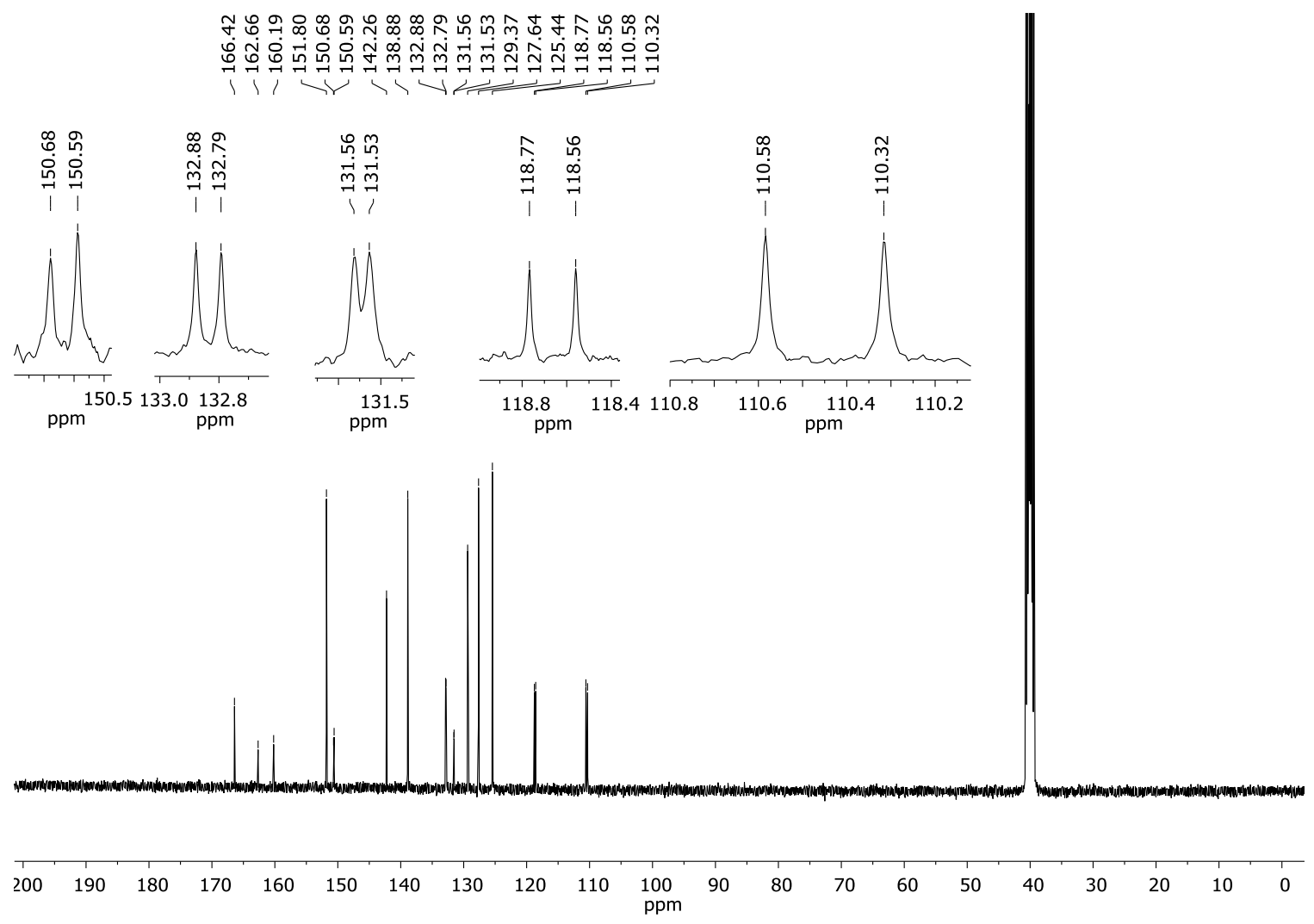

Figure A-25: ${ }^{13} \mathrm{C}$ NMR spectrum of (phen)Ag(4-F-2-NO2-benzoate) in DMSO- $d_{6}$ at $100 \mathrm{MHz}$. 
뉴윯요

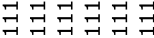

ปั

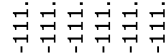

' 1 i

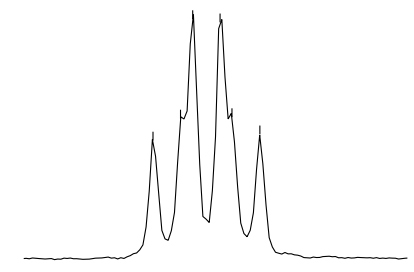

$-111.20-111.25-111.30-111.35$

ppm

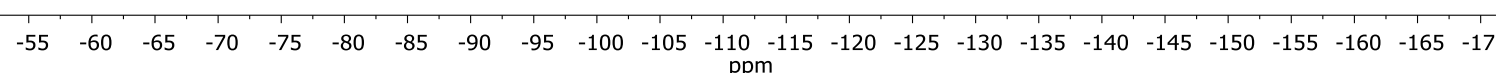

Figure A-26: ${ }^{19}$ F NMR spectrum of (phen)Ag(4-F-2-NO2-benzoate) in DMSO- $d_{6}$ at $376 \mathrm{MHz}$. 


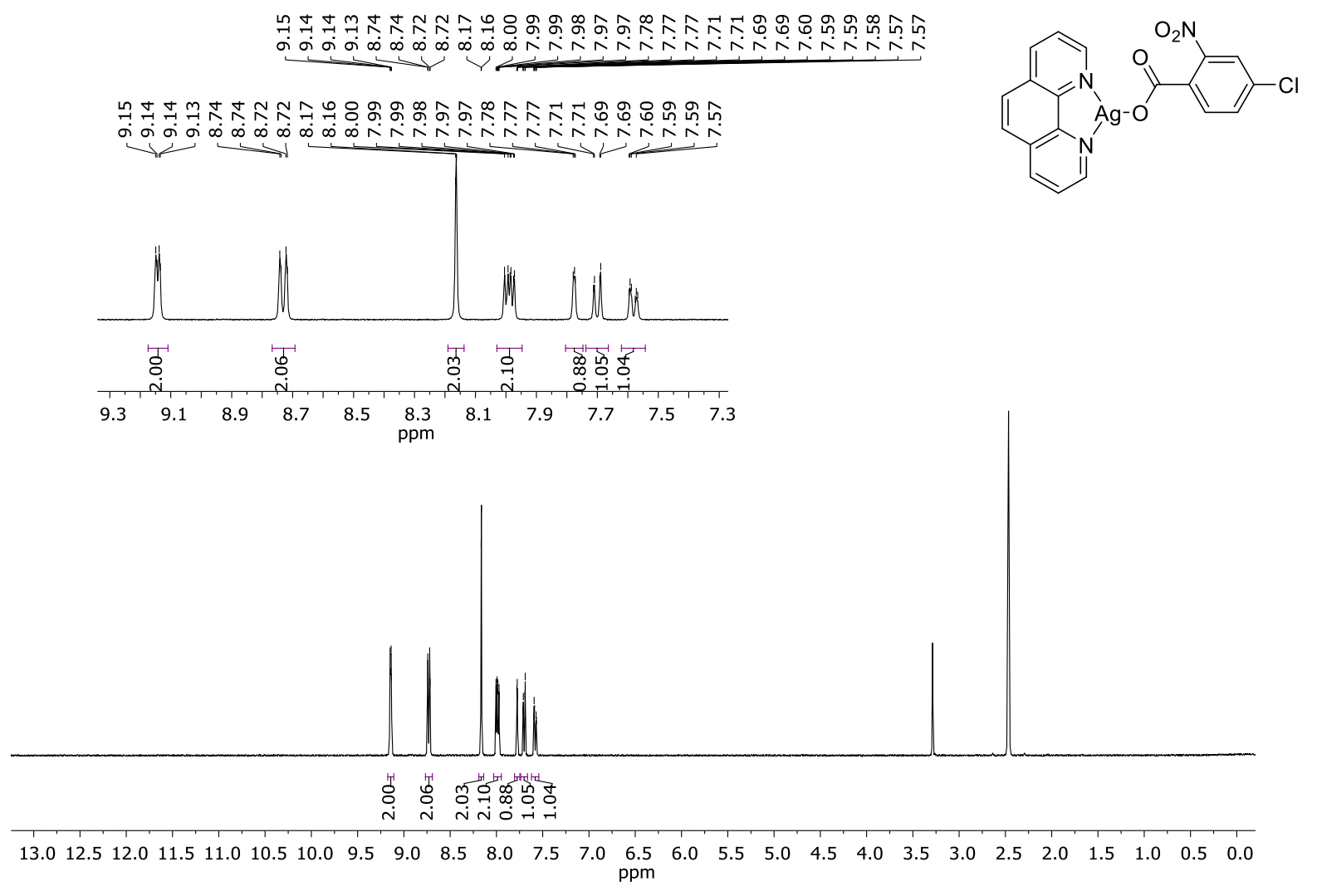

Figure A-27: ${ }^{1} \mathrm{H}$ NMR spectrum of (phen)Ag(4-Cl-2-NO2-benzoate) in DMSO- $d_{6}$ at $400 \mathrm{MHz}$. 


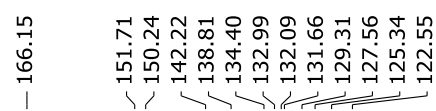

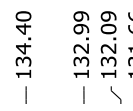
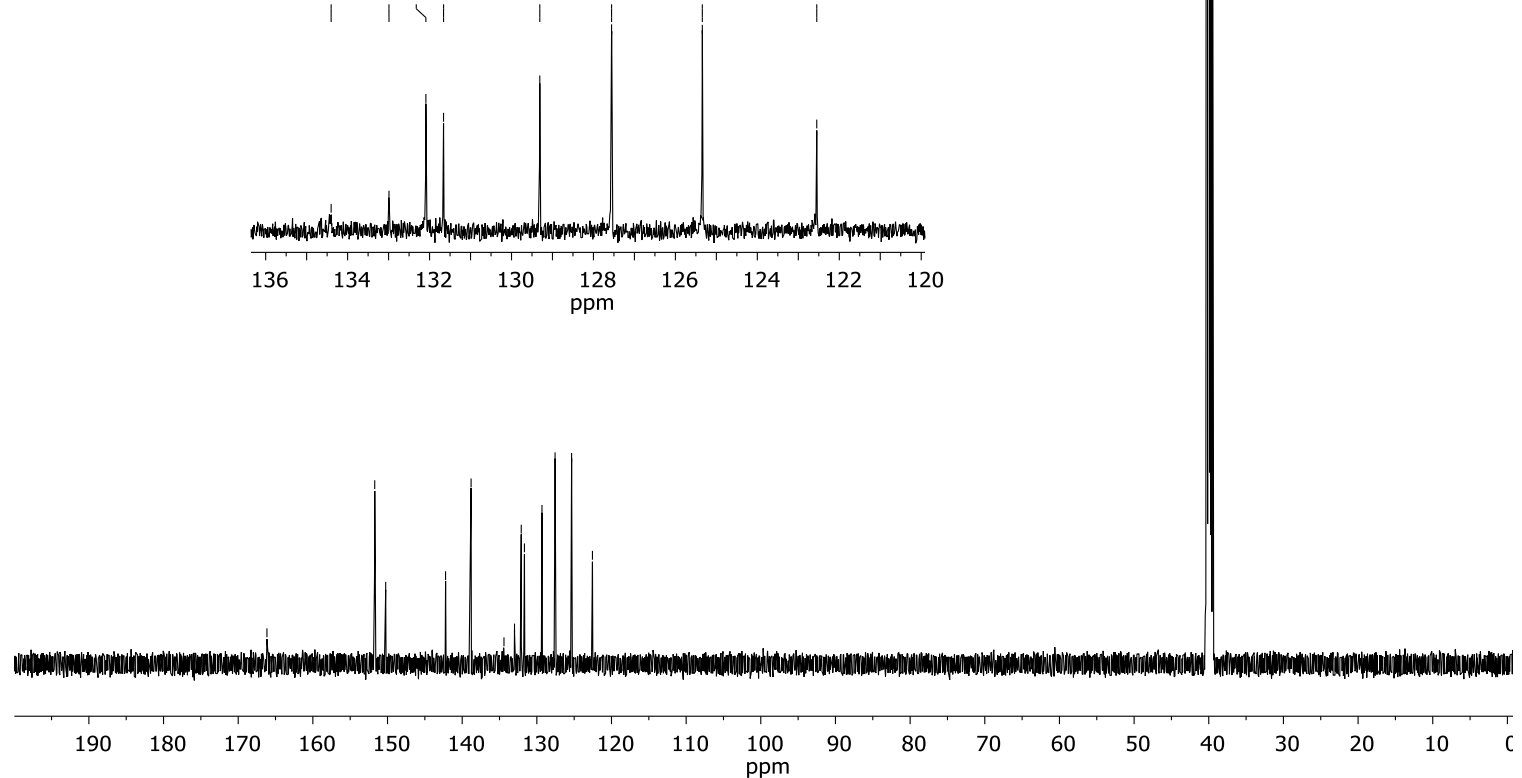

Figure A-28: ${ }^{13} \mathrm{C}$ NMR spectrum of (phen)Ag(4-Cl-2-NO2-benzoate) in DMSO- $d_{6}$ at 100 $\mathrm{MHz}$. 


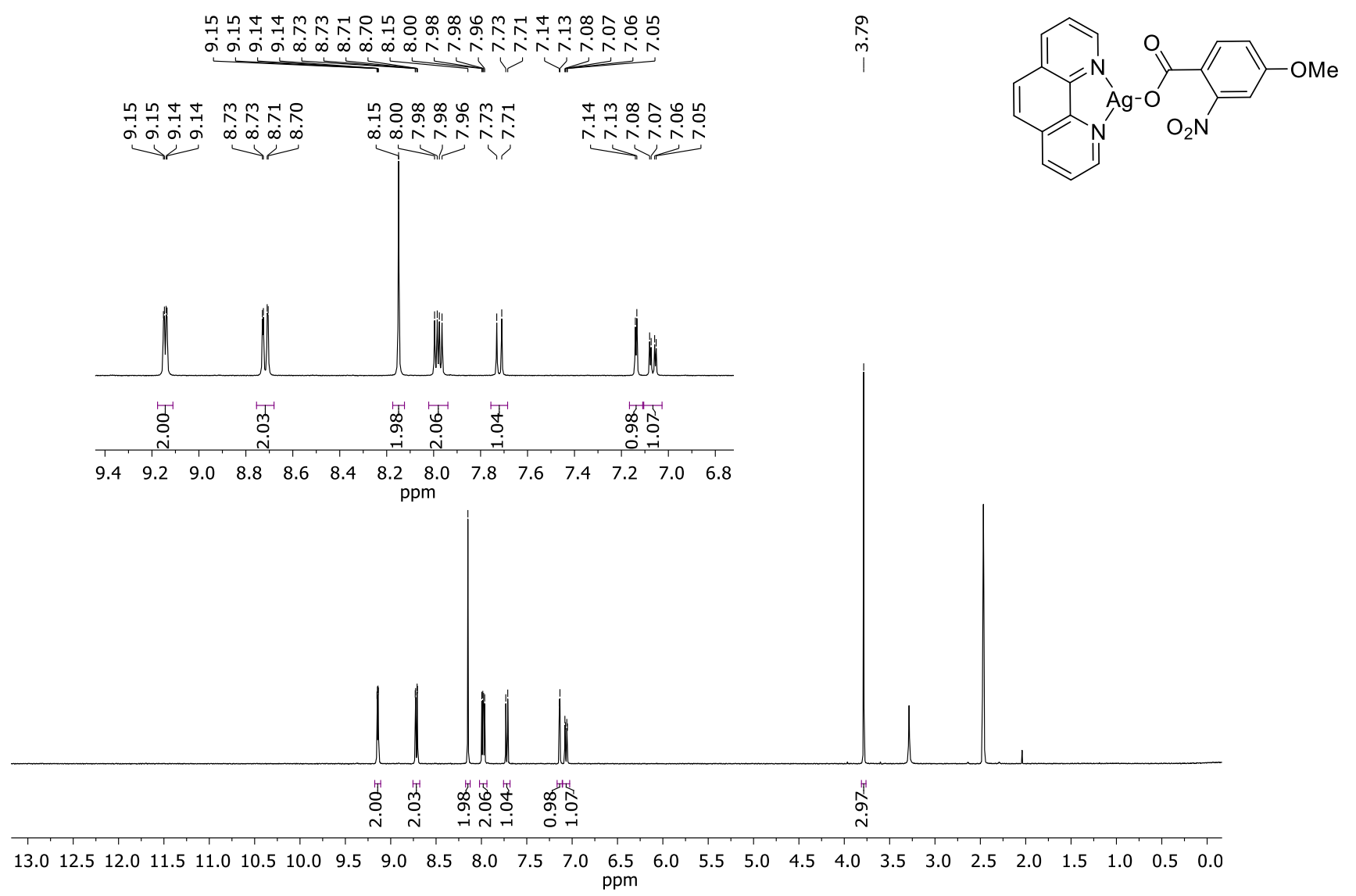

Figure A-29: ${ }^{1} \mathrm{H}$ NMR spectrum of (phen)Ag(4-OMe-2-NO2-benzoate) in DMSO- $d_{6}$ at 400 MHz. 


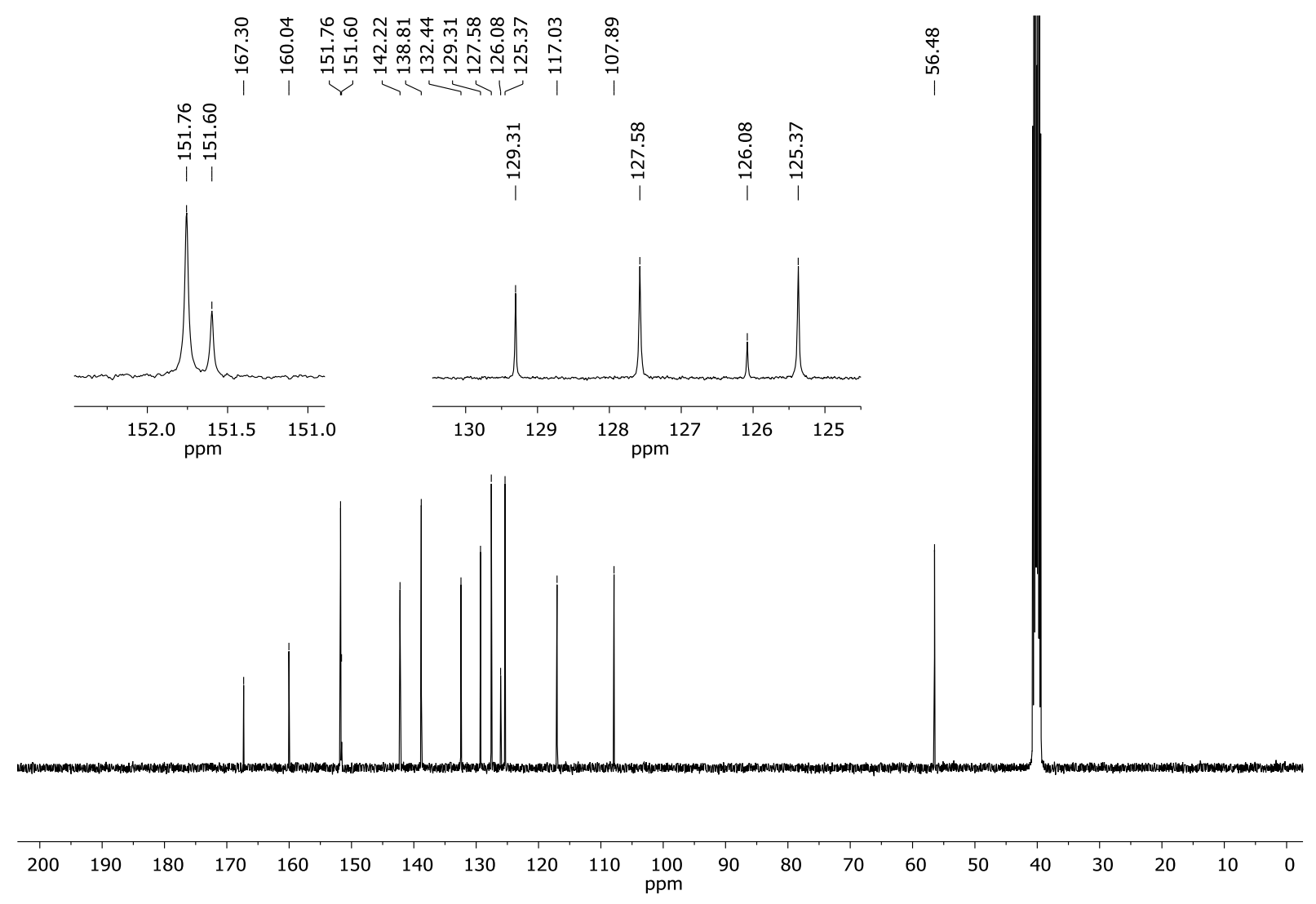

Figure A-30: ${ }^{13} \mathrm{C}$ NMR spectrum of (phen)Ag(4-OMe-2-NO2-benzoate) in DMSO- $d_{6}$ at 100 MHz. 

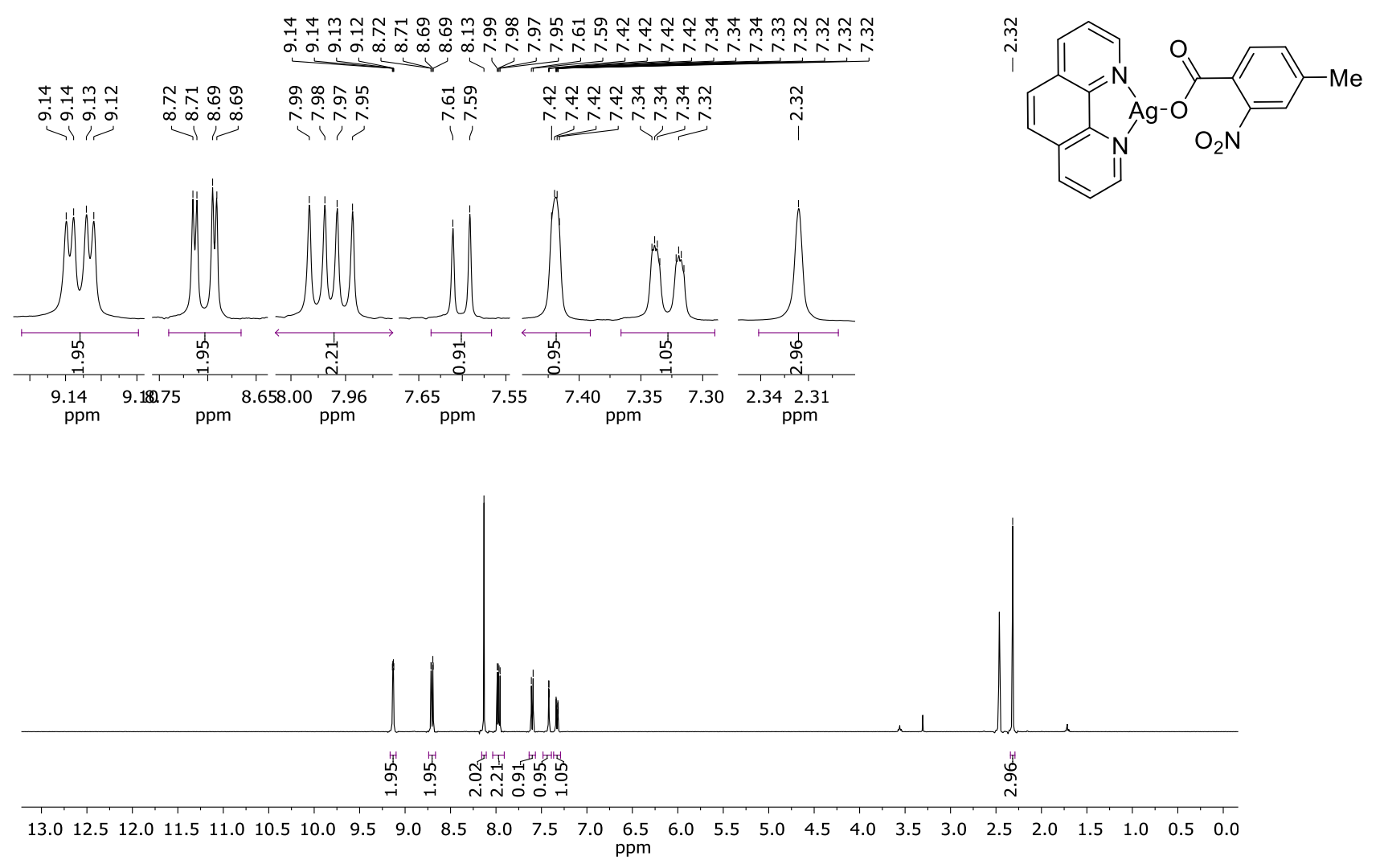

Figure A-31: ${ }^{1} \mathrm{H}$ NMR spectrum of (phen)Ag(4-Me-2-NO2-benzoate) in DMSO- $d_{6}$ at 400 $\mathrm{MHz}$. 


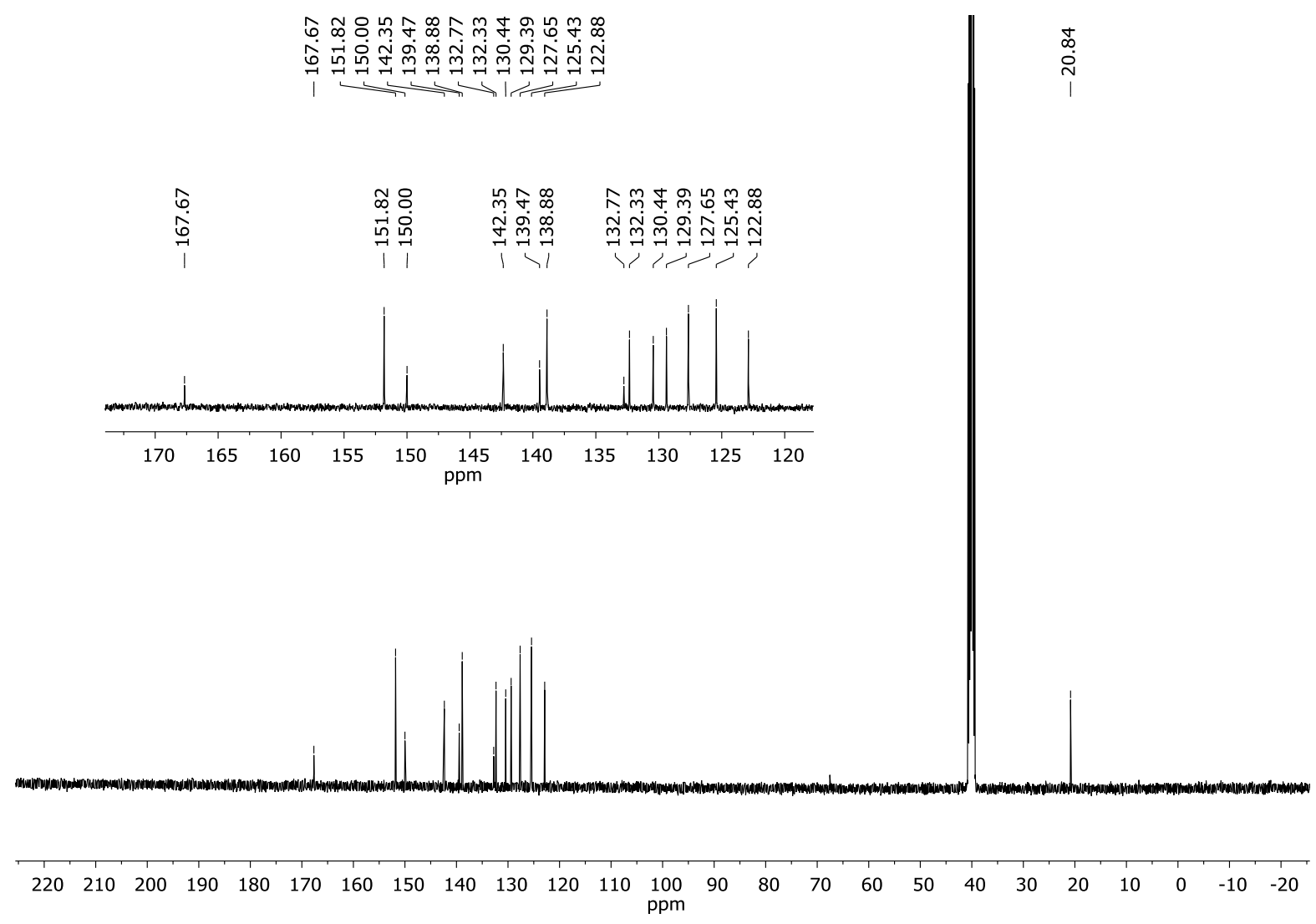

Figure A-32: ${ }^{13} \mathrm{C}$ NMR spectrum of (phen)Ag(4-Me-2-NO2-benzoate) in DMSO- $d_{6}$ at 100 MHz. 


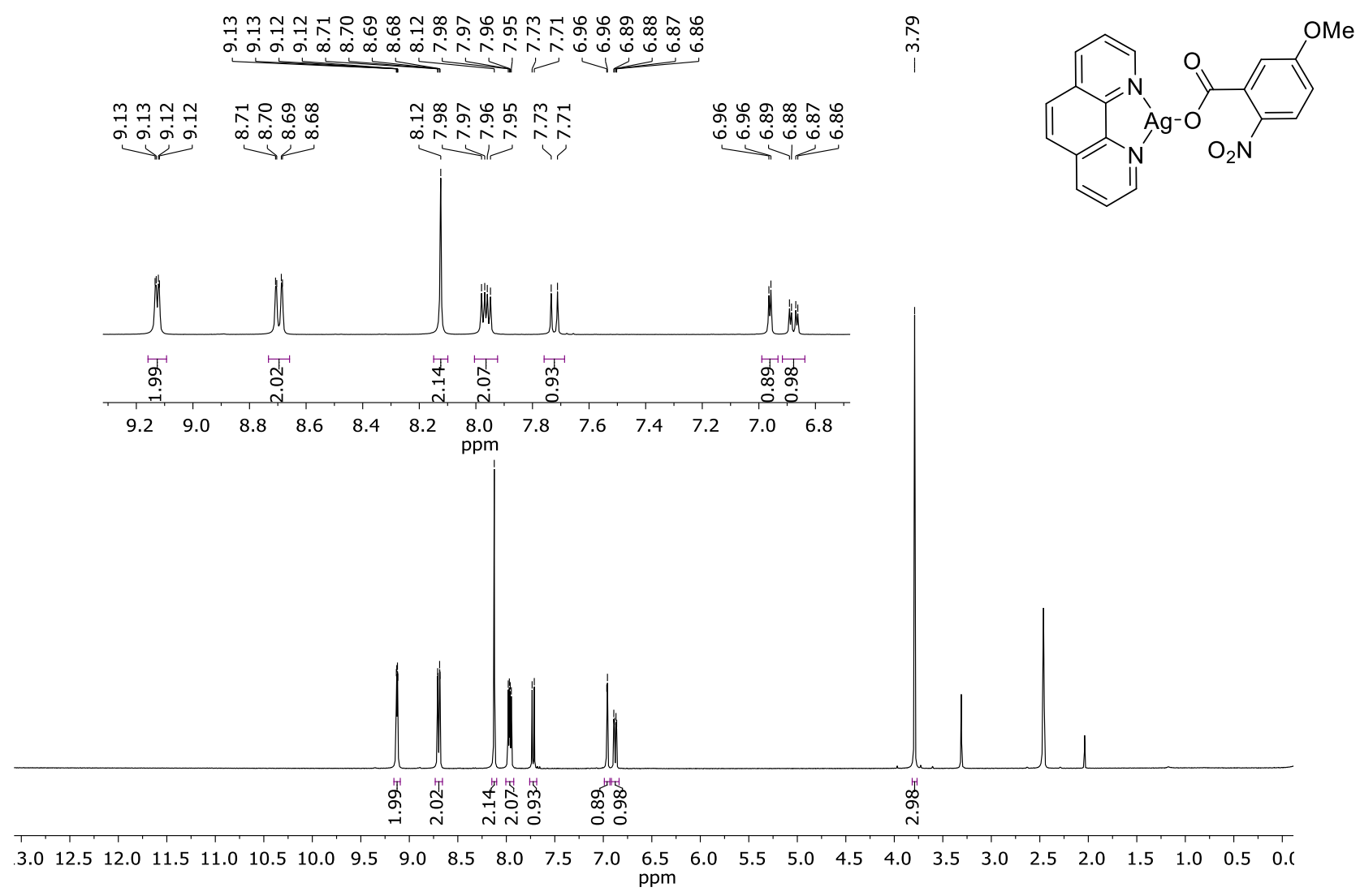

Figure A-33: ${ }^{1} \mathrm{H}$ NMR spectrum of (phen)Ag(5-OMe-2-NO2-benzoate) in DMSO- $d_{6}$ at 400 MHz. 

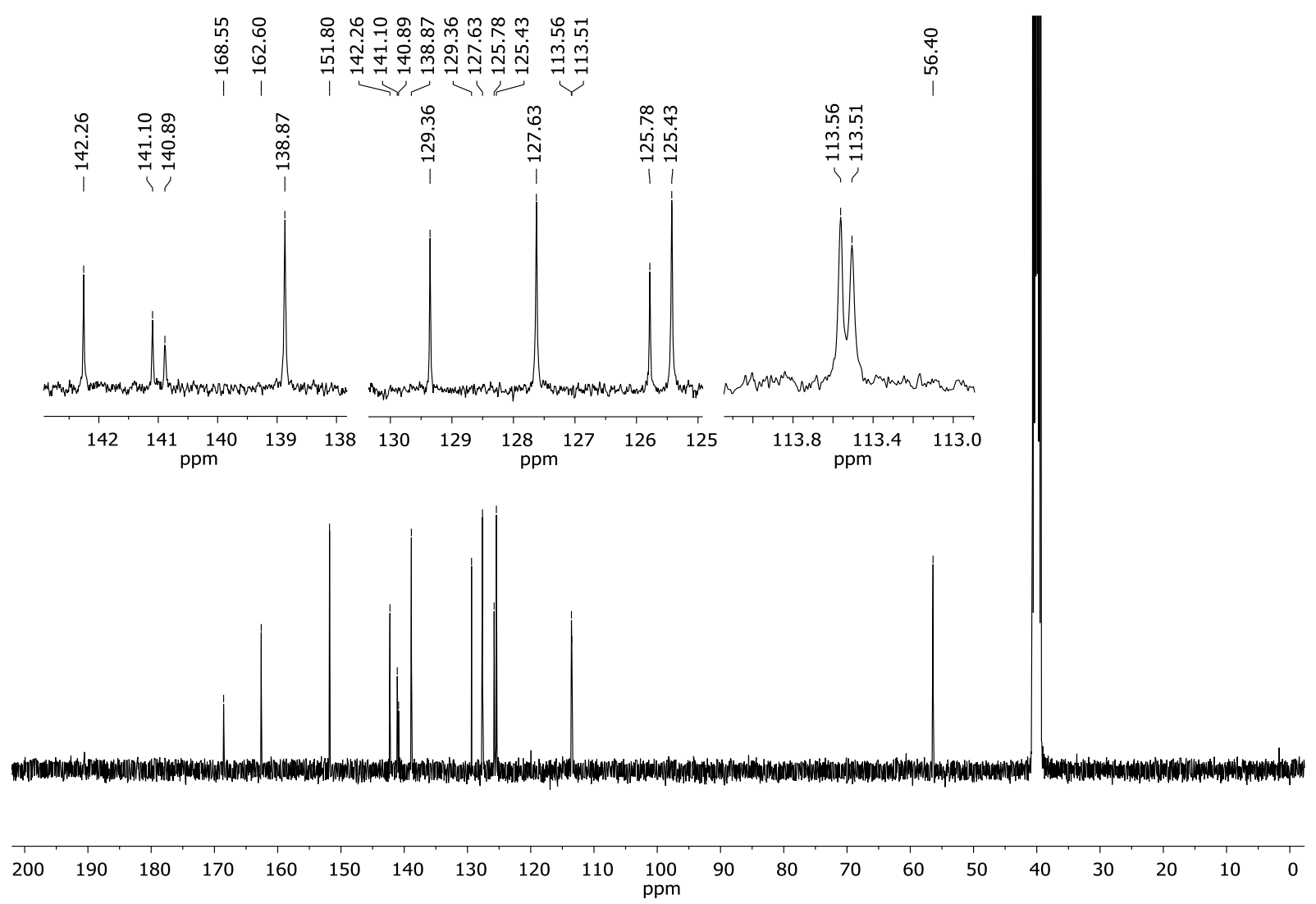

Figure A-34: ${ }^{13} \mathrm{C}$ NMR spectrum of (phen)Ag(5-OMe-2-NO2-benzoate) in DMSO- $d_{6}$ at 100 $\mathrm{MHz}$. 


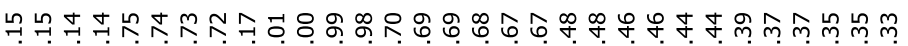
बं
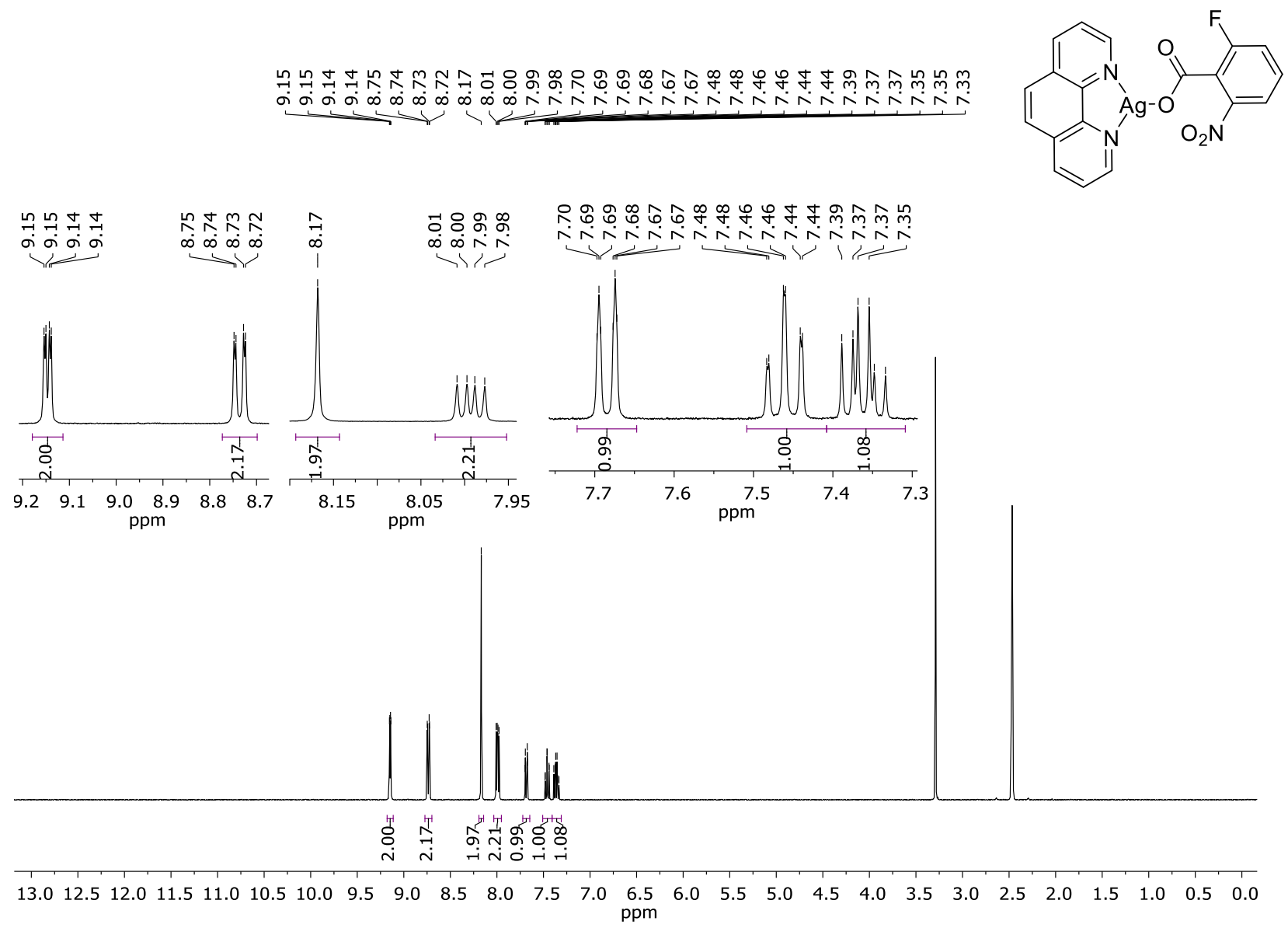

Figure A-35: ${ }^{1} \mathrm{H}$ NMR spectrum of (phen)Ag(2-F-6-NO2-benzoate) in DMSO- $d_{6}$ at $400 \mathrm{MHz}$. 


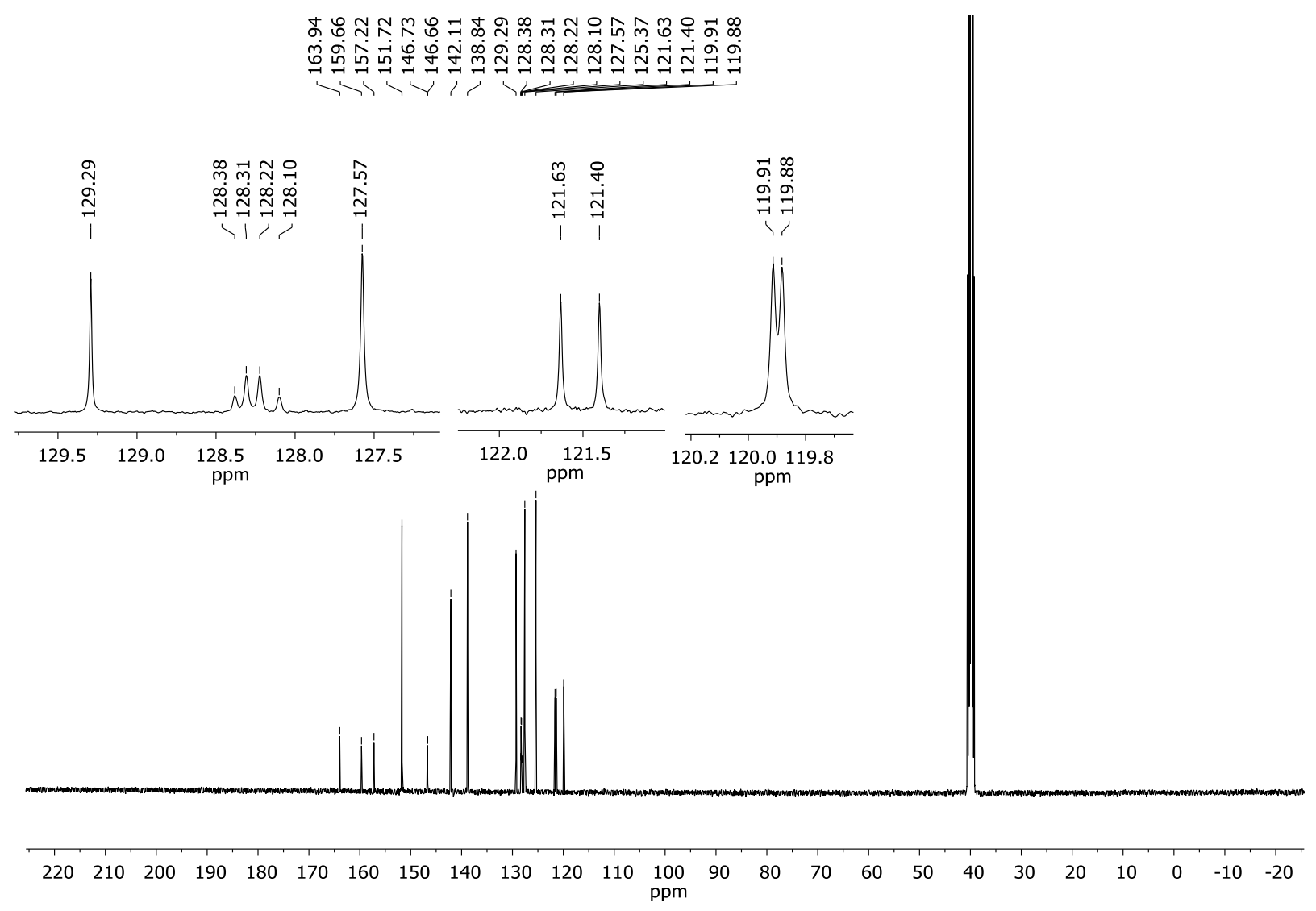

Figure A-36: ${ }^{13} \mathrm{C}$ NMR spectrum of (phen)Ag(2-F-6-NO2-benzoate) in DMSO- $d_{6}$ at $100 \mathrm{MHz}$. 


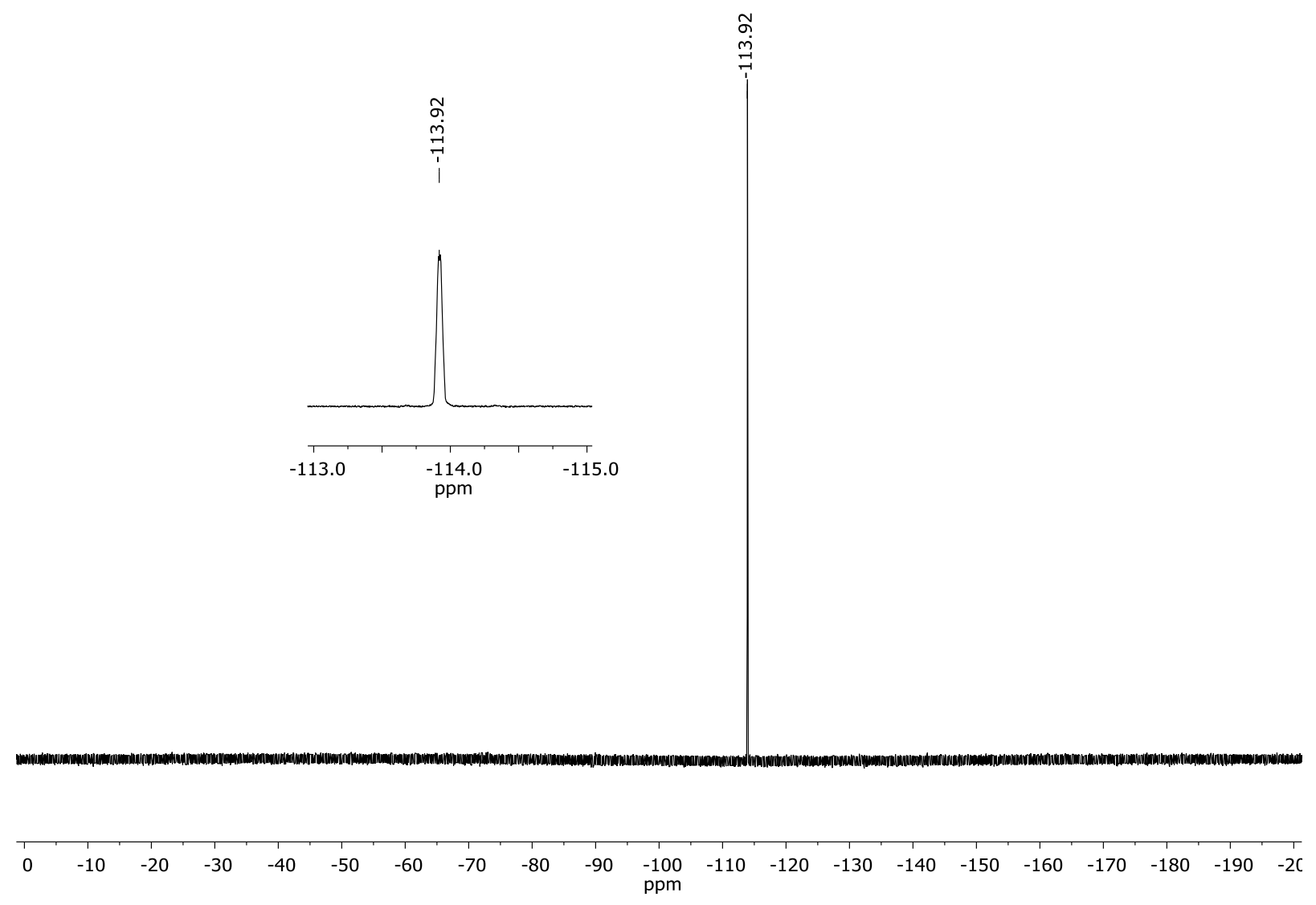

Figure A-37: ${ }^{19} \mathrm{~F}$ NMR spectrum of (phen)Ag(2-F-6-NO2-benzoate) in DMSO- $d_{6}$ at $376 \mathrm{MHz}$. 


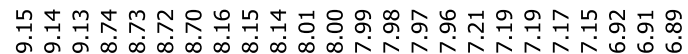

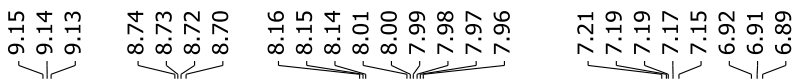
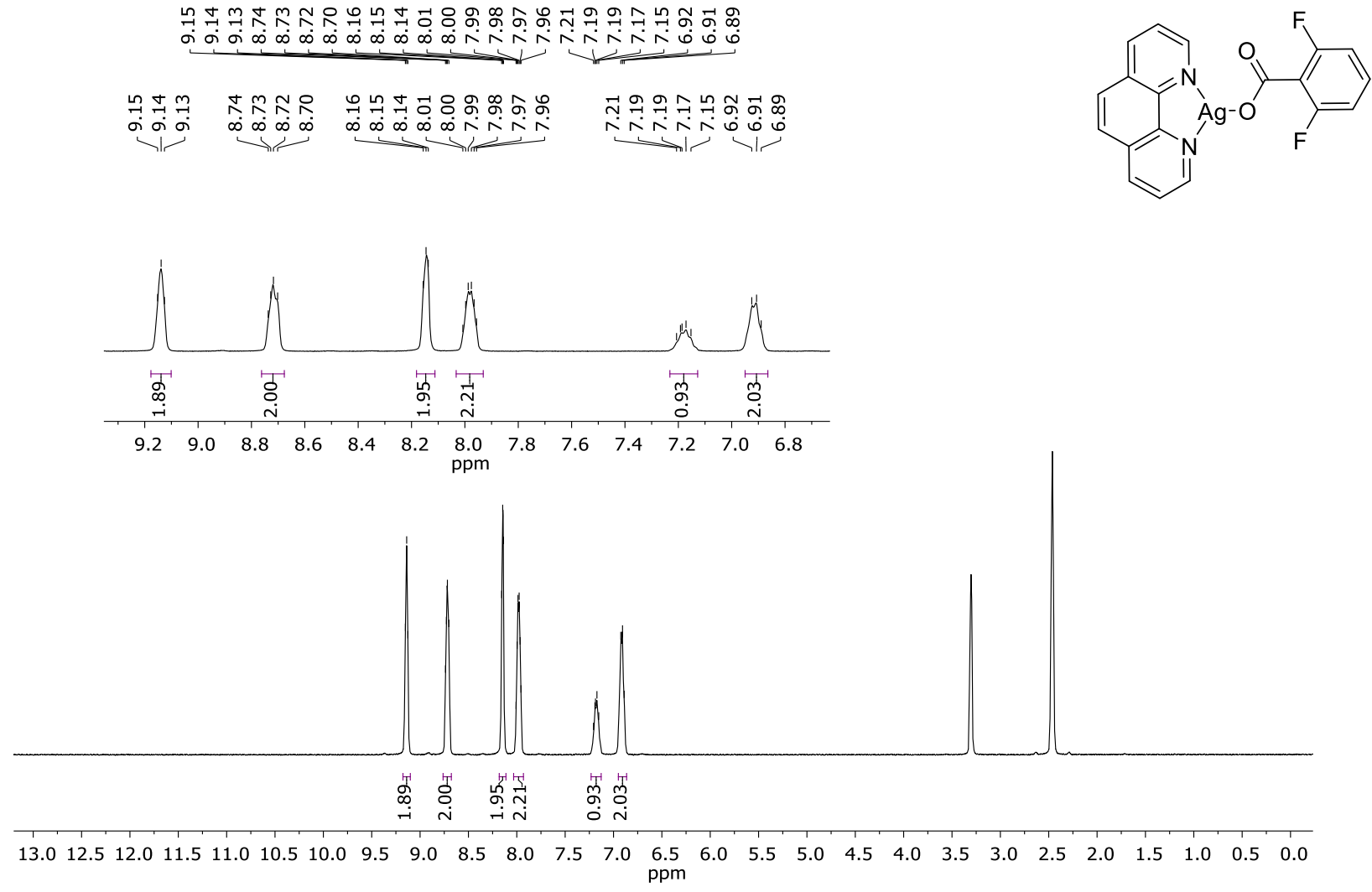

Figure A-38: ${ }^{1} \mathrm{H}$ NMR spectrum of (phen)Ag(2,6-diF-benzoate) in DMSO- $d_{6}$ at $400 \mathrm{MHz}$. 


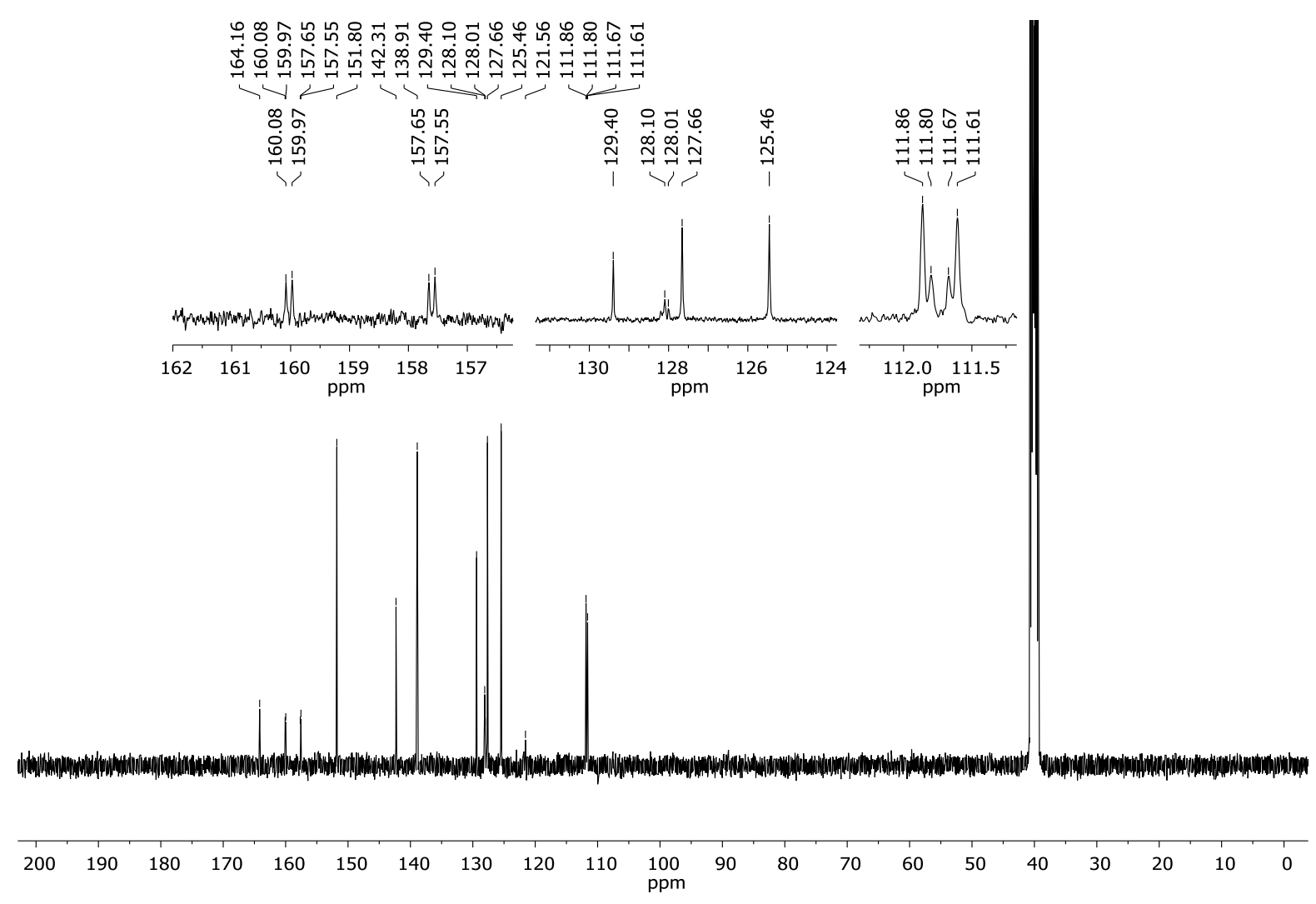

Figure A-39: ${ }^{13} \mathrm{C}$ NMR spectrum of (phen)Ag(2,6-diF-benzoate) in DMSO- $d_{6}$ at $100 \mathrm{MHz}$. 

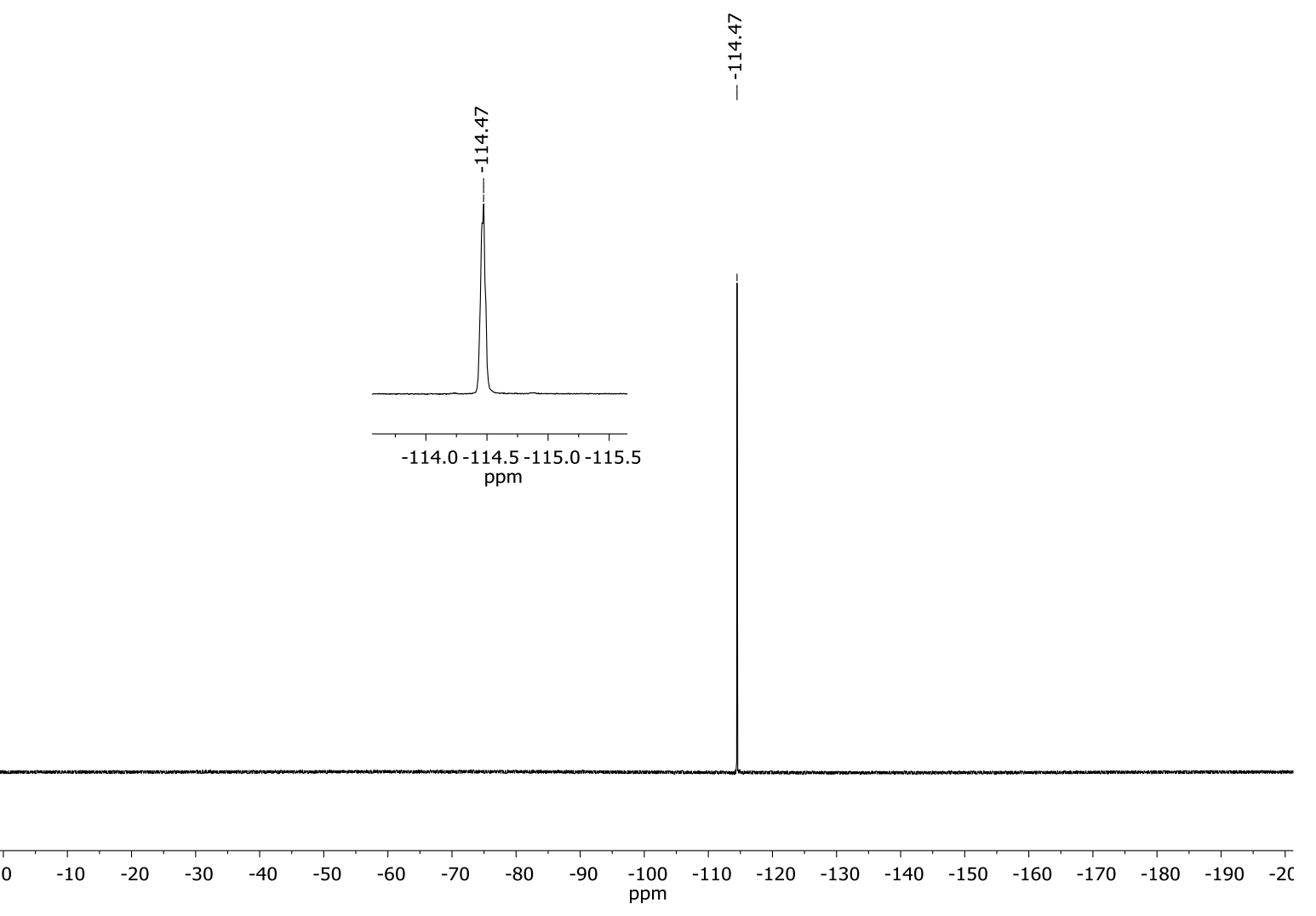

is

Figure A-40: ${ }^{19}$ F NMR spectrum of (phen)Ag(2,6-diF-benzoate) in DMSO- $d_{6}$ at $376 \mathrm{MHz}$. 


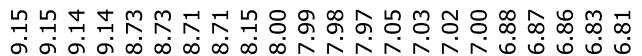

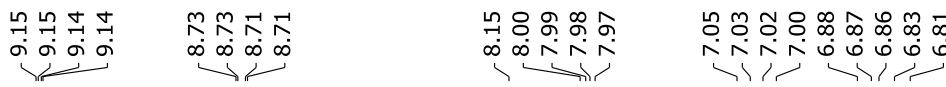
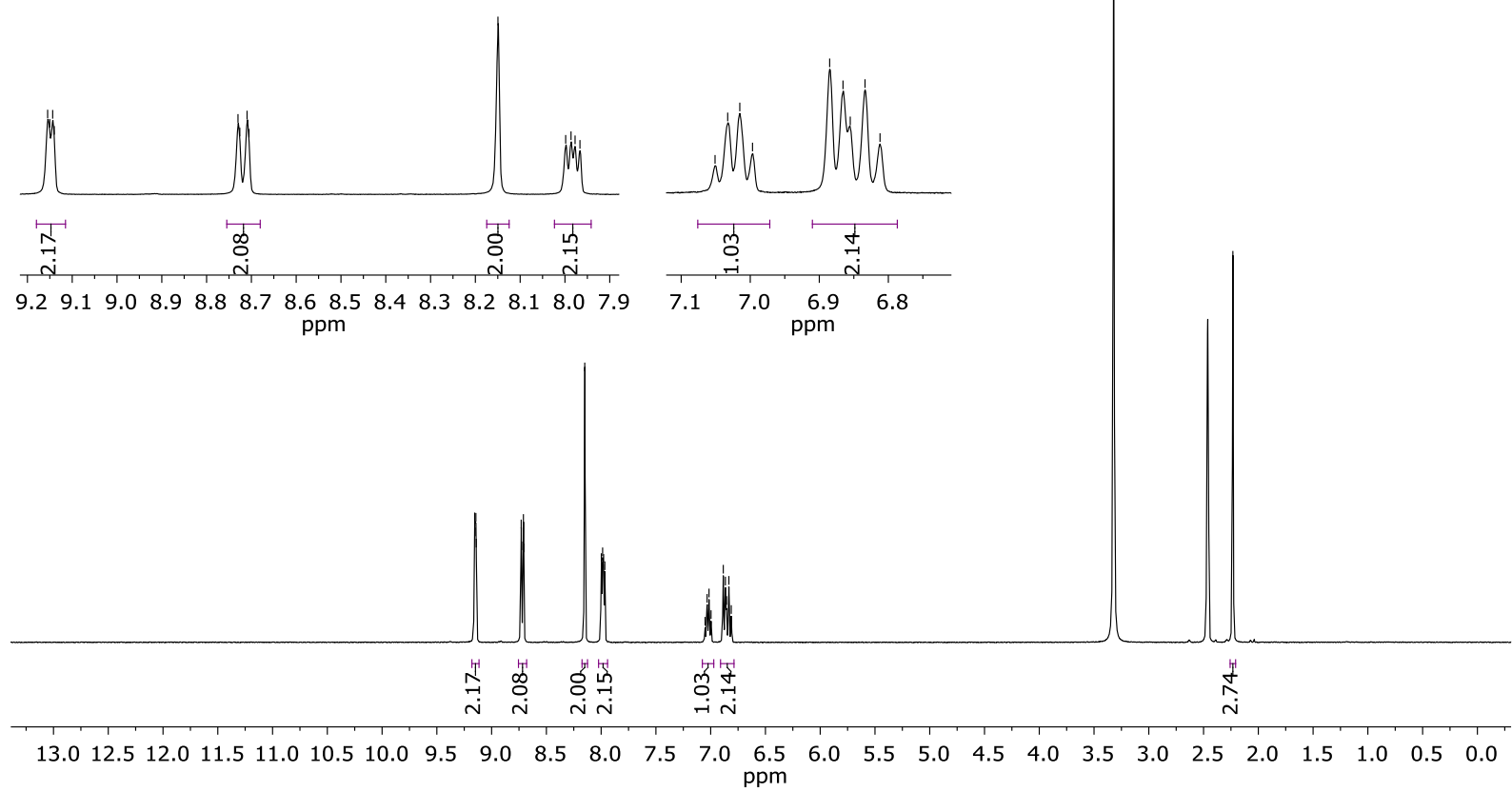

Figure A-41: ${ }^{1} \mathrm{H}$ NMR spectrum of (phen)Ag(2-F-6-Me-benzoate) in DMSO- $d_{6}$ at $400 \mathrm{MHz}$. 

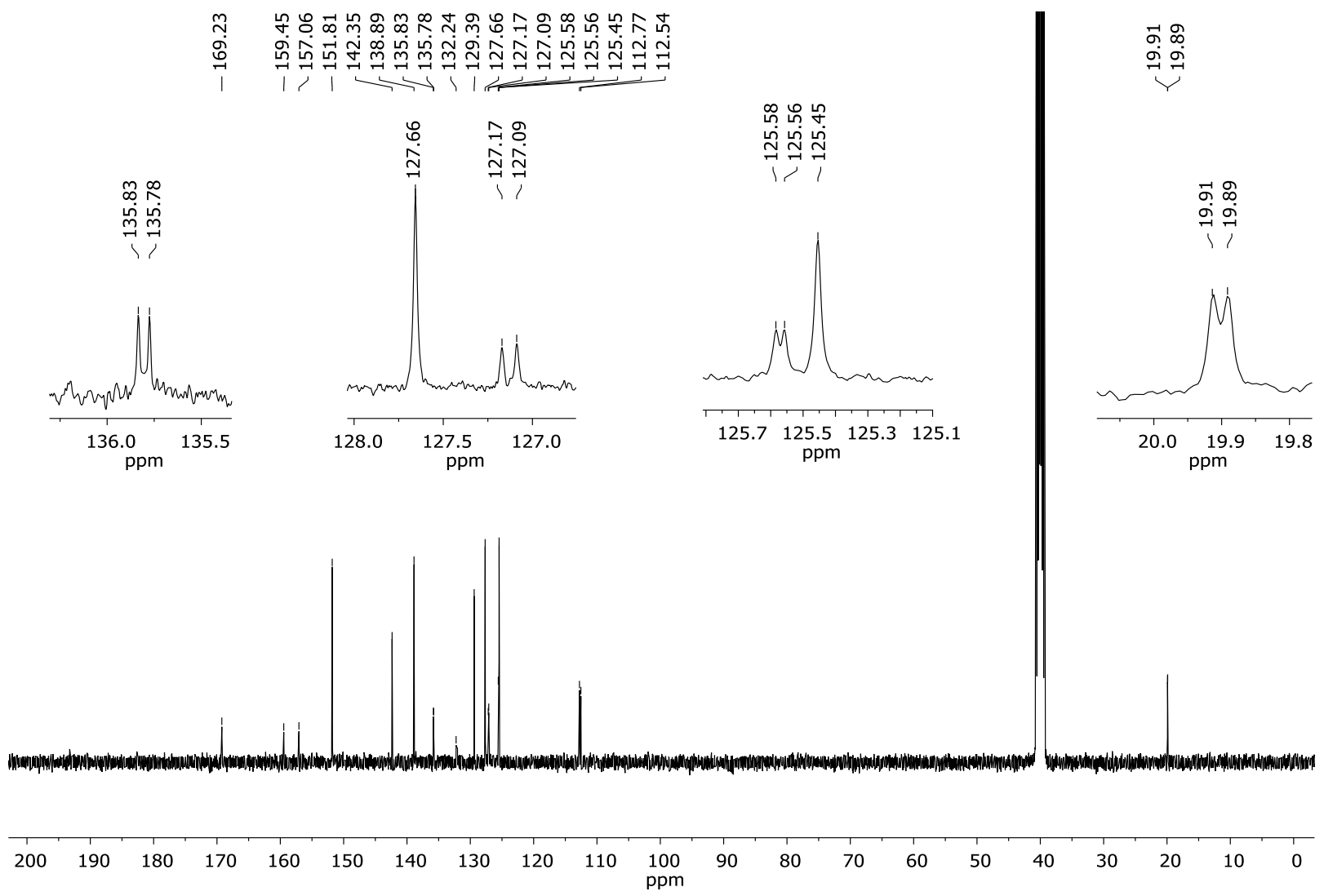

Figure A-42: ${ }^{13} \mathrm{C}$ NMR spectrum of (phen)Ag(2-F-6-Me-benzoate) in DMSO- $d_{6}$ at $100 \mathrm{MHz}$. 


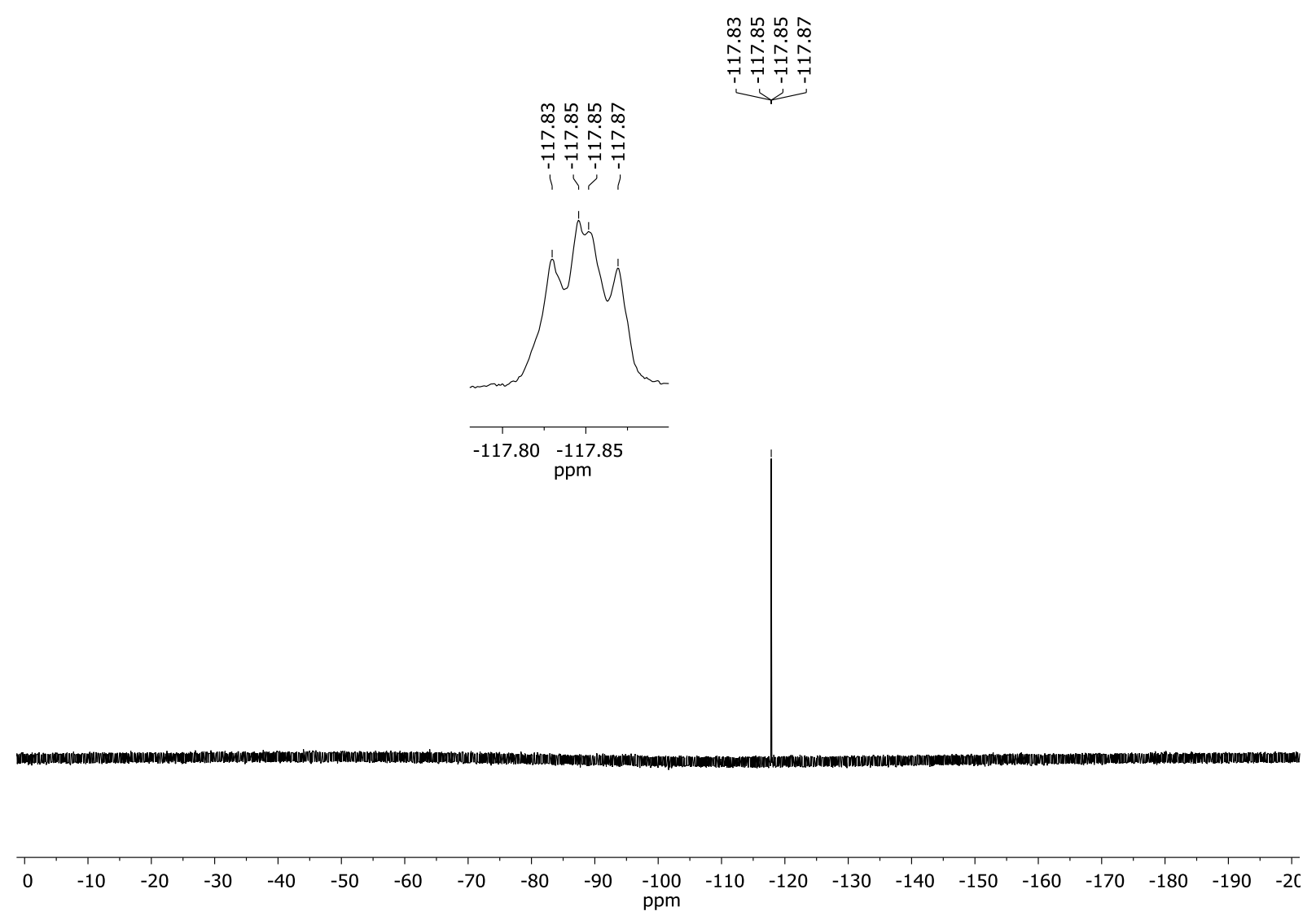

Figure A-43: ${ }^{19}$ F NMR spectrum of (phen)Ag(2-F-6-Me-benzoate) in DMSO- $d_{6}$ at $375 \mathrm{MHz}$. 


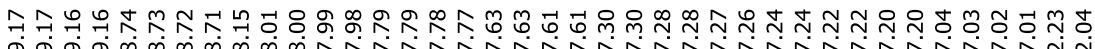
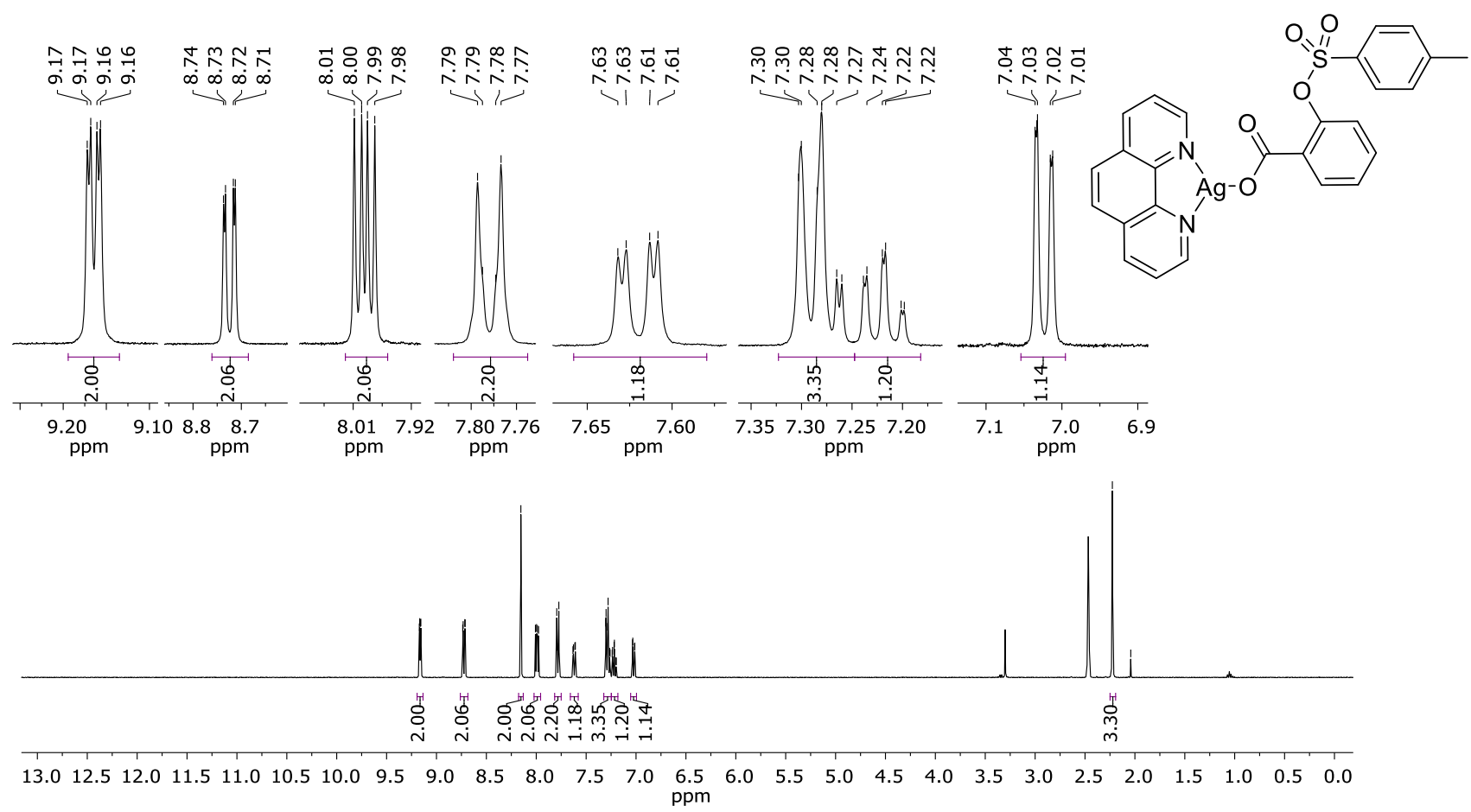

Figure A-44: ${ }^{1} \mathrm{H}$ NMR spectrum of (phen)Ag(2-OTs-benzoate) in DMSO- $d_{6}$ at $400 \mathrm{MHz}$. 


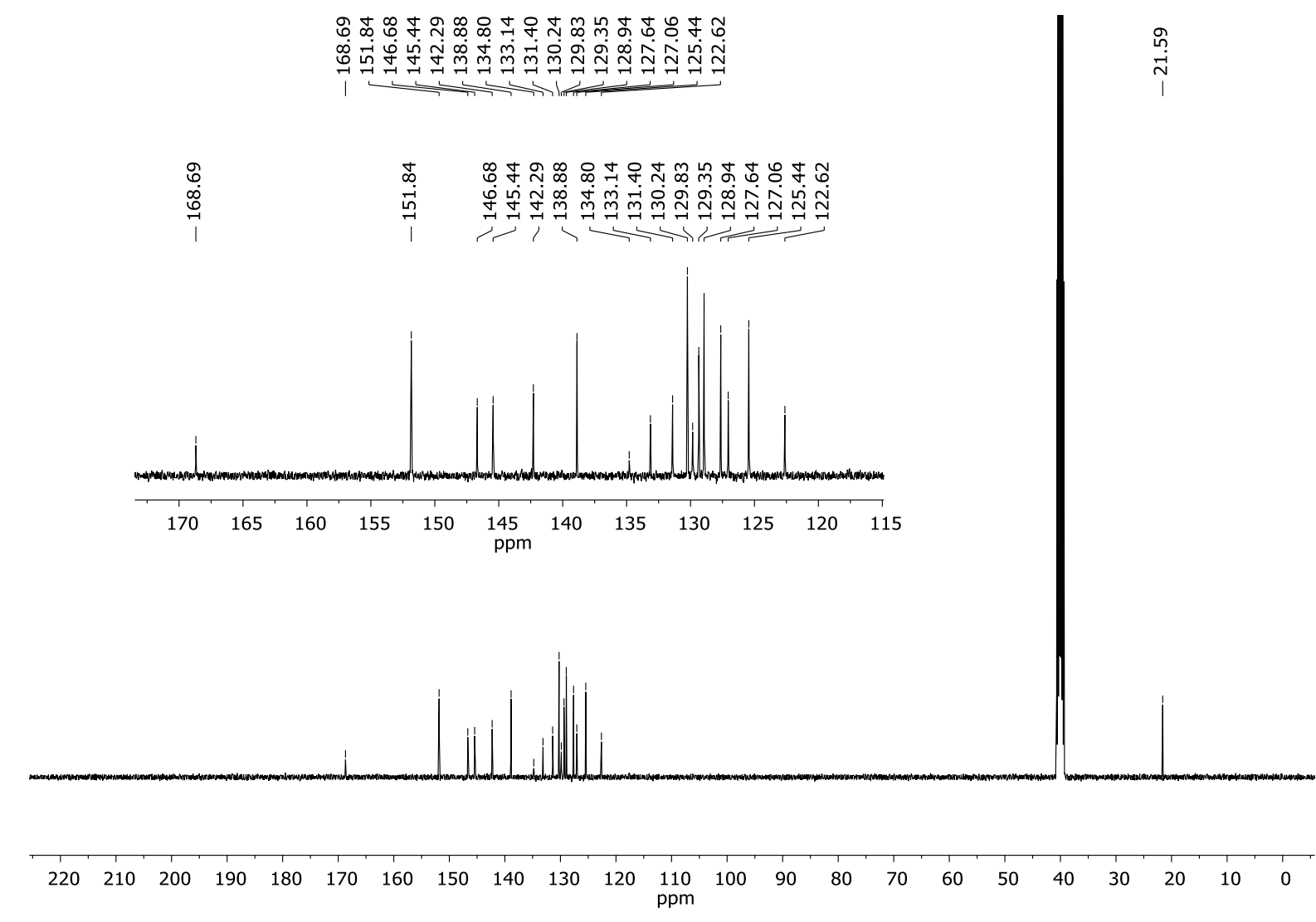

Figure A-45: ${ }^{13} \mathrm{C}$ NMR spectrum of (phen)Ag(2-OTs-benzoate) in DMSO- $d_{6}$ at $100 \mathrm{MHz}$. 


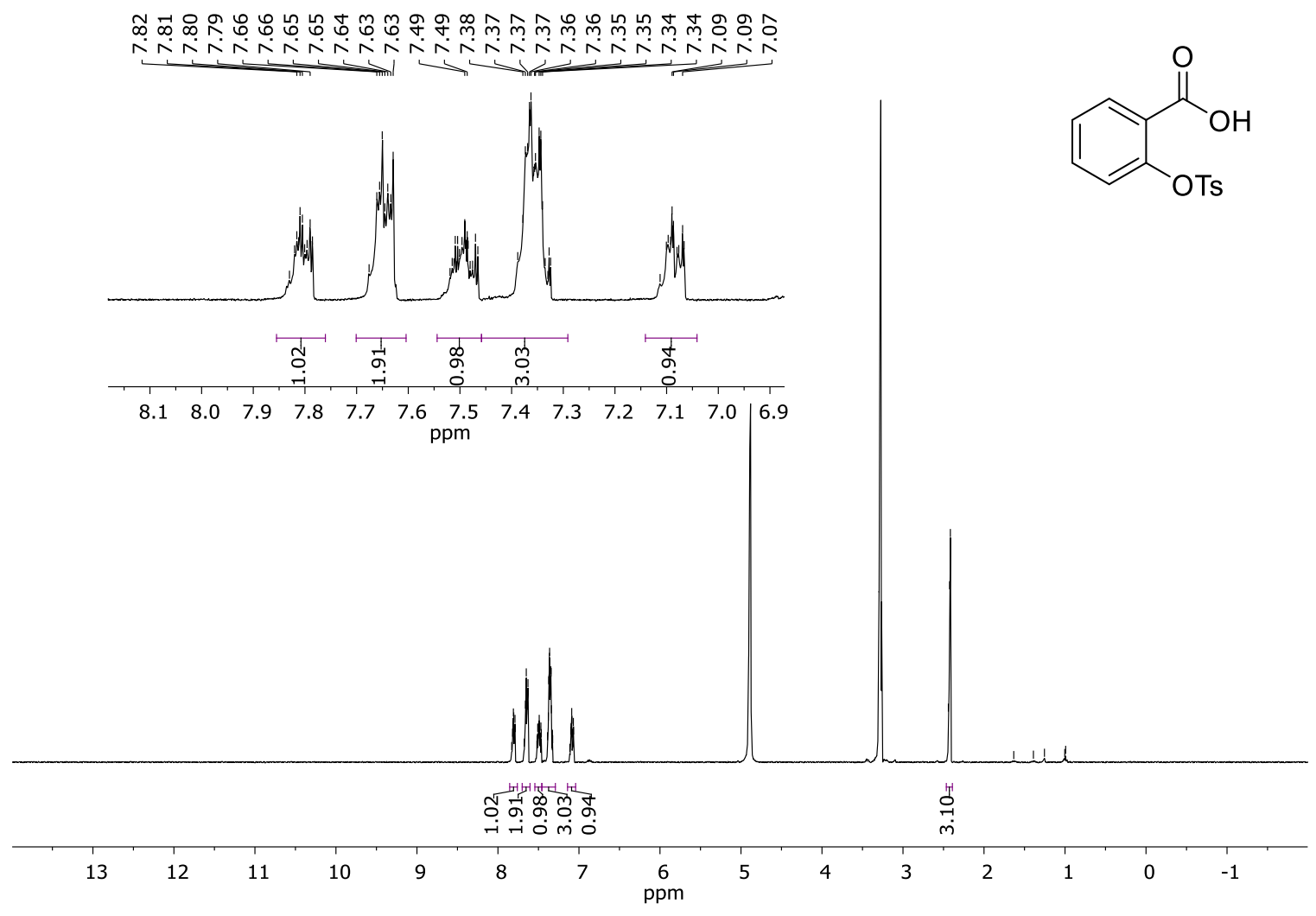

Figure A-46: ${ }^{1} \mathrm{H}$ NMR Spectra of 2-OTs-benzoic acid in methanol- $d_{4}$ at $400 \mathrm{MHz}$. 


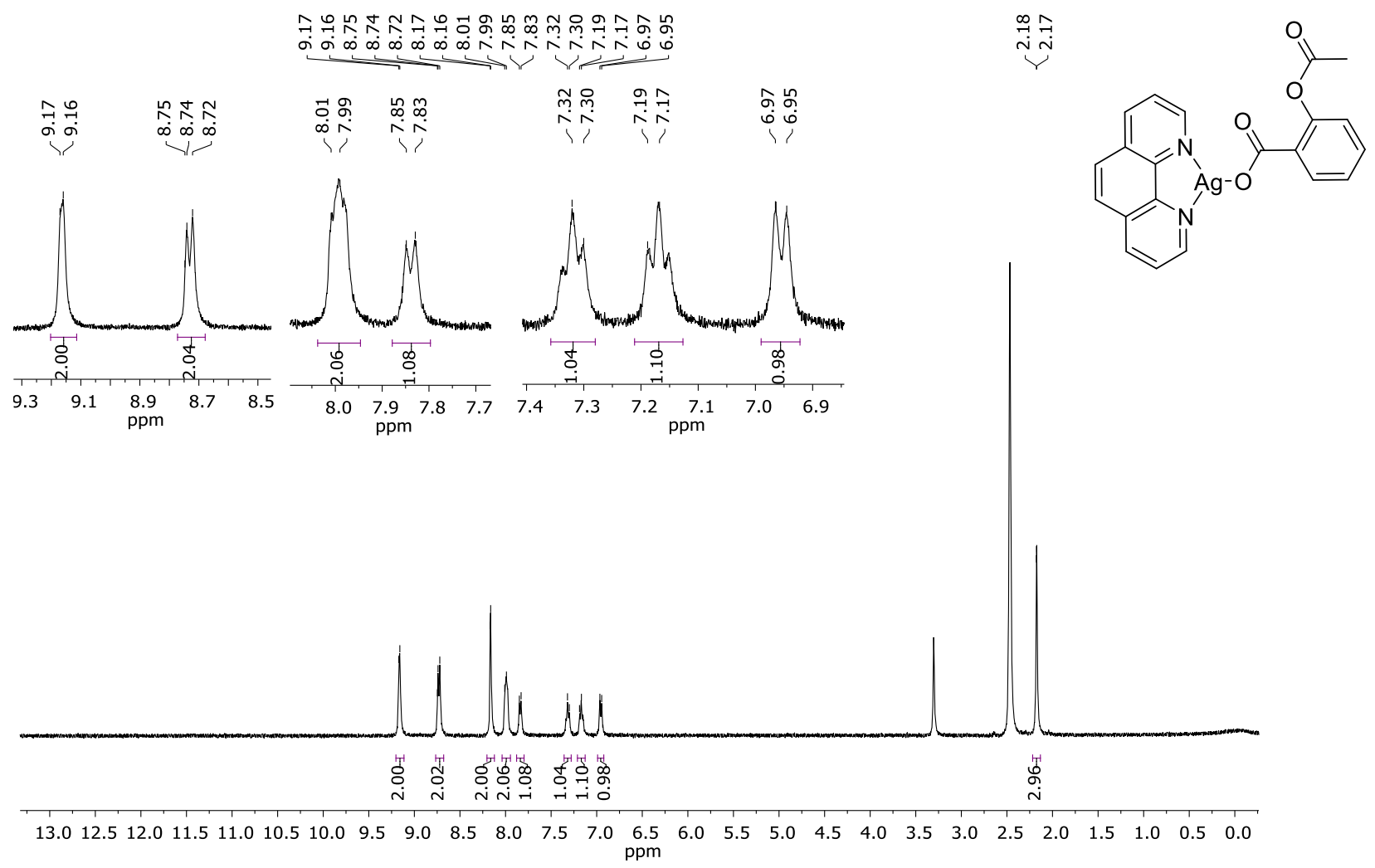

Figure A-47: ${ }^{1} \mathrm{H}$ NMR spectrum of (phen)Ag(2-OAc-benzoate) in DMSO- $d_{6}$ at $400 \mathrm{MHz}$. 


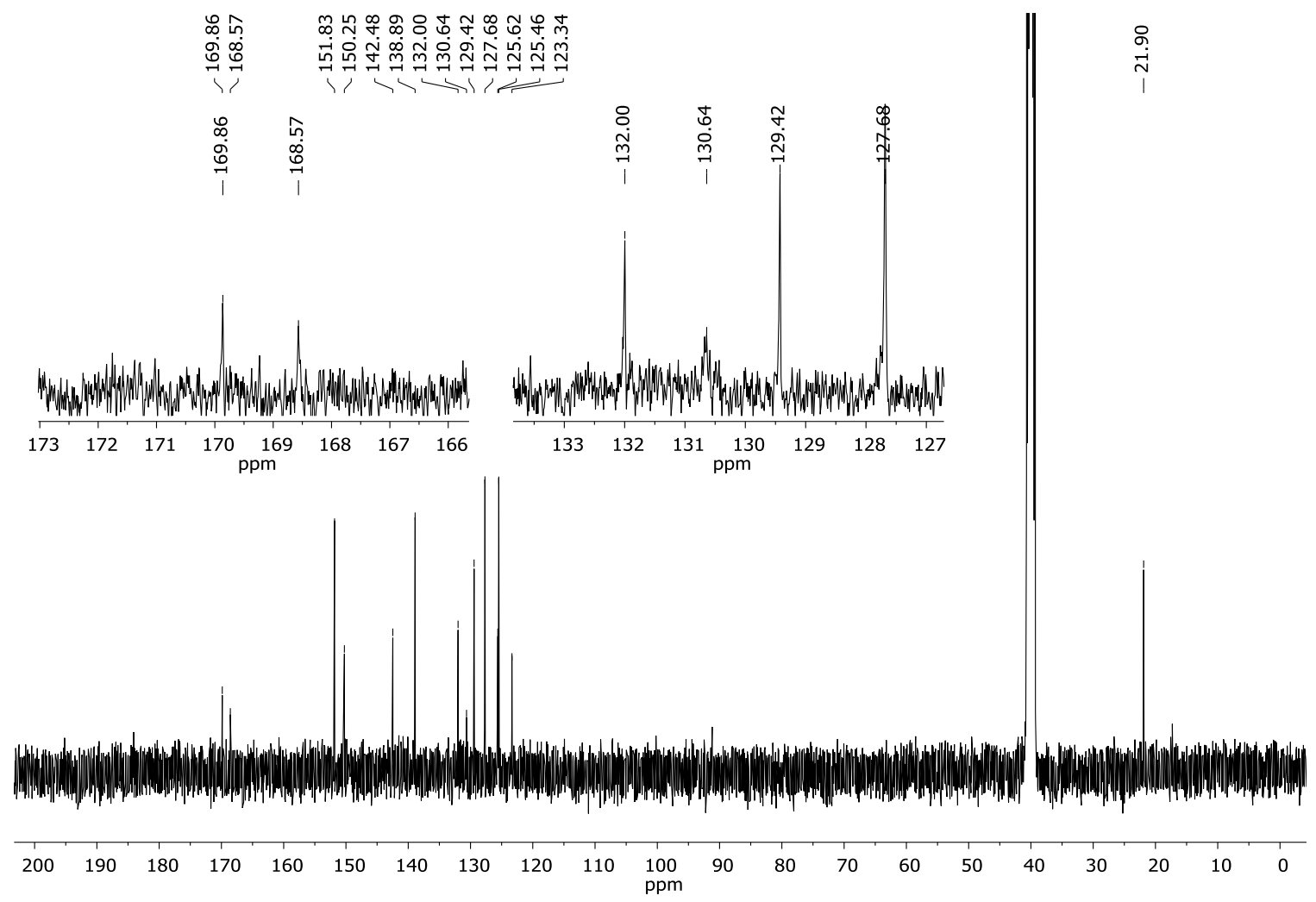

Figure A-48: ${ }^{13} \mathrm{C}$ NMR spectrum of (phen)Ag(2-OAc-benzoate) in DMSO- $d_{6}$ at $100 \mathrm{MHz}$. 


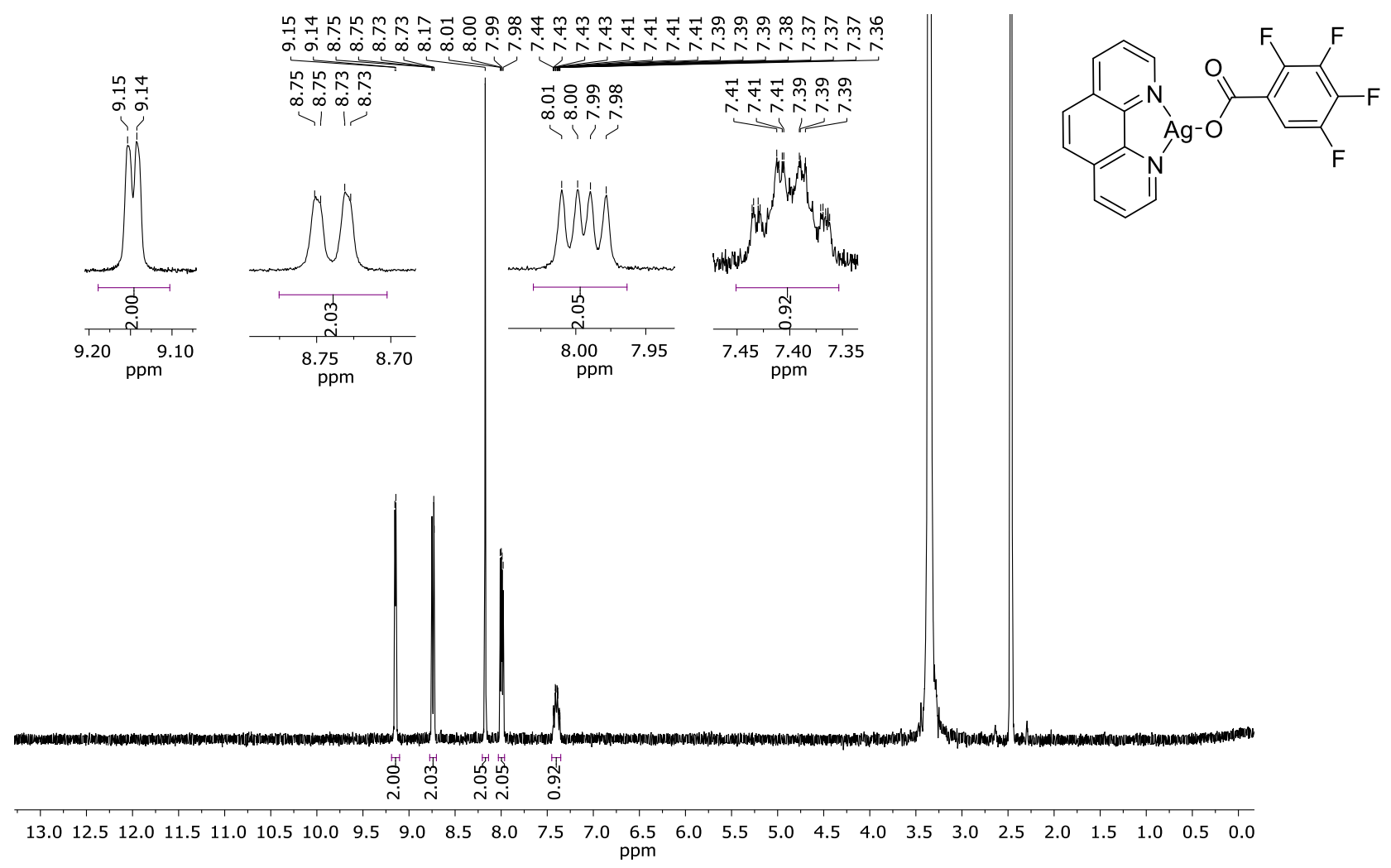

Figure A-49: ${ }^{1} \mathrm{H}$ NMR spectrum of (phen)Ag(2,3,4,5-tetraF-benzoate) in DMSO- $d_{6}$ at 400 $\mathrm{MHz}$. 

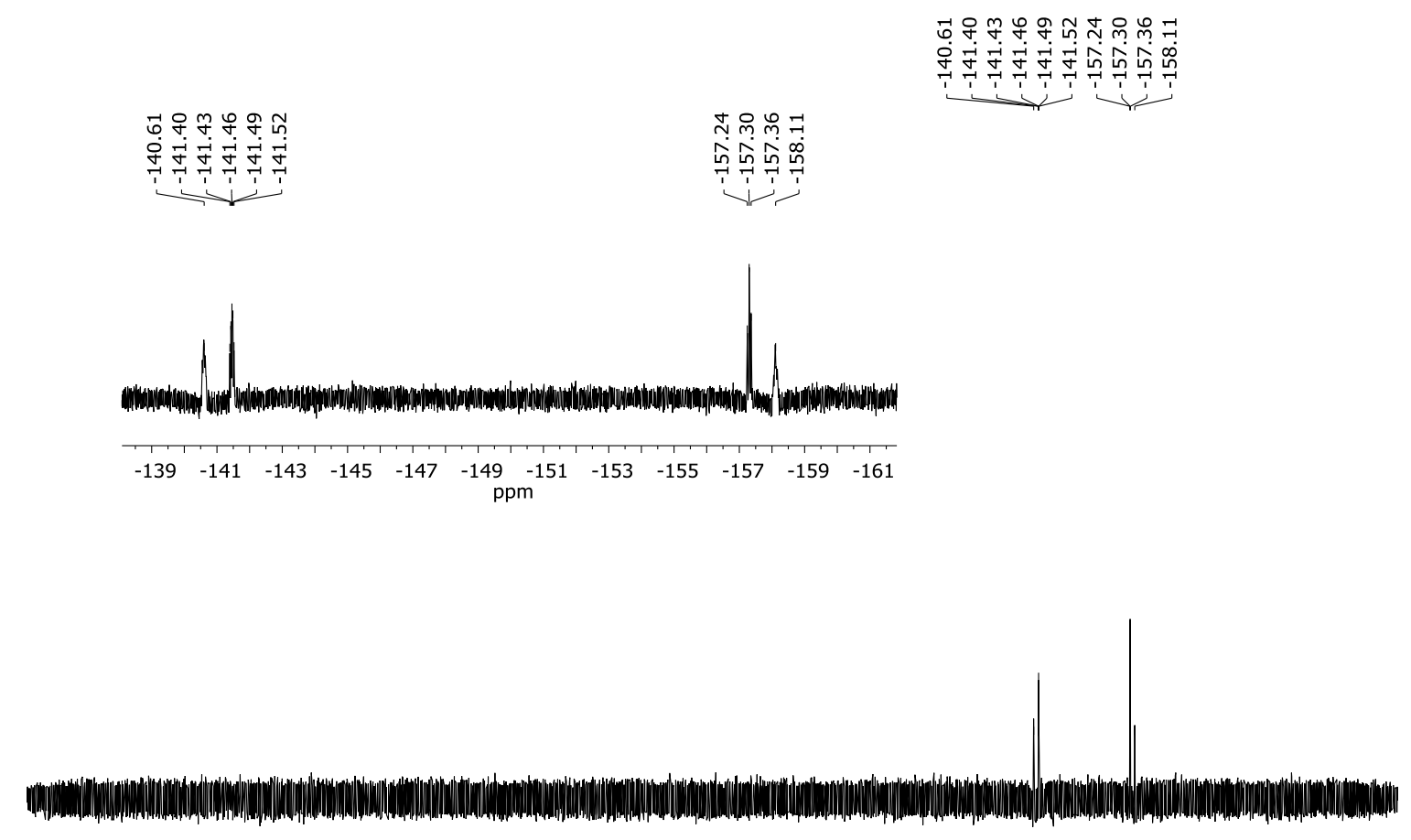

$\begin{array}{lllllllllllllllllllllllllllllll}30 & 20 & 10 & 0 & -10 & -20 & -30 & -40 & -50 & -60 & -70 & -80 & -90 & -100 & -110 & -120 & -130 & -140 & -150 & -160 & -170 & -180 & -190 & -20 C\end{array}$

Figure A-50: ${ }^{19}$ F NMR spectrum of (phen)Ag(2,3,4,5-tetraF-benzoate) in DMSO- $d_{6}$ at 376 $\mathrm{MHz}$. 


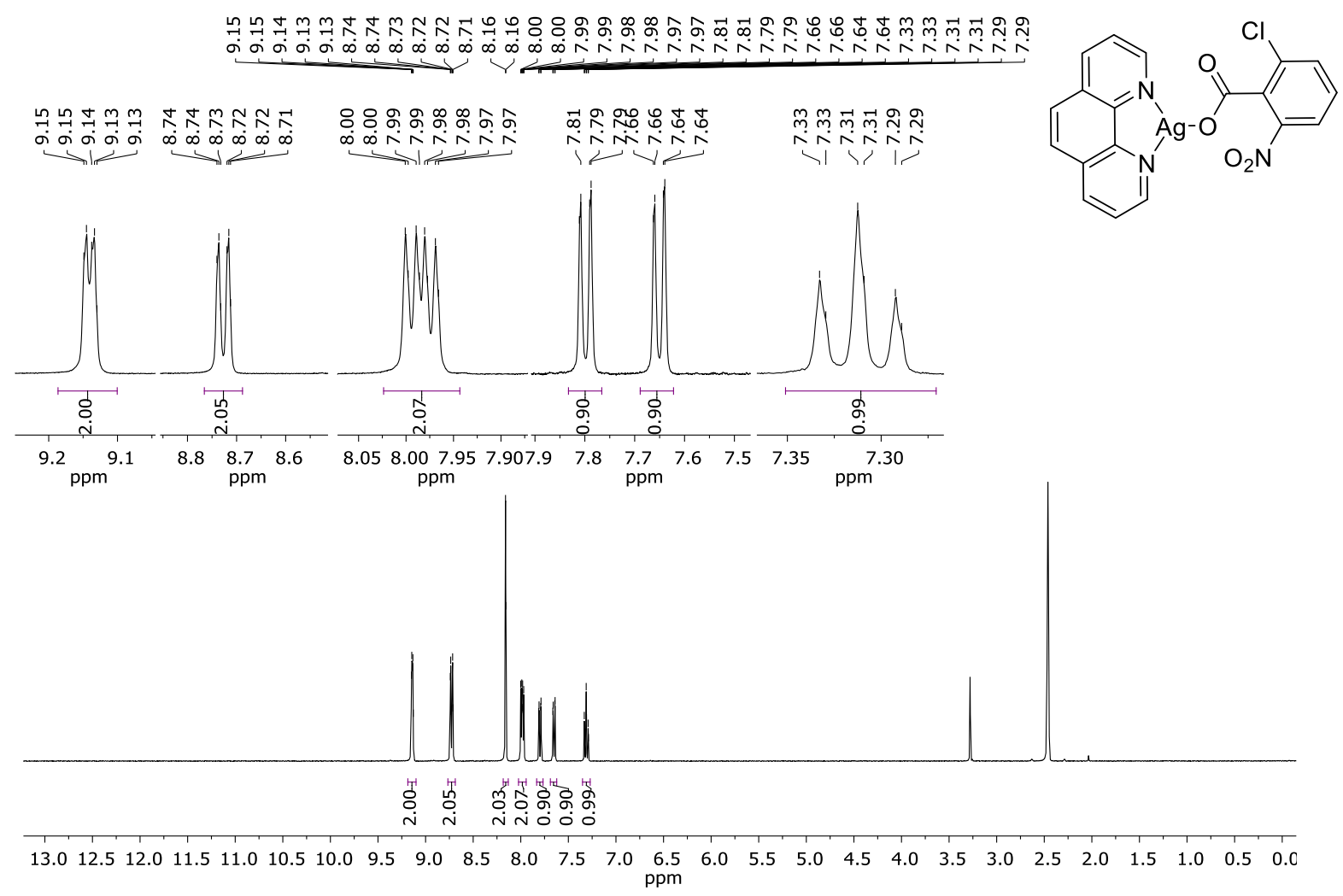

Figure A-51: ${ }^{1} \mathrm{H}$ NMR spectrum of (phen)Ag(2-Cl-6-NO2-benzoate) in DMSO- $d_{6}$ at $400 \mathrm{MHz}$. 

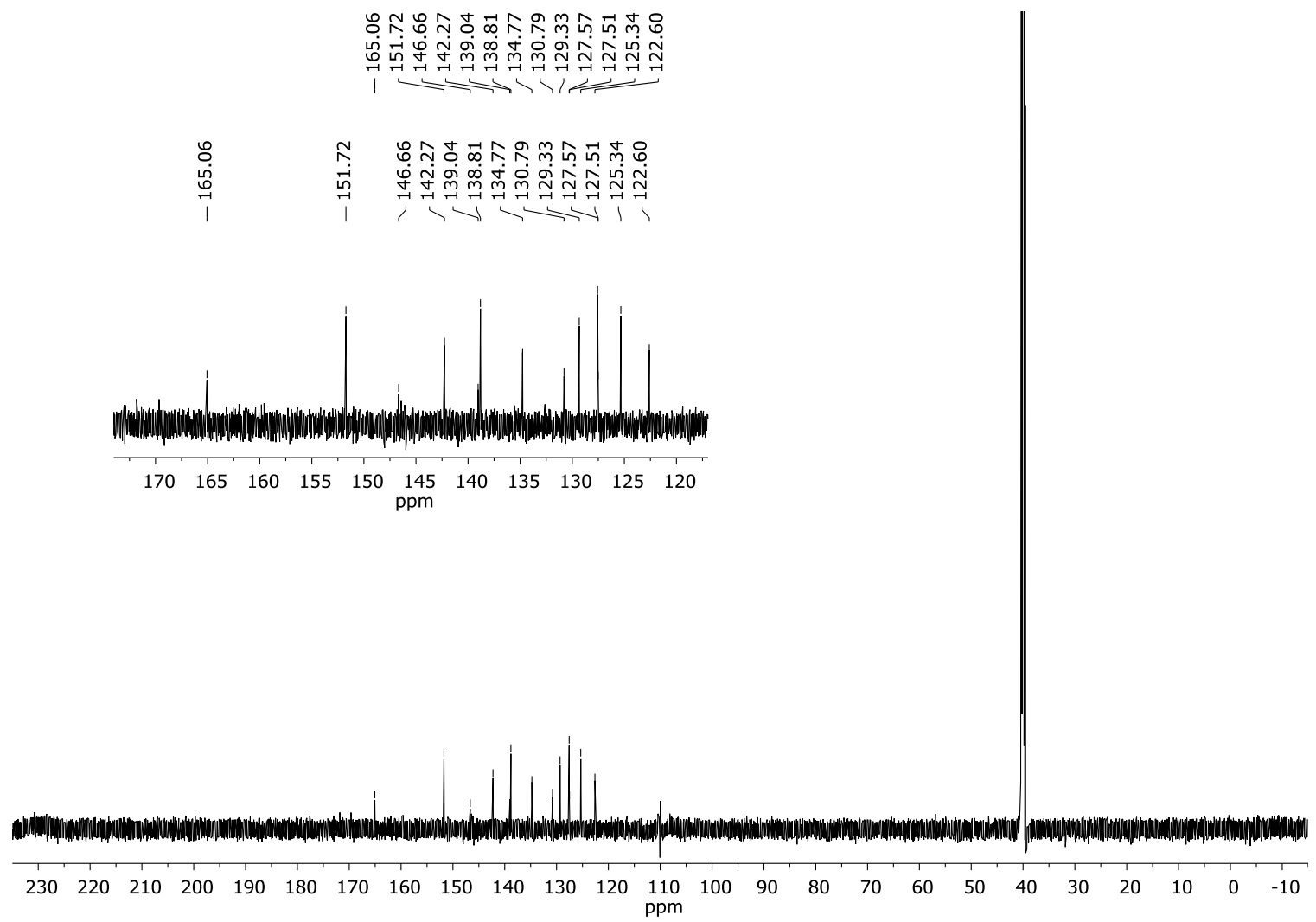

Figure A-52: ${ }^{13} \mathrm{C}$ NMR spectrum of (phen)Ag(2-Cl-6-NO2-benzoate) in DMSO- $d_{6}$ at 100 $\mathrm{MHz}$. 


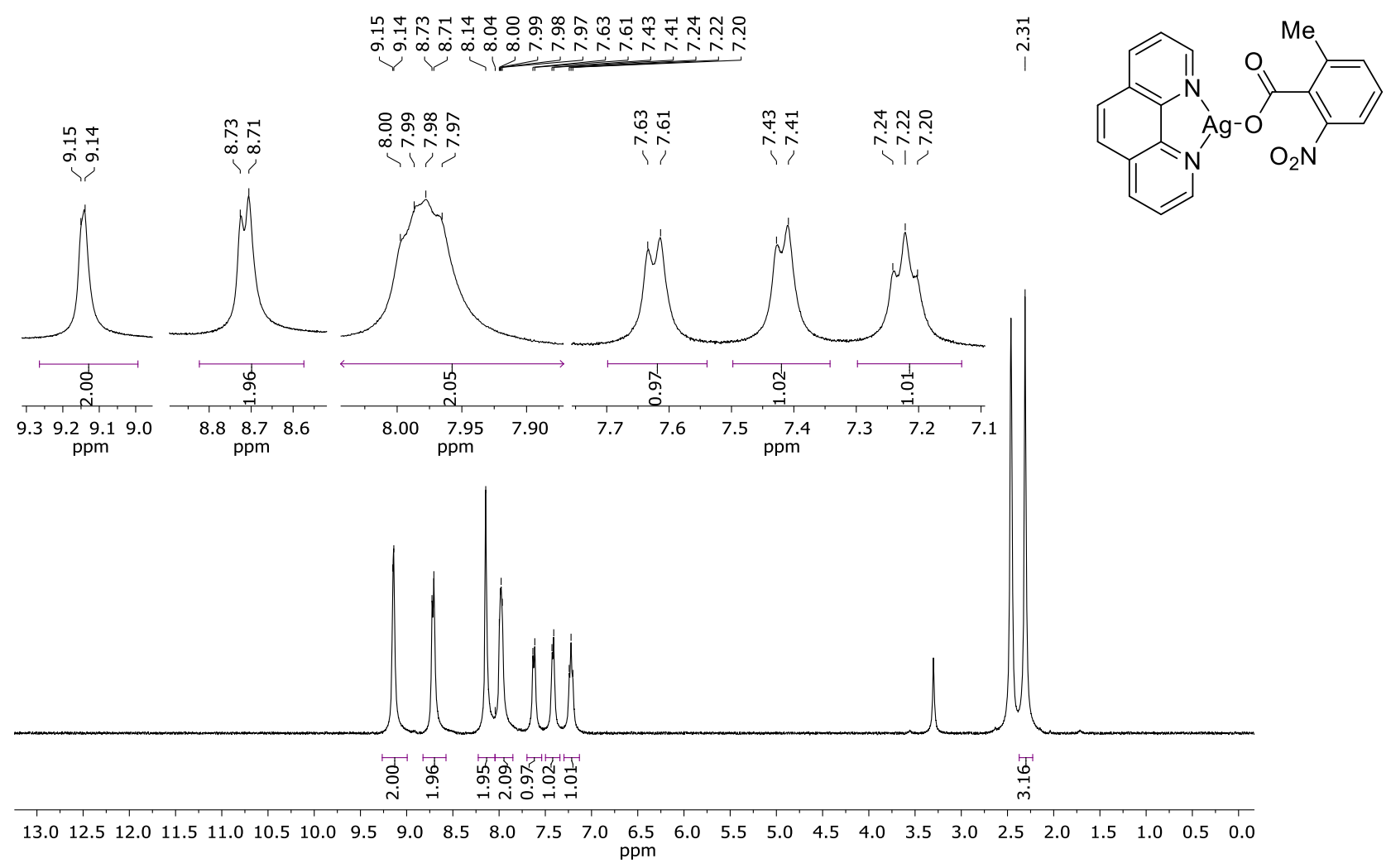

Figure A-53: ${ }^{1} \mathrm{H}$ NMR spectrum of (phen)Ag(2-Me-6-NO2-benzoate) in DMSO- $d_{6}$ at 400 $\mathrm{MHz}$. 

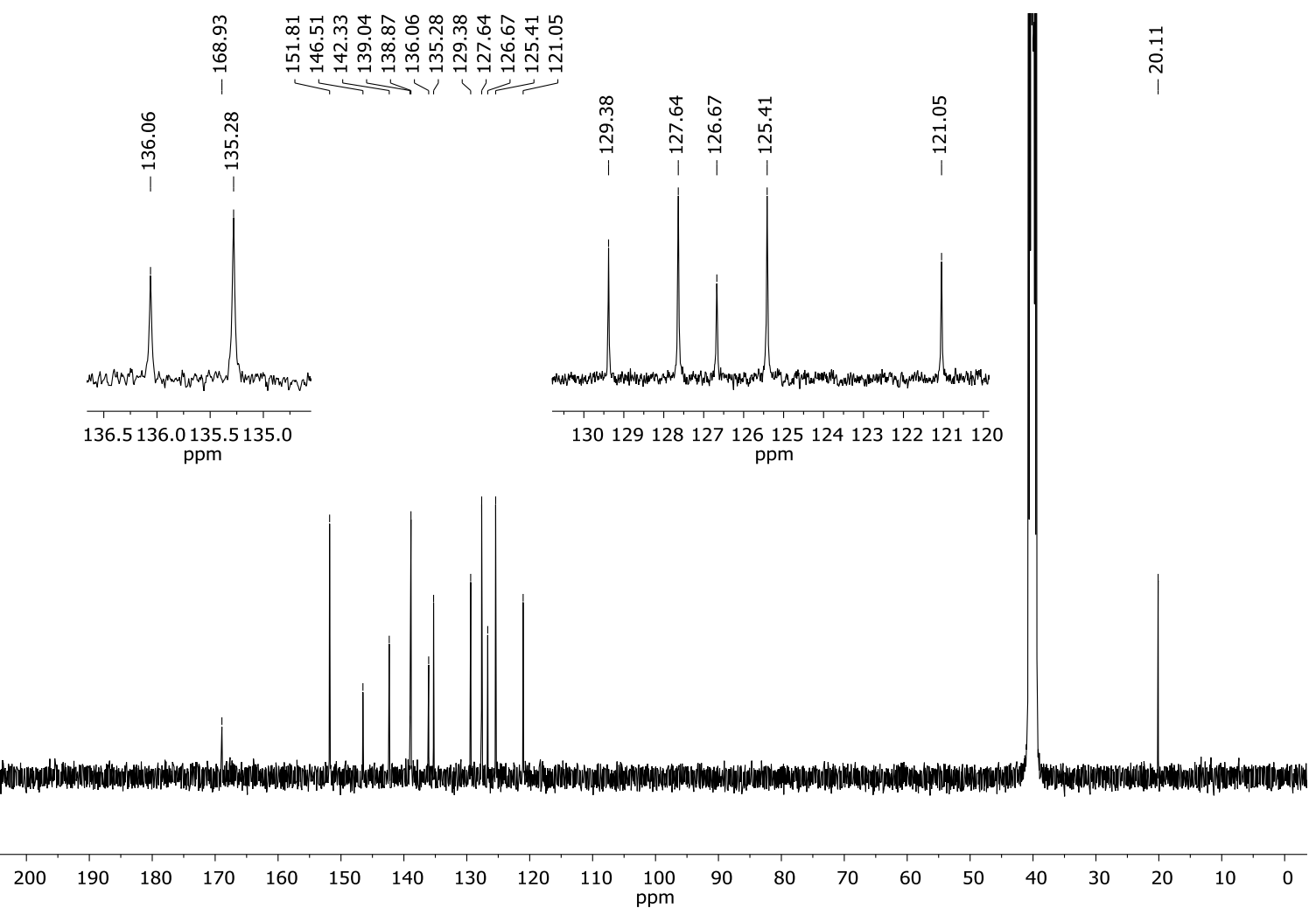

Figure A-54: ${ }^{13} \mathrm{C}$ NMR spectrum of (phen)Ag(2-Me-6-NO2-benzoate) in DMSO- $d_{6}$ at 100 $\mathrm{MHz}$. 
AI-1.2 ${ }^{1} \mathrm{H}$ and ${ }^{13} \mathrm{C}$ NMR Spectra of Silver Aryl Complexes

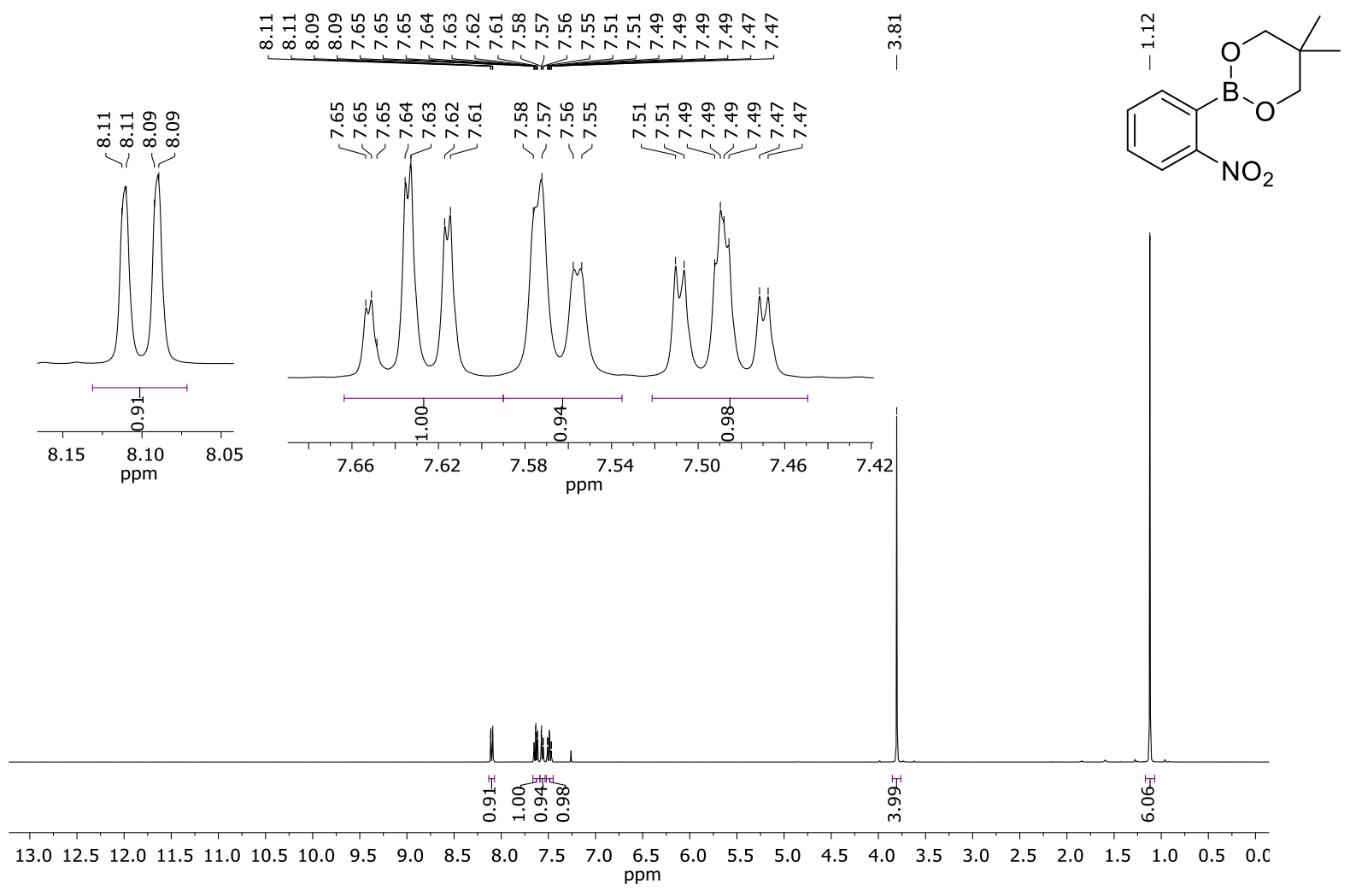

Figure A-55: ${ }^{1} \mathrm{H}$ NMR spectrum of 5,5-dimethyl-2-(2-nitrophenyl)-[1,3,2]dioxaborinane in $\mathrm{CDCl}_{3}$ at $400 \mathrm{MHz}$. 

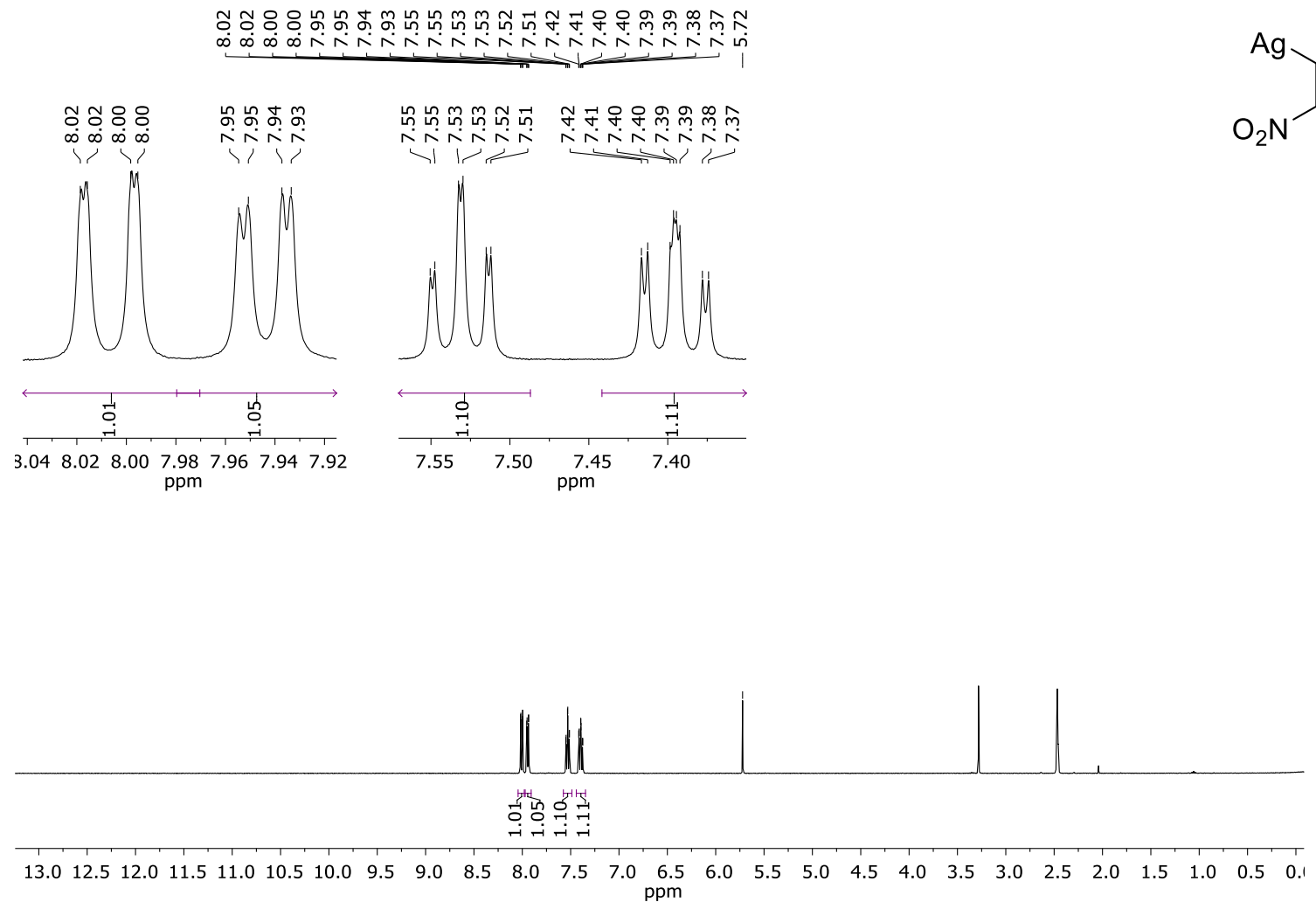

Figure A-56: ${ }^{1} \mathrm{H}$ NMR spectrum of Ag(2-NO2-phenyl) in DMSO-d $d_{6}$ at $400 \mathrm{MHz}$. 
AI-1.3 ${ }^{1} \mathrm{H}$ and ${ }^{13} \mathrm{C}$ NMR Spectra of 2-(2-benzoxazolyl)-1-(4-methylbenzenesulfonate)phenol

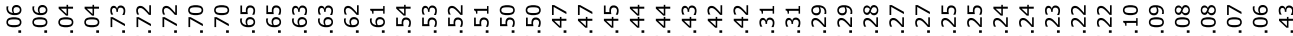

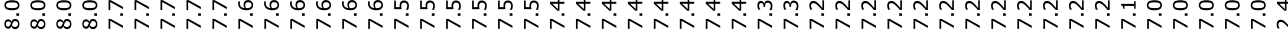

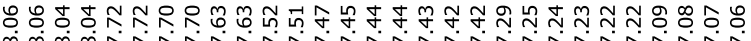

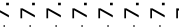
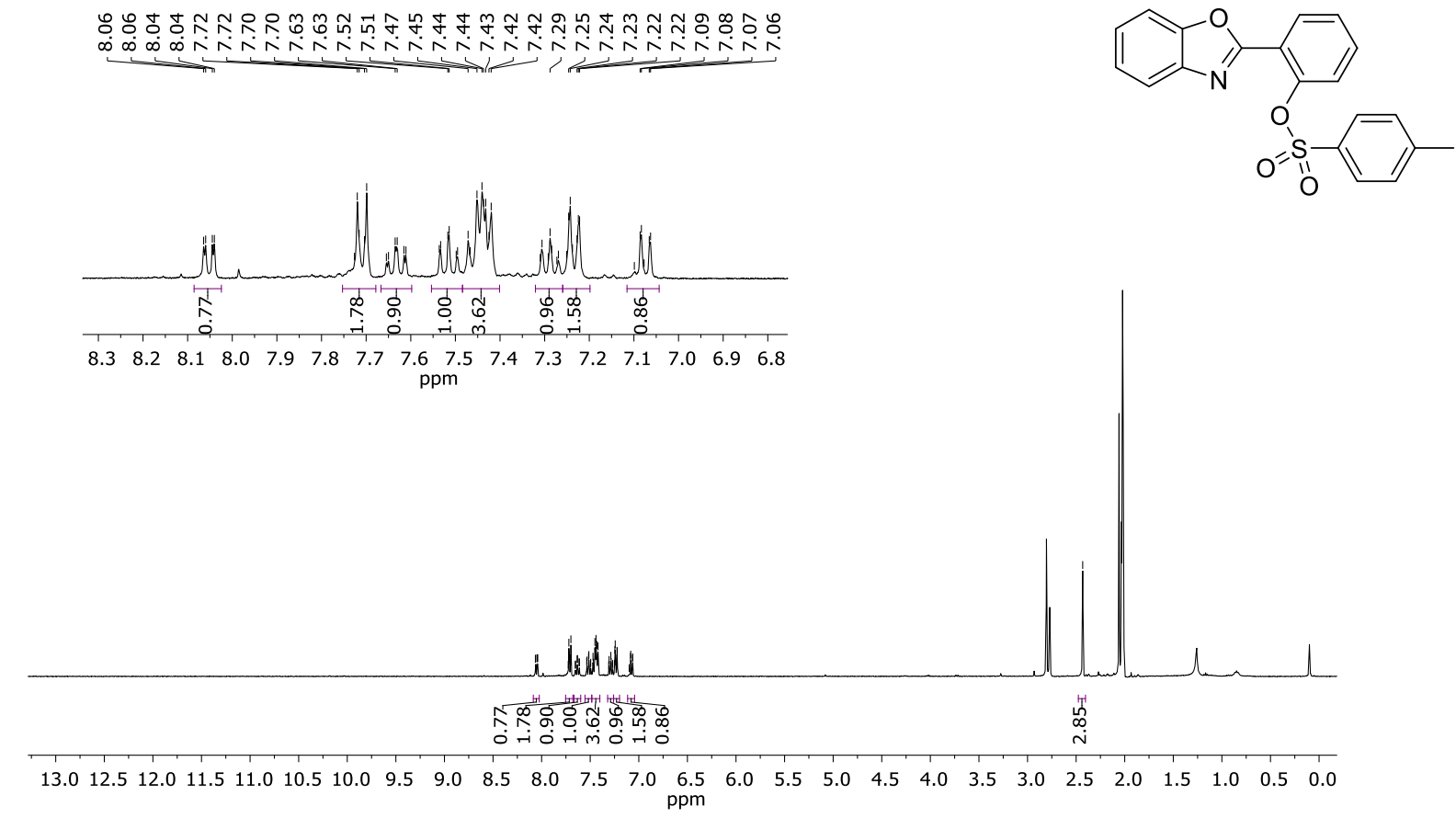

Figure A-57: ${ }^{1} \mathrm{H}$ NMR spectrum of 2-(2-benzoxazolyl)-1-(4-methylbenzenesulfonate)-phenol in acetone- $d_{6}$ at $400 \mathrm{MHz}$ 


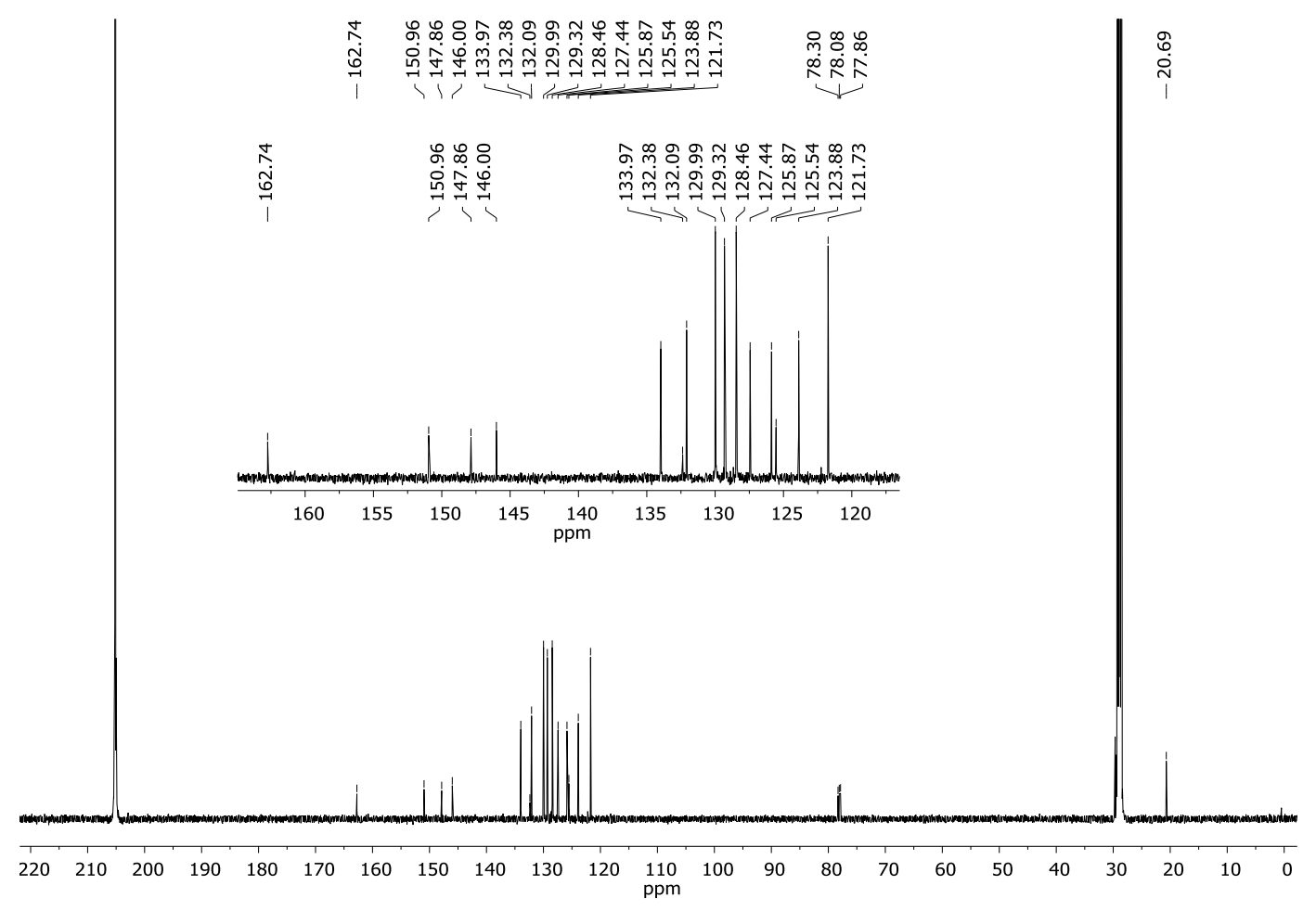

Figure A-58: ${ }^{13} \mathrm{C}$ NMR spectrum of 2-(2-benzoxazolyl)-1-(4-methylbenzenesulfonate)-phenol in acetone- $d_{6}$ at $100 \mathrm{MHz}$. 


\section{AI-2 Spectra from Chapter 3:}

\section{AI-2.1 ${ }^{1} \mathrm{H}$ and ${ }^{13} \mathrm{C}$ NMR Spectra of (1,10-Phenanthroline)Silver(Benzoate) Complexes}

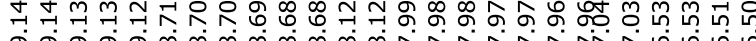

бं

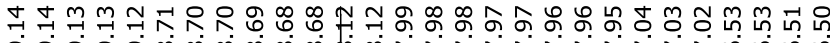

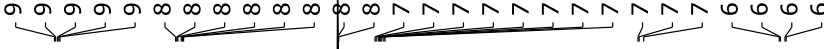
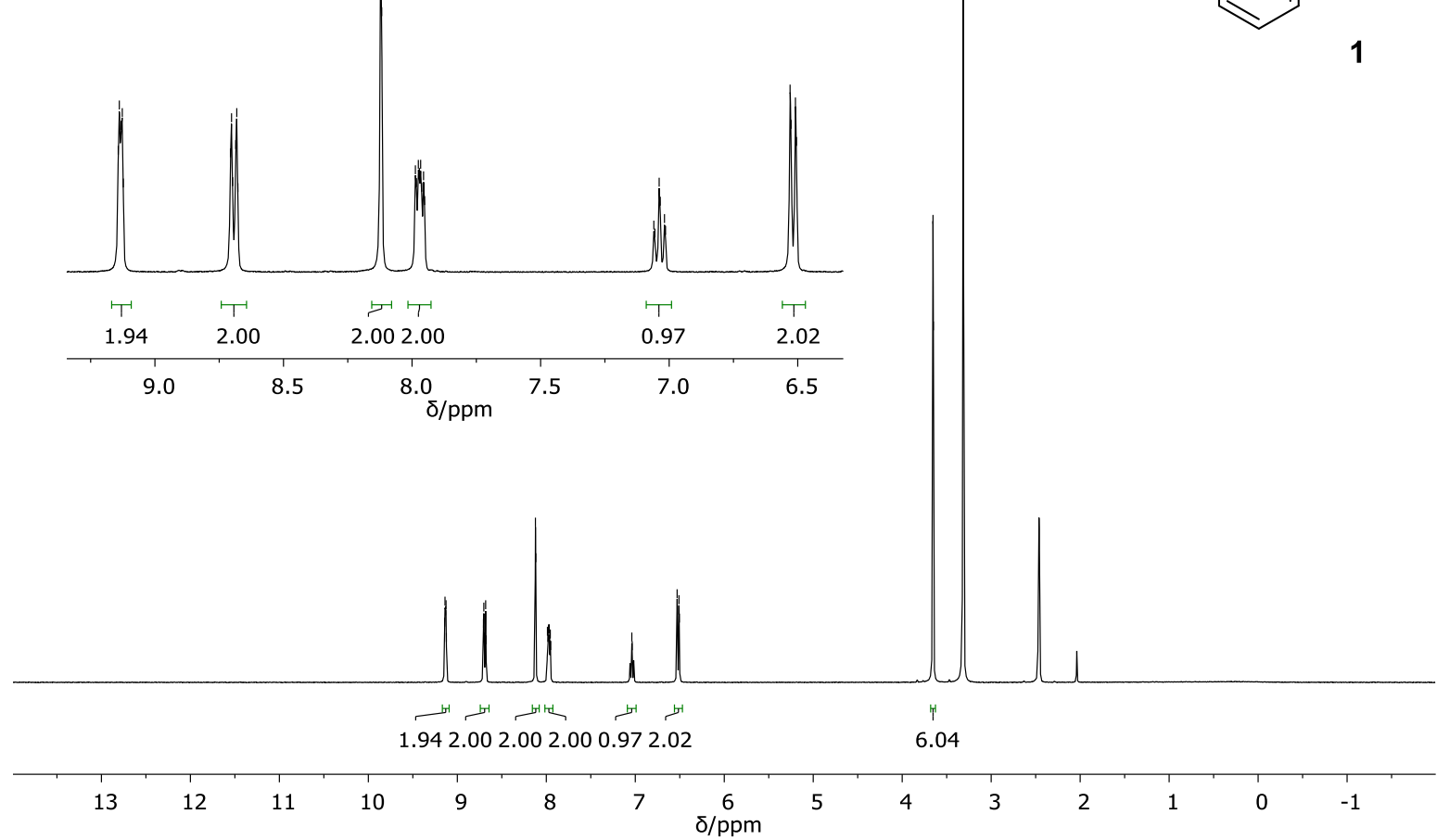

Figure A-59: ${ }^{1} \mathrm{H}$ NMR spectrum of (phen)Ag(2,6-di-OMe-benzoate) (1) in DMSO- $d_{6}$ at 400 $\mathrm{MHz}$.
மூ

mim

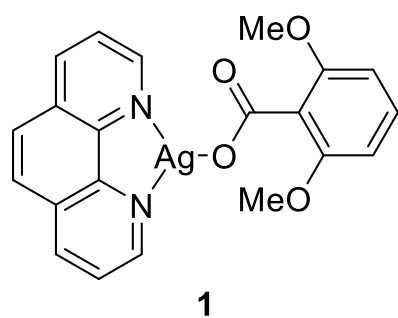

1 


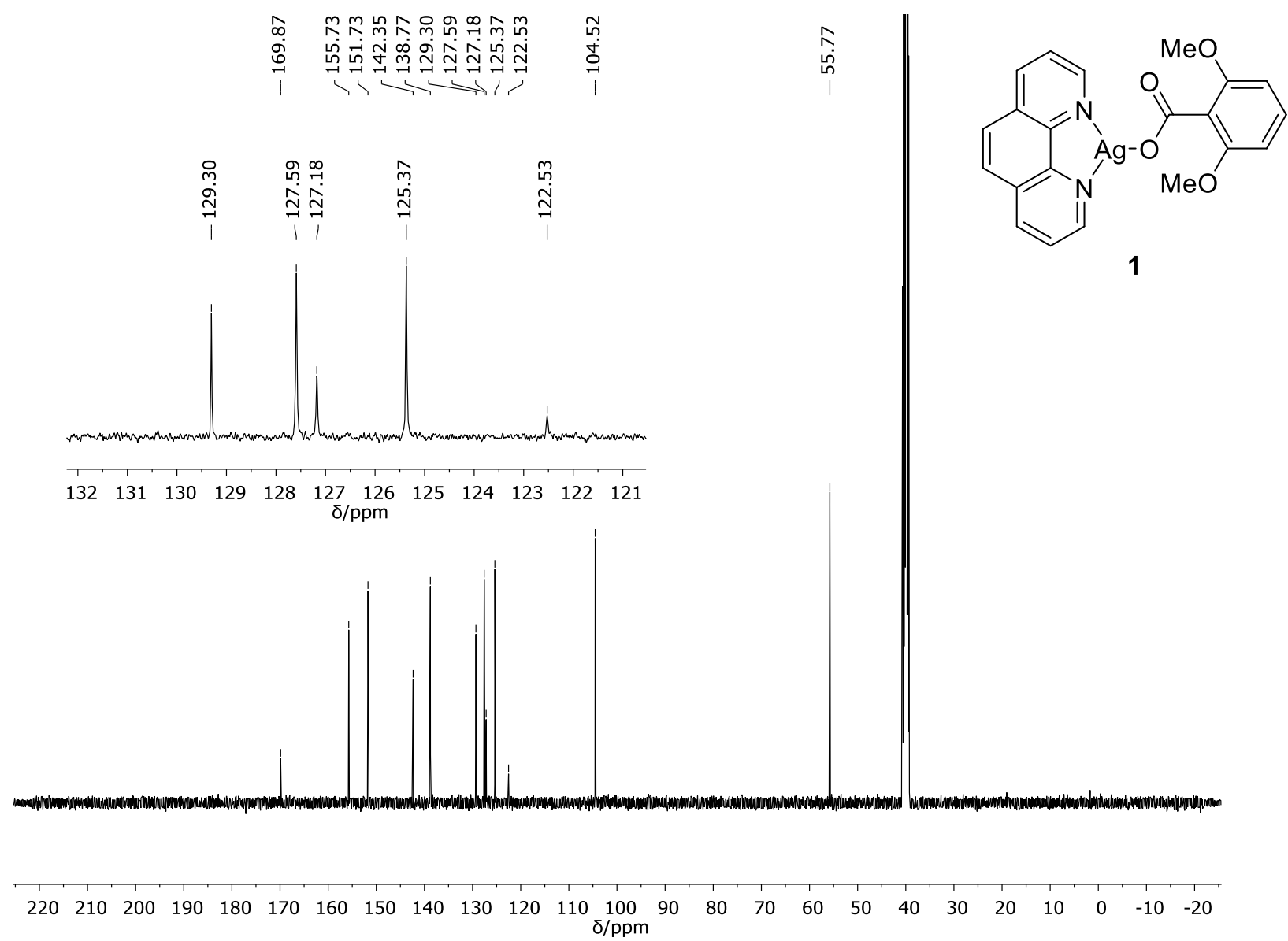

Figure A-60: ${ }^{13} \mathrm{C}$ NMR spectrum of (phen)Ag(2,6-di-OMe-benzoate) (1) in DMSO- $d_{6}$ at 100 $\mathrm{MHz}$. 
는

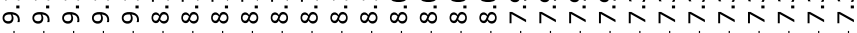

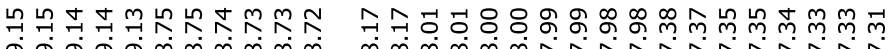

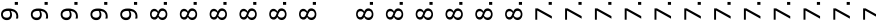
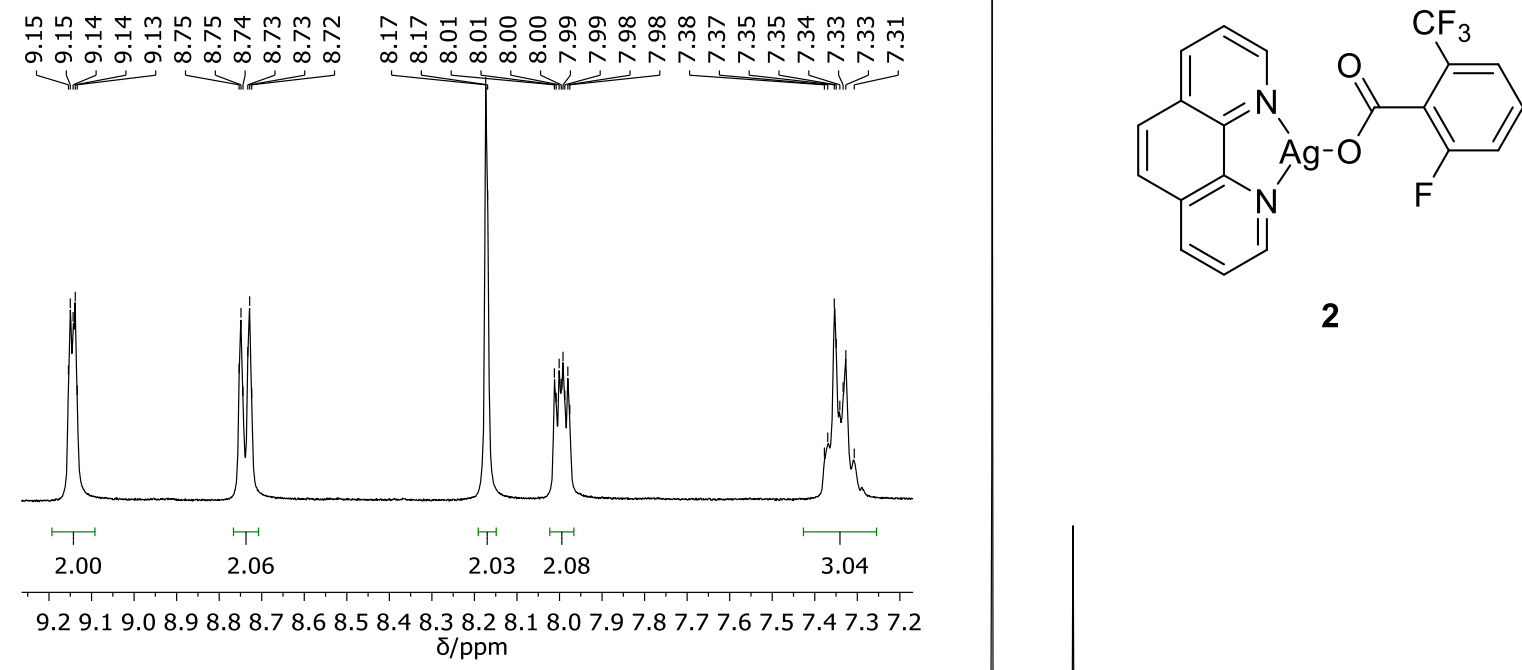

2

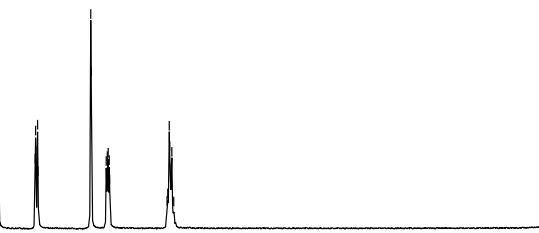

H. H T T

2.002 .062 .032 .083 .04

$\begin{array}{llllllll}13 & 12 & 11 & 10 & 9 & 8 & 7 & \begin{array}{c}6 \\ 8 / \mathrm{ppm}\end{array}\end{array}$

Figure A-61: ${ }^{1} \mathrm{H}$ NMR spectrum of (phen)Ag(2-F-6-CF 3 -benzoate) (2) in DMSO- $d_{6}$ at 400 $\mathrm{MHz}$. 


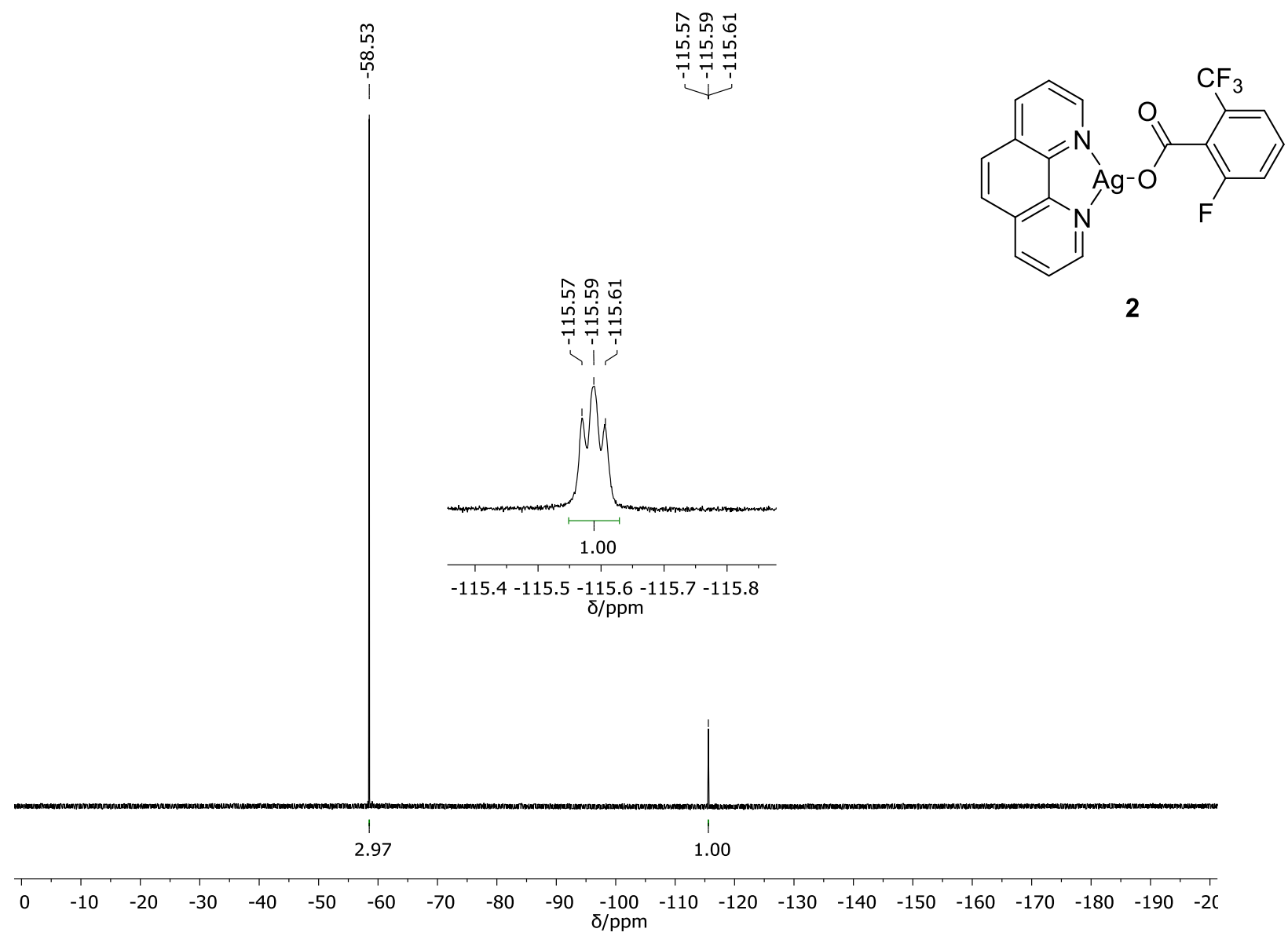

Figure A-62: ${ }^{19}$ F NMR spectrum of (phen)Ag(2-F-6-CF 3-benzoate) (2) in DMSO- $d_{6}$ at 375 $\mathrm{MHz}$. 

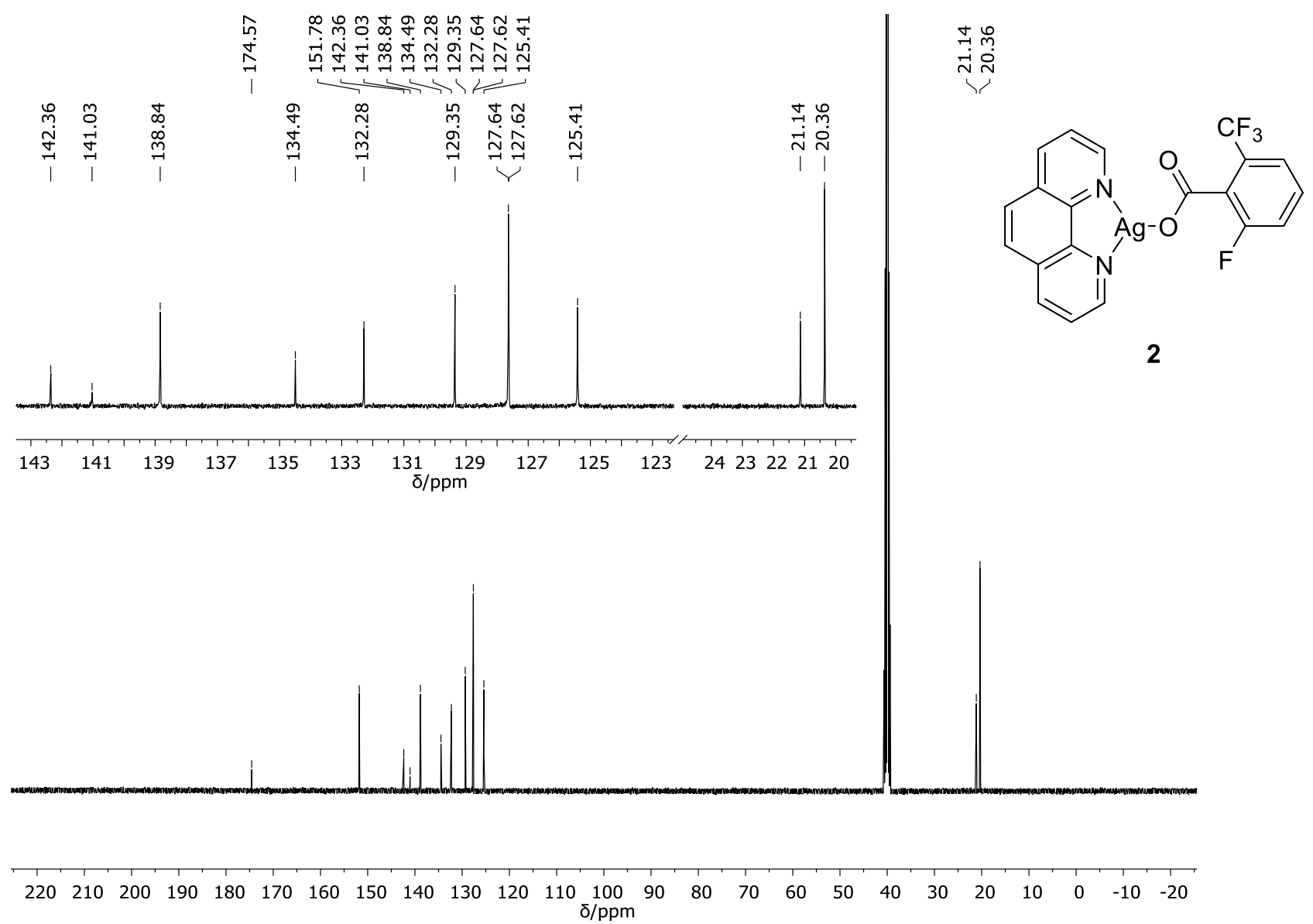

Figure A-63: ${ }^{13} \mathrm{C}$ NMR spectrum of (phen)Ag(2-F-6-CF3-benzoate) (2) in DMSO- $d_{6}$ at 100 $\mathrm{MHz}$. 


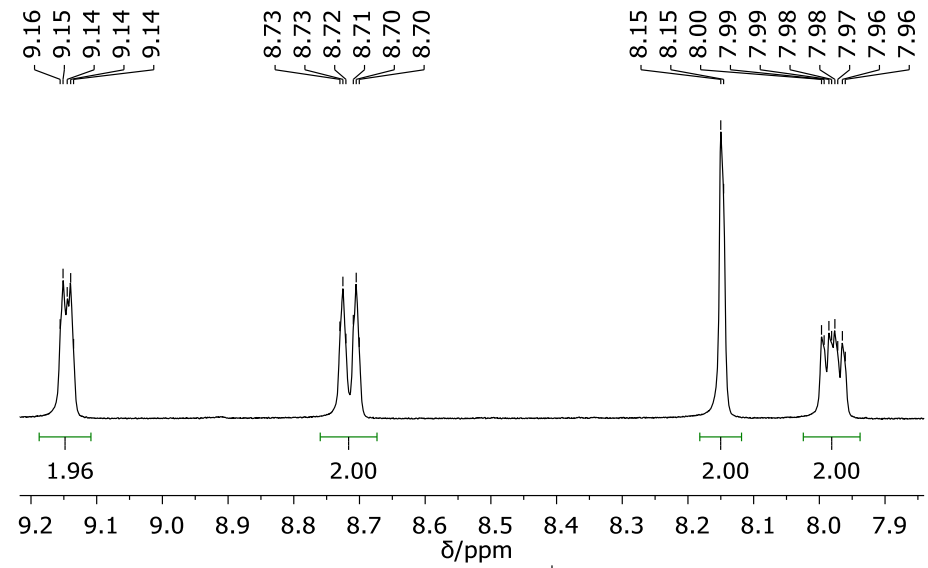

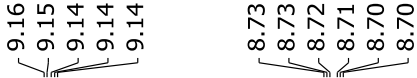

管
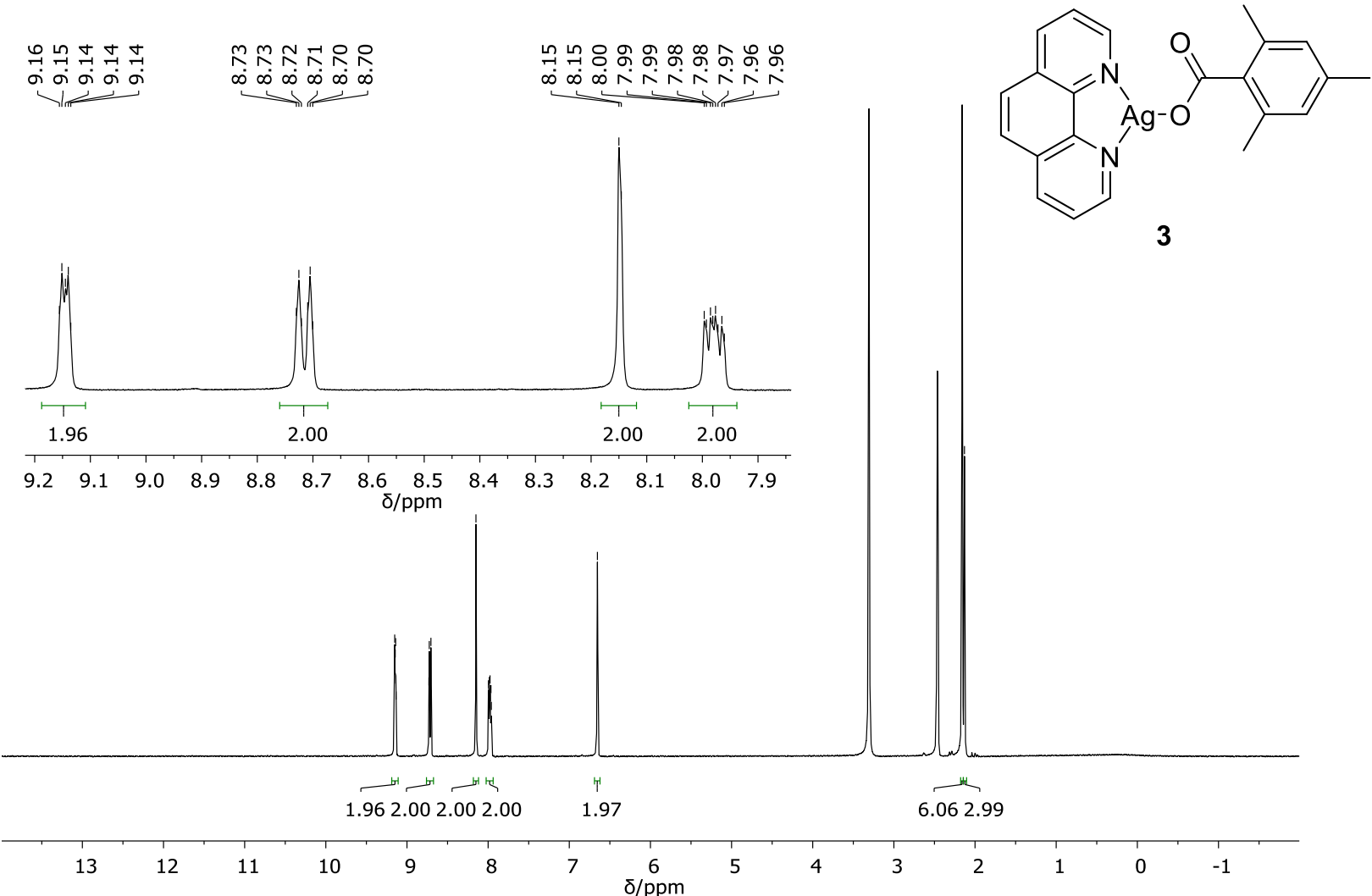

Figure A-64: ${ }^{1} \mathrm{H}$ NMR spectrum of (phen)Ag(2,4,6-tri-Me-benzoate) (3) in DMSO- $d_{6}$ at 400 $\mathrm{MHz}$. 

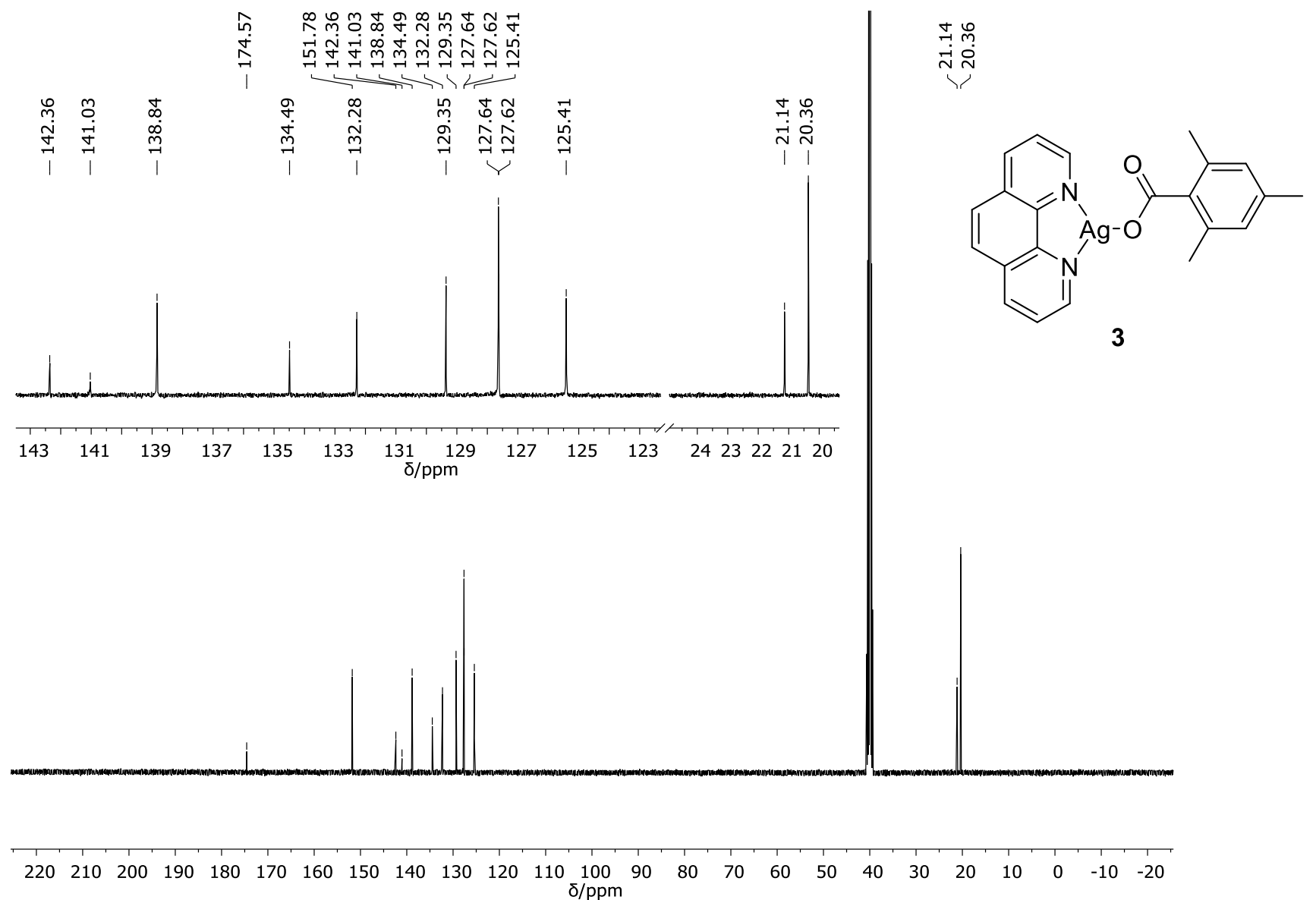

Figure A-65: ${ }^{13} \mathrm{C}$ NMR spectrum of (phen)Ag(2,4,6-tri-Me-benzoate) (3) in DMSO- $d_{6}$ at 100 $\mathrm{MHz}$. 


\section{AI-2.2 ${ }^{1} \mathrm{H}$ and ${ }^{13} \mathrm{C}$ NMR Spectra of Silver(Benzoate) Complexes}

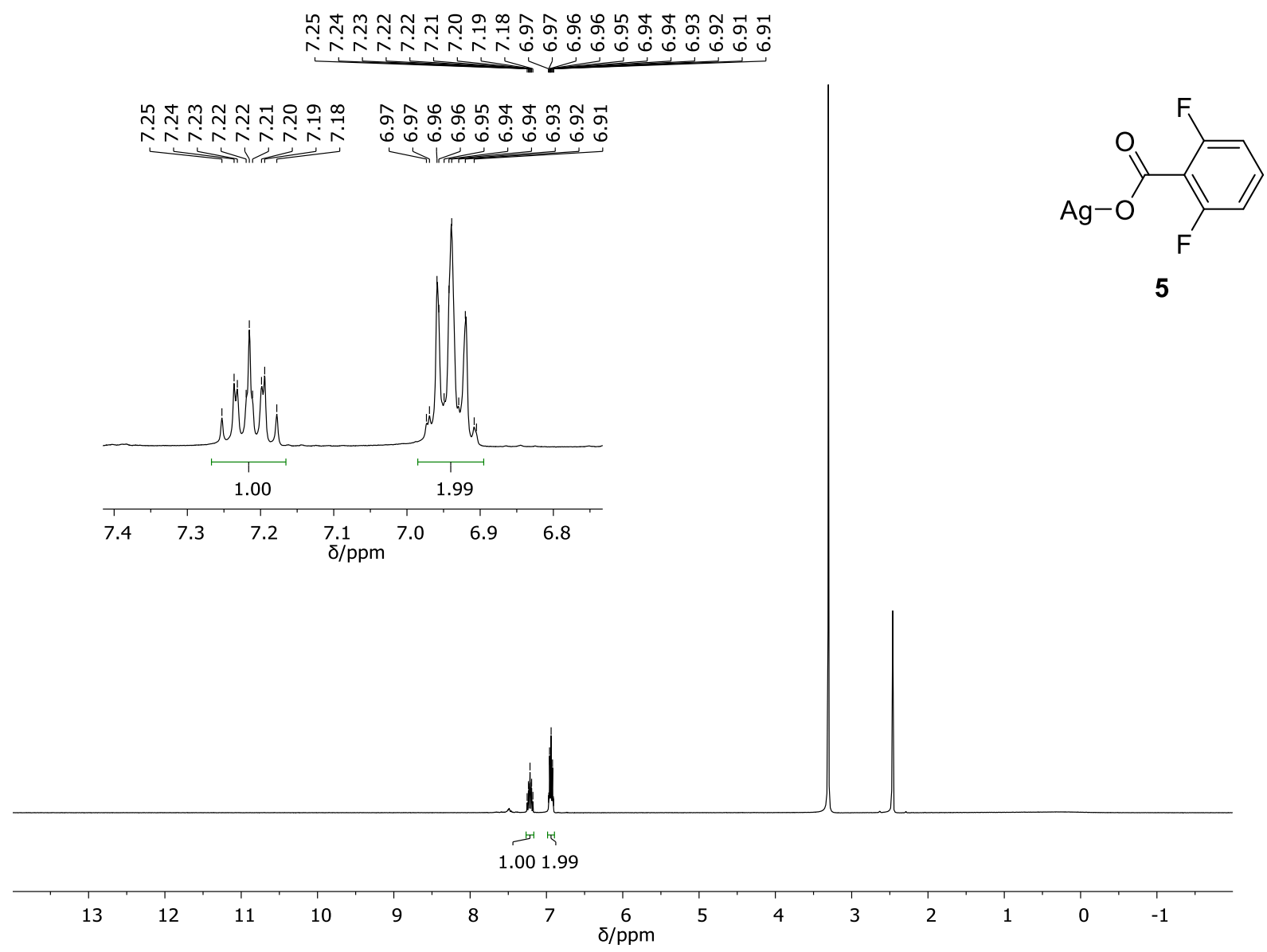

Figure A-66: ${ }^{1} \mathrm{H}$ NMR spectrum of $\mathbf{A g ( 2 , 6 - F - b e n z o a t e ) ~ ( 5 ) ~ i n ~ D M S O - ~} d_{6}$ at $400 \mathrm{MHz}$. 
굼 $\stackrel{m}{\sim} \stackrel{?}{+}$

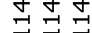
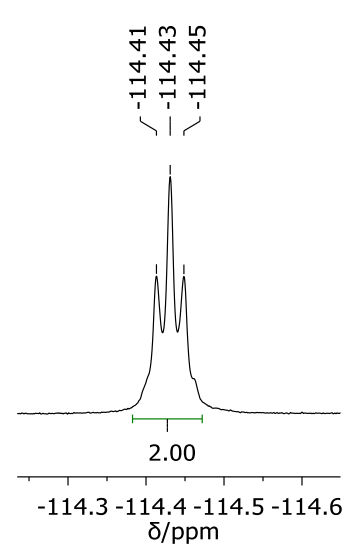

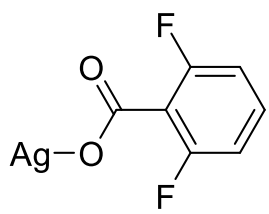

5

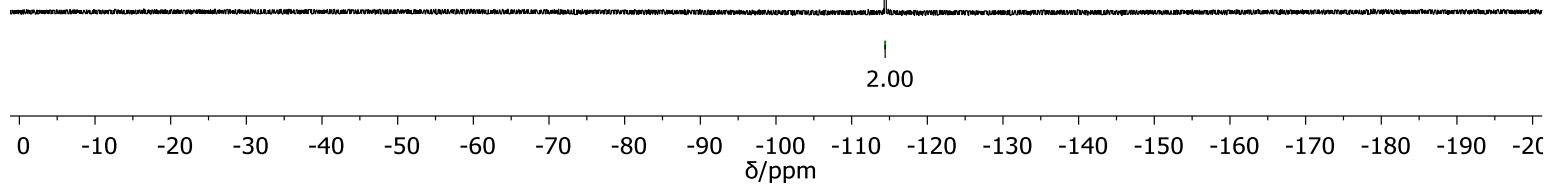

Figure A-67: ${ }^{19}$ F NMR spectrum of Ag(2,6-F-benzoate) (5) in DMSO- $d_{6}$ at $375 \mathrm{MHz}$. 


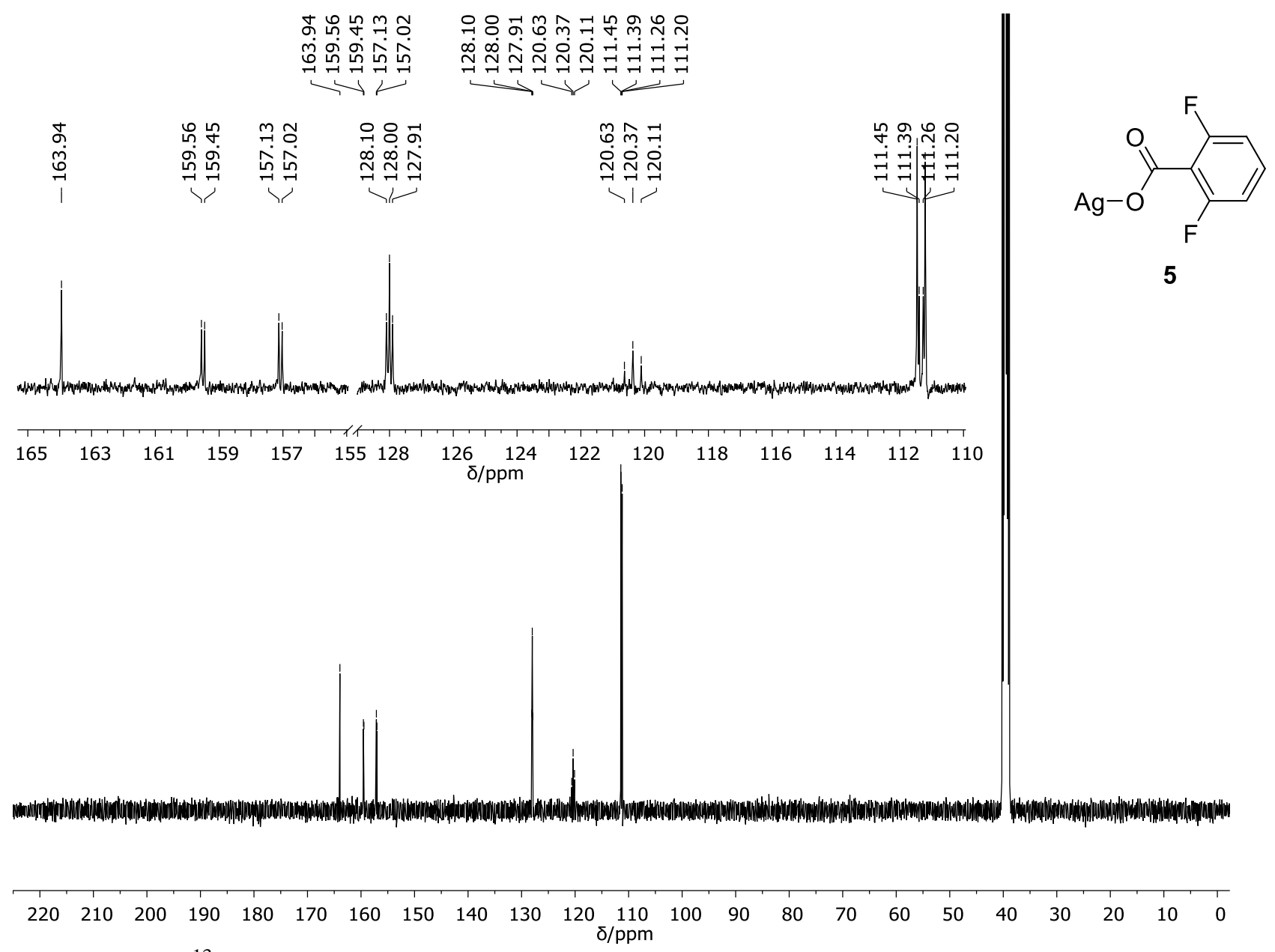

Figure A-68: ${ }^{13} \mathrm{C}$ NMR spectrum of Ag(2,6-F-benzoate) (5) in DMSO- $d_{6}$ at $100 \mathrm{MHz}$. 


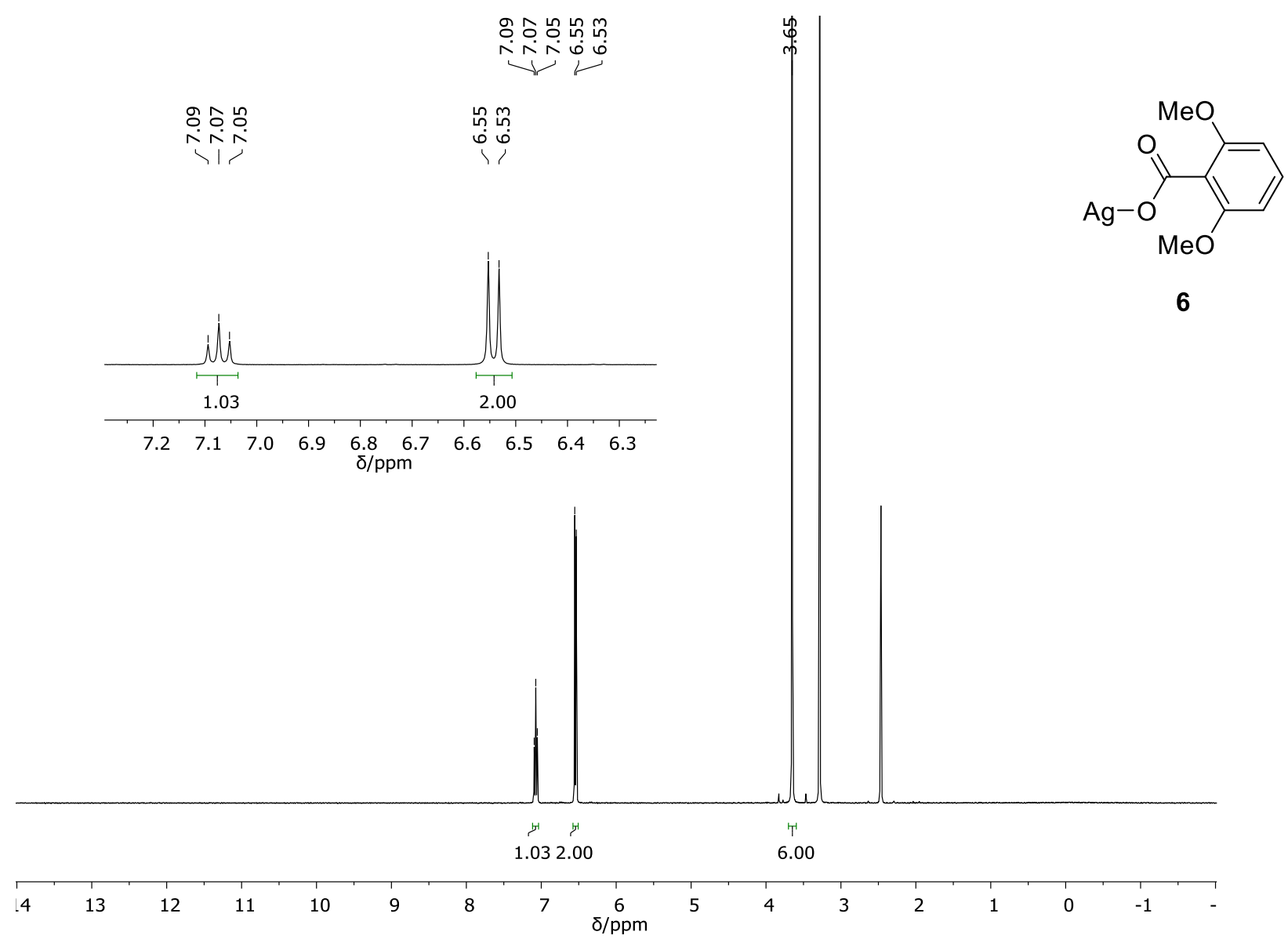

Figure A-69: ${ }^{1} \mathrm{H}$ NMR spectrum of Ag(2,6-di-OMe-benzoate) (6) in DMSO- $d_{6}$ at $400 \mathrm{MHz}$. 


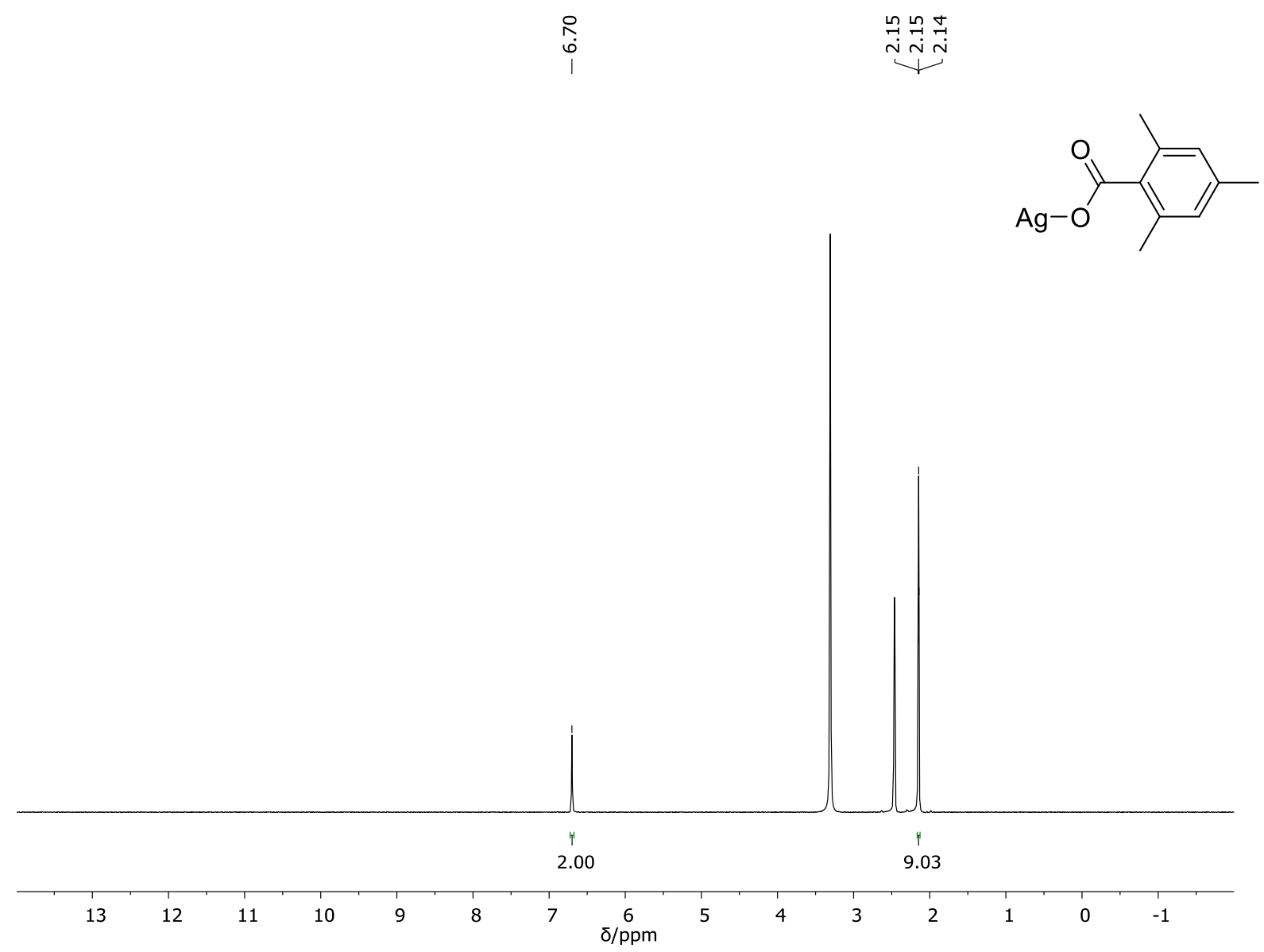

Figure A-70: ${ }^{1} \mathrm{H}$ NMR spectrum of Ag(2,4,6-tri-Me-benzoate) in DMSO-d $d_{6}$ at $400 \mathrm{MHz}$. 


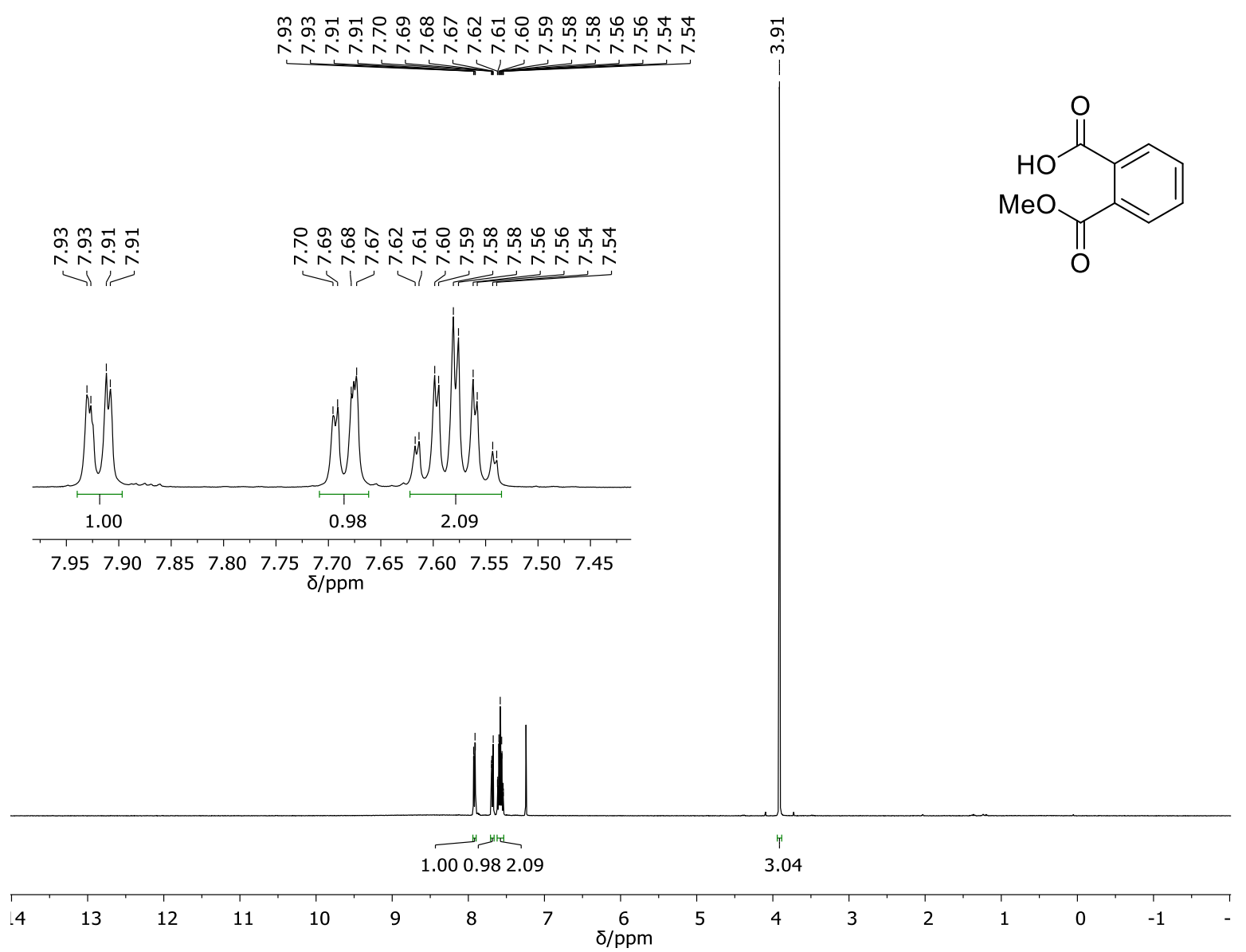

Figure A-71: ${ }^{1} \mathrm{H}$ NMR spectrum of 2-COOMe-benzoic acid in $\mathrm{CDCl}_{3}$ at $400 \mathrm{MHz}$. 


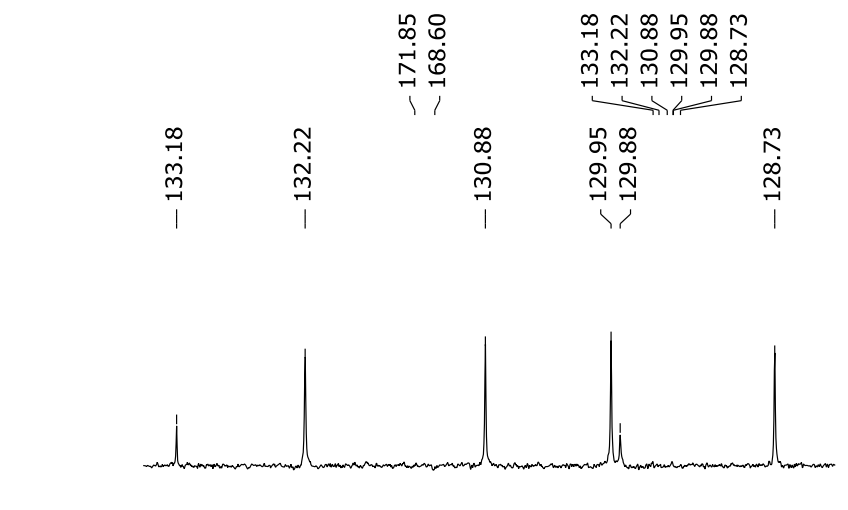

$\check{\infty}$

กิ

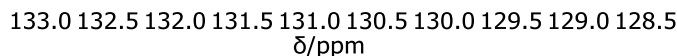

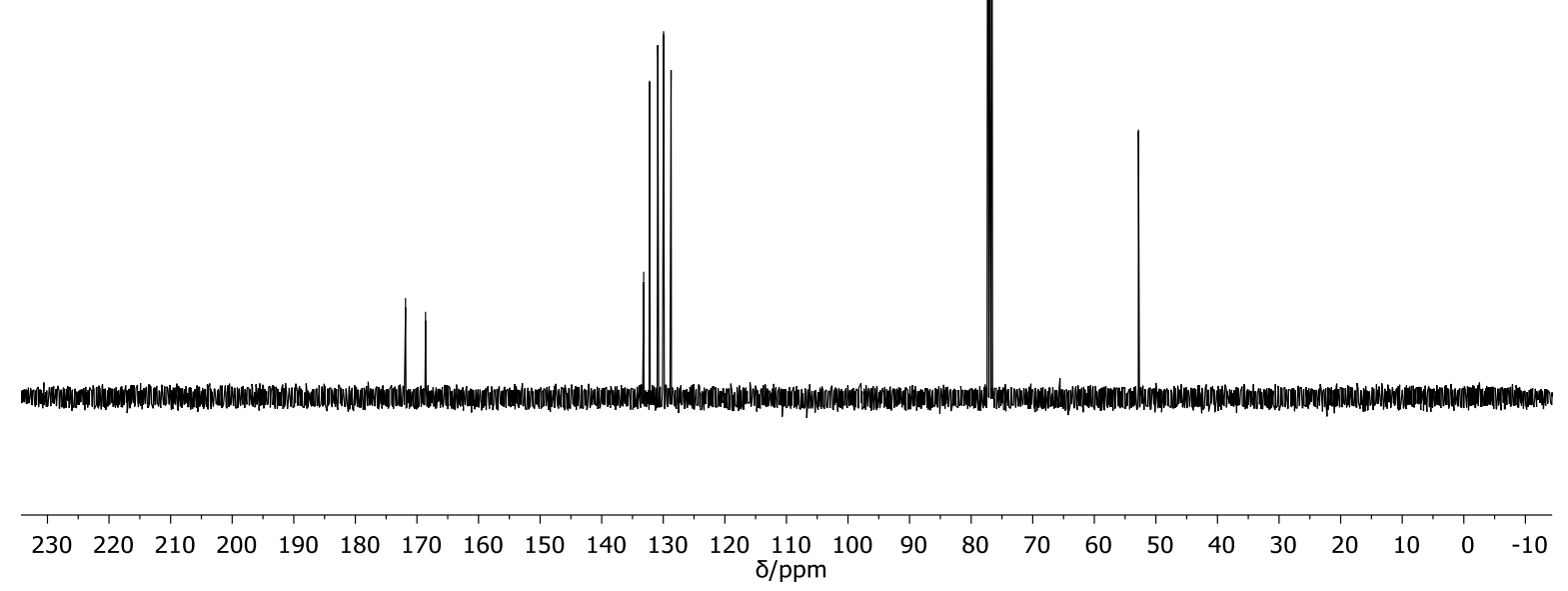

Figure A-72: ${ }^{13} \mathrm{C}$ NMR spectrum of 2-COOMe-benzoic acid in $\mathrm{CDCl}_{3}$ at $100 \mathrm{MHz}$. 


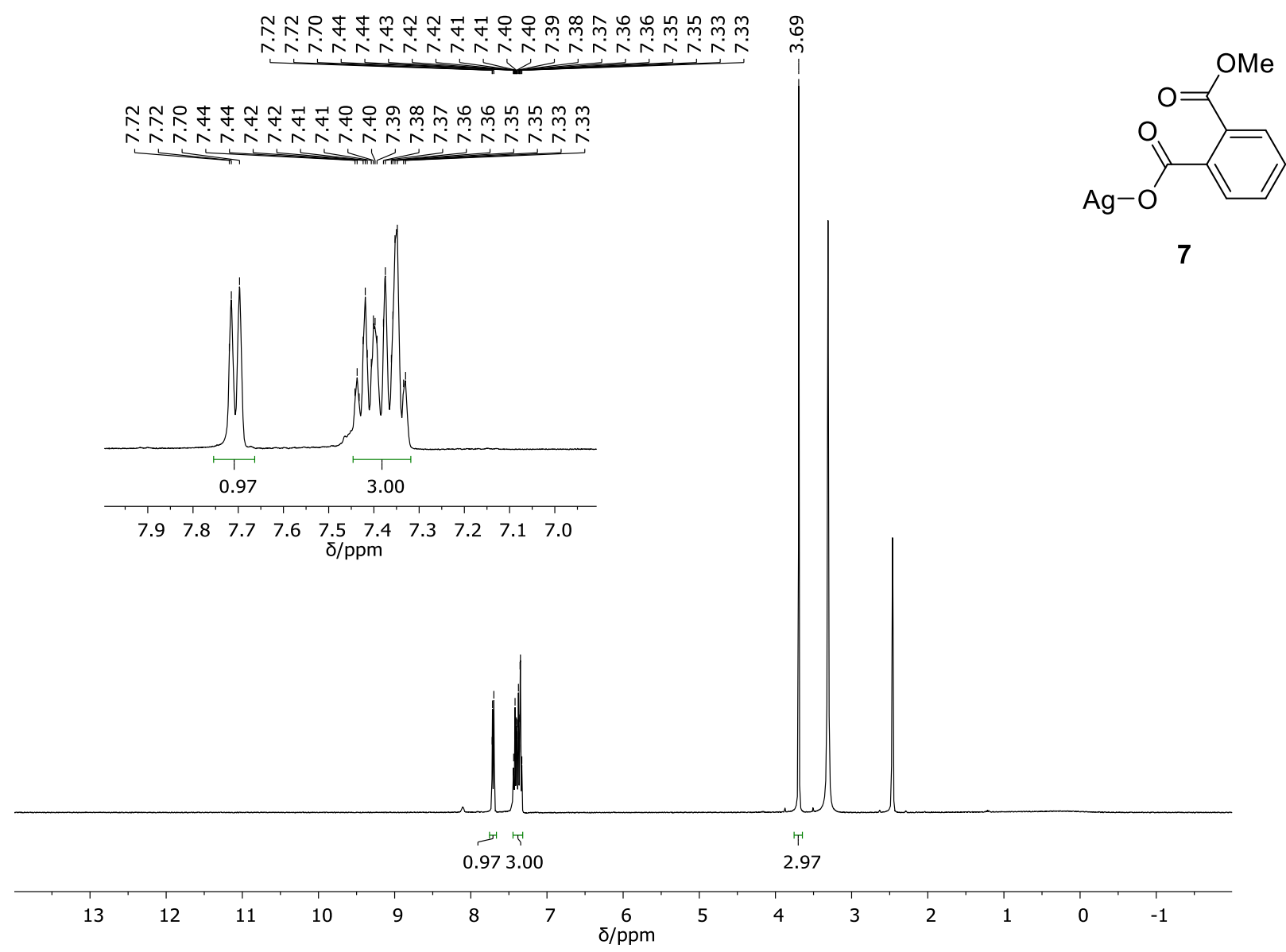

Figure A-73: ${ }^{1} \mathrm{H}$ NMR spectrum of Ag(2-COOMe-benzoate) (7) in DMSO- $d_{6}$ at $400 \mathrm{MHz}$. 


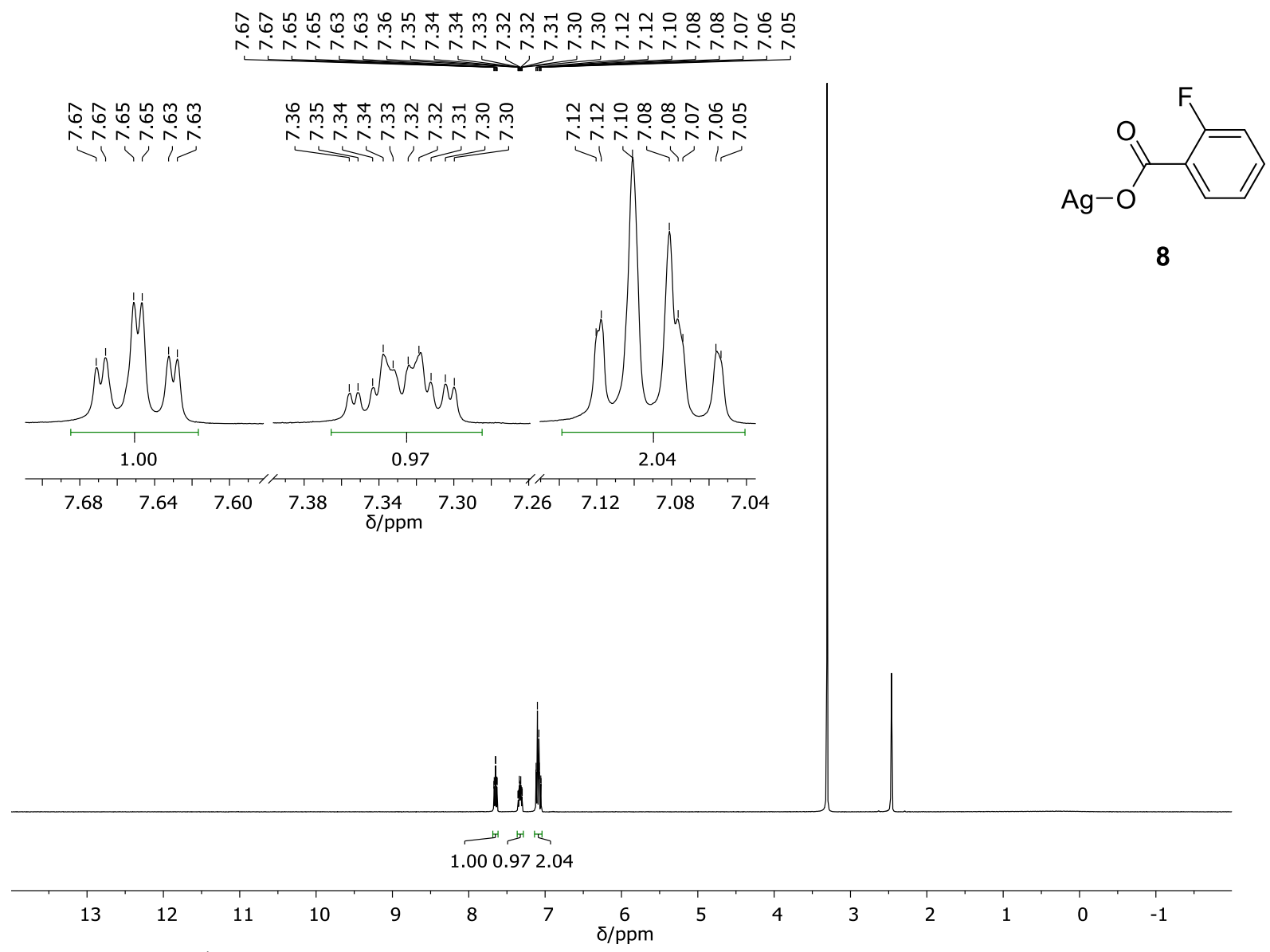

Figure A-74: ${ }^{1} \mathrm{H}$ NMR spectrum of $\mathbf{A g ( 2 - F - b e n z o a t e ) ~ ( 8 ) ~ i n ~ D M S O - ~} d_{6}$ at $400 \mathrm{MHz}$. 


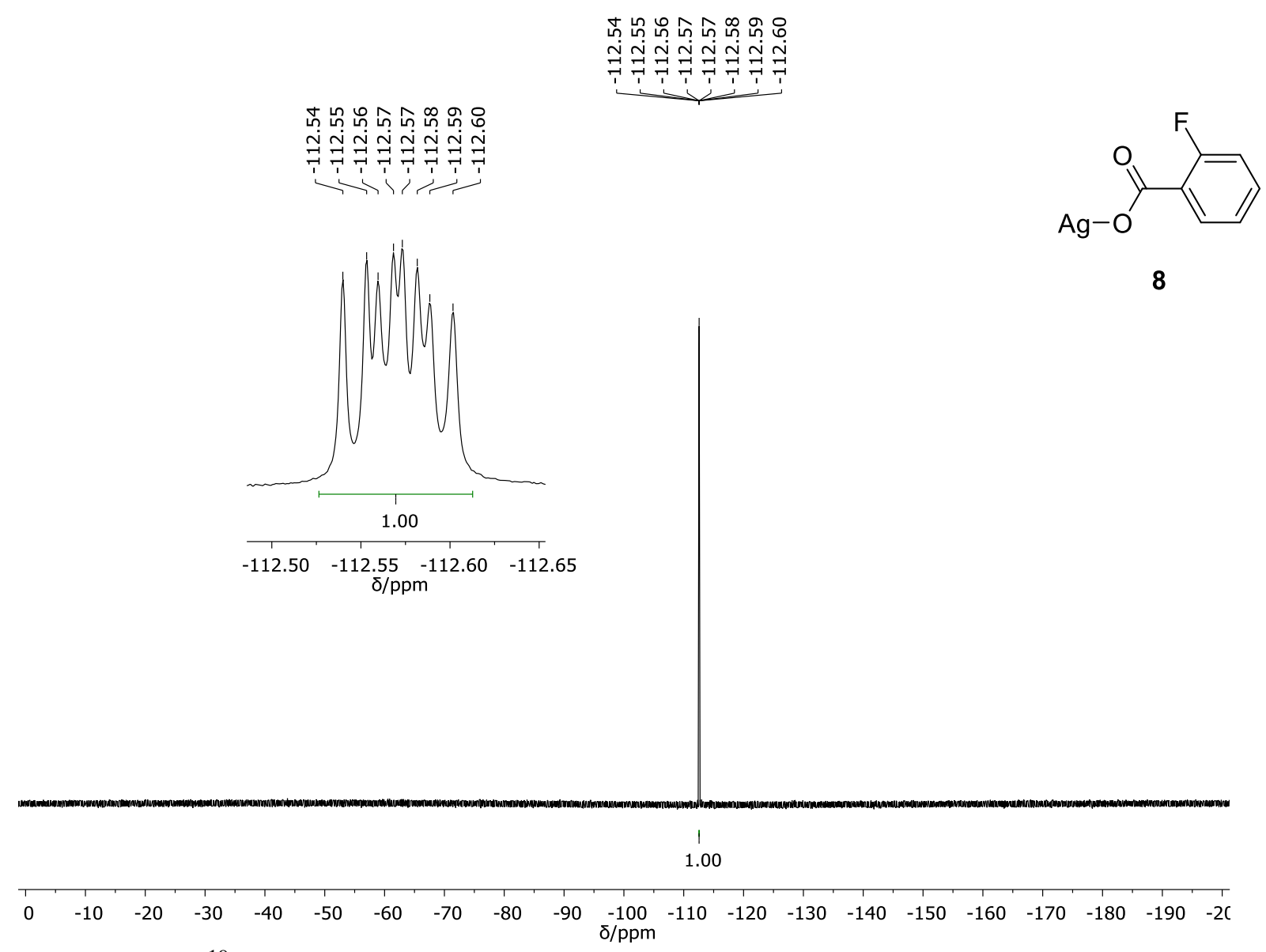

Figure A-75: ${ }^{19} \mathrm{~F}$ NMR spectrum of Ag(2-F-benzoate) (8) in DMSO- $d_{6}$ at $375 \mathrm{MHz}$. 


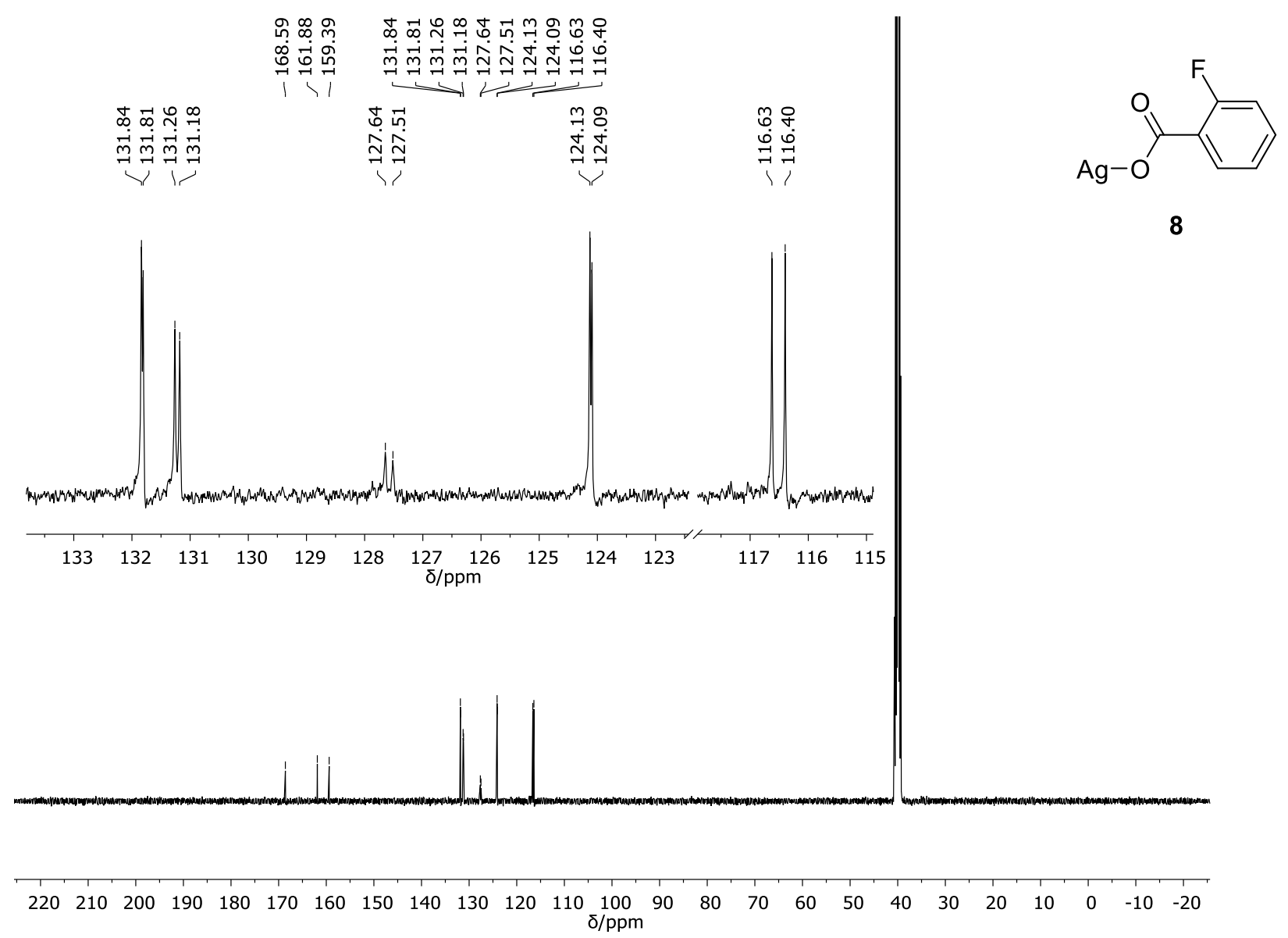

Figure A-76: ${ }^{13} \mathrm{C}$ NMR spectrum of $\mathbf{A g ( 2 - F - b e n z o a t e ) ~ ( 8 ) ~ i n ~ D M S O - ~} d_{6}$ at $100 \mathrm{MHz}$. 

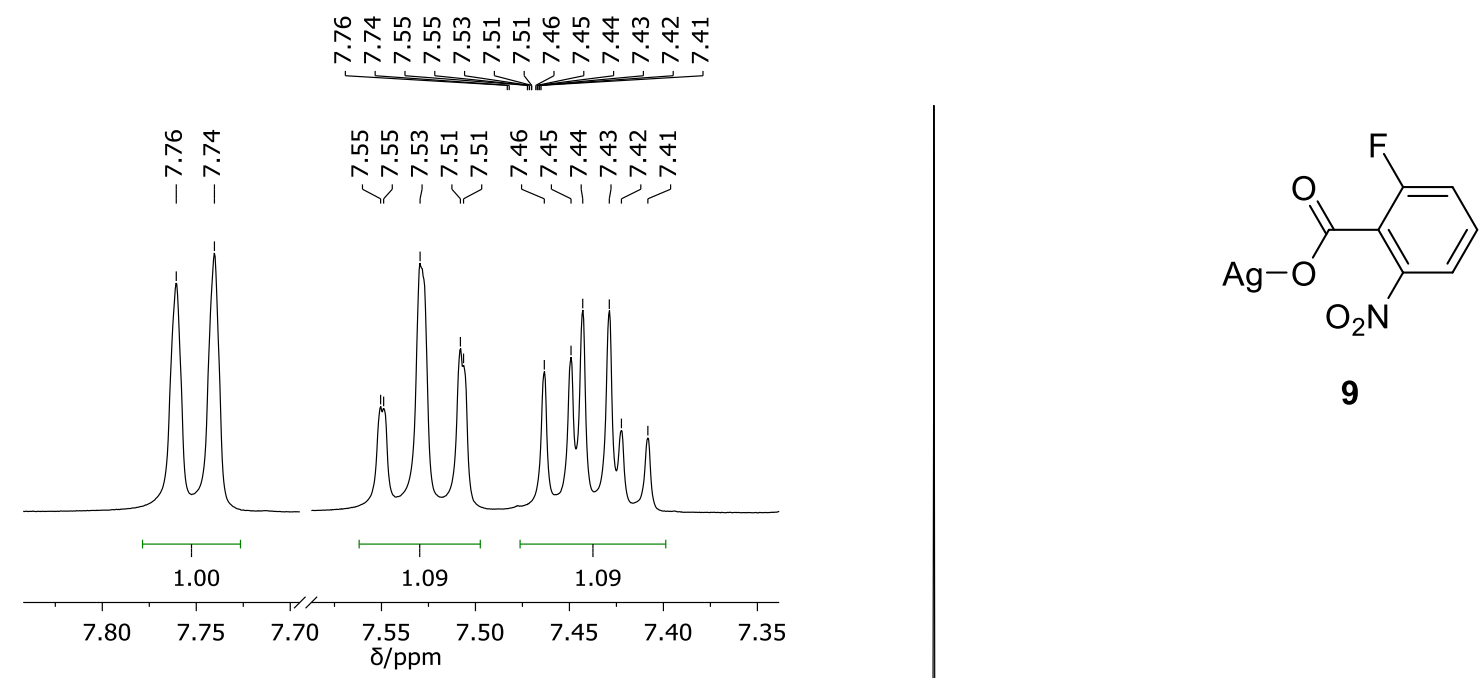

9

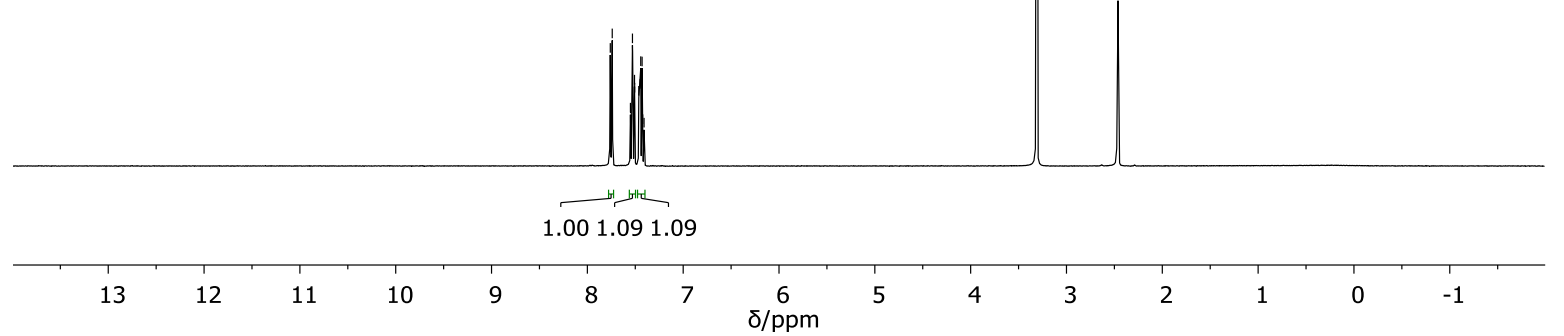

Figure A-77: ${ }^{1} \mathrm{H}$ NMR spectrum of $\mathbf{A g ( 2 - F - 6 - N O}$-benzoate) (9) in DMSO- $d_{6}$ at $400 \mathrm{MHz}$. 


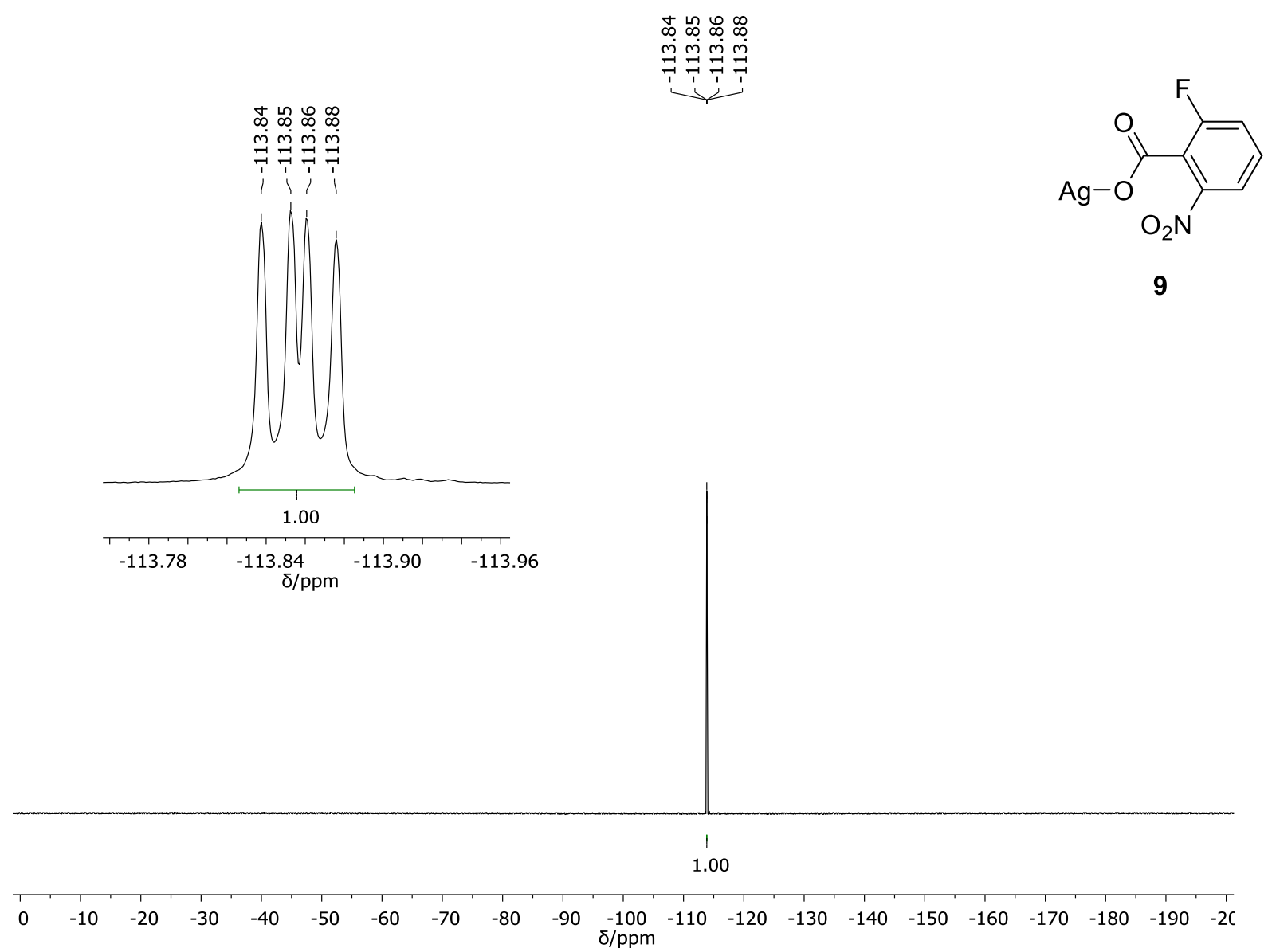

Figure A-78: ${ }^{19}$ F NMR spectrum of Ag(2-F-6-NO2-benzoate) (9) in DMSO- $d_{6}$ at $375 \mathrm{MHz}$. 


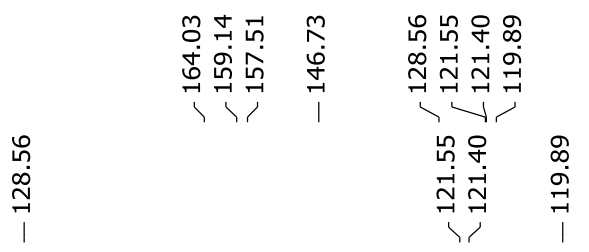

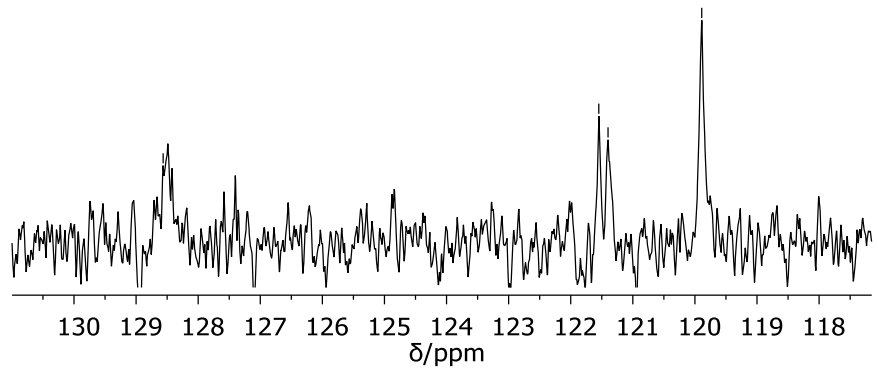<smiles>O=C(O[Ga])c1c(F)cccc1[N+](=O)[O-]</smiles>

9
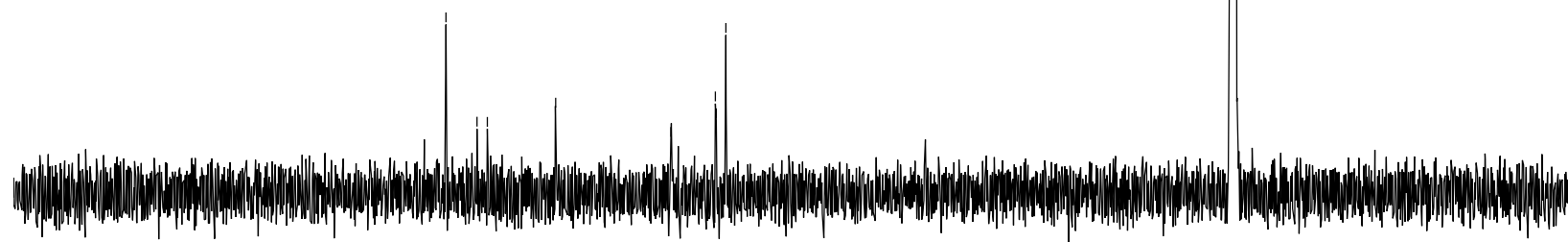

$\begin{array}{lllllllllllllllllllllllll}230 & 220 & 210 & 200 & 190 & 180 & 170 & 160 & 150 & 140 & 130 & 120 & \begin{array}{l}110 \\ \delta / \mathrm{ppm}\end{array} & 100 & 90 & 80 & 70 & 60 & 50 & 40 & 30 & 20 & 10 & 0 & -10\end{array}$ Figure A-79: ${ }^{13} \mathrm{C}$ NMR spectrum of $\mathbf{A g}\left(2-\mathrm{F}-6-\mathrm{NO}_{2}\right.$-benzoate) (9) in DMSO- $d_{6}$ at $100 \mathrm{MHz}$. 


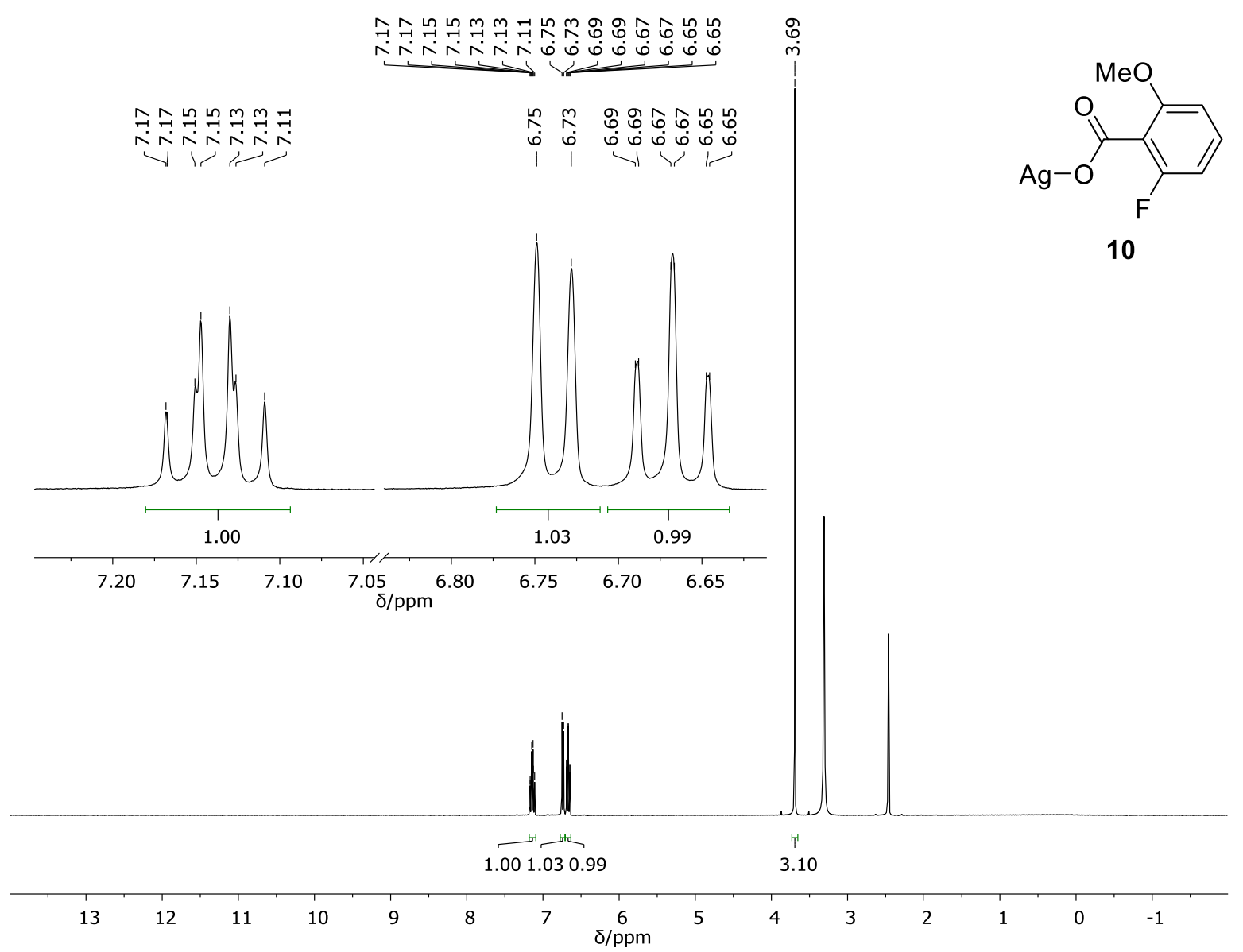

Figure A-80: ${ }^{1} \mathrm{H}$ NMR spectrum of Ag(2- F-6-OMe-benzoate) (10) in DMSO- $d_{6}$ at $400 \mathrm{MHz}$. 


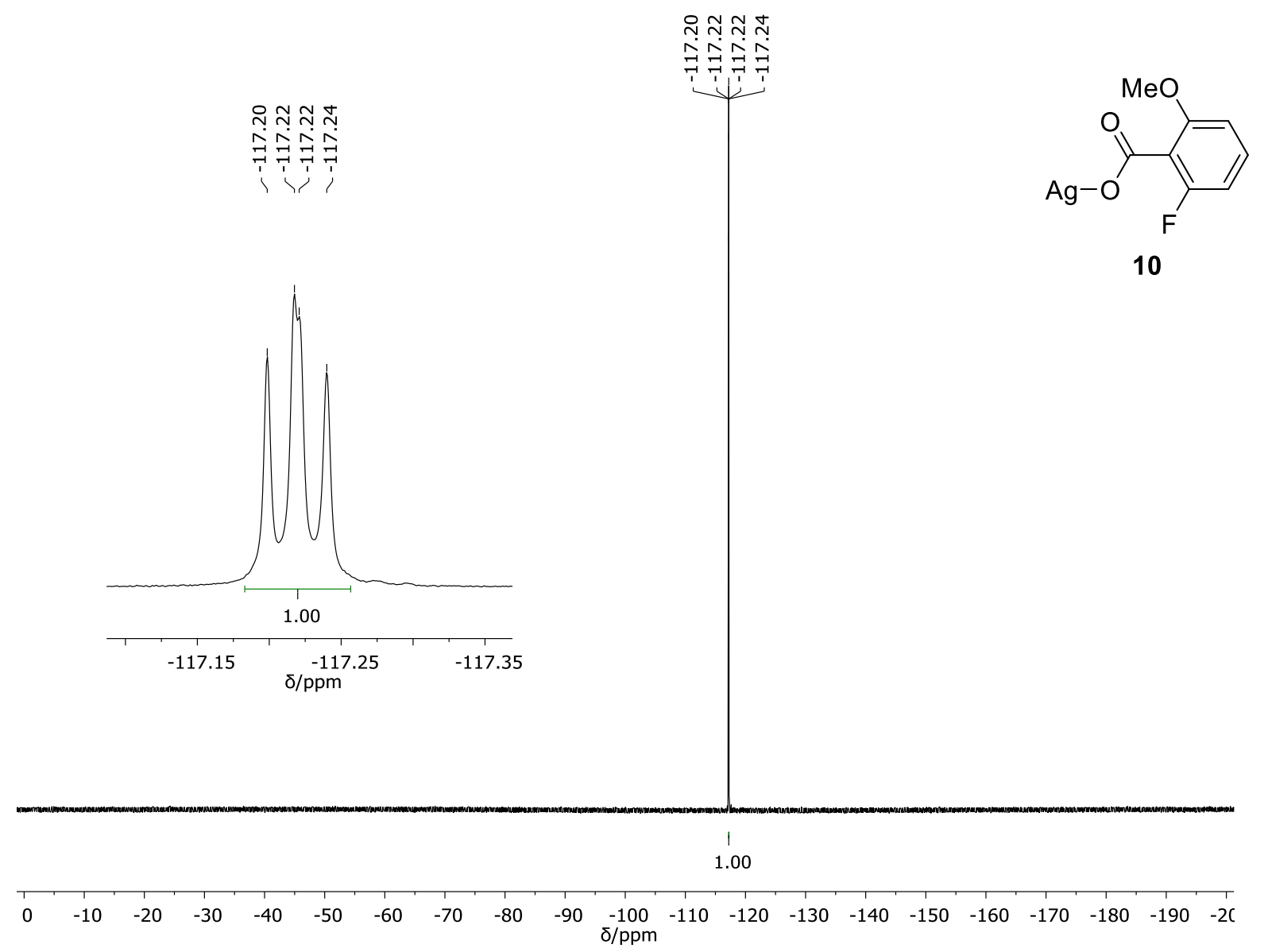

Figure A-81: ${ }^{19}$ F NMR spectrum of Ag(2-F-6-OMe-benzoate) (10) in DMSO- $d_{6}$ at $375 \mathrm{MHz}$. 


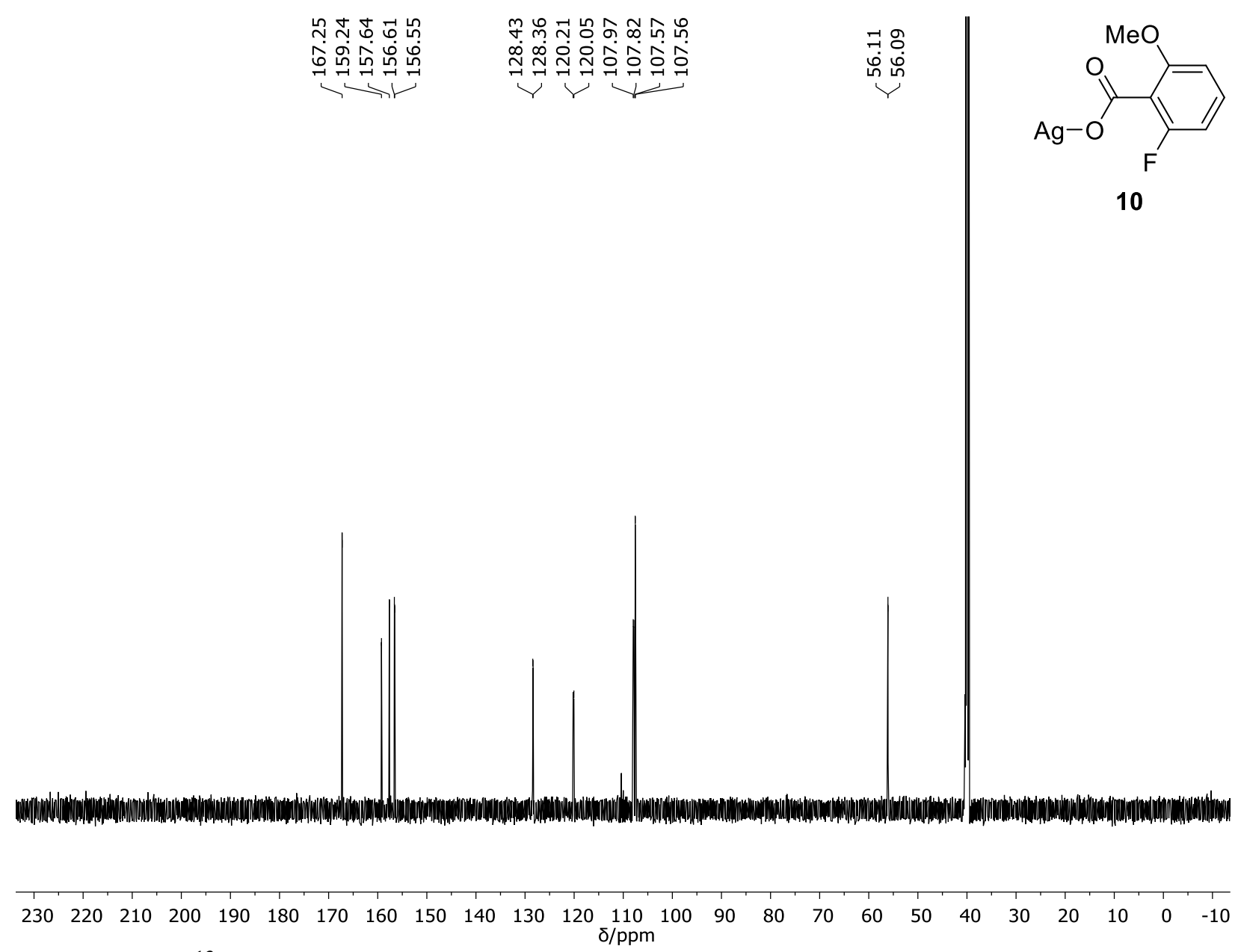

Figure A-82: ${ }^{13} \mathrm{C}$ NMR spectrum of Ag(2-F-6-OMe-benzoate) (10) in DMSO- $d_{6}$ at $100 \mathrm{MHz}$. 


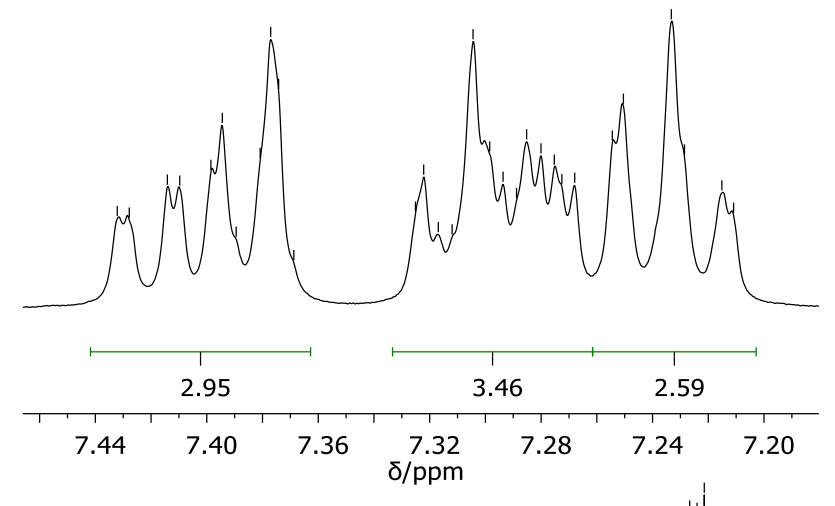<smiles>O=C(O[Ga])c1ccccc1-c1ccccc1</smiles>

11

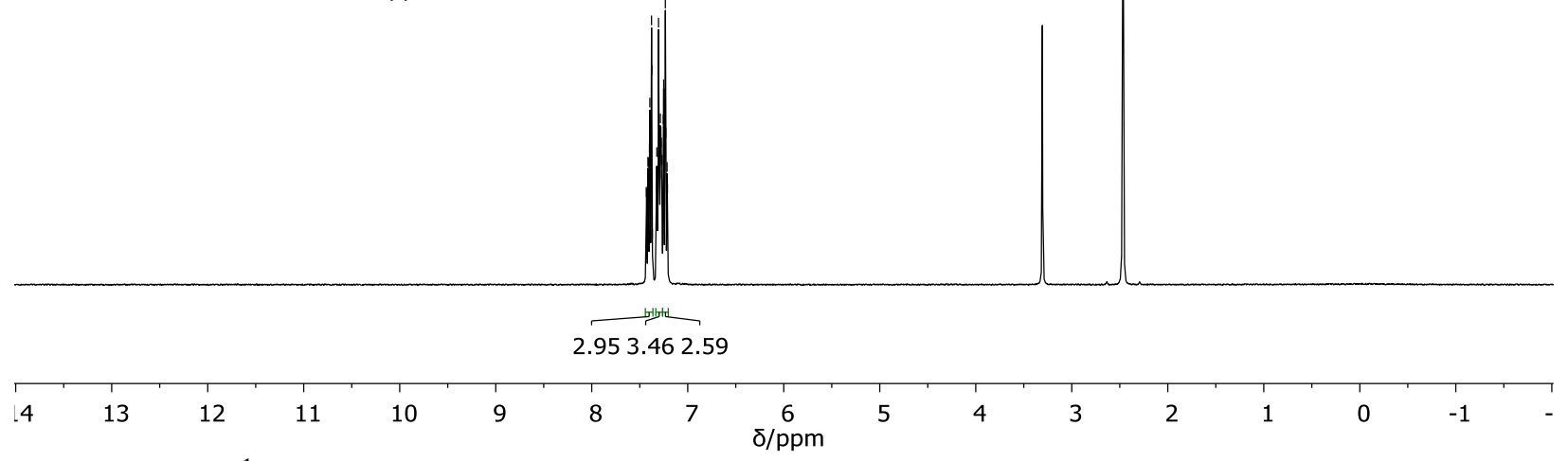

Figure A-83: ${ }^{1} \mathrm{H}$ NMR spectrum of Ag(2-phenylbenzoate) (11) in DMSO- $d_{6}$ at $400 \mathrm{MHz}$. 


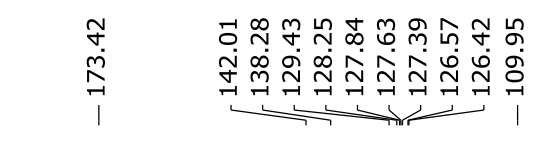

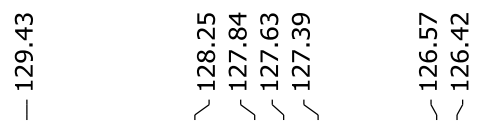
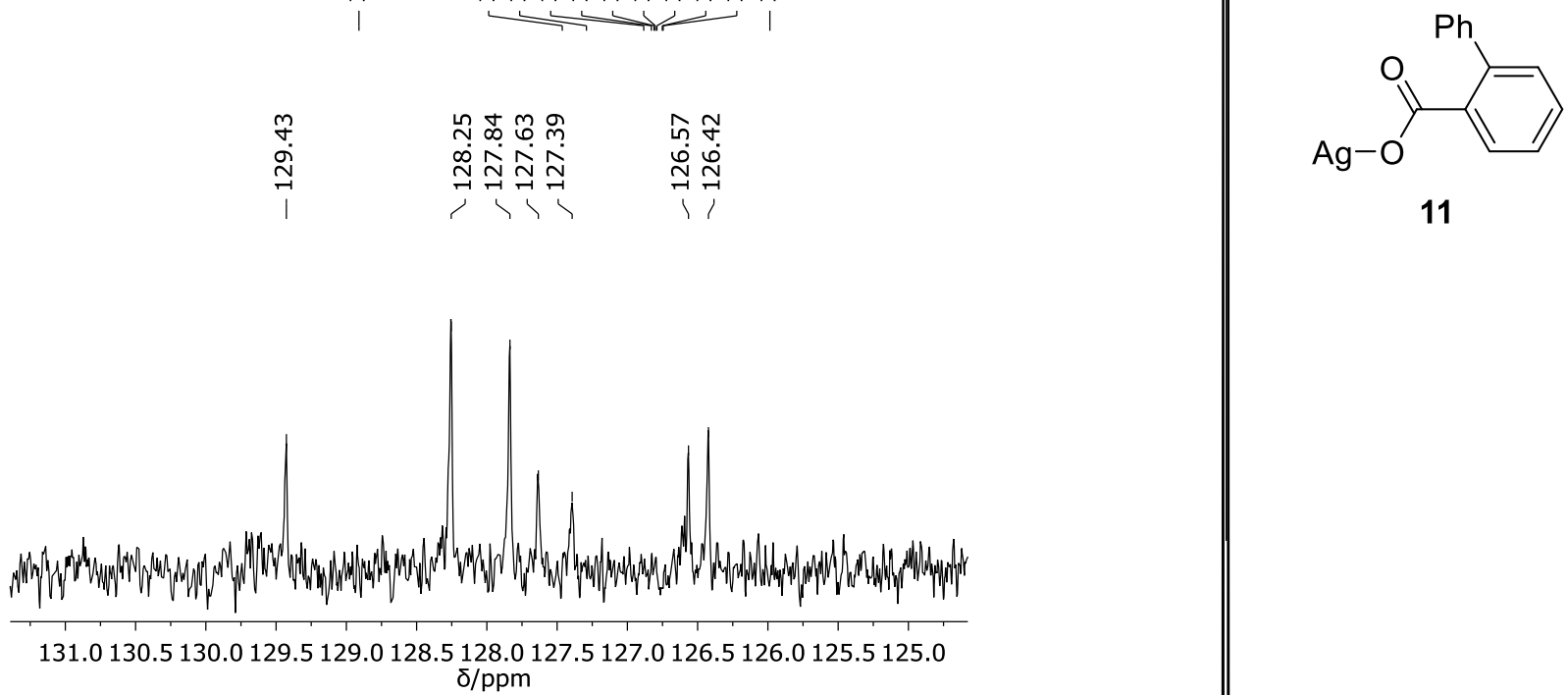

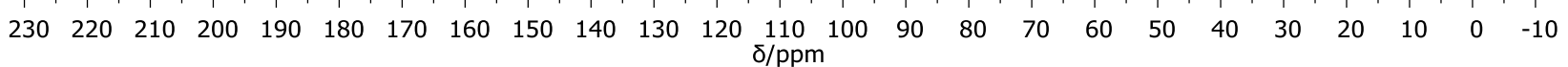

Figure A-84: ${ }^{13} \mathrm{C}$ NMR spectrum of Ag(2-phenylbenzoate) (11) in DMSO- $d_{6}$ at $100 \mathrm{MHz}$. 


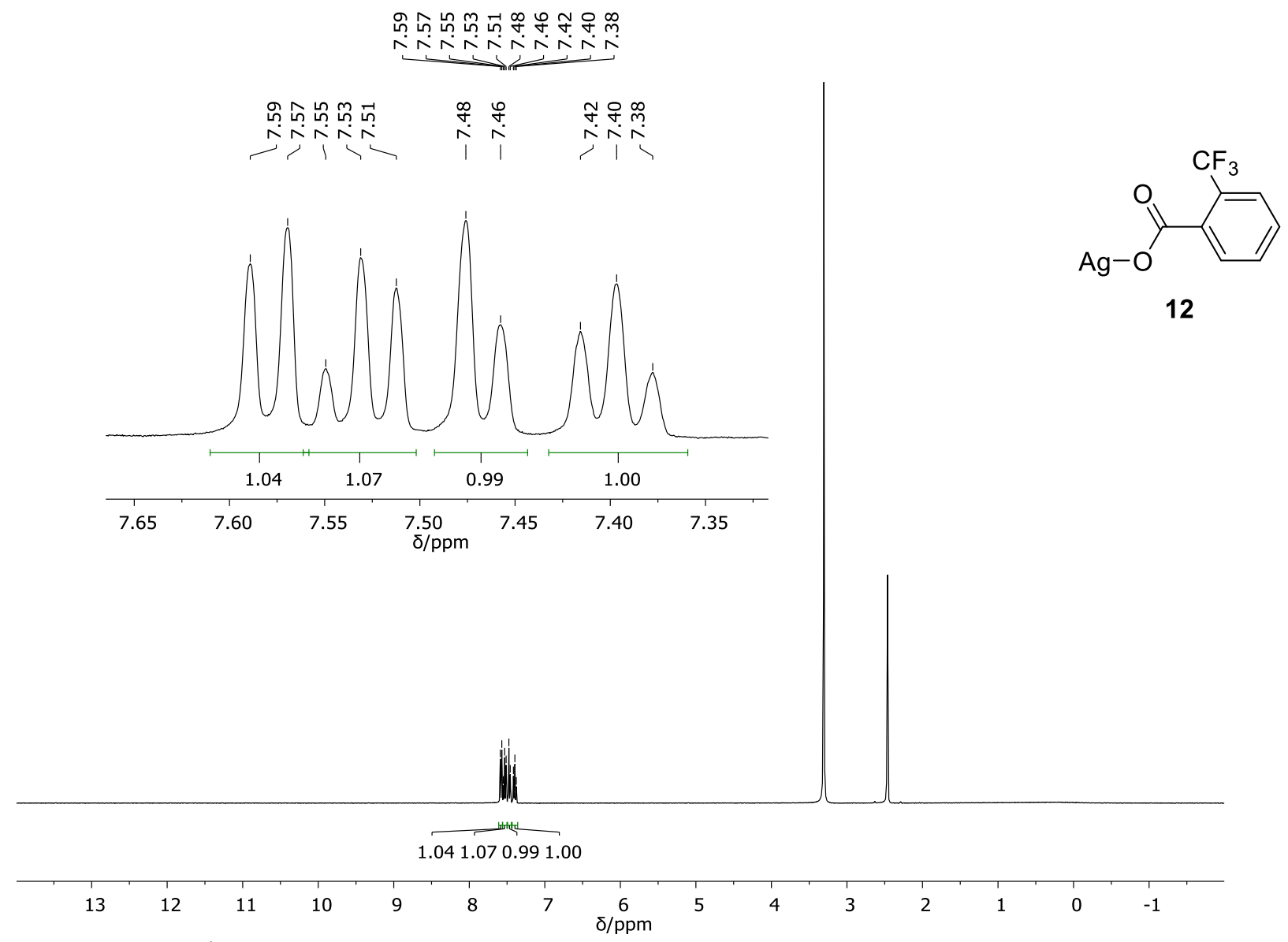

Figure A-85: ${ }^{1} \mathrm{H}$ NMR spectrum of $\mathbf{A g ( 2 - C F}$-benzoate) (12) in DMSO- $d_{6}$ at $400 \mathrm{MHz}$. 


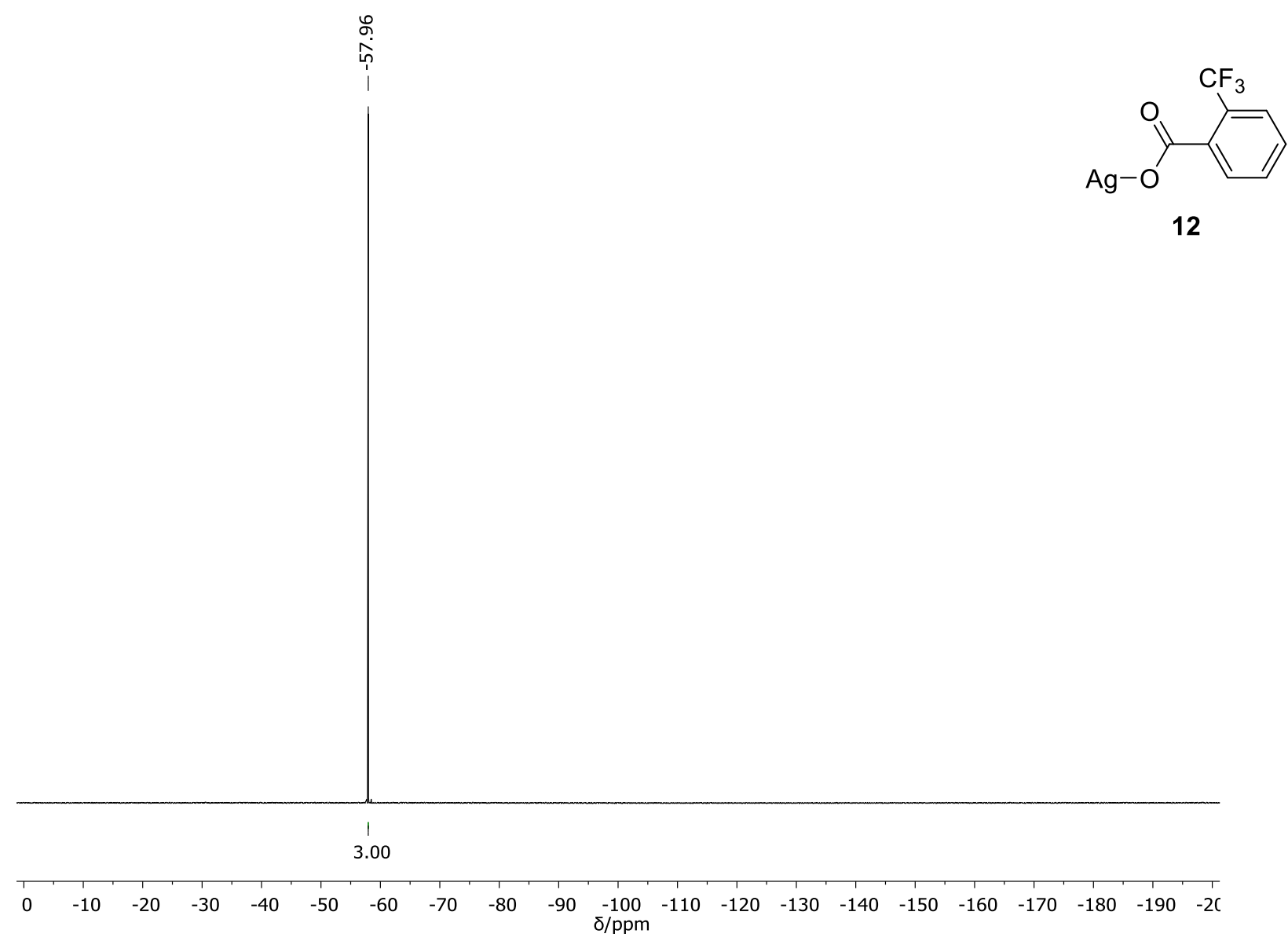

Figure A-86: ${ }^{19} \mathrm{~F}$ NMR spectrum of $\mathbf{A g}\left(\mathbf{2}-\mathbf{C F}_{3}\right.$-benzoate) (12) in DMSO- $d_{6}$ at $375 \mathrm{MHz}$. 


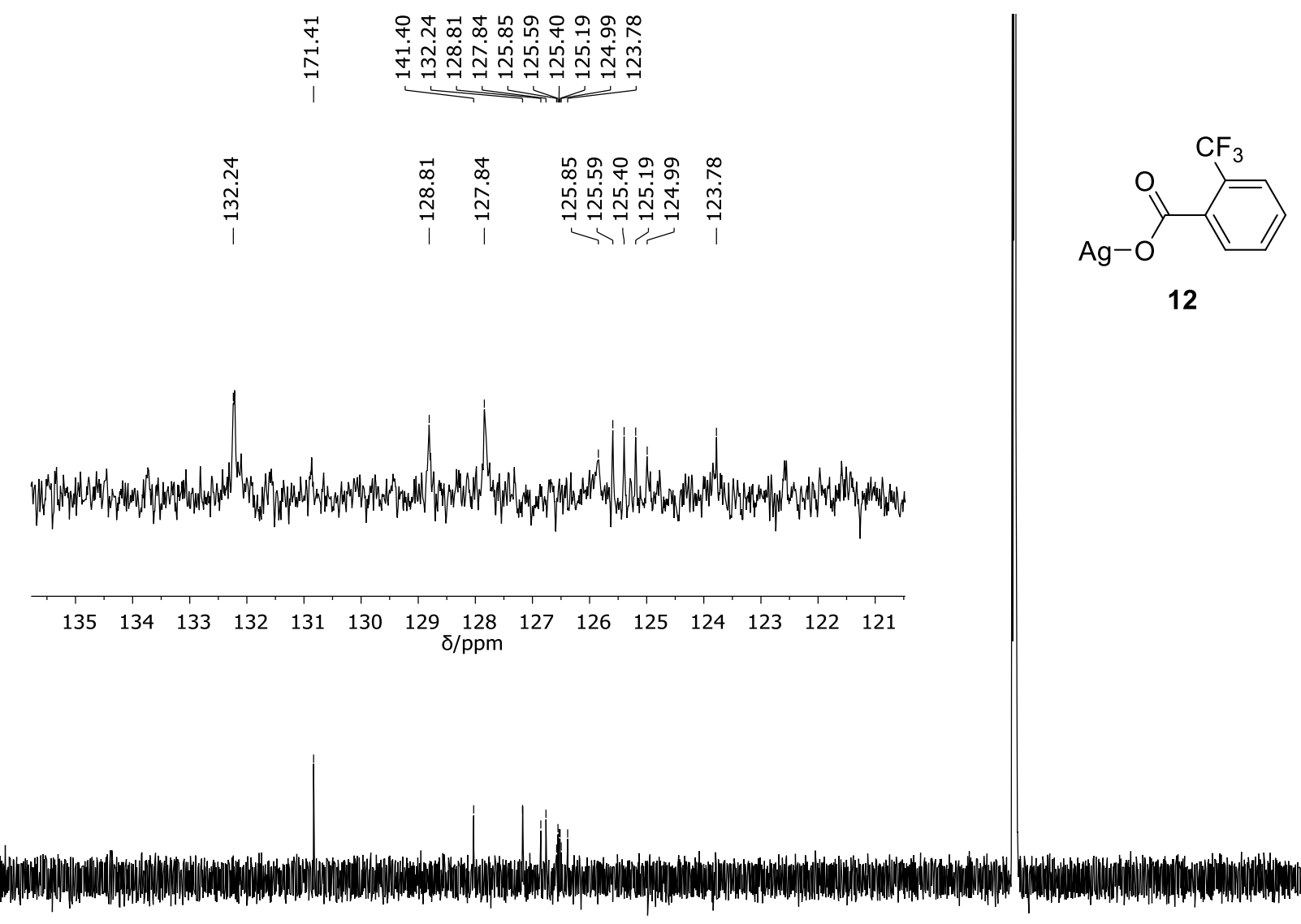

$\begin{array}{lllllllllllllllllllllllll}230 & 220 & 210 & 200 & 190 & 180 & 170 & 160 & 150 & 140 & 130 & 120 & 110 & 100 & 90 & 80 & 70 & 60 & 50 & 40 & 30 & 20 & 10 & 0 & -10\end{array}$

Figure A-87: ${ }^{13} \mathrm{C}$ NMR spectrum of $\mathbf{A g}\left(2-\mathbf{C F}_{3}\right.$-benzoate) (12) in DMSO- $d_{6}$ at $100 \mathrm{MHz}$. 


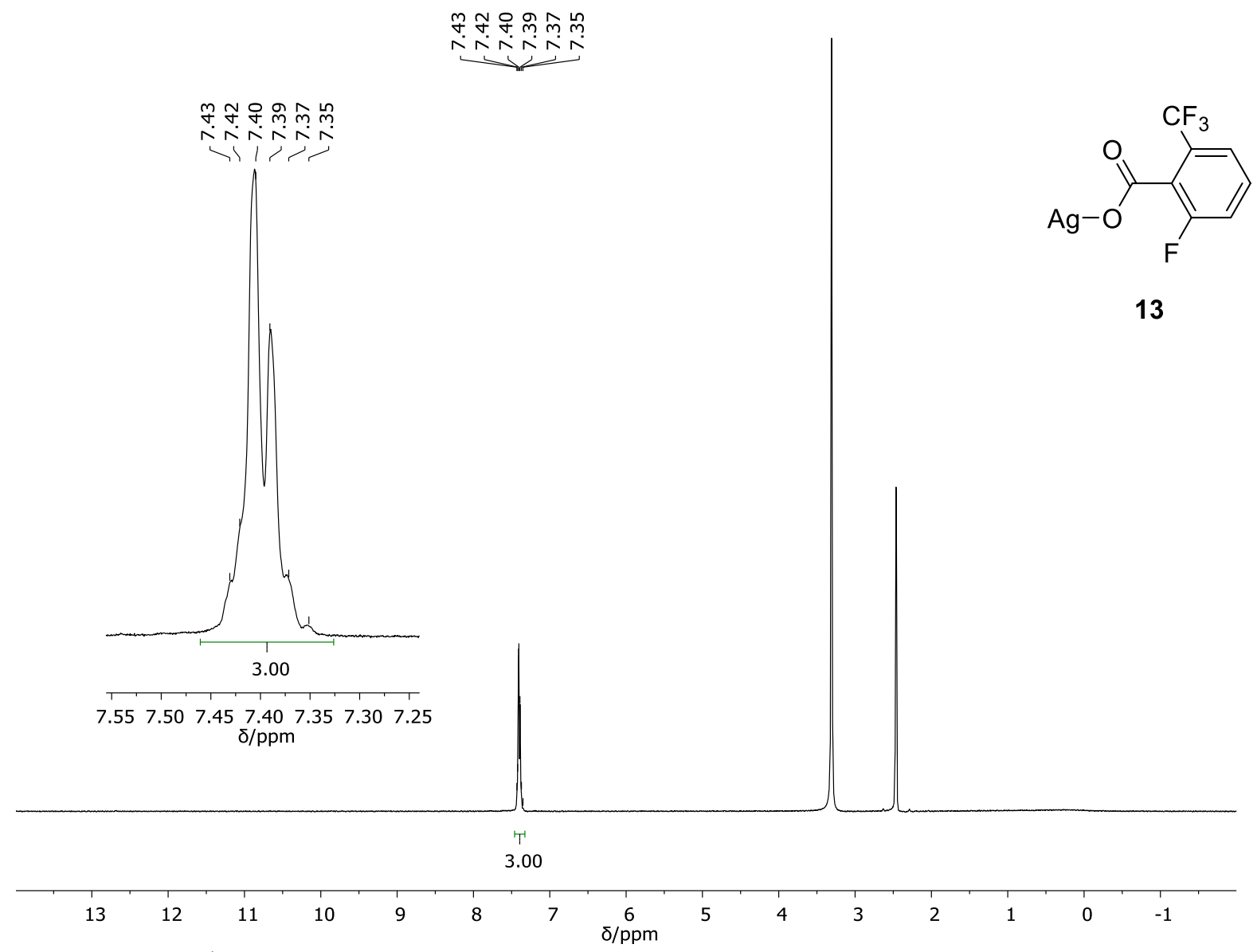

Figure A-88: ${ }^{1} \mathrm{H}$ NMR spectrum of Ag(2-F-6-CF3-benzoate) (13) in DMSO- $d_{6}$ at $400 \mathrm{MHz}$. 


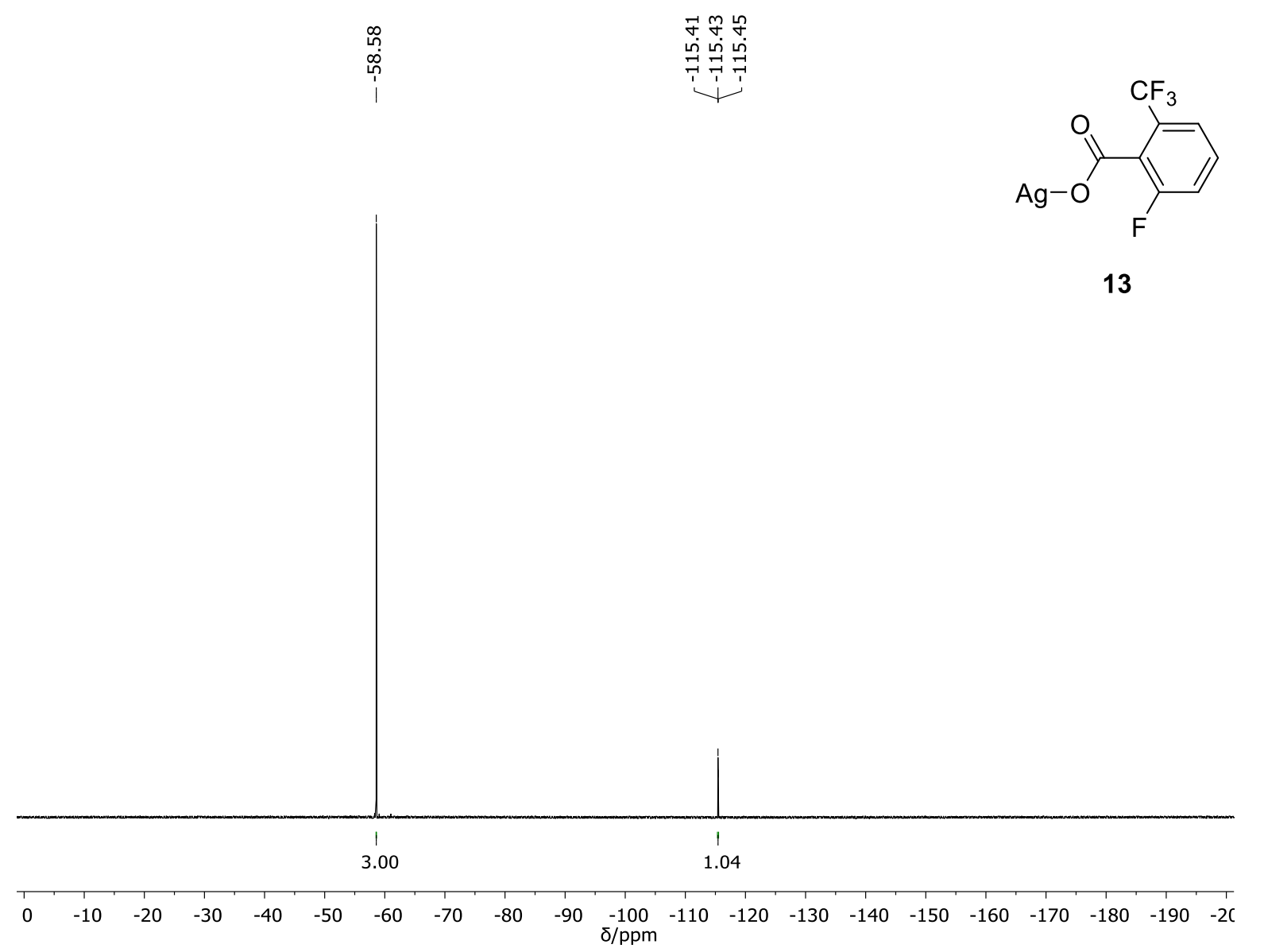

Figure A-89: ${ }^{19}$ F NMR spectrum of Ag(2-F-6-CF $3-$ benzoate) (13) in DMSO- $d_{6}$ at $375 \mathrm{MHz}$. 


\section{AI-2.3 ${ }^{1} \mathrm{H}$ and ${ }^{13} \mathrm{C}$ NMR Spectra of Silver(Heteroaromatic Carboxylate) Complexes}

\section{œ}

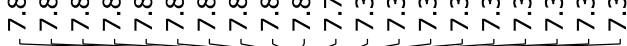<smiles>O=C(O[Ga])c1cc2ccccc2s1</smiles>

我

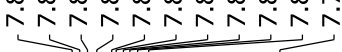
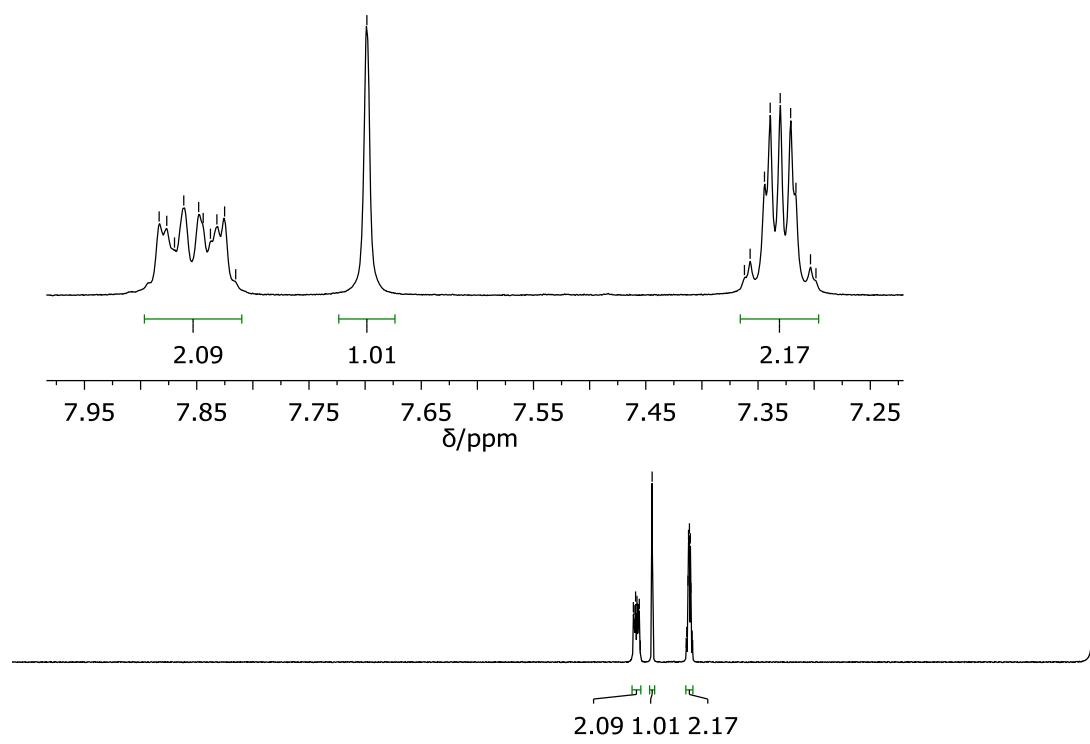

$4 \quad 13 \quad 12$

Figure A-90: ${ }^{1} \mathrm{H}$ NMR spectrum of Ag(1-benzothiophen-2-carboxylate) (14) in DMSO- $d_{6}$ at $400 \mathrm{MHz}$ 


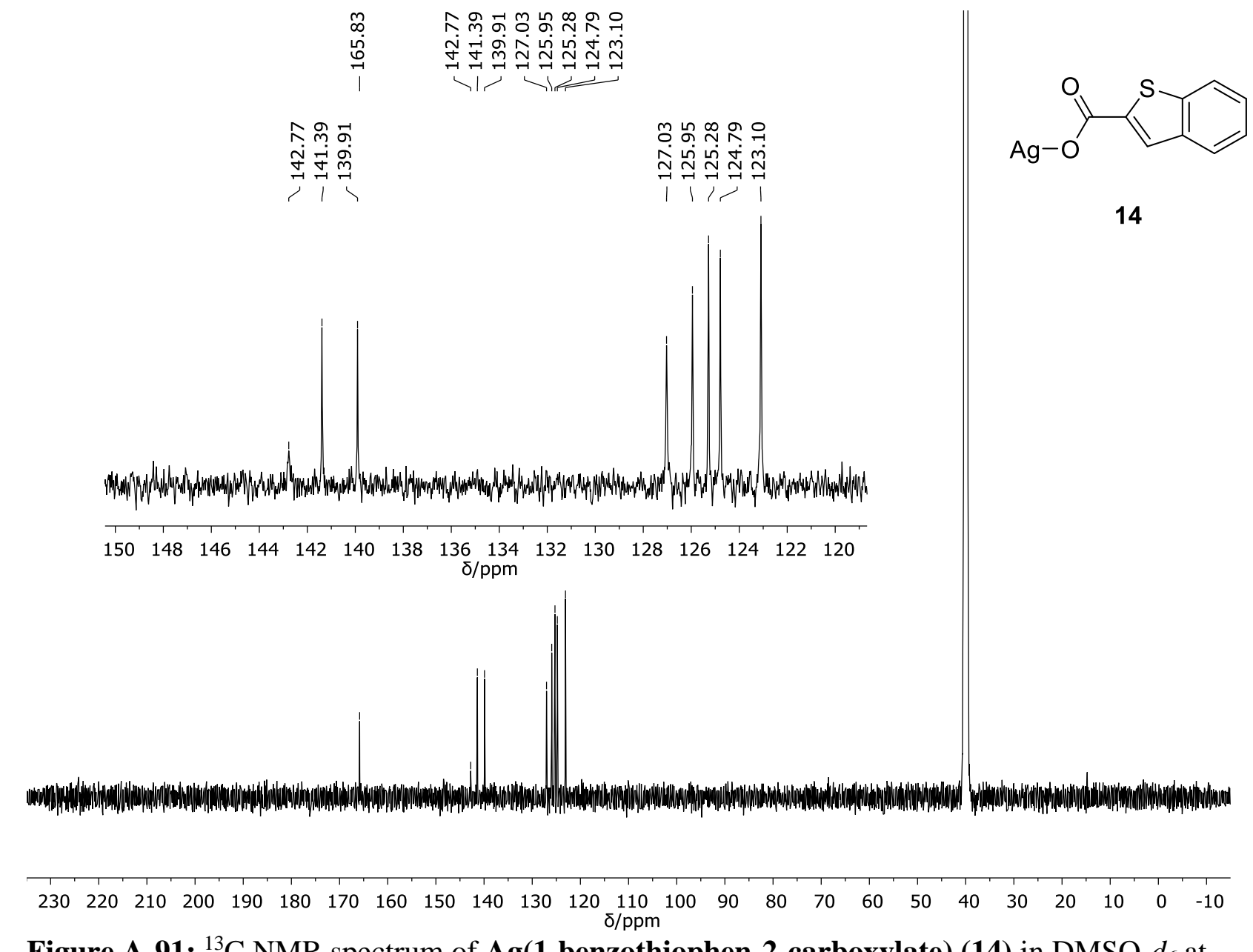

Figure A-91: ${ }^{13} \mathrm{C}$ NMR spectrum of Ag(1-benzothiophen-2-carboxylate) (14) in DMSO- $d_{6}$ at $150 \mathrm{MHz}$. 


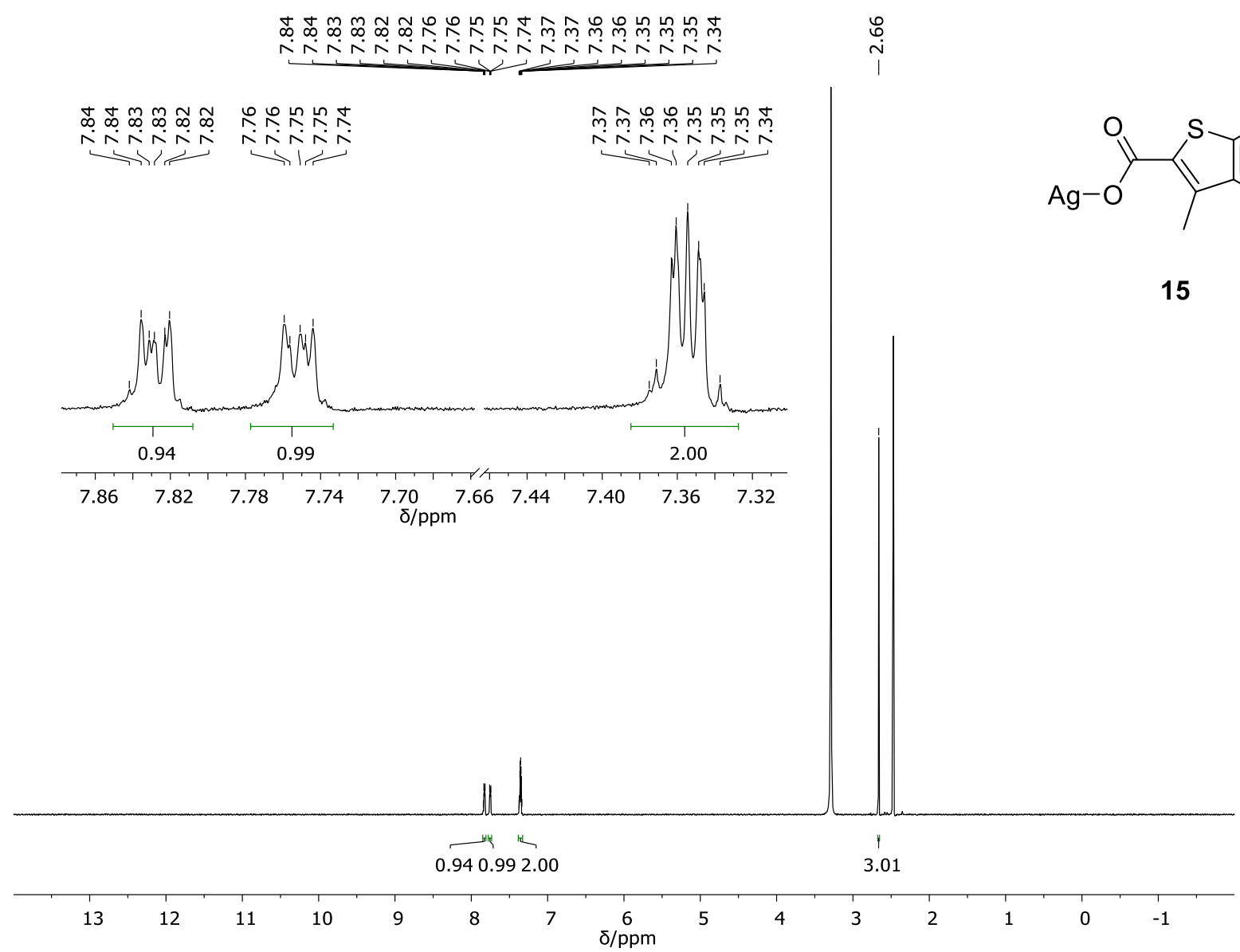

Figure A-92: ${ }^{1} \mathrm{H}$ NMR spectrum of Ag(3-methyl-1-benzothiophen-2-carboxylate) (15) in DMSO- $d_{6}$ at $600 \mathrm{MHz}$. 


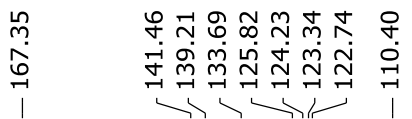

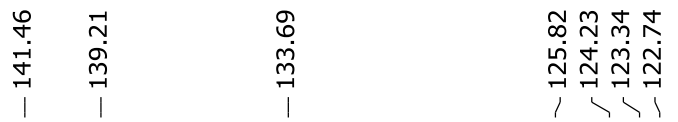
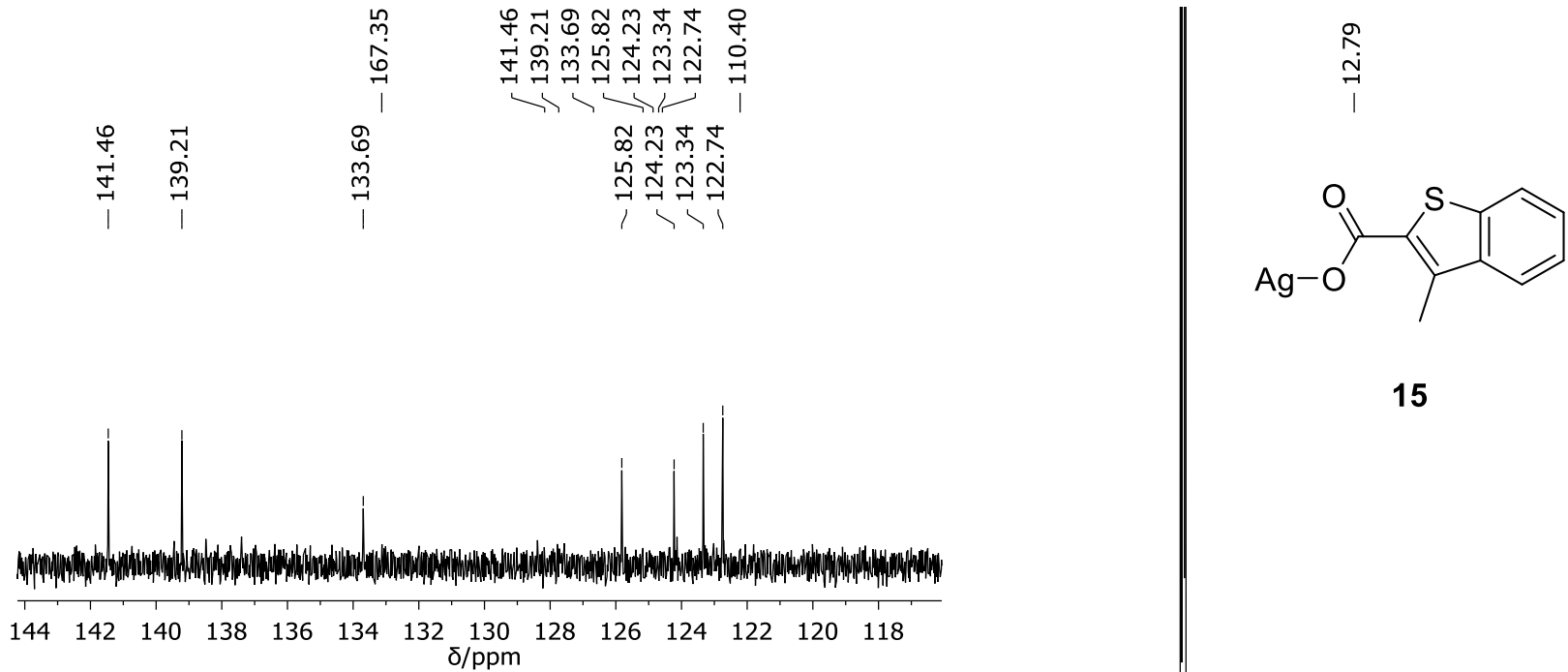

15

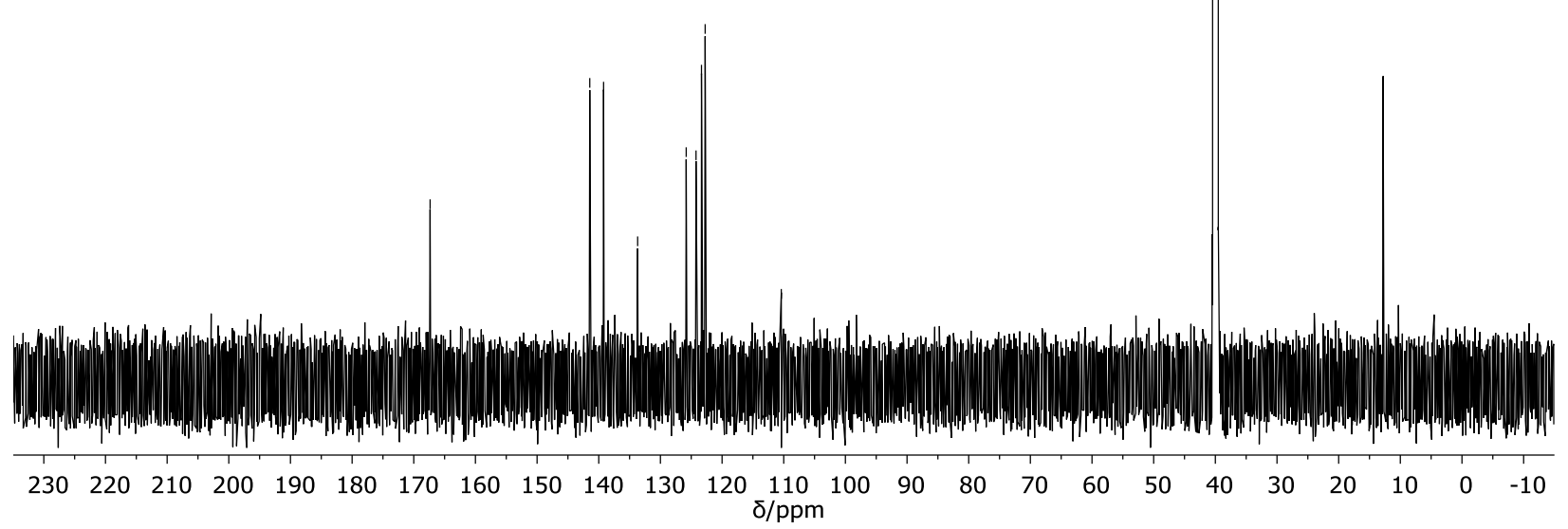

Figure A-93: ${ }^{13} \mathrm{C}$ NMR spectrum of Ag(3-methyl-1-benzothiophen-2-carboxylate) (15) in DMSO- $d_{6}$ at $150 \mathrm{MHz}$. 


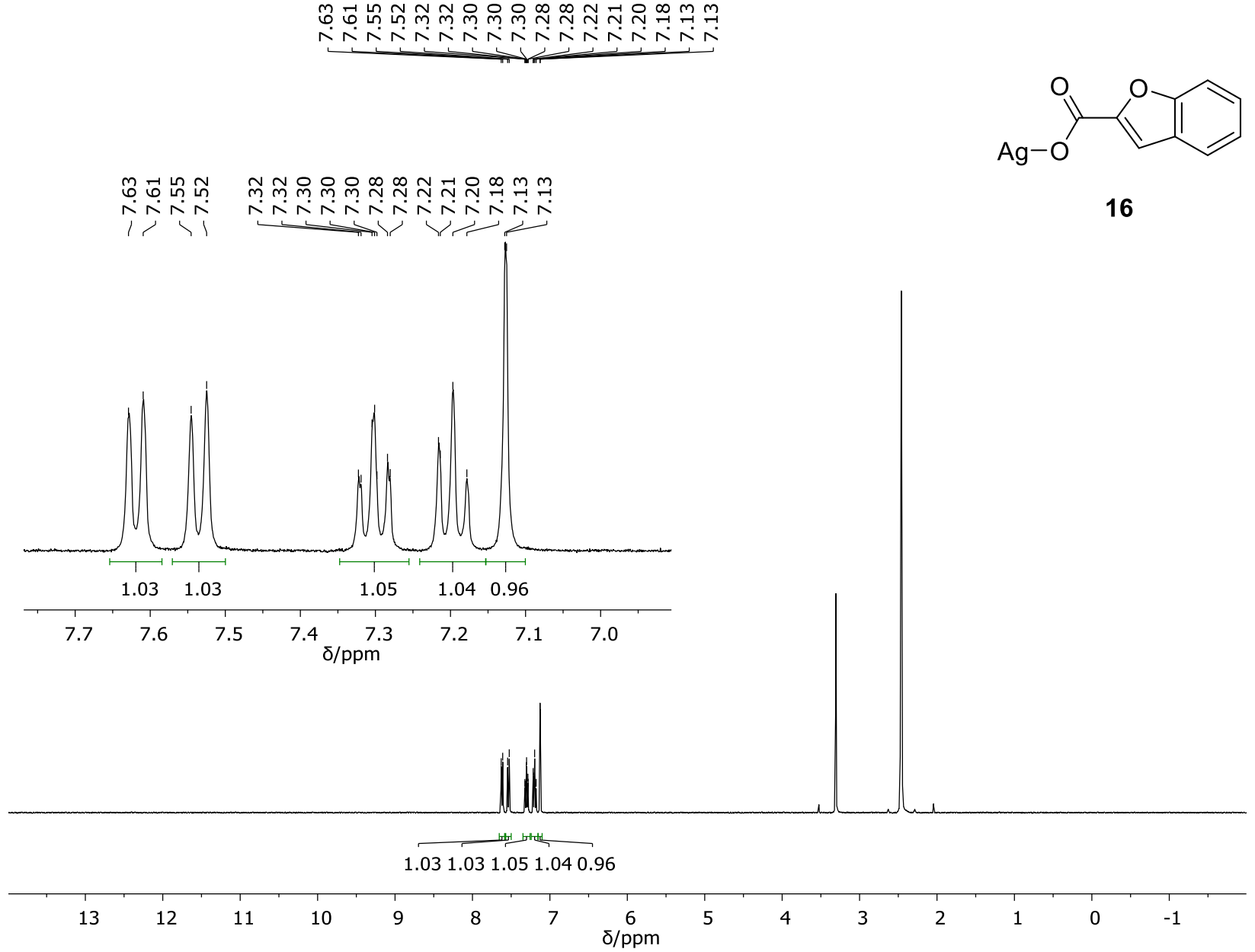

Figure A-94: ${ }^{1} \mathrm{H}$ NMR spectrum of Ag(1-benzofuran-2-carboxylate) (16) in DMSO- $d_{6}$ at 400 $\mathrm{MHz}$. 


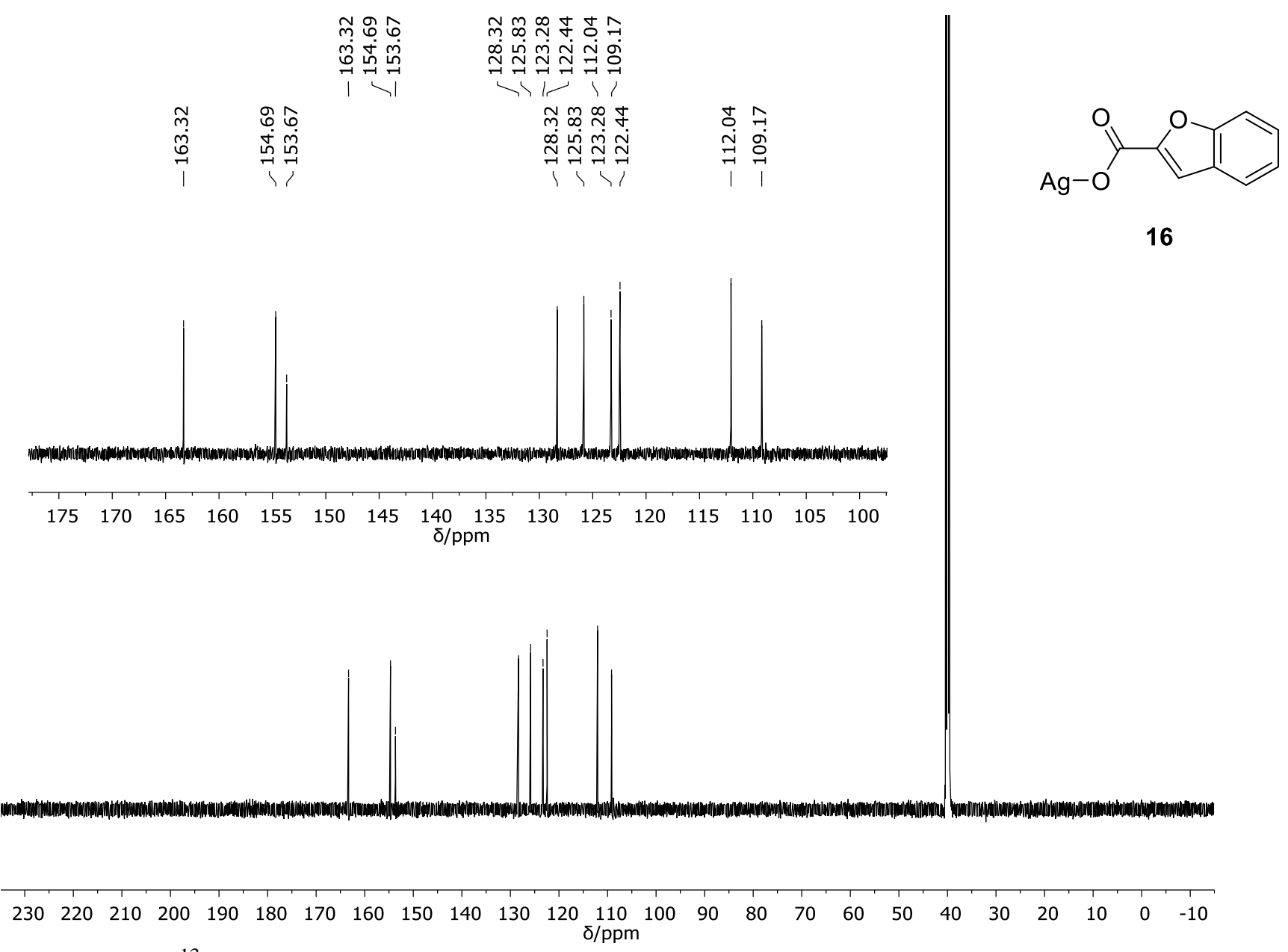

Figure A-95: ${ }^{13} \mathrm{C}$ NMR spectrum of Ag(1-benzofuran-2-carboxylate) (16) in DMSO- $d_{6}$ at 150 $\mathrm{MHz}$. 


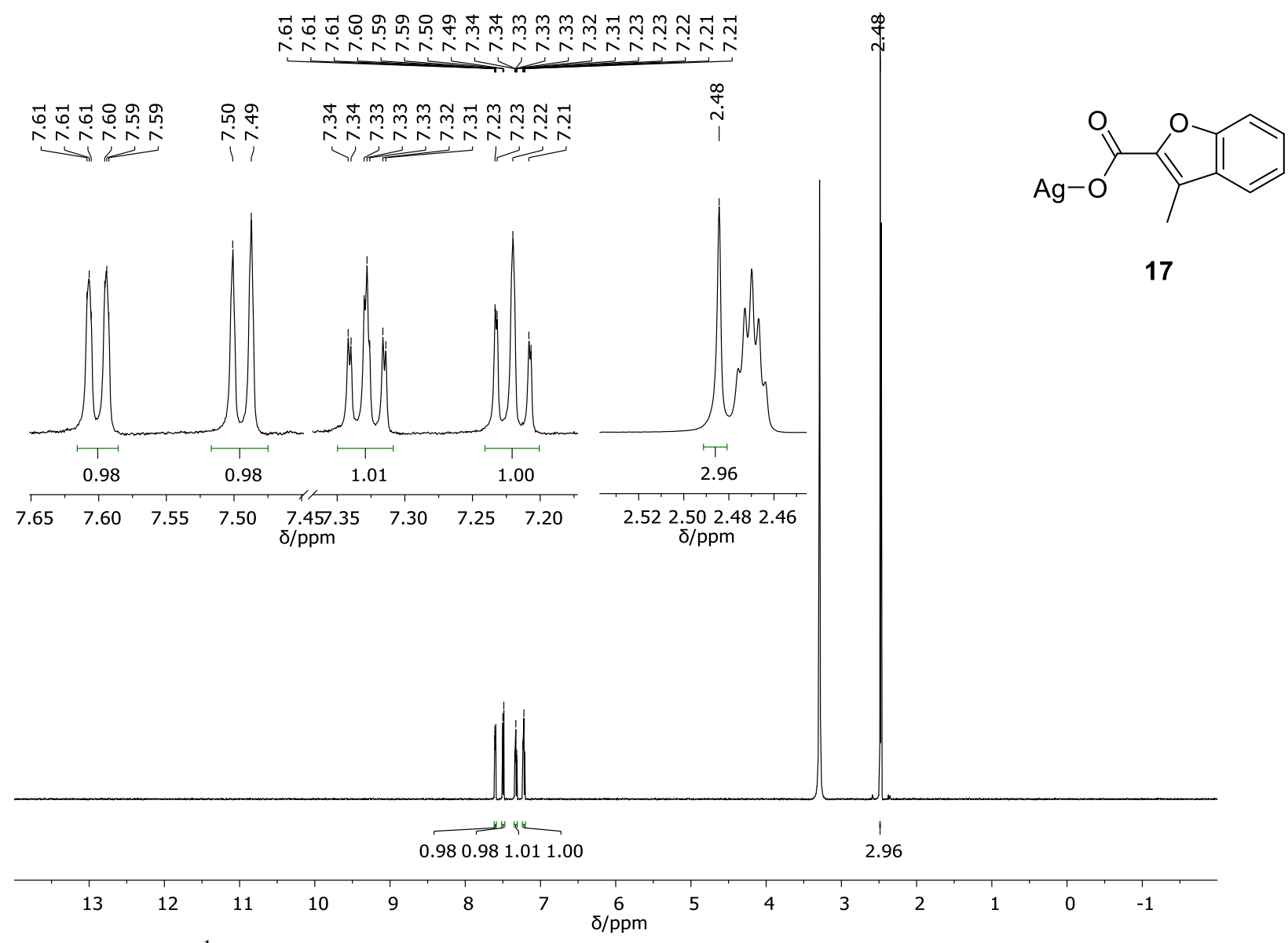

Figure A-96: ${ }^{1} \mathrm{H}$ NMR spectrum of Ag(3-methyl-1-benzofuran-2-carboxylate) (17) in DMSO$d_{6}$ at $600 \mathrm{MHz}$. 


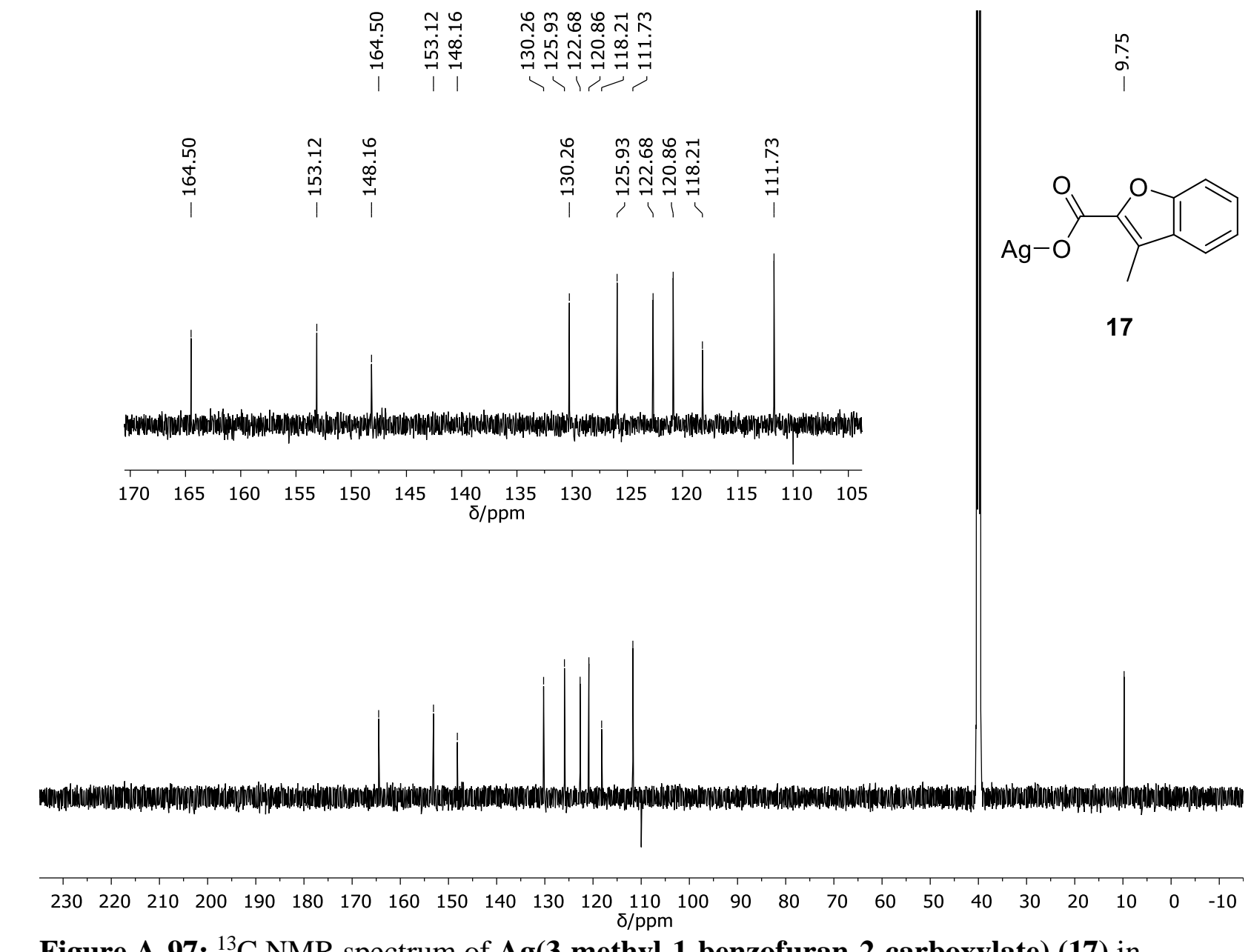

Figure A-97: ${ }^{13} \mathrm{C}$ NMR spectrum of $\mathbf{A g}$ (3-methyl-1-benzofuran-2-carboxylate) (17) in DMSO- $d_{6}$ at $150 \mathrm{MHz}$. 


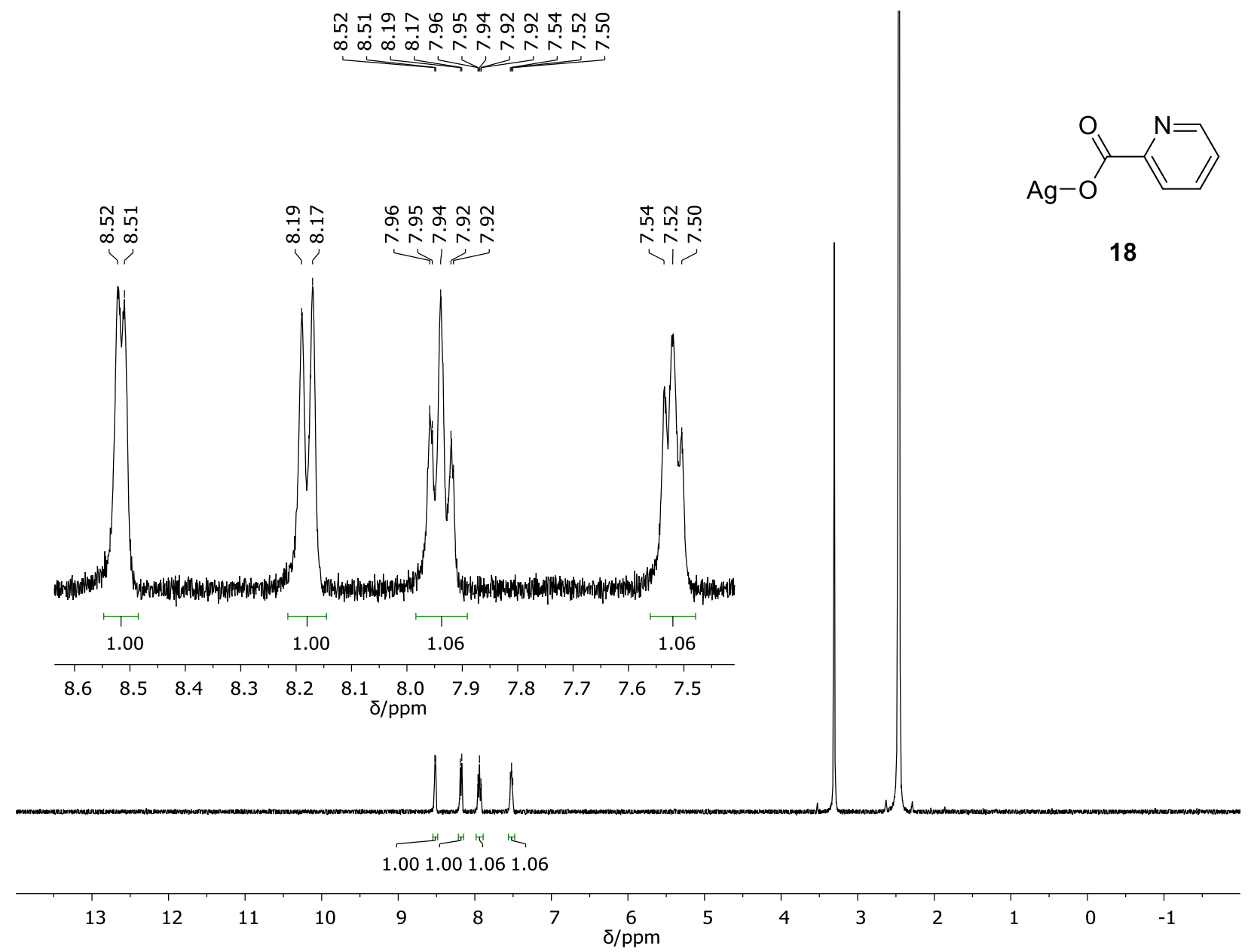

Figure A-98: ${ }^{1} \mathrm{H}$ NMR spectrum of Ag(pyridine-2-carboxylate) (18) in DMSO- $d_{6}$ at $400 \mathrm{MHz}$. 


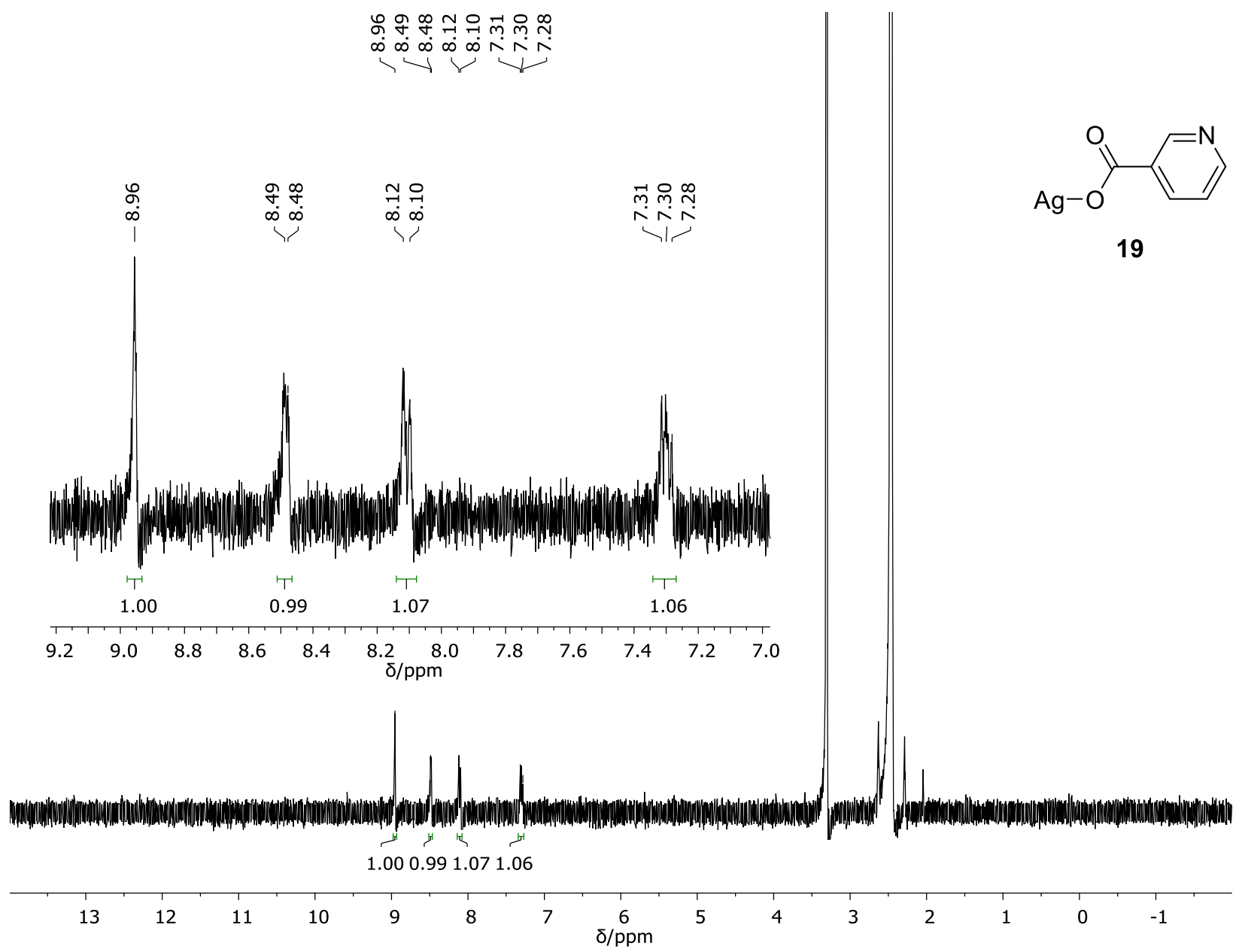

Figure A-99: ${ }^{1} \mathrm{H}$ NMR spectrum of Ag(pyridine-3-carboxylate) (19) in DMSO- $d_{6}$ at $400 \mathrm{MHz}$. 


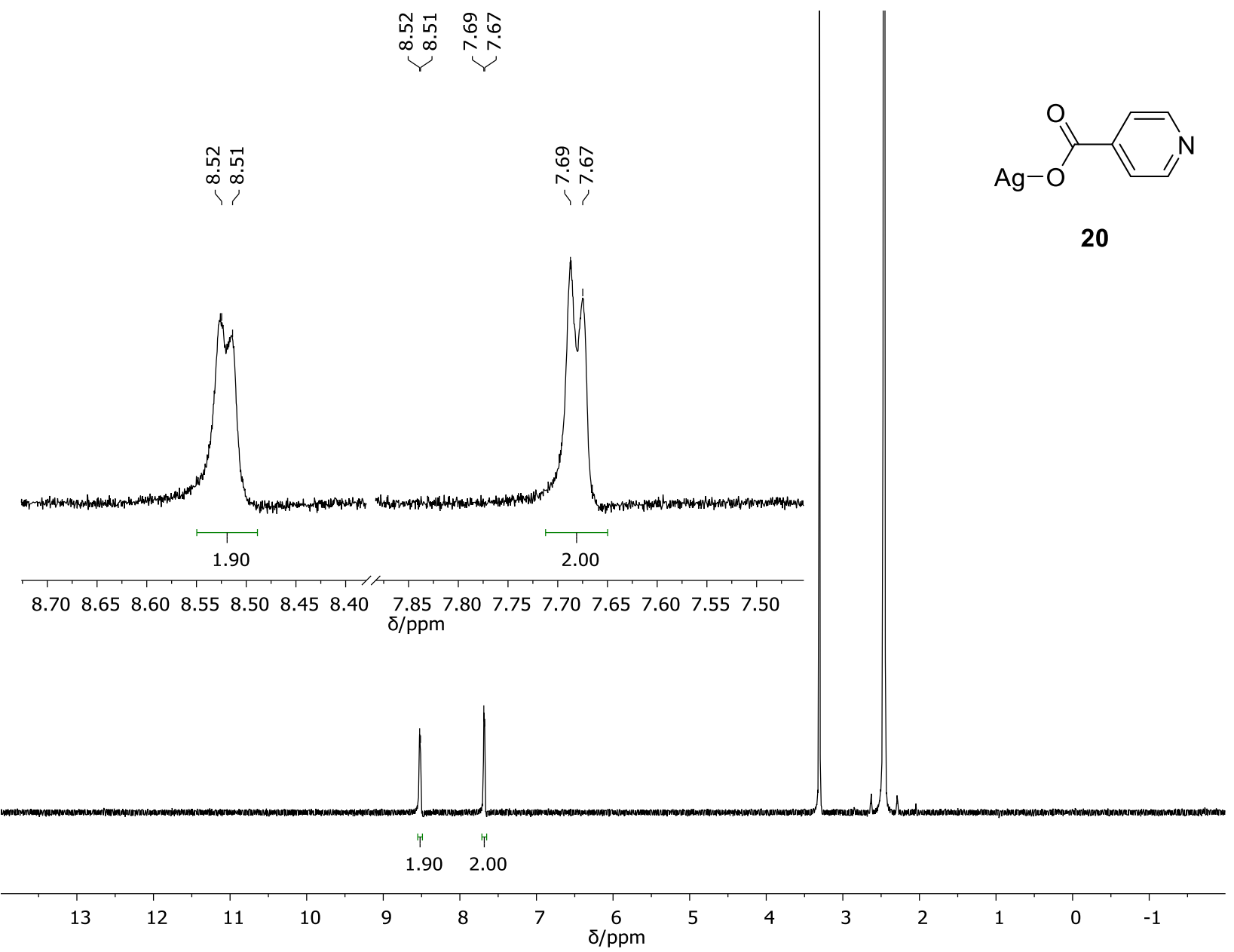

Figure A-100: ${ }^{1} \mathrm{H}$ NMR spectrum of Ag(pyridine-4-carboxylate) (20) in DMSO- $d_{6}$ at 400 $\mathrm{MHz}$. 


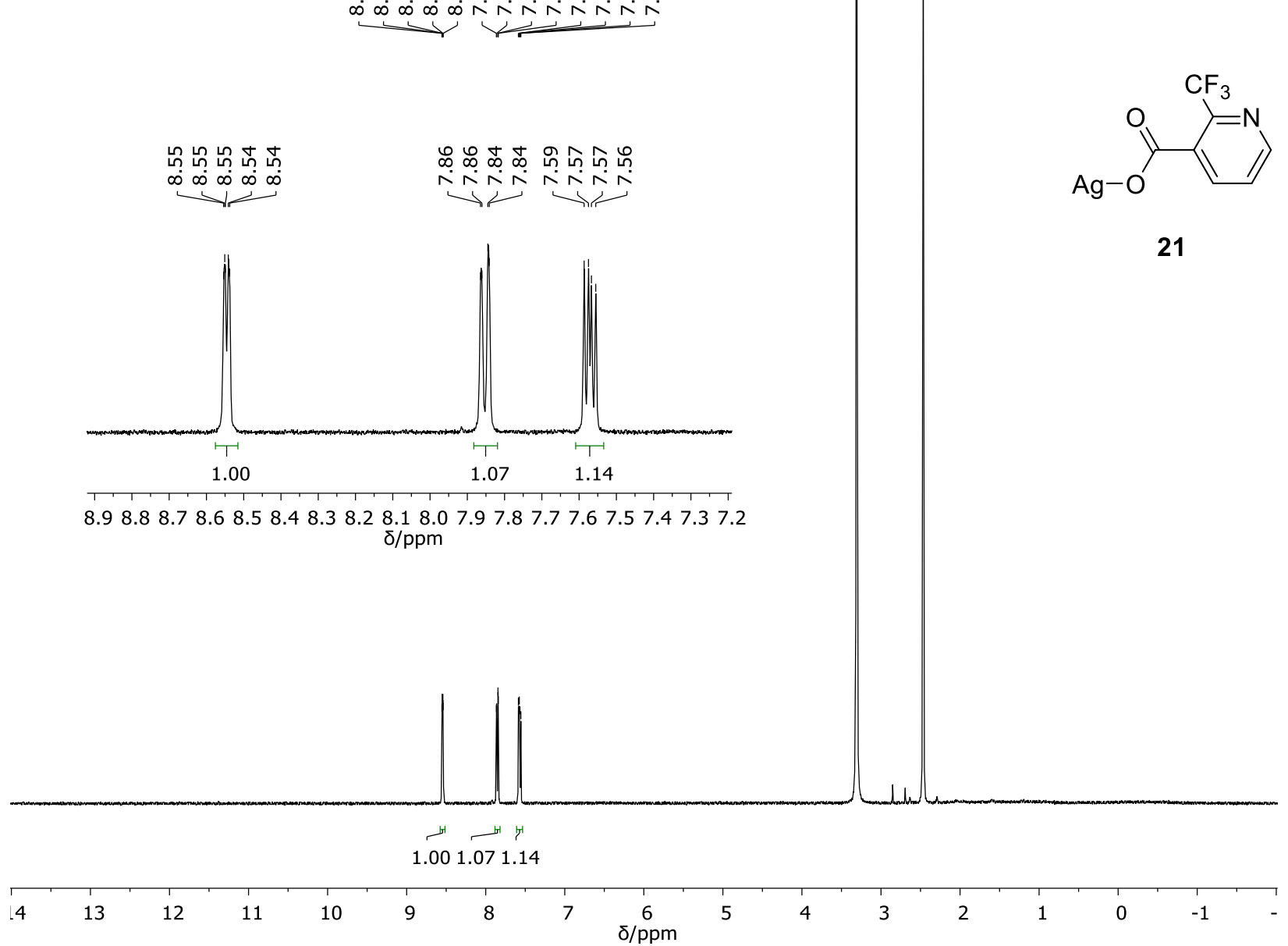

Figure A-101: ${ }^{1} \mathrm{H}$ NMR spectrum of Ag(2-trifluoromethylpyridine-3-carboxylate) (21) in DMSO- $d_{6}$ at $400 \mathrm{MHz}$. 


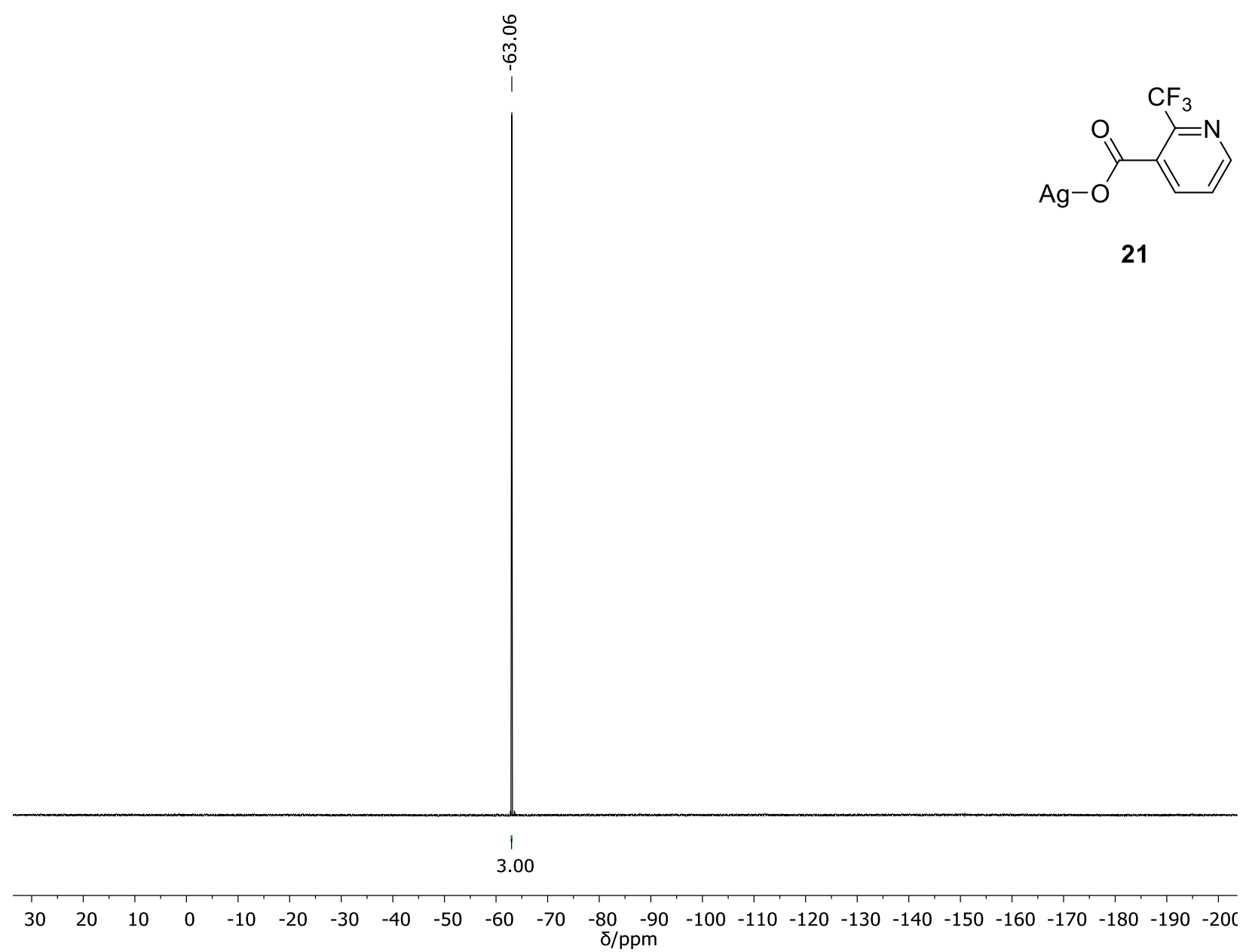

Figure A-102: ${ }^{19} \mathrm{~F}$ NMR spectrum of $\mathbf{A g}$ (2-trifluoromethylpyridine-3-carboxylate) (21) in DMSO- $d_{6}$ at $375 \mathrm{MHz}$. 


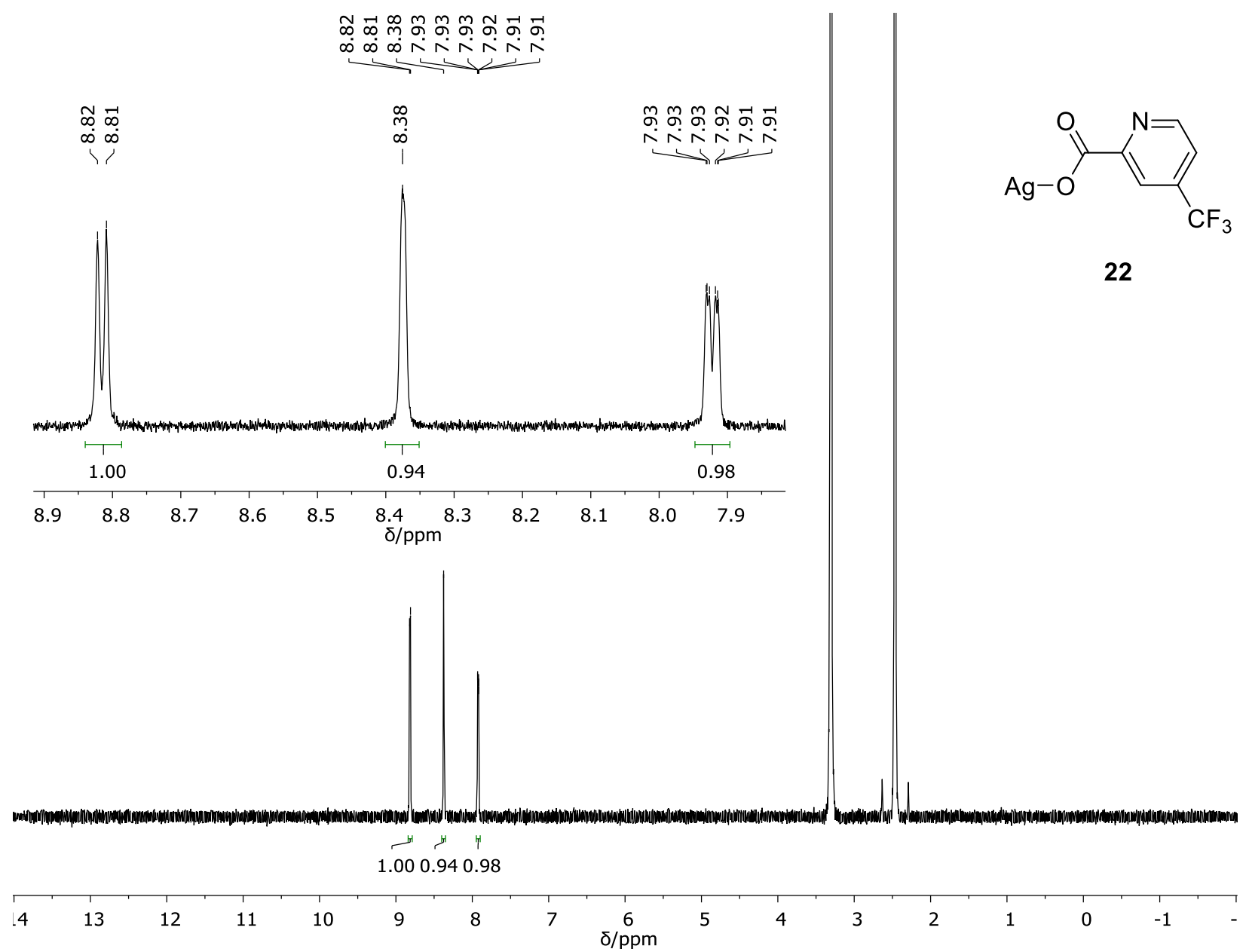

Figure A-103: ${ }^{1} \mathrm{H}$ NMR spectrum of Ag(4-trifluoromethylpyridine-2-carboxylate) (22) in DMSO- $d_{6}$ at $400 \mathrm{MHz}$. 


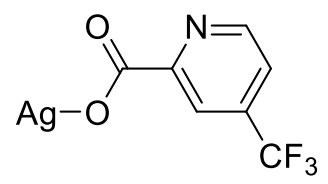

22

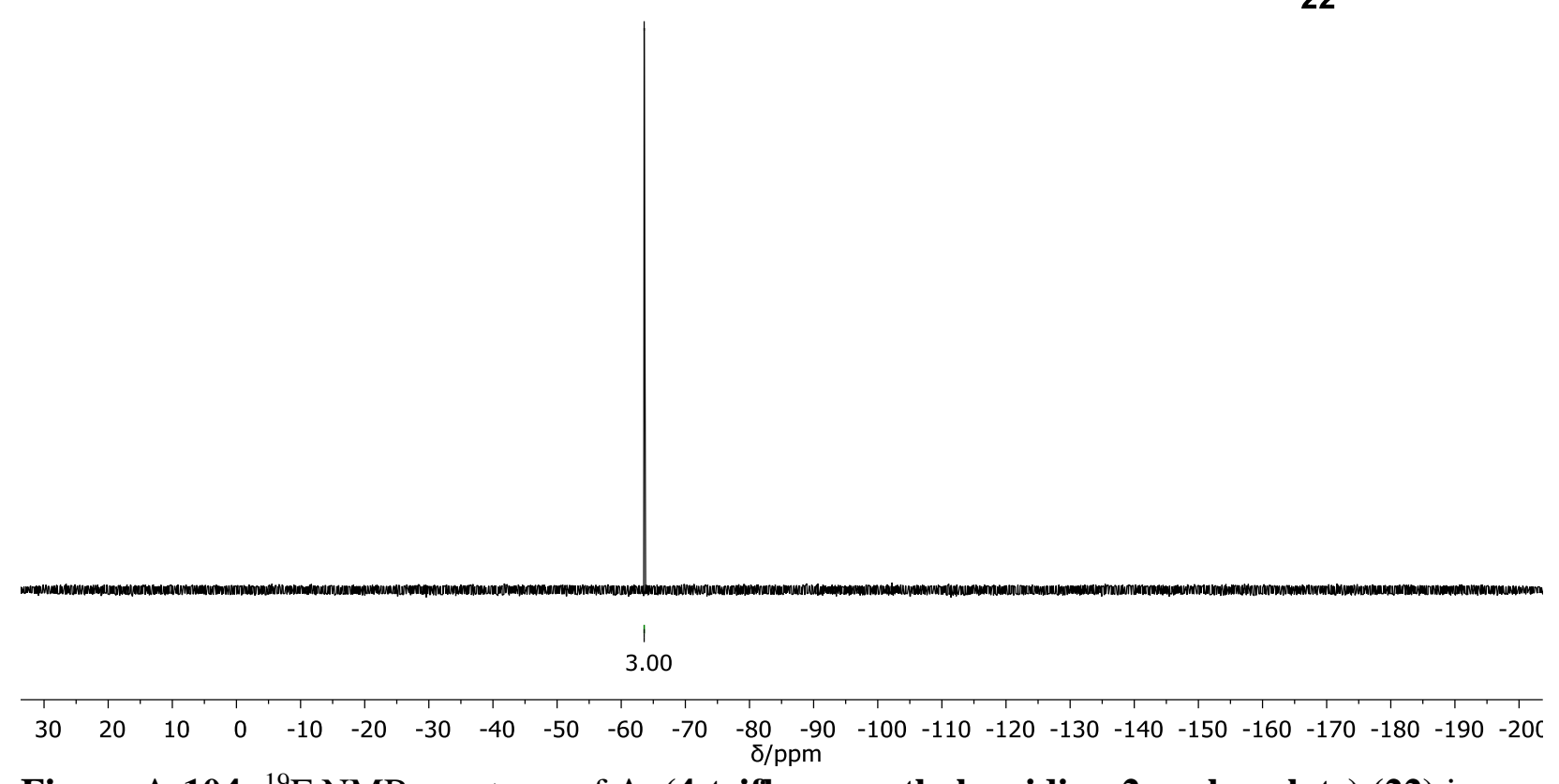

Figure A-104: ${ }^{19} \mathrm{~F}$ NMR spectrum of Ag(4-trifluoromethylpyridine-2-carboxylate) (22) in DMSO- $d_{6}$ at $375 \mathrm{MHz}$. 


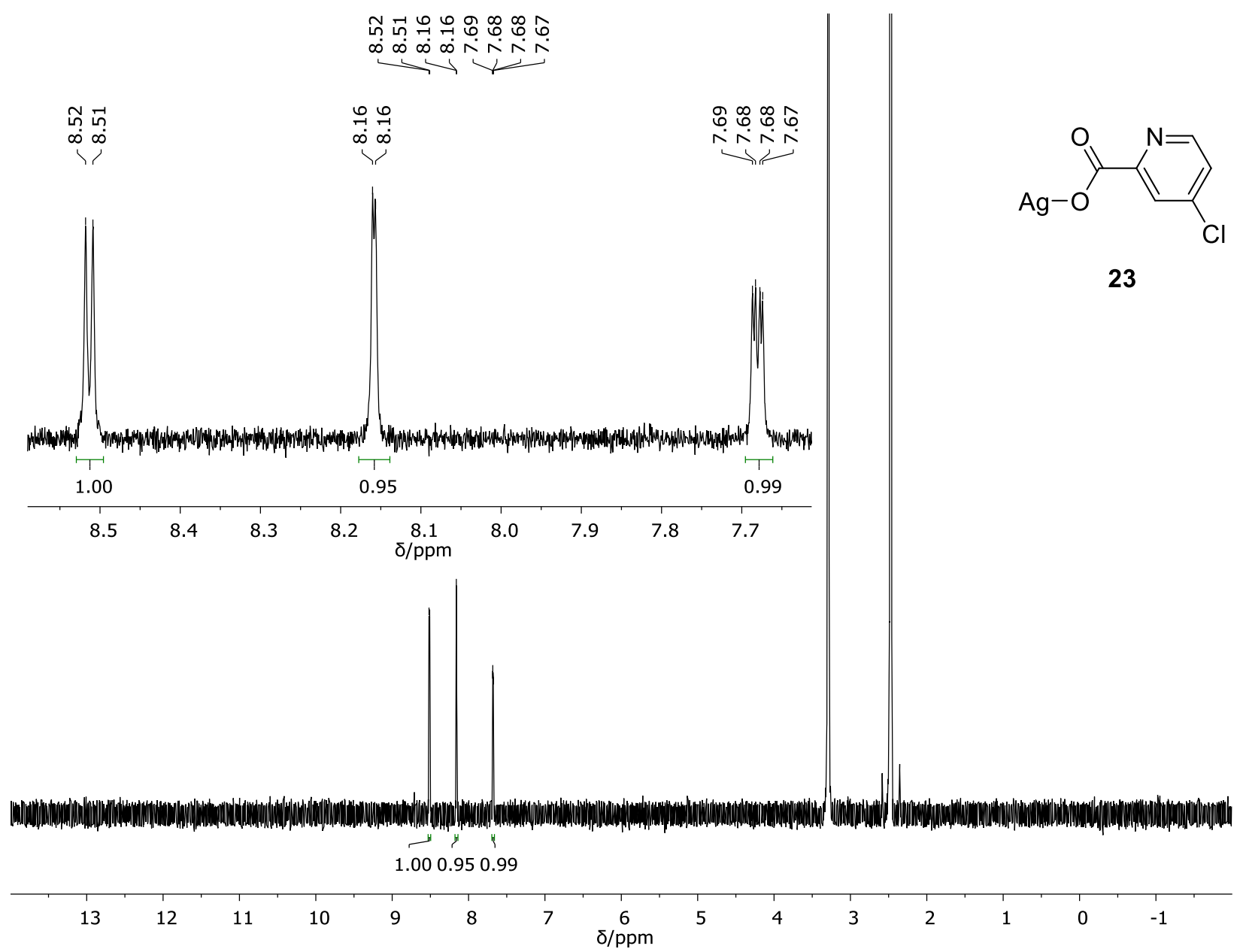

Figure A-105: ${ }^{1} \mathrm{H}$ NMR spectrum of Ag(4-chloropyridine-2-carboxylate) (23) in DMSO- $d_{6}$ at $600 \mathrm{MHz}$. 


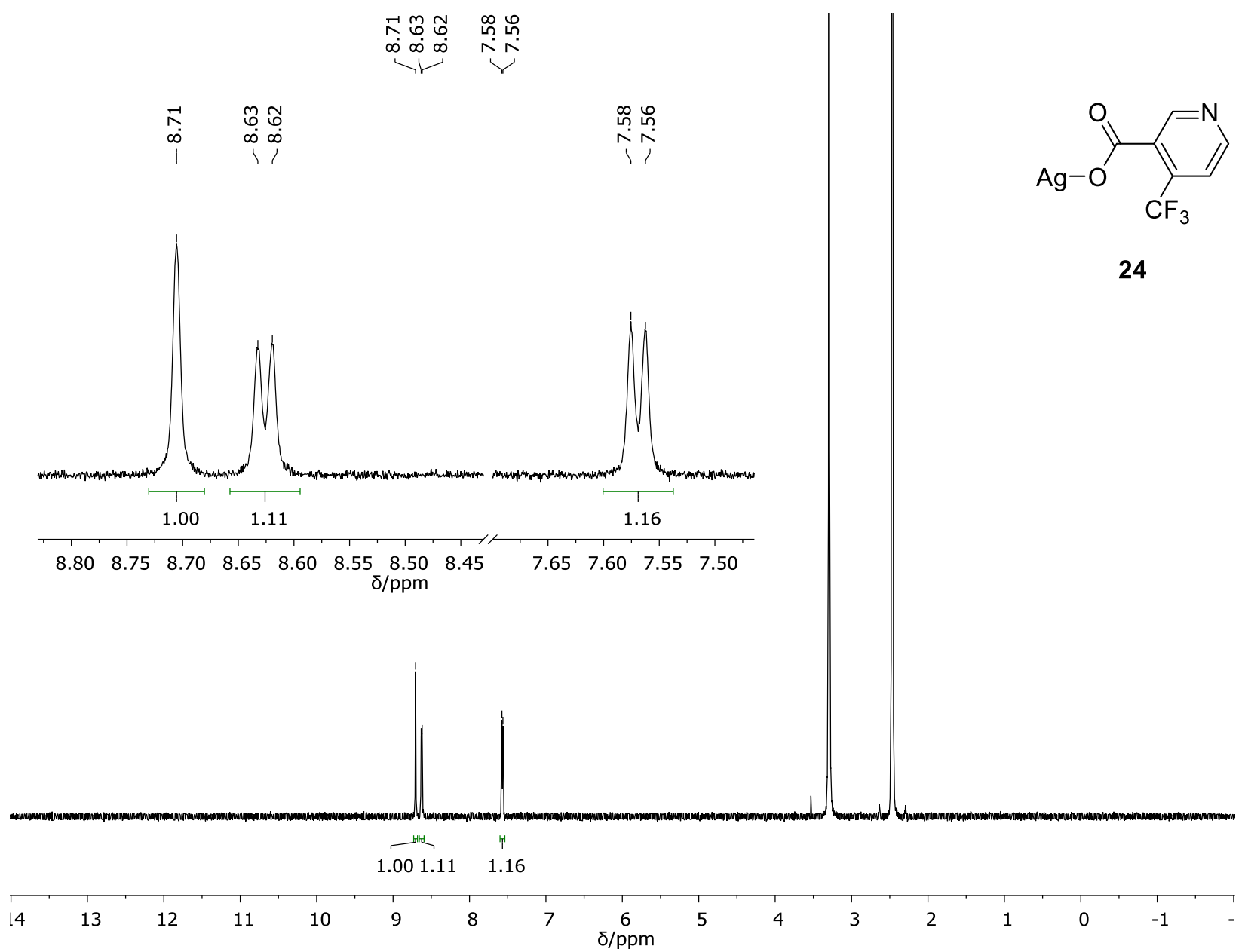

Figure A-106: ${ }^{1} \mathrm{H}$ NMR spectrum of Ag(4-trifluoromethylpyridine-3-carboxylate) (24) in DMSO- $d_{6}$ at $400 \mathrm{MHz}$. 


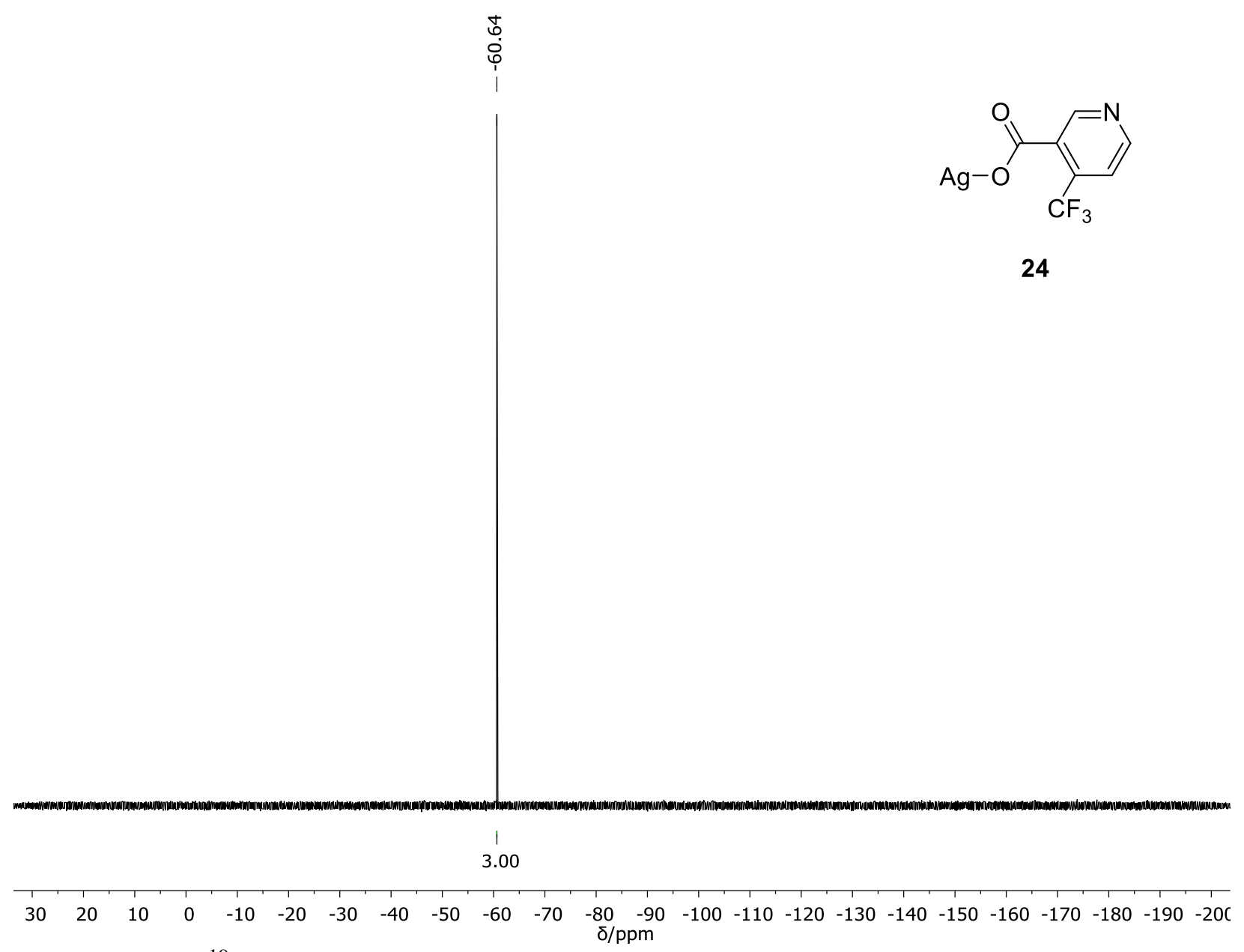

Figure A-107: ${ }^{19} \mathrm{~F}$ NMR spectrum of Ag(4-trifluoromethylpyridine-3-carboxylate) (24) in DMSO- $d_{6}$ at $375 \mathrm{MHz}$. 


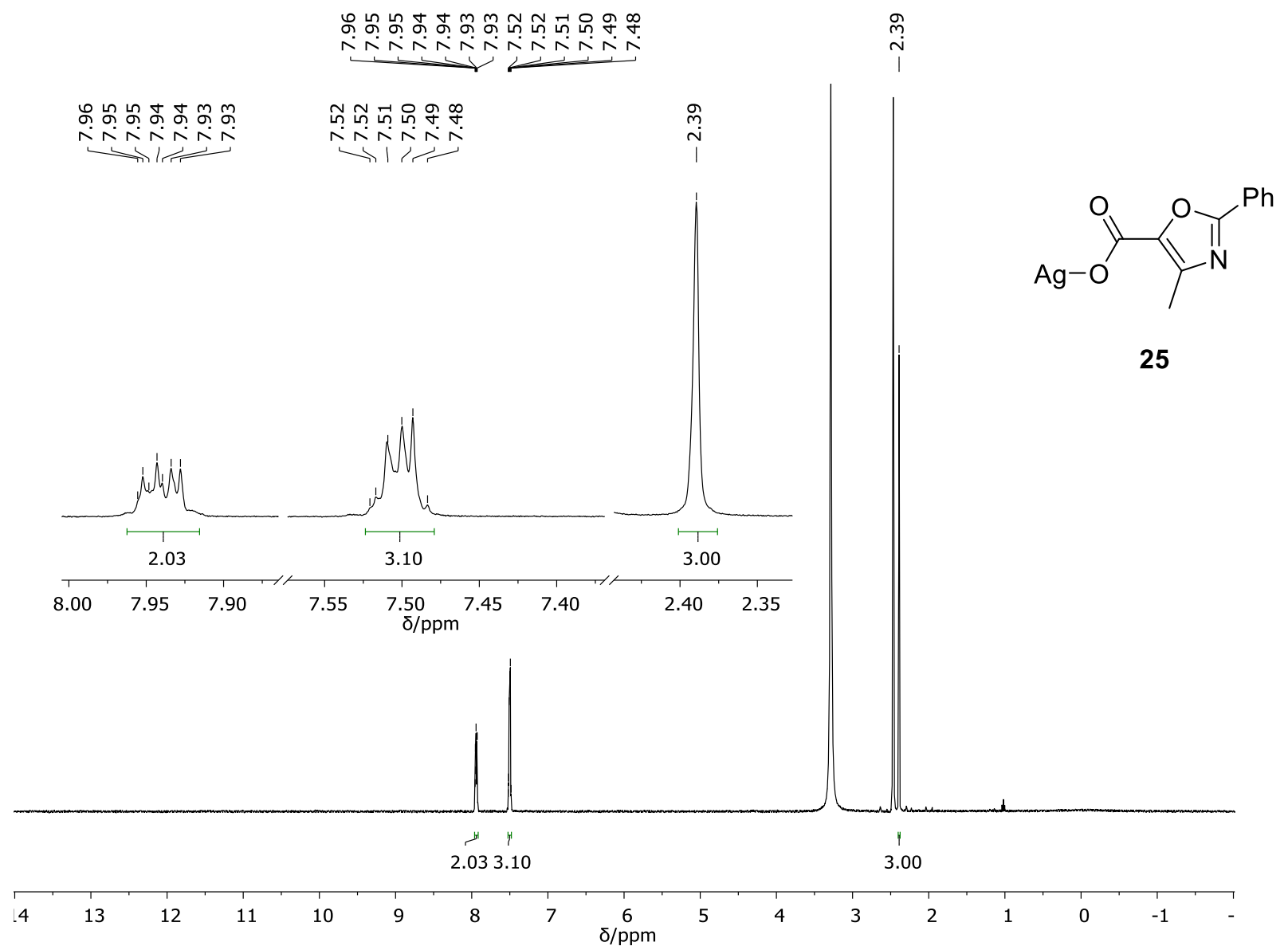

Figure A-108: ${ }^{1} \mathrm{H}$ NMR spectrum of Ag(4-methyl-2-phenyl-1,3-oxazole-5-carboxylate) (25) in DMSO- $d_{6}$ at $400 \mathrm{MHz}$. 


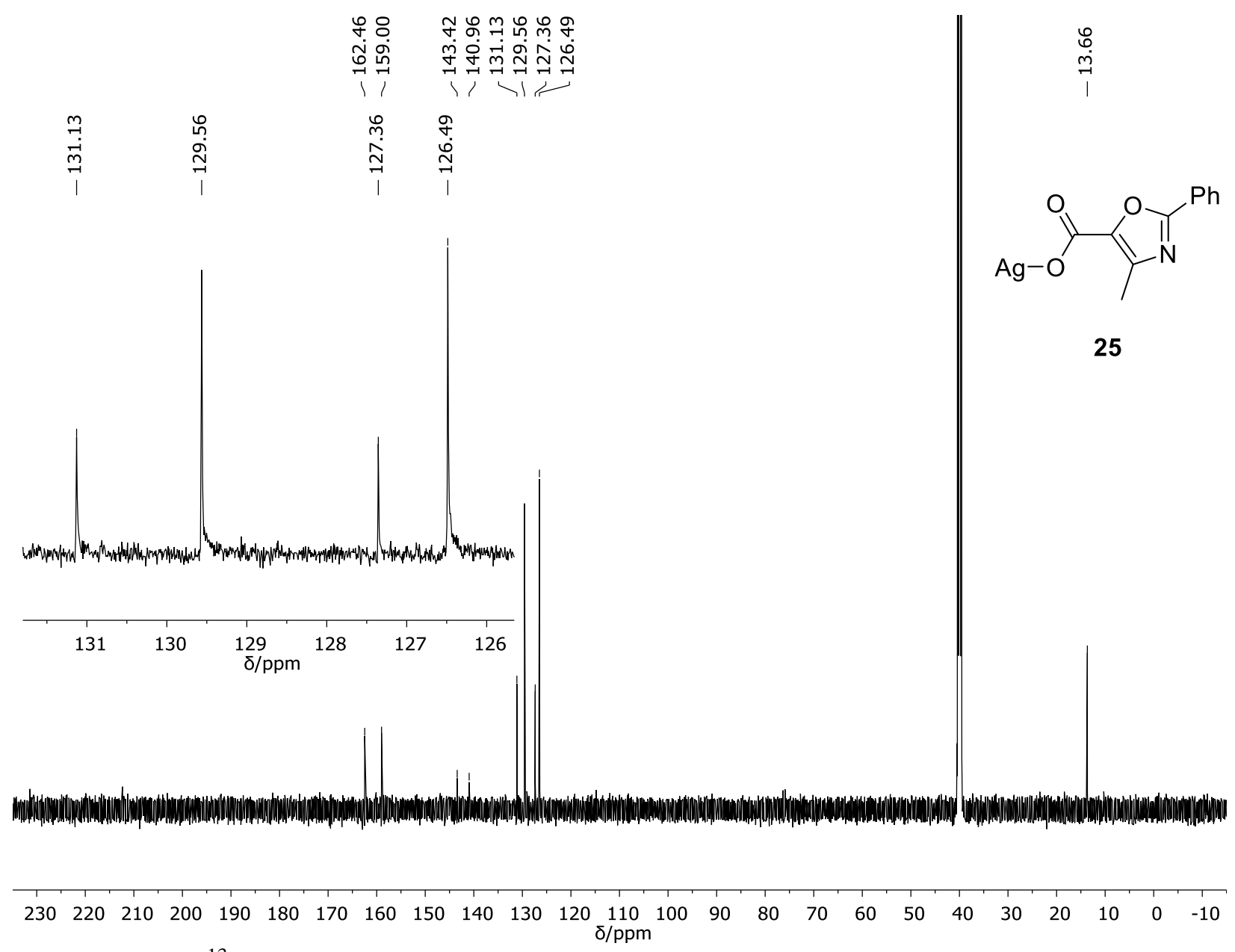

Figure A-109: ${ }^{13} \mathrm{C}$ NMR spectrum of Ag(4-methyl-2-phenyl-1,3-oxazole-5-carboxylate) (25) in DMSO- $d_{6}$ at $150 \mathrm{MHz}$. 


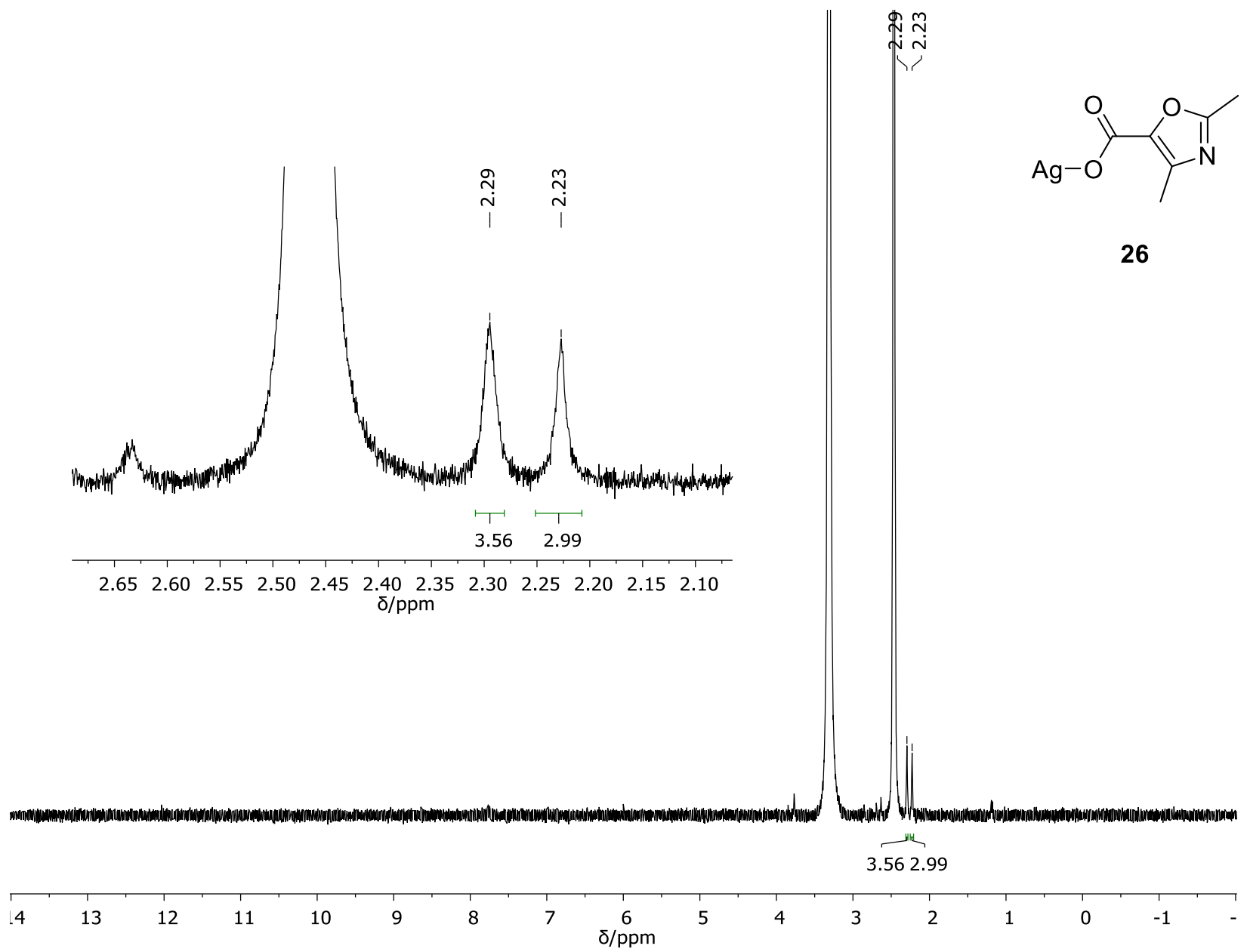

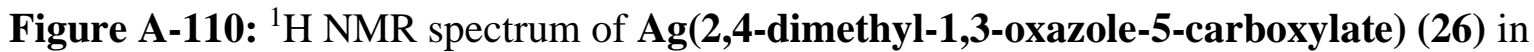
DMSO- $d_{6}$ at $400 \mathrm{MHz}$. 


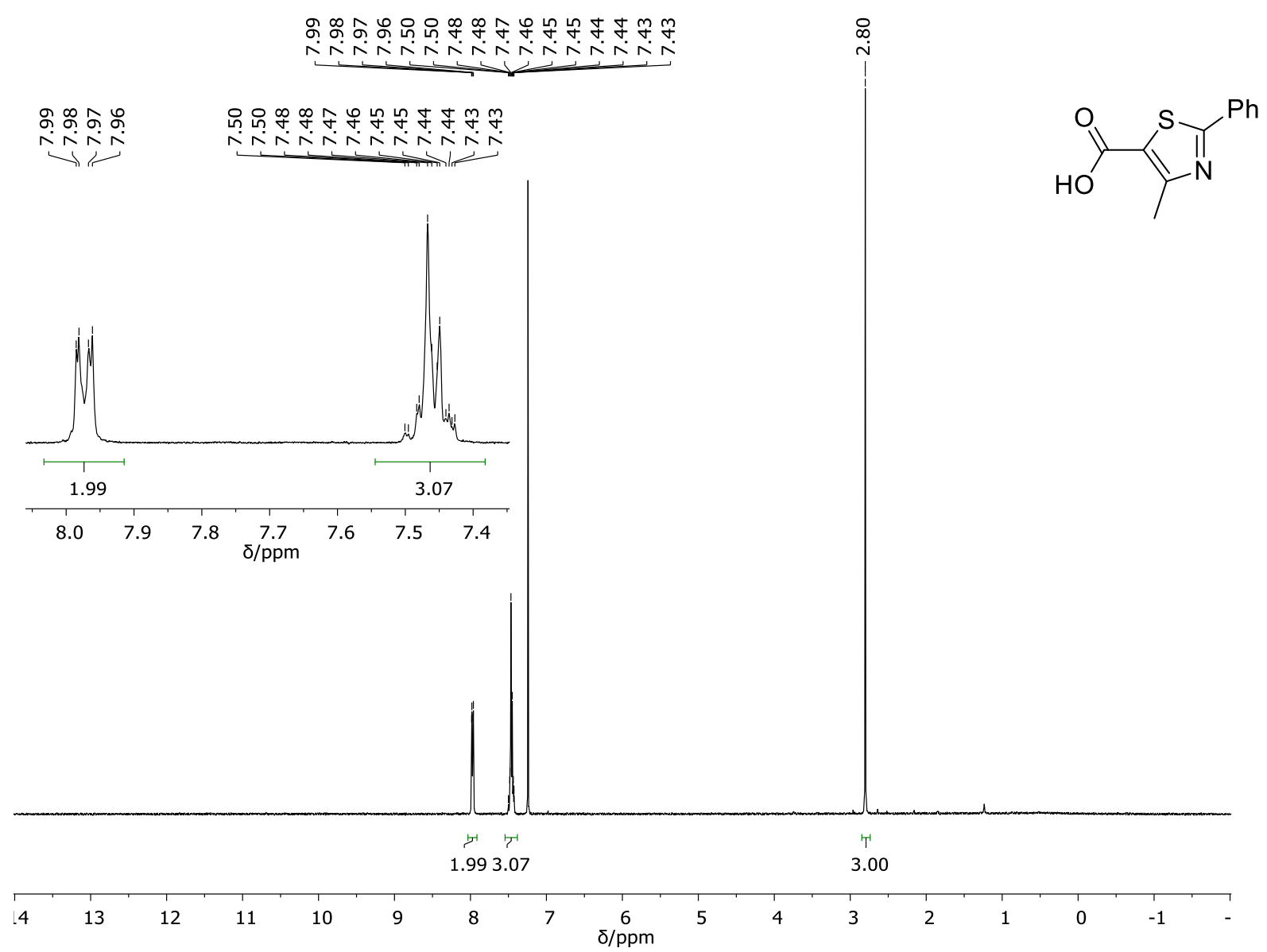

Figure A-111: ${ }^{1} \mathrm{H}$ NMR spectrum of 4-methyl-2-phenyl-1,3-thiazole-5-carboxylic acid in $\mathrm{CDCl}_{3}$ at $400 \mathrm{MHz}$. 


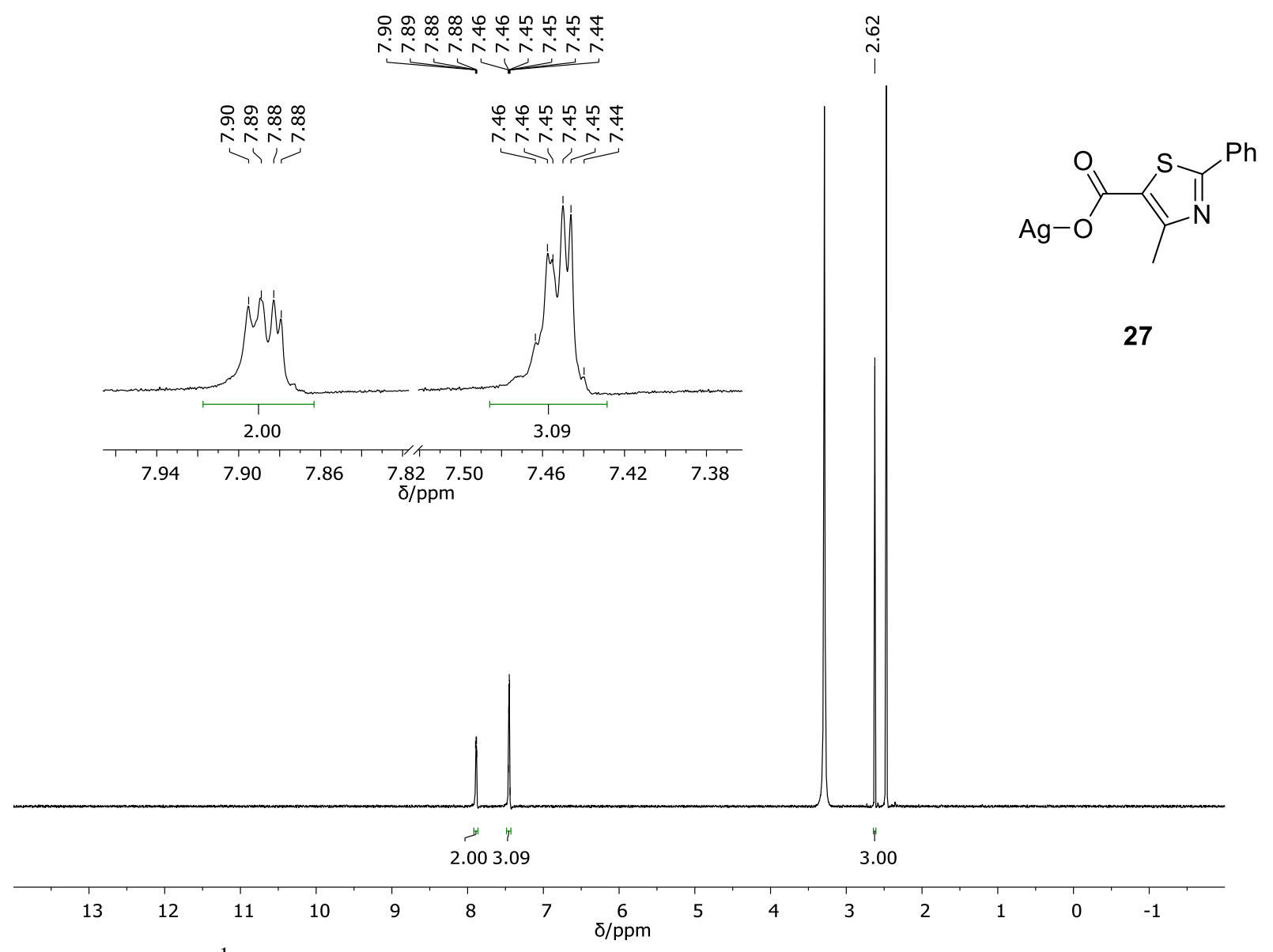

Figure A-112: ${ }^{1} \mathrm{H}$ NMR spectrum of Ag(4-methyl-2-phenyl-1,3-thiazole-5-carboxylate) (27) in DMSO- $d_{6}$ at $600 \mathrm{MHz}$. 


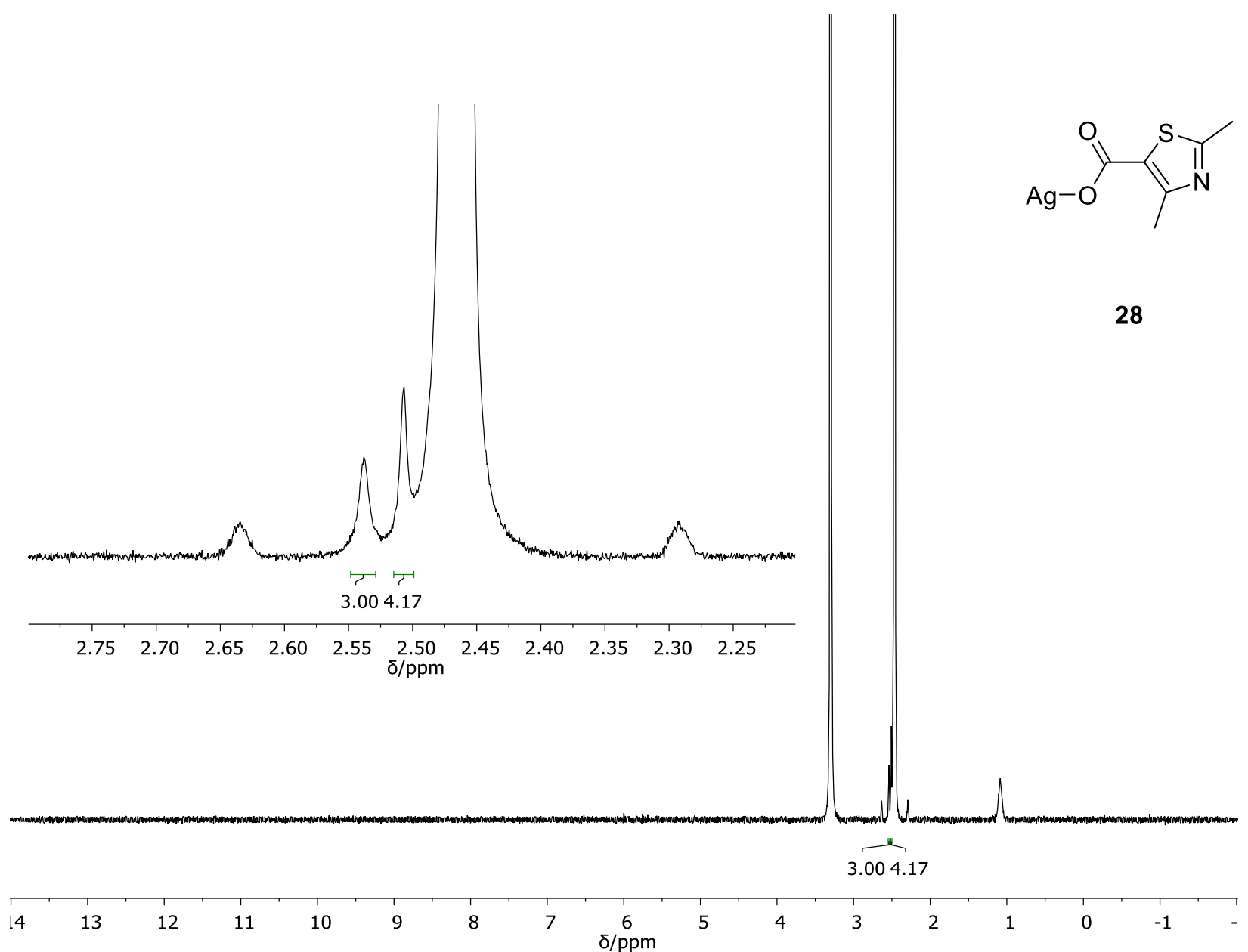

Figure A-113: ${ }^{1} \mathrm{H}$ NMR spectrum of $\mathbf{A g ( 2 , 4 - d i m e t h y l - 1 , 3 - t h i a z o l e - 5 - c a r b o x y l a t e ) ~ ( 2 8 ) ~ i n ~}$ DMSO- $d_{6}$ at $400 \mathrm{MHz}$. 


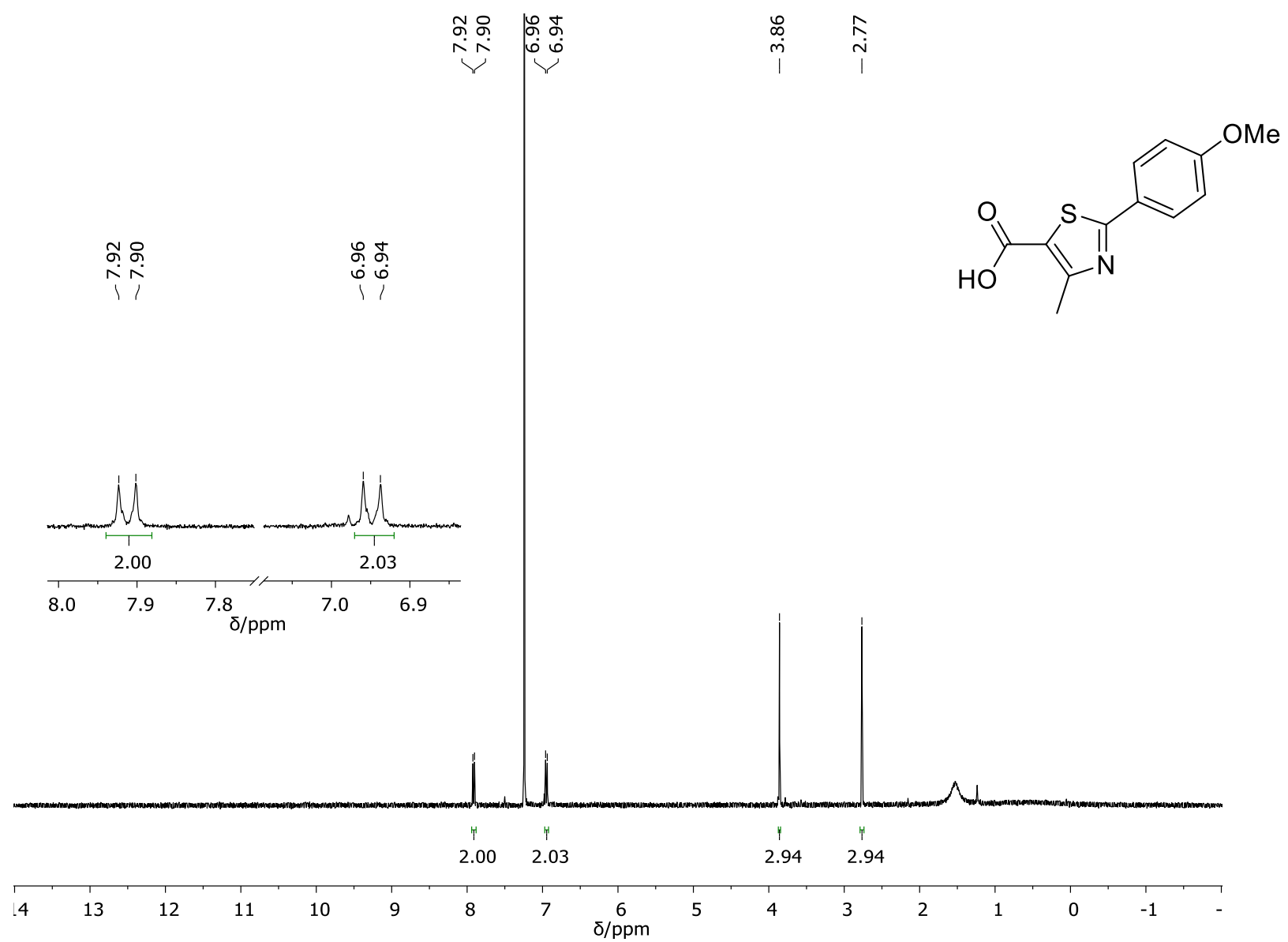

Figure A-114: ${ }^{1} \mathrm{H}$ NMR spectrum of 4-methyl-2-(4-methoxyphenyl)-1,3-thiazole-5-carboxylic acid in $\mathrm{CDCl}_{3}$ at $400 \mathrm{MHz}$. 


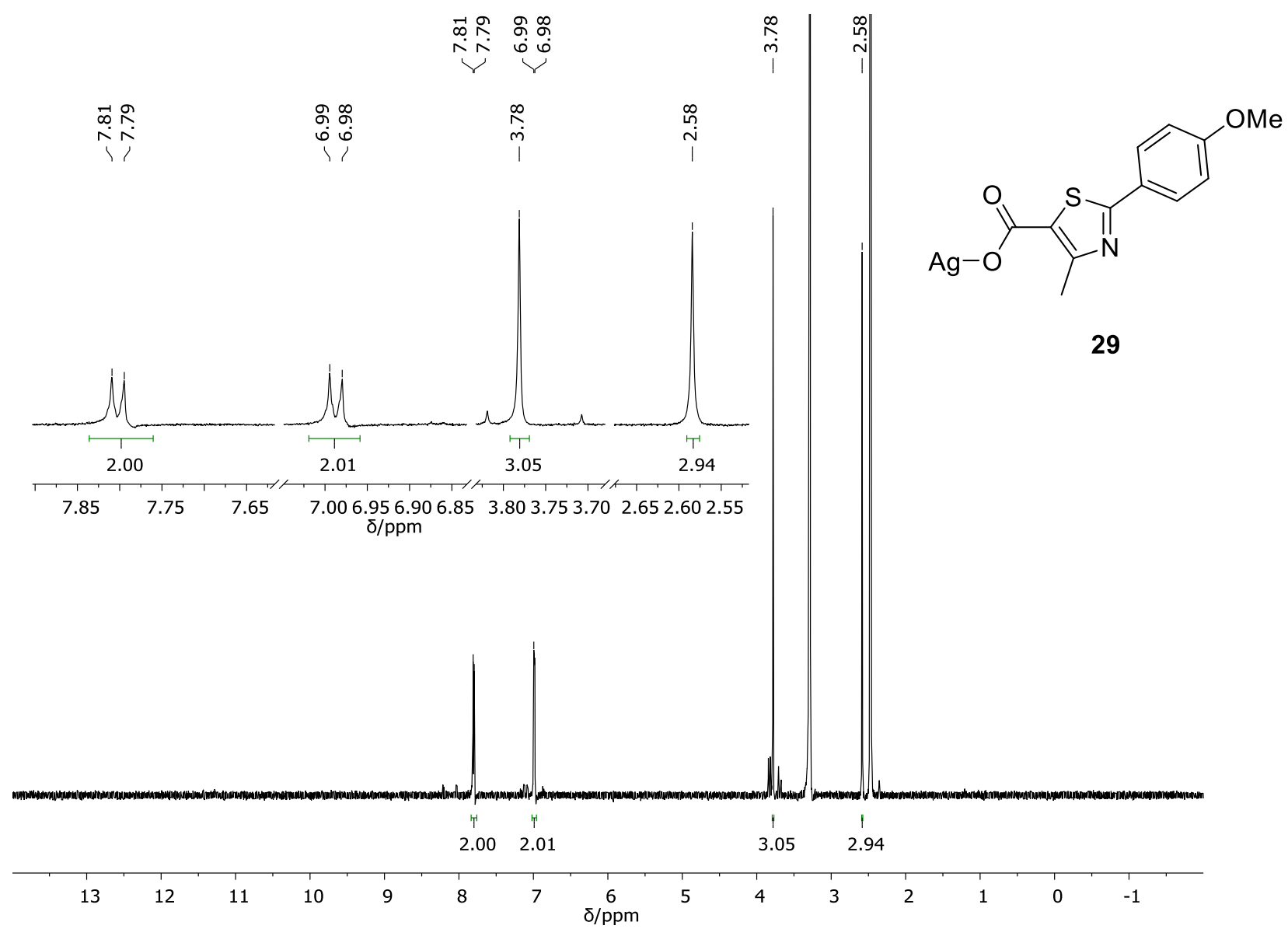

Figure A-115: ${ }^{1} \mathrm{H}$ NMR spectrum of Ag(4-methyl-2-(4-methoxyphenyl)-1,3-thiazole-5carboxylate) (29) in DMSO- $d_{6}$ at $600 \mathrm{MHz}$. 


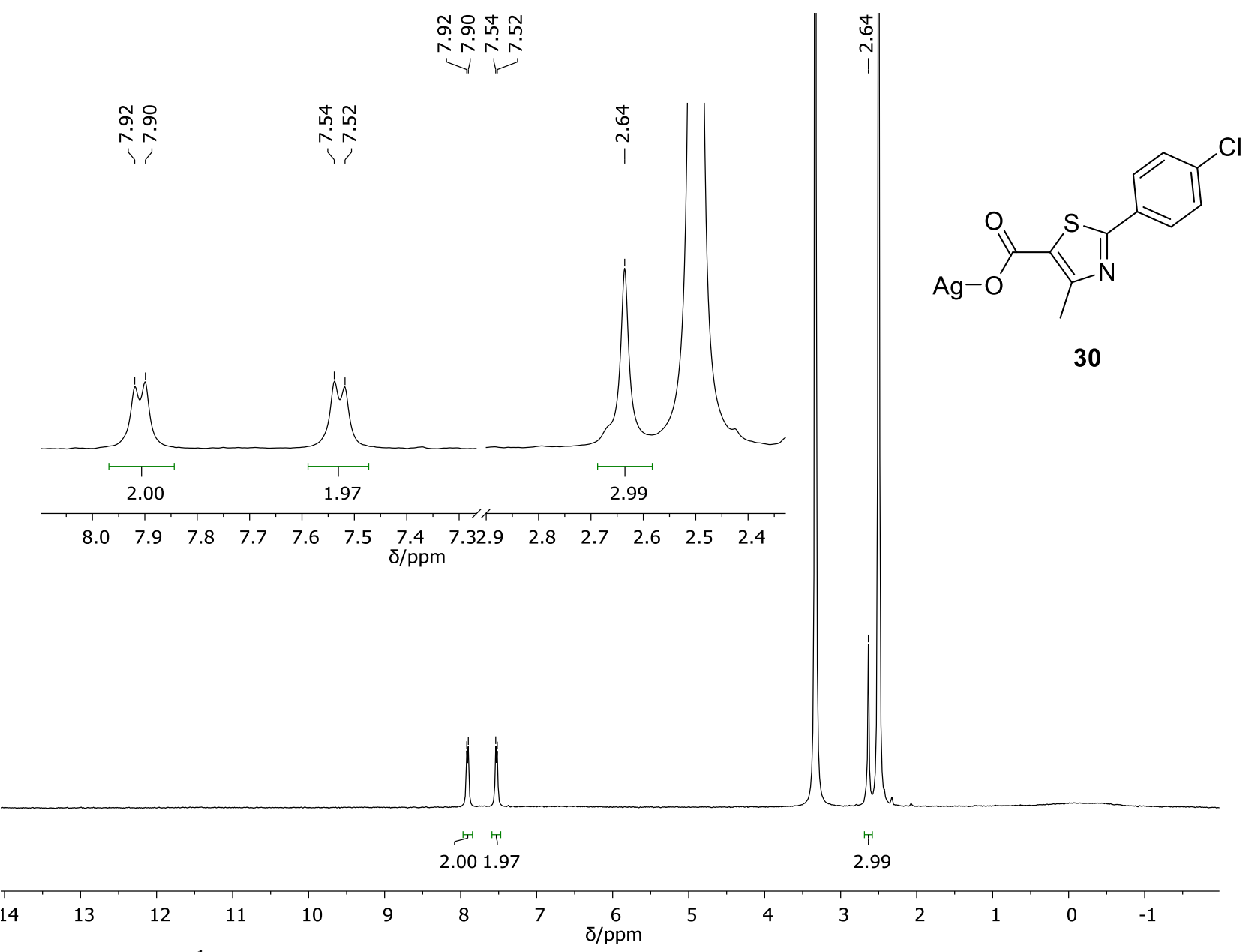

Figure A-116: ${ }^{1} \mathrm{H}$ NMR spectrum of Ag(4-methyl-2-(4-chlorophenyl)-1,3-thiazole-5carboxylate) (30) in DMSO- $d_{6}$ at $400 \mathrm{MHz}$. 


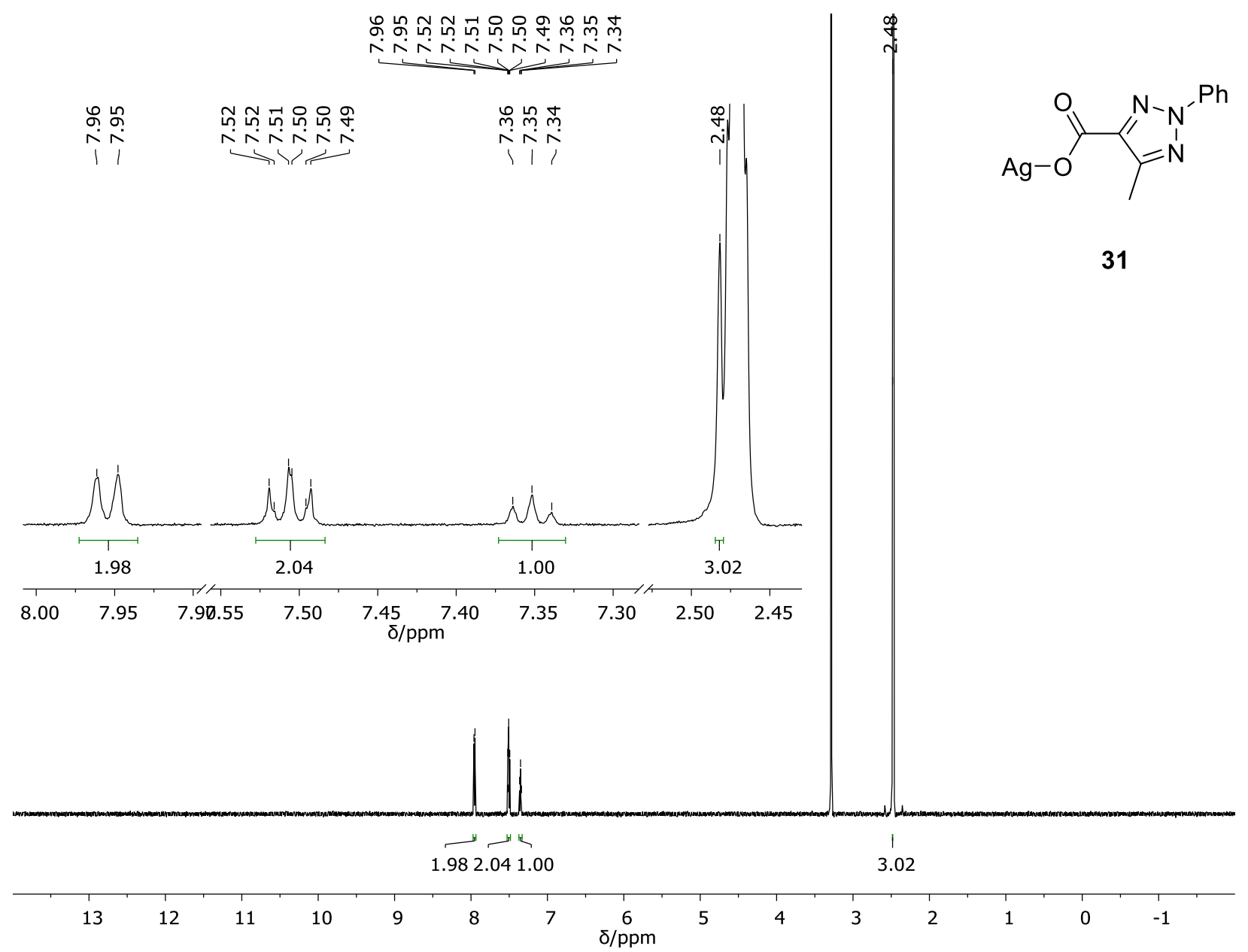

Figure A-117: ${ }^{1} \mathrm{H}$ NMR spectrum of Ag(4-methyl-2-phenyltriazole-5-carboxylate) (31) in DMSO- $d_{6}$ at $600 \mathrm{MHz}$. 


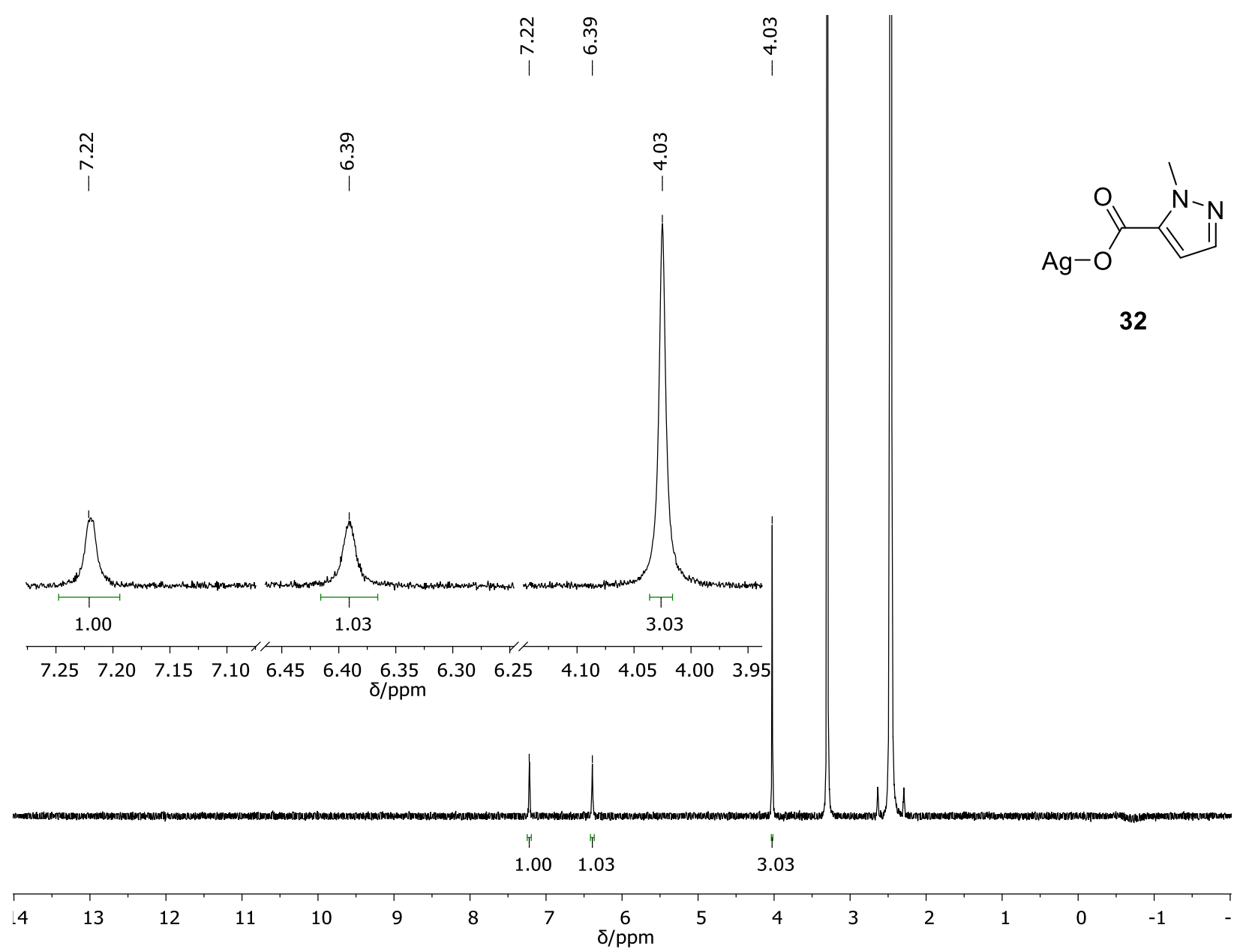

Figure A-118: ${ }^{1} \mathrm{H}$ NMR spectrum of Ag(1-methylpyrazole-5-carboxylate) (32) in DMSO- $d_{6}$ at $400 \mathrm{MHz}$. 


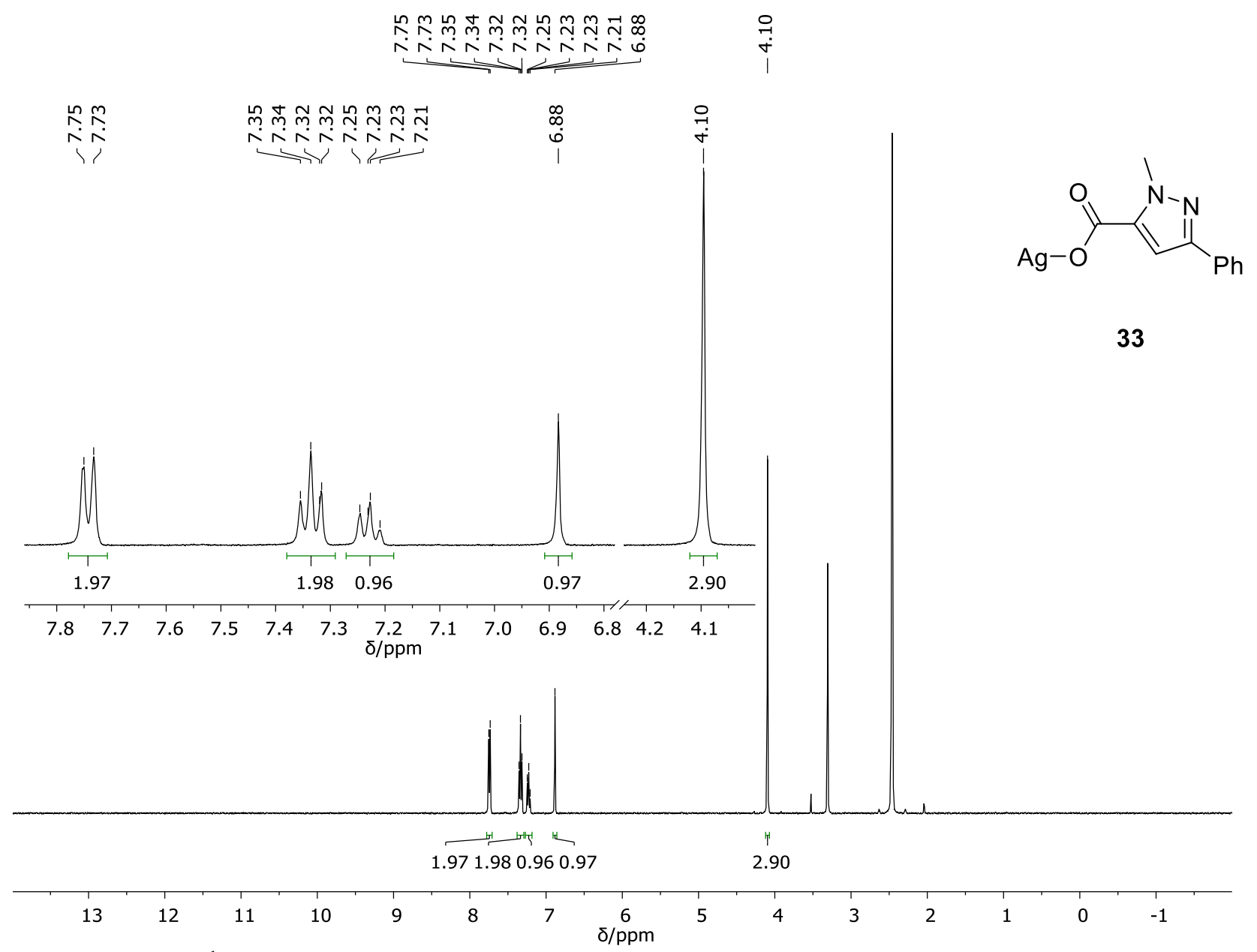

Figure A-119: ${ }^{1} \mathrm{H}$ NMR spectrum of Ag(1-methyl-3-phenylpyrazole-5-carboxylate) (33) in DMSO- $d_{6}$ at $400 \mathrm{MHz}$. 
AI-2.4 HPLC Chromatograms

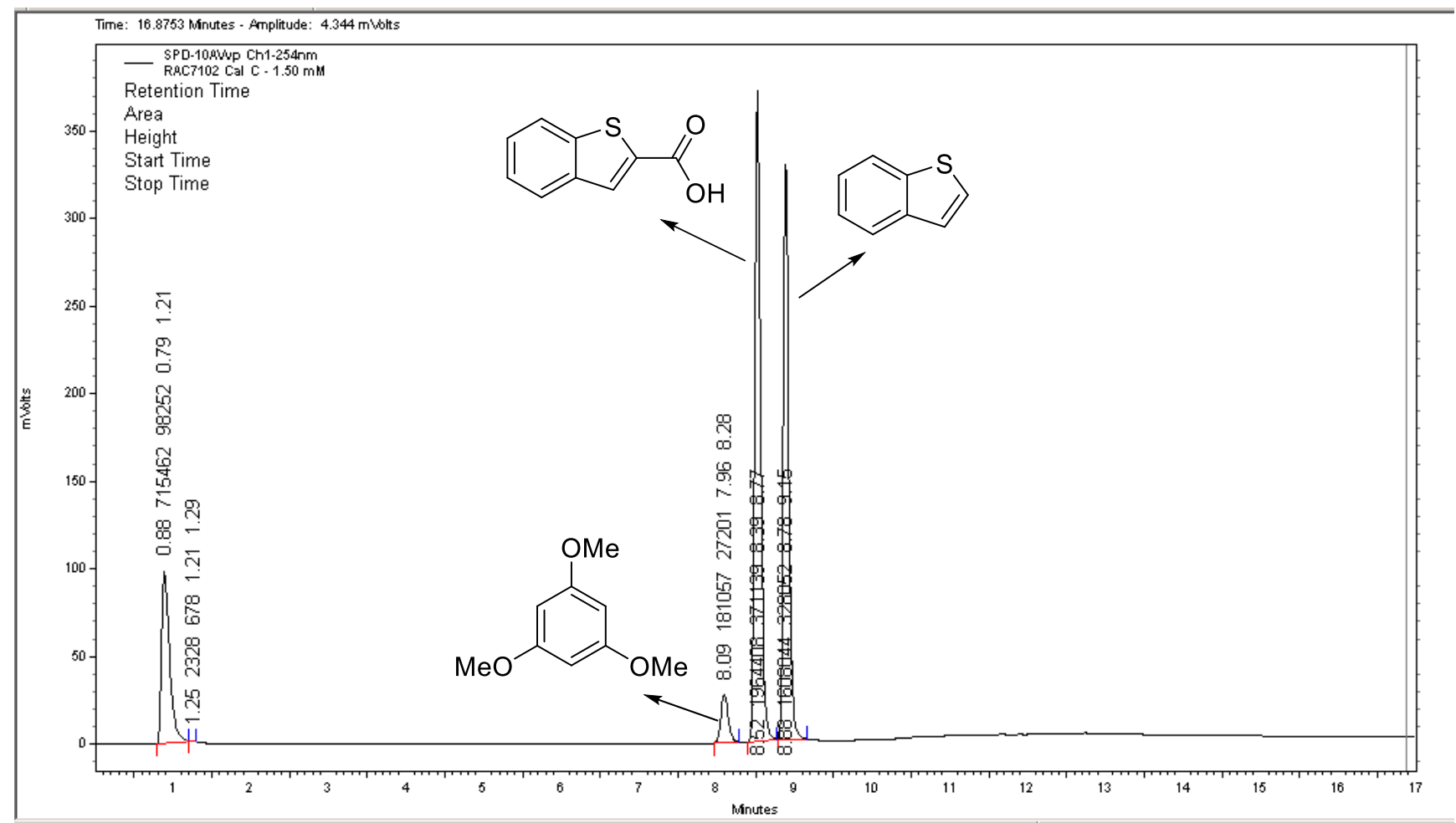

Figure A-120: Example of the separation of benzothiophene-2-carboxylic acid, benzothiophene, and 1,3,5-trimethoxybenzene. 


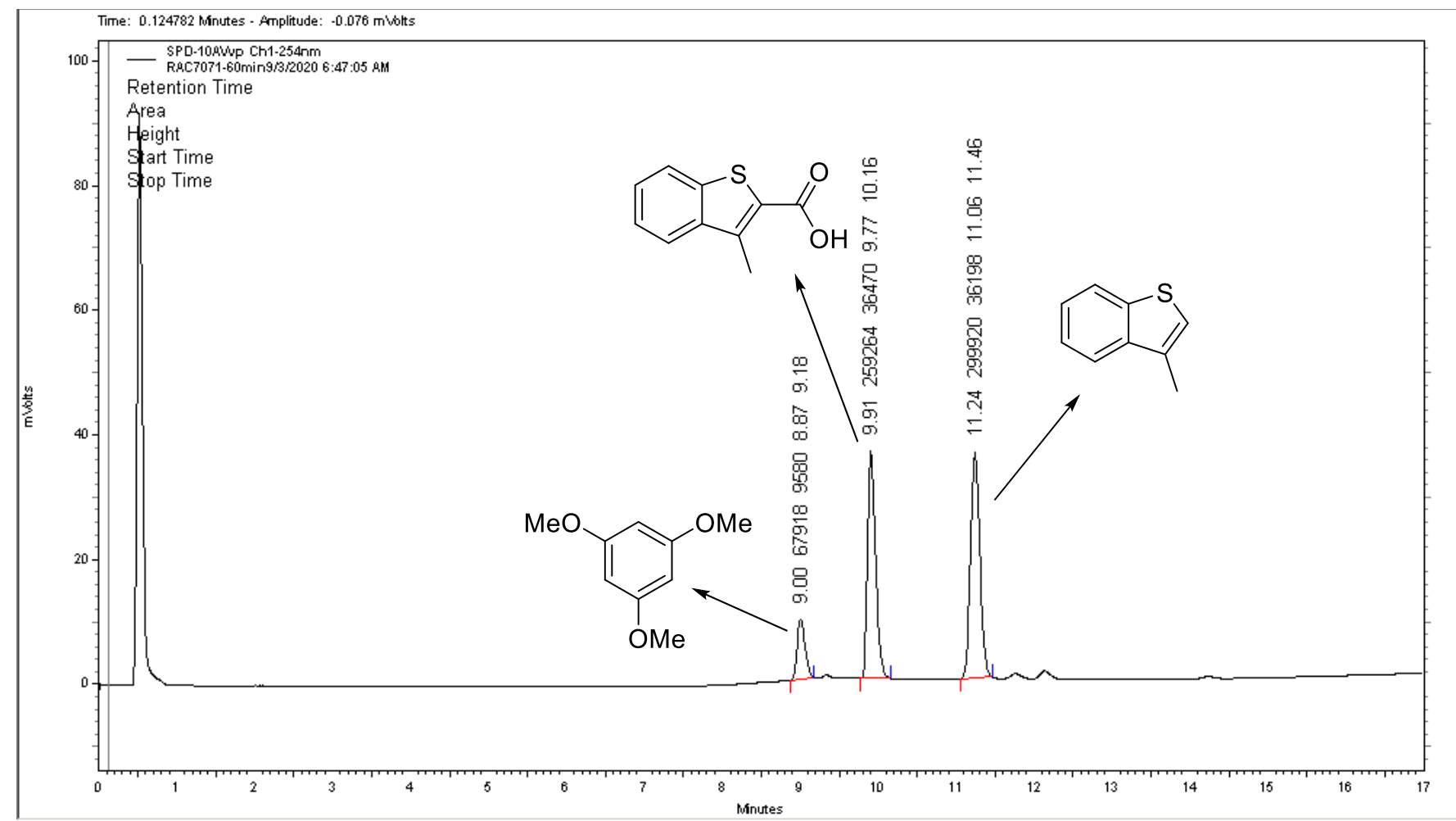

Figure A-121: Example of the separation of 3-methylbenzothiophene-2-carboxylic acid, 3methylbenzothiophene, and 1,3,5-trimethoxybenzene. 


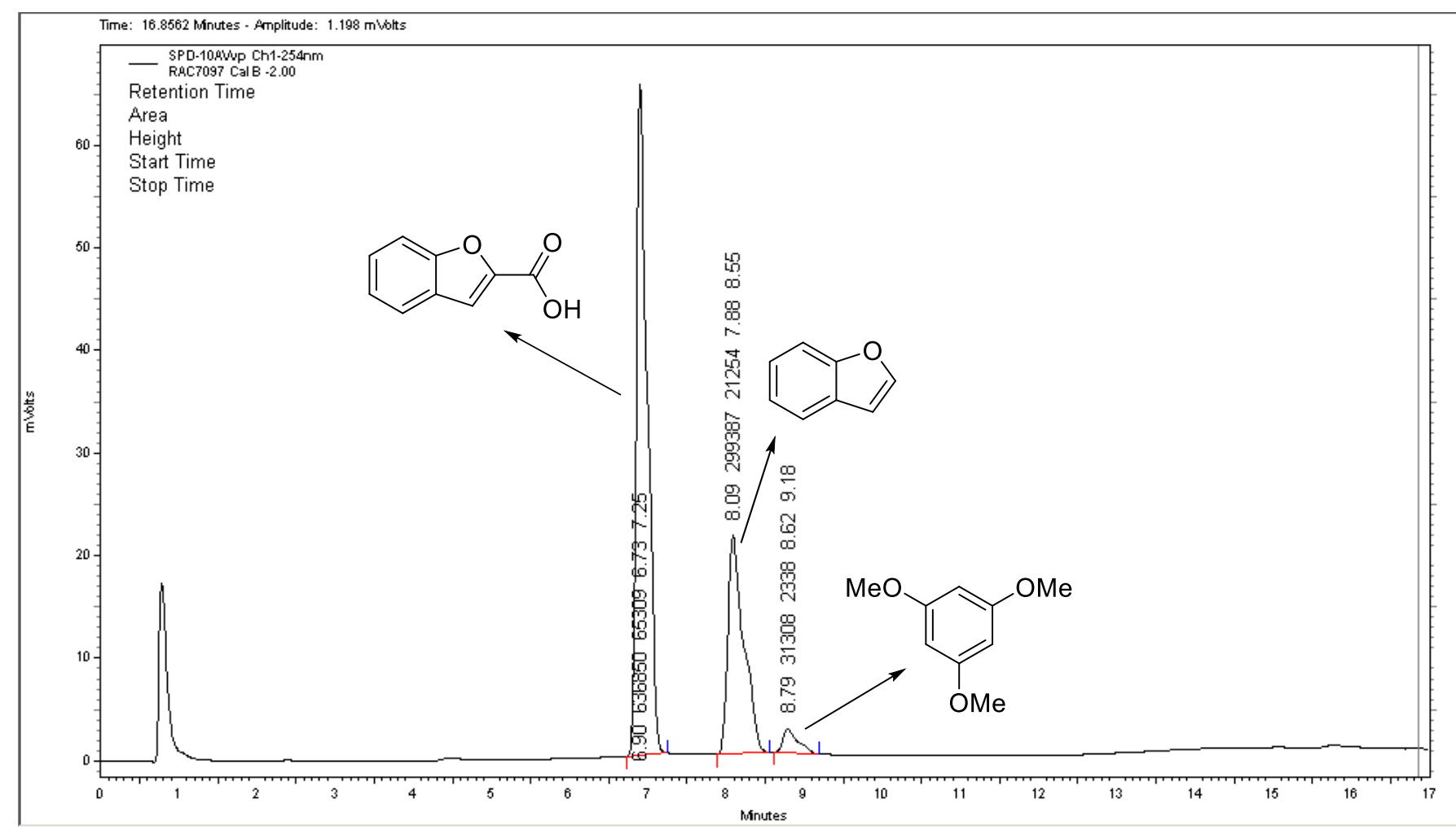

Figure A-122: Example of the separation of benzofuran-2-carboxylic acid, benzofuran, and 1,3,5-trimethoxybenzene. 


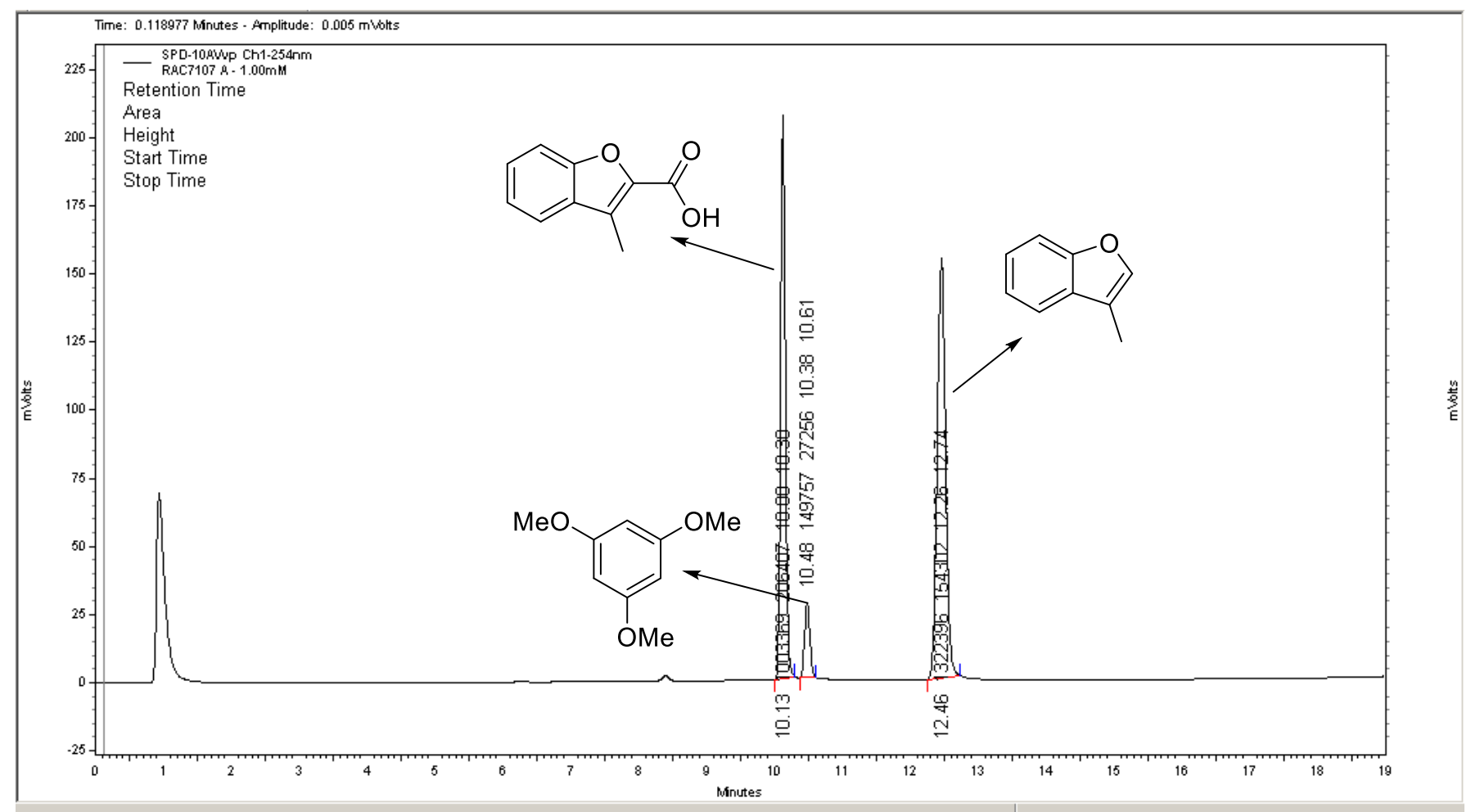

Figure A-123: Example of the separation of 3-methylbenzofuran-2-carboxylic acid, 3methylbenzofuran, and 1,3,5-trimethoxybenzene. 


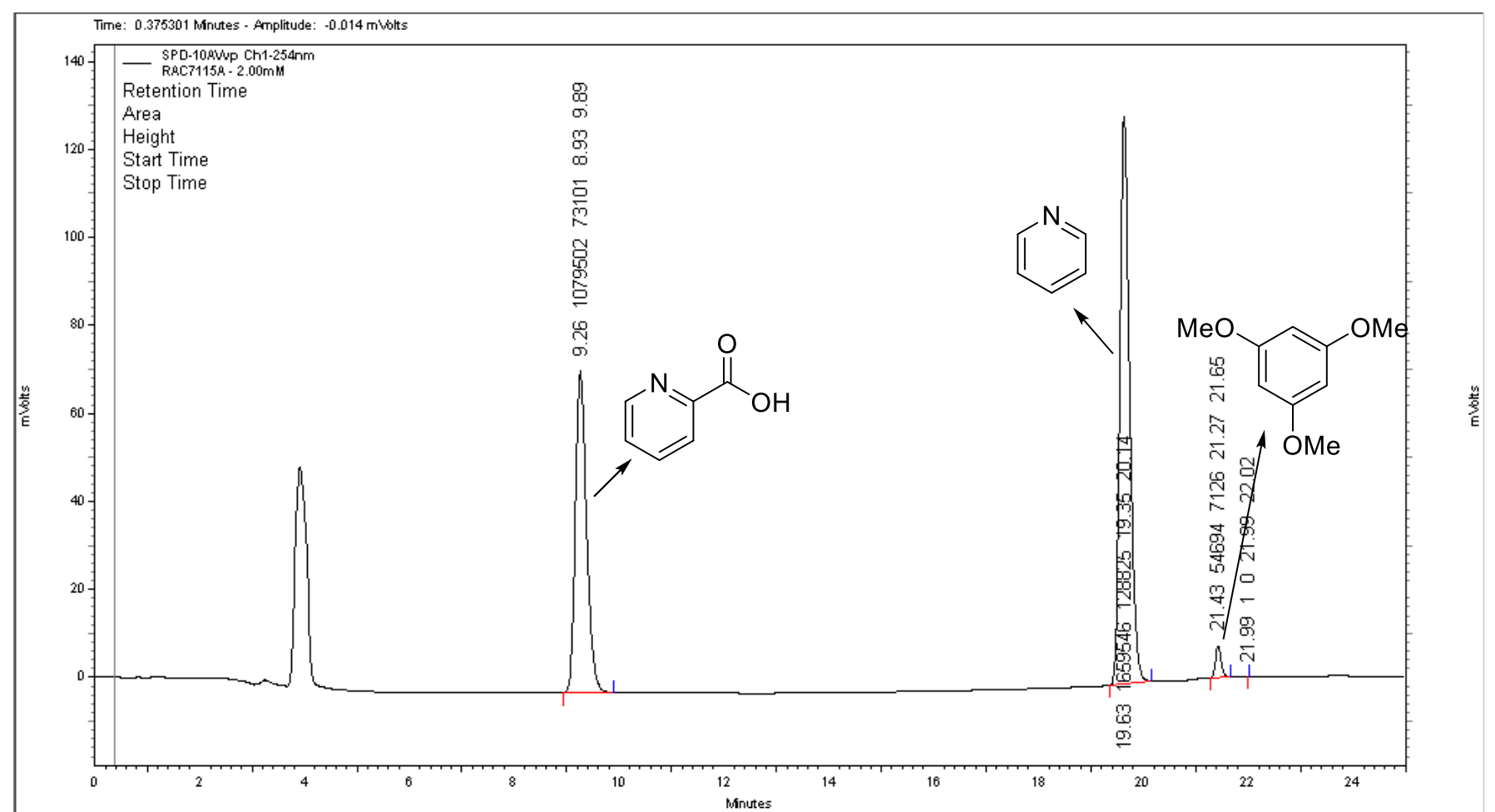

Figure A-124: Example of the separation of pyridine-2-carboxylic acid, pyridine, and 1,3,5trimethoxybenzene. 


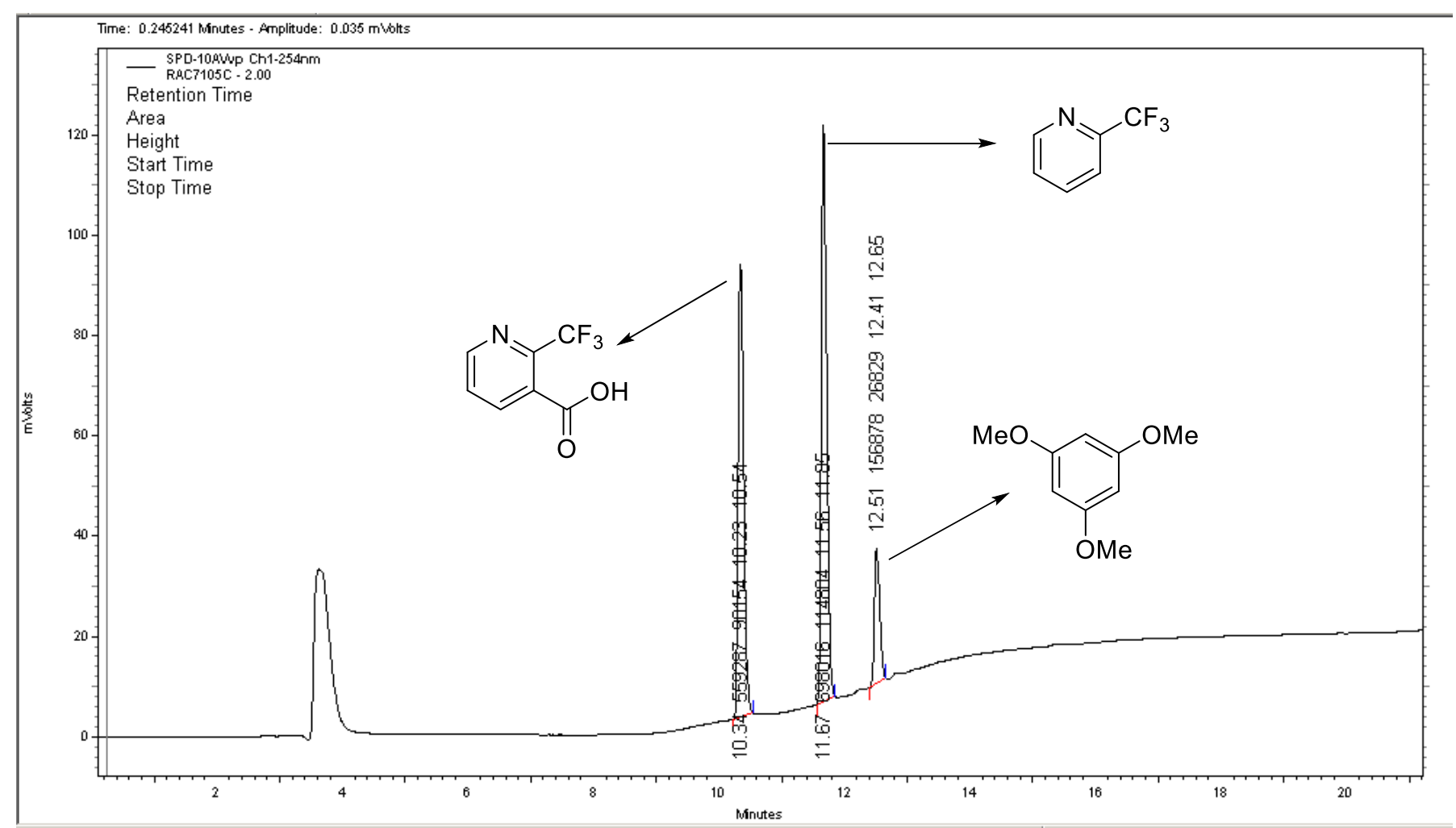

Figure A-125: Example of the separation of 3-trifluoromethylpyridine-3-carboxylic acid, 2trifluoromethylpyridine, and 1,3,5-trimethoxybenzene. 


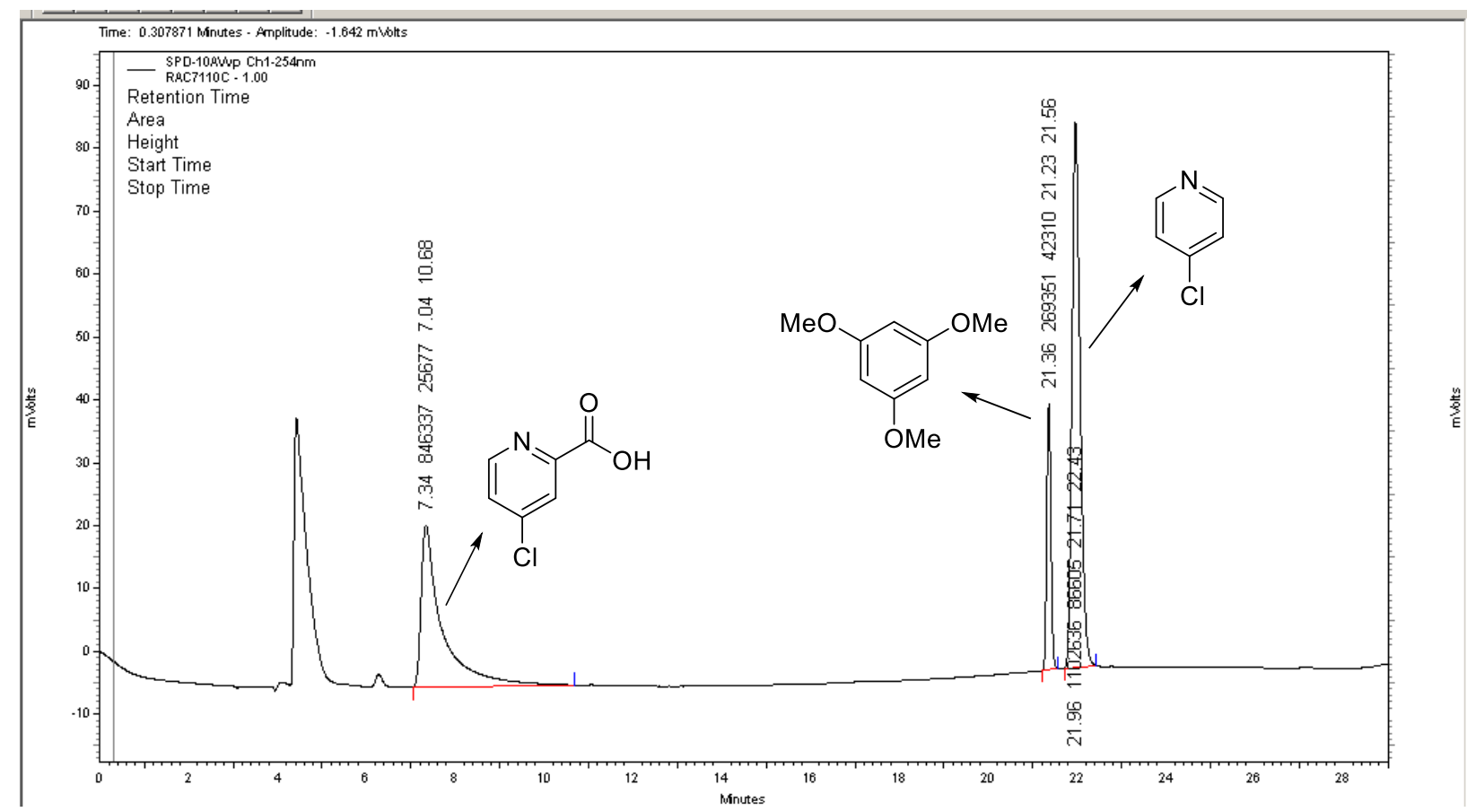

Figure A-126: Example of the separation of 4-chloropyridine-2-carboxylic acid, 4chloropyridine, and 1,3,5-trimethoxybenzene. 